\title{
DEVELOPMENT OF A DECISION SUPPORT SYSTEM FOR
}

PERFORMANCE-BASED LANDFILL DESIGN

\section{A THESIS SUBMITTED TO \\ THE GRADUATE SCHOOL OF NATURAL AND APPLIED SCIENCES OF \\ MIDDLE EAST TECHNICAL UNIVERSITY}

BY

BAŞAK ÇELIKK

IN PARTIAL FULFILLMENT OF THE REQUIREMENTS

FOR

THE DEGREE OF DOCTOR OF PHILOSOPHY

IN

ENVIRONMENTAL ENGINEERING

MAY 2008 
Approval of the thesis:

\section{DEVELOPMENT OF A DECISION SUPPORT SYSTEM FOR PERFORMANCE-BASED LANDFILL DESIGN}

submitted by BAŞAK ÇELIK in partial fulfillment of the requirements for the degree of Doctor of Philosophy in Environmental Engineering Department, Middle East Technical University by,

Prof.Dr. Canan Özgen

Dean, Graduate School of Natural and Applied Sciences

Prof.Dr. Göksel N. Demirer

Head of Department, Environmental Engineering

Prof.Dr. Kahraman Ünlü

Supervisor, Environmental Engineering Dept., METU

Prof.Dr. Adnan Yazıcı

Co-Supervisor, Computer Engineering Dept., METU

\section{Examining Committee Members:}

Prof.Dr. F. Dilek Sanin

Environmental Engineering Dept., METU

Prof.Dr. Kahraman Ünlü

Environmental Engineering Dept., METU

Prof. Dr. Erdal Çokça

Civil Engineering Dept., METU

Assoc. Prof. Dr. Ayşegül Aksoy.

Environmental Engineering Dept., METU

Prof.Dr. İzzet Öztürk

Civil Engineering Dept., İstanbul Technical University

Date: $\quad$ May 30, 2008 
I hereby declare that all information in this document has been obtained and presented in accordance with academic rules and ethical conduct. I also declare that, as required by these rules and conduct, I have fully cited and referenced all material and results that are not original to this work.

Name, Last name: Başak Çelik

Signature 


\title{
ABSTRACT \\ DEVELOPMENT OF A DECISION SUPPORT SYSTEM FOR PERFORMANCE-BASED LANDFILL DESIGN
}

\author{
Çelik, Başak \\ $\mathrm{PhD}$, Department of Environmental Engineering \\ Supervisor: Prof. Dr. Kahraman Ünlü \\ Co-supervisor: Prof. Dr. Adnan Yazıcı
}

May 2008, 312 pages

Performance-based landfill design approach is a relatively new design approach adopted recently in solid waste management and applied in USA, European Union countries and some developing-economy countries like South Africa. This approach rejects the strict design criteria and accommodates a design that selects the most appropriate design components of a landfill (final cover, bottom liner, and leachate collection system) and their design details to result in the best overall performance with respect to performance criteria (groundwater contamination and stability) considering the system variables (climatic conditions of the site, site hydrogeology, and size of the landfill). These design components, performance criteria and design variables involved in decision process make performancebased landfill design a complex environmental problem. Decision support systems 
(DSS) are among the most promising approaches to confront this complexity. The fact that different tools can be integrated under different architectures confers DSSs ability to confront complex problems, and capability to support decisionmaking processes. In this thesis study, a DSS to aid in the selection of design components considering the design variables and performance criteria for performance-based landfill design was developed. System simulation models and calculation modules were integrated under a unique DSS architecture. A decision support framework composed of preliminary design and detailed design phases were developed. The decision of appropriate design components leading to desired performance was made based on stability issues and vulnerability of groundwater, using knowledge gathered from DSS. Capabilities and use of the developed DSS were demonstrated by one real and one hypothetical landfill case studies.

Keywords: landfill modeling, performance-based design, decision support system, system simulation models 


\title{
ÖZ
}

\section{PERFORMANS-BAZLI KATI ATIK DEPOLAMA SAHASI İÇİN KARAR DESTEK SISTEMI GELISTTIRILMESI}

\author{
Çelik, Başak \\ Doktora, Çevre Mühendisliği Bölümü \\ Tez Yöneticisi: Prof. Dr. Kahraman Ünlü \\ Ortak Tez Yöneticisi: Prof. Dr. Adnan Yazıcı
}

Mayis 2008, 312 sayfa

Performans-bazlı katı atık depolama sahası tasarımı, son yıllarda katı atık yönetiminde benimsenen, $\mathrm{ABD}, \mathrm{AB}$ ülkeleri ve Güney Afrika gibi ekonomisi gelişmekte olan ülkelerde uygulanan yeni bir tasarım yaklaşımıdır. $\mathrm{Bu}$ yaklaşım "tek-tip"çi tasarım anlayışını reddetmekte ve katı atık depolama sahası tasarım elemanlarını (üst örtü, depolama tabanı ve sızıntı suyu toplama sistemi) ve bunların tasarım detaylarını, performans ölçütlerine göre (yer altı suyu kirliliği ve stabilite) en iyi performansı sağlayacak şekilde ve sistem değişkenlerine (iklim, saha hidrojeolojisi ve atık yüküne bağlı olarak depolama sahasının boyutu) uygun olarak seçen bir tasarım yaklaşımı sunmaktadır. Karar mekanizmasında yer alan tasarım elemanları, performans ölçütleri ve tasarım değişkenleri performans-bazlı katı atık depolama sahası tasarımını karmaşık bir çevresel problem haline 
getirmektedir. Karar destek sistemleri (KDS) bu karmaşıklığ1 gidermede en çok ümit vaat eden yaklaşımların başında gelmektedir. İstatistiksel/nümerik yöntemler, ve coğrafi bilgi sistemleri gibi araçların farklı mimarilerde entegre edilebiliyor olması da KDS'nin karmaşık problemleri çözme ve karar verme mekanizmalarını desteklemektedir. Bu tez çalışmasında, performans-bazlı katı atık depolama sahası tasarımı için tasarım elemanlarının, sistem değişkenleri ve performans ölçütlerini göz önüne alarak seçimine yardımcı olacak bir KDS geliştirilmiştir. Sistem simülasyon modelleri, tasarım modeli ve hesaplama modülleri özgün bir KDS mimarisinde birleştirilmiştir. Ön tasarım ve ayrıntılı tasarım aşamalarından oluşan iki aşamalı bir KDS geliştirilmiştir. İstenen performansı sağlayacak olan tasarım bileşenlerinin seçimi stabilite ve yer altı suyunun varlığı ve hassasiyetiyle ilgili kaygılar göz önünde bulundurularak, KDS'den elde edilen bilgi ve verilere dayanarak gerçekleştirilecektir, Geliştirilen KDS'nin kullanımı bir gerçek bir de varsayıma dayanan örnek saha üzerinde gösterilmiştir.

Anahtar Kelimeler: katı atık depolama sahası modellemesi, performans-bazlı tasarım, karar destek sistemi, sistem simülasyon modelleri 
To my little son Çınar and beloved husband Ahmet... 


\section{ACKNOWLEDGEMENT}

I would like to express my sincerest appreciation and thanks to my supervisor

Prof. Dr. Kahraman Ünlü. This thesis would not be possible without his skillful and scholarly guidance and encouragement. Moreover, he was a role-model for my academic life, with his diligence and manners in academic ethics. I would also like to express my deepest gratitude to my co-supervisor Prof.Dr. Adnan Yazıc1 for his support and the reassurance he provided throughout the study. I will always remember and appreciate their endless support, trust, and friendship throughout my life, and I am sure that their words and manners will enlighten the rest of my professional life.

I would like to present my sincere thanks to Prof. Dr. Erdal Çokça and Assoc. Prof. Dr. Ayşegül Aksoy for their valuable comments and contributions during the progress committees of the thesis. Also, I would like to thank to the other examiners, Prof. Dr. İzzet Öztürk and Prof. Dr. F. Dilek Sanin, for attending the defense of the thesis and for their precious comments.

I would like to thank to Serhan Poçan for taking the first steps in developing the technical codes of the decision support system platform. I would also like to thank to Serkan Girgin, who always helped me whenever I needed help or guidance on any subject, especially digital maps and software codes. My deepest gratitude goes to a miracle-man, Sertan Girgin, for his hard work on code writing, patience to my endless requests, smiling face towards the difficulties we encountered, and all of his efforts even though he was miles away from Ankara. Sertan, thank you so much for materializing our thoughts! I also would like to thank to DOLSAR 
Engineering for providing the reports of the Siirt Municipal Solid Waste Landfill Project.

I would like to present my sincere thanks to Prof. Dr. R. Kerry Rowe, for his support during the six months I spent in Queen's University, Kingston, Canada. His valuable guidance and directions helped in the evolution and maturation of the thesis. I feel so lucky that I had a chance to work with such a scholar.

I also would like to thank to all of my friends in Kingston, Canada. Carmen Li, Anastasia Bennett, and Allison (Gilmer) Doyle -you were the best roommates that a Turkish girl in Kingston can imagine. Thank you for your support since the first day I arrived to Canada, cheering me up whenever I needed, be there for me during the hardest times, and your faith in me about finishing my $\mathrm{PhD}$. Azadeh Hoor, Roya Davoodi Bilesavar, Ahmed Mabrouk, Anamika Sikdar, Chalermpol Taechakumthorn -or Bon in short-, Karina Lange, and Nooshin Kiarashi -thank you so much for your friendship and support in Civil Engineering Department at Queen's, and being a huge part of my life for six months. You, for sure, made studying easy with all your support and cheer. I will never forget the wonderful times we had in Kingston, Toronto, and Ottawa.

And, how can I forget my colleagues in the Department of Environmental Engineering, at METU? Tuba Hande Ergüder -for the last five years, you have been my friend, my confidant, my mentor... You not only supported me, cheered me up, and presented your valuable friendship, but also taught me how to be a hardworking academician, an eager PhD student, and a good person. Nuray Ateş with all your joy, friendship, and support, you made my life fun and easy. I will never forget your valuable advices, everything we shared during hard times, and your warm friendship. Okan Tarık Komesli -thank you so much for your support throughout this difficult path, and faith in me, my brother. It is good to know that you will always be there whenever I need help. Güray Doğan -I feel lucky that 
you eventually ended up in our office. Otherwise, I would never know that the world still has people like you. Thank you so much for your friendship, for being there whenever I needed without any excuses, and sharing your valuable ideas not only on academics, but also on social issues. And Meltem (Güvener) İpek - it was wonderful to feel your support, friendship, and trust for the last nine years. Thank you so much for your valuable friendship, help whenever I asked you, faith in me throughout my $\mathrm{PhD}$, and cheering me up -and calming me- during hard times. This $\mathrm{PhD}$ period would never be as easy and fun as it had been if any of you were not a part of my life...

I am deeply grateful to my family. Mom, dad, and my brother (Samiye, Bülent, and Emrah Tarhan) - thank you for making this thesis possible by providing all your resources, patience, help, encouragement, support and love. Emo, you are the best sibling I can imagine! I am so lucky that I have a brother like you, who always supported me and cheered me up. I would also like to express my deepest gratitude to my mother-in-law, my father-in-law, and my sisters-in-law (Sebahat, Hidayet, Serap and Sibel Çelik) for their understanding, patience, trust, encouragement, and love throughout my PhD. Finally, my sister Dilek Taş and her husband, my brother, Yasin Taş -you always believed in me that I will get this degree. Thank you for your faith and endless support, and being always there whenever I needed.

Last but not the least, I would like to thank to my little son Çınar, who has been in me for the last 5 months of this study, for being such a good boy and not letting his mom down during her thesis writing period. And my deepest gratitude goes to my beloved husband, Ahmet Çelik. He is the best man that a woman -especially who is a PhD candidate- can imagine. I would like to express my endless thanks to him for his understanding, faith, help, encouragement, and love he offered throughout this long path. This thesis would never be completed without his precious and priceless support. 


\section{ABBREVATIONS}

$\begin{array}{ll}\text { 2D } & \text { Two-dimensional } \\ \text { 3D } & \text { Three-dimensional } \\ \text { CCL } & \text { Compacted clay liner } \\ \text { CDS } & \text { Cover drainage system } \\ \mathrm{Cl}^{-} & \text {Chloride ion } \\ \text { CSV } & \text { Comma separated value } \\ \text { CX } & \text { Final cover design alternatives (C1, C2, C3) } \\ \text { DEM } & \text { Digital elevation model } \\ \text { DSS } & \text { Decision support system } \\ \text { ET } & \text { Evapotranspiration final cover } \\ \text { FS } & \text { Factor of safety value } \\ \text { GIS } & \text { Geographic information systems } \\ \text { GM } & \text { Geomembrane } \\ \text { GUI } & \text { Graphical user interface } \\ \text { LCS } & \text { Leachate collection system } \\ \text { LFDSS } & \text { Landfill Decision Support System } \\ \text { LX } & \text { Bottom liner design alternatives (L1, L2, L3, L4, L5, L6) } \\ \text { MacOS } & \text { Macintosh Operating System } \\ \text { MS } & \text { Microsoft } \\ \text { RDM } & \text { Regional data map } \\ \text { SSM } & \text { System simulation model } \\ \text { VLF } & \text { Virtual Landfill } \\ \end{array}$




\section{TABLE OF CONTENTS}

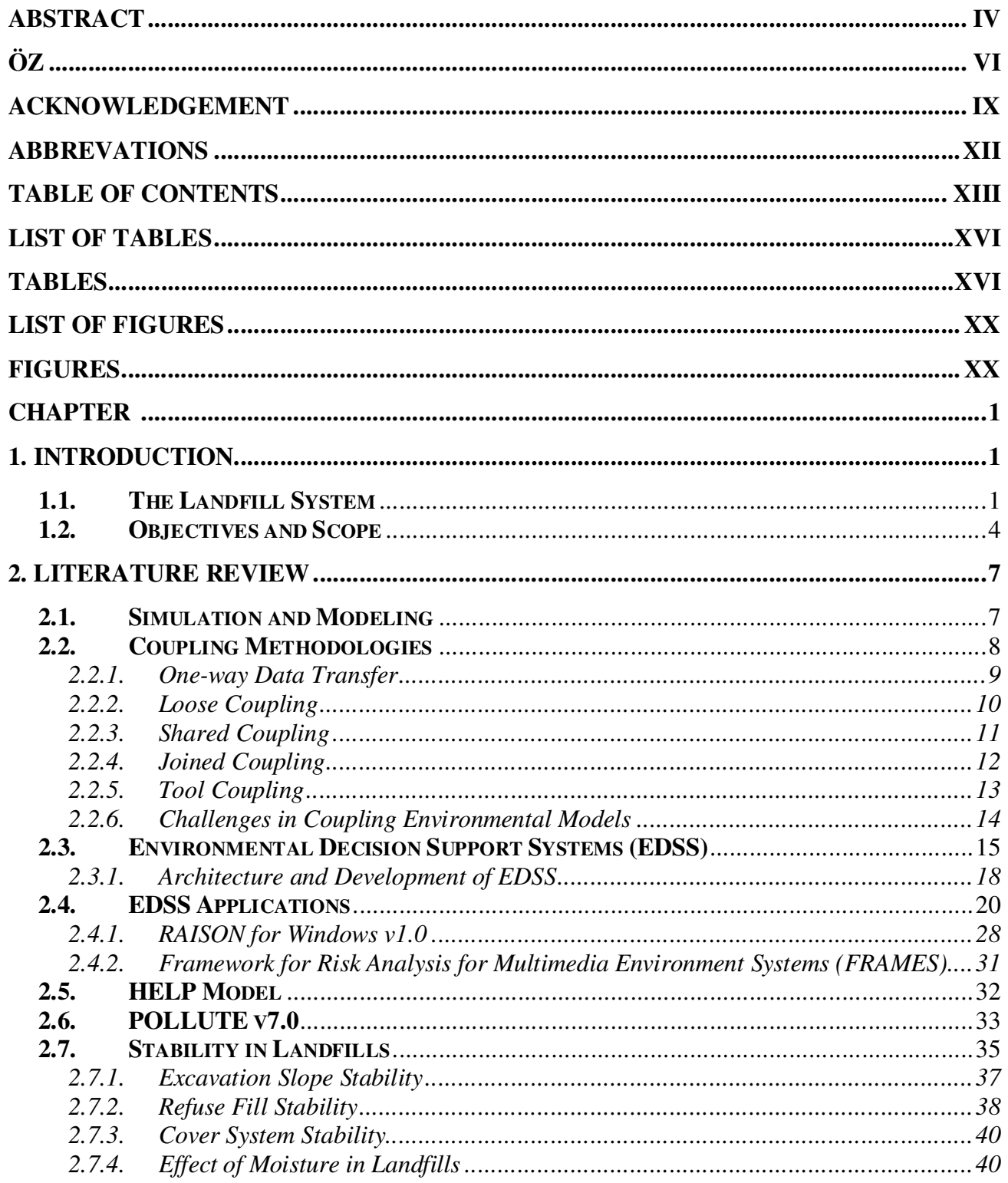


3.1. Development of Design Methodology AND the DeSign CoMponent

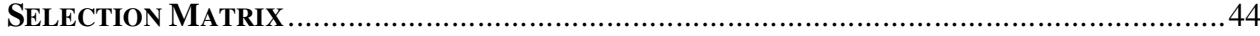

3.1.1. Development of Design Methodology .............................................................. 44

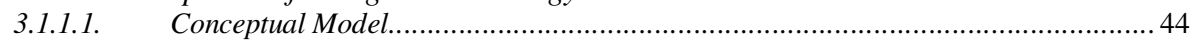

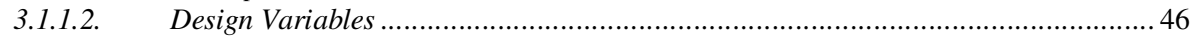

3.1.1.2.1. $\quad$ Vadose Zone Effect on Steady-state Leakage Rates....................................... 50

3.1.1.2.2. Waste Thickness and Seepage Velocity Effect on Steady-State Leakage Rates.... 55

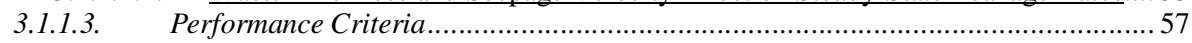

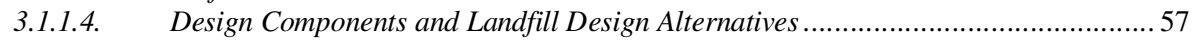

3.1.2. Development of Design Component Selection Matrix..........................................61

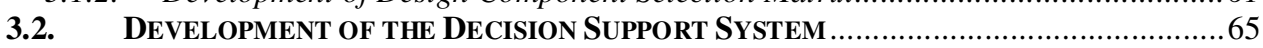

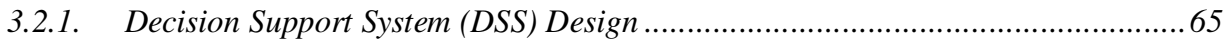

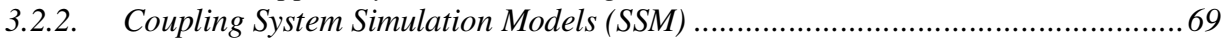

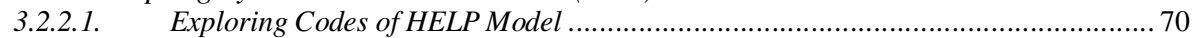

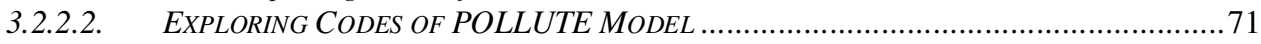

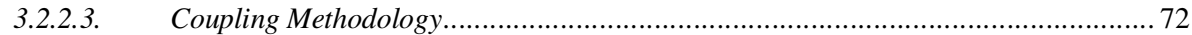

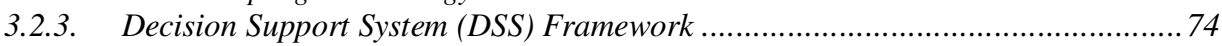

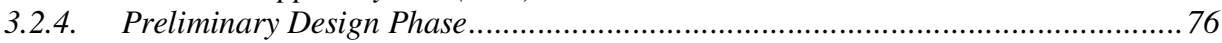

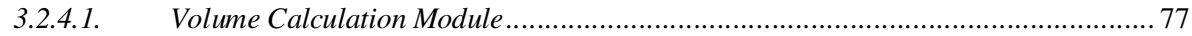

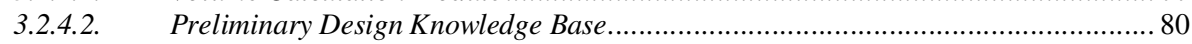

3.2.5. Detailed Design Phase ............................................................................. 83

3.2.5.1. $\quad$ Landfill Base Contour Design Model (Virtual Landfill)......................................... 84

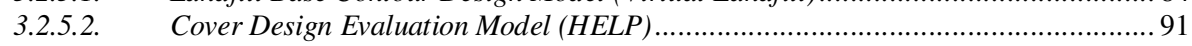

3.2.5.3. Waste and Bottom Liner Design and Subsurface Transport Model (POLLUTE)...... 95

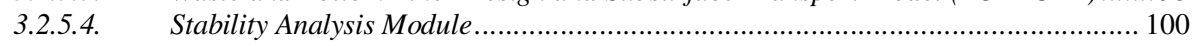

3.2.5.5. Major Design Component Approximate Cost Estimation Module …....................... 107

3.2.5.6. Decision Mechanism and Presentation of Decision Analyses .................................. 110

4. RESULTS AND DISCUSSION

4.1. EFFECT OF VADOSE ZONE ON STEADY-STATE LEAKAGE RATES FROM LANDFILL

BARRIER SYSTEMS ............................................................................................. 114

4.1.1. Barrier System: Compacted Clay Liner underlain by Coarse Textured Vadose

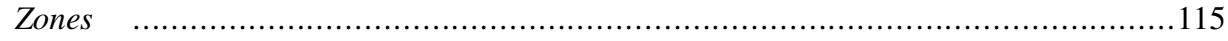

4.1.2. Barrier System: Compacted Clay Liner underlain by Fine Texture Vadose Zones

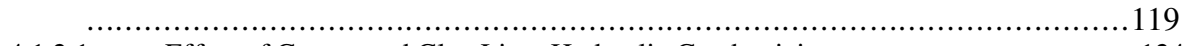

4.1.2.1. Effect of Compacted Clay Liner Hydraulic Conductivity ................................... 124

4.2. EFFECT OF WASTE THICKNESS AND SEEPage Velocity ON STEADY-STATE

LEAKAGE RATES FROM LANDFILL BARRIER SYSTEMS............................................... 125

4.3. Performance-Based Evaluation of Landfill Design Alternatives ....... 128

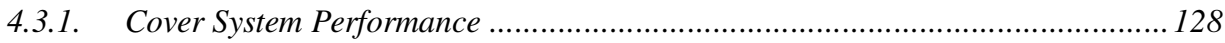

4.3.2. Compliance with the First Performance Criterion (Stability) ............................ 129

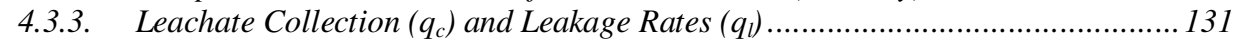

4.3.4. Compliance with the Second Performance Criterion (Contaminant Concentration)

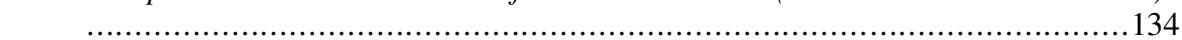

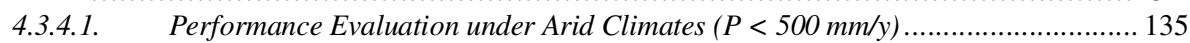

4.3.4.2. $\quad$ Performance Evaluation under Moderate Climates $(500 \leq P<1000 \mathrm{~mm} / \mathrm{y}) \ldots \ldots \ldots . . .137$

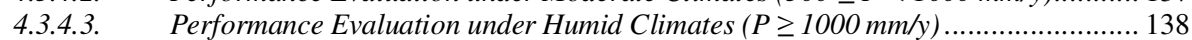

4.4. The DeSIgn COMPONENT SELECTION MATRIX ......................................... 140

4.5. LANDFILl DeSIgn CASE StUdIES USING LFDSS ............................................ 143

4.5.1. $\quad$ Siirt Municipal Solid Waste Landfill Design .................................................. 144

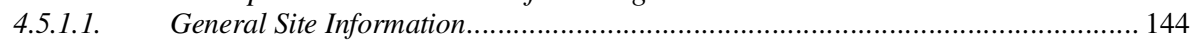

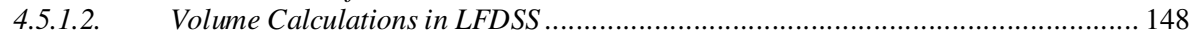

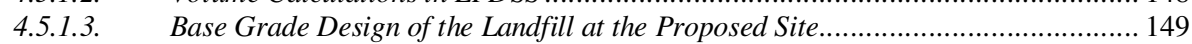

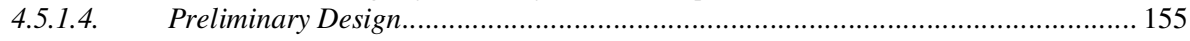




\begin{tabular}{|c|c|}
\hline 4.5.1.5. & Infiltration Rate Calculations and Final C \\
\hline 4.5.1.6. & Landfill Stability Evaluation and Soil Con \\
\hline 4.5.1.7. & Structural Stability Calculations.. \\
\hline 4.5.1.8. & Cost Calculations of Major Design Components. \\
\hline 4.5.1.9. & Presentation of the Assessments and Decision Making \\
\hline \multicolumn{2}{|c|}{ 4.5.2. Designing a Municipal Solid Waste Landfill for a Hypothetical Site.................. 172} \\
\hline 4.5.2.1. & General Site Information.................... \\
\hline 4.5.2.2. & Volume Calculations in LFDSS. \\
\hline 4.5.2.3. & Base Grade Design of the Landfill at \\
\hline 4.5.2.3.1. & Longer Side of the Landfill Perpendic \\
\hline 4.5.2.3.2. & ion of Groundwater Flow .. \\
\hline 4.5.2.4. & Preliminary Design....... \\
\hline 4.5.2.5. & Infiltration Rate Calculations and Final Cover Performance Evaluation ............... 189 \\
\hline 4.5.2.6. & Groundwater Contamination and Landfill Design Performance Evaluation........... 190 \\
\hline 4.5.2.7. & 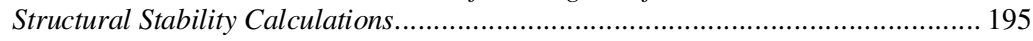 \\
\hline 4.5.2.8. & Cost Calculations of Major Design Components.. \\
\hline 4.5.2.9. & Presentation of the Assessments and Decision Making . \\
\hline
\end{tabular}

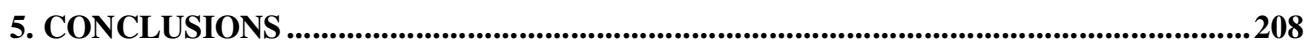

5.1. EfFects of Design VARiables on the Performance of LANDFiLls .............208

5.2. Evaluation of Performance-Based Landfill Design Simulations .......... 211

5.3. EVALUATION OF THE DEVELOPED DSS (LFDSS) ...................................... 214

6. RECOMMENDATIONS FOR FUTURE STUDIES..............................................217

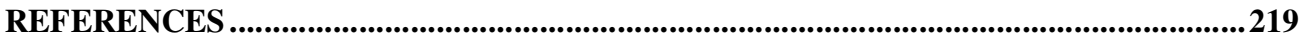

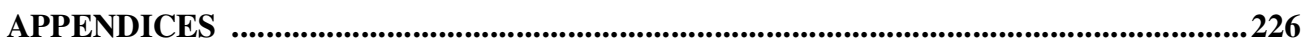

A. SCHEMATIC DRAWINGS OF LANDFILL DESIGN ALTERNATIVES ...................226

B. TECHNICAL DOCUMENTATION FOR LANDFILL DECISION SUPPORT SYSTEM

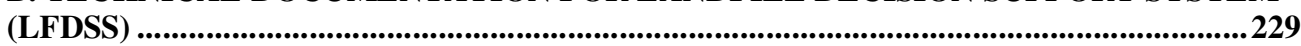

C. DESIGN COMPONENT SELECTION MATRIX RULES ........................................247

D. TECHNICAL DOCUMENTATION FOR VIRTUAL LANDFILL (VLF) ...................255

E. SIMULATION RESULTS OF LANDFILL DESIGN ALTERNATIVES ......................275

F. DIGITAL ELEVATION MODELS (DEM) FOR VIRTUAL LANDFILL MODEL........303

G. PERFORMANCE REPORTS PRESENTED BY LFDSS............................................307

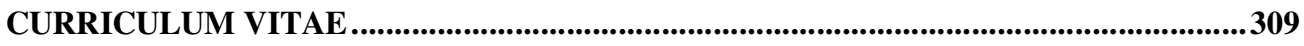




\section{LIST OF TABLES}

\section{TABLES}

Table 2. 1 Recommended minimum values of factor of safety for slope stability analyses (Sharma and Lewis, 1994) ........................................................ 36

Table 3. 1 Classification of landfills with respect to Maximum Rate of Deposition

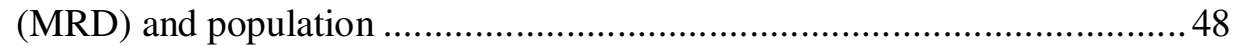

Table 3. 2 Hydraulic conductivity values for different hydrogeologic environment

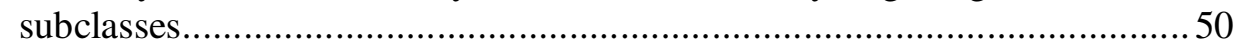

Table 3. 3 Landfill barrier system configuration in SEEP/W model................... 53

Table 3. 4 Design details of major design alternatives used for waste thickness and

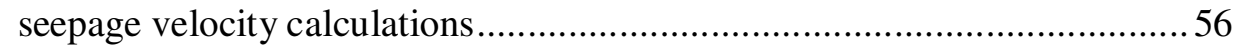

Table 3. 5 Configurations of sensitivity simulations ....................................... 56

Table 3. 6 Final Cover and Bottom Liner Alternatives ....................................5 58

Table 3. 7 Design Details of Major Design Alternatives ....................................59

Table 3. 8 Combinations of Landfill Design Alternatives Ranging from Minimal

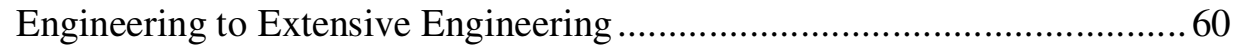

Table 3. 9 Design variable sets for the design component selection matrix .........61

Table 3. 10 Required site hydrogeology with respect to landfill design alternatives

Table 3. 11 Final cover design parameters used in HELP simulations ................63

Table 3. 12 Landfill design and subsurface hydraulic parameters used in

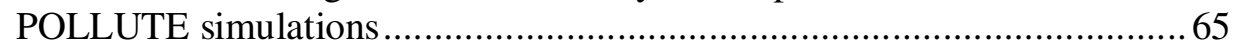

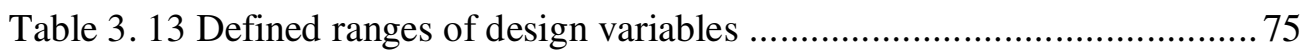

Table 3.14 Waste density values (İller Bankası, 2000) .................................... 77

Table 3. 15 Input data requirement and output data supplied by Volume Calculation Module

Table 3. 16 Input data requirement and output data supplied by Virtual Landfill VLF.....

Table 3.17 Input data requirement and output data supplied by HELP model ....92

Table 3. 18 Input data requirement and output data supplied by POLLUTE model

Table 3. 19 The formulae used in stability calculations .................................... 102

Table 3. 20 Guidance values for average seismic coefficient $\left(\mathrm{C}_{\mathrm{s}}\right)$ (Koerner and

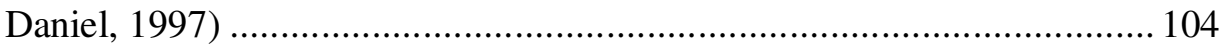


Table 3. 21 Major and additional design components for cost analyses in Cost Estimation Module in LFDSS

Table 3. 22 Format of results template provided to the user by LFDSS (produced from Figure 3.26)....

Table 4. 1 Harmonic mean hydraulic conductivity values of the coarse-textured vadose zones, effective hydraulic conductivity values of the overall barrier system and steady-state leakage rates

Table 4. 2 Harmonic mean hydraulic conductivity values of the fine textured vadose zones, effective hydraulic conductivity values of the overall barrier system and steady-state leakage rates

Table 4. 3 The effect of compacted clay liner hydraulic conductivity on the effective hydraulic conductivity and steady-state leakage rates into the aquifer......

Table 4. 4 Groundwater seepage velocity sensitivity analyses ...

Table 4. 5 Normalized concentrations occurred as a result of various seepage velocities

Table 4. 6 Normalized concentrations occurred as a result of various waste thicknesses

Table 4. 7 Waste thickness sensitivity analyses....

Table 4. 8 Respective effects of waste thickness and seepage velocity on

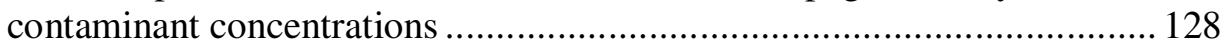

Table 4. 9 Infiltration rates by HELP model ............................................... 129

Table 4. 10 Hydraulic head values that are supposed to develop..................... 131

Table 4. 11 Effective hydraulic conductivity values of the bottom liners and the infiltration rates coming to the bottom liners ........................................ 132

Table 4. 12 Leakage rates by POLLUTE ........................................................ 133

Table 4. 13 Performance of design alternatives under arid climates $(\mathrm{P}<500$

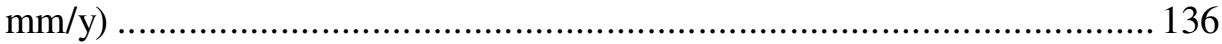

Table 4. 14 Performance of design alternatives under moderate climates $(500 \leq \mathrm{P}$

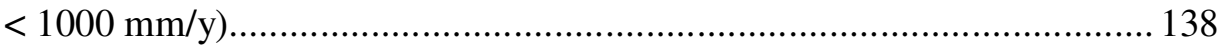

Table 4. 15 Performance of design alternatives under humid climates $(P \geq 1000$

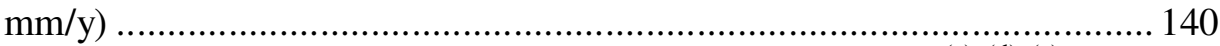

Table 4. 16 Design component selection matrix for arid climates ${ }^{(a),(d),(e)}$........ 141

Table 4. 17 Design component selection matrix for moderate climates ${ }^{(a),(d), ~(e) ~} 142$

Table 4.18 Design component selection matrix for humid climates ${ }^{\text {(a), (d), (e) }}{ }^{\text {..... }} 143$

Table 4. 19 Bore hole data for the investigation site ...................................... 145

Table 4. 20 Input parameters for volume calculation module.......................... 148

Table 4. 21 Components of final covers and bottom liners of design alternatives proposed by preliminary design module in LFDSS ................................. 156

Table 4. 22 Layer specifications used in cover designs in HELP model (soil values are obtained from HELP database) ..................................................... 157

Table 4. 23 Final cover and bottom liner specifications of the investigated design

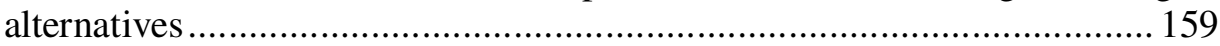

Table 4. 24 Input parameters used for POLLUTE simulations.......................... 160

Table 4.25 Stability analyses for the investigated design alternatives.............. 161 
Table 4. 26 Parameters used in stability module for factor of safety calculations 162

Table 4.27 Factor of safety values calculated by the stability module in LFDSS

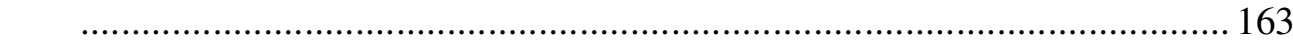

Table 4. 28 Volumes of soil used in landfill construction .

Table 4. 29 Landfill components of the design alternatives considered for cost

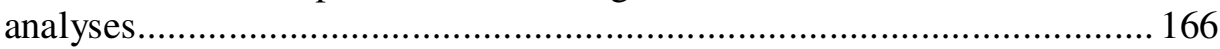

Table 4. 30 Amounts of soil to be used in landfill construction....................... 167

Table 4. 31 Amounts of soil to be used in landfill construction for additional

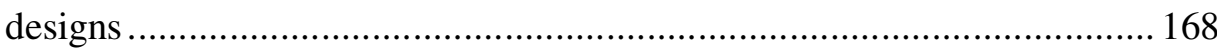

Table 4. 32 Major, additional and total costs of design alternatives ................. 170

Table 4. 33 Overall results of the landfill design simulations by LFDSS ......... 171

Table 4. 34 Bore well data for the investigation site ....................................... 174

Table 4. 35 Input parameters for volume calculation module.......................... 175

Table 4. 36 Components of final covers and bottom liners of design alternatives proposed by preliminary design module in LFDSS for X-city.................. 188

Table 4. 37 Final cover and bottom liner specifications of the investigated design alternatives for X-City.................................................................... 191

Table 4. 38 Input parameters used for POLLUTE simulations........................ 193

Table 4. 39 POLLUTE simulation results for leachate head and soil contamination

Table 4. 40 Stability analyses for the investigated design alternatives for X-City

Table 4. 41 Parameters used in stability module for factor of safety calculations for X-City ${ }^{\mathrm{f}}$.

Table 4. 42 Factor of safety values calculated by the stability module in LFDSS

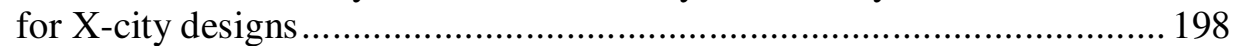

Table 4. 43 Volumes of soil used in landfill construction for X-City landfill .... 200

Table 4. 44 Landfill components of the design alternatives considered for cost analyses

Table 4. 45 Amounts of soil to be used in landfill construction for X-City landfill

Table 4. 46 Major, additional and total costs of design alternatives for X-City . 203

Table 4. 47 Overall results of the landfill design simulations by LFDSS for X-City

Table E. 1Coding of the simulations

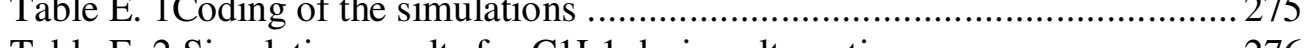

Table E. 2 Simulation results for C1L1 design alternative ............................. 276

Table E. 3 Simulation results for C1L2 design alternative ............................. 277

Table E. 4 Simulation results for C1L3 design alternative ............................ 278

Table E. 5 Simulation results for C1L4 design alternative over low hydraulic

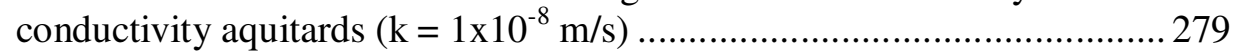

Table E. 6 Simulation results for C1L4 design alternative over high hydraulic

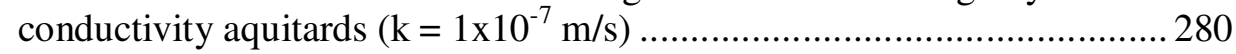

Table E. 7 Simulation results for C1L5 design alternative over low hydraulic

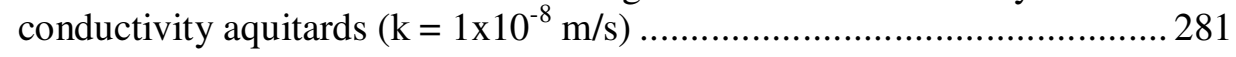


Table E. 8 Simulation results for C1L5 design alternative over high hydraulic conductivity aquitards $\left(\mathrm{k}=1 \times 10^{-7} \mathrm{~m} / \mathrm{s}\right)$...

Table E. 9 Simulation results for C1L6 design alternative over low hydraulic conductivity aquitards $\left(\mathrm{k}=1 \times 10^{-8} \mathrm{~m} / \mathrm{s}\right)$

Table E. 10 Simulation results for C1L6 design alternative over high hydraulic

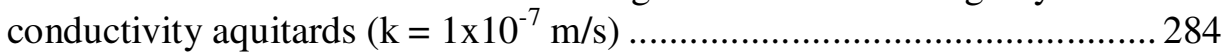

Table E. 11 Simulation results for C2L1 design alternative ..........................2285

Table E. 12 Simulation results for C2L2 design alternative ............................ 286

Table E. 13 Simulation results for C2L3 design alternative ........................... 287

Table E. 14 Simulation results for C2L4 design alternative over low hydraulic conductivity aquitards $\left(\mathrm{k}=1 \times 10^{-8} \mathrm{~m} / \mathrm{s}\right)$

Table E. 15 Simulation results for C2L4 design alternative over high hydraulic conductivity aquitards $\left(\mathrm{k}=1 \times 10^{-7} \mathrm{~m} / \mathrm{s}\right)$

Table E. 16 Simulation results for C2L5 design alternative over low hydraulic conductivity aquitards $\left(\mathrm{k}=1 \times 10^{-8} \mathrm{~m} / \mathrm{s}\right)$.

Table E. 17 Simulation results for C2L5 design alternative over high hydraulic conductivity aquitards $\left(\mathrm{k}=1 \times 10^{-7} \mathrm{~m} / \mathrm{s}\right)$

Table E. 18 Simulation results for C2L6 design alternative over low hydraulic conductivity aquitards $\left(\mathrm{k}=1 \times 10^{-8} \mathrm{~m} / \mathrm{s}\right)$

Table E. 19 Simulation results for C2L6 design alternative over high hydraulic

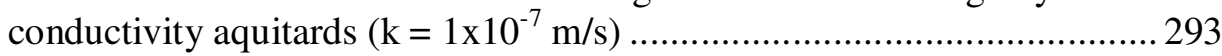

Table E. 20 Simulation results for C3L1 design alternative ............................ 294

Table E. 21 Simulation results for C3L2 design alternative ........................... 295

Table E. 22 Simulation results for C3L3 design alternative ...........................2 296

Table E. 23 Simulation results for C3L4 design alternative over low hydraulic conductivity aquitards $\left(\mathrm{k}=1 \times 10^{-8} \mathrm{~m} / \mathrm{s}\right)$

Table E. 24 Simulation results for C3L4 design alternative over high hydraulic conductivity aquitards $\left(\mathrm{k}=1 \times 10^{-7} \mathrm{~m} / \mathrm{s}\right)$

Table E. 25 Simulation results for C3L5 design alternative over low hydraulic conductivity aquitards $\left(\mathrm{k}=1 \times 10^{-8} \mathrm{~m} / \mathrm{s}\right)$

Table E. 26 Simulation results for C3L5 design alternative over high hydraulic

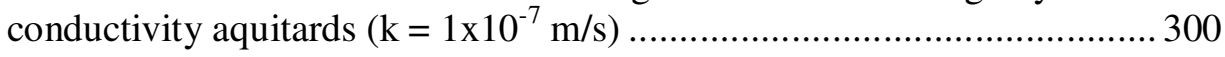

Table E. 27 Simulation results for C3L6 design alternative over low hydraulic conductivity aquitards $\left(\mathrm{k}=1 \times 10^{-8} \mathrm{~m} / \mathrm{s}\right)$

Table E. 28 Simulation results for C3L6 design alternative over high hydraulic conductivity aquitards $\left(\mathrm{k}=1 \times 10^{-7} \mathrm{~m} / \mathrm{s}\right)$ 302 


\section{LIST OF FIGURES}

\section{FIGURES}

Figure 1. 1 Landfill scheme......................................................................... 2

Figure 2.1 Progression of coupling methodologies (Brandmeyer and Karimi, 2000) .9

Figure 2. 2 One-way data transfer (Brandmeyer and Karimi, 2000)................. 10

Figure 2. 3 Loose coupling (Brandmeyer and Karimi, 2000) ............................. 11

Figure 2. 4 Shared coupling (a) GUI coupling, (b) data coupling (Brandmeyer and

Karimi, 2000) ................................................................................ 12

Figure 2. 5 Joined coupling (a) embedded coupling, (b) integrated coupling

(Brandmeyer and Karimi, 2000) ............................................................. 13

Figure 2. 6 Tool coupling (Brandmeyer and Karimi, 2000) ............................. 14

Figure 2. 7 Schematics of EDSS (Lukasheh et al., 2001) ................................. 16

Figure 2. 8 EDSS conceptual components (Poch et al., 2003)........................... 16

Figure 2. 9 Five-level EDSS architecture (Poch et al., 2003) ............................ 19

Figure 2. 10 Conceptual model for DSS development of IMPAQT (Lim et al.,

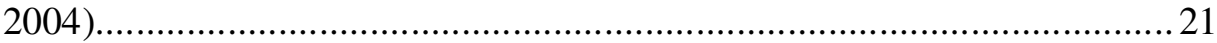

Figure 2. 11 Software linkage in TUI (Lam et al., 2004) ................................. 22

Figure 2. 12 Screen caption from FRAMES (Ho et al., 2004) ...........................23

Figure 2. 13 Hybrid intelligent approach to supervise WWTP (Poch et al., 2003)

25

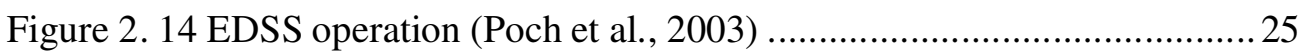

Figure 2. 15 Structure of DSS (Adenso-Diaz et al., 2005) ............................... 26

Figure 2. 16 Wrapping technique (Oxley et al., 2004) ....................................2 27

Figure 2. 17 MODULUS DSS graphical user interface (Oxley et al., 2004)....... 27

Figure 2.18 A TUI for extracting results from the hydrodynamic model to be used by box model (University of Waterloo, Delft Hydraulics, and United Nations University, 2000)

Figure 2.19 Creating rules in expert system (University of Waterloo, Delft

Hydraulics, and United Nations University, 2000).................................. 30

Figure 2.20 A simple rule-base for defining water quality (University of

Waterloo, Delft Hydraulics, and United Nations University, 2000)............. 30

Figure 2. 21 Profiles in HELP model (Waterloo Hydrogeologic, 2002) .............. 34

Figure 2. 22 Potential slip surfaces in excavation slopes (Sharma and Lewis,

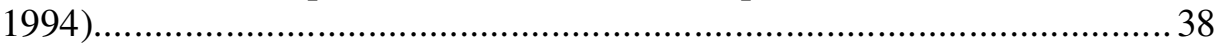


Figure 2. 23 Potential slip surfaces in landfills: (a) failure through refuse alone, (b) failure along liner system, (c) composite surface through refuse and liner system (Sharma and Lewis, 1994)......................................................... 39

Figure 2. 24 Effect of leachate head on liner at lined landfill site on FS value (Koerner and Soong, 2000).................................................................... 41

Figure 3. 1 Conceptual model for the DSS ..................................................... 45

Figure 3. 2 Hydrogeologic environment classes. S and U denote hydrogeologic environment subclasses that are suitable or unsuitable for landfill siting, respectively.....

Figure 3. 3 Hydraulic conductivity functions for (a) uniform sand (b) sand, (c) fine sand, (d) uniform silt, (e) silt, and (f) silt tailings..................................52

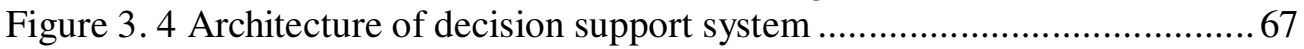

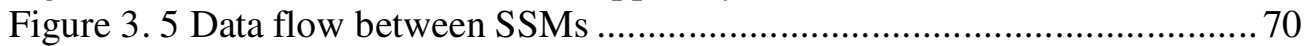

Figure 3. 6 Graphical user interface (GUI) coupling methodology.................... 73

Figure 3.7 Data flow in preliminary design phase in LFDSS ........................... 77

Figure 3. 8 Screenshot of LFDSS for the Volume Calculation Module ............... 80

Figure 3.9 Structure of decision tree to construct the rule base in preliminary design (Only a part of the branches are demonstrated due to space limitation)

Figure 3. 10 Screenshot of LFDSS for the Preliminary Design Knowledge Base 83

Figure 3.11 Data flow in detailed/final design phase in LFDSS ........................ 84

Figure 3.12 2D demonstration and excavation, fill, and surface volumes of a specified landfill on Virtual Landfill -VLF ............................................ 86

Figure 3.13 3D representation of landfill excavation and final cover in Virtual

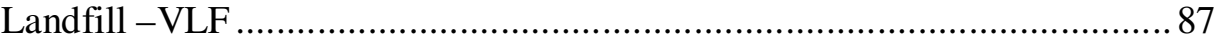

Figure 3. 14 Presenting the available clay layer beneath the landfill in Virtual

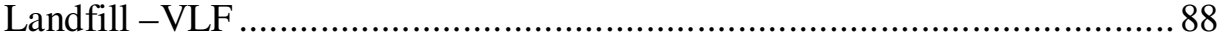

Figure 3. 15 Presenting the groundwater flow direction and aquifer depth in

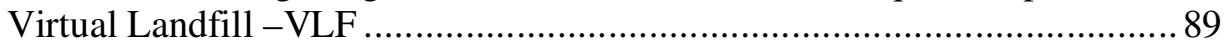

Figure 3. 16 Soil and design input window for HELP model in LFDSS............. 93

Figure 3. 17 Run menu for HELP model in LFDSS ......................................... 94

Figure 3.18 Execution of HELP model within the LFDSS .............................. 94

Figure 3. 19 Presentation of infiltration rate and HELP output data in LFDSS.... 95

Figure 3. 20 POLLUTE tabs in LFDSS. a) Parameters tab, b) Maximum concentrations tab, c) Concentrations at specified times .......................... 97

Figure 3. 21 POLLUTE execution from Maximum Concentrations tab in LFDSS

Figure 3. $22 \mathrm{FS}$ values vs. average seismic coefficient $\left(\mathrm{C}_{\mathrm{s}}\right)$ as guidance in LFDSS

(Koerner and Soong, 2005) .............................................................. 105

Figure 3. 23 Screenshots of Stability Analysis Module in LFDSS ................... 106

Figure 3. 24 Screenshot of cost estimation module in LFDSS ........................ 109

Figure 3. 25 Saving the results in LFDSS .................................................. 110

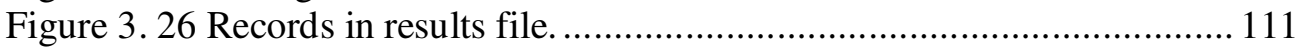

Figure 4. 1 Hydraulic conductivity change with depth for a uniform sand (US) 115 
Figure 4. 2 Change in the harmonic mean hydraulic conductivity of the vadose zone with varying sandy (S) vadose zone thickness

Figure 4. 3 Change in (a) the effective hydraulic conductivity of the overall barrier system and (b) the steady-state leakage rates with varying sandy (S) vadose zone thickness

Figure 4. 4 Normalized steady-state leakage rates with varying coarse textured vadose zone thickness

Figure 4. 5 Hydraulic conductivity change with depth for a silt ( $\mathrm{Si}$ )

Figure 4. 6 Change in the harmonic mean hydraulic conductivity of the vadose zone with varying silty $(\mathrm{Si})$ vadose zone thickness

Figure 4. 7 Change in (a) the effective hydraulic conductivity of the overall barrier system and (b) the steady-state leakage rates with varying silty $(\mathrm{Si})$ vadose zone thickness

Figure 4. 8 Normalized steady-state leakage rates with varying fine textured vadose zone thickness

Figure 4. 9 City map for Siirt

Figure 4. 10 Topographic map of Siirt landfill site and location of the bore wells in the investigation area

Figure 4. 11 Infrastructure Plan for City of Siirt .......................................... 147

Figure 4. 12 Presentation of topography and clay layers for Siirt landfill in VLF.

Figure 4. 13 Input data for VLF model and volume calculations

Figure 4. 14 Landfill excavation and fill areas by VLF -excavation areas are shown with light blue, and fill areas are shown with dark blue....

Figure 4. 15 Surface fill by VLF -lighter shades indicate higher elevations on the final cover.

Figure 4. 16 Demonstration of availability of clay layers at the base of the landfill by VLF -green color (within the landfill borders) indicates the presence of the clay layer, whereas red color indicates the absence of clay layer after excavation.

Figure 4. 17 3D demonstration of landfill without (a) and with (b) final cover by VLF

Figure 4. 18 Schematic view of the surface area of the landfill ....................... 164

Figure 4. 19 Location of the bore wells in the investigation area ................... 174

Figure 4. 20 Presentation of topography, clay layers, and groundwater depth and flow direction in VLF. Clay layers, indicated with orange color (such that darker zones indicated a clay layer thickness around $11 \mathrm{~m}$, and lighter zones indicated clay layer thickness around $5 \mathrm{~m}$ ). Purple arrows indicated groundwater direction and depth (such that, darker purple color indicated a groundwater depth of maximum $12 \mathrm{~m}$, and lighter purple colors indicated a groundwater depth of minimum $3 \mathrm{~m}$ ).

Figure 4. 21 Orientation of the landfill to the given site (a) longer side in the direction of groundwater flow (b) longer side perpendicular to the groundwater flow 
Figure 4. 22 Input data for VLF model and volume calculations for the case in which the landfill length is perpendicular to groundwater flow.....

Figure 4. 23 Landfill excavation (light blue) and fill (dark blue) areas by VLF landfill length perpendicular to groundwater

Figure 4. 24 Surface fill by VLF (lighter shades indicate higher elevations on the final cover) -landfill length perpendicular to groundwater.

Figure 4. 25 Demonstration of availability of clay layers at the base of the landfill by VLF -green color (within the landfill borders) indicates the presence of the clay layer, whereas red color indicates the absence of clay layer after excavation -landfill length perpendicular to groundwater.....

Figure 4. 26 3D demonstration of landfill with and without final cover by VLF landfill length perpendicular to groundwater

Figure 4. 27 Input data for VLF model and volume calculations for the case in which the landfill length is in the direction of groundwater flow....

Figure 4. 28 Landfill excavation (light blue) and fill (dark blue) areas by VLF landfill length in the direction of groundwater flow.

Figure 4. 29 Surface fill by VLF (lighter shades indicate higher elevations on the final cover) -landfill length in the direction of groundwater flow

Figure 4. 30 Demonstration of availability of clay layers at the base of the landfill by VLF -green color (within the landfill borders) indicates the presence of the clay layer, whereas red color indicates the absence of clay layer after excavation -landfill length in the direction of groundwater flow............... 186

Figure 4. 31 3D demonstration of landfill with and without final cover by VLF landfill length in the direction of groundwater flow ................................. 186

Figure 4. 32 Schematic view of the surface area of the landfill for X-City ........ 199

Figure A. 1 Design alternatives having evapotranspiration final cover $-\mathrm{C} 1$...... 226

Figure A. 2 Design alternatives having extensive engineering design final cover $\mathrm{C} 2$ 227

Figure A. 3 Design alternatives having intermediate design final cover -C3.... 228 Figure B. 1 Preliminary Design module in LFDSS ......................................... 230 Figure B. 2 A rule file defined in preliminary design module in LFDSS .......... 231

Figure B. 3 HELP module under LFDSS..................................................... 232

Figure B. 4 Run sub-module under HELP in LFDSS .................................. 233

Figure B. 5 POLLUTE module in LFDSS -Parameters sub-module................. 234

Figure B. 6 POLLUTE module in LFDSS. a. Maximum concentrations submodule. b. concentrations at specified times sub-module ........................ 235

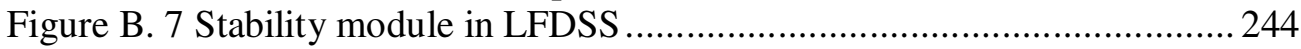

Figure B. 8 Cost calculation module in LFDSS .......................................... 245

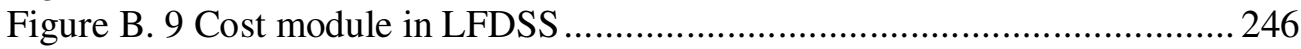

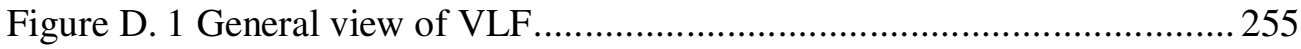

Figure D. 2 Displaying the elevation (topographic map) in VLF .................... 257

Figure D. 3 Zoom in and Zoom out functions............................................ 258

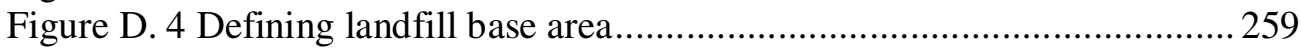

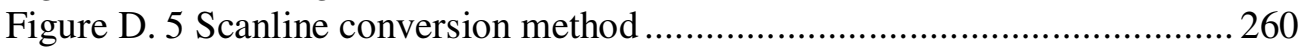

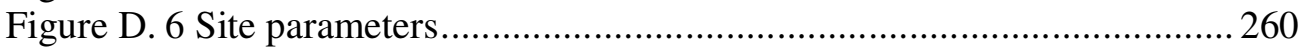


Figure D. 7 Cut and fill calculation results 261

Figure D. 8 (a) Empty edges as a result of horizontal projection (lighter shades)

(b) Areas that coincide (waving shades) and rest in the polygon (black shades) as a result of horizontal projection .............................................. 262

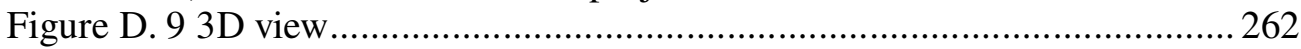

Figure D. 10 Exaggerated elevation difference ............................................263

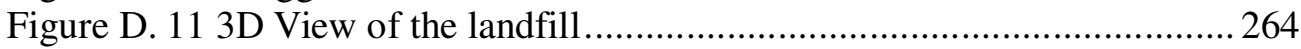

Figure D. 12 Layers window in VLF....................................................... 267

Figure D. 13 Demonstrating clay layers; darker red shade indicates clay layer thickness around $12 \mathrm{~m}$, and lighter red indicates clay layer thickness around 3

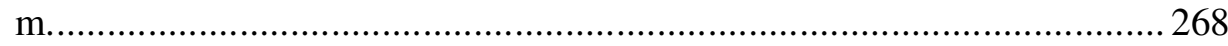

Figure D. 14 Demonstration of groundwater layers in VLF ...........................269

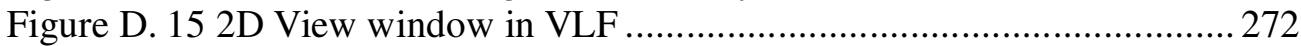

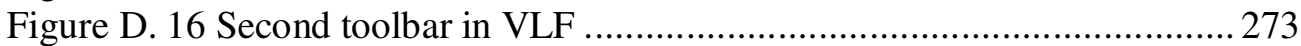

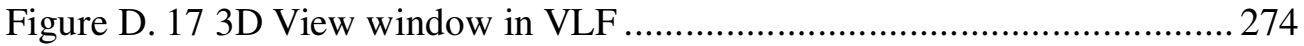




\section{CHAPTER 1}

\section{INTRODUCTION}

\subsection{The Landfill System}

A sanitary landfill is an engineered waste disposal system. In a broad sense, it is composed of a cover system (to minimize the moisture entrance into the system due to precipitation), waste contained, and a barrier system (to minimize leakage to the underlying soil and aquifer). The landfill is the first component of the landfill system. The other two components are soil (onto which the landfill is constructed) and aquifer (water containing and yielding formation) below the soil layer. Schematic view of a landfill system, together with its processes and components are shown in Figure 1.1.

Because "contamination-causing" or "alien" factor in this system is the sanitary landfill, the engineering properties of the landfill are of highest concern with respect to its impacts to the whole landfill system. Therefore, the components of a sanitary landfill should be identified in the first place. 


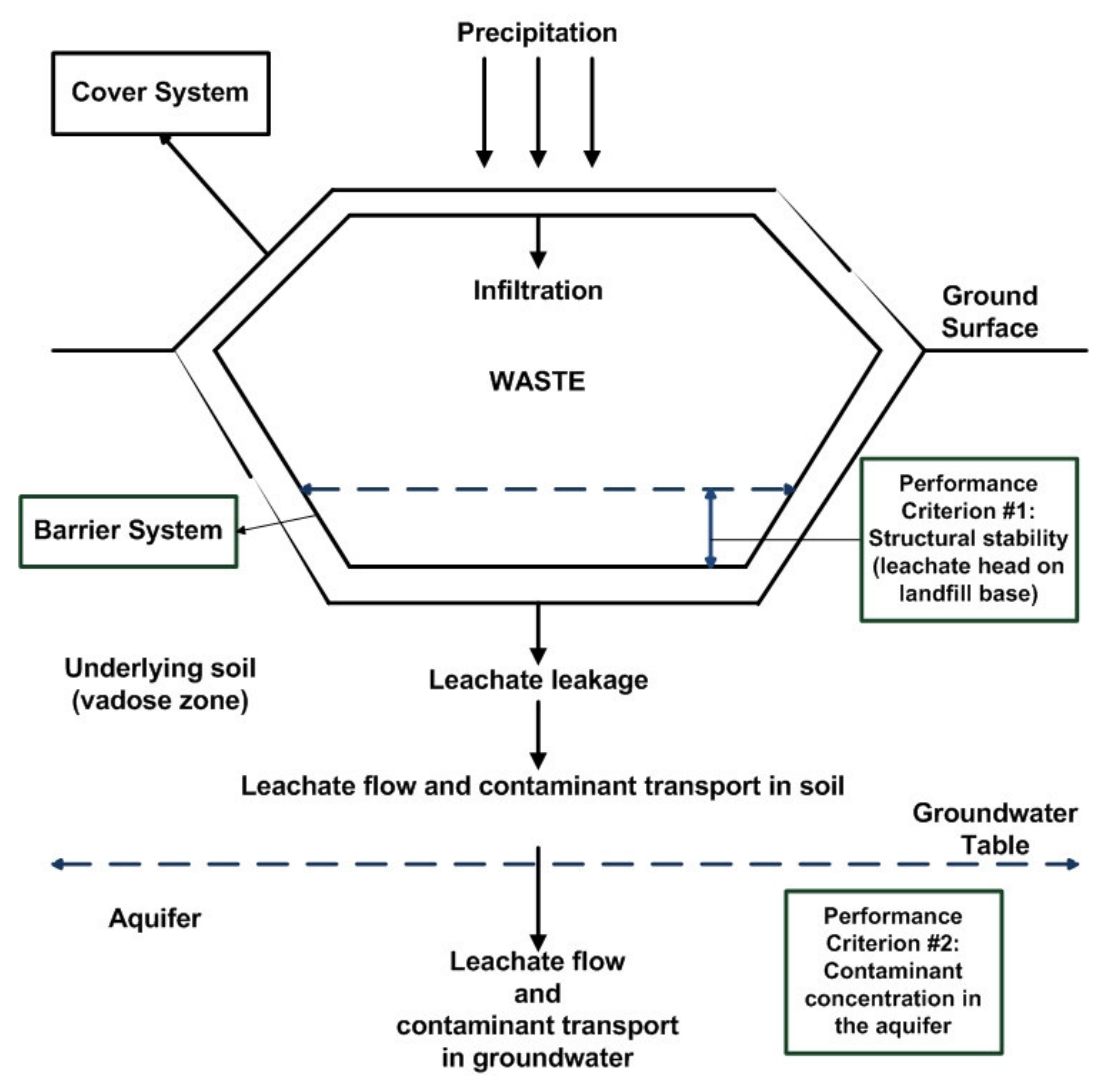

Figure 1. 1 Landfill scheme

Cover system (final cover) aims to minimize/control the moisture entrance to the landfill due to precipitation, as well as it protects the landfill from wind or soil actions and also protects the environment from the nuisance that can be caused by the landfill content. The cover system can be composed of vegetation layers, gas and leachate drainage layers, clay or mineral liners and synthetic liners. Barrier system (bottom liner) aims to minimize leakage to the underlying soil or aquifer, as well as providing a strong base to the landfill. It can be composed of leachate collection pipes and layers, clay or mineral liners, and synthetic liners. Soil and aquifer are the "natural" components of the landfill which are prone to the consequences of the landfill processes. Therefore, it is quite important to design a landfill that will result in the minimum possible contamination to the underlying soil and aquifer. 
Performance-based solid waste landfill design is an approach that enables the determination of the most appropriate landfill design components for the site and waste conditions providing the desired performance with minimal design details and low cost. With this design approach, the most appropriate design components of a landfill are selected to result in the best overall performance with respect to performance criteria considering the system variables. Design variables are climatic conditions of the site, site hydrogeology, waste thickness and size of the landfill with respect to waste load. Performance criteria are defined as maintaining a desired groundwater quality at the groundwater table, and not exceeding a predefined maximum leachate head on the bottom of the landfill at all times for cover and waste stability reasons. The design components are the final cover, leachate collection and bottom liner systems of the landfill. In this study, layers that do not effect leachate leakage into or from the landfill, such as gas drainage layers or protective liners, are not considered as components of cover (final) or barrier (bottom liner) systems. For the proposed methodology, a cover system can be composed of one of the three alternatives:

i. natural attenuation/evapotranspiration ' $E T$ '” cover -only natural soil;

ii. intermediate cover -drainage system coupled with compacted clay liner;

iii. extensive engineering cover -leachate collection system coupled with a compacted clay liner and a geomembrane.

Similarly, a barrier system can consist of one or a combination of the following:

i. a natural attenuation barrier - only natural soil/aquitard;

ii. a leachate collection system;

iii. a geomembrane in the barrier system;

iv. a compacted clay liner in the barrier system. 


\subsection{Objectives and Scope}

This thesis study aims to develop a decision support system to aid in the selection of design components considering the design variables and performance criteria for a performance-based landfill design. System simulation software models, a landfill base contour design model and calculation modules are aimed to be joined in DSS architecture. The decision of the design components leading to the best performance-based landfill design is made considering the knowledge, data and information gathered from the DSS.

The study is composed of two phases. Phase-I (base line studies) consists of four steps: (i) development of a conceptual model; (ii) selection of the appropriate system simulation models; i.e., final cover design model, and bottom liner design and subsurface transport model; (iii) determination of performance criteria for the evaluation of landfill design alternatives; and (iv) construction of the design component selection matrix. Phase-I intends to propose various landfill design alternatives considering the design variables and the performance criteria. The design component selection matrix is a design guidance and an input for the decision support system, to serve as a knowledge-base.

Phase-II (DSS development studies) also consists of four steps: (i) determination of the level of integration for the simulation models that constitute DSS, (ii) development of the landfill base contour design model (i.e. Virtual Landfill VLF) and calculation modules (i.e. waste and landfill volume, landfill stability, and major cost estimation modules), (iii) development of a DSS that accommodates system simulation models, landfill base contour design model and calculation modules; and (iv) application of the developed DSS to implement a performance-based landfill design. The purpose of Phase-II is to ease the decision process, which is composed of two steps. At the first step, appropriate design alternatives are identified and proposed by the knowledge-base (design 
component selection matrix). Then, the proposed alternatives are analyzed by system simulation software and calculation modules using site-specific values at the final landfill design phase. The selection of the suitable landfill design alternative(s) for the particular site is achieved by utilizing an automated system; namely, the decision support system.

In 2006, "Urban Solid Waste Management Strategic Plan" was prepared by the Ministry of Environment and Forestry in order to propose a solution to the solid waste problems of Turkey. According to the strategic plan, approximately 120 regional solid waste management complexes are proposed to be built in the midterm. The strategic plan clearly demonstrates a major requirement of solid waste landfills and points out that approximately 120 landfills will be constructed. In the context of the Strategic Plan, type-projects are planned to be developed regarding the needs of different regions in Turkey (MIMKO, 2006). The DDS developed in this study can be a useful tool to develop proposed type-projects by allowing the design of well-performing regional landfills at feasible costs.

Performance-based landfill design deals with numerous design variables, and design components to result in the predefined performance criteria. The interactions between these variables make the performance-based landfill design a complex environmental problem. Decision support systems can handle this complexity and guide the user in the selection of the best-performing design components of a landfill, under given design variables. However, as far as the author's knowledge is concerned, a landfill decision support system has not been reported in the literature, yet. Therefore in this study, a holistic landfill DSS is aimed to be designed to: (i) propose various design alternatives with respect to general design variables of a site, (ii) design the landfills starting from waste volume calculation, base contour design, and orienting the landfill with respect to natural in situ clay layer at the landfill base and the position of groundwater and flow direction, and (iii) simulate the proposed landfill designs using site-specific 
values to produce performance, cost and stability based evaluations. To the best of our knowledge, the developed DSS is unique in its kind, and distinguished from the other DDS presented in the literature, by being a holistic landfill design system that simultaneously handles the design of final cover system, bottom liner system, and the subsurface contaminant transport; as well as evaluates the results produced by simulation and design models and calculation modules in order to provide the user with guidance on decision making.

The thesis is organized into the following chapters. Chapter 2, Literature Review, presents the literature on modeling and system simulation, decision support systems, particularly environmental decision support systems, system simulation models, stability in landfills, and variables affecting landfill performance. Chapter 3, Methodology, is divided into two sections. In the first part, development of the design methodology and the design component selection matrix are explained. In the second part, development of the decision support system is presented. Chapter 4, Results and Discussion, presents effect of design variables on the performance of landfill designs, performance and stability results of the landfill simulations, the design component selection matrix, and results of two cases. Chapter 5 summarizes the main findings of the study and provides the important conclusions that are drawn from the results of the study. Finally, Chapter 6 offers topics for future research to make further progress along the present study. 


\section{CHAPTER 2}

\section{LITERATURE REVIEW}

\subsection{Simulation and Modeling}

Simulation and modeling provide a rapid means of investigating the expected response of a system to possible future changes, by undertaking the necessary computations which are commonly complex and data intensive. Model integration is an important goal because environmental management and studies are tending towards more holistic approaches. However, environmental models of different processes are seldom simple to link. To achieve model integration, existing models should be made fully accessible and integration software tools and standards should be provided. Object-oriented design, modular development and remodeling, the use of formalized modeling languages, development of integrated modeling frameworks and drag-and-drop style modeling environments are some of the practices that address to the aforementioned problems.

Specific for the purpose of this thesis study, there are environmental modeling software packages covering almost all environmental problem domains. Their number is growing fast due to the latest advances of computer technologies, allowing more complex models and simulations to be developed and run. These technologies can be complemented and run with geographic information systems (GIS) and expert systems (ES) by integrating them using a decision support 
system (DSS) framework (Lukasheh et al., 2001). The DSS and the methods for integration under a DSS framework are presented in the following sections.

\subsection{Coupling Methodologies}

When coupling models, it is important to identify the components required to link, resulting in a systems integration problem. There exist major obstacles to coupling models because of them being geography-specific or machine or library dependent; therefore, models often needed to be coupled in a heterogeneous, networked computing environment (Brandmeyer and Karimi, 2000). There have been many methodologies proposed by many researchers to come over these challenges. For example, Chou and Ding (1992) offered a cubic perspective using a data sharing method, a modeling method, and a user interface as the dimensions of the cube. However, some of the combinations, like shifting user interface and internal modeling cannot exist. A similar cubic approach also proposed by Lilbourne (1996), selecting functionality, interface, and integration as the dimensions. Nyerges (1992) developed four categories of coupling with GIS being isolated, loose, tight, and integrated. Loose coupling is the transfer of data between model and GIS. Tight coupling is the category in which either the model is embedded in GIS or GIS is embedded in the model. This methodology was also identified by Karimi and Houston (1996). Bivand and Lucas (2000) also presented four ways of linking GIS and modeling technologies similarly as loose coupling, tight coupling, system enhancement and full integration, with increasing degree of integration.

The synthesis of all the above approaches is presented by Brandmeyer and Karimi (2000), and this synthesized approach is widely accepted among modelers and researchers. They present five possible levels of integration: (1) one-way data transfer, (2) loose coupling (two-way data transfer), (3) shared coupling (sharing one component, graphical user interface -GUI or data storage), (4) joined 
coupling (sharing both components), (5) tool coupling (coupling under a modeling framework) (Brandmeyer and Karimi, 2000; Adenso-Diaz et al., 2005). Figure 2.1 demonstrates the progression of coupling methodologies. In this pyramid, the first level shows that in one-way data transfer, the extent of modeler interaction with component models is at minimum. At the second step (loose coupling), automation of data transfer is achieved. Shared coupling represents the level in which a GUI is constructed on top of the two previous steps. At the fourth step (joined coupling) sharing of data storage is possible, and finally the most advanced level of integration, tool coupling, allows the presence of integration and modeling tools under a framework. The advantages and disadvantages of the five coupling methodologies are presented by Brandmeyer and Karimi (2000).

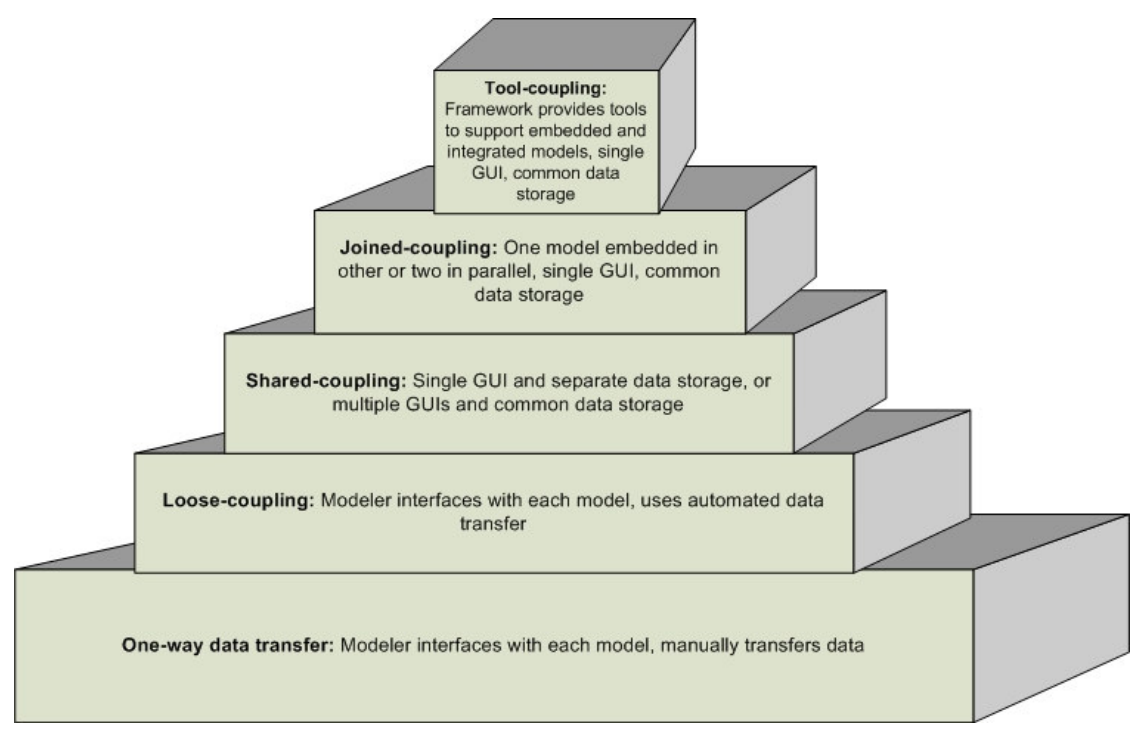

Figure 2.1 Progression of coupling methodologies (Brandmeyer and Karimi, 2000)

\subsubsection{One-way Data Transfer}

This level is presents a situation in which the only method for passing data is through a series of manual/non-automated transfer if models operate on binary data stored in different formats, are written in incompatible languages, and execute under different operating systems. Models remain completely separate at 
this level, and coupling means the transfer of the output data of one model as an input to the other model (Brandmeyer and Karimi, 2000). This method is represented in Figure 2.2.

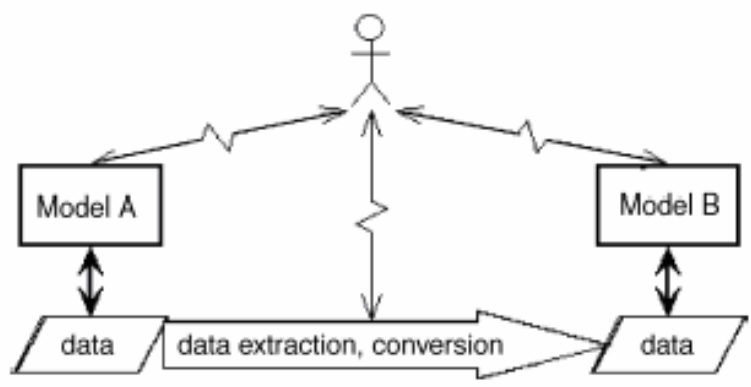

Figure 2. 2 One-way data transfer (Brandmeyer and Karimi, 2000)

\subsubsection{Loose Coupling}

Data may be interchanged automatically between models in a dynamic feedback during simulation. A series of steps involving extraction from one model's data structure and conversion to the other model's data structure is usually required. There are many examples of loosely coupled models in the literature like interface of GIS to SWAT hydrology model, GIS to CENTURY plant-soil ecosystem model, and a general circulation model (GCM) to a vegetation cover model (Brandmeyer and Karimi, 2000). Modeler interactions in loose coupling are shown in Figure 2.3. 


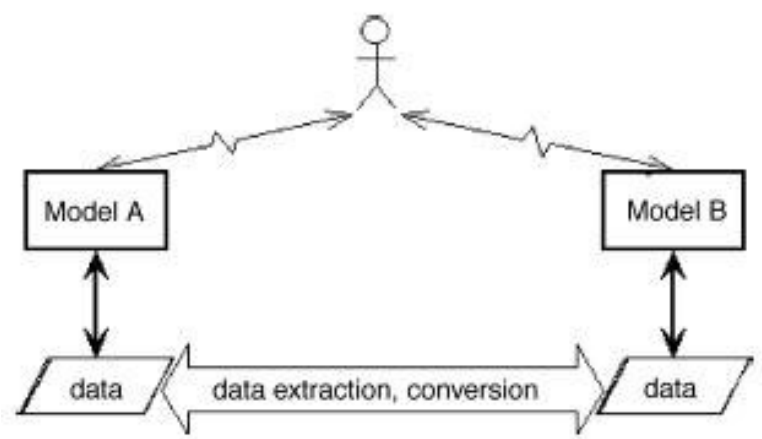

Figure 2. 3 Loose coupling (Brandmeyer and Karimi, 2000)

\subsubsection{Shared Coupling}

Models share a major component, either the graphical user interface (GUI) or data storage at this level. In GUI coupling, there is a single user interface linking the models, but the data is stored separately for each model. The modeler accesses to a virtual environment which the GUI provides, and does not deal with the locations or configurations of computer systems. The internal coupling method is hidden, making the models less confusing and more widely used. GUI coupling provides a user-friendly method of coupling (Brandmeyer and Karimi, 2000). In a project employing GUI coupling, Visual Basic provided a user interface for a GIS-based model and SWAT (Blodgett et al., 1995). In a Korean water quality study, GUI coupled two models and a spatial database (Kim et al., 1995).

In data coupling on the other hand, the user interacts directly with each model, but data files are shared by the models. This method is not frequently used because it requires models to share data storage and the proprietary nature of some models limit the ability of others to share data files. One way of sharing data is to use a published computer-dependent format such as Network Common Data Form (net $\mathrm{CDF}$ ) or generic, object-oriented open data exchange system (GOODES). Also, the personal computer industry provides additional methods of data sharing like dynamic data exchange (DDE), Open Database Connectivity (ODBC), and object 
linking and embedding (OLE). Unfortunately, none of these data-sharing methods currently supports all types of environmental modeling data, which are attribute data (integer, float, double, etc.), geospatial data (point, vector, volume, raster, etc.) and multimedia data (scanned images etc.) (Brandmeyer and Karimi, 2000). Two methods of shared coupling are demonstrated in Figure 2.4.
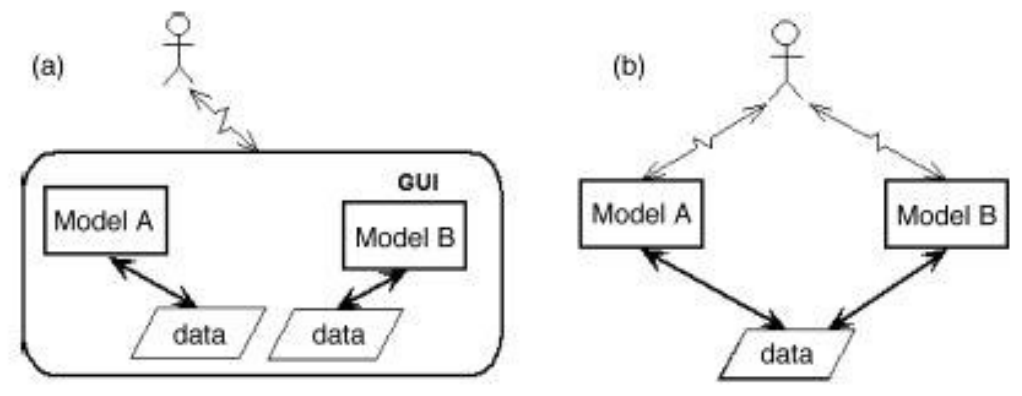

Figure 2. 4 Shared coupling (a) GUI coupling, (b) data coupling (Brandmeyer and Karimi, 2000)

\subsubsection{Joined Coupling}

The two coupling methodologies available at this level are embedded and integrated coupling. These methodologies use both the common GUI and common data storage but the structure of model interaction is different (Brandmeyer and Karimi, 2000). Methods of joined coupling are shown in Figure 2.5 . 


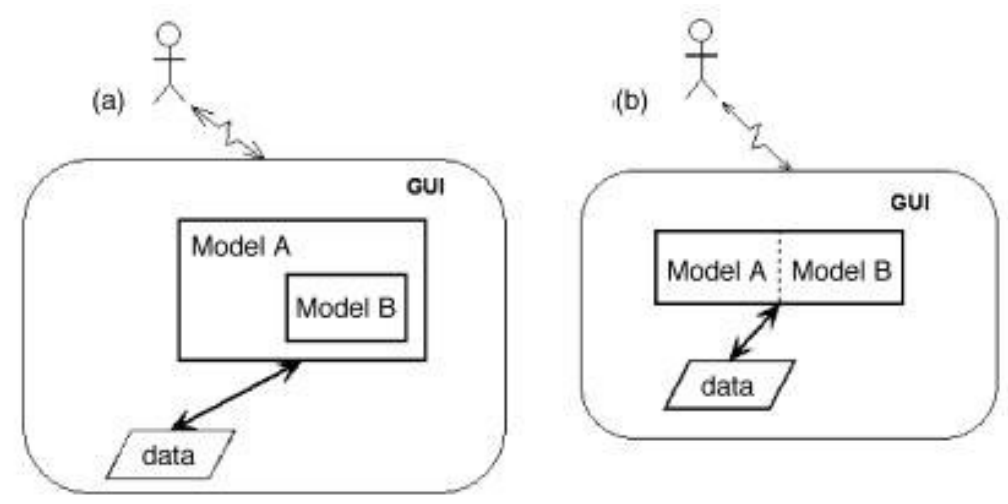

Figure 2. 5 Joined coupling (a) embedded coupling, (b) integrated coupling (Brandmeyer and Karimi, 2000)

Simple mathematical models may be easily embedded when adequate programming language is available. In embedded coupling, the models are in a master-slave relationship and the master model contains the slave model. Through the GUI, the user only interacts with the master model. Examples of this coupling methodology usually deal with embedding models in GIS (Brandmeyer and Karimi, 2000).

In integrated coupling, each model is integrated (peer of) the other model. The interaction of user with any model is provided through the common GUI. Also, functions and subroutines of one model may be reused between integrated models, by the use of shared libraries (Brandmeyer and Karimi, 2000).

\subsubsection{Tool Coupling}

Models are coupled using an overall modeling framework, which uses both shared and joined coupling, presenting a single GUI to the modeler and implementing shared data storage. The framework also provides functions and tools common to multiple models, manages data and computes resources (Brandmeyer and Karimi, 2000). This top-level methodology is presented in Figure 2.6. 


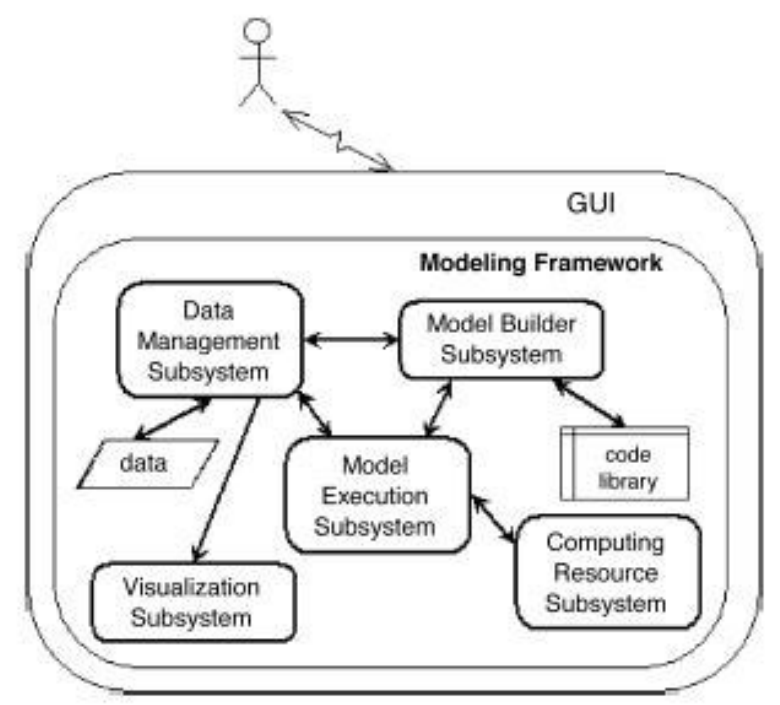

Figure 2. 6 Tool coupling (Brandmeyer and Karimi, 2000)

\subsubsection{Challenges in Coupling Environmental Models}

To be coupled, environmental models should have the capability with which two or more programs can share and process information regardless of their implementation language and platform. In another words, the models should be interoperable. Moreover, even though the models can share information, results will be meaningless if they do not have the same temporal or spatial scale. In this case, intermediate programs are required for scale conversions (Brandmeyer and Karimi, 2000).

In the framework of models, some models must be implemented to accept the output of another model as input (transformal mode); while in some cases the user may alter the input in an arbitrary manner (reactive mode). Moreover, the models may be originally implemented with different programming languages and software platforms. In this case, a program control that can understand and communicate with all of the models is required (Lam et al., 2004). During model integration, Lam et al. (2004) stated one of the most difficult challenges to hide 
information not alterable by the user and to highlight model input parameters that the user may change. They pointed out the requirement of cautions and guards to guide the input by the user to satisfy model assumptions and restrictions.

\subsection{Environmental Decision Support Systems (EDSS)}

Software systems that integrate models, or databases, or other decision aids, and package them in a way that decision-makers can use are commonly referred to as Decision Support Systems (DSS) (Rizzoli and Young, 1997). A more comprehensive definition for DSS states that it is a computer system that assists decision-makers in choosing between alternative beliefs or actions by applying knowledge about the decision domain to arrive at recommendations for the various options. An Environmental Decision Support System (EDSS) is an intelligent system that reduces the time in which decisions are made in an environmental domain, and improves the consistency and quality of these decisions (Poch et al., 2003). In a closed definition, EDSS is a computer system that combines several technologies to help environmental researchers make environmental decisions. A spatial database represented by the GIS, a knowledge base represented by an expert system (ES), a model base combining several environmental simulation models (SM), and a user interface are components of any EDSS (Lukasheh et al., 2001). Schematic of an EDSS shell and the building blocks of EDSS are shown in Figure 2.7 and 2.8 respectively. 


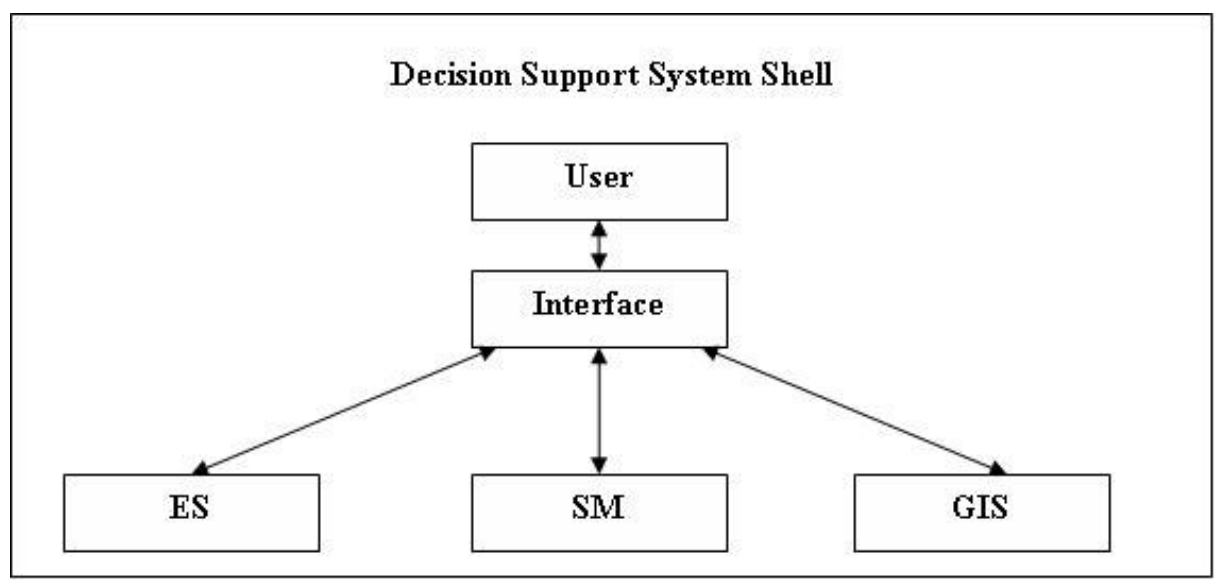

Figure 2. 7 Schematics of EDSS (Lukasheh et al., 2001)

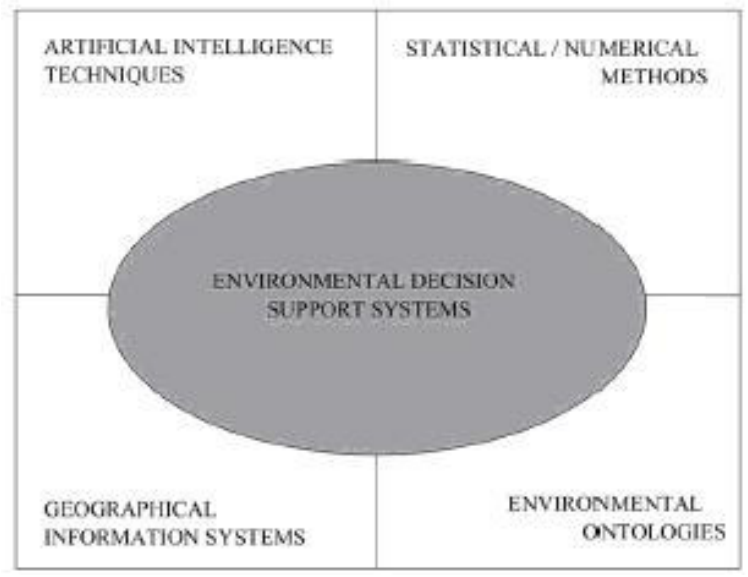

Figure 2. 8 EDSS conceptual components (Poch et al., 2003)

Environmental systems include physical resources of water, land, and air, as well as biological resources; and are characterized by fluxes of energy and materials within and between these physical and biological compartments. Because of environmental modeling systems' multidisciplinary nature, the users of these systems come from a wide range of disciplines. Therefore, software for use in modeling and managing environmental systems must be carefully designed and implemented according to the requirements of the particular type of end-user (Rizzoli and Young, 1997). Rizzoli and Young (1997) define three categories of users of EDSS as (i) Environmental scientist -who defines the problem domain, 
develops models and tests them; (ii) Environmental manager -who needs 'readyto-use" models for decision making, integrated in an EDSS; and (iii) Environmental stakeholder -who wants access to understanding about the responses of different parts of the system under proposed management decisions. This categorization brings the concept of "two-level DSS", (Soncini-Sessa at al., 1990), in which the environmental scientist employs EDSS as a modeling environment to develop new models and integrate these, while environmental manager and stakeholder -or, the end-users- can access the DSS knowledge in an easy and structured way.

The EDSS can be divided into two categories: (i) Problem-specific -can be used to solve problems relating to a specific domain of knowledge, and can be applied to different situations in the same problem domain, and (ii) Situation and problem-specific -intended to be applied to a particular problem in a given place, and is not flexible to be modified for use in new locations. The desirable features of an EDSS are the ability to acquire, represent and structure the knowledge; separation of data from models; ability to deal with a database; ability to provide expert knowledge; ability to be used efficiently for diagnosis, planning, management, and optimization; and ability to assist the user during problem formulation and selecting the solution methods (Rizzoli and Young, 1997).

In a review study conducted by Poch et al. (2003), it is observed that the range of environmental problems to which EDSSs have been applied is wide and varied. Most of the EDSSs are dealing with water management issues $(251 \%$ of the references), and these are followed by EDSSs on risk assessment (11.51\%) and forest management (111\%). Although landfill design and waste management problems can greatly benefit from the use of a DSS, very few DSSs were actually developed on the area of solid waste management and landfill design (Lukasheh et al., 2001). 


\subsubsection{Architecture and Development of EDSS}

The architecture of a DSS is based on the concept of DMM (Data, Dialog, Model). Data is the information that serves as the starting point for decision making, dialog is the information to the user in a user-adapted format, and model enables information that will help the user make decisions to be generated (Adenso-Diaz et al., 2005). Poch et al. (2003) propose an EDSS architecture based on five levels:

1. Data gathering: Original raw data are often defective, requiring a number of pre-processing procedures before being registered in an understandable and interpretable way.

2. Diagnosis: The reasoning models are used to infer the state of the process so that a reasonable proposal of actuation can be reached. This is accomplished with the help of statistical, numerical and artificial intelligence models.

3. Decision support level: The conclusions derived from the knowledgebased and numerical techniques are gathered and merged. litem Plans are formulated and presented as a list of general actions to solve a specific problem.

4. The set of actions to be performed to solve problems in the domain are considered. The system recommends not only the action or a sequence of actions, but also a value that has to be accepted by the decision-maker.

This five-level approach is presented in Figure 2.9 below: 


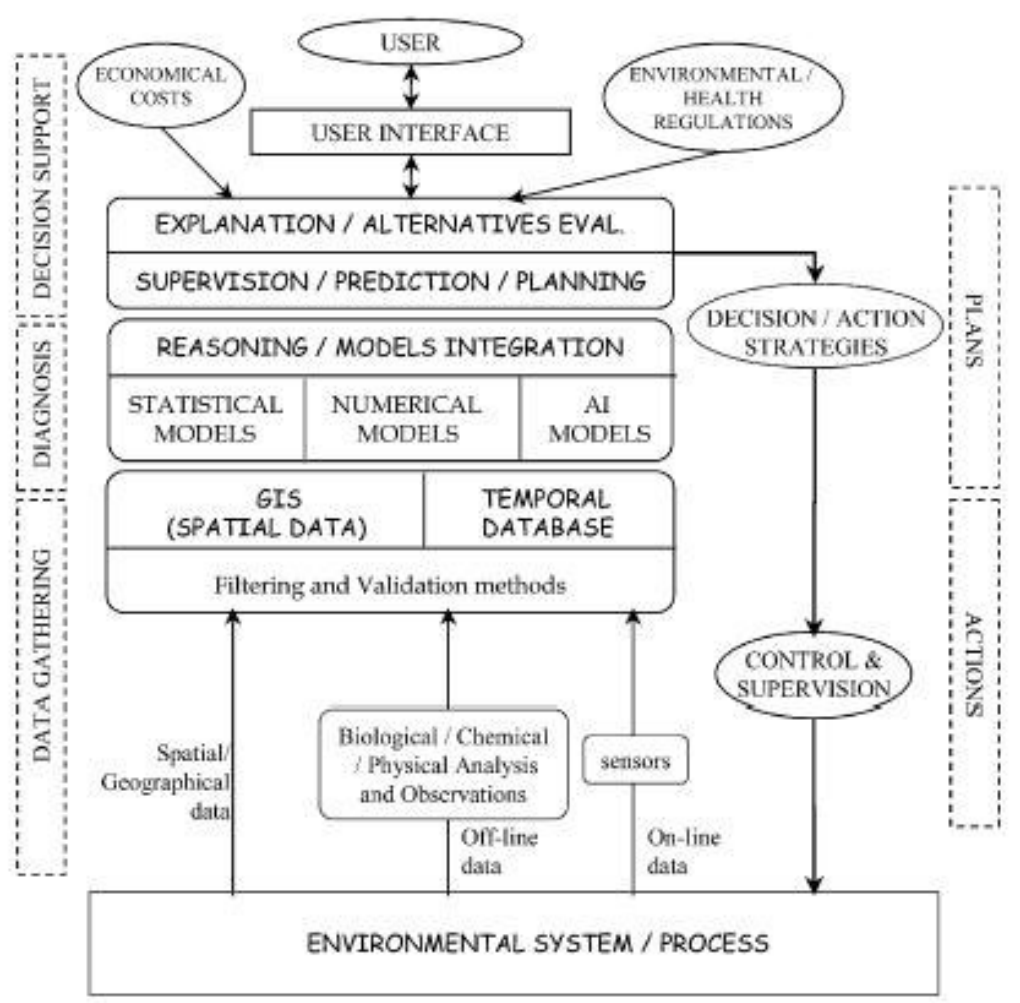

Figure 2. 9 Five-level EDSS architecture (Poch et al., 2003)

There are three generally accepted approaches for EDSS development and delivery. The techniques and their advantages and disadvantages are summarized as follows:

1. Using programming languages: This approach brings flexibility and coupling with techniques from model integration and reuse leads to high quality results with possible future extensions. However, using programming languages should usually be avoided because they require substantial amount of time, financial and human resources.

2. Using modeling and simulation software tools: This approach is very effective for generating EDSS prototypes and these can provide a test-bed for further investigation and development. However this approach is only 
achievable only if the software packages are structured to allow the interface to control their functions and access data stored in their files.

3. Using model integration and re-use techniques: A software framework for model integration allows the scientist to prototype several different EDSS using a wider set of software resources to satisfy the requirements of each EDSS. Therefore, it is advantageous over the standard tools of modeling and simulation. However, this approach is still under research (Rizzoli and Young, 1997; Lukasheh et al., 2001; Booty et al., 2001).

The first approach has the benefit of control in the model design and linkage; but as previously stated, it requires longer development time. The second and third approaches save on development time, but they require additional work to link up existing models. Usually, the second approach is used when previously developed models are suitable for the purpose of the system designer (Lam et al., 2004).

\subsection{EDSS Applications}

In this section, examples of decision support systems recently developed and applied in various environmental research areas are presented. At the end of the section, two particular systems (RAISON and FRAMES) offering an integration platform for environmental models are discussed and presented specifically at the end of this section.

IMPAQT (Integrated Modular Program for Air Quality Tools) is software in the form of a decision support system. It was developed to create a flexible framework which allows communication between various air quality tools with minimal system requirements. The objectives of IMPAQT are to help local authorities by increasing the efficiency of the air quality assessment process. The system links a transportation model, an emissions inventory, a dispersion model and a geographic information system (GIS). Transportation, emission, hourly 
meteorological and statistical meteorological data are types of data to be processed by the DSS. Interface modules were developed to process each type of data in the system (Lim et al., 2004). A conceptual model for the DSS is presented in Figure 2.10.

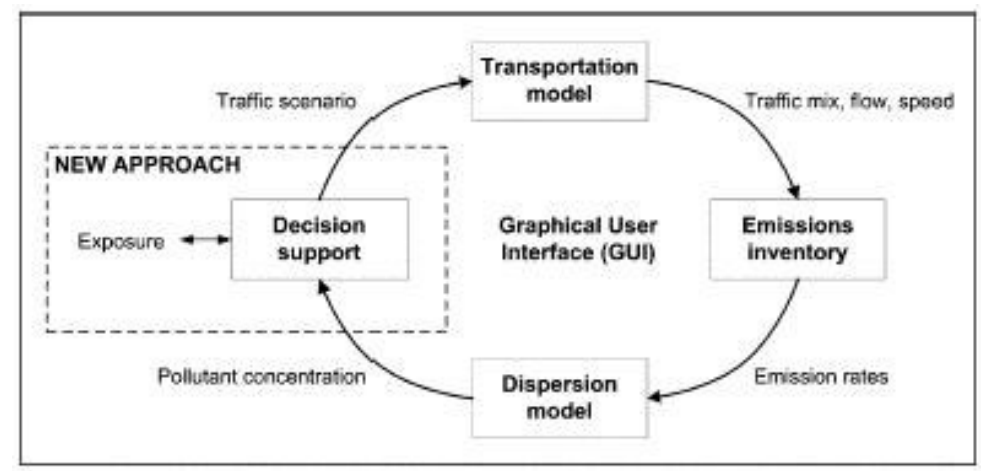

Figure 2. 10 Conceptual model for DSS development of IMPAQT (Lim et al., 2004)

A technical user interface (TUI) which can link meteorological, hydrological, terrestrial, hydrodynamic, and water quality models to simulate complex physical, chemical and biological processes is developed by Lam et al. (2004). The main goal of this TUI is to use the data and models in a simple, step-by-step and effective DSS. The developed DSS is aimed to help watershed managers to evaluate water turbidity and quality consequences of their management practices, prior to application. RAISON Object System (ROS) software, programmed with Visual Basic, is the core of linkage with other systems such as Access for database manipulation, Excel for watershed model, GIS maps, and the surface runoff model. A vital part of TUI is EnSim system, which offers visualization and animation tools for the results from hydrodynamic, transport, and dispersion models. EnSim is connected to ROS via component object model (COM) technologies in software design (Lam et al., 2004). Software linkage in TUI is presented in Figure 2.11. 


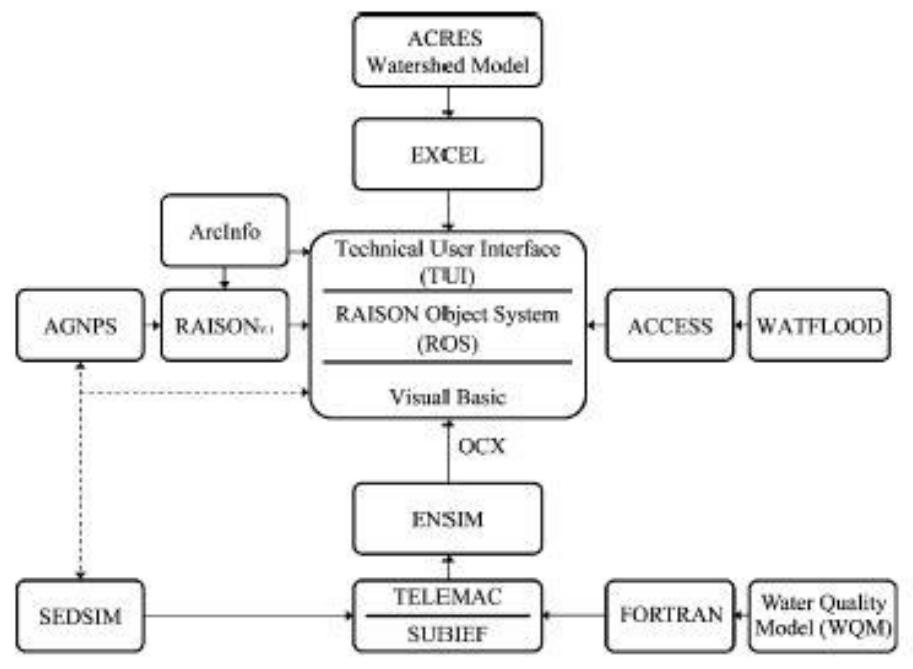

Figure 2. 11 Software linkage in TUI (Lam et al., 2004)

A probabilistic performance-assessment model and software tool was developed for evaluating the total system performance of long term landfill cover systems by Ho et al. (2004). Performance assessment is described by the authors as "an iterative technical analysis aimed at evaluating the performance of a disposal site with respect to regulatory compliance, often using probabilistic models" (Ho et al., 2004). Each scenario identified by the software contains a combination of models that represent process in vadose zone, saturated zone, air, etc. These process models describe water percolation through cover (HELP), radon gas transport through cover (RAECOM), source term release (MEPAS), vadose-zone transport (MEPAS), saturated zone transport (MEPAS), and human exposure (MEPAS). As these models do not originate from the same numerical code, they are integrated under a framework called FRAMES (Framework for Risk Analysis in Multimedia Environmental Systems). FRAMES system employs a GUI that helps user in setting up and simulating each model. A screen capture from FRAMES GUI is presented in Figure 2.12. 


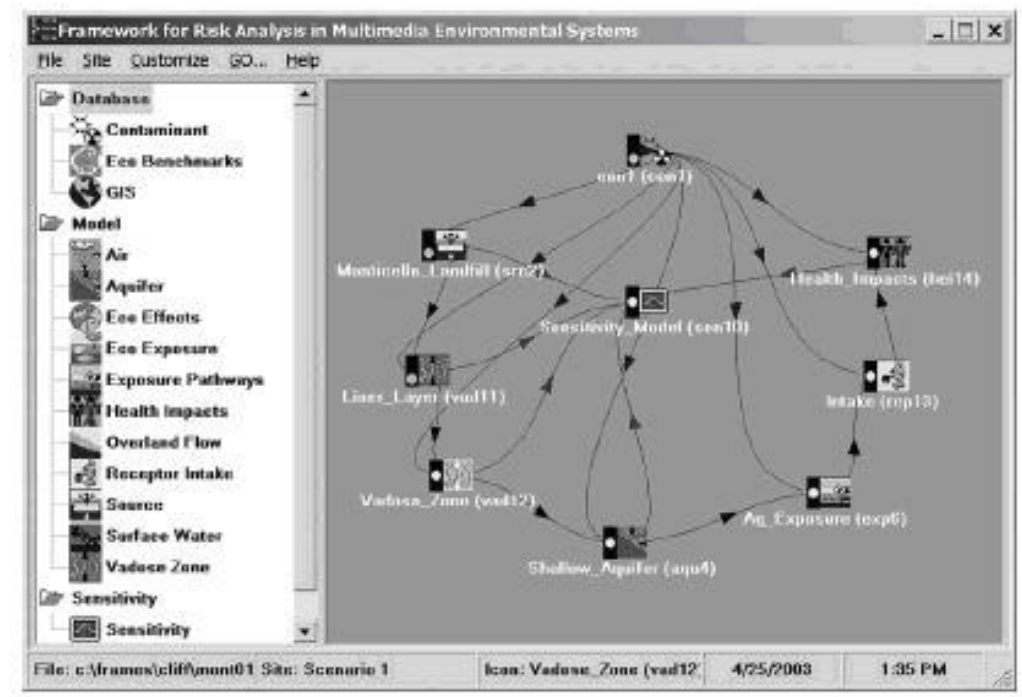

Figure 2. 12 Screen caption from FRAMES (Ho et al., 2004)

Short descriptions of many EDSS were presented in the review paper by Lukasheh et al. (2001). An environmental DSS shell system was developed combining ARC/INFO GIS and Nexpert Object expert system for the analysis and preparation of input data for HEC-1 rainfall runoff model by Djokic (1996). This DSS example has the spatial component (mostly characterized by a GIS); however, there are DSSs (like SLEUTH and MSW Management Systems Planning) laking this spatial component. SLEUTH (Shallow Landfill Evaluation Using Transport and Hydrology) was developed for design and remediation of shallow landfill burial systems (Ascough II et al., 1994). This DSS provides decision support for the design of landfill elements based on a multi-objective decision module embedded in HELP model. The Municipal Solid Waste Management Systems Planning (Barlishen et al., 1994) is a DSS developed in the area of waste management, to assist with the preliminary planning of municipal solid waste (MSW) management systems. It combines optimization, simulation and spreadsheet models to perform waste forecasting, technology evaluation, source separation, facility cost and operational data estimation, facility location, sizing and investment timing, and simulation of an existing or proposed MSW management system. 
DEEM (Dynamic Environmental Effects Model) is "a software framework intended to support multi-disciplinary modeling of terrestrial, aquatic and atmospheric processes" (Rizzoli and Young, 1997). It was developed by Argonne Laboratory at the University of Chicago, and if widely adopted, presented to become a standard for model integration and reuse. HYDRA project aims to integrate different existing modeling systems using a federated systems approach to architectural design into a unique EDSS for water quality management. It uses a GIS-based interface, and seeks to develop a GUI. EDSS developed by Environmental Programs Group at North Carolina Supercomputing Center can handle alternative formulations for advection, diffusion, clouds and chemistry models, to work on air quality modeling. The simulation management module of EDSS helps in connecting models to create more complex models (Rizzoli and Young, 1997).

An EDSS was developed by Poch et al. (2003) to supervise wastewater treatment plants (WWTP) and to select wastewater treatment and disposal systems in Catalonia. Rule-based reasoning models (expert system) and case-based reasoning models were selected to acquire knowledge and to form a knowledge-based DSS. The hybrid intelligent approach to supervise WWTP and EDSS operation are presented in Figure 2.13 and 2.14. 


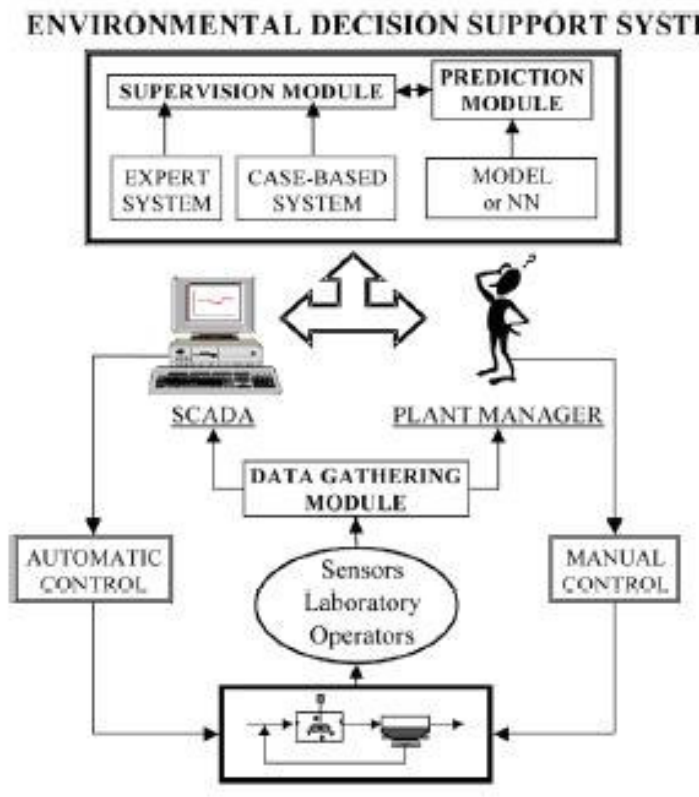

Figure 2. 13 Hybrid intelligent approach to supervise WWTP (Poch et al., 2003)

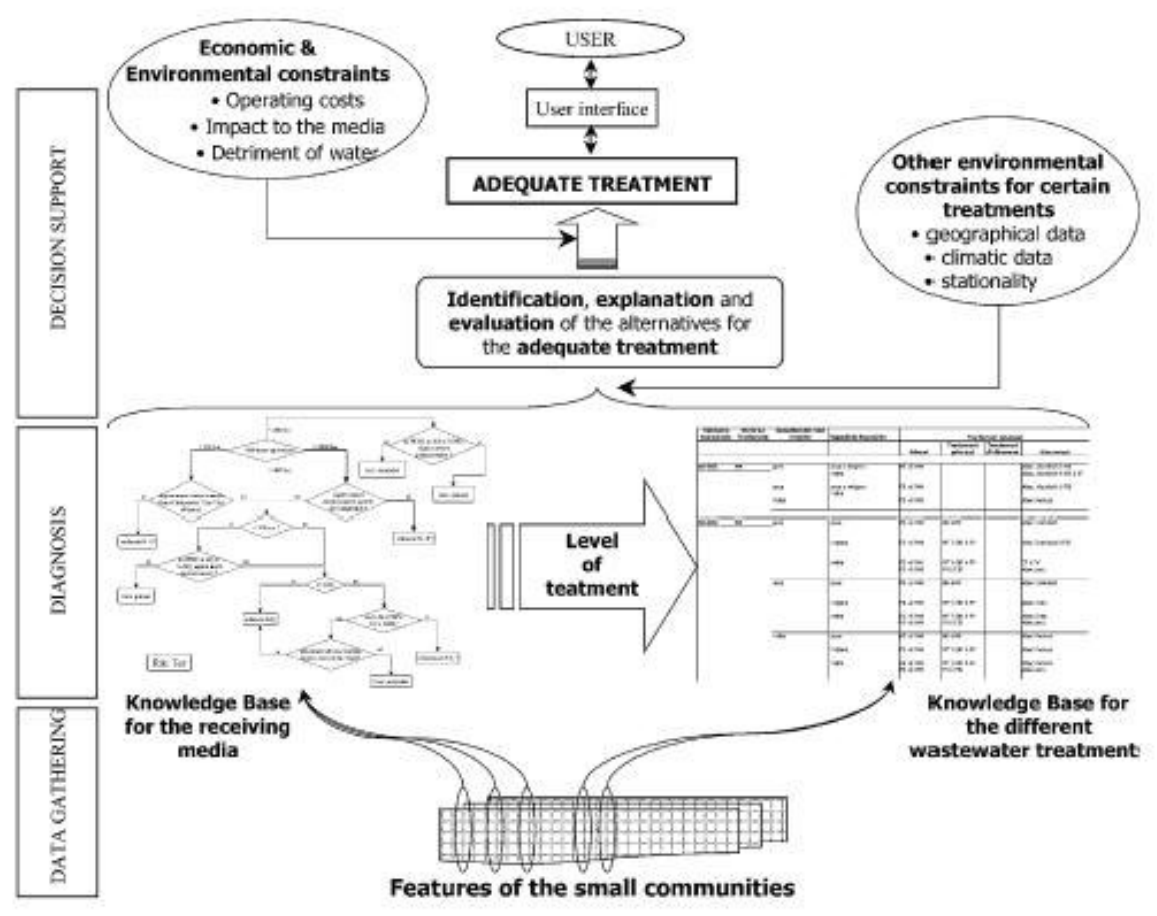

Figure 2. 14 EDSS operation (Poch et al., 2003) 
A GIS-based DSS was developed by Adenso-Diaz et al. (2005) for the evaluation of alternatives in wastewater collecting systems design. The DSS considers the criteria of cost, environmental quality and social cost as factors. A pseudocode was written for the search algorithm. A structure of the proposed system is given in Figure 2.15.

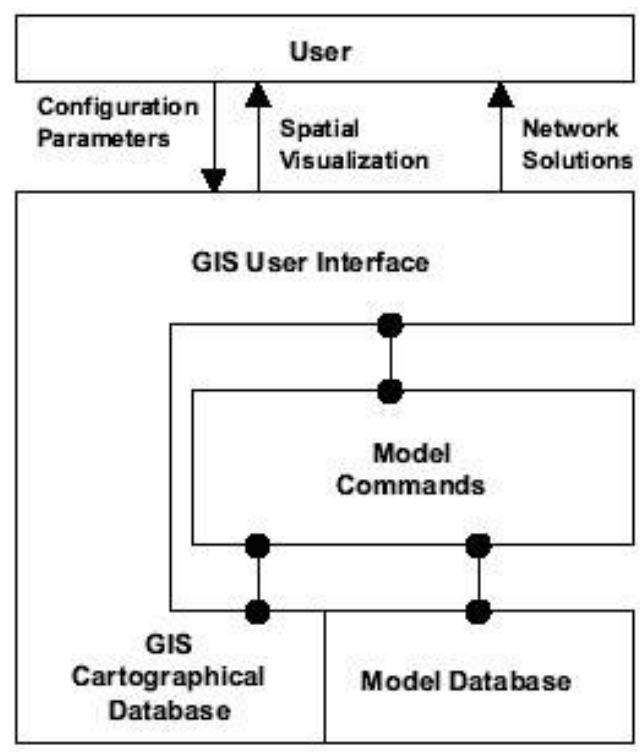

Figure 2. 15 Structure of DSS (Adenso-Diaz et al., 2005)

MODULUS project was developed to integrate research models to produce a tool to support integrated environmental decision making addressing physical, economic and social aspects of land degradation in the Mediterranean. 10 submodels (climate and weather, hillslope hydrology, plant growth, natural vegetation, groundwater, surface water, crop choice, irrigation and land use) having different spatial and temporal scales were integrated under MODULUS DSS. The DSS was built as an integrated model composed of a number of selfregistering COM components (ActiveX) called Model Building Blocks (MBB). Each MBB corresponds to the sub-models. The integration of existing models was achieved by the use of a wrapping technique without having to completely recode. In this technique, each sub-model is transformed from its native code into a 
MBB. This technique is represented in Figure 2.16. Also, the MODULUS DSS

GUI is presented in Figure 2.17 (Oxley et al., 2004).

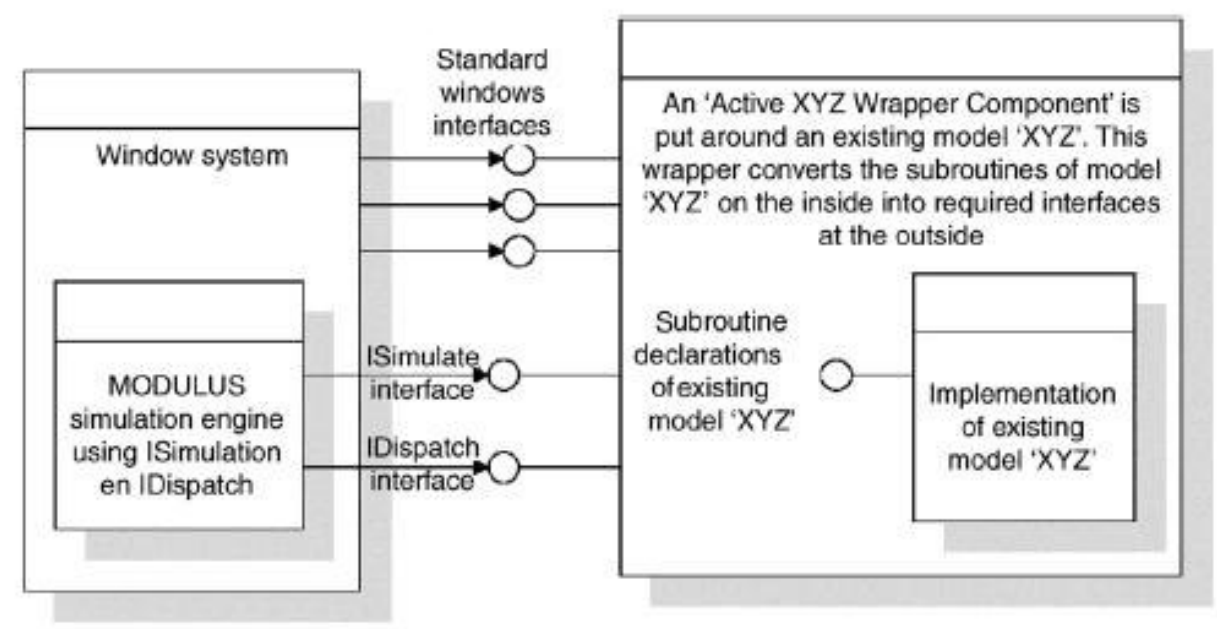

Figure 2. 16 Wrapping technique (Oxley et al., 2004)

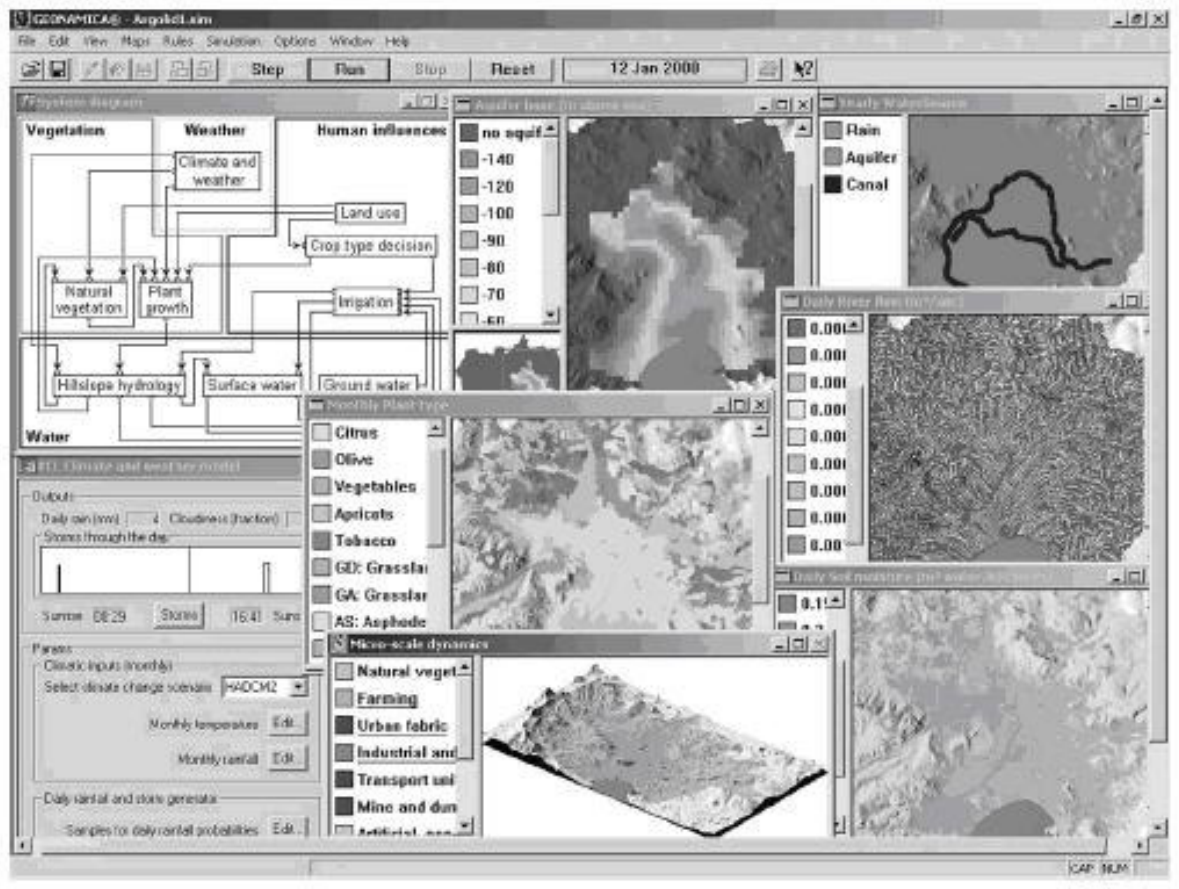

Figure 2. 17 MODULUS DSS graphical user interface (Oxley et al., 2004) 


\subsubsection{RAISON for Windows v1.0}

RAISON decision support system was designed based upon a knowledge-based approach which incorporates a hierarchy of tools. The system consists of database, spreadsheet, GIS layer, statistics, expert system, contouring, spatial visualization and graphs. RAISON design provides generic software tools for fast prototyping and practical implementation of EDSS. All the modules are directly linked with functions and tools including modeling interfaces, neural network, fuzzy logic, uncertainty analysis, animation, visualization, and optimization procedures. RAISON system imports data, text and graphics; and performs advanced environmental analysis, synthesis and prediction. RAISON database uses Microsoft Access 2.0 (*.mdb) files as the database standard. Worksheet is similar to any other commercial spreadsheets, which is designed to be fully integrated with all other modules. RAISON object system is the GIS module of the system. The statistics module includes basic statistics such as mean, median, mode, percentiles, hypothesis tests, normal and lognormal distribution analysis. RAISON expert system is a rule-based system with fuzzy logic. There are also neural network module, contour module, and visualization module in the system (Booty et al., 2001; Environment Canada, 2003). RAISON system accepts various types of data, text, maps and images from external sources. These are stored in its internal fully-linked database, map system and graphic components (University of Waterloo, Delft Hydraulics, and United Nations University, 2000).

The system is composed of two phases, technical user interface (TUI) and public user interface (PUI). TUIs are used by technical users to connect databases, rulebases and other information; whereas, PUIs are used by managers and stakeholders, or in public consultation meetings. TUIs, which form the basis for PUIs, are for more technical functions like converting the output of a three-

dimensional hydrodynamic model to be used as input to a water quality box model. The main purpose of the TUIs is to provide a human-machine interface to 
enable communication with software system. Some of the TUIs required by the RAISON model are an input/output display interface, a data extraction interface, and a control interface for specifying model parameters and initial concentrations to run models. As can be seen in Figure 2.18, these interfaces are implemented in a tool-bar format (University of Waterloo, Delft Hydraulics, and United Nations University, 2000).

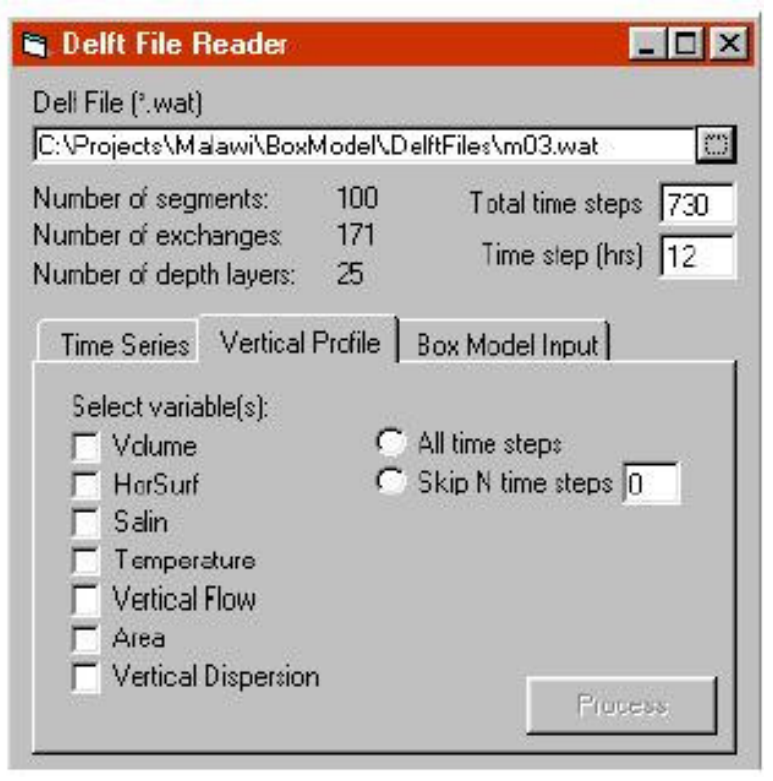

Figure 2. 18 A TUI for extracting results from the hydrodynamic model to be used by box model (University of Waterloo, Delft Hydraulics, and United Nations University, 2000)

RAISON system offers an expert system component, which is a rule-based system to facilitate consensus-building. A rule-base in RAISON system can be created using the Expert System toolbar. When this is selected, a window, divided into three regions, containing the empty rule-base opens (Figure 2.19). The regions are the top table for the parameters of the rule-base, bottom table for the rules of the rule-base, and the decision tree after the rule-base is created. Information on the parameters and rules should be entered by the user. The decision tree is generated automatically after the information is complete. The rules can be entered in a 
simple spreadsheet format and saved as a rule-base file (Figure 2.20) (University of Waterloo, Delft Hydraulics, and United Nations University, 2000).

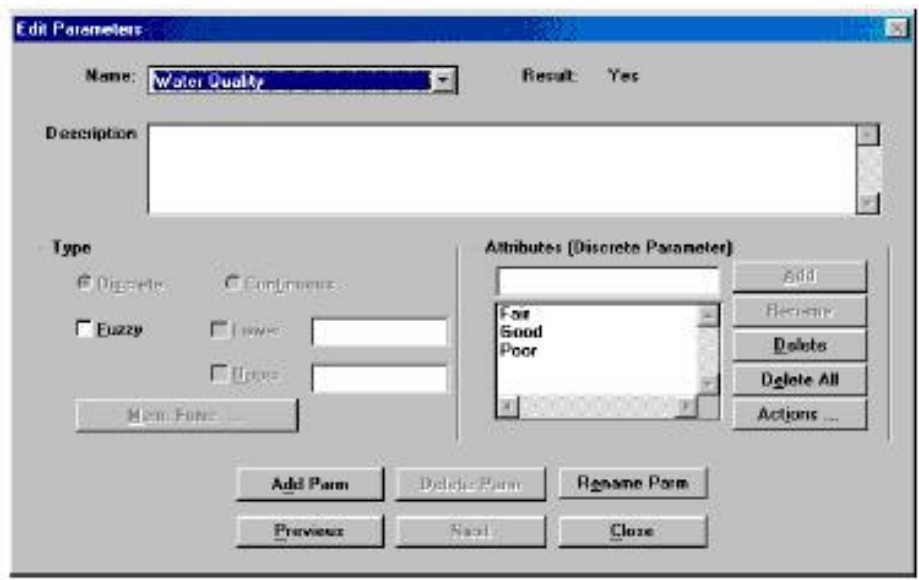

Figure 2. 19 Creating rules in expert system (University of Waterloo, Delft Hydraulics, and United Nations University, 2000)

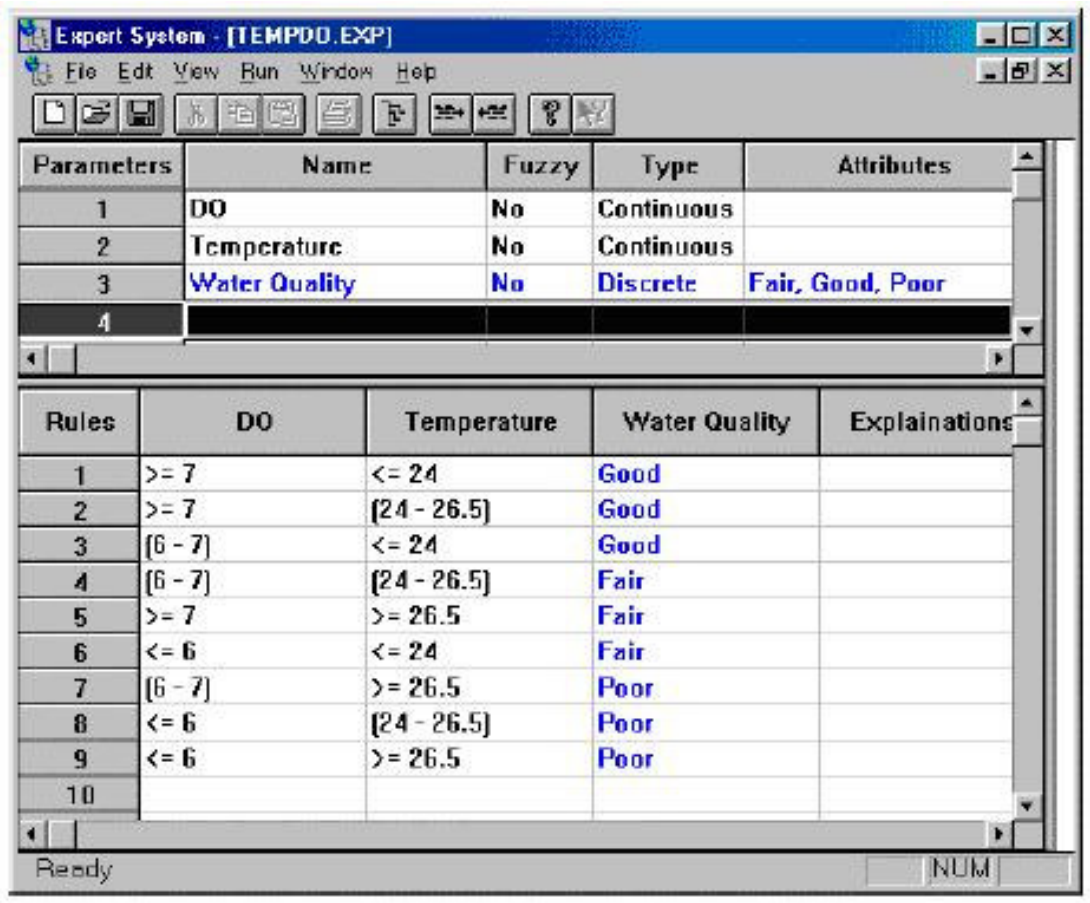

Figure 2. 20 A simple rule-base for defining water quality (University of Waterloo, Delft Hydraulics, and United Nations University, 2000) 
RAISON system not only integrates the databases, but also links some of the models or their results. There are three methods to incorporate models in RAISON. The first method is to run the model separately from RAISON and feed the model results into RAISON as input. The second method offers linking model to RAISON, by making use of RAISON databases, maps and graphical facilities. The third method is to rewrite the code for the model in a programming language to link to RAISON. One or all of the methods can be used to link models under RAISON system (University of Waterloo, Delft Hydraulics, and United Nations University, 2000).

\subsubsection{Framework for Risk Analysis for Multimedia Environment Systems (FRAMES)}

The FRAMES system provides a holistic approach to modeling in which source, fate and transport, exposure and health impact models, resolution (analytical, semi-analytical and numerical), and operating platforms can be combined as a part of overall assessment of contaminant fate and transport in the environment (Ho et al., 2004). In a broader sense, it is a software platform for selecting and implementing environmental software models for risk assessment and management problems. There are different types of modules present under FRAMES platform such as air, ecological effects, ecological exposure, exposure pathway, human health impacts, overland, receptor intake, saturated zone, source term, surface water, and vadose zone (Pacific Northwest National Laboratory, 2007). The system provides a user-friendly platform for integrating medium specific computer models, an extensive and editable contaminant database, a sensitivity/uncertainty module, and textual and graphical viewers for presenting model outputs. The disadvantage of this modeling framework is that only the simple, one-dimension, homogeneous and analytical component models run quickly under FRAMES (Ho et al., 2004). 


\subsection{HELP Model}

The Hydrogeologic Evaluation of Landfill Performance (HELP) is a quasi -twodimensional hydrologic model of water movement across, into, through and out of landfills (EPA, 1994). It is a versatile model for predicting landfill hydrogeologic processes and testing the effectiveness of landfill designs; therefore, enabling the prediction of landfill design failure resulting in groundwater contamination (Waterloo Hydrogeologic, 2002).

The model requires (i) weather -precipitation, solar radiation, temperature, evapotranspiration parameters, (ii) soil -porosity, field capacity, wilting point, and hydraulic conductivity, and (iii) engineering design data -liners, leachate and runoff collection systems, surface slope as input parameters. The profile structure can be multilayered, consisting of natural (soil) and artificial materials (waste, geomembranes) with an option to install horizontal drainage, and change the slope of profile parts like landfill cap, leachate collection and removal systems (Waterloo Hydrogeologic, 2002).

HELP uses numerical solution techniques that account for the effects of surface storage, snowmelt, runoff, infiltration, evapotranspiration, vegetative growth, soil moisture storage, lateral subsurface drainage, leachate recirculation, unsaturated vertical drainage, or leakage through soil, geomembrane, or composite liners. With in the Visual HELP 2.2.0.2 model, built-in database and tools like (i) weather generator, which is a tool for synthetic data generation for up to 100 years of daily values of precipitation, air temperature and solar radiation, and (ii) soil, waste and geomembrane database which contains parameters for 42 materials (Waterloo Hydrogeologic, 2002).

HELP model simulates the landfill as a set of profiles as shown in Figure 2.21. Vertical percolation layer is usually a topsoil, suitable for vegetative growth, or a 
waste layer. The primary purpose of a vertical percolation layer is to provide moisture storage. Lateral drainage layer is a material with moderate to high permeability, like sand and gravel, which is underlaid by a liner with a lateral drainage collection and removal system. The primary purpose of a lateral drainage layer is to transport water towards the drainage pipe. Barrier soil liner is a soil with low permeability, like loam or clay, often compacted, which is designed to limit percolation and leakage. Geomembrane liner is a synthetic flexible membrane designed to restrict vertical drainage, and limit leakage. Geotextiles and geonets are synthetic materials designed to drain water laterally (Waterloo Hydrogeologic, 2002). All of the profile properties can be modified, except for the properties of geotextiles and geonets. HELP model has some basic rules to arrange the profiles. Additional details of profile set-up can be found in Waterloo Hydrogeologic (2002).

\subsection{POLLUTE v7.0}

POLLUTE is a semi-analytical, finite-layer contaminant migration model used for landfill design and comprehensive contaminant migration analysis (Rowe, 1990). The model implements "1.5-dimensional" solution to the advection-dispersion equation. Landfill designs that can be considered range from simple systems, on a natural clayey aquitards to composite liners with multiple barriers and multiple aquifers. The model also considers adsorption, radioactive and biological decay, phase changes, and transport through fractures. It also has a graphical user interface for user-friendly editing, execution and printing of data (Scientific Software Group, 1998). 


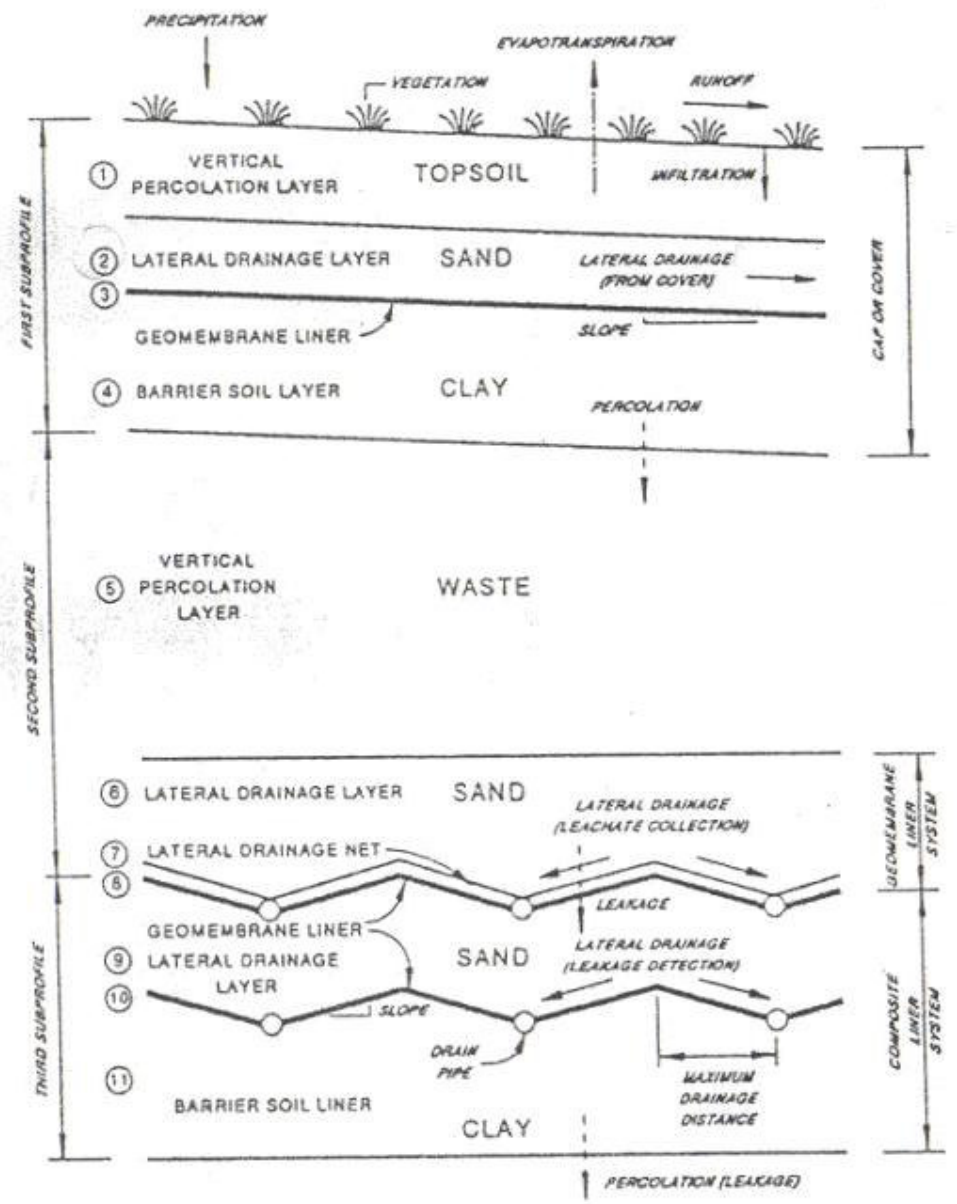

Figure 2. 21 Profiles in HELP model (Waterloo Hydrogeologic, 2002)

POLLUTE model can be applied to model contaminant migration from composite liner and single-liner landfills, as well as contaminant transport from spills, lagoons, and buried waste deposits, either vertically or horizontally through multiple aquitards and aquifers. The model can calculate maximum and temporal concentrations at any depth and time, model 1D, 2D or 3D fractures, vary source and layer properties with time to simulate effects of a failure of engineered systems, and assess uncertainty in parameter values using Monte Carlo simulation. Two boundary conditions, either finite mass boundary to represent a contaminant source such as a landfill or fixed outflow velocity to represent an 
aquifer below the layers in the dataset can be defined. The concentration of the contaminant can be calculated at any number of specific depths or the maximum concentration can be determined automatically at any selected depth. The results of the simulations can be obtained graphically for concentration versus time, concentration versus depth, and flux versus time. Moreover, the model outputs a color concentration plot (Scientific Software Group, 1998).

\subsection{Stability in Landfills}

Stability in landfills are controlled by properties of the supporting soil, strength characteristics and weight of refuse, inclination of the slope, leachate levels and movements within the landfill, type of cover, and cover resistance to erosion. In all cases, water acts as a destabilizing agent for reducing the strength. The unit weight of refuse and its strength are difficult to determine and vary over a wide range. Therefore, the assessment of these variables is based on case histories and site-specific investigations (Daniel, 1995).

Stability in landfills can be assessed using two methods; limit-equilibrium and finite-element analyses. However, as the parameters required for finite-element analysis (strength, stress-strain, and modulus) are poorly defined in refuse, limitequilibrium analyses are preferred to assess stability in landfills (Sharma and Lewis, 1994).

Potential instability can occur in the foundation soil, the refuse, or the cover. The safety margin for all cases is expressed in terms of factor of safety, FS (Sharma and Lewis, 1994):

$$
F S=\frac{\sum \text { Re sistingforces, } \text { moments }}{\sum \text { Drivingforces, } \text { moments }}
$$


In waste disposal sites, the driving force causing the development of a slip surface is the weight of the waste and leachate. The resisting (or restoring) forces occur due to the shear strength of waste and soil and the weights of soil, water and waste located near the toe of slope (Daniel, 1995). A factor of safety of 1 indicates imminent slippage, and a factor of safety below 1 indicates unstable conditions. The slope is stable if the factor of safety value is greater than 1 (Sharma and Lewis, 1994). Typical factor of safety values are given in Table 2.1:

Table 2. 1 Recommended minimum values of factor of safety for slope stability analyses (Sharma and Lewis, 1994)

\section{Consequences of Slope Failure}

Uncertainty of Strength

\section{Measurements ${ }^{\mathrm{a}}$}

Small $^{\mathrm{b}} \quad$ Large $^{\mathrm{c}}$

No imminent danger to human life or major

environmental impact if slope fails

Imminent danger to human life or major

environmental impact if slope fails

1.25

\subsection{2 .0 or greater}

\footnotetext{
${ }^{\mathrm{a}}$ numbers without parentheses apply for static conditions and $\overline{t h o s e}$ within parentheses apply to seismic conditions.

${ }^{b}$ uncertainty of strength measurements is smallest when soil conditions are uniform and highquality strength test data provide a consistent, complete and logical picture of strength characteristics.

${ }^{c}$ uncertainty of strength measurements is largest when soil conditions are complex and when available strength data do not provide a consistent, complete and logical picture of strength characteristics.
}

Three common types of limit equilibrium analyses are infinite slope, wedge method and the method of slices. Infinite slope analyses deal with one-directional failures and movements parallel to the slope; i.e. final cover soils placed on a refuse slope. Wedge methods are used when the failure mass has a simple geometry, which can be divided into wedge-shape sections. This approach is less conservative and more realistic than infinite slope. The method of slices is used 
for circular or wedge/block-type slip surfaces. Circular slip surfaces occur in homogeneous soils; whereas, wedge/block-type surfaces occur when a weak plane, such as a geomembrane liner, is present (Sharma and Lewis, 1994).

The stability analyses for landfills are divided into excavation slope, refuse fill, and cover systems (Sharma and Lewis, 1994). Potential slip mechanisms, analytical parameters and factor of safety for each of the analyses are given in the following sections.

\subsubsection{Excavation Slope Stability}

Excavation slope stability analyses, which are thought to be most critical in the preliminary site development and layout stages, are required to estimate acceptable grades for slopes. Typical excavation slopes for covered pit and trenched landfills are approximately 3:1 (horizontal:vertical), as the clay liners may be constructed on the side slopes at this grade. Potential slip surfaces in excavation slopes are presented in Figure 2.22 (Sharma and Lewis, 1994).

Limit-equilibrium analysis is performed using a circular slip surface. Block-type surface is preferred if a potential weak plane exists. Usually, as the water table is significantly below the base of the landfill, slope stability analyses do not include water table. If a non-flowing water table exists, effect of water table should be included in the form of a hydrostatic pressure distribution. If seepage conditions exist, internal pore pressures should be determined. Strength parameters of soils, like effective friction angle $\left(\varphi^{\prime}\right)$ and unit weight $\left(\gamma_{t}\right)$, should be considered. Typical factor of safety values range between 1.3 and 1.5 (Sharma and Lewis, 1994). 


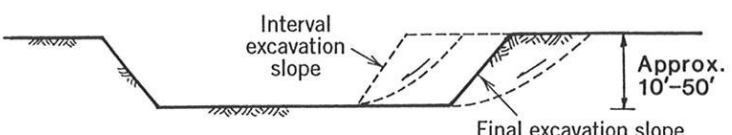

(a)

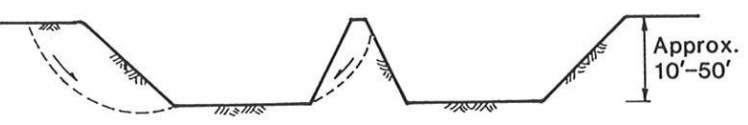

(b)

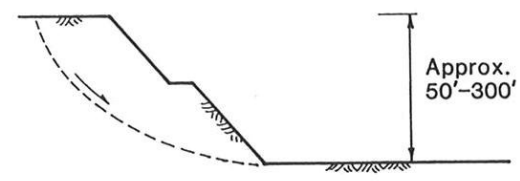

(c)

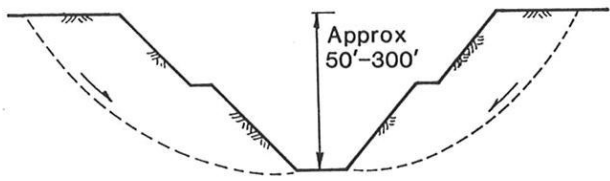

(d)

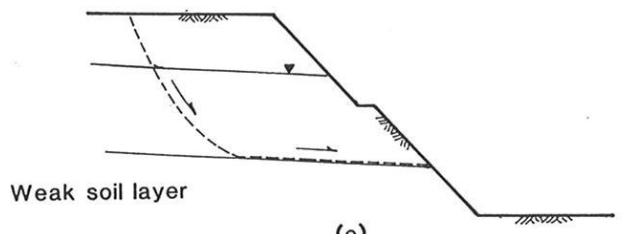

(e)

Figure 2. 22 Potential slip surfaces in excavation slopes (Sharma and Lewis, 1994)

\subsubsection{Refuse Fill Stability}

Refuse fill stability analyses are important for both final and interim landfill configuration. Critical stability concerns may occur, especially when liner systems using geomembranes are used. Potential slip surfaces may occur through refuse, along the liner system, or may be a composite surface through refuse and along liner (Figure 2.23). Refuse fill stability analyses are performed using circular surfaces. If a geosynthetic liner system is placed in landfill, translational block surface along the liner system or a composite slip surface through refuse and along liner may be of concern (Sharma and Lewis, 1994). 


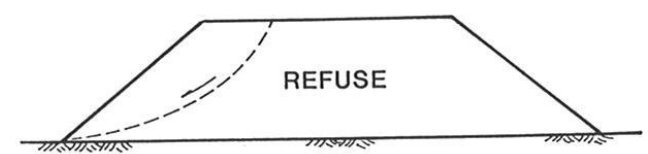

(a)

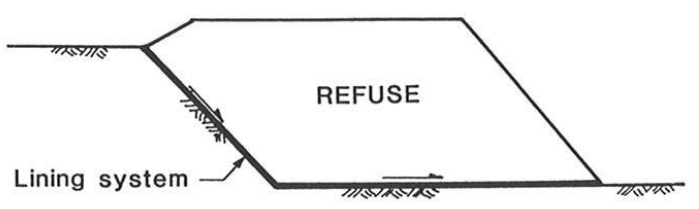

(b)

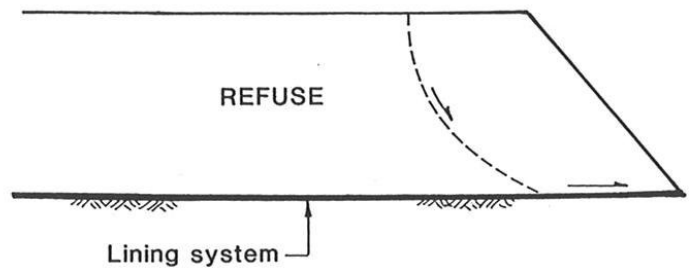

(c)

Figure 2. 23 Potential slip surfaces in landfills: (a) failure through refuse alone, (b) failure along liner system, (c) composite surface through refuse and liner system (Sharma and Lewis, 1994).

Refuse fill analyses employ limit equilibrium approach using a circular slip surface through refuse. When the landfill is lined with geosynthetic materials, limit equilibrium methods using composite or block-type surfaces are required. Refuse material properties, i.e. refuse shear strength, moisture content, and density, liner material strength properties, and interface strength properties are required. The material strengths of clay, granular soils, geotextiles and geomembranes should be considered to select the weak plane. Shear strength values of clay and granular soils exceed interface material strengths; therefore, do not represent a weak plane. Geotextile-soil interfaces have strengths that are approximately equal to or greater than 70 percent of the adjacent soil; therefore, they do not represent a weak plane, either. Weak planes occur between geomembranes and clays, and between geomembranes and other geosynthetics. Subgrade soil strengths should be known for assessing subgrade landfill 
stabilities. For refuse fill stability analyses, factor of safety values greater than 1.5 are recommended (Sharma and Lewis, 1994).

\subsubsection{Cover System Stability}

Stability of the landfill final cover system is important for the final landfill grades. Landfills are constructed with final grades of 3:1, which are stable for soil cover systems. However, the soil cover systems may deform with underlying refuse settlements. To increase their flexibility, geosynthetics are used; however, they create stability concerns. Potential slip mechanisms are generally planar in final cover systems, between material interfaces or through the material itself. Therefore, infinite-slope analyses of limit equilibrium approach are suitable. The stability of each material type and/or interface strength should be considered separately. As the final cover system is easily repairable, factor of safety values less than refuse fills (i.e. between 1.3 and 1.5) are acceptable (Sharma and Lewis, 1994).

\subsubsection{Effect of Moisture in Landfills}

Moisture in waste affects the stability in landfills. Typically, incoming waste is at a moisture content of $20-40 \%$. But, depending on the nature of waste, the moisture content may increase. As the moisture content in the refuse increases, unit weight of the waste also increases. This results in a decrease in factor of safety, namely unstabilizes the landfill. Therefore, leachate head above the landfill liner is regarded as one of the most important indicators for assessing the moisture-related landfill stability. Typically, $30 \mathrm{~cm}$ of leachate head on landfill liner is acceptable to maintain stability in landfills. The effect of leachate head over waste thickness ratio on the factor of safety is demonstrated in Figure 2.24 (Koerner and Soong, 2000). 

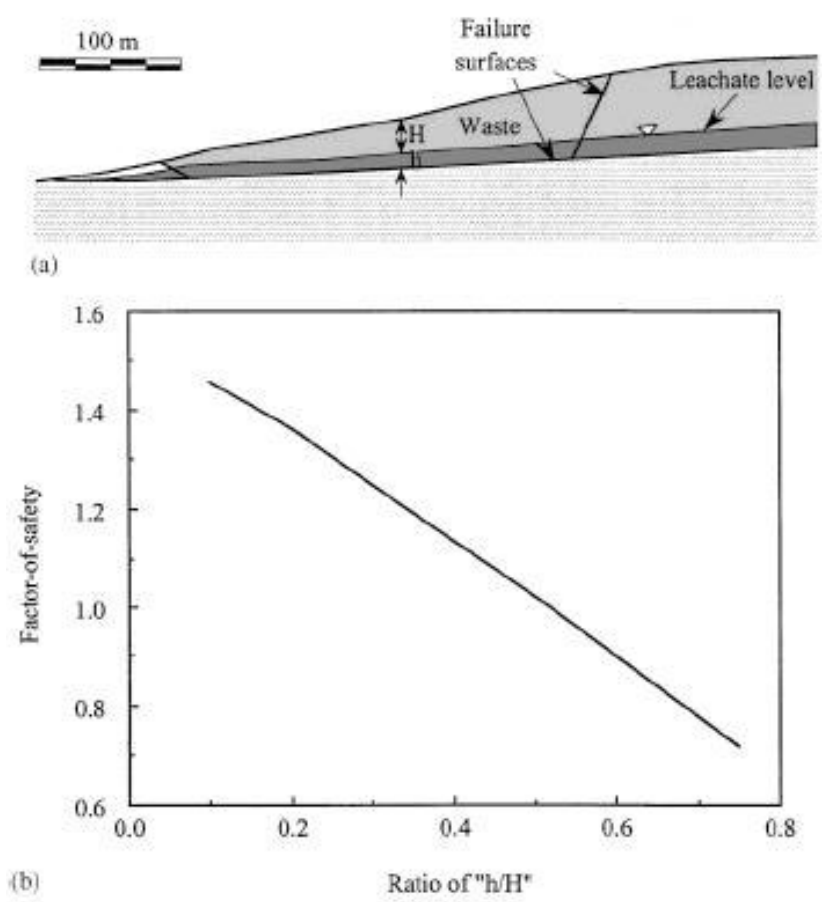

Figure 2. 24 Effect of leachate head on liner at lined landfill site on FS value (Koerner and Soong, 2000).

\subsection{Effect of Groundwater Velocity on Contaminant Concentrations}

The groundwater flow velocity, seepage velocity, is referred to as one of the most significant factors affecting solute transport in the subsurface for both organic and conservative pollutants, and growth and decay of microorganisms suspended in liquid (Mohammed and Allayla, 2000). The groundwater velocities occurring in natural aquifers are reported to be in the range of $0.01-10 \mathrm{~m} / \mathrm{d}, 0.1-1 \mathrm{~m} / \mathrm{d}$ being typical (Maekawa et al., 2002; Hudak, 2005; Hazardous Substances Research Centre, 2002). For example, a typical sandy aquifer with a hydraulic conductivity of $10 \mathrm{~cm} / \mathrm{s}$, hydraulic gradient of 0.005 , and a porosity of 0.3 has a seepage velocity of $0.144 \mathrm{~m} / \mathrm{d}$ (Wu and Tang, 2004). For organic contaminants, higher contaminant removal is observed at lower velocity values due to high detention time, and high detention of microorganisms. Biodegradation rate constant (e.g. for BTX compounds) is strongly dependent on seepage velocity (Mohammed and 
Allayla, 2000). For inorganic compounds (e.g. chloride), as the seepage velocity increases, retardation rate constant decreases due to shortened reaction time between chloride and the medium; however, the dispersion coefficient increases due to mechanical dispersion. For velocity values higher than $0.086 \mathrm{~m} / \mathrm{d}$, mechanical dispersion prevails (Visudmedanukul et al., 2007). Due to dispersion, the contaminants received by the aquifer are diluted, and this phenomenon affects the concentrations observed at the receptor points. 


\section{CHAPTER 3}

\section{METHODOLOGY}

Regarding the two-phase structure of the study, the methodology is presented in two parts. In the first part, development of the design methodology and design component selection matrix is explained. In this context, the conceptual model integrating the related sub-models and modules, landfill design variables, performance criteria, design components and landfill design alternatives, and design component selection matrix are described. The second part is dedicated to the development of the decision support system (DSS). DSS design, architecture, and framework, coupling methodology of system simulation models (SSMs), preliminary and detailed design phases, and models and modules used for the DSS are explained under this part. The chapter is completed by the presentation of the decision mechanism and decision analysis methodology of the DSS. 


\title{
3.1. Development of Design Methodology and the Design Component Selection Matrix
}

\author{
3.1.1. Development of Design Methodology
}

\subsubsection{Conceptual Model}

A conceptual model was developed to effectively integrate preliminary knowledge-base, simulation models, landfill base contour design model, and calculation modules. The conceptual model is composed of physical and functional components. Physical components are preliminary design knowledgebase, landfill base contour design model, cover design evaluation model, waste and bottom liner evaluation and subsurface contaminant transport model, volume calculation module, stability module, and major design component approximate cost estimation module. Cover design evaluation model, and waste and bottom liner evaluation and subsurface contaminant transport model are referred to as system simulation models (SSM). Volume calculation module, stability module, and major design component approximate cost estimation module are referred to as calculation modules. Functional components are design variables, design components and the performance criteria. Design variables are climate (i.e. total annual precipitation rate), waste load (i.e. landfill area and waste thickness), and hydrogeology of the site (i.e. groundwater seepage velocity, porosity and hydraulic conductivity of the vadose zone). Design components are the final cover system, leachate collection and drainage system, and bottom liner system. Performance criteria are defined as meeting prespecified groundwater quality at a downgradient receptor point such as a well or water table and a maximum allowable leachate head on the bottom of the landfill at all times, the latter being adopted for cover and waste stability reasons. In the conceptual model, functional components are defined as the tasks that physical components perform (Figure $3.1)$. 


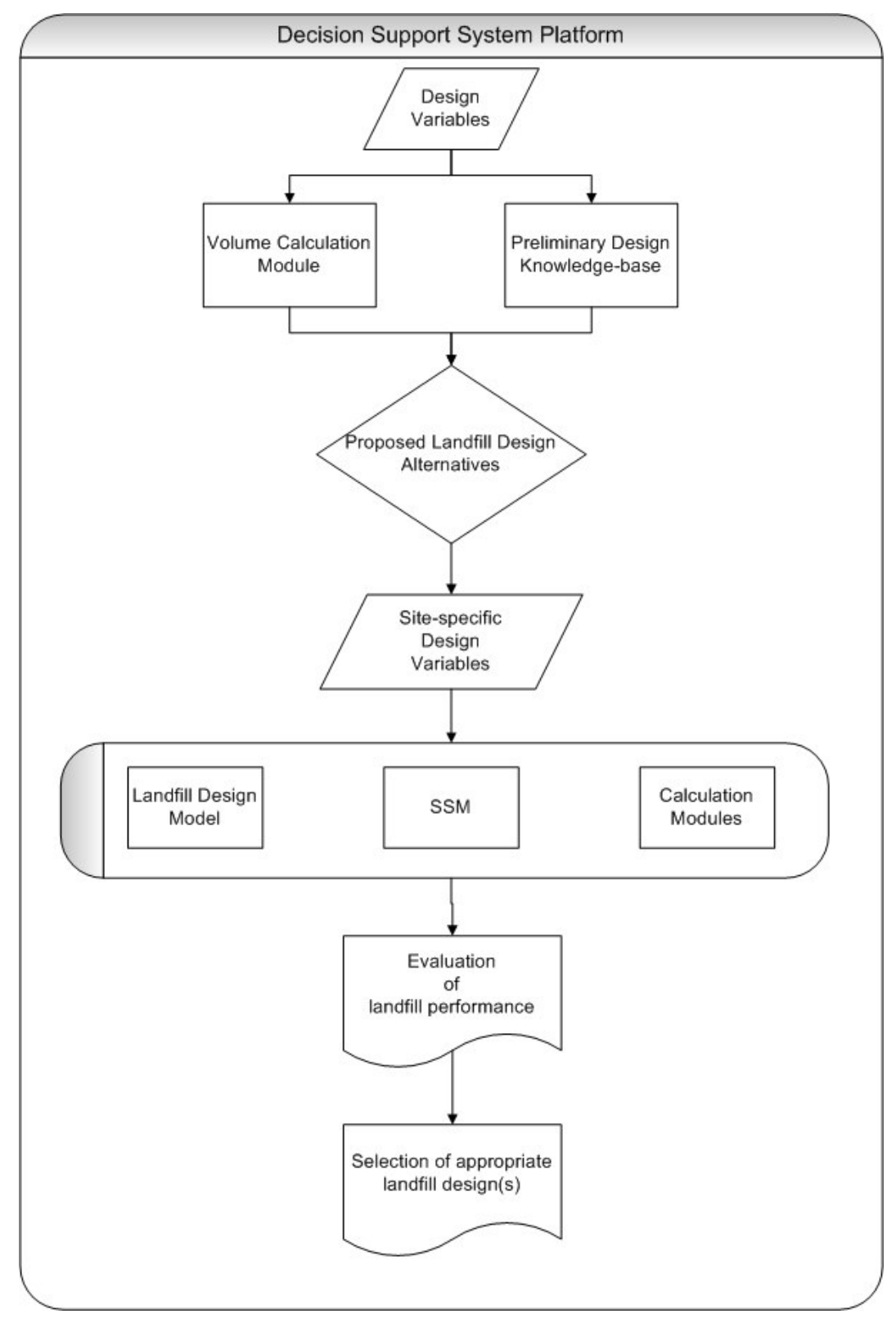

Figure 3. 1 Conceptual model for the DSS

Volume calculation module and landfill base contour design model (Virtual Landfill) handle and analyze site specific geographic, hydrogeologic, climatic and waste data associated with the design variables; and SSMs and other calculation modules (i.e. stability and major design component approximate cost estimation) 
evaluate the performance of the landfill design alternatives with respect to the performance criteria. Therefore, the physical components of the conceptual model help in the selection of the most appropriate design components.

\subsubsection{Design Variables}

The basic design variables that should be considered for the design of landfills were defined as:

i. climate (i.e. annual total precipitation rate)

ii. waste loading rate (i.e. size of landfill)

iii. waste thickness

iv. groundwater seepage velocity

v. hydrogeologic properties of the landfill site (i.e. porosity, hydraulic conductivity, and vadose zone thickness)

The climate variable was defined by annual total precipitation amount; and, classified as arid (annual precipitation amount $\leq 500 \mathrm{~mm} / \mathrm{yr}$ ), moderate (annual precipitation amount between 500 and $1000 \mathrm{~mm} / \mathrm{yr}$ ) and humid (annual precipitation amount $\geq 1000 \mathrm{~mm} / \mathrm{yr}$ ) (Kampf et al, 2002). As the climate is the major variable affecting leakage, the classification of the design alternatives was based primarily on annual total precipitation amount. All of the climatic parameters for the region (temperature, evapotranspiration, solar radiation, wind speed, humidity, growing season start and end day, and maximum leaf area index) were obtained from the weather generator module of Visual HELP 2.2.0.2. To represent the arid, moderate and humid climatic conditions, the simulations were performed using the meteorological data of Afyon (annual precipitation, $\mathrm{P}=340$ $\mathrm{mm} / \mathrm{y})$, İstanbul $(\mathrm{P}=660 \mathrm{~mm} / \mathrm{y})$ and Zonguldak $(\mathrm{P}=1150 \mathrm{~mm} / \mathrm{y})$, respectively. Also, climate sensitivity analyses were performed to asses whether the determined ranges are suitable for evaluating and classifying design alternatives. 
As waste loading rate affects the landfill size directly, this variable is represented by the landfill area. Landfill area (or the landfill length in the direction of groundwater flow) is one of the most important parameters affecting contaminant concentrations in leachate. Landfills were classified as communal (A $\leq 2$ ha), small $(2<\mathrm{A} \leq 15$ ha), medium $(15<\mathrm{A} \leq 50 \mathrm{ha})$, and large $(\mathrm{A}>50$ ha), with respect to size. For the calculations of landfill capacity, the operational lifetime of landfill was taken as 20 years. The landfill size is related to the maximum rate of waste deposition (MRD) that the landfill receives. The MRD and the related landfill sizes were calculated as (RSA DWAF, 1998):

$$
\begin{aligned}
& M R D=I M R D \times(1+d)^{t} \\
& A=\frac{M R D \times t}{\rho_{w} \times T_{w}}
\end{aligned}
$$

where $I M R D$ is initial maximum rate of deposition $[\mathrm{M} / \mathrm{T}]$; $d$ is projected population growth rate; $t$ is the operational time of landfill [T]; $\rho_{\mathrm{w}}$ is the density of in-situ compacted waste and taken as $550 \mathrm{~kg} / \mathrm{m}^{3}$ (İller Bankası, 2000); and $\mathrm{T}_{\mathrm{w}}$ is the thickness of waste in landfill and taken as $20 \mathrm{~m}$. The average waste production rate in Turkey is accepted as $1 \mathrm{~kg} / \mathrm{cap} / \mathrm{day}$ (DİE, 2001 TURKAY REFS). Using equation 3.1 and 3.2, landfill sizes were classified according to the MRD as shown in Table 3.1. 
Table 3. 1 Classification of landfills with respect to Maximum Rate of Deposition (MRD) and population

\begin{tabular}{cccc}
\hline Landfill Class & Population & $\begin{array}{c}\text { MRD } \\
\text { (tons/day) }\end{array}$ & $\begin{array}{c}\text { Landfill Size } \\
\text { (ha) }\end{array}$ \\
\hline Communal (C) & $\leq 25000$ & $<25$ & $\leq 2$ \\
Small (S) & $25001-150000$ & $25-150$ & $2-15$ \\
Medium (M) & $150001-500000$ & $150-500$ & $15-50$ \\
Large (L) & $>500000$ & $>500$ & $>50$ \\
\hline
\end{tabular}

A previously formed database (Tarhan, 2003) was used to evaluate the hydrogeologic conditions. The hydrogeologic formations were classified according to their suitability for serving as a barrier for landfill bottom. Generally, clays, silts, clay stones, marlstones, and unfractured igneous and metamorphic rocks are considered to be potential barrier geologic materials that a landfill can be constructed on (Dörhöfer and Siebert, 1997). Therefore, these geologic formations were classified as suitable (S), and the rest of them, like sand and gravel, were classified as unsuitable (U) formations for landfill construction (Figure 3.2). 


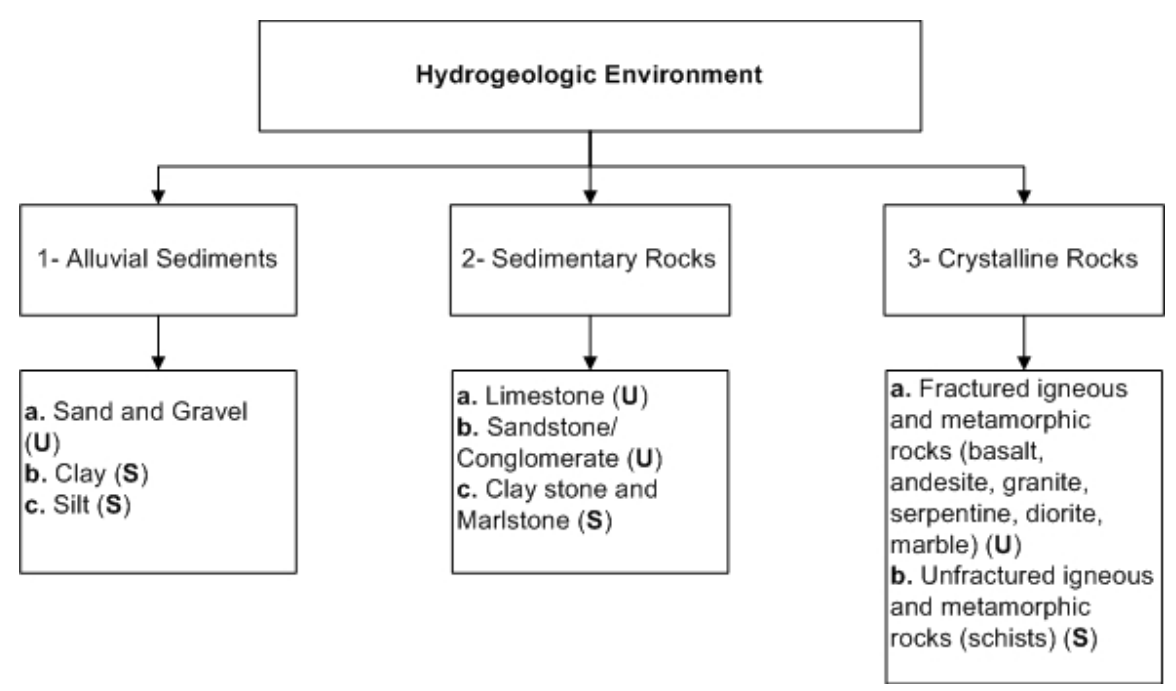

Figure 3. 2 Hydrogeologic environment classes. S and U denote hydrogeologic environment subclasses that are suitable or unsuitable for landfill siting, respectively

The main geologic formations used in the model were selected on the basis of their suitability for being a barrier material and their hydraulic conductivities. The hydraulic conductivities of water yielding U-class formations are obtained form the database (Tarhan, 2003) and values for the non-water-yielding S-class formations were obtained from Newell et al. (1990), and Domenico and Schwartz (1990), as seen in Table 3.2. Accordingly, they are classified into two groups as low conductivity $\left(10^{-8}-10^{-6} \mathrm{~m} / \mathrm{s}\right)$ and high conductivity $\left(>10^{-5} \mathrm{~m} / \mathrm{s}\right)$.

Waste thickness, seepage velocity and vadose zone parameters are other three important parameters affecting design of landfills. Detailed analyses of these effects are given in Sections 3.1.1.2.1 and Section 3.1.1.2.2. 
Table 3. 2 Hydraulic conductivity values for different hydrogeologic environment subclasses

\begin{tabular}{lcc}
\hline \multicolumn{1}{c}{ HGE Subclasses } & $\begin{array}{c}\text { Maximum Value } \\
(\mathbf{m} / \mathbf{s})\end{array}$ & $\begin{array}{c}\text { Minimum Value } \\
(\mathbf{m} / \mathbf{s})\end{array}$ \\
\hline Clay -Silt & $5 \times 10^{-6}$ & $1 \times 10^{-9}$ \\
Clay stone-Marl & $5 \times 10^{-9}$ & $1 \times 10^{-11}$ \\
Unfractured metamorphic and igneous & $2 \times 10^{-10}$ & $4 \times 10^{-14}$ \\
rocks & $4 \times 10^{-2}$ & $2 \times 10^{-6}$ \\
Sand and Gravel & $6 \times 10^{-6}$ & $1 \times 10^{-9}$ \\
Limestone & $6 \times 10^{-6}$ & $4 \times 10^{-10}$ \\
Sandstone and Conglomerate & $4 \times 10^{-4}$ & $8 \times 10^{-9}$ \\
Fractured metamorphic and igneous rocks & & \\
\hline
\end{tabular}

\subsection{Vadose Zone Effect on Steady-state Leakage Rates}

To evaluate the effect of vadose zone on steady-state leakage rates, a landfill barrier system having a compacted clay liner underlain by a vadose zone of varying thickness is modeled using SEEP/W seepage analysis software. The vadose zone is modeled to be composed of either coarse textured or fine textured soil. Simulations of both models are performed assuming steady state conditions. Coarse textured vadose zones are represented by sandy soils, and fine textured vadose zones are represented by silty soils for both model configurations. Effect of uniform saturated hydraulic conductivity values and unsaturated soil hydraulic conductivity functions, texture and thickness of vadose zone, and compacted clay liner hydraulic conductivity on leakage rates is assessed.

To describe the landfill barrier system in numerical unsaturated flow model SEEP/W, two specified head boundary conditions are defined.

As the top boundary condition, 0.3-m-pressure head is defined to describe a design leachate head of $0.3 \mathrm{~m}$ in the drainage layer over the compacted clay liner (CCL) (i.e. a typical design leachate head (Rowe, 2005)). For conditions where 
leachate head above the CCL increases significantly beyond the typical design value of $0.3 \mathrm{~m}$ due to clogging of drainage layer, a coarse gravel drainage layer was selected because of its excellent long-term performance (Rowe, 2005; Ont. Reg. 232/98) and hence, a drastic increase in the leachate leakage rate through the CCL should not be expected. Since there is a significant hydraulic conductivity contrast between the CCL and the vadose zone, unsaturated moisture flow conditions will prevail in the vadose even under relatively high leachate head conditions above the CCL.

Zero pressure head is defined at the bottom boundary to represent the groundwater table at the bottom of the vadose zone. It is possible to model unsaturated flow conditions with SEEP/W, assigning soil hydraulic conductivity functions to the vadose zone. As hydraulic conductivity is defined as the capacity of soil to conduct water, it is dependent on the water content and is a function of pore-water pressure. SEEP/W estimates the hydraulic conductivity function from a soil-water characteristic function by using the Green and Corey (1971) procedure. When the hydraulic conductivity is defined for negative pore-water pressure regions, it is possible to analyze both unsaturated and saturated flow problems (SEEP/W, 2002). Therefore, simulations are performed both by using soil hydraulic conductivity functions and uniform saturated hydraulic conductivity values to asses the implications of using saturated hydraulic conductivity values. Uniform sand, sand, and fine sand hydraulic conductivity functions and uniform silt, silt, and silt tailings hydraulic conductivity functions are chosen to represent coarse and fine textured soils, respectively. The respective saturated hydraulic conductivity values of uniform sand, sand and fine sand are specified as $1 \times 10^{-4}$ $\mathrm{m} / \mathrm{s}, 5 \times 10^{-5} \mathrm{~m} / \mathrm{s}$, and $4 \times 10^{-6} \mathrm{~m} / \mathrm{s}$; whereas, those of uniform silt, silt and silt tailings are specified as $1 \times 10^{-8} \mathrm{~m} / \mathrm{s}, 2.5 \times 10^{-7} \mathrm{~m} / \mathrm{s}$, and $5.8 \times 10^{-8} \mathrm{~m} / \mathrm{s}$, respectively. The hydraulic conductivity versus pressure curves of these functions are given in Figure 3.3. The configuration of the landfill barrier system in SEEP/W model is given in Table 3.3. In order to evaluate the effect of the 
compacted clay liner hydraulic conductivity on the performance of the overall landfill barrier system, barrier systems having compacted clay liner of one order of magnitude lower hydraulic conductivity (i.e. $1 \times 10^{-10} \mathrm{~m} / \mathrm{s}$ ) than the common practice (i.e. $1 \times 10^{-9} \mathrm{~m} / \mathrm{s}$ ) are also simulated.
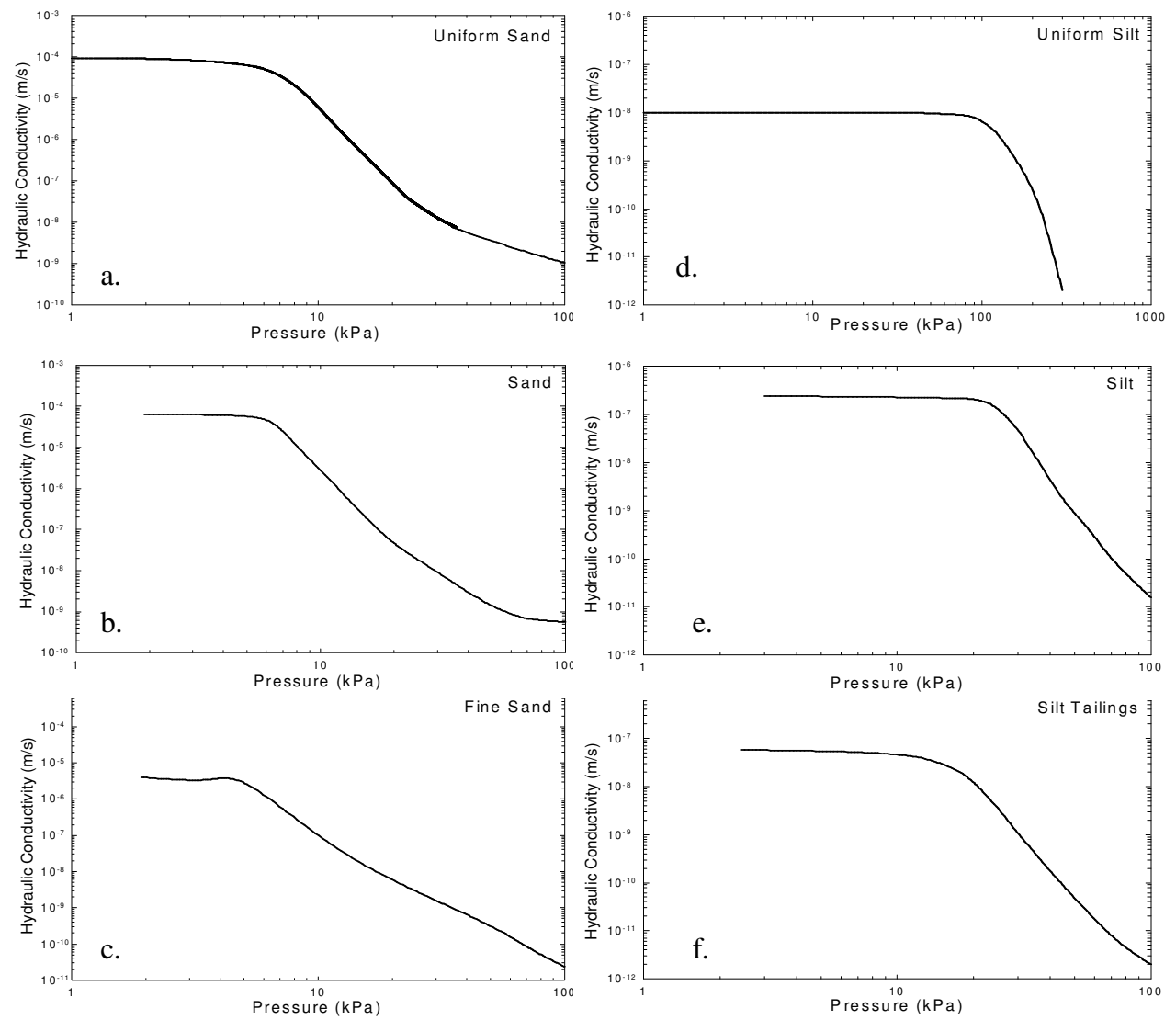

Figure 3. 3 Hydraulic conductivity functions for (a) uniform sand (b) sand, (c) fine sand, (d) uniform silt, (e) silt, and (f) silt tailings. 
Table 3. 3 Landfill barrier system configuration in SEEP/W model

\begin{tabular}{|c|c|c|c|c|}
\hline \multirow{2}{*}{ Barrier System Design } & \multicolumn{2}{|c|}{$\begin{array}{l}\text { Compacted Clay } \\
\text { Liner (CCL) }\end{array}$} & \multicolumn{2}{|c|}{$\begin{array}{c}\text { Vadose Zone } \\
\text { (VZ) }\end{array}$} \\
\hline & $\begin{array}{l}\mathrm{K}_{\mathrm{sat}}^{(\mathrm{a})} \\
(\mathrm{m} / \mathrm{s})\end{array}$ & $\begin{array}{l}\text { Thickness } \\
\text { (m) }\end{array}$ & $\begin{array}{l}\mathrm{K}_{\mathrm{sat}}^{(\mathrm{a})} \\
(\mathrm{m} / \mathrm{s})\end{array}$ & $\begin{array}{c}\text { Thickness } \\
\text { (m) }\end{array}$ \\
\hline $\begin{array}{l}\text { Vadose zone under CCL } \\
\text {-uniform sand (US) }\end{array}$ & $1 \times 10^{-9}$ & 0.6 & $1 \times 10^{-4}$ & 1,5 or 10 \\
\hline $\begin{array}{l}\text { Vadose zone under CCL } \\
\text {-sand }(S)\end{array}$ & $1 \times 10^{-9}$ & 0.6 & $5 \times 10^{-5}$ & 1,5 or 10 \\
\hline $\begin{array}{l}\text { Vadose zone under CCL } \\
\text {-fine sand }(F S)\end{array}$ & $1 \times 10^{-9}$ & 0.6 & $4 \times 10^{-6}$ & 1,5 or 10 \\
\hline $\begin{array}{l}\text { Vadose zone under CCL - } \\
\text { uniform silt (USi) }\end{array}$ & $1 \times 10^{-9}$ & 0.6 & $1 \times 10^{-8}$ & 1,5 or 10 \\
\hline $\begin{array}{l}\text { Vadose zone under CCL } \\
\text {-silt (Si) }\end{array}$ & $1 \times 10^{-9}$ & 0.6 & $2.5 \times 10^{-7}$ & 1,5 or 10 \\
\hline $\begin{array}{l}\text { Vadose zone under CCL } \\
\text {-silt tailings }(\text { SiT) }\end{array}$ & $1 \times 10^{-9}$ & 0.6 & $5.8 \times 10^{-8}$ & 1,5 or 10 \\
\hline $\begin{array}{l}\text { Vadose zone under CCL } \\
\text {-sand }(S)\end{array}$ & $1 \times 10^{-10}$ & 0.6 & $5 \times 10^{-5}$ & 5 or 10 \\
\hline $\begin{array}{l}\text { Vadose zone under CCL } \\
\text {-silt (Si) }\end{array}$ & $1 \times 10^{-10}$ & 0.6 & $2.5 \times 10^{-7}$ & 5 or 10 \\
\hline
\end{tabular}

To check the accuracy of SEEP/W results, steady state leakage rates into the aquifer are hand calculated using the effective hydraulic conductivity of the overall barrier system, following Darcy's Law. The effective hydraulic conductivity of the barrier system is taken as the harmonic mean of the compacted clay hydraulic conductivity and vadose zone harmonic mean hydraulic conductivity (Eq.3.3); and, the steady state leakage rate (Eq.3.5) is calculated simply by multiplying the gradient occurring across the barrier system (Eq.3.6) by the effective hydraulic conductivity: 


$$
\bar{k}=\frac{D_{V Z}+D_{C C L}}{\left(\frac{D_{V Z}}{\bar{k}_{V Z h}}\right)+\left(\frac{D_{C C L}}{k_{C C L}}\right)}
$$

where $\bar{k}$ is the effective (combined harmonic mean) hydraulic conductivity of the vadose zone and $\mathrm{CCL} ; \mathrm{D}_{\mathrm{VZ}}$ is the thickness of the vadose zone underlying the $\mathrm{CCL} ; \mathrm{D}_{\mathrm{CCL}}$ is the thickness of the CCL; $\bar{k}_{\mathrm{VZh}}$ is the harmonic mean hydraulic conductivity of the vadose zone; $\mathrm{k}_{\mathrm{CCL}}$ is the hydraulic conductivity of the CCL. The value of $\bar{k}_{\text {VZh }}$ was calculated using the hydraulic conductivity values corresponding to each of the nodes (elements) across the vadose zone as

$$
\bar{k}_{V Z h}=\frac{n}{\frac{1}{k_{1}}+\frac{1}{k_{2}}+\ldots+\frac{1}{k_{n}}}=\frac{n}{\sum_{i=1}^{n} \frac{1}{k_{i}}}
$$

where $\mathrm{k}_{\mathrm{i}}$ is the hydraulic conductivity value corresponding to the finite element node $\mathrm{i}$, and $\mathrm{n}$ is the number of nodes, or number of hydraulic conductivity values. The $\mathrm{k}_{\mathrm{VZh}}$ value calculated from Eq. 3.4 is used in Eq. 3.3 to calculate $\bar{k}$. In Eq. 3.3, the thicknesses of CCL and vadose zone were taken into account separately, as this would have an impact on the value $\bar{k}$, which was used as a representative hydraulic conductivity value for the overall barrier system.

Steady state leakage rates into the aquifer were also hand calculated following the Darcy's Law:

$$
q_{S S}=i \times \bar{k}
$$

where 


$$
i=\frac{z_{T}+h}{z_{T}}
$$

and $\mathrm{q}_{\mathrm{SS}}$ is the steady-state leakage rate through the CCL and the vadose zone into the aquifer; $i$ is the hydraulic gradient across the CCL and vadose zone; $\mathrm{z}_{\mathrm{T}}$ is the combined thickness of the CCL and vadose zone; and $\mathrm{h}$ is the pressure head on the top of the CCL.

\subsection{Waste Thickness and Seepage Velocity Effect on Steady-State Leakage Rates}

To determine the effect of waste thickness and groundwater seepage velocity on the contaminant concentrations at the receptor, 3 sets of sensitivity analyses were performed. In the first set, waste thickness was held constant and simulations were performed with 5 different seepage velocity values. In the second set, seepage velocity was held constant and simulations were performed with 5 different waste thickness values. Set 3 was performed to demonstrate the combined effect. The simulations were performed for a communal landfill ( $\mathrm{A}<2$ ha) placed on a sandy vadose zone of $10 \mathrm{~m}$ and having a mean hydraulic conductivity of $10^{-7} \mathrm{~m} / \mathrm{s}$. The climate was set as moderate $(500 \mathrm{~mm} / \mathrm{yr}<\mathrm{P}<1000 \mathrm{~mm} / \mathrm{yr})$. The simulations were performed with the major design alternatives (Table 3.4). The configurations of the three sets were given in Table 3.5. The infiltration rates obtained by HELP model simulations for some major design alternatives, namely natural attenuation landfill, extensive engineering design and intermediate engineering design are $0.249 \mathrm{~m} / \mathrm{yr}, 0.00423 \mathrm{~m} / \mathrm{yr}$ and $0.245 \mathrm{~m} / \mathrm{yr}$, respectively. 
Table 3. 4 Design details of major design alternatives used for waste thickness and seepage velocity calculations

\begin{tabular}{lll}
\hline \multicolumn{1}{c}{ Design } & \multicolumn{1}{c}{ Final Cover } & \multicolumn{1}{c}{ Bottom Liner } \\
\hline Natural attenuation & 0.6 -m-thick natural & Natural aquitard below \\
landfill & topsoil & waste \\
Extensive engineering & 0.6 -m-thick natural & 0.3-m-thick leachate \\
design & topsoil & collection layer \\
& 0.3 -m-thick cover & 2-mm-thick \\
& drainage layer & geomembrane \\
& 1 -mm-thick & 0.6-m-thick compacted \\
& geomembrane & clay liner \\
& 0.6 -m-thick clay layer & Vadose zone/aquitard \\
& 0.6 -m-thick natural & 0.3-m-thick leachate \\
Intermediate engineering & collection layer \\
design & topsoil & 0.6-m-thick compacted \\
& 0.3 -m-thick cover & clay liner \\
& drainage layer & Vadose zone/aquitard \\
\hline
\end{tabular}

Table 3. 5 Configurations of sensitivity simulations

\begin{tabular}{ccc}
\hline Set Number & $\begin{array}{c}\text { Waste Thickness } \\
(\mathbf{m})\end{array}$ & $\begin{array}{c}\text { Seepage Velocity } \\
(\mathbf{m} / \mathbf{d})\end{array}$ \\
\hline & 20 & 0.01 \\
$\mathbf{1}$ & 20 & 0.05 \\
$(\mathbf{1 5}$ runs $)$ & 20 & 0.1 \\
& 20 & 0.5 \\
& 20 & 1 \\
$\mathbf{2}$ & 5 & 1.2 \\
$(\mathbf{1 5}$ runs $)$ & 10 & 1.2 \\
& 15 & 1.2 \\
& 20 & 1.2 \\
$\mathbf{3}$ & 30 & 1.2 \\
$(\mathbf{7 5}$ runs $)$ & 5 & 0.01 \\
& 10 & 0.05 \\
& 15 & 0.1 \\
& 20 & 0.5 \\
\end{tabular}




\subsubsection{Performance Criteria}

The performance of the landfill is evaluated on the basis of compliance to contamination and stability criteria.

Leachate head on the liner acts hydrostatically and can readily be incorporated into stability analyses. Therefore, as the stability criterion, leachate head above the landfill liner should not exceed $1 \mathrm{~m}$ due to landfill stability concerns (Koerner and Soong, 2000).

As a conservative approach, chemicals in leachate are modeled by chloride $\left(\mathrm{Cl}^{-}\right)$, often used as a conservative environmental tracer to estimate groundwater recharge rates in arid and semiarid regions (O'Green et al., 2002). Chloride concentrations in the leachate and solid waste were assumed as $1000 \mathrm{mg} / \mathrm{L}$ and $1000 \mathrm{mg} / \mathrm{kg}$, respectively (İller Bankas1, 2000). The contamination criterion was specified such that the maximum chloride $\left(\mathrm{Cl}^{-}\right)$concentration at the groundwater table should not exceed $25 \mathrm{mg} / \mathrm{L}$.

\subsubsection{Design Components and Landfill Design Alternatives}

Selection of design components is based on the design variables of the landfill and the performance criteria. Three final cover and six bottom liner options were identified. These cover and liner options were composed of different combinations of design components shown in Table 3.6.

Three types of final covers (evapotranspiration cover $-\mathrm{C} 1$, extensive engineering final cover $-\mathrm{C} 2$, and intermediate design final cover $-\mathrm{C} 3$ ) were considered. Evapotranspiration final cover $(\mathrm{C} 1)$ is composed of only natural topsoil on top of waste (Hauser et al., 2001). Extensive engineering final cover (C2) is composed of 
natural topsoil, drainage layer, geomembrane, and clay liner. Intermediate design final cover (C3) is composed of natural topsoil, drainage layer, and clay liner.

Six different types of bottom liner systems were used. Natural attenuation bottom liner (L1) is composed of only natural aquitard below waste; extensive engineering bottom liner (L2) is composed of leachate collection system, geomembrane, and compacted clay liner over vadose zone; $L 3$ bottom liner is composed of leachate collection system placed over low conductivity aquitards; L4 bottom liner is composed of leachate collection system and geomembrane over vadose zone; intermediate engineering bottom liner (L5) is composed of leachate collection system and compacted clay liner over vadose zone; and finally L6 bottom liner is composed of compacted clay liner over vadose zone.

Table 3. 6 Final Cover and Bottom Liner Alternatives

\begin{tabular}{|c|c|}
\hline Final Cover & Design Components \\
\hline C1 & Natural soil \\
\hline $\mathbf{C 2}$ & Natural soil $+\mathrm{CDS}^{\mathrm{a}}+$ geomembrane + clay liner \\
\hline C3 & Natural soil + CDS + clay liner \\
\hline Bottom Liner & Design Components \\
\hline $\mathbf{L 1}$ & Only aquitard below waste \\
\hline $\mathbf{L 2}$ & $\begin{array}{c}\mathrm{LCS}^{\mathrm{b}}+\text { geomembrane }+\mathrm{CCL}^{\mathrm{c}}+ \\
\text { aquitard/unsaturated zone }\end{array}$ \\
\hline $\mathbf{L 3}$ & LCS + aquitard \\
\hline L4 & LCS + geomembrane + aquitard/unsaturated zone \\
\hline $\mathbf{L 5}$ & $\mathrm{LCS}+\mathrm{CCL}+$ aquitard/unsaturated zone \\
\hline L6 & $\mathrm{CCL}+$ aquitard/unsaturated zone \\
\hline
\end{tabular}

The developed methodology was applied to 18 design alternatives formed using different combinations of final cover and bottom liner options. Appendix-A 
presents the schematic drawings of 18 possible landfill design profiles obtained from various combinations of final cover and bottom liner selections. Three of these designs among 18 alternatives, C1L1, C2L2 and C3L5, were selected as major designs and the design details are given in Table 3.7. The combinations of 18 design alternatives are presented in Table 3.8. These alternatives are produced using different combinations of the design components described in Table 3.7.

Table 3. 7 Design Details of Major Design Alternatives

\begin{tabular}{|c|c|c|}
\hline Design & \multicolumn{2}{|c|}{ Design Details } \\
\hline Alternative & Final Cover & Bottom Liner \\
\hline $\begin{array}{c}\text { C1L1 } \\
\text { Natural } \\
\text { attenuation }\end{array}$ & $-60 \mathrm{~cm}$ fine sandy loam & $\begin{array}{l}\text { - Natural aquitard } \\
\text { (clay, } \mathrm{k}=10^{-8} \mathrm{~m} / \mathrm{s} \text { ) }\end{array}$ \\
\hline C2L2 & $\begin{array}{l}-60 \mathrm{~cm} \text { fine sandy loam } \\
-30 \mathrm{~cm} \text { coarse sand (drainage) }\end{array}$ & $\begin{array}{l}\text { - 30cm gravel (drainage) } \\
\text { - } 2 \mathrm{~mm} \text { high density }\end{array}$ \\
\hline $\begin{array}{c}\text { Extensive } \\
\text { engineering }\end{array}$ & $\begin{array}{l}\text { - 1mm low density polyethylene } \\
\text { (LDPE) } \\
\text { - } 60 \mathrm{~cm} \text { silty clay, } \mathrm{K}=1 \times 10^{-8} \mathrm{~m} / \mathrm{s}\end{array}$ & $\begin{array}{l}\text { - } 60 \mathrm{~cm} \text { compacted clay, } \\
\mathrm{k}=1 \times 10^{-9} \mathrm{~m} / \mathrm{s} \\
\text { - Natural soil }\left(\mathrm{k}_{\text {mean }}=10^{-7} \mathrm{~m} / \mathrm{s}\right)\end{array}$ \\
\hline $\begin{array}{c}\text { C3L5 } \\
\text { Intermediate } \\
\text { design }\end{array}$ & $\begin{array}{l}-60 \mathrm{~cm} \text { fine sandy loam } \\
-30 \mathrm{~cm} \text { coarse sand (drainage) } \\
-60 \mathrm{~cm} \text { silty clay, } \mathrm{K}=1 \times 10^{-8} \mathrm{~m} / \mathrm{s}\end{array}$ & $\begin{array}{l}\text { - 30cm gravel (drainage) } \\
\text { - } 60 \mathrm{~cm} \text { compacted clay, } \\
\mathrm{k}=1 \times 10^{-9} \mathrm{~m} / \mathrm{s} \\
\text { - Natural soil }\left(\mathrm{k}_{\text {mean }}=10^{-7} \mathrm{~m} / \mathrm{s}\right)\end{array}$ \\
\hline
\end{tabular}


Table 3. 8 Combinations of Landfill Design Alternatives Ranging from Minimal Engineering to Extensive Engineering

\begin{tabular}{|c|c|c|}
\hline \multirow{2}{*}{ Design } & \multicolumn{2}{|c|}{ Design Combination } \\
\hline & Final Cover & Bottom Liner \\
\hline C1L1 $^{a}$ & Natural soil & Only natural aquitard below waste \\
\hline C1L2 & Natural soil & $\begin{array}{l}\mathrm{LCS}^{\mathrm{e}}+\text { geomembrane + compacted } \\
\text { clay liner + unsaturated zone }\end{array}$ \\
\hline C1L3 & Natural soil & LCS + aquitard \\
\hline C1L4 & Natural soil & $\begin{array}{l}\text { LCS + geomembrane + } \\
\text { aquitard/unsaturated zone }\end{array}$ \\
\hline C1L5 & Natural soil & $\begin{array}{l}\text { LCS + compacted clay liner + } \\
\text { aquitard/unsaturated zone }\end{array}$ \\
\hline C1L6 & Natural soil & $\begin{array}{l}\text { compacted clay liner }+ \\
\text { aquitard/unsaturated zone }\end{array}$ \\
\hline C2L1 & $\begin{array}{c}\text { Natural soil }+\mathrm{CDS}^{\mathrm{d}}+\text { geomembrane }+ \\
\text { clay liner }\end{array}$ & Only aquitard below waste \\
\hline $\mathrm{C} 2 \mathrm{~L} 2^{\mathrm{b}}$ & $\begin{array}{c}\text { Natural soil }+ \text { CDS }+ \text { geomembrane }+ \\
\text { clay liner }\end{array}$ & $\begin{array}{l}\text { LCS + geomembrane + compacted } \\
\text { clay liner + unsaturated zone }\end{array}$ \\
\hline C2L3 & $\begin{array}{c}\text { Natural soil }+ \text { CDS }+ \text { geomembrane }+ \\
\text { clay liner }\end{array}$ & LCS + aquitard \\
\hline C2L4 & $\begin{array}{c}\text { Natural soil }+ \text { CDS }+ \text { geomembrane }+ \\
\text { clay liner }\end{array}$ & $\begin{array}{l}\text { LCS + geomembrane + } \\
\text { aquitard/unsaturated zone }\end{array}$ \\
\hline C2L5 & $\begin{array}{c}\text { Natural soil }+ \text { CDS }+ \text { geomembrane }+ \\
\text { clay liner }\end{array}$ & $\begin{array}{l}\text { LCS + compacted clay liner }+ \\
\text { aquitard/unsaturated zone }\end{array}$ \\
\hline C2L6 & $\begin{array}{l}\text { Natural soil }+ \text { CDS }+ \text { geomembrane }+ \\
\text { clay liner }\end{array}$ & $\begin{array}{l}\text { compacted clay liner }+ \\
\text { aquitard/unsaturated zone }\end{array}$ \\
\hline C3L1 & Natural soil + CDS + clay liner & Only aquitard below waste \\
\hline C3L2 & Natural soil + CDS + clay liner & $\begin{array}{l}\text { LCS + geomembrane + compacted } \\
\text { clay liner + unsaturated zone }\end{array}$ \\
\hline C3L3 & Natural soil + CDS + clay liner & LCS + aquitard \\
\hline C3L4 & Natural soil + CDS + clay liner & $\begin{array}{l}\text { LCS + geomembrane + } \\
\text { aquitard/unsaturated zone }\end{array}$ \\
\hline $\mathbf{C 3}^{2} \mathbf{L 5}^{\mathrm{c}}$ & Natural soil + CDS + clay liner & $\begin{array}{l}\text { LCS + compacted clay liner + } \\
\text { aquitard/unsaturated zone }\end{array}$ \\
\hline C3L6 & Natural soil + CDS + clay liner & $\begin{array}{l}\text { compacted clay liner }+ \\
\text { aquitard/unsaturated zone }\end{array}$ \\
\hline
\end{tabular}




\subsubsection{Development of Design Component Selection Matrix}

A design component selection matrix was built in order to develop a knowledgebase for the decision support system and to propose different design alternatives that are supposed to comply with the performance criteria under different site (design) conditions. It is used as guidance for the selection of most appropriate design components for a given site and waste conditions. The matrix accommodates all the design variables (i.e. climate -total annual precipitation rate, waste load -landfill area and waste thickness, and site hydrogeology hydraulic conductivity, porosity and thickness of vadose zone, and groundwater seepage velocity) and is beneficial in selecting a preliminary design alternative among the feasible designs listed, when the ranges of design variables are known (Table 3.9). The alternative design combinations presented in the matrix were selected based on simulated landfill performance evaluations.

Table 3. 9 Design variable sets for the design component selection matrix

\begin{tabular}{|c|c|c|c|c|}
\hline Climate & Area & $\begin{array}{c}\text { Waste } \\
\text { Thickness }\end{array}$ & $\begin{array}{l}\text { Seepage } \\
\text { Velocity }\end{array}$ & $\begin{array}{c}\text { Site } \\
\text { Hydrogeology }\end{array}$ \\
\hline Arid & 2 ha & $5 \mathrm{~m}$ & $0.05 \mathrm{~m} / \mathrm{d}$ & Sandy vadose \\
\hline$(\mathrm{P}<500 \mathrm{~mm} / \mathrm{yr})$ & $(\mathrm{L}=200 \mathrm{~m})$ & $20 \mathrm{~m}$ & $0.1 \mathrm{~m} / \mathrm{d}$ & zone: \\
\hline Moderate & 15 ha & & $0.5 \mathrm{~m} / \mathrm{d}$ & $\mathrm{T}=10 \mathrm{~m}$ \\
\hline$(500<\mathrm{P}<1000$ & $(\mathrm{L}=500 \mathrm{~m})$ & & $1 \mathrm{~m} / \mathrm{d}$ & $\mathrm{K}_{\text {mean }}{ }^{\text {(a) }}=10^{-7} \mathrm{~m} / \mathrm{s}$ \\
\hline $\mathrm{mm} / \mathrm{yr})$ & 50 ha & & & $\phi=0.35$ \\
\hline Humid & $(\mathrm{L}=1000 \mathrm{~m})$ & & & Clayey vadose \\
\hline \multirow[t]{4}{*}{$(\mathrm{P}>1000$ mm/yr $)$} & & & & zone: \\
\hline & & & & $\mathrm{T}=10 \mathrm{~m}$ \\
\hline & & & & $\mathrm{K}_{\text {mean }}=10^{-8} \mathrm{~m} / \mathrm{s}$ \\
\hline & & & & $\phi=0.45$ \\
\hline
\end{tabular}

(a) The mean hydraulic conductivity of the vadose zone. 
As climate is the major variable affecting leachate production, classification is based primarily on total annual precipitation rate. Waste loading rate directly affects the landfill area; therefore, these variables were combined to represent the size of the landfill. Contaminant loading rate coming to the aquifer increases with waste thickness. Groundwater seepage velocity dilutes the contaminants; therefore, lower contaminant concentrations in the aquifer are observed under faster velocities. Therefore, waste thickness and seepage velocity were added to the matrix as design variables. As sandy soils demonstrate a similar hydraulic behavior to silty soils under unsaturated conditions, the type and hydrogeology of the vadose zone was implicitly included in the design component selection matrix. This distinction appears in the configuration of the design alternatives. For example, natural attenuation landfills are only allowed to be constructed over silty-clay aquitards; whereas, extensive engineering landfills are appropriate to be constructed on sandy vadose zones (Table 3.10).

Table 3. 10 Required site hydrogeology with respect to landfill design alternatives

\begin{tabular}{lc}
\hline \multicolumn{1}{c}{ Bottom Liner Design } & Hydrogeology of Vadose Zone (VZ) \\
\hline L1: Only aquitard below waste & Low conductivity, silty-clay soils \\
L2: $\mathrm{LCS}^{\mathrm{a}}+\mathrm{GM}^{\mathrm{b}}+\mathrm{CCL}^{\mathrm{c}}+\mathrm{VZ}^{\mathrm{d}}$ & High conductivity, sandy soils \\
L3: $\mathrm{LCS}+\mathrm{VZ}$ & Low conductivity, silty-clay soils \\
L4: $\mathrm{LCS}+\mathrm{GM}+\mathrm{VZ}$ & High conductivity, sandy soils \\
L5: $\mathrm{LCS}+\mathrm{CCL}+\mathrm{VZ}$ & High conductivity, sandy soils / \\
& Low conductivity, silty-clay soils \\
L6: CCL + VZ & High conductivity, sandy soils / \\
\hline${ }^{\mathrm{a}}$ leachate collection system & Low conductivity, silty-clay soils \\
\hline
\end{tabular}

As incorporation of all five design variables would make design component selection matrix too complicated to use, three different matrices were formed with respect to three different climatic conditions (i.e. arid, moderate, and humid). 
Moreover, as site hydrogeology is implicitly identified within the design alternatives, three design variables (i.e. waste thickness, seepage velocity, and size of landfill -landfill area) were accommodated in each matrix.

To construct the matrix, over 1300 simulations of 18 landfill design alternatives were performed using system simulation models considering the aforementioned design variables. Visual HELP 2.2.0.2 was selected as landfill final cover design model, and POLLUTE v7 was selected as landfill bottom liner design and subsurface contaminant transport model.

Visual HELP was used to calculate annual total leachate production rate (infiltration rate to waste layer) by simulating final covers of design alternatives under different design conditions. The leachate production rate produced by HELP was used as input for infiltration rate in POLLUTE. The final cover design parameters used in HELP simulations are given in Table 3.11.

Table 3. 11 Final cover design parameters used in HELP simulations

\begin{tabular}{|c|c|c|c|c|c|c|c|}
\hline \multirow{2}{*}{$\begin{array}{c}\text { Design } \\
\text { component }\end{array}$} & $\mathbf{T}^{\mathbf{b}}$ & Slope & $\begin{array}{l}\text { Slope } \\
\text { length }\end{array}$ & $\begin{array}{c}\text { Total } \\
\text { porosity }\end{array}$ & $\begin{array}{c}\text { Field } \\
\text { capacity }\end{array}$ & $\begin{array}{c}\text { Wilting } \\
\text { point }\end{array}$ & $\mathbf{K}_{\mathrm{sat}}{ }^{\mathrm{c}}$ \\
\hline & (m) & $(\%)$ & (m) & (vol/vol) & (vol/vol) & (vol/vol) & $(\mathrm{m} / \mathrm{s})$ \\
\hline $\begin{array}{l}\text { Natural top } \\
\text { soil }\end{array}$ & 0.60 & 3 & 30 & 0.473 & 0.222 & 0.104 & $5 \times 10^{-6}$ \\
\hline $\begin{array}{l}\text { Drainage } \\
\text { layer }\end{array}$ & 0.30 & 2 & 30 & 0.417 & 0.045 & 0.018 & $1 \times 10^{-3}$ \\
\hline Clay liner & 0.60 & - & - & 0.479 & 0.371 & 0.251 & $1 \times 10^{-7}$ \\
\hline \multirow[t]{2}{*}{$\begin{array}{c}\text { Design } \\
\text { component }\end{array}$} & $\mathbf{T}$ & Slope & $\begin{array}{l}\text { Slope } \\
\text { length }\end{array}$ & $\begin{array}{c}\text { Hole } \\
\text { frequency }\end{array}$ & Defects & $\begin{array}{c}\text { Placement } \\
\text { quality }\end{array}$ & $\mathbf{K}_{\text {sat }}$ \\
\hline & (m) & $(\%)$ & (m) & (\#/ha) & (\#/ha) & $(-)$ & $(\mathrm{m} / \mathrm{s})$ \\
\hline $\mathrm{LDPE}^{\mathrm{a}}$ & 0.001 & - & - & 2 & 4 & 4 & $4 \times 10^{-15}$ \\
\hline
\end{tabular}


POLLUTE was used to model waste layer, landfill bottom liner, and the subsurface below the landfill bottom liner. The hydraulic head value on top of the landfill barrier liner (either compacted clay liner or natural low conductivity aquitard) was evaluated by POLLUTE model and the compliance of the design alternatives to the first performance criterion (i.e. hydraulic head on top of landfill barrier should be less than $1 \mathrm{~m}$ ) was determined. The design alternatives complying with the first performance criterion were further simulated by POLLUTE and the contaminant concentrations at the groundwater table were obtained. By this way, the compliance of design alternatives with the second performance criterion (i.e. the contaminant concentration $\left(\mathrm{Cl}^{-}\right)$at the groundwater table should be less than $25 \mathrm{mg} / \mathrm{L}$ ) were determined. The design parameters used in POLLUTE simulations are given in Table 3.12.

Sensitivity analysis on climate and landfill area were carried out in order to confirm the compliance of the selected design alternatives presented in the design selection matrix under whole determined range of conditions. Further HELP and POLLUTE simulations for the design alternatives, yielding contaminant concentration close to the maximum contaminant level at the point of compliance (i.e. groundwater table) $\left(\mathrm{C}_{\max }=10-25 \mathrm{mg} \mathrm{Cl}^{-} / \mathrm{L}\right)$, were performed under higher end of arid climate range $(\mathrm{P}=450 \mathrm{~mm} / \mathrm{yr})$ and for a wetter moderate climatic condition $(\mathrm{P}=760 \mathrm{~mm} / \mathrm{yr})$. The results of the sensitivity runs were also included in the design selection matrix considering different landfill sizes. For example, the intermediate-engineering design alternative (C3L5) yielding a maximum chloride concentration of $21.1 \mathrm{mg} \mathrm{Cl}^{-} / \mathrm{L}$ at the compliance point, under moderate climate with an annual precipitation amount of $660 \mathrm{~mm} / \mathrm{y}$ and for a landfill size of 50 ha, was not included in the relevant section of the matrix. This is due to the fact that, as a result of climate sensitivity analyses, this alternative will not comply with the contamination criteria at the wetter range of that climate. All the design alternatives were tested and evaluated in the same manner, and the matrix was refined considering the wetter edges of the climate ranges. 
Table 3. 12 Landfill design and subsurface hydraulic parameters used in POLLUTE simulations

\begin{tabular}{|c|c|c|c|}
\hline Source & Value & Geomembrane & Value \\
\hline $\begin{array}{l}\text { Contaminant } \\
\text { concentration }\end{array}$ & $1000 \mathrm{mg} / \mathrm{L}$ & Thickness & $2 \mathrm{~mm}$ \\
\hline Landfill length $^{\mathrm{a}}$ & $\begin{array}{c}2 \text { ha } \rightarrow 200 \mathrm{~m} \\
15 \text { ha } \rightarrow 500 \mathrm{~m} \\
50 \text { ha } \rightarrow 1000 \mathrm{~m}\end{array}$ & Wrinkle frequency & 10/ha \\
\hline Waste thickness & $\begin{array}{c}5 \mathrm{~m} \\
20 \mathrm{~m}\end{array}$ & Wrinkle width & $0.3 \mathrm{~m}$ \\
\hline Infiltration rate & HELP output & Wrinkle spacing & $10 \mathrm{~m}$ \\
\hline Waste density & $550 \mathrm{~kg} / \mathrm{m}^{3}$ & Wrinkle length & $100 \mathrm{~m}$ \\
\hline $\begin{array}{l}\text { Percent of } \\
\text { contaminant }\end{array}$ & 0.1 & Hole radius & $0.00564 \mathrm{~m}$ \\
\hline Hydraulic head & & Diffusion coefficient & $3 \times 10^{-5} \mathrm{~m}^{2} / \mathrm{y}$ \\
\hline $\begin{array}{l}\text { Hydraulic head on top } \\
\text { of barrier }\end{array}$ & $0.3 \mathrm{~m}$ & Transmissivity & $1 \times 10^{-10} \mathrm{~m}^{2} / \mathrm{s}$ \\
\hline $\begin{array}{c}\text { Groundwater level } \\
\text { with respect to the top } \\
\text { of aquifer }\end{array}$ & $0 \mathrm{~m}$ & $\begin{array}{l}\text { Hydraulic conductivity } \\
\text { of the drainage layer }\end{array}$ & $0.001 \mathrm{~m} / \mathrm{s}$ \\
\hline Compacted clay liner & & Vadose zone & \\
\hline Thickness & $0.6 \mathrm{~m}$ & Thickness & $0.6 \mathrm{~m}$ \\
\hline Density & $1.9 \mathrm{~g} / \mathrm{cm}^{3}$ & Density & $1.9 \mathrm{~g} / \mathrm{cm}^{3}$ \\
\hline $\begin{array}{l}\text { Hydraulic } \\
\text { conductivity }\end{array}$ & $1 \times 10^{-9} \mathrm{~m} / \mathrm{s}$ & Hydraulic conductivity & $\begin{array}{l}1 \times 10^{-7} \mathrm{~m} / \mathrm{s} \text { (sand) } \\
1 \times 10^{-8} \mathrm{~m} / \mathrm{s}(\text { clay })\end{array}$ \\
\hline Diffusion coefficient & $0.02 \mathrm{~m}^{2} / \mathrm{y}$ & Diffusion coefficient & $0.02 \mathrm{~m}^{2} / \mathrm{y}$ \\
\hline Dispersion coefficient & $0 \mathrm{~mL} / \mathrm{g}$ & Dispersion coefficient & $0 \mathrm{~mL} / \mathrm{g}$ \\
\hline Porosity & 0.4 & Porosity & 0.35 (sand) \\
\hline & & & 0.45 (clay) \\
\hline Aquifer & & Aquifer & \\
\hline Thickness & $3 \mathrm{~m}$ & Seepage velocity & $\begin{array}{c}0.05 \mathrm{~m} / \mathrm{d} \\
0.1 \mathrm{~m} / \mathrm{d} \\
0.5 \mathrm{~m} / \mathrm{d} \\
1 \mathrm{~m} / \mathrm{d}\end{array}$ \\
\hline
\end{tabular}

${ }^{a}$ Landfil length in the direction of groundwater flow

\subsection{Development of the Decision Support System}

\subsubsection{Decision Support System (DSS) Design}

The design of a "landfill system" involves the interaction and simultaneous consideration of many variables and processes, which makes it a complex engineering problem. As stated before, decision support systems (DSS) can 
handle this complexity and can lead to the solution of this complex environmental problem. Therefore, a two-step DSS was developed for performance-based landfill design.

The architecture of DSS is composed of data gathering, diagnosis and decision support stages. In data gathering stage, data required for design variables are compiled by the DSS as input to the preliminary design knowledge-base. In the diagnosis stage, the gathered data are evaluated by the preliminary design knowledge-base (design component selection matrix) and feasible landfill alternatives are proposed by the DSS. Proposed landfill design alternatives are simulated using site-specific design data by the models and modules running under DSS, and finally, the performance, stability, and cost evaluation of the landfill design alternatives are presented to the user in the final decision support stage (Figure 3.4).

Two approaches were evaluated for the development of DSS for landfill design using readily available DSS platforms to integrate system simulation models (SSMs), and developing a new code and platform for integration.

For the first approach, two DSS platforms for model integration (i.e. RAISON, FRAMES) were evaluated. RAISON had seemed to be the most promising platform because the object system can process GIS maps and databases and it is suitable for the application of technical user interfaces to link models. However, based on the communications with the developers of the program (Environment Canada), although the RASION object system (ROS) is the only system that offers a rule-based expert system component for decision making, ROS is not a "shrink-wrapped" system and it lacks flexibility to easily integrate external models for challenging tasks. Moreover, the platform is not user-friendly, and integrating external models requires assistance of the developers. Therefore, RAISON has been excluded from the list of alternative DSS platforms. 


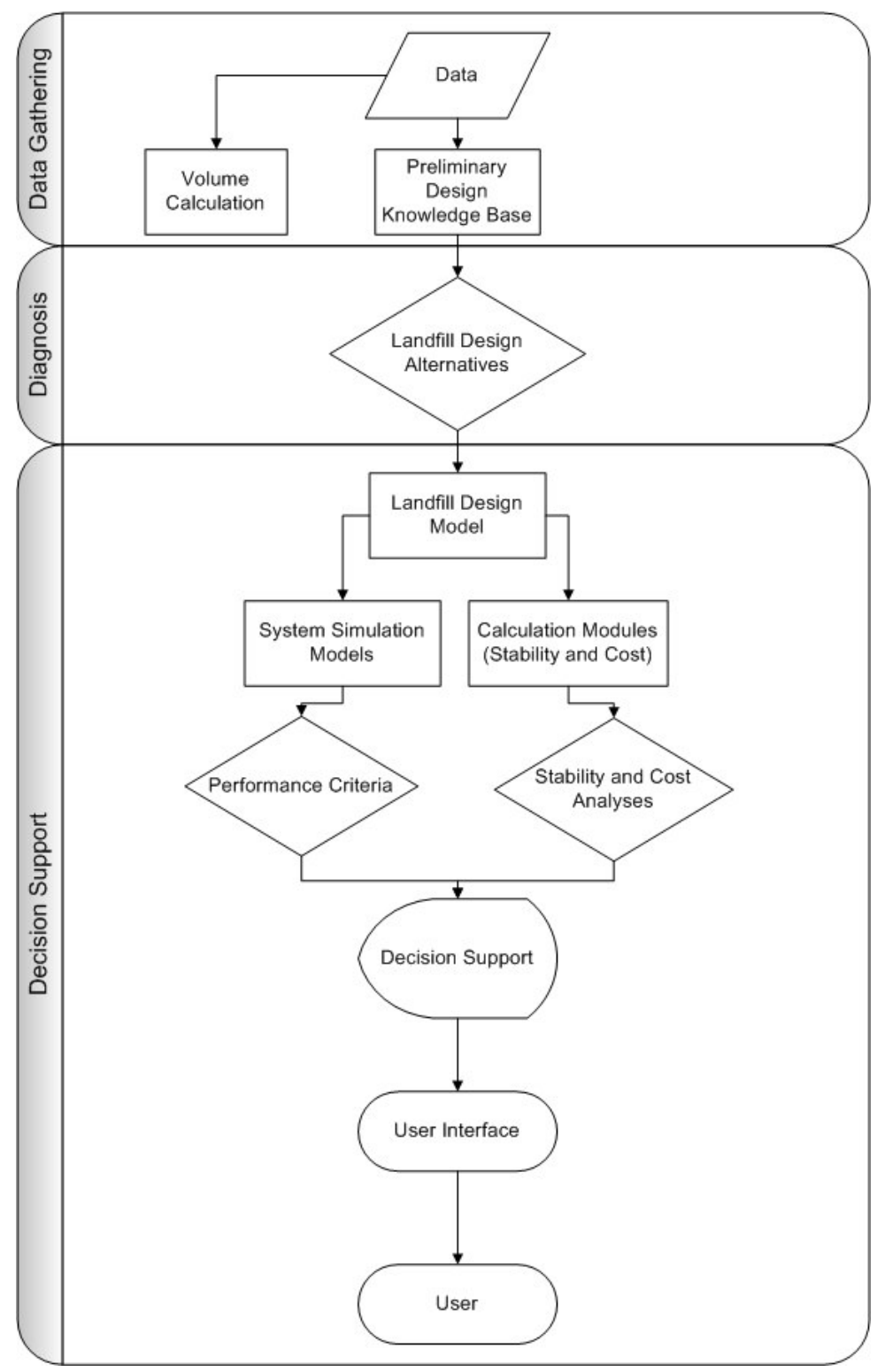

Figure 3. 4 Architecture of decision support system

The second DSS platform, FRAMES, on the other hand, is an open-architecture framework, which allows for the seamless communication of disparate models and databases, using pre-determined file formats. However, FRAMES not only lacks the expert system module, which is required during the preliminary design phase and to interpret the results of the detailed design phase, but also the 
platform is not capable of interfacing new external models under the framework to run the SSMs or linking SSMs for data transfer. Therefore, FRAMES has also been excluded from the alternative DSS platform list.

Besides RAISON and FRAMES, opportunity of integration under another platform, ARGUS ONE, was investigated. ARGUS ONE is an intelligent GIS having an open numerical environment to link models and databases. Using the plug-in extensions (PIEs) of ARGUS ONE, it is possible to link external codes to the platform and to couple models running under the platform. PIEs do not require algorithms of the models to be interfaced. The models are linked as DLLs/SharedLibraries, and saved into a special directory from which they are seamlessly linked to Argus ONE. Instructions to ARGUS ONE to format the output of a particular model in the required input format for a second model can be created by a simple export script language. ARGUS ONE does not offer a decision-making component; however, it is possible to plug-in a rule-base expert system component using PIEs. Although ARGUS ONE seemed to be a promising platform, the communications with the developers showed that, due to its numerical nature, the platform is too complicated to be used for the purposes of the conceptual model developed for the thesis study.

Detailed examination of the readily available DSS platforms exposed that the most robust technique to integrate the SSMs, design model, and modules is to develop a new DSS from the ground up, which would run based on the requirements of the conceptual model and would also be flexible enough to incorporate new models or algorithms when necessary. Thus, a new DSS named as LFDSS, abbreviation for "Landfill Decision Support System", was developed with the assistance of a technical staff on code writing. LFDSS integrates four main components; design component selection matrix, a custom landfill base contour design model (Virtual Landfill -VLF), system simulation models (SSMs; HELP model and POLLUTE model), and calculation modules (i.e. stability, 
volume, cost). The integration of these components and the design of the platform adhere to the conceptual model.

The new DSS consists of a common user interface which runs without using the interfaces of HELP or POLLUTE models. LFDSS runs under Microsoft .NET platform, and is developed using $\mathrm{C \#}$ programming language. The technical details of LFDSS are presented in Appendix-B. All components except VLF are unified under a common user interface application, accessible from LFDSS, in order to give the user flexibility of performing landfill base contour designs independently. The components are further divided into one or multiple modules that encapsulate core functionality or interaction with the user. In particular, a special attention is paid to ease of use and the number of parameters that need to be entered by the user is minimized as much as possible without compromising functionality. Consequently, this also led to a simplified user interface providing a user-friendly SSM input platform. Under the LFDSS, HELP, POLLUTE, and Virtual Landfill directories are defined at the beginning of the DSS setup. This prevents the operation corruptions when the directories of either of the SSMs change. The unified set of parameters is stored in XML format, which facilitates portability and also allows editing them even on a computer that does not have LFDSS installed (for example, using an XML editor).

\subsubsection{Coupling System Simulation Models (SSM)}

Coupling of models, which are not directly inter-operable, under a DSS platform requires the exchange and/or processing of input and/or output data among them and also other components of the system. Availability of the models for data exchange/process can be understood by accessing the codes of the models and their input/output data format. The major models (SSMs) to be integrated under LFDSS platform are HELP and POLLUTE models. The landfill base contour design model, namely Virtual Landfill -VLF, is embedded in the platform. 
Therefore, input parameters of the SSMs (i.e. HELP, and POLLUTE) were analyzed, categorized, and feasible data-exchange possibilities were investigated to design a compatible data flow (Figure 3.5). The data flow to and from calculation modules and landfill base contour design model (i.e. Virtual Landfill VLF) are also investigated and explained in Sections 3.2.4 and 3.2.5.

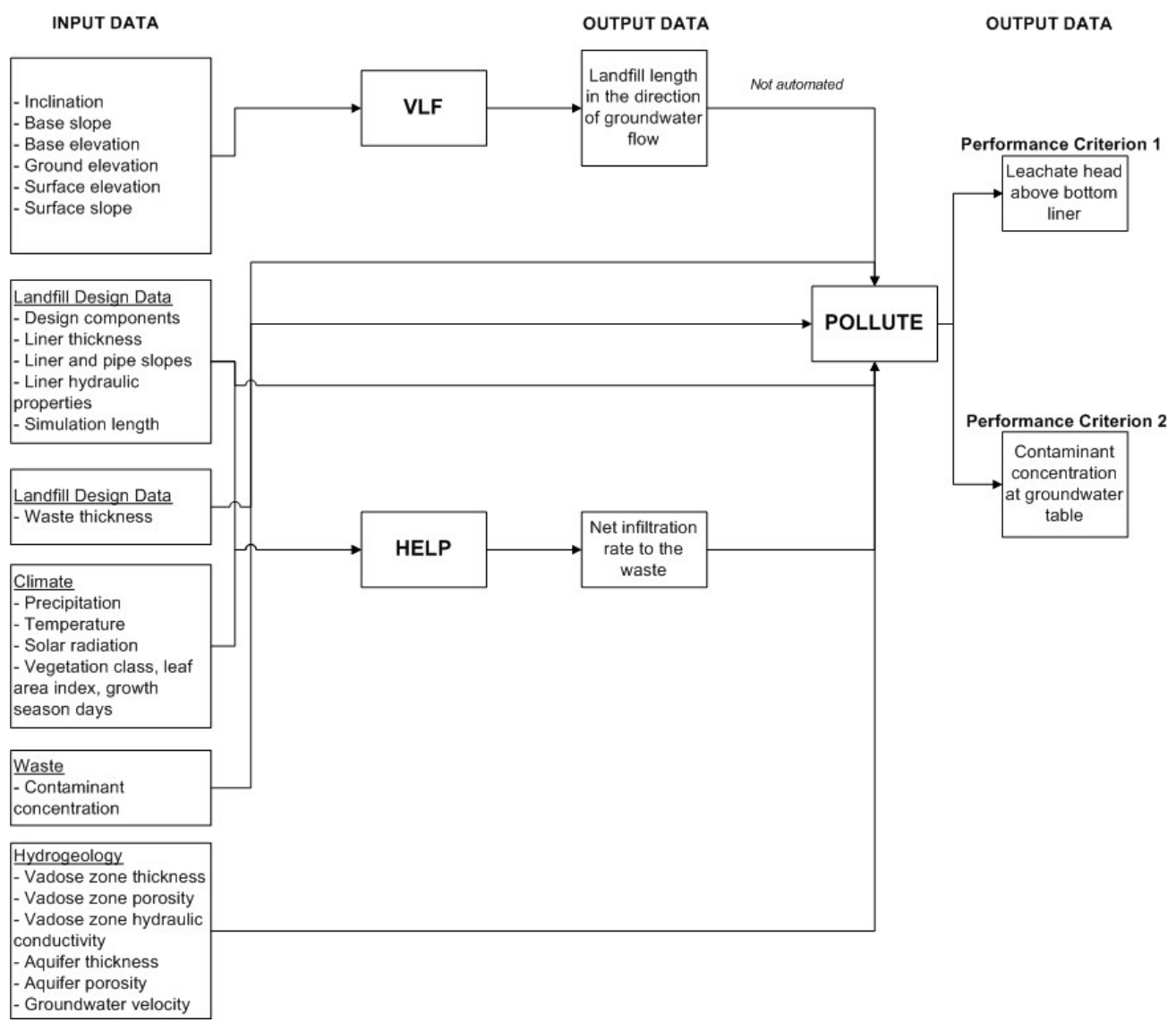

Figure 3. 5 Data flow between SSMs

\subsubsection{Exploring Codes of HELP Model}

HELP version 3.0, cover design model, was developed using FORTRAN programming language. All of the source codes of the program are available and, the output data format can be accessed by using these codes. 
As can be seen from Figure 3.5, HELP uses the climatic and final cover liner property data. All of these data are either defined or present in the model's databases, or can be specified by the user. Therefore, HELP model does not require input data from the waste and bottom liner design and subsurface transport model (i.e. POLLUTE). However, the model creates an important output; infiltration below the final cover to the waste. This output is used by POLLUTE, as input data. Therefore, the output data format of HELP model needs to be compatible with the input data format of POLLUTE, or acceptable by the DSS platform. HELP model gives output in ASCII format. This format is acceptable by POLLUTE and also by the DSS platform.

HELP model is operated under 5 submenus: soil and design, evapotranspiration, temperature, precipitation, and solar radiation. The model is executed within the LFDSS via another submenu called "Run". Details for the input/output requirements and operation of the model under LFDSS are provided in Section 3.2.5.2.

\subsubsection{Exploring Codes of POLLUTE Model}

POLLUTE is the waste and bottom liner design and subsurface transport model. The model was also developed using FORTRAN programming language. Source codes of the program are available and, the output data format can be accessed by using these codes.

Figure 3.5 demonstrates that, POLLUTE requires the landfill design (e.g. waste thickness, liner and soil properties, etc.), hydrogeologic and net infiltration rate data. Landfill design data (i.e. landfill length in the direction of groundwater flow and waste thickness) are either specified by the user or obtained from landfill base contour design model -Virtual Landfill (VLF). Leakage rate to the waste data from the HELP model is used by POLLUTE model as net infiltration rate. 
POLLUTE first determines the compliance to the first performance criterion, stability criterion, as soon as the input data are entered. The simulations are carried out for the landfill design alternatives which satisfy the stability criterion. As POLLUTE is the last SSM used in the DSS, output of the model is not transferred. Output data of POLLUTE, which is also in ASCII format, either indicate the maximum contaminant concentration at the groundwater table or at specified depths throughout the landfill profile, or contaminant concentrations at specified times at the groundwater table or at all depths. These results are directly processed by the DSS to evaluate the overall landfill design.

POLLUTE model is operated under three tabs separated into subsections for proper data entry. First tab is the Parameters tab, where waste and bottom liner design parameters are specified. Second tab is the Maximum Concentrations tab, where the run parameters are specified and results of maximum concentration and time of occurrence of maximum concentration are presented to the user. In the third tab, Concentrations at Specified Times, contamination trend with time can be observed, if required. The model is simulated by cursor touches via a macro, as if the user is clicking on the mouse. Therefore, when POLLUTE model is run under LFDSS, the macro executes the main execution module of POLLUTE outside the LFDSS. Therefore, this integration requires the POLLUTE model to be a registered software in the computer that LFDSS is located. Further details for the input/output requirements and operation of the model under LFDSS are provided in Section 3.2.5.3.

\subsubsection{Coupling Methodology}

HELP and POLLUTE are implemented by third-party applications. For the integration of these SSMs to the DSS platform, Graphical User Interface (GUI) coupling method is used (Figure 3.6). In this method, a common interface integrates the models. The user does not directly interacts with the models and 
corresponding applications, but rather the provided user interface acts as a bridge between the user and models, effectively hiding the details of complex configurations and operations that need to be set and executed. This level of integration is a robust, simple and user-friendly way of modeling.

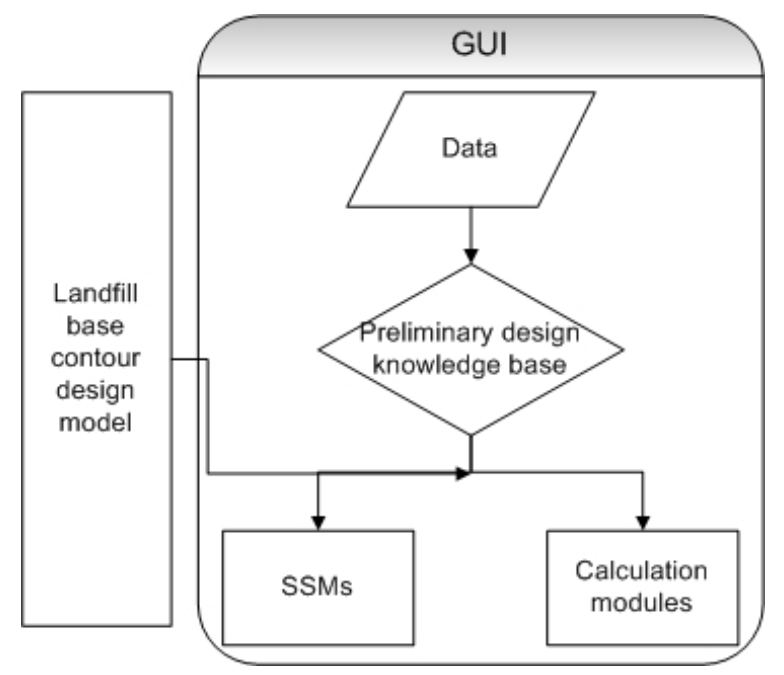

Figure 3. 6 Graphical user interface (GUI) coupling methodology

In order to realize this method, special modules that interface with the aforementioned SSMs were developed. The version of HELP model used is a command line (DOS) application, which requires input as a series of text files and similarly produces output as a text file. Therefore, the module for the HELP model (i) creates the specially formatted text files based on the parameters entered by the user, (ii) runs the model, (iii) parses the resulting output file generated by the model and extracts the information required for further calculations (in particular, the value of "maximum leakage rate through the final cover"), and finally (iv) transfers extracted information back to LFDSS. POLLUTE model, on the other hand, is a graphical application, which requires the user to enter the model parameters and export the results interactively by filling several forms and editing dialog boxes. For the POLLUTE module, scripted macros were used. The macros allowed defining a combination of simulated keystrokes, mouse 
movement and window/control manipulation in order to automate Windows GUI tasks (Appendix-B). The POLLUTE module generates a set of parameters required by the POLLUTE model based on the parameters entered by the user, saves them in the form of text files which can be loaded by the scripts, starts the POLLUTE model and executes the scripts. The scripts are responsible for (i) automatically transferring the generated parameters to the POLLUTE model as if the user is entering them manually, (ii) running the model, and (iii) transferring the results back to LFDSS or in some cases commanding the model to display them visually to the user.

\subsubsection{Decision Support System (DSS) Framework}

A framework was defined in order to describe the model interactions and the function of DSS. Performance based landfill design is composed of two steps; preliminary landfill design phase and detailed/final landfill design phase.

In the preliminary design phase, ranges or classes of design variables are determined; i.e. the design variable is classified to be in arid climate range if it indicates a precipitation amount less than $500 \mathrm{~mm} / \mathrm{y}$. All the design variables (climate, landfill size, seepage velocity, waste thickness and hydraulic conductivity) are classified according to the defined ranges (Table 3.13) and classes are entered to the rule base. The matching results are selected from the design selection matrix decision tree via rule base. Therefore, the preliminary design phase requires the expert system rule base involvement. Communication between SSMs and calculation modules are not necessary at this stage. This phase is completed by the list of landfill design alternatives which are expected to result in desired acceptable performance. 
Table 3. 13 Defined ranges of design variables

\begin{tabular}{cc}
\hline & Value \\
Climate & \\
Arid & $\mathrm{P} \leq 500 \mathrm{~mm} / \mathrm{y}$ \\
Moderate & $500<\mathrm{P} \leq 1000 \mathrm{~mm} / \mathrm{y}$ \\
Humid & $\mathrm{P}>1000 \mathrm{~mm} / \mathrm{y}$ \\
Landfill Size & $\mathrm{A} \leq 2 \mathrm{ha}$ \\
Communal & $2<\mathrm{A} \leq 15 \mathrm{ha}$ \\
Small & $15<\mathrm{A} \leq 50 \mathrm{ha}$ \\
Medium & $\mathrm{A}>50 \mathrm{ha}$ \\
Large & $10 \mathrm{~m}, 10^{-7} \mathrm{~m} / \mathrm{s}$ \\
Hydrogeology & $10 \mathrm{~m}, 10^{-8} \mathrm{~m} / \mathrm{s}$ \\
Sandy vadose zone & $5 \mathrm{~m}$ \\
Clayey vadose zone & $20 \mathrm{~m}$ \\
Waste Thickness & \\
Shallow & $v \leq 0.05 \mathrm{~m} / \mathrm{d}$ \\
Deep & $0.05<v \leq 0.1 \mathrm{~m} / \mathrm{d}$ \\
Seepage Velocity & $0.1<v \leq 0.5 \mathrm{~m} / \mathrm{d}$ \\
Very slow & $0.5<v \leq 1 \mathrm{~m} / \mathrm{d}$ \\
Slow & \\
Medium & \\
Fast &
\end{tabular}

In the detailed design phase each of the proposed design alternatives is evaluated by using site-specific parameter values. This phase requires the communication between HELP and POLLUTE models, and between landfill base contour design model (Virtual Landfill -VLF) and POLLUTE models. Selected design alternatives are simulated using site-specific data as input to the SSMs. The value of design variable can be selected from the databases or literature, in case sitespecific data are not available. Data are entered to HELP model first and transferred to POLLUTE. POLLUTE model uses the infiltration rate output generated by HELP model and exported to the GUI (graphical user interface) and produces leachate head over bottom liner and groundwater contaminant concentration results. If the design satisfies the performance criteria (i.e. maximum leachate head over bottom liner and maximum groundwater contaminant concentration under the selected landfill base contour design), stability analyses are carried out and costs of major design components are 
calculated. The procedure would be repeated for each of the proposed design alternative in the preliminary design phase. The DSS evaluates the results of all contamination, stability, and cost analyses, and proposes the comparative results of each evaluated landfill design alternative to the user in tables. By this way, it is possible to conduct performance, stability, and cost-based comparison among different landfill designs.

\subsubsection{Preliminary Design Phase}

As previously stated, the DSS framework consists of two steps; preliminary design phase and the final/detailed design phase. The preliminary design phase enables the user to calculate the volume of landfill required for the anticipated amount of waste and to enter the design variable classes of a site of concern. It is possible to calculate approximate waste thickness and landfill area regarding the calculated landfill volume. When the approximate values of the design variables are entered to the system, the DSS proposes the user a selection of appropriate design alternatives, using the knowledge-base (i.e. design component selection matrices). There are two modules in the preliminary design phase: volume calculation module and preliminary design knowledge base. Data flow scheme of the modules in preliminary landfill design phase is given in Figure 3.7. These modules are explained in the following sections. 


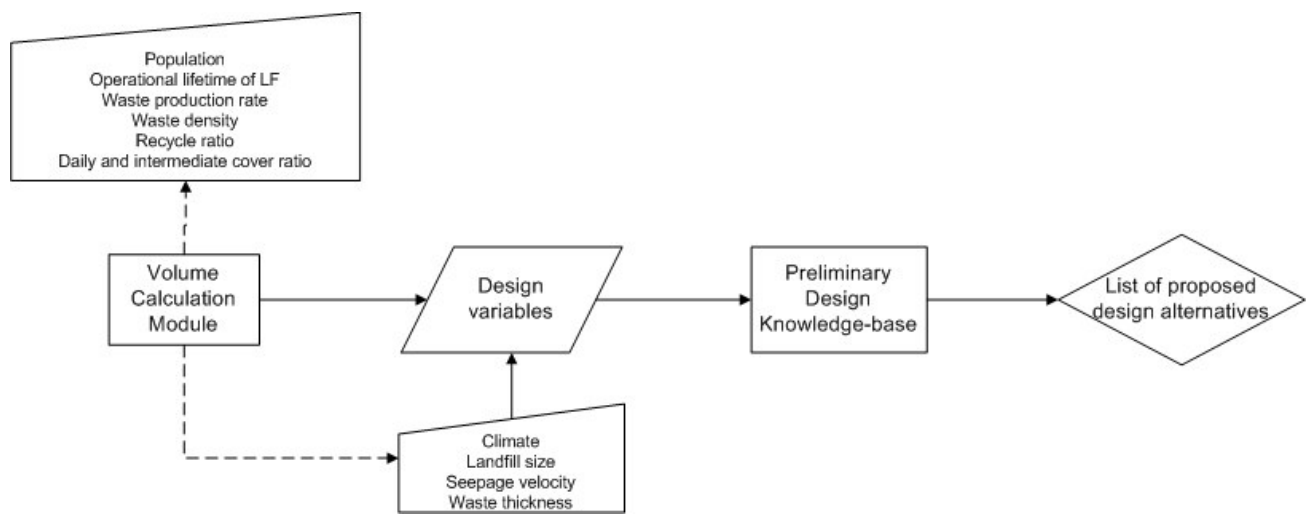

Figure 3. 7 Data flow in preliminary design phase in LFDSS

\subsubsection{Volume Calculation Module}

Volume calculation module was developed as an MS Excel spreadsheet to calculate the required volume of landfill when the projected design population, operational lifetime of landfill, waste production rate, waste density, recycle ratio, and daily and intermediate cover ratio are known. Turkish guidance values for waste production rate $(0.5-2.0 \mathrm{~kg} / \mathrm{cap} /$ day; typical being $1.04 \mathrm{~kg} / \mathrm{cap} / \mathrm{day}$ (DIE, 2001)) and reference values for waste density (İller Bankas1, 2000) are provided within the module (Table 3.14).

Table 3. 14 Waste density values (İller Bankası, 2000)

\begin{tabular}{lc}
\hline \multicolumn{1}{c}{ Waste Type } & Waste Density $\left(\mathbf{k g} / \mathbf{m}^{\mathbf{3}}\right)$ \\
\hline Municipal waste, uncompacted & $90-200$ \\
Municipal waste, compacted in truck & $180-450$ \\
Municipal waste, compacted in landfill & $360-510$ \\
Municipal waste, well compacted in landfill & $600-750$ \\
Municipal waste, shredded but uncompacted & $120-270$ \\
Municipal waste, shredded and compacted & $660-1080$ \\
\hline
\end{tabular}


The amount of waste to be disposed in the landfill $\left(\mathrm{V}_{\text {waste }}\right)$ is calculated using Eq. 3.7 .

$$
V_{\text {waste }}=\frac{P \times t_{L F} \times 365 \times r_{w}}{\rho_{w}}
$$

Where $\mathrm{P}$ is projected design population, $\mathrm{t}_{\mathrm{LF}}$ is operational lifetime of landfill (years), $r_{w}$ is waste production rate $\left(\mathrm{kg} / \mathrm{cap} /\right.$ day), and $\rho_{\mathrm{w}}$ is waste density $\left(\mathrm{kg} / \mathrm{m}^{3}\right)$. The required volume of landfill is then calculated by considering recycling ratio if applicable, and daily and intermediate cover ratio (Eq. 3.8):

$$
\begin{aligned}
& V_{\text {waste_after_recycling }}=V_{\text {waste }}-r_{\text {recycle }} \times V_{\text {waste }} \\
& V_{L F}=V_{\text {waste(or_waste_after_recycling) }}+r_{d \& i} \times V_{\text {waste(or_waste_after_recycling) }}
\end{aligned}
$$

Where $\mathrm{V}_{\text {waste_after_recycling }}$ is the volume of waste after recycled materials are removed from waste stream $\left(\mathrm{m}^{3}\right), \mathrm{r}_{\text {recycle }}$ is the recycling ratio $(\%), \mathrm{V}_{\mathrm{LF}}$ is the volume of landfill $\left(\mathrm{m}^{3}\right)$, and $r_{d \& I}$ is the daily and intermediate cover ratio (in decimals).

The calculated landfill volume can be divided into expected waste thickness in order to obtain an approximate landfill base area to be used as input to the preliminary knowledge base. Moreover, the calculated landfill volume can be compared with the volume calculated by the landfill base contour design model (Virtual Landfill -VLF) to check whether the landfill orientation applied by the user in VLF is fulfilling the volume requirements. The input data requirements and output data supplied by the module are presented in Table 3.15. 
Table 3. 15 Input data requirement and output data supplied by Volume Calculation Module

\begin{tabular}{lccc}
\hline \multicolumn{1}{c}{ Input } & $\begin{array}{c}\text { From } \\
\text { Model/Module }\end{array}$ & Output & $\begin{array}{c}\text { To } \\
\text { Model/Module }\end{array}$ \\
\hline Design & User defined & $\begin{array}{c}\text { Required landfill } \\
\text { vopulation }\end{array}$ & Virtual Landfill \\
Waste production & User defined & Landfill base & Preliminary \\
rate & & area & knowledge base \\
Operational & User defined & & \\
lifetime of & & & \\
landfill & & & \\
Waste density & User defined & & \\
Recycling ratio & User defined & & \\
Daily and & User defined & & \\
intermediate & & & \\
cover ratio & & & \\
\hline
\end{tabular}

MS Excel spreadsheet accommodating the volume calculation formulae was used as basis for the formation of Volume Calculation Module in LFDSS. It is possible to input data manually or via copy and paste from other sources (e.g. MS Excel) in a tabular form using the DataGridView property of Visual C\#. This property creates a user-friendly environment for data input, and also, eases multiple calculations under a single menu in LFDSS (Figure 3.8). 


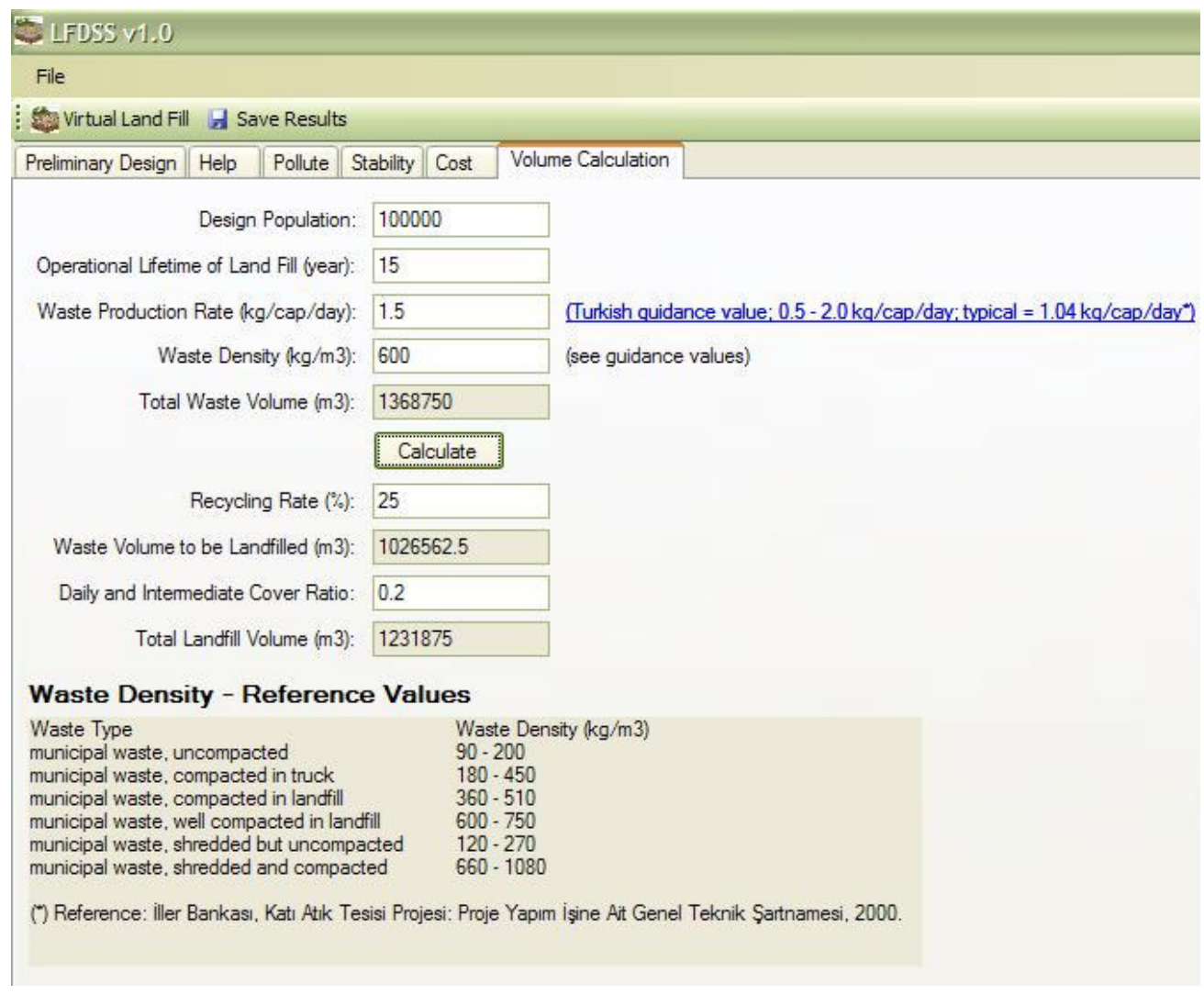

Figure 3. 8 Screenshot of LFDSS for the Volume Calculation Module

\subsubsection{Preliminary Design Knowledge Base}

Preliminary design knowledge base was developed from the design component selection matrices. The rules of the matrices were defined (Appendix-C) to construct a decision tree (Figure 3.9). 


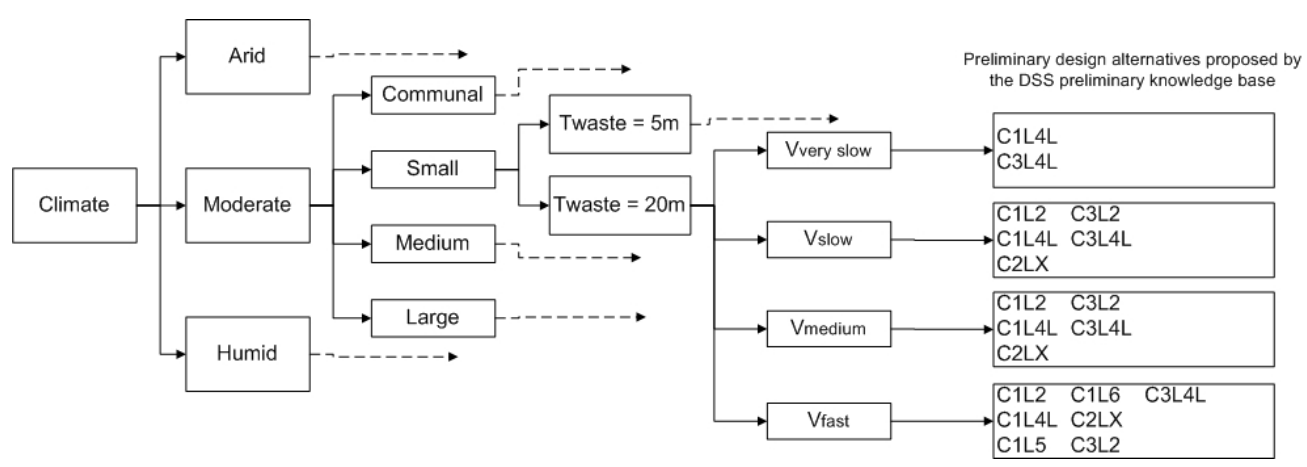

Figure 3. 9 Structure of decision tree to construct the rule base in preliminary design (Only a part of the branches are demonstrated due to space limitation)

As the LFDSS platform is coded in C\# language under .NET platform, the rules and the user interface for the user to enter design variable ranges were also defined using C\# code. The user interface is a form to select the design variable (i.e. climate, landfill area, seepage velocity, and waste thickness) ranges. The design component selection matrices are text files defined in CSV (commaseparated values) format in MS Excel. Each cell was separated by a semicolon (;), and if a cell included multiple values (e.g. more than one design alternative) then these values were separated by commas (,) (e.g. presentations of the columns A8A12 and A15-A18 are as follows: C1L2,C1LAL,C2LX,C3L2,C3LAL;C1L2,C1LAL,C3L2,C3LAL).

A parser is a part of software that processes the rules of the matrices and separates them into sub-rules, and prepares the rules in a form that the computer can read and understand. Therefore, a parser was written to identify definitions and the rules of the matrix in a text file. Using this parser, the related columns in the matrix could be read by the DSS, or, warnings to the user could be displayed on the screen. For example, for a humid climate, to present the design alternatives for a shallow waste thickness (i.e. $5 \mathrm{~m}$ ), slow seepage velocity (i.e. $0.05-0.1 \mathrm{~m} / \mathrm{d}$ ), and a small landfill size (i.e. 2 - 15 ha), the definitions in the text file are defined as: 
climate $>1000$, thickness $=5$, velocity $>0.05$, velocity $<=0.1$, size $>2$, size $<=15$;

sample.csv:K8-K12

And the design alternatives between columns K8 and K12 are presented to the user. Or, to display the warning "USE DOUBLE LINER SYSTEMS" on the screen when the selected ranges are -for example, for moderate climate, deep waste thickness (i.e. $20 \mathrm{~m}$ ), very slow seepage velocity (i.e. $\leq 0.05 \mathrm{~m} / \mathrm{d}$ ), and large landfill size (i.e. $>50$ ha), the definitions in the text file were defined as:

climate $>500$, climate $<=1000$, thickness $=20$, velocity $>0$, velocity $<=0.05$, size $>50$;

"USE DOUBLE LINER SYSTEMS; OR EXTENSIVE ENGINEERING LANDFILL DESIGN ON CLAYEY SOILS"

And the warning "USE DOUBLE LINER SYSTEMS; OR EXTENSIVE ENGINEERING LANDFILL DESIGN ON CLAYEY SOILS" is displayed on the screen. Therefore, the component of the DSS to perform preliminary design assessments was completed. This component enables the user to enter the design variable ranges into the DSS via a user interface and the DSS proposes a list of best-performing preliminary design alternatives for the given site conditions. When any of the landfill designs from the list is clicked, a schematic drawing is presented to the user as an illustration of the design conditions (Figure 3.10). 


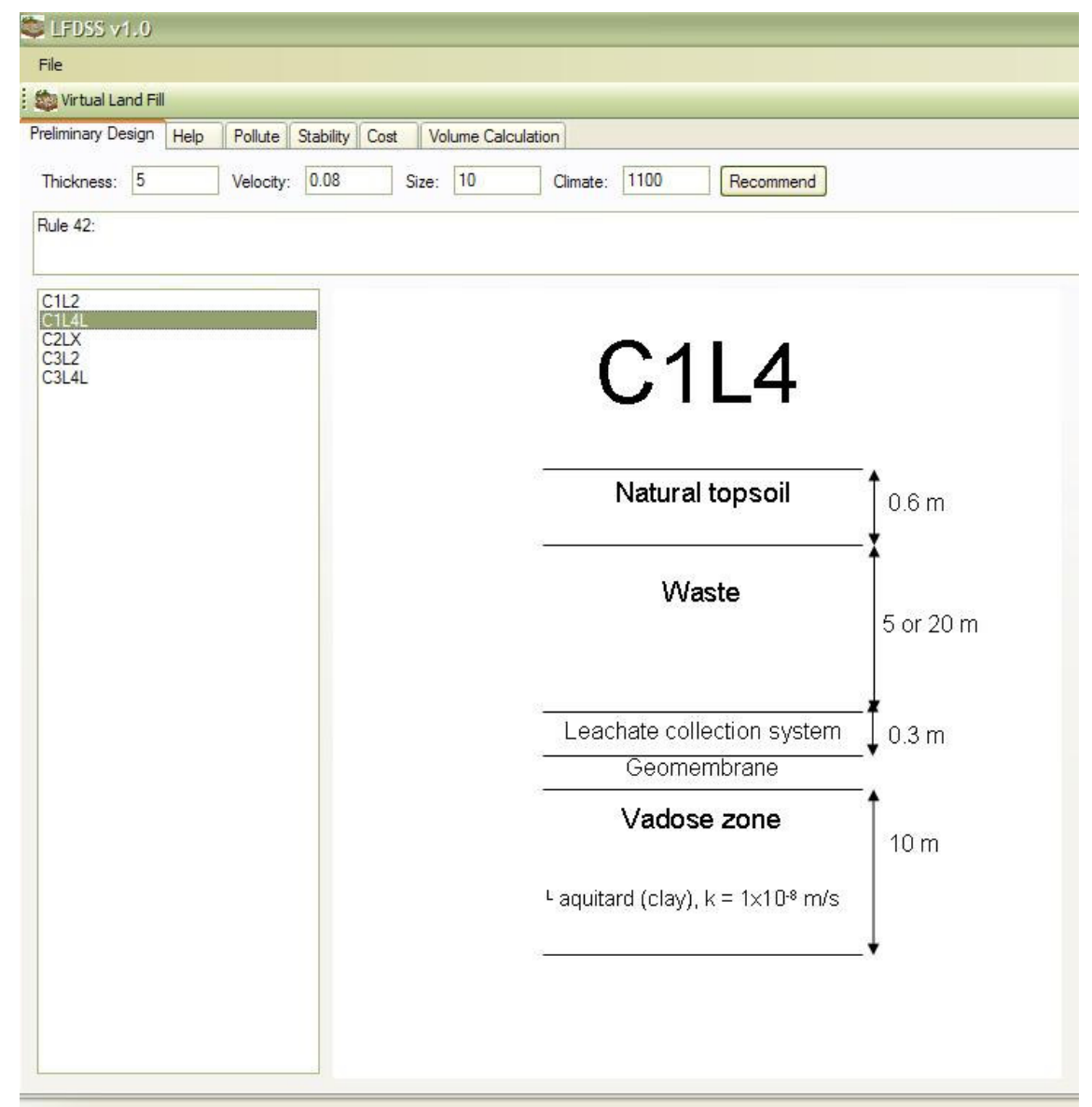

Figure 3. 10 Screenshot of LFDSS for the Preliminary Design Knowledge Base

\subsubsection{Detailed Design Phase}

After the landfill design alternatives are proposed by the preliminary design knowledge base in the preliminary design phase, these proposed alternatives are further simulated using site-specific parameter values obtained by site investigations (e.g. well logs, hydrogeologic and geotechnical investigations, etc.). The purpose of the detailed design phase is to compare the proposed landfill design alternatives performance-wise, stability-wise, and cost-wise; and, to aid in the decision making process for the optimum design under the given site conditions. 
A landfill base contour design model (Virtual Landfill -VLF) to orientate and design the landfill for a given site, two SSMs (HELP and POLLUTE) to simulate the landfill design alternatives for evaluating their compliance to performance criteria, and two calculation modules (stability and cost) to evaluate the stability of landfill design alternatives and to calculate the costs of major design components are used at this stage. The output data supplied by models and modules are presented to the user to aid in the decision making process. The data flow scheme of detailed design phase is given in Figure 3.11. In the following sections, the input data requirements of models and modules and output data supplied by the models and modules, data transfer methods, and integration methods to the LFDSS are explained in further detail.

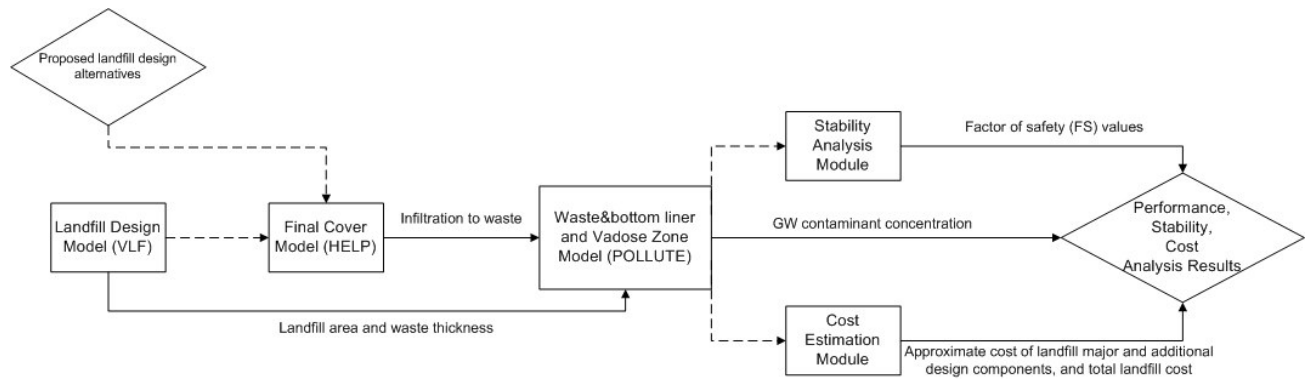

Figure 3. 11 Data flow in detailed/final design phase in LFDSS

\subsubsection{1. $\quad$ Landfill Base Contour Design Model (Virtual Landfill)}

Instead of integrating commercial GIS packages into the developed DSS, a specific code for performing required landfill calculations was conceptualized. The new code was designed to perform map digitization, 3D image viewing, and length, area and volume calculations on the digital maps. The programme was required to be capable of presenting the coordinates of the landfill placed on a topographic map, available clay layer beneath the landfill, location of groundwater and direction of groundwater flow, excavation and fill volumes calculated according to the given excavation depth and landfill area, and 3D views 
of landfill (with or without final cover). The programme was designed to be flexible enough to test desired base grades and landfill orientations as many times as needed with respect to the topography and recalculate excavation and fill volumes and landfill area according to the new orientation. After the conceptual requirements were defined, the virtual landfill base contour design programme, called Virtual Landfill (VLF) was developed. The technical details of VLF are presented in Appendix-D.

The primary function of VLF is to help user in the selection of base grade and orientation of the landfill on the site considering the site topography, available clay layer beneath the landfill, and groundwater depth and flow direction. The model is capable of calculating excavation and fill volumes once the landfill base area, base elevation, side slopes, and ground elevation of the landfill are given as input. Moreover, to be included to the volume calculations, the surface (final cover) of the landfill can be identified to the model by entering surface elevation and surface slope. The model is capable of visually demonstrating the landfill both with or without final cover- in 3D.

To design a landfill of specific volume and base area (e.g. volume and area may be specified using volume calculation module), first the Base-DEM (digital elevation model) file of the topography of concern is required to be uploaded to the model. If available, clay layer and groundwater layer DEM files are also required to be uploaded for orientation purposes. The base area is drawn on the topography, and the size of the base in hectares (ha) is followed from the base area box in the knowledge sheet on the left hand side. The depth of excavation, base slope and the value of side slopes (inclination) must be determined by user to calculate and define base and ground elevations. For the situations where the topography is rough, maximum excavation depths and maximum waste heights can be defined in the model using margin functions for stability reasons. Besides the base slope, base slope directions can also be defined. To model the final cover, 
surface slope and height of waste from ground elevation to the top of the landfill should be determined by user to calculate the horizontal surface length and to define the surface elevation and surface slope to the model. Finally, the ground offset parameter can be defined to identify the anticipated thickness of final cover over the landfill. After defining the input parameters, the excavation, fill, surface volumes are calculated by hitting "calculate" button and the results are presented in the knowledge sheet in cubic decameters. The excavated areas are shown with light blue, whereas the parts required to be filled are shown with dark blue on the map (Figure 3.12). The 3D views of the landfill with and without surface cover are also presented to the user (Figure 3.13).

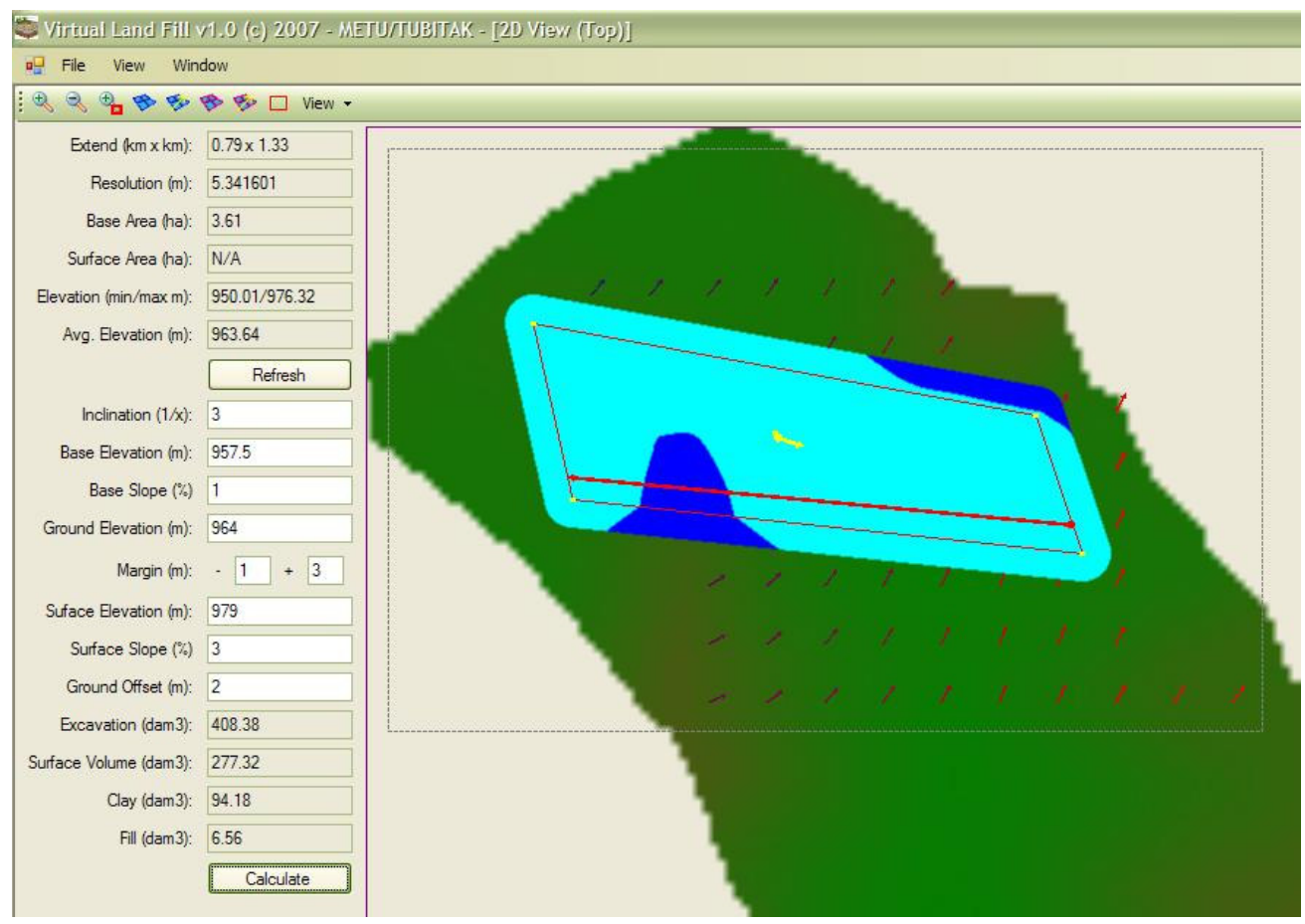

Figure 3. 12 2D demonstration and excavation, fill, and surface volumes of a specified landfill on Virtual Landfill -VLF 


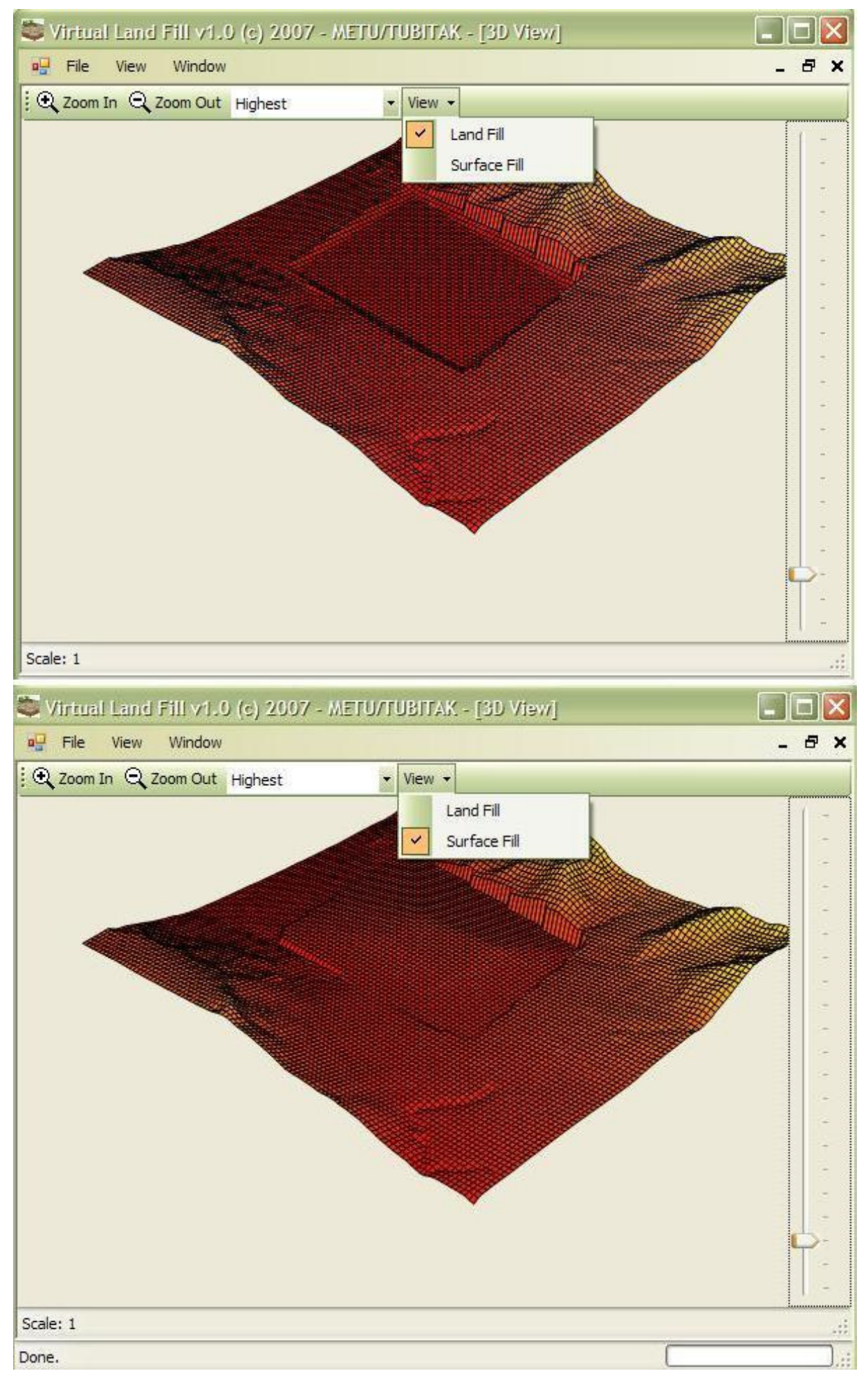

Figure 3. 13 3D representation of landfill excavation and final cover in Virtual Landfill -VLF 
If available, DEM files of in situ clay present at the site can be added to the model. To represent the clay layer, DEM files of top and bottom of the clay profile are uploaded from the "Layers" dialog box. The layer is represented by user-defined colors and the thickness is indicated with a color scale (darker color indicates thicker layers, whereas lighter color thinner layers) on the topographic map. When the "Clay Layer" option in the "View" menu is turned on, the relation between the landfill base and the clay layer is presented to the user. The areas shown by red indicate the absence of the clay layer, areas shown by green indicate that the clay layer begins below the vadose zone beneath the landfill (i.e. there is a non-clay material between the landfill base and the top of the clay layer), and the areas shown by blue indicate that the base of the landfill intersects with the clay layer (i.e. the landfill sits on top of the clay layer). Available clay volume remaining at the base of the landfill after excavation is shown in the knowledge sheet in cubic decameters (Figure 3.14).

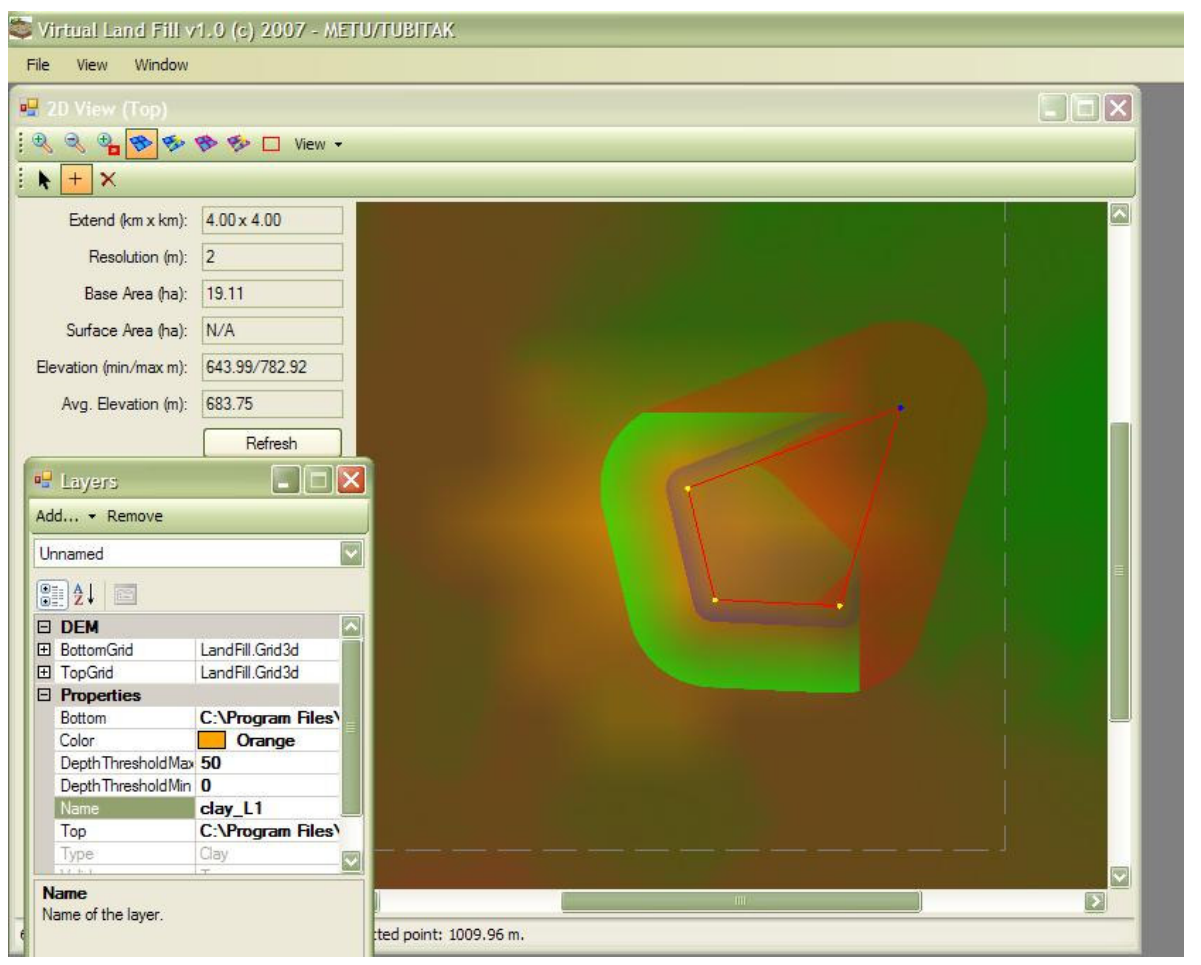

Figure 3. 14 Presenting the available clay layer beneath the landfill in Virtual Landfill -VLF 
If also available and present at the site, groundwater depth and flow direction can be specified on the topographic map in VLF using Groundwater-DEMs. Two DEM files, depth and direction, must be defined and uploaded to represent groundwater layers. Groundwater DEMs are uploaded from "Layers" dialog box. Minimum and maximum depth tresholds of the aquifer, and color scale to represent these tresholds are specified by the user in Layers dialog box. The groundwater flow direction and depth of aquifer (e.g. deeper side of the aquifer is represented by midnight blue, whereas shallower side is represented by red on the figure) are presented to the user on the topographic map (Figure 3.15).

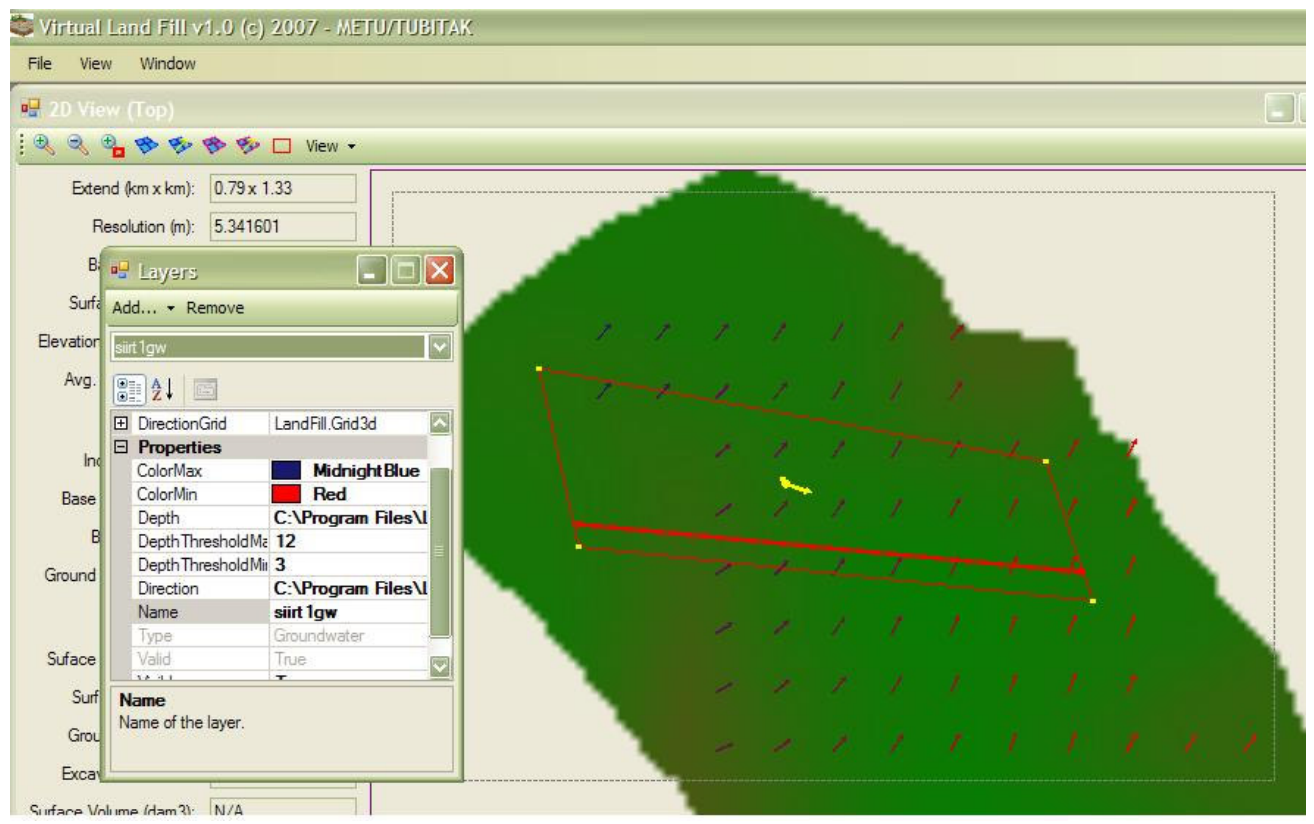

Figure 3. 15 Presenting the groundwater flow direction and aquifer depth in Virtual Landfill -VLF

The input data requirements and output data supplied by the model are presented in Table 3.16. 
Table 3. 16 Input data requirement and output data supplied by Virtual Landfill -VLF

\begin{tabular}{|c|c|c|c|}
\hline Input & $\begin{array}{c}\text { From } \\
\text { Model/Module }\end{array}$ & Output & $\begin{array}{c}\text { To } \\
\text { Model/Module }\end{array}$ \\
\hline Base DEM & User defined & $\begin{array}{c}\text { Required landfill } \\
\text { volume }\end{array}$ & $\begin{array}{c}\text { Volume Calculation } \\
\text { Module }\end{array}$ \\
\hline Clay DEM & User defined & $\begin{array}{l}\text { Landfill base area } \\
\text { (Landfill length } \\
\text { in the direction of } \\
\text { groundwater } \\
\text { flow) }\end{array}$ & POLLUTE \\
\hline $\begin{array}{c}\text { Groundwater } \\
\text { DEM }\end{array}$ & User defined & Waste thickness & POLLUTE \\
\hline $\begin{array}{l}\text { Inclination } \\
\text { (side slope) }\end{array}$ & User defined & & \\
\hline Base elevation & User defined & & \\
\hline Base slope & User defined & & \\
\hline Ground elevation & User defined & & \\
\hline Margins & User defined & & \\
\hline Surface elevation & User defined & & \\
\hline Surface slope & User defined & & \\
\hline Ground offset & User defined & & \\
\hline
\end{tabular}

The base area (landfill length in the direction of groundwater flow) and average waste thickness obtained by using VLF are used as design specific values for POLLUTE simulations. The transfer of these data is achieved manually.

Virtual Landfill (VLF) is embedded into LFDSS platform as an externally operating tool, and it is run by clicking on the Virtual Landfill button at the top menu. As the LFDSS platform is based on .NET, any open-coded software can be added to the platform as a tool and run under it. To locate VLF in the LFDSS, the 
directory of the model is required to be defined at the start-up of the DSS platform.

\subsubsection{Cover Design Evaluation Model (HELP)}

HELP model was included within the LFDSS to obtain the infiltration rate from the final cover reaching the waste. Performance of different final cover types (i.e. evapotranspiration cover $-\mathrm{C} 1$, extensive engineering final cover $-\mathrm{C} 2$, and intermediate design final cover -C3) composed of different design components (i.e. natural top soil, cover drainage system, geomembrane, and clay liner) are evaluated and net infiltration rate leaving the final cover is calculated by the model.

HELP model is operated under five submenus: soil and design, evapotranspiration, precipitation, temperature, and solar radiation. Input data requirements of each submenu are given in Table 3.17. The input data can either be defined by the user regarding the specific properties of the landfill final cover design, or HELP databases for soil properties can be used (Figure 3.16). 
Table 3. 17 Input data requirement and output data supplied by HELP model

\begin{tabular}{|c|c|c|c|}
\hline Input Data ${ }^{a}$ & Input Data $^{a}$ & Output & $\begin{array}{c}\text { To } \\
\text { Model/Module }\end{array}$ \\
\hline Soil\&design data & Evapotranspiration & Infiltration rate & POLLUTE \\
\hline Landfill area & Latitude & & \\
\hline $\begin{array}{l}\% \text { of area where } \\
\text { runoff is possible }\end{array}$ & $\begin{array}{l}\text { Evaporative zone } \\
\text { depth }\end{array}$ & & \\
\hline Initial moisture & Max. leaf area index & & \\
\hline $\begin{array}{l}\text { Amount of water } \\
\text { or snow on surface }\end{array}$ & $\begin{array}{l}\text { Growing season start } \\
\text { day }\end{array}$ & & \\
\hline Layer type (natural & & & \\
\hline $\begin{array}{l}\text { So1l } \\
\text { (1)/geomembrane } \\
\text { (4) /barrier-clay } \\
\text { (3)/drainage (2)) }\end{array}$ & $\begin{array}{l}\text { Growing season end } \\
\text { day }\end{array}$ & & \\
\hline Layer thickness & Average wind speed & & \\
\hline $\begin{array}{l}\text { Soil type (numbers } \\
\text { defining soil codes } \\
\text { are given in HELP } \\
\text { database) }\end{array}$ & $\begin{array}{l}1^{\text {st }} \text { quarter relative } \\
\text { humidity }\end{array}$ & & \\
\hline Total porosity & $\begin{array}{l}2^{\text {nd }} \text { quarter relative } \\
\text { humidity }\end{array}$ & & \\
\hline Field capacity & $\begin{array}{l}3^{\text {rd }} \text { quarter relative } \\
\text { humidity }\end{array}$ & & \\
\hline Wilting point & $\begin{array}{l}4^{\text {th }} \text { quarter relative } \\
\text { humidity }\end{array}$ & & \\
\hline Initial moisture & Climatic data & & \\
\hline $\begin{array}{l}\text { Saturated } \\
\text { hydraulic } \\
\text { conductivity }\end{array}$ & Daily precipitation & & \\
\hline Drainage length & Daily temperature & & \\
\hline Drain slope & Daily solar radiation & & \\
\hline $\begin{array}{l}\text { Leachate } \\
\text { recirculation }\end{array}$ & & & \\
\hline Recirculation to & & & \\
\hline $\begin{array}{l}\text { layer \# (number of } \\
\text { the layer) }\end{array}$ & & & \\
\hline Subsurface inflow & & & \\
\hline $\begin{array}{l}\text { Geomembrane } \\
\text { pinhole density }\end{array}$ & & & \\
\hline $\begin{array}{l}\text { Geomembrane } \\
\text { installation defects }\end{array}$ & & & \\
\hline $\begin{array}{l}\text { Geomembrane } \\
\text { placement quality }\end{array}$ & & & \\
\hline $\begin{array}{l}\text { Geotextile } \\
\text { transmissivity }\end{array}$ & & & \\
\hline
\end{tabular}




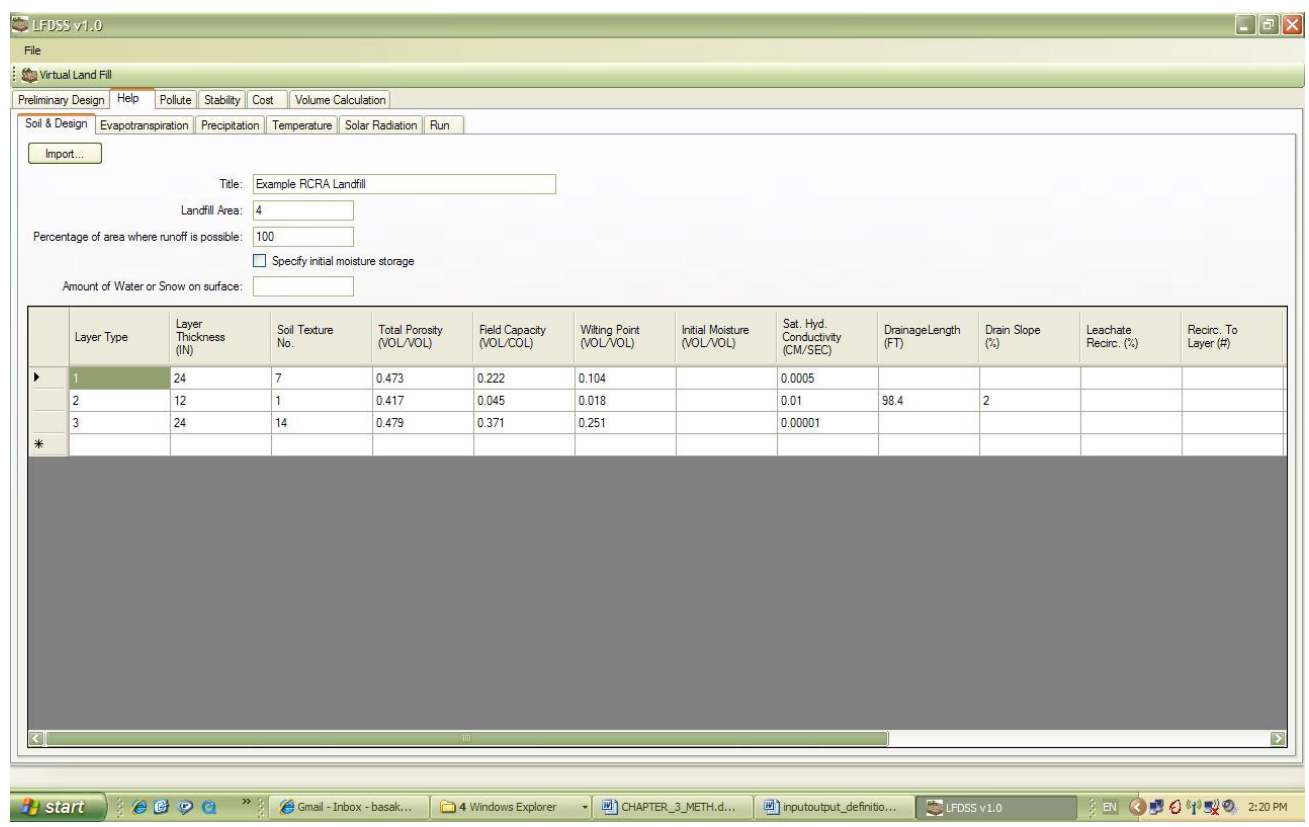

Figure 3. 16 Soil and design input window for HELP model in LFDSS

The sixth submenu (Run) is used to execute the HELP model. Units to display the results, number of years for simulation, and output type are required to be defined by the user (Figure 3.17). HELP model is executed within the LFDSS (Figure 3.18). The simulation is completed by the presentation of annual values of precipitation, evapotranspiration, surface runoff, drainage from, percolation to, and average head over final cover layers, water budget and the "Infiltration" rate under the Run menu (Figure 3.19). The infiltration value is automatically transferred to POLLUTE dialog box. The integration of HELP model and data transfer method to POLLUTE was previously given in Section 3.2.2.3. 
File

Virtual Land Fill
\begin{tabular}{|l|l|l|l|l|}
\hline Preliminary Design Help Pollute & Stability & Cost & Volume Calculation \\
\hline Soil \& Design & Evapotranspiration & Precipitation & Temperature & Solar Radiation Run \\
\hline Units (1: Customary, 2: Metric): & 2 \\
Number of years to simulate: & 20 \\
& Generate $\square$ daily output $\square$ monthly output $\square$ annual output.
\end{tabular}

\section{Run}

Infiltration:

Figure 3. 17 Run menu for HELP model in LFDSS

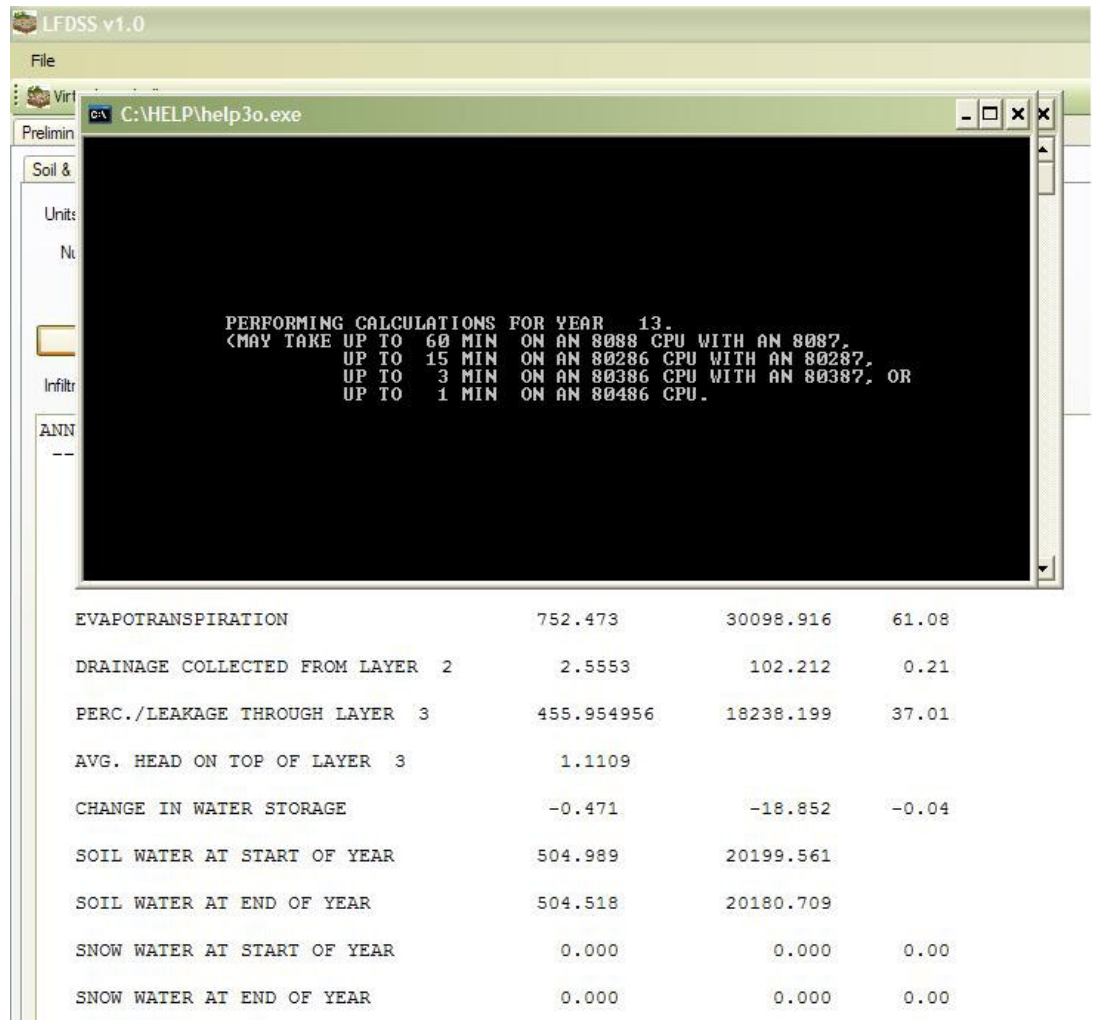

Figure 3. 18 Execution of HELP model within the LFDSS 


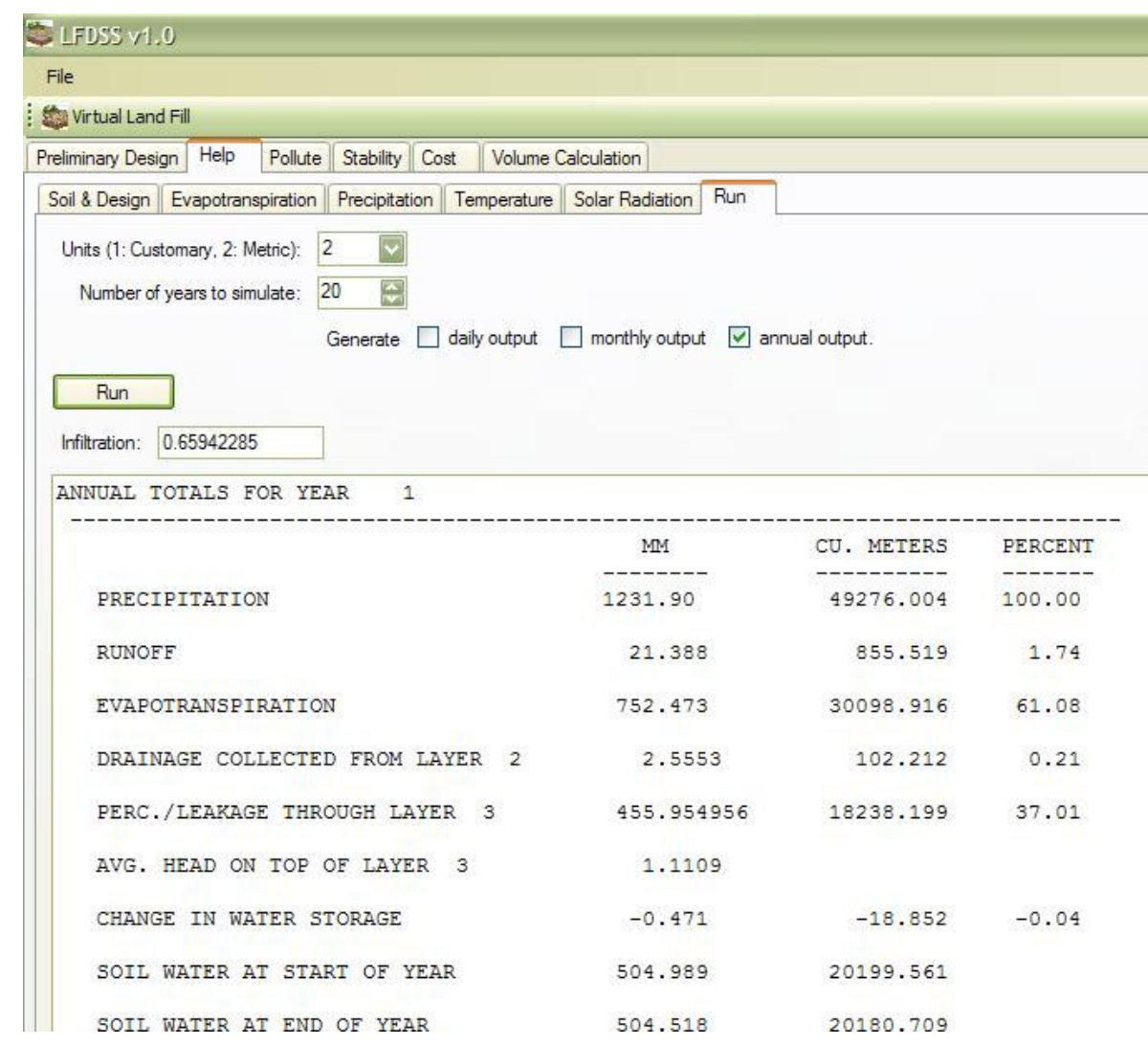

Figure 3. 19 Presentation of infiltration rate and HELP output data in LFDSS

\subsubsection{Waste and Bottom Liner Design and Subsurface Transport Model (POLLUTE)}

POLLUTE model is used to model waste and bottom liner of the landfill, as well as the vadose zone beneath the bottom liner. The model evaluates the compliance of the design alternative to the first performance criterion (i.e. leachate head on top of bottom liner should be less than $1 \mathrm{~m}$ for stability reasons). Also, POLLUTE uses infiltration rate data from HELP model to calculate the contaminant concentration at the groundwater table or in soil beneath the landfill, where groundwater is not present. The model results are evaluated by the LFDSS to assess the compliance of the landfill design alternative with the second 
performance criterion (i.e. maximum contaminant $\left(\mathrm{Cl}^{-}\right)$concentration at the groundwater table should be less than $25 \mathrm{mg} / \mathrm{L}$ ).

POLLUTE functions were simplified regarding the input requirements of the performance evaluations under LFDSS; therefore, the model is operated under three tabs, divided into sections related with different design components. First tab is the Parameters tab, where waste and bottom liner design parameters are specified (Figure 3.20.a). Second tab is the Maximum Concentrations tab, where the run parameters are specified and results of maximum concentration and time of occurrence of maximum concentration are presented to the user (Figure 3.20.b). In the third tab, Concentrations at Specified Times, contamination trend with time can be observed, if required (Figure 3.20.c). In the Parameters tab, the design components that would be used for the specific landfill design are selected from the General section. Waste type is defined by the "concentration" and "density" value under Source section. Dimensions of the landfill (i.e. waste thickness and landfill length in the direction of groundwater flow) are also defined by the user considering the output of Virtual Landfill model in the Source section. Infiltration rate is transferred from HELP model automatically (see Section 3.2.2.3 for details). The technical properties of design components (e.g. leachate collection system, geomembrane, compacted clay liner, vadose zone) and the aquifer are also defined under relevant sections. When any of the design components are unchecked (e.g. compacted clay liner), the technical properties entered for the component would not be taken into consideration during the simulations. In the Maximum Concentrations tab, lower and upper time limits are defined by the user to determine the simulation time. Search depth is the total length of the design components used in the bottom liner design (excluding the waste layer but including the vadose zone thickness) and required to obtain the maximum concentration at the groundwater table. In the Concentrations at specified times tab, the user can define specific times (in hours, days, years, or seconds) to observe the contaminant concentrations that would occur at the groundwater table 
at the selected times. The results are not transferred to LFDSS, demonstrated from POLLUTE main programme.

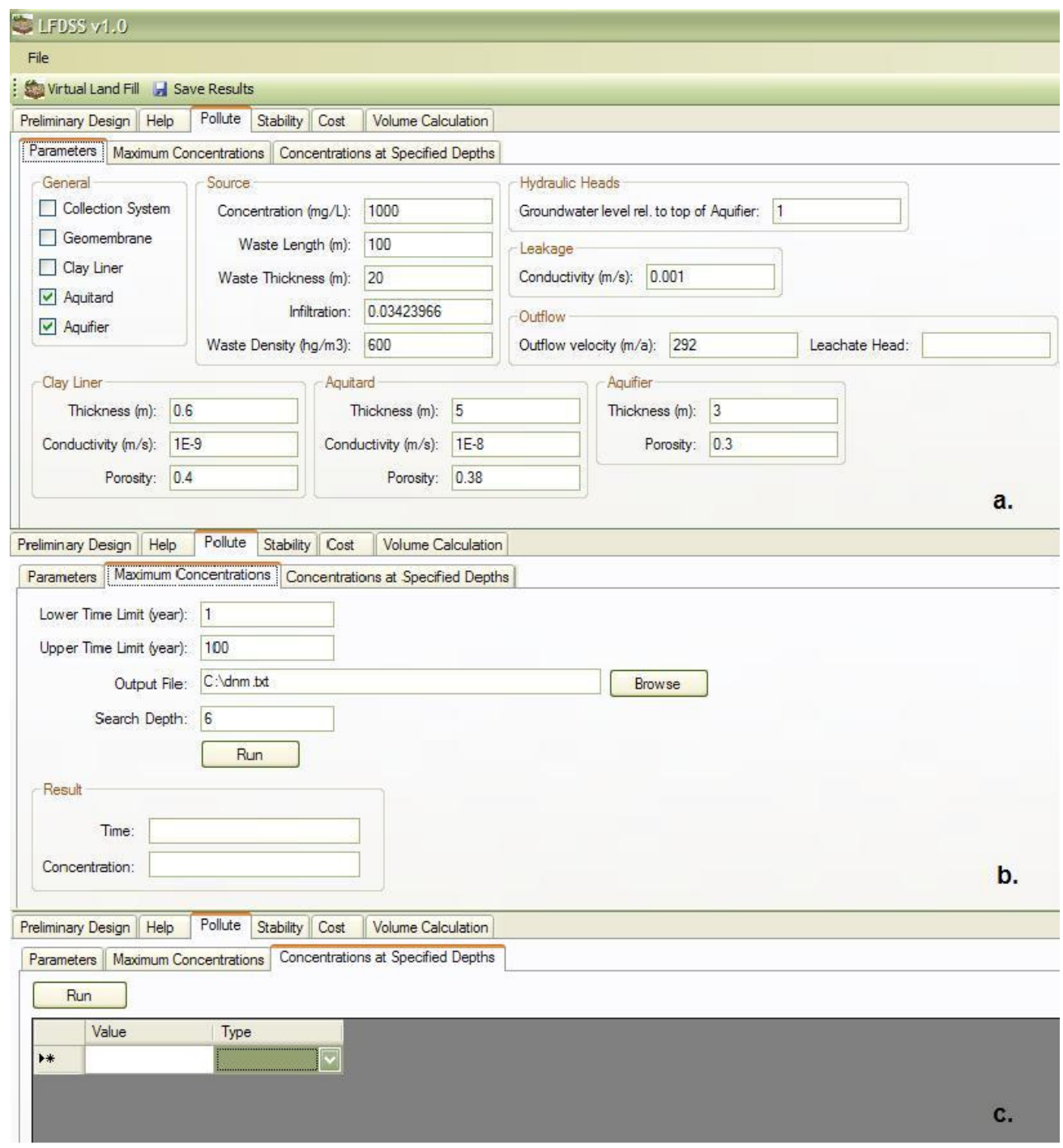

Figure 3. 20 POLLUTE tabs in LFDSS. a) Parameters tab, b) Maximum concentrations tab, c) Concentrations at specified times

When the model is executed from Maximum Concentrations tab, results for maximum concentrations and time of occurrence of maximum concentration are given in Result subsection. If the maximum concentration exceeds the predefined contaminant concentration at the groundwater table (i.e. $25 \mathrm{mg} / \mathrm{L}$ ) the 
concentration values is highlighted with red to warn the user. Also, after the execution, if the "Leachate head" box in the parameter menu should be controlled by the user for the designs without leachate collection systems, in order to determine whether the design satisfies the first performance criterion (i.e. leachate head over bottom liner should be less than $1 \mathrm{~m}$ ) (Figure 3.21).

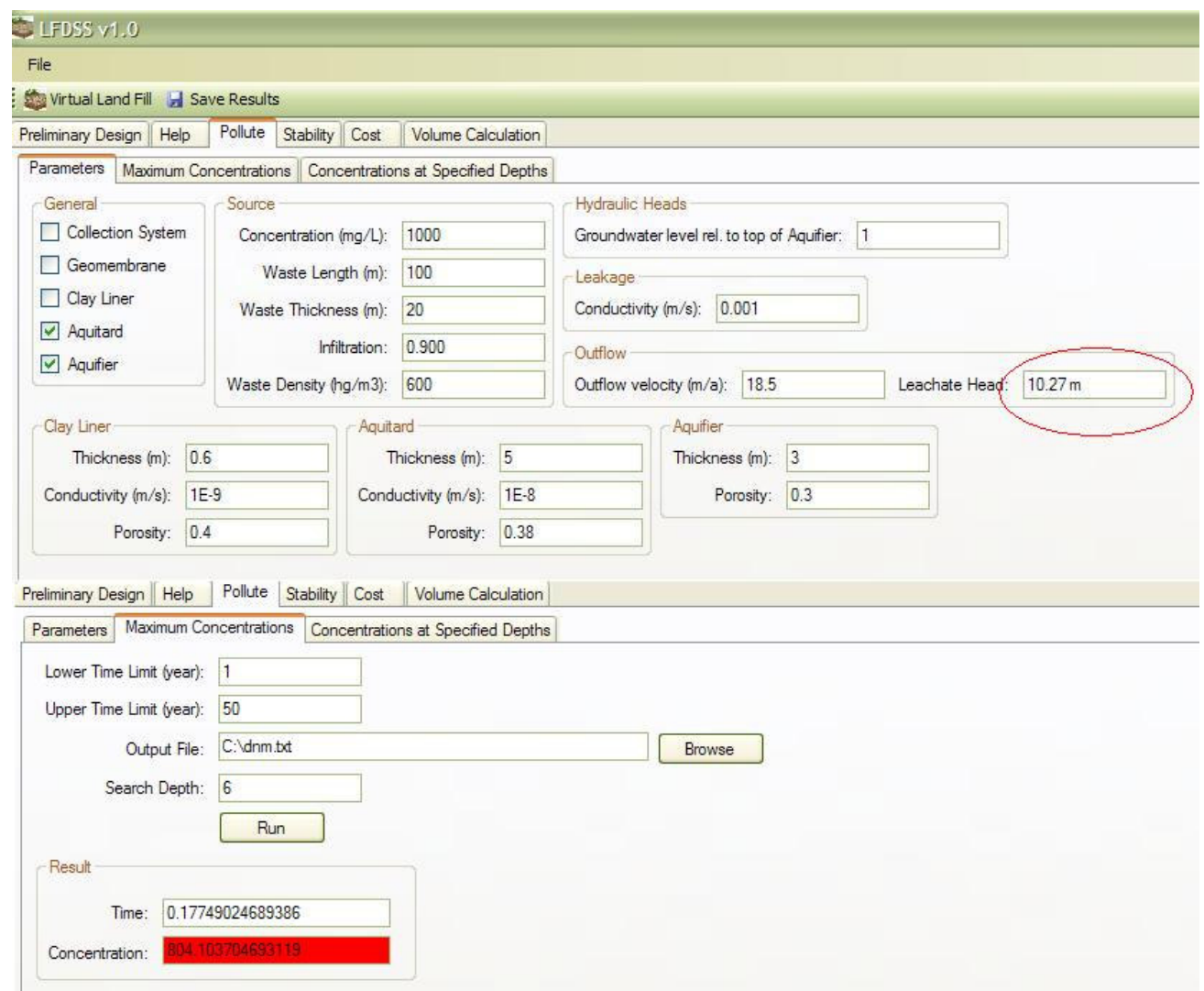

Figure 3. 21 POLLUTE execution from Maximum Concentrations tab in LFDSS

The input data requirements and the output data supplied by POLLUTE model are given in Table 3.18 . 
Table 3. 18 Input data requirement and output data supplied by POLLUTE model

\begin{tabular}{|c|c|c|c|}
\hline Input & $\begin{array}{c}\text { From } \\
\text { Model/Module }\end{array}$ & Output & $\begin{array}{c}\text { To } \\
\text { Model/Module }\end{array}$ \\
\hline Waste length & Observed from VLF & $\begin{array}{c}\text { Contaminant } \\
\text { concentration at } \\
\text { the groundwater } \\
\text { table }\end{array}$ & $\begin{array}{l}\text { LFDSS decision } \\
\text { interface }\end{array}$ \\
\hline Waste thickness & Observed from VLF & $\begin{array}{l}\text { Leachate head } \\
\text { on landfill } \\
\text { bottom liner }\end{array}$ & User \\
\hline Infiltration & $\begin{array}{c}\text { Transferred from } \\
\text { HELP }\end{array}$ & & \\
\hline Waste density & User defined & & \\
\hline $\begin{array}{l}\text { Groundwater level } \\
\text { relative to the top of } \\
\text { aquifer }\end{array}$ & User defined & & \\
\hline $\begin{array}{l}\text { Leachate head on } \\
\text { primary liner }\end{array}$ & $\begin{array}{c}\text { default as } 0.3 \mathrm{~m} \text { for } \\
\text { designs including } \\
\text { LCS }^{\mathrm{b}} \\
\text { OR } \\
\text { automatically } \\
\text { calculated by } \\
\text { POLLUTE for } \\
\text { designs excluding } \\
\text { LCS }^{\mathrm{b}}\end{array}$ & & \\
\hline $\begin{array}{l}\text { Hydraulic conductivity } \\
\text { (of drainage material) }\end{array}$ & User defined & & \\
\hline Thickness of $\mathrm{CCL}^{\mathrm{a}}$ & User defined & & \\
\hline $\begin{array}{l}\text { Hydraulic conductivity } \\
\text { of } \mathrm{CCL}^{\mathrm{a}}\end{array}$ & User defined & & \\
\hline Porosity of CCL ${ }^{a}$ & User defined & & \\
\hline $\begin{array}{l}\text { Thickness of vadose } \\
\text { zone }\end{array}$ & User defined & & \\
\hline $\begin{array}{l}\text { Hydraulic conductivity } \\
\text { of vadose zone }\end{array}$ & User defined & & \\
\hline Porosity of vadose zone & User defined & & \\
\hline Thickness of the aquifer & User defined & & \\
\hline Porosity of the aquifer & User defined & & \\
\hline $\begin{array}{l}\text { Outflow velocity } \\
\text { (groundwater seepage } \\
\text { velocity) }\end{array}$ & User defined & & \\
\hline $\begin{array}{l}\text { Lower and upper time } \\
\text { limits }\end{array}$ & User defined & & \\
\hline Search depth & User defined & & \\
\hline $\begin{array}{l}\text { Contaminant } \\
\text { concentration }\end{array}$ & User defined & & \\
\hline Search year & User defined & & \\
\hline
\end{tabular}


As previously stated, once the landfill design is simulated from Maximum Concentrations tab, for the designs not having leachate collection system, POLLUTE calculates the leachate head on bottom liner to help in the assessment of the landfill design to the stability criterion. The user should be aware that if the value of the leachate head on primary liner is calculated to be greater than $1 \mathrm{~m}$, the landfill design alternative is not appropriate for the given site conditions. Also, maximum contaminant concentration, and the time of occurrence of maximum concentration are indicated in Result subsection. When the landfill design does not satisfy the contamination criterion (i.e. $\mathrm{Cl}^{-}$concentration below $25 \mathrm{mg} / \mathrm{L}$ ), the concentration box is highlighted with red. Therefore, the user is guided that the landfill design violates the design criterion.

The LFDSS executes the POLLUTE model outside the platform using a macro (see Section 3.2.2.2). The output file in text file format is saved to the specified destination from the Maximum Concentrations tab. The final concentration record in Results subsection is read by the LFDSS decision interface and written on the results file. The details of decision interface are explained in Section 3.2.5.6.

\subsubsection{Stability Analysis Module}

Stability Analysis Module was developed to assess the stability of the landfill design alternatives complying with the performance criteria. After the landfill design alternatives are simulated by LFDSS, the geotechnical data related with the design alternatives are entered to the stability analysis module to obtain factor of safety (FS) values. Stability analysis module does not require data transfer from any other module. It is an independent and/or optional module for the performance evaluation of the landfill design alternatives. The equations used in stability calculations, and hence the input data requirement, are explained in this section. 
In the literature, the stability analyses for the landfills cover three main issues, which are excavation slope stability, refuse fill stability, and cover system stability. Besides the three main analyses, geomembrane stability and seismic stability components are included in the Stability Module. The module is developed using MS Excel spreadsheet. The module consists of 5 submenus; each is capable of calculating one of the five stability issues occurring in landfills.

The equations used for factor of safety calculations for each of the stability issues are summarized in Table 3.19.

In the "excavation slope menu" the analyses are performed using the method of slices (Eq. 3.9). The total weight $\left(\mathrm{W}_{\mathrm{T}}\right)$ includes vertical and horizontal seismic loads; and the surcharge (Eq. 3.10). For a first degree seismic zone, horizontal seismic parameter, $\mathbf{k}_{\mathbf{h}}$, is accepted as 0.15 , and vertical seismic parameter, $\mathbf{k}_{\mathbf{v}}$, is accepted as 0.08 (Kramer, 1996). According to the common practice, for excavation slope stability calculations, it is accepted that no leakage will be observed at the base during construction; therefore, pore water pressure, $\boldsymbol{u}$, is accepted as zero. Equation 3.9 and 3.10 are also used for the "refuse fill stability menu"; however, surcharge is excluded from the total weight.

$$
\begin{aligned}
& F S=\frac{\sum c(\delta l)+\sum \tan \phi(W \cos \alpha-u(\delta l))}{\sum W_{T} \sin \alpha} \\
& F_{v}=k_{v} \times W \\
& F_{h}=k_{h} \times W
\end{aligned}
$$


Table 3. 19 The formulae used in stability calculations

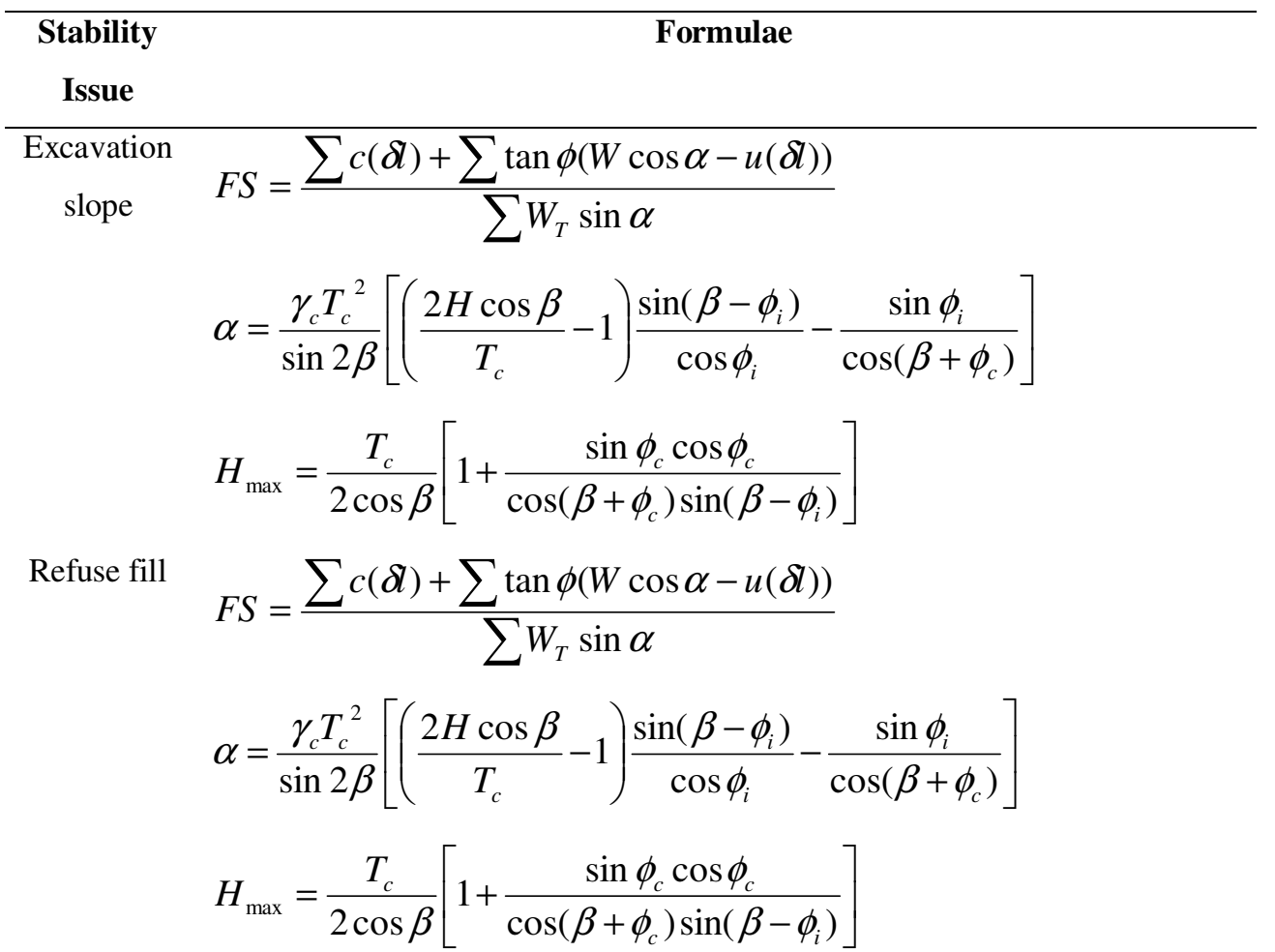

Cover

system

$F S=\frac{\tan \phi}{\tan \beta}$ cohesionless, dry

$F S=\frac{\gamma_{b} \tan \phi^{\prime}}{\gamma_{t} \tan \beta}$ cohesionless, seepage

$F S=\frac{c^{\prime}+\sigma^{\prime} \tan \phi^{\prime}}{\tau_{r}{ }^{\prime}}=\frac{c^{\prime}+\gamma_{b} H \cos ^{2} \beta \tan \phi^{\prime}}{\gamma_{t} t \sin \beta \cos \beta}$ cohesive

$\mathrm{GM}^{\mathrm{a}} \quad F S=\frac{F n e t}{T}=\frac{\left(\not H \tan ^{2}\left(45+\varphi_{c} / 2\right)\right)-\left(\not H \tan ^{2}\left(45-\varphi_{c} / 2\right)\right)}{\left(W \sin \varphi_{i}-W \sin \phi_{i} \tan \varphi_{i}\right)}$

Seismic

Stability

$F S=\frac{-b+\sqrt{b^{2}-4 a c}}{2 a}$

$a=\left(C_{S} W_{A}+N_{A} \sin \beta\right) \cos \beta+C_{S} W_{P} \cos \beta$

$b=-\left[\left(C_{S} W_{A}+N_{A} \sin \beta\right) \sin \beta \tan \phi+\left(N_{A} \tan \delta+C_{a}\right) \cos ^{2} \beta+\left(C+W_{p} \tan \phi\right) \cos \beta\right]$

$c=\left(N_{A} \tan \delta+C_{a}\right) \cos \beta \sin \beta \tan \phi$

${ }^{\mathrm{a}}$ Geomembrane 
Usually, planar slip surfaces occur in final covers; therefore, infinite slope analysis of limit equilibrium approach is implemented in "Cover system stability menu". The method has different analysis techniques for cohesionless and cohesive soils. Cohesionless soils are also divided into two, as dry or seepage conditions. Factor of safety calculations are summarized below for each of the aforementioned cases (Sharma and Lewis, 1994):

- Cohesionless soils, dry conditions:

$$
F S=\frac{\tan \phi}{\tan \beta}
$$

Parameters that should be defined are $\phi$, angle of internal friction; and $\beta$, slope angle.

- Cohesionless soils, seepage conditions:

$$
F S=\frac{\gamma_{b} \tan \phi}{\gamma_{t} \tan \beta}
$$

Parameters that should be defined are $\phi$, effective friction angle; $\gamma_{b}$, buoyant unit weight of soil; $\gamma_{t}$, total unit weight of soil; and $\beta$, slope angle. Usually, the slope angle with seepage is half of the one without seepage.

- Cohesive soils:

$$
F S=\frac{c^{\prime}+\sigma^{\prime} \tan \phi^{\prime}}{\tau_{r}{ }^{\prime}}=\frac{c^{\prime}+\gamma_{b} H \cos ^{2} \beta \tan \phi^{\prime}}{\gamma_{t} t \sin \beta \cos \beta}
$$

Parameters that should be defined are c', effective cohesion; $\sigma$, effective normal stress; $\phi$, effective friction angle; $\gamma_{b}$, buoyant unit weight of soil; $\gamma_{t}$, total unit weight of soil; $\mathrm{H}$, vertical depth to slip plane; t, soil thickness; and $\beta$, slope angle. $\tau_{\mathrm{r}}$ is the Mohr envelope. 
For "the geomembrane menu", factor of safety values are calculated based on the determined anchorage height (Eq. 3.14). In equation 3.14, $\gamma$ is the unit weight of soil, $\mathrm{H}$ is anchorage height, $\varphi_{\mathrm{i}}$ is interface friction angle between geomembrane and geotextile, $\varphi_{c}$ is the friction angle of granular soil.

$$
F S=\frac{F n e t}{T}=\frac{\left(\not H \tan ^{2}\left(45+\varphi_{c} / 2\right)-\left(\not H \tan ^{2}\left(45-\varphi_{c} / 2\right)\right.\right.}{\left(W \sin \varphi_{i}-W \sin \phi_{i} \tan \varphi_{i}\right)}
$$

In "the seismic stability menu" seismic forces were taken into account for the evaluation of seismic stability of final covers. Especially for places with high earthquake risk (e.g. western and eastern regions of Turkey), this type of stability analysis appears to be important. A factor of safety value is calculated by adding the horizontal force acting at the centroid of the cover soil cross-section. The horizontal force is in proportion to the anticipated seismic activity, which is indicated by an average seismic coefficient $\left(\mathrm{C}_{\mathrm{s}}\right) . \mathrm{C}_{\mathrm{s}}$ is the ratio of bedrock acceleration to gravitational acceleration, and can be obtained from a seismic zone map (Koerner and Soong, 2005). Guidance values for $\mathrm{C}_{\mathrm{s}}$ presented to the users are given in Table 3.20.

Table 3. 20 Guidance values for average seismic coefficient $\left(C_{s}\right)$ (Koerner and Daniel, 1997)

\begin{tabular}{ccc}
\hline Modified Mercalli Scale & Remark & $\mathbf{C}_{\mathbf{s}}$ \\
\hline- & No damage & 0 \\
V and VI & Minor damage & $0.3-0.7$ \\
VII & Moderate damage & 0.13 \\
VII and higher & Major damage & 0.27 \\
\hline
\end{tabular}

The factor of safety value is then calculated according to Eq. 3.15 (Koerner and Soong, 2005): 


$$
\begin{aligned}
& F S=\frac{-b+\sqrt{b^{2}-4 a c}}{2 a} \\
& a=\left(C_{S} W_{A}+N_{A} \sin \beta\right) \cos \beta+C_{S} W_{P} \cos \beta \\
& b=-\left[\left(C_{S} W_{A}+N_{A} \sin \beta\right) \sin \beta \tan \phi+\left(N_{A} \tan \delta+C_{a}\right) \cos ^{2} \beta+\left(C+W_{p} \tan \phi\right) \cos \beta\right] \\
& c=\left(N_{A} \tan \delta+C_{a}\right) \cos \beta \sin \beta \tan \phi
\end{aligned}
$$

Where $C_{\mathrm{s}}$ is the average seismic coefficient, $\mathrm{W}_{\mathrm{A}}$ is the weight of active wedge, $\mathrm{N}_{\mathrm{A}}$ is the effective force normal to the failure plane of the active wedge, $\beta$ is the soil slope angle, $\mathrm{W}_{\mathrm{P}}$ is the total weight of the passive wedge, $\phi$ is the friction angle of the cover soil, $\delta$ is the interface friction angle between cover soil and geomembrane, and $\mathrm{C}_{\mathrm{a}}$ is the adhesive force between cover soil of the active edge and the geomembrane. The relation between the FS value and the average seismic coefficient $\left(\mathrm{C}_{\mathrm{s}}\right)$ are presented in Figure 3.22. The curve presented in Figure 3.22 is drawn for the parameters given in the legend of the figure. This curve is also presented as guidance to the user (Koerner and Soong, 2005).

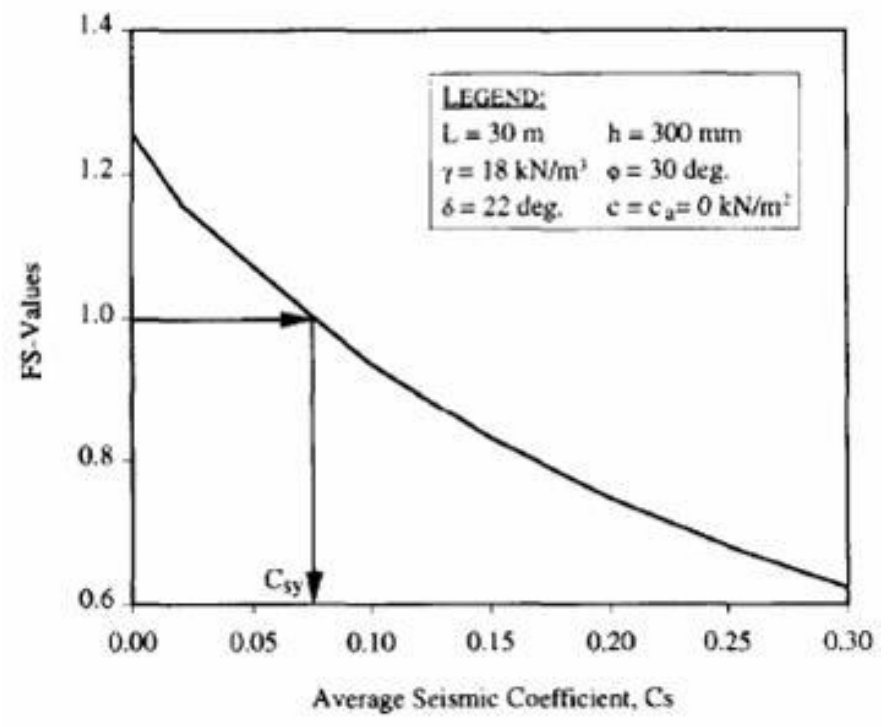

Figure 3. $22 \mathrm{FS}$ values vs. average seismic coefficient $\left(\mathrm{C}_{\mathrm{s}}\right)$ as guidance in LFDSS (Koerner and Soong, 2005) 
MS Excel spreadsheet accommodating the stability formulae was used as basis for the formation of Stability Analysis Module in LFDSS. It is possible to input data manually or via copy and paste from other sources (e.g. MS Excel) in a tabular form using the DataGridView property of Visual C\#. This property creates a userfriendly environment for data input, and also, eases multiple calculations under a single menu in LFDSS (Figure 3.23).

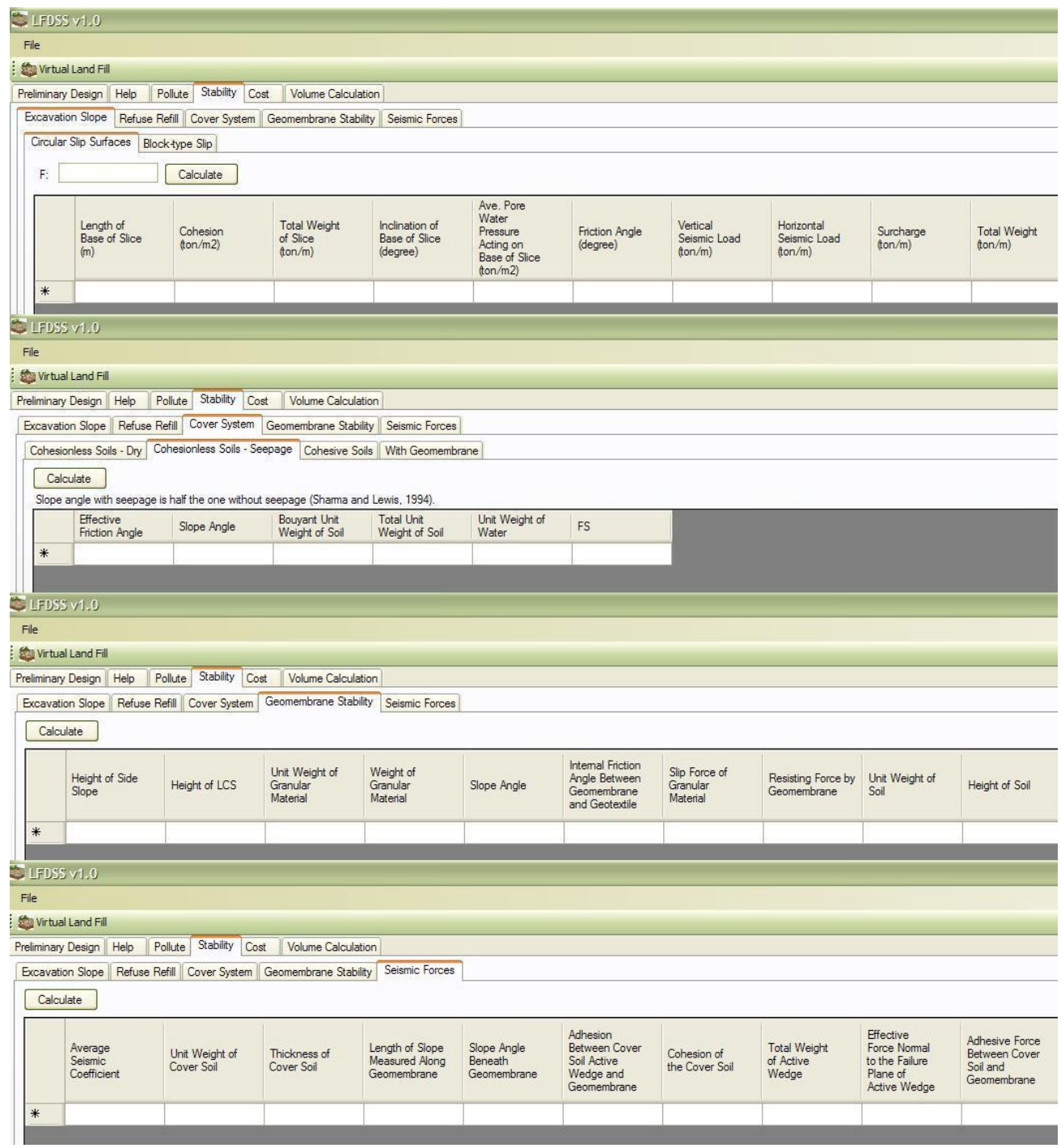

Figure 3. 23 Screenshots of Stability Analysis Module in LFDSS 
The factor of safety (FS) values calculated under each submenu are read by the LFDSS decision interface and written on the results file. The details of decision interface are explained in Section 3.2.5.6.

\subsubsection{Major Design Component Approximate Cost Estimation Module}

A Major Design Component Approximate Cost Estimation Module (referred to as cost estimation module from now on throughout the thesis) was included in the LFDSS to calculate the approximate costs of major landfill design components (i.e. natural soil, surface drainage and leachate collection system, (compacted) clay liner, and geomembrane). Besides the major design component costs, it is also possible to calculate the costs of some additional components (i.e. not directly affecting the performance of the design, such as geotextiles, and vegetative cover requirements). Similar to the other calculation modules, Cost Estimation Module was prepared using MS Excel spreadsheets. The module is also an independent module for the performance evaluation of the landfill design alternatives, and it does not require data from any other model within the LFDSS.

The quantity of the design component used for the landfill design alternative of concern is required to be provided by the user. LFDSS is able to offer guidance values for unit costs of major and additional design components; therefore, the user can either define specific unit costs, or use the guidance values. Input data for the module are presented in Table 3.21. 
Table 3. 21 Major and additional design components for cost analyses in Cost Estimation Module in LFDSS

\begin{tabular}{|c|c|}
\hline Design Component & Processes \\
\hline \multicolumn{2}{|c|}{ Major design components } \\
\hline \multirow[t]{5}{*}{ Natural soil } & Excavation \\
\hline & Loading \\
\hline & Hauling \\
\hline & Spreading \\
\hline & Compaction \\
\hline \multirow[t]{4}{*}{ Top soil } & Purchase \\
\hline & Hauling \\
\hline & Spreading \\
\hline & Compaction \\
\hline \multirow[t]{3}{*}{ Drainage } & Gravel purchase \\
\hline & Hauling \\
\hline & Spreading the gravel \\
\hline \multirow[t]{3}{*}{ Drainage system } & Pipes \\
\hline & Hauling \\
\hline & Trenching \\
\hline \multirow[t]{7}{*}{ Clay (Onsite/Offside) } & Clay purchase \\
\hline & Excavation \\
\hline & Processing onsite clay \\
\hline & Loading \\
\hline & Hauling \\
\hline & Spreading \\
\hline & Compaction \\
\hline \multirow[t]{4}{*}{ Geomembrane } & $\begin{array}{l}\text { 60mil }(2 \mathrm{~mm}) \mathrm{HDPE}-\text { High density } \\
\text { polyethylene }\end{array}$ \\
\hline & 40mil PVC -polyvynlchloride \\
\hline & 40mil VFPE -very flexible polyethylene \\
\hline & Installation and testing \\
\hline \multicolumn{2}{|c|}{ Additional design components } \\
\hline \multirow[t]{2}{*}{ Geotextiles/geonets } & Purchase \\
\hline & Installation \\
\hline Geosynthetic clay liner & Bentomat purchase \\
\hline Vegetative topsoil & Hydroseeding \\
\hline
\end{tabular}

MS Excel spreadsheet accommodating the stability formulae was used as basis for the formation of Cost Estimation Module in LFDSS. It is possible to input data manually or via copy and paste from other sources (e.g. MS Excel) in a tabular form using the DataGridView property of Visual C\#. This property creates a user- 
friendly environment for data input, and also, eases multiple calculations under a single menu in LFDSS (Figure 3.24).

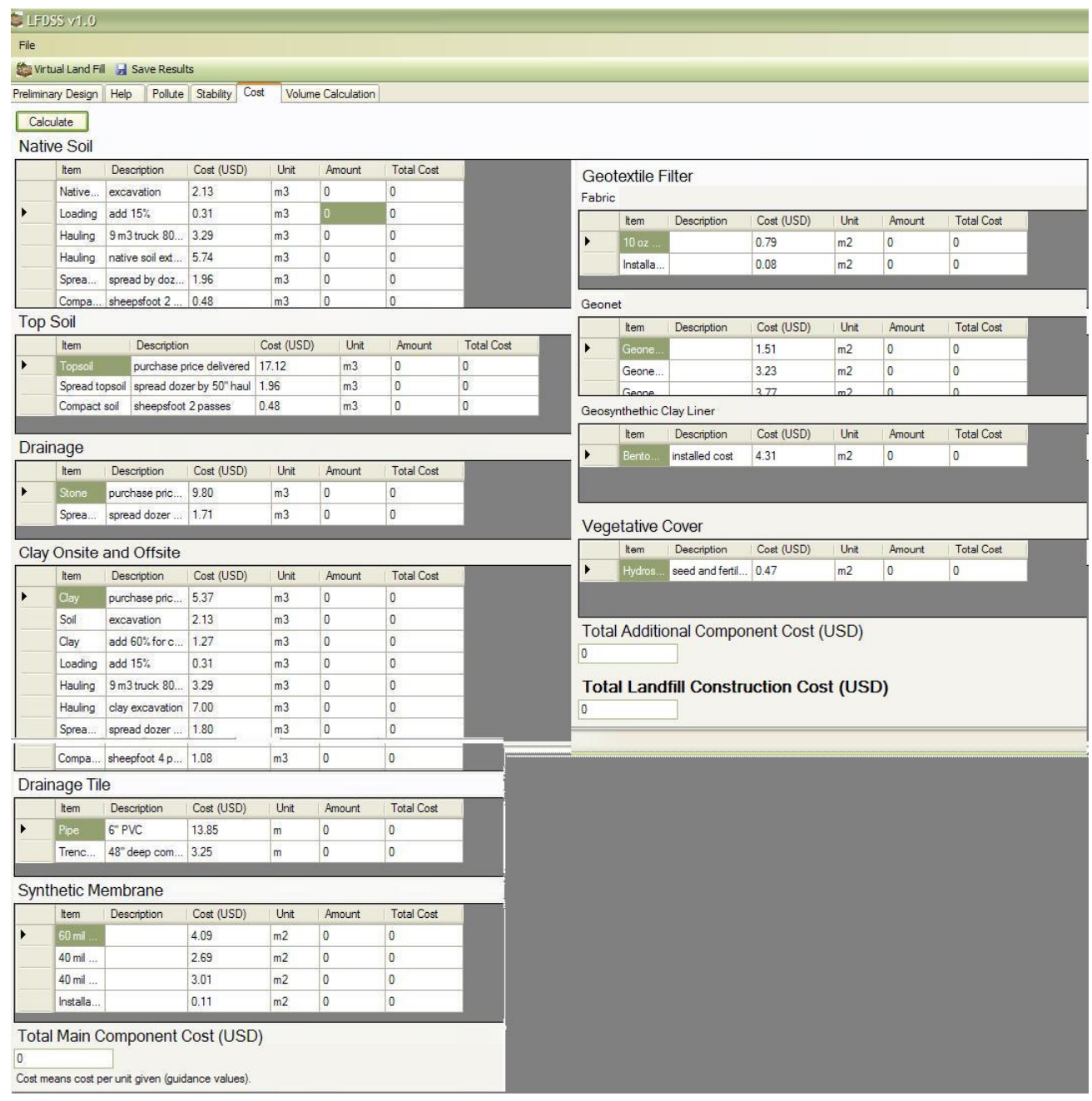

Figure 3. 24 Screenshot of cost estimation module in LFDSS

The cost calculated for each major design component are read by the LFDSS decision interface and written on the results file. The details of decision interface are explained in Section 3.2.5.6. 


\subsubsection{Decision Mechanism and Presentation of Decision Analyses}

After the performance, stability, and cost analyses are completed, the results of the simulations are saved to a text file (i.e. results file) by the "Save Results" button (Figure 3.25).

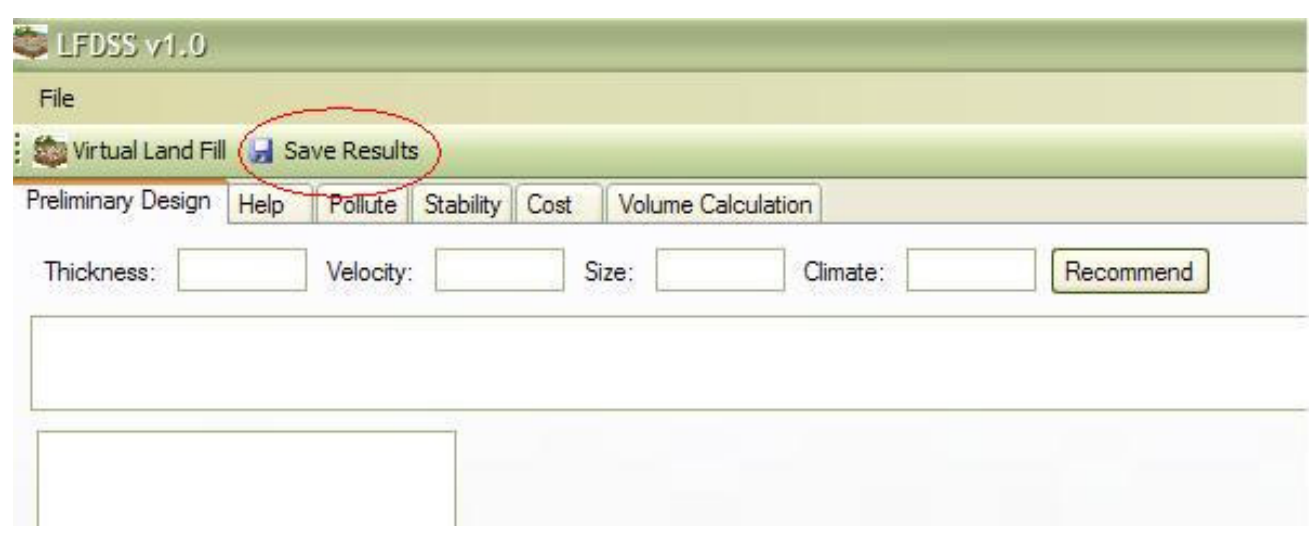

Figure 3. 25 Saving the results in LFDSS

Once the button is clicked (at any stage of the LFDSS simulations), the results of preliminary design module, POLLUTE (maximum concentration and time of occurrence), stability module (FS), and cost estimation module (major, additional, and total costs) are recorded on the results file, separated with commas (,). If either of the model/modules is not run, then the place reserved for the result belonging to that model/module is left blank between commas. If more than one value is calculated for a specific parameter (e.g. factor of safety), then these calculated values are separated with colons (:). The order of records are as follows: design alternative, maximum concentration, time of occurrence of maximum concentration, factor of safety value for excavation slope circular slip surfaces, factor of safety value for excavation slope block type slip, factor of safety value for refuse fill circular slip surfaces, factor of safety value for refuse fill block type slip, factor of safety value for final cover cohesionless dry soils, 
factor of safety value for final cover cohesionless soils with seepage, factor of safety value for final cover cohesive soils, factor of safety value for final cover stability with geomembrane, factor of safety value for geomembrane stability, factor of safety value for seismic stability for final covers, major cost, additional cost, and total landfill cost (Figure 3.26). Figure 3.26 shows that two design alternatives, C3L4 ${ }^{\mathrm{L}}$ and $\mathrm{C} 2 \mathrm{~L} 1$, were simulated using LFDSS. Factor of safety value for excavation slope block type slip, factor of safety values for final cover cohesionless soils, and with geomembrane, and factor of safety value for seismic forces were not calculated for $\mathrm{C} 3 \mathrm{~L} 4{ }^{\mathrm{L}}$ design alternative. Moreover, the report demonstrates that four different factor of safety values were calculated for geomembrane stability for the same design.

C3L4L, 1.21587401637304,135.54014234375, 3 .19753280971486, , 3.4893 $9250033159,,, 45.6805678449124,, 2.41804742076412: 1.612031613842$ 74:5.44060669671926:3.62707113114617, , 2097873 .51, 30450, 2128323. 51

C2L1, 27.300851078987,91.7644375, 3.19753280971486, , 3.48939250033

159 , , , , , , 9.16546829404725 , , , 2224323.51,43500,2267823.51

Figure 3. 26 Records in results file.

The results file is not in a proper format to be evaluated easily by the user; however, it can be imported to results template (MS Excel file) provided with the LFDSS software. The format of the template in MS Excel is similar to the one demonstrated in Table 3.22. 
Table 3. 22 Format of results template provided to the user by LFDSS (produced from Figure 3.26)

\begin{tabular}{|c|c|c|c|c|c|c|c|}
\hline \multirow[t]{2}{*}{ Design } & \multicolumn{2}{|c|}{ Performance } & \multicolumn{2}{|l|}{ Stability } & \multicolumn{3}{|c|}{ Cost (USD) } \\
\hline & $\begin{array}{c}\mathrm{Cl}_{\max } \\
(\mathrm{mg} / \mathrm{L})\end{array}$ & $\begin{array}{c}T_{\max } \\
(y r)\end{array}$ & FS values & & $\begin{array}{c}\text { Major } \\
\text { Cost }\end{array}$ & $\begin{array}{c}\text { Additiona } \\
\text { l Cost }\end{array}$ & Total Cost \\
\hline \multirow[t]{17}{*}{$\mathrm{C} 3 \mathrm{~L}_{4}^{\mathrm{L}}$} & 1.22 & 136 & Excavation slope & & 2097873.5 & 30450 & 2128323.5 \\
\hline & & & Circular slip & 3.20 & & & \\
\hline & & & Block-type slip & - & & & \\
\hline & & & Refuse-fill & & & & \\
\hline & & & Circular slip & 3.49 & & & \\
\hline & & & Block-type slip & - & & & \\
\hline & & & Cover system & & & & \\
\hline & & & Cohesionless -dry & - & & & \\
\hline & & & Cohesionless - & - & & & \\
\hline & & & seepaage & 45.68 & & & \\
\hline & & & Cohesive & - & & & \\
\hline & & & W/ geomembrane & & & & \\
\hline & & & Geomembrane & 2.42: & & & \\
\hline & & & & 1.61: & & & \\
\hline & & & & 5.44: & & & \\
\hline & & & & 3.63 & & & \\
\hline & & & Seismic & - & & & \\
\hline \multirow[t]{14}{*}{$\mathrm{C} 2 \mathrm{~L} 1$} & 27.3 & 92 & Excavation slope & & 2224323.5 & 43500 & 2267823.5 \\
\hline & & & Circular slip & 3.20 & & & \\
\hline & & & Block-type slip & - & & & \\
\hline & & & Refuse-fill & & & & \\
\hline & & & Circular slip & 3.49 & & & \\
\hline & & & Block-type slip & - & & & \\
\hline & & & Cover system & & & & \\
\hline & & & Cohesionless -dry & - & & & \\
\hline & & & Cohesionless - & - & & & \\
\hline & & & seepaage & - & & & \\
\hline & & & Cohesive & 9.17 & & & \\
\hline & & & W/ geomembrane & & & & \\
\hline & & & Geomembrane & - & & & \\
\hline & & & Seismic & - & & & \\
\hline
\end{tabular}

LFDSS does not select an optimum design; the platform offers guidance to the user by providing performance, stability, and cost analyses. Observing the outcomes of simulations for different design alternatives, the user should decide on the particular design/designs depending on the case-specific concerns. For example, for a site where groundwater is not present, stability issues present a much more important decision mechanism on the selection of the most appropriate design. The importance of decision mechanism is demonstrated in two case studies, presented in Chapter 4, Sections 4.5.1 and 4.5.2. 


\section{CHAPTER 4}

\section{RESULTS AND DISCUSSION}

In the first part of the previous chapter, the conceptual model for designing a performance-based landfill was developed and presented. Design variables, performance criteria, and design components were identified to be the main components of the conceptual model. Design variables were identified to be site conditions that affect the performance of a landfill design, performance criteria were the pre-defined limits that a landfill design should satisfy, and design components were the parts of a landfill design to reach the desired performance. A design methodology, and consequently a design component selection matrix, identifying the relations between these components were developed. In the second part, based on the developed methodology, the development of a decision support system was explained.

Chapter 4 is organized under two main parts: results of simulations of the landfill design alternatives, and case studies performed using LFDSS.

First, the results demonstrating the effect of design variables, vadose zone, waste thickness, and seepage velocity, on steady-state leakage rates from landfill barrier systems are presented and discussed. Then the performance-based evaluation of the 18 landfill design alternatives and their compliances with the performance criteria are discussed. The results of the performance-based simulations of the 18 
landfill design alternatives are coalesced to develop the design component selection matrices. The discussion is completed with the presentation of the design component selection matrices, which are used as knowledge base in the preliminary design phase of the developed DSS. .

The capabilities and the use of the developed DSS for landfill design (LFDSS) were demonstrated by one hypothetical and one real landfill case studies.

\subsection{Effect of Vadose Zone on Steady-State Leakage Rates from Landfill Barrier Systems}

To understand the effect of vadose zone on the steady-state leakage rates, a barrier system composed of a compacted clay liner underlain by a vadose zone is simulated by SEEP/W model by using both unsaturated soil hydraulic conductivity functions and uniform saturated hydraulic conductivity values, for both coarse textured and fine textured vadose zones. In the present analysis, the focus was on the case of a single low conductivity CCL underlain by a vadose zone. With respect to leakage rates, this case represents a more conservative situation compared to the case of composite liner, involving a geomembrane and a compacted clay liner (CCL), underlain by a vadose zone, since the geomembrane would further reduce the overall leakage rates through the CCL. As long as the flux through the CCL is not increased significantly (i.e. several orders of magnitude), the underlying vadose zone would not be fully saturated and its barrier function would not be impaired. Therefore, the findings of this work are also expected to be conservative for the case of composite liners. The results are discussed under the relevant headings. 
4.1.1. Barrier System: Compacted Clay Liner underlain by Coarse Textured Vadose Zones

According to the simulations performed using unsaturated soil hydraulic conductivity functions, the hydraulic conductivity values in the coarse grained vadose zone was as low as $9 \times 10^{-9} \mathrm{~m} / \mathrm{s}$ at the top of the vadose zone, near the compacted clay liner; and, reached $8 \times 10^{-5} \mathrm{~m} / \mathrm{s}$ at the bottom of the vadose zone, near the water table (Figure 4.1). This phenomenon occurred as the suction decreased with the depth of the vadose zone. As the unsaturated hydraulic conductivity is a function of pore-water pressures, the decreased suction resulted in increased hydraulic conductivity in the vadose zone towards the water table. As the thickness of the vadose zone increased, the portion of the vadose zone having lower hydraulic conductivity values also increased; therefore, the harmonic mean hydraulic conductivity of the vadose zone decreased. The decrease in the hydraulic conductivity reaches an asymptotic value for the vadose zone thicknesses greater than $5 \mathrm{~m}$ (Figure 4.2).

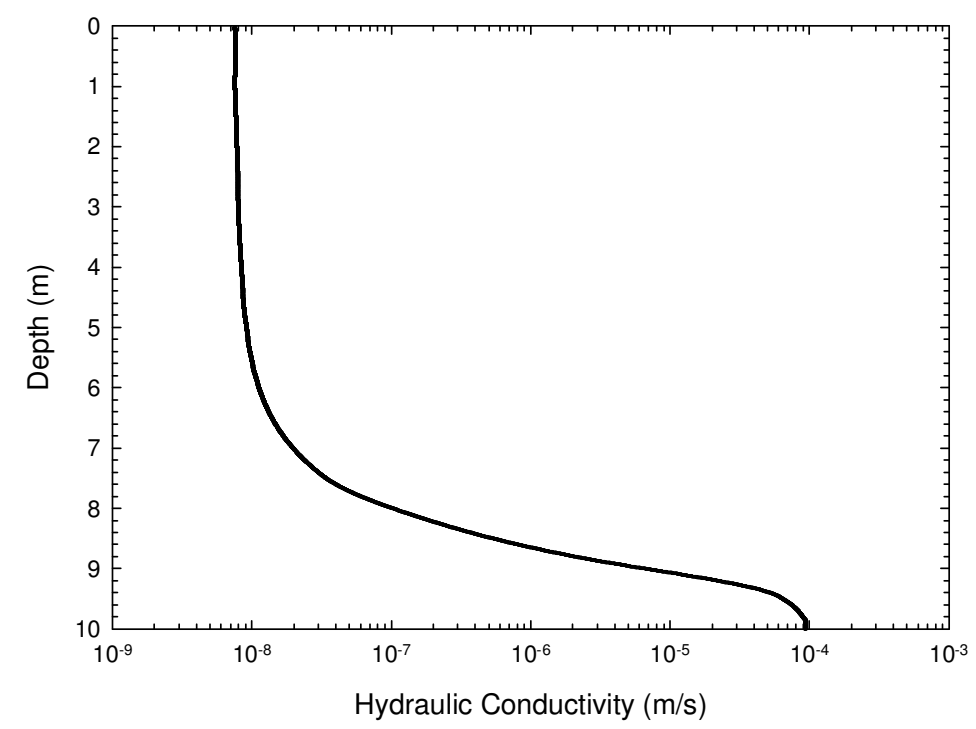

Figure 4. 1 Hydraulic conductivity change with depth for a uniform sand (US) 


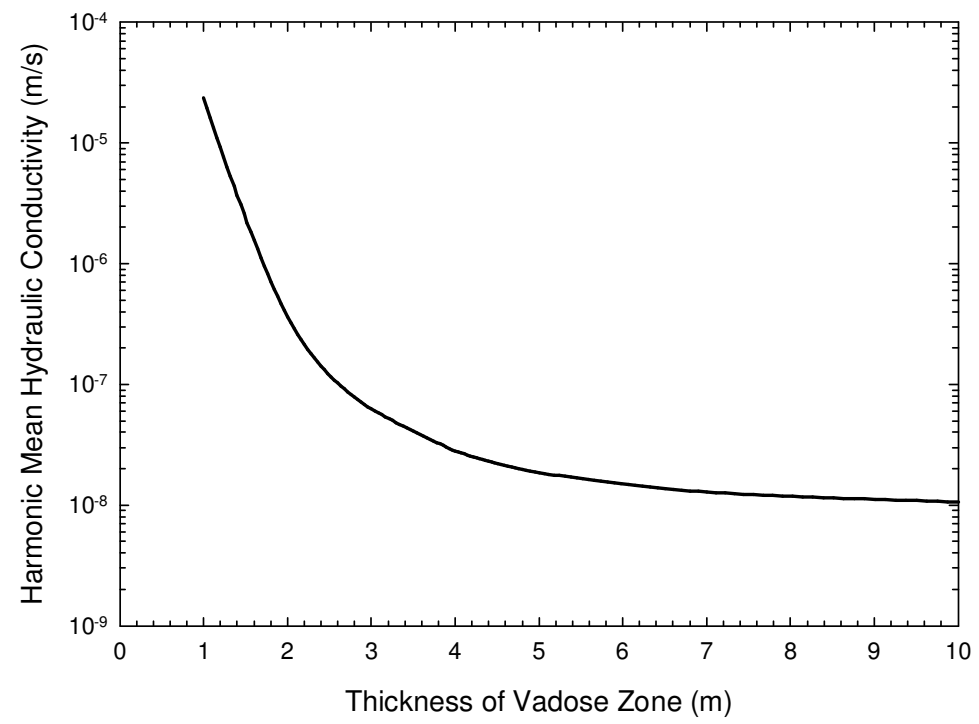

Figure 4. 2 Change in the harmonic mean hydraulic conductivity of the vadose zone with varying sandy $(\mathrm{S})$ vadose zone thickness

Although the harmonic mean hydraulic conductivity of the vadose zone decreased when the thickness of the vadose zone increased, the overall effective hydraulic conductivity of the combined clay barrier and unsaturated sandy soil system increased (Table 4.1). This occurred because the thickness of higher hydraulic conductivity material (i.e. vadose zone) increased relative to the thickness of lower hydraulic conductivity material (i.e. compacted clay liner). The increased effective hydraulic conductivity of the overall barrier system resulted in a gradual increase in the steady-state leachate leakage rates into the aquifer. As the thickness of the overall barrier system increases, the steady-state leakage rates increase gradually; however, similar to the hydraulic conductivity, they reach an asymptotic value between the vadose zone thicknesses of 5-10 m and do not change much beyond $10 \mathrm{~m}$ (Figure 4.3). Steady-state leakage rate results obtained from SEEP/W model are verified using the results obtained from hand calculations. It is shown that model results are in agreement with the handcalculated steady-state leakage rates (Table 4.2). 
Table 4. 1 Harmonic mean hydraulic conductivity values of the coarse-textured vadose zones, effective hydraulic conductivity values of the overall barrier system and steady-state leakage rates

\begin{tabular}{|c|c|c|c|c|c|}
\hline Soil type & $\begin{array}{l}\text { Thickness of } \\
\text { Vadose Zone }\end{array}$ & $\bar{k}_{v z}{ }^{(a)}$ & $\bar{k}_{v z c l}(\mathbf{b})$ & $\mathbf{q}_{\mathbf{h c}}{ }^{(\mathrm{c})}$ & $\mathbf{q}_{\mathbf{m c}}{ }^{(\mathbf{d})}$ \\
\hline & (m) & $(\mathbf{m} / \mathbf{s})$ & $(\mathbf{m} / \mathbf{s})$ & $(\mathbf{m} / \mathbf{a})$ & $(\mathbf{m} / \mathbf{a})$ \\
\hline US & 1 & $3.48 \times 10^{-5}$ & $2.67 \times 10^{-9}$ & 0.0999 & 0.0999 \\
\hline US & 5 & $2.37 \times 10^{-8}$ & $6.91 \times 10^{-9}$ & 0.229 & 0.229 \\
\hline US & 10 & $1.20 \times 10^{-8}$ & $7.40 \times 10^{-9}$ & 0.240 & 0.239 \\
\hline$S$ & 1 & $2.35 \times 10^{-5}$ & $2.67 \times 10^{-9}$ & 0.0999 & 0.0999 \\
\hline$S$ & 5 & $1.86 \times 10^{-8}$ & $6.45 \times 10^{-9}$ & 0.214 & 0.214 \\
\hline S & 10 & $1.06 \times 10^{-8}$ & $6.87 \times 10^{-9}$ & 0.222 & 0.223 \\
\hline FS & 1 & $9.17 \times 10^{-7}$ & $2.66 \times 10^{-9}$ & 0.0997 & 0.0997 \\
\hline FS & 5 & $8.91 \times 10^{-9}$ & $4.82 \times 10^{-9}$ & 0.160 & 0.160 \\
\hline FS & 10 & $6.86 \times 10^{-9}$ & $5.15 \times 10^{-9}$ & 0.167 & 0.167 \\
\hline
\end{tabular}

(a) Harmonic mean of vadose zone hydraulic conductivity

(b) Harmonic mean of vadose zone and compacted clay liner hydraulic conductivity

(c) Steady-state leakage rate as a result of hand calculations

(d) Model calculated steady-state leakage rate

When the barrier system is simulated using uniform saturated hydraulic conductivities for the vadose zone, steady-state leakage rates (denoted by $\mathrm{q}_{\mathrm{Kuni}}$ ) are 2.0 to 3.5 times greater than the leakage rates simulated using soil hydraulic conductivity functions (denoted by $\mathrm{q}_{\mathrm{Kfxn}}$ ) (Figure 4.4). When the uniform saturated hydraulic conductivities are used, the steady-state leakage rates are overestimated for coarse textured vadose zones; therefore, unsaturated conditions and thus soil hydraulic conductivity functions should be considered when a barrier system having a CCL is underlain by a coarse textured vadose zone. 

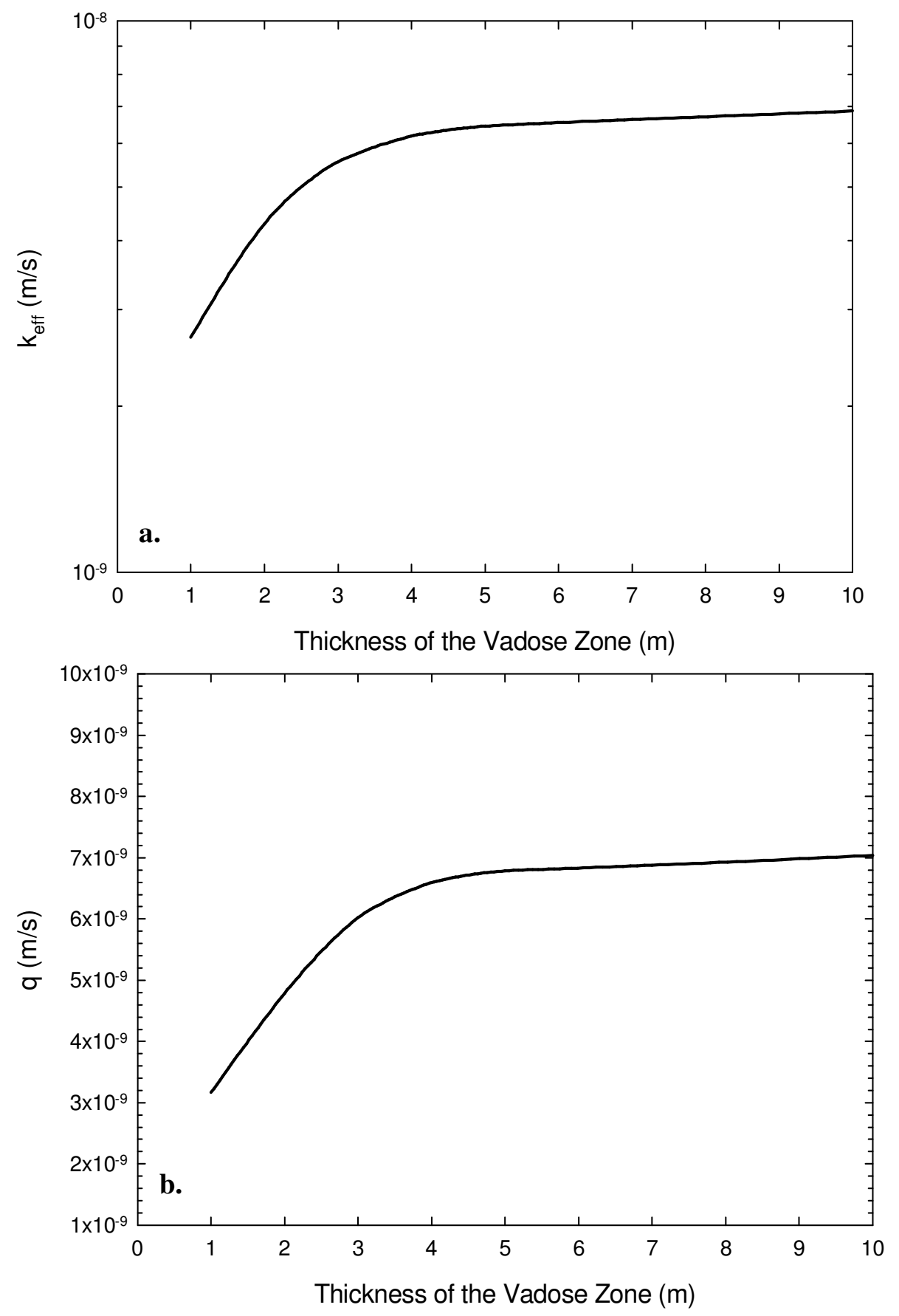

Figure 4. 3 Change in (a) the effective hydraulic conductivity of the overall barrier system and (b) the steady-state leakage rates with varying sandy $(\mathrm{S})$ vadose zone thickness 


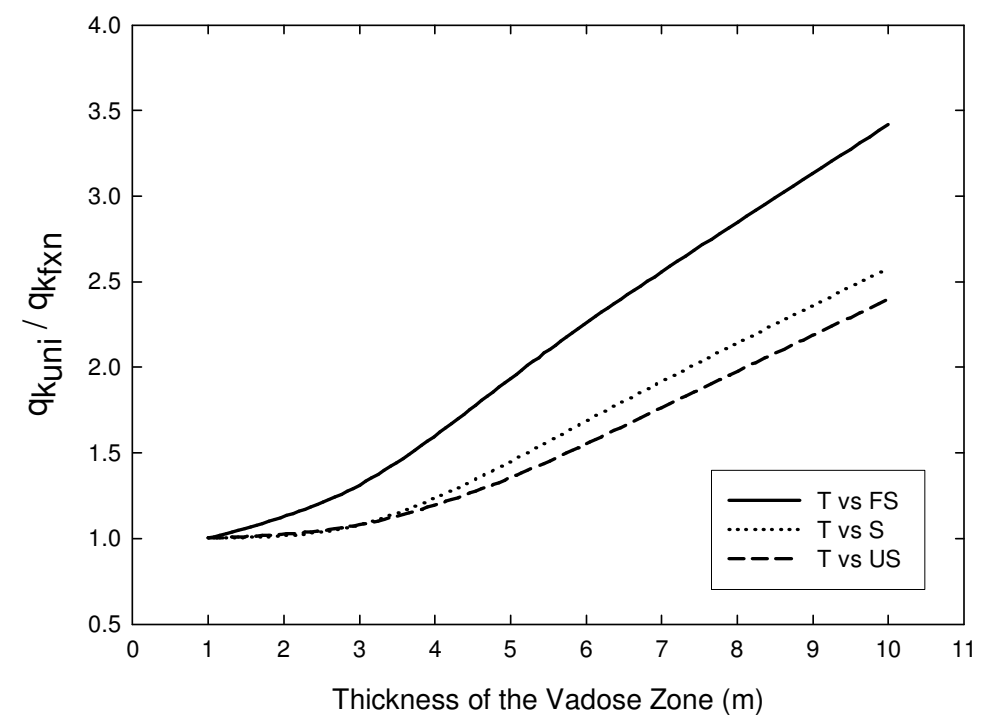

Figure 4. 4 Normalized steady-state leakage rates with varying coarse textured vadose zone thickness (T stands for vadose zone thickness, FS stands for fine sand, S stands for sand, and US stands for uniform sand)

\subsubsection{Barrier System: Compacted Clay Liner underlain by Fine Texture} Vadose Zones

Hydraulic conductivity profile of the fine textured vadose zones is not affected much by the pore-water pressure change within the vadose zone. According to Figure 3.3 (d), the hydraulic conductivity of the uniform silt shows a significant change after $100 \mathrm{kPa}$. Up to a thickness of $10 \mathrm{~m}$, the pressure within the vadose zone does not reach $100 \mathrm{kPa}$, and it is observed to be around $35 \mathrm{kPa}$. Therefore, for vadose zones composed of uniform silt and that are shallower than $10 \mathrm{~m}$, the hydraulic conductivity values and therefore the steady state leakage rates do not change with varying thickness of the vadose zone. The hydraulic conductivity values for silt and silt tailings change in the range of $6 \times 10^{-8}-5 \times 10^{-9} \mathrm{~m} / \mathrm{s}$ between the bottom of the compacted clay liner and the top of water table (Figure 4.5). The harmonic mean hydraulic conductivity of the vadose zone also does not show a substantial difference with varying vadose zone thickness. It decreases 
only almost half order of magnitude when the thickness is changed from $1 \mathrm{~m}$ to 5 $\mathrm{m}$, and reaches an asymptotic value for vadose zones thicker than $5 \mathrm{~m}$ (Figure 4.6).

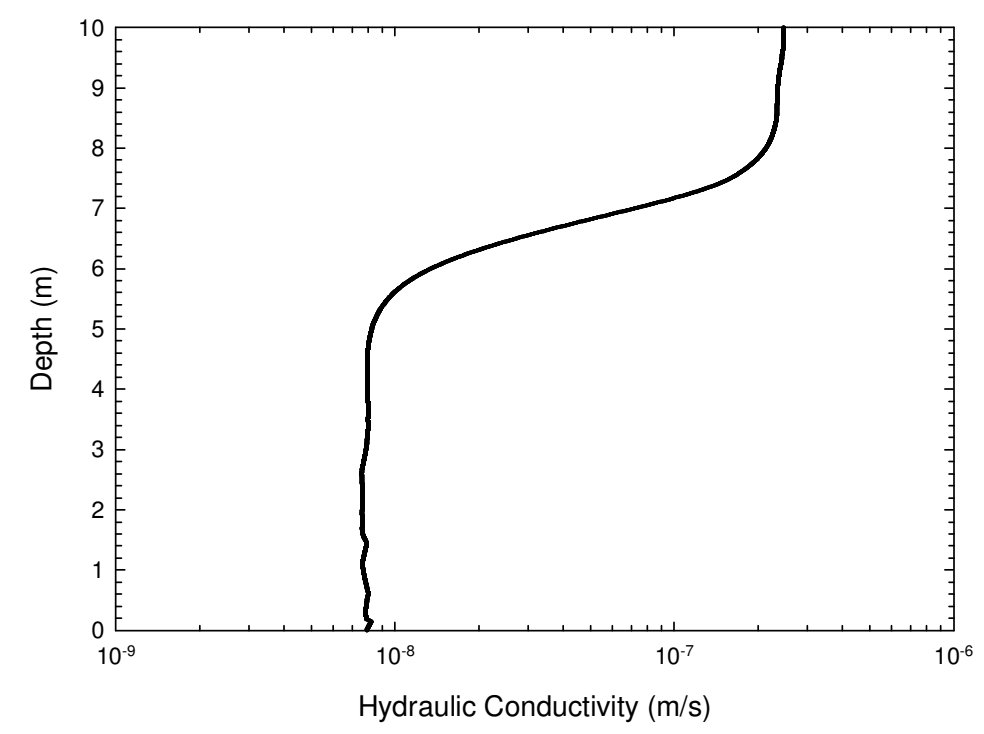

Figure 4. 5 Hydraulic conductivity change with depth for a silt $(\mathrm{Si})$

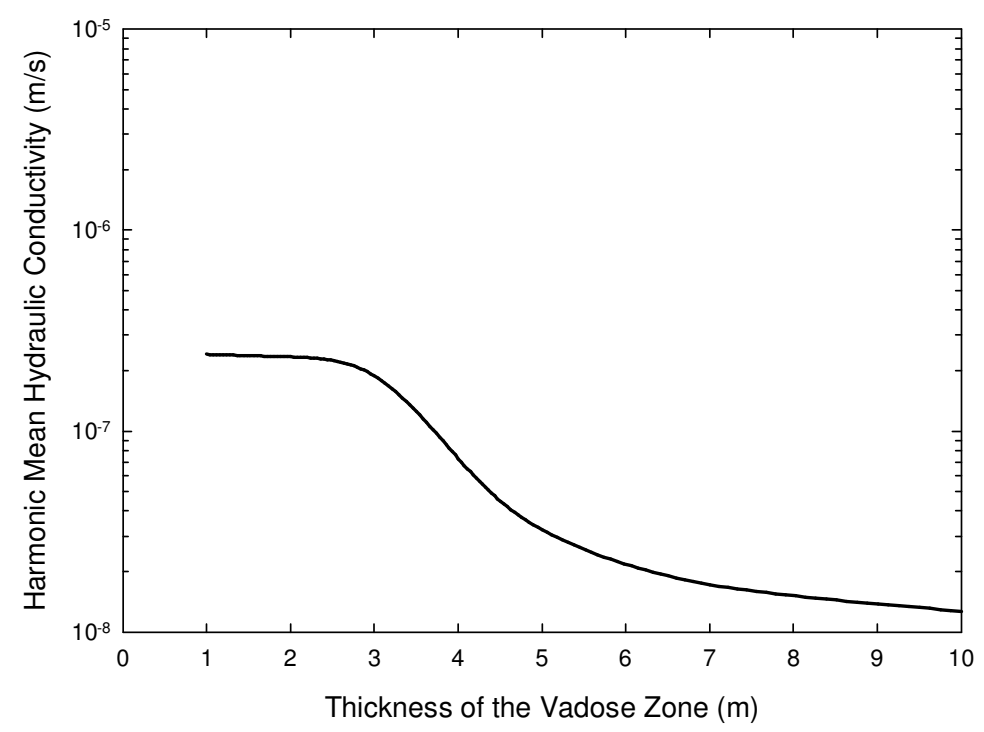

Figure 4. 6 Change in the harmonic mean hydraulic conductivity of the vadose zone with varying silty $(\mathrm{Si})$ vadose zone thickness 
Similar to the coarse textured vadose zones, the effective hydraulic conductivity of the barrier system increased with the thickness of the fine textured vadose zone (Table 4.2). The increased effective hydraulic conductivity of the overall barrier system resulted in a gradual increase in the steady-state leakage rates into the aquifer, which reach a constant value beyond $5 \mathrm{~m}$. (Figure 4.7). Hand-calculated steady-state leakage rates also agree with the SEEP/W model results for fine textured vadose zones (Table 4.2).

Table 4. 2 Harmonic mean hydraulic conductivity values of the fine textured vadose zones, effective hydraulic conductivity values of the overall barrier system and steady-state leakage rates

\begin{tabular}{|c|c|c|c|c|c|}
\hline Soil type & $\begin{array}{l}\text { Thickness of } \\
\text { Vadose Zone }\end{array}$ & $\bar{k}_{v z}{ }^{(\mathbf{a})}$ & $\bar{k}_{v z c l}(\mathbf{b})$ & $\mathbf{q}_{\mathrm{hc}}^{(\mathbf{c})}$ & $\mathbf{q}_{\mathbf{m c}}{ }^{(d)}$ \\
\hline & (m) & $(\mathrm{m} / \mathrm{s})$ & $(\mathrm{m} / \mathrm{s})$ & $(\mathbf{m} / \mathbf{a})$ & $(\mathbf{m} / \mathbf{a})$ \\
\hline $\mathrm{Si}$ & 1 & $2.41 \times 10^{-7}$ & $2.65 \times 10^{-9}$ & 0.0992 & 0.0990 \\
\hline $\mathrm{Si}$ & 5 & $3.22 \times 10^{-8}$ & $7.41 \times 10^{-9}$ & 0.246 & 0.246 \\
\hline $\mathrm{Si}$ & 10 & $1.27 \times 10^{-8}$ & $7.64 \times 10^{-9}$ & 0.248 & 0.248 \\
\hline SiT & 1 & $5.46 \times 10^{-8}$ & $2.59 \times 10^{-9}$ & 0.0969 & 0.0968 \\
\hline $\mathrm{SiT}$ & 5 & $1.04 \times 10^{-8}$ & $5.18 \times 10^{-9}$ & 0.172 & 0.172 \\
\hline $\mathrm{SiT}$ & 10 & $7.13 \times 10^{-9}$ & $5.29 \times 10^{-9}$ & 0.172 & 0.172 \\
\hline USi & 1 & $1.00 \times 10^{-8}$ & $2.29 \times 10^{-9}$ & 0.0856 & 0.0855 \\
\hline USi & 5 & $1.00 \times 10^{-8}$ & $5.09 \times 10^{-9}$ & 0.169 & 0.169 \\
\hline USi & 10 & $1.00 \times 10^{-8}$ & $6.81 \times 10^{-9}$ & 0.215 & 0.216 \\
\hline
\end{tabular}

(a) Harmonic mean of vadose zone hydraulic conductivity

(b) Harmonic mean of vadose zone and compacted clay liner hydraulic conductivity

(c) Steady-state leakage rate as a result of hand calculations

(d) Model calculated steady-state leakage rate 

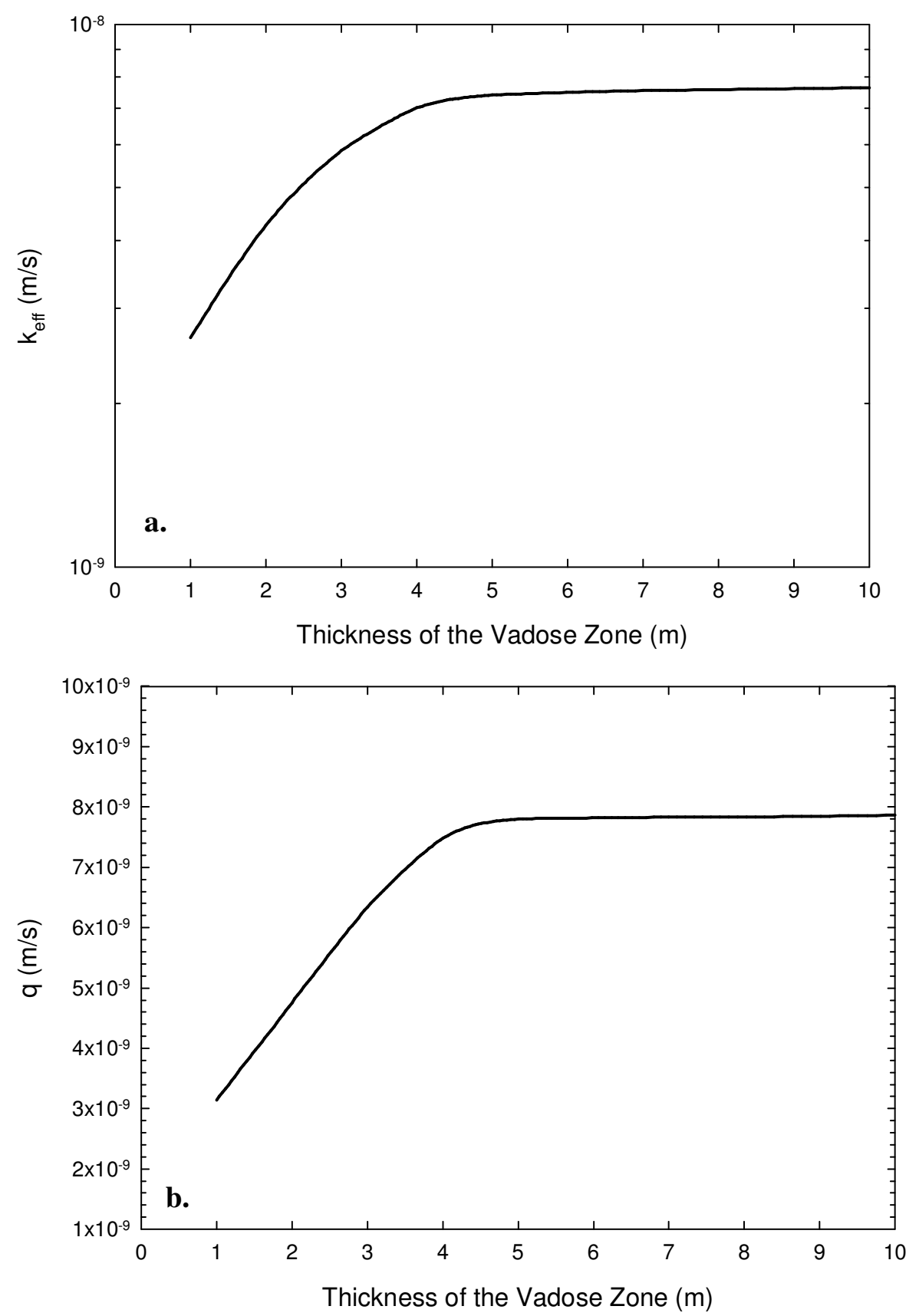

Figure 4. 7 Change in (a) the effective hydraulic conductivity of the overall barrier system and (b) the steady-state leakage rates with varying silty $(\mathrm{Si})$ vadose zone thickness 
When the barrier system is simulated using uniform saturated hydraulic conductivities, the steady-state leakage rates (denoted by $\mathrm{q}_{\mathrm{Kuni}}$ ) are the same as the leakage rates simulated using soil hydraulic conductivity functions of silt and silt tailings (denoted by $\mathrm{q}_{\mathrm{Kuni}}$ ), for vadose zone thicknesses less than $5 \mathrm{~m}$. Vadose zones composed of silty soils and thicker than $5 \mathrm{~m}$ resulted in steady-state leakage rates that are 1.5 to 2.5 times greater than the ones obtained by using soil hydraulic conductivity functions. As previously stated, the hydraulic conductivity and therefore the steady state leakage rates occurring in uniform silts are not affected by pressure for vadose zones shallower than $10 \mathrm{~m}$ (Figure 4.8). Although the normalized leakage rates demonstrate a significant difference between saturated and unsaturated conditions, there is only one order of magnitude difference between saturated hydraulic conductivity values and the harmonic mean conductivity values for silty soils. Therefore, fine textured vadose zones can be modeled using uniform saturated hydraulic conductivity values.

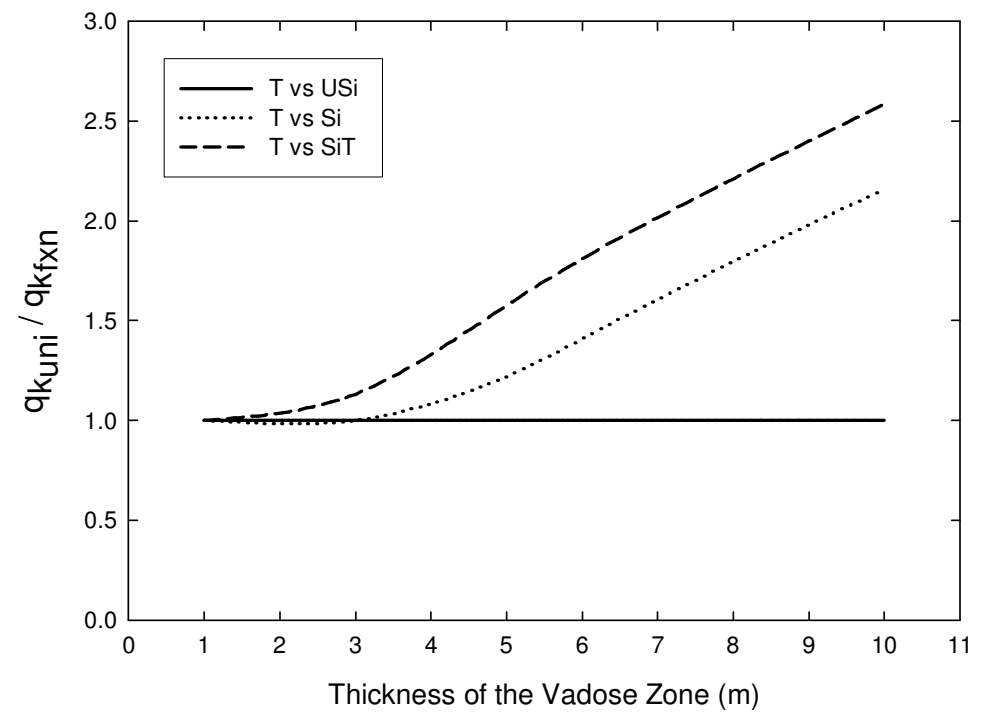

Figure 4. 8 Normalized steady-state leakage rates with varying fine textured vadose zone thickness ( $\mathrm{T}$ stands for vadose zone thickness, USi stands for uniform silt, Si stands for silt, and SiT stands for silt tailings) 


\subsubsection{Effect of Compacted Clay Liner Hydraulic Conductivity}

The effect of compacted clay liner hydraulic conductivity on the overall performance of the barrier system is also evaluated using a saturated compacted clay liner hydraulic conductivity of $1 \times 10^{-10} \mathrm{~m} / \mathrm{s}$. For both coarse textured and fine textured vadose zones, one order of magnitude decrease in the compacted clay liner hydraulic conductivity (i.e. $1 \times 10^{-10} \mathrm{~m} / \mathrm{s}$ is used instead of $1 \times 10^{-9} \mathrm{~m} / \mathrm{s}$ ) resulted in almost the same order (one order) of magnitude decrease in the effective hydraulic conductivity of the overall barrier system and steady-state leakage rates into the aquifer (Table 4.3). An order of magnitude increase in the vadose zone thickness, on the other hand, resulted in half order of magnitude increase in the steady-state leakage rate, and the effective hydraulic conductivity (Table 4.1 and Table 4.2). Therefore, the effect of compacted clay liner hydraulic conductivity is dominant over the vadose zone thickness and it should be considered as the controlling factor for leakage into the aquifer.

Table 4. 3 The effect of compacted clay liner hydraulic conductivity on the effective hydraulic conductivity and steady-state leakage rates into the aquifer

\begin{tabular}{ccccc|cccc}
\hline \multicolumn{5}{c|}{ Coarse textured VZ } & \multicolumn{5}{c}{ Fine textured VZ } \\
\hline $\begin{array}{c}\mathbf{T}_{\mathbf{V Z}} \\
(\mathbf{m})\end{array}$ & 5 & 10 & 5 & 10 & 5 & 10 & 5 & 10 \\
$\mathbf{k}_{\mathbf{C C L}}$ & $1 \times 10^{-9}$ & $1 \times 10^{-9}$ & $1 \times 10^{-10}$ & $1 \times 10^{-10}$ & $1 \times 10^{-9}$ & $1 \times 10^{-9}$ & $1 \times 10^{-10}$ & $1 \times 10^{-10}$ \\
$(\mathbf{m} / \mathbf{s})$ & & & & & & & & \\
\hline $\mathbf{q}$ & 0.214 & 0.223 & 0.028 & 0.034 & 0.246 & 0.248 & 0.029 & 0.031 \\
$(\mathbf{m} / \mathbf{y r})$ & & & & & & & & \\
\hline $\begin{array}{c}\mathbf{k}_{\mathbf{v z c l}} \\
(\mathbf{m} / \mathbf{s})\end{array}$ & $6.45 \times 10^{-9}$ & $6.87 \times 10^{-9}$ & $8.51 \times 10^{-10}$ & $1.04 \times 10^{-9}$ & $7.41 \times 10^{-9}$ & $7.64 \times 10^{-9}$ & $8.70 \times 10^{-10}$ & $9.61 \times 10^{-10}$ \\
\hline
\end{tabular}




\subsection{Effect of Waste Thickness and Seepage Velocity on Steady-State Leakage Rates from Landfill Barrier Systems}

The first set of simulations (groundwater seepage velocity sensitivity) showed that seepage velocity considerably affects the contaminant concentrations in the aquifer, due to dilution. As the seepage velocity in the aquifer increases, the contaminant concentrations decrease (Table 4.4). For the designs having geosynthetics in the bottom liners (C2L2), the relation between the decrease in the contaminant concentrations and increase in the seepage velocity is linear. For the designs with natural bottom liners or having compacted clay liners (C1L1, C3L5), the relation is not linear. This is due to the fact that lower concentrations are affected by dilution more than higher concentrations (Table 4.5). In Table 4.5, seepage velocities are normalized by the previously used seepage velocity of 1.2 $\mathrm{m} / \mathrm{d}$; and, concentrations are normalized with the concentration values calculated for $20 \mathrm{~m}$ waste thickness and $1.2 \mathrm{~m} / \mathrm{d}$ seepage velocity. The representative seepage velocity values are selected as $0.05,0.1,0.5$, and $1 \mathrm{~m} / \mathrm{d}$ for the simulations.

Table 4. 4 Groundwater seepage velocity sensitivity analyses

\begin{tabular}{|c|c|c|c|c|c|c|c|c|}
\hline \multirow{2}{*}{ C1L1 $^{a}$} & $\mathbf{C}_{\max }$ & $\mathbf{T}_{\max }$ & \multirow{2}{*}{$\mathrm{C} 2 \mathrm{~L} 2^{\mathrm{b}}$} & $\mathbf{C}_{\max }$ & $\mathbf{T}_{\max }$ & \multirow{2}{*}{$\mathrm{CHL5}^{\mathrm{c}}$} & $\mathbf{C}_{\max }$ & $\mathbf{T}_{\max }$ \\
\hline & $\mathrm{mg} / \mathrm{L}$ & yr & & $\mathrm{mg} / \mathrm{L}$ & yr & & $\mathrm{mg} / \mathrm{L}$ & yr \\
\hline$v_{\mathrm{s}}=0.05 \mathrm{~m} / \mathrm{d}$ & 735 & 21 & $v_{\mathrm{s}}=0.05 \mathrm{~m} / \mathrm{d}$ & 11.6 & 1067 & $v_{\mathrm{s}}=0.05 \mathrm{~m} / \mathrm{d}$ & 725 & 23 \\
\hline$v_{\mathrm{s}}=0.1 \mathrm{~m} / \mathrm{d}$ & 398 & 18 & $v_{\mathrm{s}}=0.1 \mathrm{~m} / \mathrm{d}$ & 5.8 & 1067 & $v_{\mathrm{s}}=0.1 \mathrm{~m} / \mathrm{d}$ & 392 & 19 \\
\hline$v_{\mathrm{s}}=0.5 \mathrm{~m} / \mathrm{d}$ & 85.3 & 14 & $v_{\mathrm{s}}=0.5 \mathrm{~m} / \mathrm{d}$ & 1.16 & 1067 & $v_{\mathrm{s}}=0.5 \mathrm{~m} / \mathrm{d}$ & 84 & 16 \\
\hline$v_{\mathrm{s}}=1 \mathrm{~m} / \mathrm{d}$ & 43 & 14 & $v_{\mathrm{s}}=1 \mathrm{~m} / \mathrm{d}$ & 0.58 & 992 & $v_{\mathrm{s}}=1 \mathrm{~m} / \mathrm{d}$ & 42 & 16 \\
\hline
\end{tabular}


Table 4. 5 Normalized concentrations occurred as a result of various seepage velocities

\begin{tabular}{cccc}
\hline \multirow{2}{*}{ Normalized $\boldsymbol{v}_{\mathrm{s}}$} & Normalized C & Normalized C & Normalized C \\
\cline { 2 - 4 } & C1L1 $^{\mathbf{a}}$ & $\mathbf{C 2 L 2}^{\mathbf{b}}$ & $\mathbf{C 3 L 5}^{\mathbf{c}}$ \\
\hline 0.042 & 20.531 & 24.167 & 20.714 \\
0.083 & 11.117 & 12.083 & 11.200 \\
0.417 & 2.383 & 2.417 & 2.400 \\
0.833 & 1.201 & 1.208 & 1.200
\end{tabular}

${ }^{\mathrm{a}}$ natural attenuation landfill ${ }^{\mathrm{b}}$ extensive engineering landfill

${ }^{\mathrm{c}}$ intermediate engineering landfill

Waste thickness sensitivity analyses, on the other hand, showed that the effect of waste thickness is not as evident as seepage velocity (Table 4.6). The waste thickness values are normalized by $20 \mathrm{~m}$, and concentrations are normalized by the concentration values from a 20-m-thick waste. While contaminant concentration from a 30 -m-thick waste is only 1.06 times higher than contaminant concentration from a 20 -m-thick waste; contaminant concentration from a $15-\mathrm{m}$ thick waste is 1.45 times higher than contaminant concentration from a 5 -m-thick waste (Table 4.7). This may be expected because $30 \mathrm{~m}$ is considered as a threshold depth (Yen and Scanlan, 1975) after which the biodegradation is very slow (El-Fadel and Khoury, 2000). Therefore, the waste thickness values to be used in the simulations were determined as $5 \mathrm{~m}$ and $20 \mathrm{~m}$ to represent shallow and deep landfills. 
Table 4. 6 Normalized concentrations occurred as a result of various waste thicknesses

\begin{tabular}{cccc}
\hline \multirow{2}{*}{ Normalized $\mathbf{T}_{\mathbf{w}}$} & Normalized C & Normalized C & Normalized C \\
\cline { 2 - 4 } & $\mathbf{C 1 L 1}^{\mathbf{a}}$ & $\mathbf{C 2 L 2}^{\mathbf{b}}$ & $\mathbf{C 3 L 5}^{\mathbf{c}}$ \\
\hline 0.25 & 0.88 & 0.65 & 0.88 \\
0.50 & 0.95 & 0.85 & 0.96 \\
0.75 & 0.98 & 0.94 & 0.99 \\
1.00 & 1.00 & 1.00 & 1.00 \\
1.50 & 1.02 & 1.08 & 1.02 \\
${ }^{\mathrm{a}}$ natural attenuation landfill & ${ }^{\mathrm{b}}$ extensive engineering landfill & \\
${ }^{\mathrm{c}}$ intermediate engineering landfill & &
\end{tabular}

Table 4. 7 Waste thickness sensitivity analyses

\begin{tabular}{|c|c|c|c|c|c|c|c|c|}
\hline \multirow{2}{*}{$\operatorname{C1L1}^{\mathrm{a}}$} & $\mathbf{C}_{\max }$ & $\mathbf{T}_{\max }$ & \multirow{2}{*}{$\mathrm{C} 2 \mathrm{~L} 2^{\mathrm{b}}$} & $\mathbf{C}_{\max }$ & $\mathbf{T}_{\max }$ & \multirow{2}{*}{$\mathrm{CHL5}^{\mathrm{c}}$} & \multirow{2}{*}{$\begin{array}{c}\mathrm{C}_{\max } \\
\mathrm{mg} / \mathrm{L}\end{array}$} & \multirow{2}{*}{$\begin{array}{c}T_{\text {max }} \\
y r\end{array}$} \\
\hline & $\mathrm{mg} / \mathrm{L}$ & yr & & $\mathrm{mg} / \mathrm{L}$ & yr & & & \\
\hline $\mathrm{T}_{\mathrm{w}}=5 \mathrm{~m}$ & 31.4 & 14 & $\mathrm{~T}_{\mathrm{w}}=5 \mathrm{~m}$ & 0.31 & 737 & $\mathrm{~T}_{\mathrm{w}}=5 \mathrm{~m}$ & 30.8 & 15 \\
\hline $\mathrm{T}_{\mathrm{w}}=10 \mathrm{~m}$ & 34.1 & 14 & $\mathrm{~T}_{\mathrm{w}}=10 \mathrm{~m}$ & 0.41 & 860 & $\mathrm{~T}_{\mathrm{w}}=10 \mathrm{~m}$ & 33.5 & 15 \\
\hline $\mathrm{T}_{\mathrm{w}}=15 \mathrm{~m}$ & 35.1 & 14 & $\mathrm{~T}_{\mathrm{w}}=15 \mathrm{~m}$ & 0.45 & 934 & $\mathrm{~T}_{\mathrm{w}}=15 \mathrm{~m}$ & 34.5 & 15 \\
\hline $\mathrm{T}_{\mathrm{w}}=20 \mathrm{~m}$ & 35.8 & 14 & $\mathrm{~T}_{\mathrm{w}}=20 \mathrm{~m}$ & 0.48 & 1009 & $\mathrm{~T}_{\mathrm{w}}=20 \mathrm{~m}$ & 35 & 16 \\
\hline $\mathrm{T}_{\mathrm{w}}=30 \mathrm{~m}$ & 36.4 & 14 & $\mathrm{~T}_{\mathrm{w}}=30 \mathrm{~m}$ & 0.52 & 1009 & $\mathrm{~T}_{\mathrm{w}}=30 \mathrm{~m}$ & 35.7 & 16 \\
\hline
\end{tabular}

Third set of sensitivity analyses were performed to observe the respective effects of waste thickness and seepage velocity. As stated above, the seepage velocity is dominant over waste thickness. However, their combined effect is stronger. Table 4.8 shows that, keeping the seepage velocity constant, 4 folds increase in waste thickness increases contaminant concentrations 1.1 folds; however, keeping the waste thickness constant, 5 folds decrease in seepage velocity results in a 4.3 times increase in contaminant concentrations. Their combined effect results in a 5.3 times increase in contaminant concentration in the aquifer. These results show that actually the effects of waste thickness and seepage velocity are almost summed, which is expected as there is no corrrelation between these parameters. 
Table 4. 8 Respective effects of waste thickness and seepage velocity on contaminant concentrations

\begin{tabular}{ccc}
\hline $\begin{array}{c}\text { Waste Thickness } \\
(\mathbf{m})\end{array}$ & $\begin{array}{c}\text { Seepage Velocity } \\
(\mathbf{m} / \mathbf{d})\end{array}$ & $\begin{array}{c}\text { Concentration }\left(\mathbf{C 1 L 1}^{\mathbf{a}}\right) \\
(\mathbf{m g} / \mathbf{L})\end{array}$ \\
\hline 5 & 0.5 & 74.7 \\
5 & 0.1 & 318.3 \\
20 & 0.5 & 85.3 \\
20 & 0.1 & 398 \\
\hline${ }^{a}$ natural attenuation landfill & &
\end{tabular}

a natural attenuation landfill

As a result of sensitivity analyses, $0.05,0.1,0.5$ and $1 \mathrm{~m} / \mathrm{d}$ values are selected to be used as seepage velocities and 5 and $20 \mathrm{~m}$ values are selected to be used as waste thicknesses in landfill design simulations.

\subsection{Performance-Based Evaluation of Landfill Design Alternatives}

Performance of the design alternatives is evaluated under 4 headings: cover system performance, compliance to first performance criterion (hydraulic head on top of barrier liner), leachate collection and leakage rates, and compliance to second performance criterion (contaminant concentrations at the groundwater table) with respect to arid, moderate, and humid climates. The results presented in this section were evaluated to emphasize the importance of a performance-based design assessment and coalesced to construct the design component selection matrix which is used as the knowledge-base of the preliminary design phase in LFDSS.

\subsubsection{Cover System Performance}

A total of 9 HELP simulations for 3 different final covers (i.e. evapotranspiration final cover $-\mathrm{C} 1$, extensive engineering final cover $-\mathrm{C} 2$, and intermediate design final cover $-\mathrm{C} 3$ ) and 3 different climatic conditions (i.e. arid, moderate, and 
humid) were performed to calculate the amount of infiltration into waste layers. The results of the simulations are presented in Table 4.9.

Table 4. 9 Infiltration rates by HELP model

\begin{tabular}{|c|c|c|c|}
\hline & $\begin{array}{c}\text { Arid } \\
(\mathrm{P}<\mathbf{5 0 0} \mathbf{~ m m} / \mathrm{y})\end{array}$ & $\begin{array}{c}\text { Moderate } \\
(\mathbf{5 0 0} \leq \mathrm{P}<\mathbf{1 0 0 0} \mathbf{~ m m} / \mathbf{y})\end{array}$ & $\begin{array}{c}\text { Humid } \\
(P \geq 1000 \mathrm{~mm} / \mathrm{y})\end{array}$ \\
\hline Final cover & $\begin{array}{c}\text { Infiltration }\left(q_{0}\right) \\
(\mathrm{m} / \mathrm{y})\end{array}$ & $\begin{array}{c}\text { Infiltration }\left(q_{0}\right) \\
(m / y)\end{array}$ & $\begin{array}{c}\text { Infiltration }\left(q_{0}\right) \\
(\mathrm{m} / \mathrm{y})\end{array}$ \\
\hline $\mathrm{C} 1$ & 0.046 & 0.249 & 0.585 \\
\hline $\mathrm{C} 2$ & 0.00141 & 0.00423 & 0.00889 \\
\hline C3 & 0.045 & 0.245 & 0.577 \\
\hline
\end{tabular}

Table 4.9 indicates that the evapotranspiration final cover which is composed of only natural topsoil (C1) produced the highest infiltration. Extensive engineering final cover composed of natural topsoil, cover drainage layer, geomembrane, and clay liner $(\mathrm{C} 2)$ restricted infiltration to a great extent. The intermediate design final cover from which the geomembrane was excluded (C3) was not sufficient in restricting infiltration. The data presented in Table 4.9 was used as "infiltration" input data in POLLUTE model.

\subsubsection{Compliance with the First Performance Criterion (Stability)}

The maximum allowable hydraulic head on top of barrier liner have been determined to be less than $1 \mathrm{~m}$ for stability reasons. For the design alternatives lacking drainage or leachate collection system in the final cover or bottom liner, the hydraulic head on top of the barrier liner can exceed the maximum allowable hydraulic head $(1 \mathrm{~m})$. POLLUTE was used to calculate the hydraulic head development on the barrier liner; and therefore, to evaluate the compliance of the design alternatives to the first performance criterion. 
Under arid climates $(\mathrm{P}<500 \mathrm{~mm} / \mathrm{y})$, as the infiltration was too low, no hydraulic head problems were observed, even for the designs coupled with final covers lacking drainage layer and/or geomembrane. Regardless of climatic conditions, when the vadose zone in which the landfill was placed had a hydraulic conductivity in the order of $10^{-7} \mathrm{~m} / \mathrm{s}$, the hydraulic head development was not significant. However, for lower conductivity vadose zones $\left(10^{-8} \mathrm{~m} / \mathrm{s}\right)$, under moderate climates $(500 \mathrm{~mm} / \mathrm{y} \leq \mathrm{P}<1000 \mathrm{~mm} / \mathrm{y})$ the bottom liner design composed of compacted clay liner placed on vadose zone $\left(\mathrm{L}^{\mathrm{L}} ; \mathrm{k}=6,63 \times 10^{-9}\right.$ $\left.\mathrm{m} / \mathrm{s}^{1,2}\right)$, and under humid climates $(\mathrm{P} \geq 1000 \mathrm{~mm} / \mathrm{y})$ both $\mathrm{L}^{\mathrm{L}}$ and natural attenuation bottom liner composed of only the vadose zone below waste $\left(\mathrm{L}^{\mathrm{L}} ; \mathrm{k}=\right.$ $1 \times 10^{-8} \mathrm{~m} / \mathrm{s}$ ) resulted in hydraulic head development exceeding $1 \mathrm{~m}$, because their effective hydraulic conductivities were lower than the infiltration rate coming to the bottom liner $\left(\mathrm{q}_{0}=1,4 \times 10^{-9} \mathrm{~m} / \mathrm{s}\right.$ for moderate climates; $\mathrm{q}_{0}=1,6 \times 10^{-8} \mathrm{~m} / \mathrm{s}$ for humid climates) (Table 4.10). Therefore, $\mathrm{L}^{\mathrm{L}}$ and $\mathrm{L} 6^{\mathrm{L}}$ bottom liner designs are not appropriate for moderate and humid climates unless they are coupled with an extensive engineering final cover $(\mathrm{C} 2)$. So, the aforementioned design alternatives $\left(\mathrm{C} 1 \mathrm{~L} 1^{\mathrm{L}}, \mathrm{C} 1 \mathrm{~L} 6^{\mathrm{L}}, \mathrm{C} 3 \mathrm{~L} 1^{\mathrm{L}}, \mathrm{C} 3 \mathrm{~L} 6^{\mathrm{L}}\right)$ were excluded from the simulation list.

\footnotetext{
${ }^{1}$ Superscript $\mathrm{L}$ indicates that the design alternative is suitable for low permeability aquitards $(\mathrm{k}=$ $\left.1 \times 10^{-8} \mathrm{~m} / \mathrm{s}\right)$.

${ }^{2}$ The effective hydraulic conductivity values stated here and in the rest of the thesis are the harmonic means of liner and vadose zone hydraulic conductivities.
} 
Table 4. 10 Hydraulic head values that are supposed to develop

\begin{tabular}{|c|c|c|c|c|c|c|}
\hline \multirow{3}{*}{ Design } & \multicolumn{2}{|c|}{$\begin{array}{c}\text { Arid } \\
(\mathrm{P}<\mathbf{5 0 0} \mathbf{~ m m} / \mathbf{y})\end{array}$} & \multicolumn{2}{|c|}{$\begin{array}{c}\text { Moderate } \\
(\mathbf{5 0 0}<\mathbf{P} \leq \mathbf{1 0 0 0} \mathbf{~ m m} / \mathbf{y})\end{array}$} & \multicolumn{2}{|c|}{$\begin{array}{c}\text { Humid } \\
(P>1000 \mathrm{~mm} / \mathrm{y})\end{array}$} \\
\hline & \multicolumn{2}{|c|}{ Hydraulic Head (m) } & \multicolumn{2}{|c|}{ Hydraulic Head (m) } & \multicolumn{2}{|c|}{ Hydraulic Head (m) } \\
\hline & $\begin{array}{c}k^{(a)}=10^{-7} \mathrm{~m} / \mathrm{s} \\
\phi=0.35\end{array}$ & $\begin{array}{c}k=10^{-8} \mathrm{~m} / \mathrm{s} \\
\phi=0.45\end{array}$ & $\begin{array}{c}k=10^{-7} \mathrm{~m} / \mathrm{s} \\
\phi=0.35\end{array}$ & $\begin{array}{c}k=10^{-8} \mathrm{~m} / \mathrm{s} \\
\phi=0.45\end{array}$ & $\begin{array}{c}k=10^{-7} \mathrm{~m} / \mathrm{s} \\
\phi=0.35\end{array}$ & $\begin{array}{c}k=10^{-8} \mathrm{~m} / \mathrm{s} \\
\phi=0.45\end{array}$ \\
\hline C1L1 & & - & & - & & 8.56 \\
\hline C1L6 & - & - & - & 2.03 & 2.39 & 19.09 \\
\hline C2L1 & & - & & - & & - \\
\hline C2L6 & - & - & - & - & - & - \\
\hline C3L1 & & - & & - & & 8.30 \\
\hline C3L6 & - & - & - & 1.83 & 2.21 & 18.68 \\
\hline
\end{tabular}

(a) The given hydraulic conductivity $(\mathrm{k})$ and porosity $(\phi)$ values belong to vadose zone.

\subsubsection{Leachate Collection $\left(\mathrm{q}_{\mathrm{c}}\right)$ and Leakage Rates $\left(\mathrm{q}_{1}\right)$}

Leachate collection $\left(\mathrm{q}_{\mathrm{c}}\right)$ and leakage rates $\left(\mathrm{q}_{1}\right)$ were calculated using POLLUTE. When the infiltration coming to the bottom liner is greater than the effective hydraulic conductivity $\left(\mathrm{k}_{\mathrm{eff}}\right)$ of the bottom liner, the leachate collection system is effective and allows a leakage rate equal to the effective hydraulic conductivity of the bottom liner. Bottom liner designs having leachate collection systems, and the infiltration rates they receive are presented in Table 4.11. According to Table 4.11 , leachate collection systems coupled with geomembranes are effective in leachate collection. Under arid climates $(\mathrm{P}<500 \mathrm{~mm} / \mathrm{y})$, as the infiltration rate coming to the bottom liner $\left(1.4 \times 10^{-9} \mathrm{~m} / \mathrm{s}\right)$ was lower than the effective hydraulic conductivity of bottom liner composed of leachate collection system over aquitard $\left(\mathrm{L} 3 ; \mathrm{k}=1 \times 10^{-8} \mathrm{~m} / \mathrm{s}\right)$ and intermediate design bottom liner composed of leachate collection system and compacted clay liner $\left(\mathrm{L}^{\mathrm{L}} ; \mathrm{k}=6.6 \times 10^{-9} \mathrm{~m} / \mathrm{s}\right)$, hydraulic head did not develop and leachate collection system was not functional. A leachate collection system is not necessary under these conditions, and the leakage is controlled primarily by final cover. Under moderate climates $(500 \mathrm{~mm} / \mathrm{y} \leq \mathrm{P}<$ $1000 \mathrm{~mm} / \mathrm{y})$, leachate collection system was effective when it was coupled with a 
compacted clay liner (L5). Leachate collection system is required under humid (P $\geq 1000 \mathrm{~mm} / \mathrm{y}$ ) climates as the infiltration rates are greater than any of the bottom liner effective hydraulic conductivities.

Table 4. 11 Effective hydraulic conductivity values of the bottom liners and the infiltration rates coming to the bottom liners

\begin{tabular}{|c|c|c|c|c|}
\hline \multirow{2}{*}{$\begin{array}{c}\text { Design } \\
\text { Alternative }\end{array}$} & \multirow{2}{*}{$\begin{array}{c}\mathbf{k}_{\text {eff }} \\
(\mathbf{m} / \mathbf{s})\end{array}$} & $\begin{array}{c}\text { Arid } \\
(\mathrm{P}<500 \mathrm{~mm} / \mathrm{y})\end{array}$ & $\begin{array}{c}\text { Moderate } \\
(500 \leq \mathrm{P}<1000 \mathrm{~mm} / \mathrm{y})\end{array}$ & $\begin{array}{c}\text { Humid } \\
(\mathrm{P} \geq 1000 \mathrm{~mm} / \mathrm{y})\end{array}$ \\
\hline & & $\mathbf{q}_{0}{ }^{(\mathrm{a})}(\mathrm{m} / \mathrm{s})$ & $q_{0}(\mathrm{~m} / \mathrm{s})$ & $q_{0}(\mathbf{m} / \mathbf{s})$ \\
\hline \multirow[t]{3}{*}{ L2 } & $<10^{-12}$ & $\mathrm{C} 1 ; 1.4 \times 10^{-9}$ & $\mathrm{C} 1 ; 7.9 \times 10^{-9}$ & $\mathrm{C} 1 ; 1.6 \times 10^{-8}$ \\
\hline & & $\mathrm{C} 2 ; 4.5 \times 10^{-11}$ & $\mathrm{C} 2 ; 1.3 \times 10^{-10}$ & $\mathrm{C} 2 ; 2.8 \times 10^{-10}$ \\
\hline & & $\mathrm{C} 3 ; 1.4 \times 10^{-9}$ & $\mathrm{C} 3 ; 7.8 \times 10^{-9}$ & $\mathrm{C} 3 ; 1.8 \times 10^{-8}$ \\
\hline \multirow[t]{3}{*}{ L3 } & $1 \times 10^{-8}$ & $\mathrm{C} 1 ; 1.4 \times 10^{-9}$ & $\mathrm{C} 1 ; 7.9 \times 10^{-9}$ & $\mathrm{C} 1 ; 1.6 \times 10^{-8}$ \\
\hline & & $\mathrm{C} 2 ; 4.5 \times 10^{-11}$ & $\mathrm{C} 2 ; 1.3 \times 10^{-10}$ & $\mathrm{C} 2 ; 2.8 \times 10^{-10}$ \\
\hline & & $\mathrm{C} 3 ; 1.4 \times 10^{-9}$ & $\mathrm{C} 3 ; 7.8 \times 10^{-9}$ & $\mathrm{C} 3 ; 1.8 \times 10^{-8}$ \\
\hline \multirow[t]{3}{*}{$\mathrm{L} 4$} & $<10^{-12}$ & $\mathrm{C} 1 ; 1.4 \times 10^{-9}$ & $\mathrm{C} 1 ; 7.9 \times 10^{-9}$ & $\mathrm{C} 1 ; 1.6 \times 10^{-8}$ \\
\hline & & $\mathrm{C} 2 ; 4.5 \times 10^{-11}$ & $\mathrm{C} 2 ; 1.3 \times 10^{-10}$ & $\mathrm{C} 2 ; 2.8 \times 10^{-10}$ \\
\hline & & $\mathrm{C} 3 ; 1.4 \times 10^{-9}$ & $\mathrm{C} 3 ; 7.8 \times 10^{-9}$ & $\mathrm{C} 3 ; 1.8 \times 10^{-8}$ \\
\hline \multirow[t]{3}{*}{ L5 } & $6.63 \times 10^{-9}$ & $\mathrm{C} 1 ; 1.4 \times 10^{-9}$ & $\mathrm{C} 1 ; 7.9 \times 10^{-9}$ & $\mathrm{C} 1 ; 1.6 \times 10^{-8}$ \\
\hline & & $\mathrm{C} 2 ; 4.5 \times 10^{-11}$ & $\mathrm{C} 2 ; 1.3 \times 10^{-10}$ & $\mathrm{C} 2 ; 2.8 \times 10^{-10}$ \\
\hline & & $\mathrm{C} 3 ; 1.4 \times 10^{-9}$ & $\mathrm{C} 3 ; 7.8 \times 10^{-9}$ & $\mathrm{C} 3 ; 1.8 \times 10^{-8}$ \\
\hline
\end{tabular}

(a) $\mathrm{C} 1, \mathrm{C} 2, \mathrm{C} 3$ indicates the final cover design producing the infiltration

As previously stated, the bottom liner designs allow leakage equal to their effective hydraulic conductivities. Effective hydraulic conductivity is the harmonic mean of the compacted clay liner hydraulic conductivity and the vadose zone hydraulic conductivity. For geomembranes, as they are not natural materials, an effective hydraulic conductivity value cannot be calculated; however, can be estimated (Table 4.11). The leakage rates from the bottom liner to the aquifer are presented in Table 4.12. As can be seen from the table, the hydraulic properties of the vadose zone played an important role in leachate collection and leakage. As the high conductivity vadose zones did not help in leachate collection, they resulted in higher leakage to the aquifers. Therefore, design of landfills on low 
conductivity vadose zones should be considered for an efficient leachate collection and lower leakage rates to the aquifers.

Table 4. 12 Leakage rates by POLLUTE

\begin{tabular}{|c|c|c|c|c|c|c|}
\hline \multirow{2}{*}{$\begin{array}{c}\text { Design } \\
\text { Alternative }\end{array}$} & \multicolumn{2}{|c|}{$\begin{array}{c}\text { Arid } \\
(\mathrm{P}<\mathbf{5 0 0} \mathbf{~ m m} / \mathbf{y})\end{array}$} & \multicolumn{2}{|c|}{$\begin{array}{c}\text { Moderate } \\
(500 \leq \mathrm{P}<1000 \mathrm{~mm} / \mathrm{y})\end{array}$} & \multicolumn{2}{|c|}{$\begin{array}{c}\text { Humid } \\
(\mathrm{P} \geq \mathbf{1 0 0 0} \mathrm{mm} / \mathrm{y})\end{array}$} \\
\hline & $\mathbf{q}_{\mathrm{c}}(\mathrm{m} / \mathbf{y})$ & $\mathbf{q}_{\mathrm{l}}(\mathrm{m} / \mathbf{y})$ & $\mathbf{q}_{\mathrm{c}}(\mathrm{m} / \mathbf{y})$ & $q_{l}(m / y)$ & $\mathbf{q}_{\mathrm{c}}(\mathrm{m} / \mathrm{y})$ & $q_{1}(m / y)$ \\
\hline C1-infiltration & & 0.046 & & 0.249 & & 0.585 \\
\hline C1L1 & - & 0.046 & - & 0.249 & - & - \\
\hline C1L2 & - & 0.046 & 0.234 & 0.015 & 0.570 & 0.015 \\
\hline C1L3 & - & 0.046 & - & 0.249 & 0.260 & 0.325 \\
\hline \multirow[t]{2}{*}{ C1L4 } & - & 0.046 & 0.150 & $0.099\left(\mathrm{k}_{\mathrm{h}}\right)$ & 0.486 & $\begin{array}{c}0.099 \\
\left(\mathrm{k}_{\mathrm{h}}\right)\end{array}$ \\
\hline & & & 0.239 & $0.010\left(\mathrm{k}_{\mathrm{l}}\right)$ & 0.575 & $\begin{array}{c}0.010 \\
\left(\mathrm{k}_{\mathrm{l}}\right)\end{array}$ \\
\hline \multirow[t]{2}{*}{ C1L5 } & - & 0.046 & - & $0.249\left(\mathrm{k}_{\mathrm{h}}\right)$ & 0.094 & $\begin{array}{c}0.491 \\
\left(\mathrm{k}_{\mathrm{h}}\right)\end{array}$ \\
\hline & & & 0.034 & $0.215\left(\mathrm{k}_{1}\right)$ & 0.370 & $\begin{array}{c}0.215 \\
\left(\mathrm{k}_{\mathrm{l}}\right)\end{array}$ \\
\hline C1L6 & - & 0.046 & & - & & - \\
\hline C2 -infiltration & & 0.0014 & & 0.00423 & & 0.0089 \\
\hline C2L1 & - & 0.0014 & - & 0.00423 & - & 0.0089 \\
\hline $\mathrm{C} 2 \mathrm{~L} 2$ & - & 0.0014 & - & 0.00423 & - & 0.0089 \\
\hline C2L3 & - & 0.0014 & - & 0.00423 & - & 0.0089 \\
\hline C2L4 & - & 0.0014 & - & 0.00423 & - & 0.0089 \\
\hline C2L5 & - & 0.0014 & - & 0.00423 & - & 0.0089 \\
\hline C2L6 & - & 0.0014 & - & 0.00423 & - & 0.0089 \\
\hline C3-infiltration & & 0.045 & & 0.245 & & 0.577 \\
\hline C3L1 & - & 0.045 & - & 0.245 & - & - \\
\hline C3L2 & 0.030 & 0.015 & 0.230 & 0.015 & 0.562 & 0.015 \\
\hline C3L3 & - & 0.045 & - & 0.245 & 0.252 & 0.325 \\
\hline \multirow[t]{2}{*}{$\mathrm{C} 3 \mathrm{~L} 4$} & - & $\begin{array}{c}0.045 \\
\left(k_{h}{ }^{a}\right)\end{array}$ & 0.146 & $0.099\left(\mathrm{k}_{\mathrm{h}}\right)$ & 0.478 & $\begin{array}{c}0.099 \\
\left(\mathrm{k}_{\mathrm{h}}\right)\end{array}$ \\
\hline & 0.035 & $\begin{array}{c}0.010 \\
\left(k_{1}^{b}\right)\end{array}$ & 0.235 & $0.010\left(\mathrm{k}_{\mathrm{l}}\right)$ & 0.567 & $\begin{array}{c}0.010 \\
\left(\mathrm{k}_{1}\right)\end{array}$ \\
\hline \multirow[t]{2}{*}{ C3L5 } & - & 0.045 & - & $0.245\left(\mathrm{k}_{\mathrm{h}}\right)$ & 0.086 & $\begin{array}{c}0.491 \\
\left(\mathrm{k}_{\mathrm{h}}\right)\end{array}$ \\
\hline & & & 0.030 & $0.215\left(\mathrm{k}_{\mathrm{l}}\right)$ & 0.362 & $\begin{array}{c}0.215 \\
\left(\mathrm{k}_{1}\right)\end{array}$ \\
\hline C3L6 & - & 0.045 & - & - & - & - \\
\hline
\end{tabular}

${ }^{\mathrm{a}}$ Indicates high conductivity vadose zone ${ }^{\mathrm{b}}$ Indicates low conductivity vadose zone 


\subsubsection{Compliance with the Second Performance Criterion (Contaminant}

Concentration)

The maximum contaminant $\left(\mathrm{Cl}^{-}\right)$concentration that can be allowed at the receptor point had been determined to be $25 \mathrm{mg} / \mathrm{L}$ due to Turkish Drinking Water Standards (TSE, 1997). However, this standard was updated in 2005, and the maximum allowable chloride concentration was accepted to be $250 \mathrm{mg} / \mathrm{L}$ (TSE, 2005). In order to obtain conservative results, $25 \mathrm{mg} / \mathrm{L}$ was considered as the performance criterion for the preliminary evaluation of the design alternatives and for the design component selection matrix.

To evaluate the contamination that each of the 18 design alternatives would cause at the top of the aquifer, 1300 POLLUTE simulations were performed under 3 climatic conditions, with 2 different waste thicknesses, 4 different seepage velocity values, and 3 different landfill areas. In the main body of the thesis, only the results of major design alternatives (C1L1, C2L2, and C3L5) with medium and fast seepage velocities $(0.5 \mathrm{~m} / \mathrm{d}$ and $1 \mathrm{~m} / \mathrm{d})$ are presented in Tables; however, the discussions are based on the overall results of 1300 simulations. The complete results of simulations are given in Appendix-E.

Regardless of the climate, the natural attenuation landfill (C1L1) caused the highest contaminant concentration at the receptor, much above the accepted limit of $25 \mathrm{mg} / \mathrm{L}$; such that, for a landfill of 50 ha, having 20-m-waste thickness, and with a slow seepage velocity of $0.1 \mathrm{~m} / \mathrm{d}$, the contaminant concentrations at the groundwater table were $227.8 \mathrm{mg} / \mathrm{L}, 557.9 \mathrm{mg} / \mathrm{L}$, and $571.1 \mathrm{mg} / \mathrm{L}$, for arid, moderate, and humid climates, respectively. As extensive engineering landfill (C2L2) removed most of the contaminant mass by leachate collection, this design resulted in the lowest contaminant concentrations at the receptor; such that, for a landfill of 50 ha, having 20-m-waste thickness, and with a slow seepage velocity of $0.5 \mathrm{~m} / \mathrm{d}$, the contaminant concentrations at the groundwater table were 2.16 
$\mathrm{mg} / \mathrm{L}, 5.6 \mathrm{mg} / \mathrm{L}$, and $12.3 \mathrm{mg} / \mathrm{L}$, for arid, moderate, and humid climates, respectively. Lower hydraulic conductivity vadose zones increased the efficiency of the leachate collection system by decreasing the effective hydraulic conductivity of the landfill bottom liner, and therefore, increased the performance of the landfill design alternative.

\subsubsection{Performance Evaluation under Arid Climates $(P<500$ $\mathrm{mm} / \mathrm{y})$}

As stated in Section 4.3.3, because the infiltration rate was less than the effective hydraulic conductivities of natural attenuation bottom liner (L1) and bottom liners having leachate collection systems coupled with compacted clay liners (L5), the leachate collection systems were not functional. Therefore, the leakage was controlled by the final cover.

When the seepage velocity was in the range of medium to fast $(0.5-1 \mathrm{~m} / \mathrm{d})$, and the landfill area was less than 15 ha, all design alternatives complied with the contamination performance criterion. When the landfill size was medium (15 - 50 ha) and waste thickness could be designed as $5 \mathrm{~m}$, all design alternatives placed on low conductivity vadose zones complied with the contamination criterion. Except under very slow seepage velocities $(\leq 0.05 \mathrm{~m} / \mathrm{d})$, all landfill bottom liner designs coupled with extensive engineering final cover having geomembrane (C2) satisfied less than $25 \mathrm{mg} / \mathrm{L}$ chloride concentration at the receptor. When the seepage velocity in the aquifer was in the range of very slow to slow $(0.05-0.1$ $\mathrm{m} / \mathrm{d}$ ), only the design alternatives having geomembranes in their bottom liners (L2, L4) satisfied the performance criterion. For large landfills (A $>50$ ha) with 20-m-waste thickness, seepage velocity also lost its effect of dilution and design alternatives lacking geomembranes either in their final covers or bottom liners did not comply with the performance criterion. For situations where the waste 
thickness could be decreased to $5 \mathrm{~m}$, designs lacking geomembranes also complied with the contamination criterion.

Extensive engineering bottom liners composed of leachate collection systems, geomembranes, and compacted clay liners (L2) satisfied the performance criterion under most of the design conditions. When L2 does not satisfy the performance criterion, the design alternative can be used on lower conductivity aquitards; or, double liner designs can be considered for very large (A > 100 ha) landfills.

The simulation results for arid climates are given in Table 4.13.

Table 4. 13 Performance of design alternatives under arid climates $(\mathrm{P}<500 \mathrm{~mm} / \mathrm{y})$

\begin{tabular}{|c|c|c|c|c|c|c|c|c|}
\hline & $\mathbf{T}_{\max }$ & $C_{\max }$ & & $\mathbf{T}_{\max }$ & $C_{\max }$ & & $\mathbf{T}_{\max }$ & $C_{\max }$ \\
\hline C1L1 & $(\mathbf{y})$ & $(\mathrm{mg} / \mathrm{L})$ & C2L2 & $(\mathbf{y})$ & $(\mathrm{mg} / \mathrm{L})$ & C3L5 & $(\mathbf{y})$ & $(\mathrm{mg} / \mathrm{L})$ \\
\hline C-S-m ${ }^{(a)}$ & 115 & 9.5 & C-S-m ${ }^{(a)}$ & 1339 & 0.27 & C-S-m ${ }^{(a)}$ & 123 & 9.2 \\
\hline C-S-f & 115 & 4.8 & C-S-f & 1339 & 0.14 & C-S-f & 123 & 4.6 \\
\hline C-D-m & 127 & 13.7 & C-D-m & 1834 & 0.43 & C-D-m & 138 & 13.3 \\
\hline C-D-f & 127 & 6.8 & C-D-f & 1834 & 0.22 & C-D-f & 138 & 6.7 \\
\hline S-S-m & 115 & 23.8 & S-S-m & 1339 & 0.69 & S-S-m & 123 & 23.0 \\
\hline S-S-f & 115 & 11.9 & S-S-f & 1339 & 0.34 & S-S-f & 123 & 11.5 \\
\hline S-D-m & 131 & 34.3 & S-D-m & 1834 & 1.08 & S-D-m & 138 & 33.3 \\
\hline S-D-f & 127 & 17.1 & S-D-f & 1834 & 0.54 & S-D-f & 138 & 16.7 \\
\hline M-S-m & 119 & 47.4 & M-S-m & 1339 & 1.37 & M-S-m & 126 & 45.6 \\
\hline M-S-f & 118 & 23.8 & M-S-f & 1339 & 0.69 & M-S-f & 123 & 23.0 \\
\hline M-D-m & 134 & 68.4 & M-D-m & 1834 & 2.16 & M-D-m & 143 & 66.6 \\
\hline M-D-f & 131 & 34.3 & M-D-f & 1834 & 1.08 & M-D-f & 138 & 33.3 \\
\hline
\end{tabular}




\subsubsection{Performance Evaluation under Moderate Climates (500 $\leq$ $P<1000 \mathrm{~mm} / \mathrm{y})$}

Under moderate conditions, as the infiltration rate $\left(7.9 \times 10^{-9} \mathrm{~m} / \mathrm{s}\right)$ was lower than the hydraulic conductivities of natural attenuation bottom liner composed of only aquitard below waste (L1; $\mathrm{k}=1 \times 10^{-8} \mathrm{~m} / \mathrm{s}$ ) and bottom liners composed of leachate collection system placed on aquitards ( $\left.\mathrm{L} 3 ; \mathrm{k}=1 \times 10^{-8} \mathrm{~m} / \mathrm{s}\right)$, the leachate collection system was not functional. Although the hydraulic conductivity of bottom liners composed of leachate collection system coupled with compacted clay liners ( $\mathrm{L} 5 ; \mathrm{k}=6.6 \times 10^{-9} \mathrm{~m} / \mathrm{s}$ ) was lower than the infiltration rate, the leachate collection was not sufficient $\left(\mathrm{q}_{\mathrm{c}}=0.03 \mathrm{~m} / \mathrm{y}\right)$, and the bottom liner design did not satisfy the performance criterion.

When the bottom liner designs lacking geomembranes (L1, L3, L5, L6) were coupled with final covers having geomembranes (C2), the composed design alternatives satisfied less than $25 \mathrm{mg} / \mathrm{L}$ chloride concentration at the receptor point, except for very slow seepage velocities $(0.05 \mathrm{~m} / \mathrm{d})$. In the range of very slow to slow seepage velocities $(0.05-0.1 \mathrm{~m} / \mathrm{d})$, only the design alternatives having geomembranes either in their bottom liners (L2, L4) or final cover (C2) satisfied the performance criterion. For faster seepage velocities $(>0.1 \mathrm{~m} / \mathrm{d})$, communal to medium size landfills $(<1-50$ ha) with bottom liners having compacted clay (L5, L6) complied with the performance criterion. However, for large landfills (A > 50 ha), seepage velocity lost its effect of dilution and design alternatives having compacted clay liners did not comply with the performance criterion.

Extensive engineering bottom liners composed of leachate collection systems, geomembranes, and compacted clay liners (L2) satisfied the performance criterion under most of the design conditions. When L2 does not satisfy the performance 
criterion, the design alternative can be designed on lower conductivity aquitards; or, double liner designs can be considered for very large (A > 100 ha) landfills.

The simulation results of the design alternatives under moderate climates are given in Table 4.14 .

Table 4. 14 Performance of design alternatives under moderate climates ( $500 \leq \mathrm{P}<1000 \mathrm{~mm} / \mathrm{y})$

\begin{tabular}{|c|c|c|c|c|c|c|c|c|}
\hline & $\mathbf{T}_{\max }$ & $\mathrm{C}_{\max }$ & & $\mathbf{T}_{\max }$ & $\mathrm{C}_{\max }$ & & $\mathbf{T}_{\max }$ & $\overline{C_{\max }}$ \\
\hline C1L1 & $(\mathbf{y})$ & $(\mathrm{mg} / \mathrm{L})$ & C2L2 & $(\mathbf{y})$ & $(\mathrm{mg} / \mathrm{L})$ & C3L5 & $(\mathbf{y})$ & $(\mathrm{mg} / \mathrm{L})$ \\
\hline C-S-m ${ }^{(a)}$ & 21 & 66.9 & C-S-m ${ }^{(a)}$ & 818 & 0.69 & C-S-m ${ }^{(a)}$ & 25 & 54.7 \\
\hline C-S-f & 21 & 33.6 & C-S-f & 818 & 0.35 & C-S-f & 25 & 27.5 \\
\hline C-D-m & 22 & 82.3 & C-D-m & 1067 & 1.12 & C-D-m & 27 & 69.6 \\
\hline C-D-f & 22 & 41.2 & C-D-f & 1067 & 0.56 & C-D-f & 26 & 34.9 \\
\hline S-S-m & 21 & 162.5 & S-S-m & 818 & 1.73 & S-S-m & 26 & 134.1 \\
\hline S-S-f & 21 & 83.5 & S-S-f & 818 & 0.86 & S-S-f & 25 & 68.3 \\
\hline S-D-m & 22 & 203.0 & S-D-m & 1067 & 2.79 & S-D-m & 28 & 172.4 \\
\hline S-D-f & 22 & 102.6 & S-D-f & 1067 & 1.40 & S-D-f & 27 & 86.9 \\
\hline M-S-m & 22 & 302.5 & M-S-m & 818 & 3.46 & M-S-m & 27 & 252.5 \\
\hline M-S-f & 21 & 162.7 & M-S-f & 818 & 1.73 & M-S-f & 26 & 134.1 \\
\hline M-D-m & 25 & 392.4 & M-D-m & 1067 & 5.58 & M-D-m & 29 & 335.5 \\
\hline M-D-f & 22 & 203.0 & M-D-f & 1067 & 2.79 & M-D-f & 28 & 172.4 \\
\hline
\end{tabular}

\subsubsection{3. $\quad$ Performance Evaluation under Humid Climates $(P \geq 1000$ $\mathrm{mm} / \mathrm{y})$}

Under humid climates, as the infiltration rate $\left(1.6 \times 10^{-8} \mathrm{~m} / \mathrm{s}\right)$ was close to hydraulic conductivity of natural attenuation bottom liner composed of only aquitard below waste $\left(\mathrm{L} 1 ; \mathrm{k}=1 \times 10^{-8} \mathrm{~m} / \mathrm{s}\right)$, the hydraulic properties of the vadose zone were insufficient to satisfy the performance criterion. Leachate collection systems were required under such conditions. However, even hydraulic 
conductivity of bottom liners composed of leachate collection system coupled with compacted clay liner ( $\mathrm{L} 5 ; \mathrm{k}=6.6 \times 10^{-9} \mathrm{~m} / \mathrm{s}$ ) was lower than the infiltration rate, the leachate collection efficiency $\left(\mathrm{q}_{\mathrm{c}}=0.03 \mathrm{~m} / \mathrm{y}\right)$ was not sufficient.

Under humid climates, design alternatives lacking geomembranes did not comply with the performance criterion. Only for communal landfill sizes ( $\mathrm{A} \leq 2 \mathrm{ha}$ ), intermediate engineering landfill designs composed of leachate collection system, and compacted clay liner placed on low conductivity aquitards (C1L5, C3L5) satisfied the contaminant criterion at the receptor. For small landfills ( $\mathrm{A}<15 \mathrm{ha})$, geomembranes were not required in the bottom liners when the design alternative had an extensive engineering final cover having geomembrane (C2). As the landfill size increased ( $\mathrm{A}>15 \mathrm{ha}$ ), design alternatives composed of extensive engineering final cover having geomembranes and bottom liners lacking geomembranes (C2L1, C2L3, C2L5) complied with the performance criterion only with seepage velocities faster than $0.5 \mathrm{~m} / \mathrm{d}$. Design alternatives having geomembranes in their bottom liners (C1L2, C1L4, C3L2, C3L4) complied with the contamination criterion. Waste thickness was not a controlling factor under humid climates.

As previously stated, extensive engineering bottom liners composed of leachate collection systems, geomembranes, and compacted clay liners (L2) satisfied the performance criterion under most of the design conditions. When L2 does not satisfy the performance criterion, the design alternative can be used on lower conductivity aquitards; or, double liner designs can be considered for very large (A > 100 ha) landfills.

Performance of the design alternatives under humid climates are presented in Table 4.15. 
Table 4. 15 Performance of design alternatives under humid climates $(P \geq 1000 \mathrm{~mm} / \mathrm{y})$

\begin{tabular}{|c|c|c|c|c|c|c|c|c|}
\hline & $\mathbf{T}_{\max }$ & $\mathrm{C}_{\max }$ & & $\mathbf{T}_{\max }$ & $\mathrm{C}_{\max }$ & & $\mathbf{T}_{\max }$ & $\mathrm{C}_{\max }$ \\
\hline C1L1 & (y) & $(\mathrm{mg} / \mathrm{L})$ & C2L2 & (y) & $(\mathrm{mg} / \mathrm{L})$ & C3L5 & $(\mathbf{y})$ & $(\mathrm{mg} / \mathrm{L})$ \\
\hline C-S-m ${ }^{(a)}$ & 9 & 164.3 & C-S-m ${ }^{(a)}$ & 467 & 1.57 & C-S-m ${ }^{(a)}$ & 25 & 40.3 \\
\hline C-S-f & 9 & 85.4 & C-S-f & 467 & 0.79 & C-S-f & 24 & 20.3 \\
\hline C-D-m & 9 & 195.6 & C-D-m & 602 & 2.45 & C-D-m & 26 & 61.9 \\
\hline C-D-f & 9 & 99.4 & C-D-f & 602 & 1.22 & C-D-f & 26 & 31.0 \\
\hline S-S-m & 10 & 359.0 & S-S-m & 467 & 3.92 & S-S-m & 25 & 97.7 \\
\hline S-S-f & 9 & 200.8 & S-S-f & 467 & 1.96 & S-S-f & 25 & 50.2 \\
\hline S-D-m & 11 & 460.0 & S-D-m & 602 & 6.12 & S-D-m & 26 & 152.4 \\
\hline S-D-f & 10 & 241.9 & S-D-f & 602 & 3.06 & S-D-f & 26 & 77.2 \\
\hline M-S-m & 10 & 571.1 & M-S-m & 484 & 7.84 & M-S-m & 26 & 179.8 \\
\hline M-S-f & 10 & 359.0 & $M-S-f$ & 467 & 3.92 & M-S-f & 25 & 97.7 \\
\hline M-D-m & 12 & 795.4 & M-D-m & 602 & 12.23 & M-D-m & 28 & 291.1 \\
\hline M-D-f & 11 & 459.6 & M-D-f & 602 & 6.12 & M-D-f & 26 & 152.4 \\
\hline
\end{tabular}

\subsection{The Design Component Selection Matrix}

Following the methodology described in Section 3.1.2, design component selection matrices were constructed by coalescing the results of over 1300 simulations of 18 landfill design alternatives using system simulation models (i.e. HELP and POLLUTE) considering the design variables (i.e. climate -total annual precipitation amount, waste load -landfill area, waste thickness, seepage velocity, and site hydrogeology -hydraulic conductivity, porosity and thickness of vadose zone). The alternative design combinations presented in the matrix were selected based on simulated landfill performance evaluations. The design component selection matrices (Table 4.16, 4.17, and 4.18) are used as knowledge-base in LFDSS in the preliminary design phase, as guidance for the selection of most appropriate design components for a given site and waste conditions. 
Table 4. 16 Design component selection matrix for arid climates ${ }^{\text {a, d, e }}$

\begin{tabular}{|c|c|c|c|c|c|c|c|c|c|c|}
\hline & \multirow{3}{*}{$\underset{\text { (ha) }}{\operatorname{Area}^{b}}$} & \multicolumn{4}{|c|}{$T_{w}(5 \mathrm{~m})$} & \multicolumn{4}{|c|}{$T_{w}(20 \mathrm{~m})$} & \\
\hline & & $\mathbf{A A}$ & AB & AC & AD & AE & AF & AG & AH & \\
\hline & & $v_{\text {s-vs }}{ }^{c}$ & $v_{\mathrm{s}-\mathrm{s}}$ & $v_{\mathrm{s}-\mathrm{m}}$ & $v_{\text {s-f }}$ & $v_{\mathrm{s}-\mathrm{vs}}$ & $v_{\mathrm{s}-\mathrm{s}}$ & $v_{\mathrm{s}-\mathrm{m}}$ & $v_{\text {s-f }}$ & \\
\hline 1 & & C1L2 & C1L2 & C1L1 & C1L1 & C1L4L & C1L2 & C1L1 & C1L1 & 1 \\
\hline 2 & & $\mathrm{C} 1 \mathrm{~L} 4^{\mathrm{L}}$ & $\mathrm{C} 1 \mathrm{~L} 4^{\mathrm{L}}$ & C1L2 & C1L2 & C2LX & $\mathrm{C} 1 \mathrm{~L} 4^{\mathrm{L}}$ & C1L2 & C1L2 & 2 \\
\hline 3 & & C2LX & C2LX & C1L3 & C1L3 & C3L2 & C2LX & C1L3 & C1L3 & 3 \\
\hline 4 & & C3L2 & C3L2 & C1L4 & C1L4 & $\mathrm{C} 3 \mathrm{~L} 4^{\mathrm{L}}$ & C3L2 & C1L4 & C1L4 & 4 \\
\hline 5 & & $\mathrm{C} 3 \mathrm{~L} 4^{\mathrm{L}}$ & $\mathrm{C} 3 \mathrm{~L} 4^{\mathrm{L}}$ & C1L5 & C1L5 & & $\mathrm{C} 3 \mathrm{~L} 4^{\mathrm{L}}$ & C1L5 & C1L5 & 5 \\
\hline 6 & & & & C1L6 & C1L6 & & & C1L6 & C1L6 & 6 \\
\hline 7 & $\mathrm{C}$ & & & $\mathrm{C} 2 \mathrm{LX}$ & C2LX & & & C2LX & C2LX & 7 \\
\hline 8 & & & & C3L1 & C3L1 & & & C3L1 & C3L1 & 8 \\
\hline 9 & & & & C3L3 & C3L3 & & & C3L3 & C3L3 & 9 \\
\hline 10 & & & & C3L2 & C3L2 & & & C3L2 & C3L2 & 10 \\
\hline 11 & & & & C3L4 & C3L4 & & & C3L4 & C3L4 & 11 \\
\hline 12 & & & & C3L5 & C3L5 & & & C3L5 & C3L5 & 12 \\
\hline 13 & & & & C3L6 & C3L6 & & & C3L6 & C3L6 & 13 \\
\hline 14 & & $\mathrm{C} 1 \mathrm{~L} 4^{\mathrm{L}}$ & C1L2 & C1L1 & C1L1 & C2LX & $\mathrm{C} 1 \mathrm{~L} 4^{\mathrm{L}}$ & C1L2 & C1L1 & 14 \\
\hline 15 & & C2LX & $\mathrm{C} 1 \mathrm{~L} 4^{\mathrm{L}}$ & C1L2 & C1L2 & C3L2 & C2LX & $\mathrm{C} 1 \mathrm{~L} 4^{\mathrm{L}}$ & C1L2 & 15 \\
\hline 16 & & C3L2 & C2LX & C1L3 & C1L3 & & C3L2 & C2LX & C1L3 & 16 \\
\hline 17 & & $\mathrm{C} 3 \mathrm{~L} 4^{\mathrm{L}}$ & C3L2 & $\mathrm{C} 1 \mathrm{~L} 4^{\mathrm{L}}$ & C1L4 & & $\mathrm{C} 3 \mathrm{~L} 4^{\mathrm{L}}$ & C3L2 & C1L4 & 17 \\
\hline 18 & & & $\mathrm{C} 3 \mathrm{~L} 4^{\mathrm{L}}$ & $\mathrm{C} 1 \mathrm{~L} 5^{\mathrm{L}}$ & C1L5 & & & $\mathrm{C} 3 \mathrm{~L} 4^{\mathrm{L}}$ & C1L5 & 18 \\
\hline 19 & & & & $\mathrm{C} 1 \mathrm{~L} 6^{\mathrm{L}}$ & C1L6 & & & & C1L6 & 19 \\
\hline 20 & $S$ & & & $\mathrm{C} 2 \mathrm{LX}$ & C2LX & & & & C2LX & 20 \\
\hline 21 & $(2-15]$ & & & C3L1 & $\mathrm{C} 3 \mathrm{~L} 1$ & & & & C3L1 & 21 \\
\hline 22 & & & & C3L3 & C3L3 & & & & C3L3 & 22 \\
\hline 23 & & & & C3L2 & C3L2 & & & & C3L2 & 23 \\
\hline 24 & & & & $\mathrm{C} 3 \mathrm{~L} 4^{\mathrm{L}}$ & C3L4 & & & & C3L4 & 24 \\
\hline 25 & & & & C3L $5^{\mathrm{L}}$ & C3L5 & & & & C3L5 & 25 \\
\hline 26 & & & & C $3 \mathrm{~L} 6^{\mathrm{L}}$ & C3L6 & & & & C3L6 & 26 \\
\hline 27 & & C2LX & $\mathrm{C} \mathrm{L} 4^{\mathrm{L}}$ & C1L2 & C1L1 & C2LX & C2LX & C1L2 & C1L2 & 27 \\
\hline 28 & & C3L2 & C2LX & $\mathrm{C} 1 \mathrm{~L} 4^{\mathrm{L}}$ & C1L2 & & C3L2 & $\mathrm{C} 1 \mathrm{~L} 4^{\mathrm{L}}$ & $\mathrm{C} 1 \mathrm{~L} 4^{\mathrm{L}}$ & 28 \\
\hline 29 & & & C3L2 & C2LX & C1L3 & & & C2LX & C2LX & 29 \\
\hline 30 & & & $\mathrm{C} 3 \mathrm{~L} 4^{\mathrm{L}}$ & C3L2 & $\mathrm{C} 1 \mathrm{~L} 4^{\mathrm{L}}$ & & & $\mathrm{C} 3 \mathrm{~L} 2$ & C3L2 & 30 \\
\hline 31 & & & & $\mathrm{C} 3 \mathrm{~L} 4^{\mathrm{L}}$ & $\mathrm{C} 1 \mathrm{~L} 5^{\mathrm{L}}$ & & & $\mathrm{C} 3 \mathrm{~L} 4^{\mathrm{L}}$ & $\mathrm{C} 3 \mathrm{~L} 4^{\mathrm{L}}$ & 31 \\
\hline 32 & & & & & C1L6 ${ }^{\mathrm{L}}$ & & & & & 32 \\
\hline 33 & $\stackrel{M}{M}$ & & & & C2LX & & & & & 33 \\
\hline 34 & & & & & $\mathrm{C} 3 \mathrm{~L} 1$ & & & & & 34 \\
\hline 35 & & & & & C3L3 & & & & & 35 \\
\hline 36 & & & & & C3L2 & & & & & 36 \\
\hline 37 & & & & & $\mathrm{C} 3 \mathrm{~L} 4^{\mathrm{L}}$ & & & & & 37 \\
\hline 38 & & & & & $\mathrm{C} 3 \mathrm{~L} 5^{\mathrm{L}}$ & & & & & 38 \\
\hline 39 & & & & & $\mathrm{C} 3 \mathrm{~L} 6^{\mathrm{L}}$ & & & & & 39 \\
\hline 40 & & C3L2 & C2LX & $\mathrm{C}^{2} \mathrm{L4}^{\mathrm{L}}$ & C1L2 & & C2LX & $\mathrm{C} 1 \mathrm{~L} 4^{\mathrm{L}}$ & C1L2 & 40 \\
\hline 41 & & & C3L2 & C2LX & $\mathrm{C} 1 \mathrm{~L} 4^{\mathrm{L}}$ & & & C2LX & $\mathrm{C} 1 \mathrm{~L} 4^{\mathrm{L}}$ & 41 \\
\hline 42 & L & & & C3L2 & $\mathrm{C} 2 \mathrm{LX}$ & & & $\mathrm{C} 3 \mathrm{~L} 2$ & C2LX & 42 \\
\hline 43 & & & & $\mathrm{C} 3 \mathrm{~L} 4^{\mathrm{L}}$ & $\mathrm{C} 3 \mathrm{~L} 2$ & & & $\mathrm{C} 3 \mathrm{~L} 4^{\mathrm{L}}$ & C3L2 & 43 \\
\hline 44 & & & & & $\mathrm{C} 3 \mathrm{~L} 4^{\mathrm{L}}$ & & & & $\mathrm{C} 3 \mathrm{~L} 4^{\mathrm{L}}$ & 44 \\
\hline $\begin{array}{l}\mathrm{R} / \\
\mathrm{C}\end{array}$ & & $\mathbf{A A}$ & $\mathbf{A B}$ & AC & AD & $\mathbf{A E}$ & $\mathbf{A F}$ & AG & $\mathbf{A H}$ & $\begin{array}{l}\mathrm{R} / \\
\mathrm{C}\end{array}$ \\
\hline
\end{tabular}

${ }^{\mathrm{a}} \mathrm{L} 1$, L3 are designed for low conductivity aquitards (unsaturated hydraulic conductivity, $\mathrm{K}_{\mathrm{ave}}=10^{-}$ $\left.{ }^{7}-10^{-8} \mathrm{~m} / \mathrm{s}\right)$; L2 is designed for higher conductivity vadose zones $\left(\mathrm{K}_{\mathrm{ave}}=10^{-7} \mathrm{~m} / \mathrm{s}\right)$ and L4, L5, L6 are designed for higher conductivity $\left(\mathrm{K}_{\mathrm{ave}}=10^{-7} \mathrm{~m} / \mathrm{s}\right)$ or lower conductivity vadose zones $\left(\mathrm{K}_{\mathrm{ave}}=\right.$ $10^{-8} \mathrm{~m} / \mathrm{s}$ ). ${ }^{\mathrm{b}}$ Landfill area $\rightarrow$ C: 0- 2ha (communal), S: 2 - 15ha (small), M: 15- 50ha (medium); L: $50-100 \mathrm{ha} \mathrm{(large)}{ }^{\mathrm{c}}$ Seepage velocity values: $v_{\mathrm{s}-\mathrm{vs}}=0.05 \mathrm{~m} / \mathrm{d}$ (very slow), $v_{\mathrm{s}-\mathrm{s}}=0.1 \mathrm{~m} / \mathrm{d}$ (slow), $v_{\mathrm{s}-}$ $\mathrm{m}=0.5 \mathrm{~m} / \mathrm{d}$ (medium), $\mathrm{v}_{\mathrm{s}-\mathrm{f}}=1 \mathrm{~m} / \mathrm{d}$ (fast). ${ }^{\mathrm{d}}$ Subscript $\mathrm{L}$ indicates the design alternative is designed for lower conductivity aquitards with hydraulic conductivity of $1 \times 10^{-8} \mathrm{~m} / \mathrm{s}$. ${ }^{\mathrm{e}} \mathrm{LX}$ indicates that all the bottom liner design alternatives (L1, L2, L3, L4, L5, L6) are appropriate. 
Table 4. 17 Design component selection matrix for moderate climates ${ }^{\text {a, d, e }}$

\begin{tabular}{|c|c|c|c|c|c|c|c|c|c|c|}
\hline & \multirow{3}{*}{$\begin{array}{c}\text { Area }^{b} \\
\text { (ha) }\end{array}$} & \multicolumn{4}{|c|}{$T_{w}(5 \mathrm{~m})$} & \multicolumn{4}{|c|}{$T_{w}(20 \mathrm{~m})$} & \\
\hline & & MA & MB & MC & MD & ME & MF & MG & MH & \\
\hline & & $v_{s-v s}^{c}$ & $v_{s-s}$ & $\mathbf{v}_{\mathrm{s}-\mathrm{m}}$ & $v_{s-f}$ & $v_{\text {s-vs }}$ & $v_{\mathrm{s}-\mathrm{s}}$ & $v_{s-m}$ & $v_{\text {s-f }}$ & \\
\hline 1 & & C1L2 & C1L2 & C1L2 & C1L2 & C1L2 & C1L2 & C1L2 & C1L2 & 1 \\
\hline 2 & & $\mathrm{C} 1 \mathrm{~L} 4^{\mathrm{L}}$ & $\mathrm{C} 1 \mathrm{~L} 4^{\mathrm{L}}$ & C1L4 & $\mathrm{C} 1 \mathrm{~L} 4$ & $\mathrm{C} 1 \mathrm{~L} 4^{\mathrm{L}}$ & $\mathrm{C} 1 \mathrm{~L} 4^{\mathrm{L}}$ & $\mathrm{C} 1 \mathrm{~L} 4^{\mathrm{L}}$ & C1L4 & 2 \\
\hline 3 & & C2LX & C2LX & C1L5 & C1L5 & C2LX & C2LX & C1L5 & C1L5 & 3 \\
\hline 4 & & C3L2 & C3L2 & C1L6 & C1L6 & C3L2 & $\mathrm{C} 3 \mathrm{~L} 2$ & C1L6 & C1L6 & 4 \\
\hline 5 & $\mathbf{A} \leq \mathbf{2}$ & $\mathrm{C} 3 \mathrm{~L} 4^{\mathrm{L}}$ & $\mathrm{C} 3 \mathrm{~L} 4^{\mathrm{L}}$ & C2LX & C2LX & $\mathrm{C} 3 \mathrm{~L} 4^{\mathrm{L}}$ & $\mathrm{C} 3 \mathrm{~L} 4^{\mathrm{L}}$ & C2LX & C2LX & 5 \\
\hline 6 & & & & C3L2 & C3L2 & & & C3L2 & C3L2 & 6 \\
\hline 7 & & & & C3L4 & C3L4 & & & $\mathrm{C} 3 \mathrm{~L} 4^{\mathrm{L}}$ & C3L4 & 7 \\
\hline 8 & & C1L2 & C1L2 & C1L2 & C1L2 & $\mathrm{C} 1 \mathrm{~L} 4^{\mathrm{L}}$ & C1L2 & C1L2 & C1L2 & 8 \\
\hline 9 & & $\mathrm{C} 1 \mathrm{~L} 4^{\mathrm{L}}$ & $\mathrm{C} 1 \mathrm{~L} 4^{\mathrm{L}}$ & $\mathrm{C} 1 \mathrm{~L} 4^{\mathrm{L}}$ & $\mathrm{C} 1 \mathrm{~L} 4$ & $\mathrm{C} 3 \mathrm{~L} 4^{\mathrm{L}}$ & $\mathrm{C} 1 \mathrm{~L} 4^{\mathrm{L}}$ & $\mathrm{C} 1 \mathrm{~L} 4^{\mathrm{L}}$ & $\mathrm{C} 1 \mathrm{~L} 4^{\mathrm{L}}$ & 9 \\
\hline 10 & & C2LX & $\mathrm{C} 2 \mathrm{LX}$ & $\mathrm{C} 1 \mathrm{L5}^{\mathrm{L}}$ & C1L5 & & C2LX & C2LX & C1L5 & 10 \\
\hline 11 & $S$ & C3L2 & C3L2 & $\mathrm{C} 1 \mathrm{~L} 6^{\mathrm{L}}$ & C1L6 & & $\mathrm{C} 3 \mathrm{~L} 2$ & C3L2 & C1L6 & 11 \\
\hline 12 & & $\mathrm{C} 3 \mathrm{~L} 4^{\mathrm{L}}$ & $\mathrm{C} 3 \mathrm{~L} 4^{\mathrm{L}}$ & C2LX & C2LX & & $\mathrm{C} 3 \mathrm{~L} 4^{\mathrm{L}}$ & $\mathrm{C} 3 \mathrm{~L} 4^{\mathrm{L}}$ & C2LX & 12 \\
\hline 13 & & & & C3L2 & C3L2 & & & & C3L2 & 13 \\
\hline 14 & & & & $\mathrm{C} 3 \mathrm{~L} 4^{\mathrm{L}}$ & C3L4 & & & & $\mathrm{C} 3 \mathrm{~L} 4^{\mathrm{L}}$ & 14 \\
\hline 15 & & C1L2 & C1L2 & C1L2 & C1L2 & $\mathrm{C} 1 \mathrm{~L} 4^{\mathrm{L}}$ & $\mathrm{C} 1 \mathrm{~L} 4^{\mathrm{L}}$ & C1L2 & C1L2 & 15 \\
\hline 16 & & $\mathrm{C} 1 \mathrm{~L} 4^{\mathrm{L}}$ & $\mathrm{C} 1 \mathrm{~L}^{\mathrm{L}}$ & $\mathrm{C} 1 \mathrm{~L} 4^{\mathrm{L}}$ & $\mathrm{C} 1 \mathrm{~L} 4^{\mathrm{L}}$ & $\mathrm{C} 3 \mathrm{~L} 4^{\mathrm{L}}$ & $\mathrm{C} 3 \mathrm{~L} 4^{\mathrm{L}}$ & $\mathrm{C} 1 \mathrm{~L} 4^{\mathrm{L}}$ & $\mathrm{C} 1 \mathrm{~L} 4^{\mathrm{L}}$ & 16 \\
\hline 17 & & C3L2 & C2LX & $\mathrm{C} 2 \mathrm{LX}$ & $\mathrm{C} 1 \mathrm{~L} 5^{\mathrm{L}}$ & & & C2LX & C2LX & 17 \\
\hline 18 & M & $\mathrm{C} 3 \mathrm{~L} 4^{\mathrm{L}}$ & C3L2 & $\mathrm{C} 3 \mathrm{~L} 2$ & $\mathrm{C} 1 \mathrm{~L} 6^{\mathrm{L}}$ & & & C3L2 & C3L2 & 18 \\
\hline 19 & & & $\mathrm{C} 3 \mathrm{~L} 4^{\mathrm{L}}$ & $\mathrm{C} 3 \mathrm{~L} 4^{\mathrm{L}}$ & C2LX & & & $\mathrm{C} 3 \mathrm{~L} 4^{\mathrm{L}}$ & $\mathrm{C} 3 \mathrm{~L} 4^{\mathrm{L}}$ & 19 \\
\hline 20 & & & & & C3L2 & & & & & 20 \\
\hline 21 & & & & & $\mathrm{C} 3 \mathrm{~L} 4^{\mathrm{L}}$ & & & & & 21 \\
\hline 22 & & $\mathrm{C}_{\mathrm{L}} 4^{\mathrm{L}}$ & C1L2 & C1L2 & C1L2 & & C1L4 $^{\mathrm{L}}$ & C1L2 & C1L2 & 22 \\
\hline 23 & & $\mathrm{C} 3 \mathrm{~L} 4^{\mathrm{L}}$ & $\mathrm{C} 1 \mathrm{~L}^{\mathrm{L}}$ & $\mathrm{C} 1 \mathrm{~L} 4^{\mathrm{L}}$ & $\mathrm{C} 1 \mathrm{~L} 4^{\mathrm{L}}$ & & $\mathrm{C} 3 \mathrm{~L} 4^{\mathrm{L}}$ & $\mathrm{C} 1 \mathrm{~L} 4^{\mathrm{L}}$ & $\mathrm{C} 1 \mathrm{~L} 4^{\mathrm{L}}$ & 23 \\
\hline 24 & L & & C3L2 & C2LX & C2LX & & & C2LX & C2LX & 24 \\
\hline 25 & & & $\mathrm{C} 3 \mathrm{~L} 4^{\mathrm{L}}$ & C3L2 & C3L2 & & & $\mathrm{C} 3 \mathrm{~L} 2$ & C3L2 & 25 \\
\hline 26 & & & & $\mathrm{C} 3 \mathrm{~L} 4^{\mathrm{L}}$ & $\mathrm{C} 3 \mathrm{~L} 4^{\mathrm{L}}$ & & & $\mathrm{C} 3 \mathrm{~L} 4^{\mathrm{L}}$ & $\mathrm{C} 3 \mathrm{~L}_{4}^{\mathrm{L}}$ & 26 \\
\hline $\begin{array}{l}\mathrm{R} / \\
\mathrm{C}\end{array}$ & & MA & MB & MC & MD & ME & MF & MG & MH & $\begin{array}{l}\mathbf{R} / \\
\mathbf{C}\end{array}$ \\
\hline
\end{tabular}

${ }^{\mathrm{a}} \mathrm{L} 1, \mathrm{~L} 3$ are designed for low conductivity aquitards (unsaturated hydraulic conductivity, $\mathrm{K}_{\mathrm{ave}}=10^{-}$ $\left.{ }^{7}-10^{-8} \mathrm{~m} / \mathrm{s}\right)$; L2 is designed for higher conductivity vadose zones $\left(\mathrm{K}_{\mathrm{ave}}=10^{-7} \mathrm{~m} / \mathrm{s}\right)$ and L4, L5, L6 are designed for higher conductivity $\left(\mathrm{K}_{\mathrm{ave}}=10^{-7} \mathrm{~m} / \mathrm{s}\right)$ or lower conductivity vadose zones $\left(\mathrm{K}_{\mathrm{ave}}=\right.$ $10^{-8} \mathrm{~m} / \mathrm{s}$ ). ${ }^{\mathrm{b}}$ Landfill area $\rightarrow$ C: 0- 2ha (communal), S: 2 - 15ha (small), M: 15- 50ha (medium); L: $50-100 \mathrm{ha}$ (large). ${ }^{\mathrm{c}}$ Seepage velocity values: $v_{\mathrm{s}-\mathrm{s}}=0.05 \mathrm{~m} / \mathrm{d}$ (very slow), $v_{\mathrm{s}-\mathrm{s}}=0.1 \mathrm{~m} / \mathrm{d}(\mathrm{slow}), v_{\mathrm{s}-}$ $\mathrm{m}=0.5 \mathrm{~m} / \mathrm{d}$ (medium), $v_{\mathrm{s}-\mathrm{f}}=1 \mathrm{~m} / \mathrm{d}$ (fast). ${ }^{\mathrm{d}}$ Subscript $\mathrm{L}$ indicates the design alternative is designed for lower conductivity aquitards with hydraulic conductivity of $1 \times 10^{-8} \mathrm{~m} / \mathrm{s}$. ${ }^{\mathrm{e}} \mathrm{LX}$ indicates that all the bottom liner design alternatives (L1, L2, L3, L4, L5, L6) are appropriate. 
Table 4. 18 Design component selection matrix for humid climates ${ }^{\text {a, d, e }}$

\begin{tabular}{|c|c|c|c|c|c|c|c|c|c|c|}
\hline & \multirow{3}{*}{$\begin{array}{c}\operatorname{Area}^{b} \\
\text { (ha) }\end{array}$} & \multicolumn{4}{|c|}{$T_{w}(5 \mathrm{~m})$} & \multicolumn{4}{|c|}{$T_{w}(20 \mathrm{~m})$} & \\
\hline & & HA & HB & $\mathrm{HC}$ & HD & HE & HF & HG & HH & \\
\hline & & $v_{\mathrm{s}-\mathrm{vs}} \mathrm{c}$ & $v_{s-s}$ & $\mathbf{v}_{\mathrm{s}-\mathrm{m}}$ & $v_{s-f}$ & $\mathbf{v}_{\mathrm{s}-\mathrm{vs}}$ & $v_{s-s}$ & $v_{s-m}$ & $v_{\text {s-f }}$ & \\
\hline 1 & & C1L2 & C1L2 & C1L2 & C1L2 & C1L2 & C1L2 & C1L2 & C1L2 & 1 \\
\hline 2 & & $\mathrm{C} 1 \mathrm{~L} 4^{\mathrm{L}}$ & $\mathrm{C} 1 \mathrm{~L} 4^{\mathrm{L}}$ & C1L4 & C1L4 & $\mathrm{C} 1 \mathrm{~L} 4^{\mathrm{L}}$ & $\mathrm{C} 1 \mathrm{~L} 4^{\mathrm{L}}$ & $\mathrm{C} 1 \mathrm{~L} 4$ & C1L4 & 2 \\
\hline 3 & & C2LX & C2LX & C2LX & C1L5 $5^{\mathrm{L}}$ & C2LX & C2LX & C2LX & C2LX & 3 \\
\hline 4 & $1<$ & C3L2 & C3L2 & C3L2 & C2LX & C3L2 & C3L2 & C3L2 & C3L2 & 4 \\
\hline 5 & $A \leq 2$ & $\mathrm{C} 3 \mathrm{~L} 4^{\mathrm{L}}$ & $\mathrm{C} 3 \mathrm{~L} 4^{\mathrm{L}}$ & C3L4 & C3L2 & $\mathrm{C} 3 \mathrm{~L} 4^{\mathrm{L}}$ & $\mathrm{C} 3 \mathrm{~L} 4^{\mathrm{L}}$ & C3L4 & C3L4 & 5 \\
\hline $\begin{array}{l}6 \\
7\end{array}$ & & & & & $\begin{array}{l}\text { C3L4 } \\
\text { C3L5 }^{\mathrm{L}}\end{array}$ & & & & & $\begin{array}{l}6 \\
7\end{array}$ \\
\hline 8 & & C1L2 & C1L2 & C1L2 & C1L2 & C1L2 & C1L2 & C1L2 & C1L2 & 8 \\
\hline 9 & & $\mathrm{C} 1 \mathrm{~L}^{\mathrm{L}}$ & $\mathrm{C} 1 \mathrm{~L} 4^{\mathrm{L}}$ & $\mathrm{C} 1 \mathrm{~L} 4^{\mathrm{L}}$ & C1L4 & $\mathrm{C} 1 \mathrm{~L} 4^{\mathrm{L}}$ & $\mathrm{C} 1 \mathrm{~L} 4^{\mathrm{L}}$ & $\mathrm{C} 1 \mathrm{~L} 4^{\mathrm{L}}$ & $\mathrm{C} 1 \mathrm{~L}^{\mathrm{L}}$ & 9 \\
\hline 10 & $S$ & $\mathrm{C} 3 \mathrm{~L} 2$ & C2LX & C2LX & C2LX & C3L2 & C3L2 & C2LX & C2LX & 10 \\
\hline 11 & & $\mathrm{C} 3 \mathrm{~L} 4^{\mathrm{L}}$ & C3L2 & C3L2 & C3L2 & $\mathrm{C} 3 \mathrm{~L} 4^{\mathrm{L}}$ & $\mathrm{C} 3 \mathrm{~L} 4^{\mathrm{L}}$ & C3L2 & C3L2 & 11 \\
\hline 12 & & & $\mathrm{C} 3 \mathrm{~L} 4^{\mathrm{L}}$ & $\mathrm{C} 3 \mathrm{~L}_{4}^{\mathrm{L}}$ & C3L4 & & & $\mathrm{C} 3 \mathrm{~L} 4^{\mathrm{L}}$ & $\mathrm{C} 3 \mathrm{~L}_{4}^{\mathrm{L}}$ & 12 \\
\hline 13 & & C1L2 & C1L2 & C1L2 & C1L2 & C1L4 ${ }^{\mathrm{L}}$ & C1L2 & C1L2 & C1L2 & 13 \\
\hline 14 & & $\mathrm{C} 1 \mathrm{~L}^{\mathrm{L}}$ & $\mathrm{C} 1 \mathrm{~L} 4^{\mathrm{L}}$ & $\mathrm{C} 1 \mathrm{~L} 4^{\mathrm{L}}$ & $\mathrm{C} 1 \mathrm{~L}^{\mathrm{L}}$ & $\mathrm{C} 3 \mathrm{~L} 4^{\mathrm{L}}$ & $\mathrm{C} 1 \mathrm{~L} 4^{\mathrm{L}}$ & $\mathrm{C} 1 \mathrm{~L} 4^{\mathrm{L}}$ & $\mathrm{C} 1 \mathrm{~L} 4^{\mathrm{L}}$ & 14 \\
\hline 15 & M & C3L2 & C3L2 & C2LX & C2LX & & C3L2 & C2LX & C2LX & 15 \\
\hline 16 & & $\mathrm{C} 3 \mathrm{~L} 4^{\mathrm{L}}$ & $\mathrm{C} 3 \mathrm{~L} 4^{\mathrm{L}}$ & C3L2 & C3L2 & & $\mathrm{C} 3 \mathrm{~L} 4^{\mathrm{L}}$ & C3L2 & $\mathrm{C} 3 \mathrm{~L} 2$ & 16 \\
\hline 17 & & & & $\mathrm{C} 3 \mathrm{~L} 4^{\mathrm{L}}$ & $\mathrm{C} 3 \mathrm{~L} 4^{\mathrm{L}}$ & & & $\mathrm{C} 3 \mathrm{~L} 4^{\mathrm{L}}$ & $\mathrm{C} 3 \mathrm{~L}_{4}^{\mathrm{L}}$ & 17 \\
\hline 18 & & C1L2 & C1L2 & C1L2 & C1L2 & $\mathrm{C}^{2} 4^{\mathrm{L}}$ & $\mathrm{C}^{2} 4^{\mathrm{L}}$ & C1L2 & C1L2 & 18 \\
\hline 19 & & $\mathrm{C} 1 \mathrm{~L}^{\mathrm{L}}$ & $\mathrm{C} 1 \mathrm{~L} 4^{\mathrm{L}}$ & $\mathrm{C} 1 \mathrm{~L} 4^{\mathrm{L}}$ & $\mathrm{C} 1 \mathrm{~L} 4^{\mathrm{L}}$ & $\mathrm{C} 3 \mathrm{~L} 4^{\mathrm{L}}$ & $\mathrm{C} 3 \mathrm{~L} 4^{\mathrm{L}}$ & $\mathrm{C} 1 \mathrm{~L} 4^{\mathrm{L}}$ & $\mathrm{C} 1 \mathrm{~L} 4^{\mathrm{L}}$ & 19 \\
\hline 20 & $L$ & $\mathrm{C} 3 \mathrm{~L} 4^{\mathrm{L}}$ & $\mathrm{C} 3 \mathrm{~L} 4^{\mathrm{L}}$ & C2LX & C2LX & & & C2LX & C2LX & 20 \\
\hline 21 & & & & C3L2 & $\mathrm{C} 3 \mathrm{~L} 2$ & & & C3L2 & C3L2 & 21 \\
\hline 22 & & & & $\mathrm{C} 3 \mathrm{~L}^{\mathrm{L}}$ & $\mathrm{C} 3 \mathrm{~L}^{\mathrm{L}}$ & & & $\mathrm{C} 3 \mathrm{~L} 4^{\mathrm{L}}$ & $\mathrm{C} 3 \mathrm{~L}^{\mathrm{L}}$ & 22 \\
\hline $\begin{array}{l}\mathrm{R} / \\
\mathrm{C}\end{array}$ & & HA & HB & HC & HD & HE & HF & HG & HH & $\begin{array}{l}\mathrm{R} / \\
\mathrm{C}\end{array}$ \\
\hline
\end{tabular}

${ }^{a} \mathrm{~L} 1, \mathrm{~L} 3$ are designed for low conductivity aquitards (unsaturated hydraulic conductivity, $\mathrm{K}_{\mathrm{ave}}=10^{-}$ $\left.{ }^{7}-10^{-8} \mathrm{~m} / \mathrm{s}\right)$; L2 is designed for higher conductivity vadose zones $\left(\mathrm{K}_{\mathrm{ave}}=10^{-7} \mathrm{~m} / \mathrm{s}\right)$ and L4, L5, L6 are designed for higher conductivity $\left(\mathrm{K}_{\mathrm{ave}}=10^{-7} \mathrm{~m} / \mathrm{s}\right)$ or lower conductivity vadose zones $\left(\mathrm{K}_{\mathrm{ave}}=\right.$ $10^{-8} \mathrm{~m} / \mathrm{s}$ ). ${ }^{\mathrm{b}}$ Landfill area $\rightarrow$ C: 0- 2 ha (communal), S: 2 - 15ha (small), M: 15- 50ha (medium); L: 50 - 100ha (large). ${ }^{c}$ Seepage velocity values: $v_{\mathrm{s}-\mathrm{ss}}=0.05 \mathrm{~m} / \mathrm{d}$ (very slow), $v_{\mathrm{s}-\mathrm{s}}=0.1 \mathrm{~m} / \mathrm{d}$ (slow), $v_{\mathrm{s}-}$ $\mathrm{m}=0.5 \mathrm{~m} / \mathrm{d}$ (medium), $v_{\mathrm{s}-\mathrm{f}}=1 \mathrm{~m} / \mathrm{d}$ (fast). ${ }^{\mathrm{d}}$ Subscript L indicates the design alternative is designed for lower conductivity aquitards with hydraulic conductivity of $1 \times 10^{-8} \mathrm{~m} / \mathrm{s}$. ${ }^{\mathrm{e}} \mathrm{LX}$ indicates that all the bottom liner design alternatives (L1, L2, L3, L4, L5, L6) are appropriate.

\subsection{Landfill Design Case Studies using LFDSS}

To demonstrate the use and capabilities of the developed decision support system, a real (Siirt) and a generic (hypothetical) landfill case were designed using LFDSS software. 


\subsubsection{Siirt Municipal Solid Waste Landfill Design}

Siirt Municipal Solid Waste Landfill project was adjudicated by Directorate of Regional Development Administration of Southeastern Anatolia Project to DOLSAR Engineering Company. All the information used for the case study presented herein is gathered from the project reports prepared by DOLSAR Engineering Company.

\subsubsection{General Site Information}

Siirt is located between $37^{\circ} 55^{\prime}$ northern latitude and $41^{\circ} 57^{\prime}$ eastern longitude. It is surrounded by the provinces of Şırnak, Van, Batman, Bitlis and Mardin (Figure 4.9). The population of Siirt according to 2000 census is 98281 .

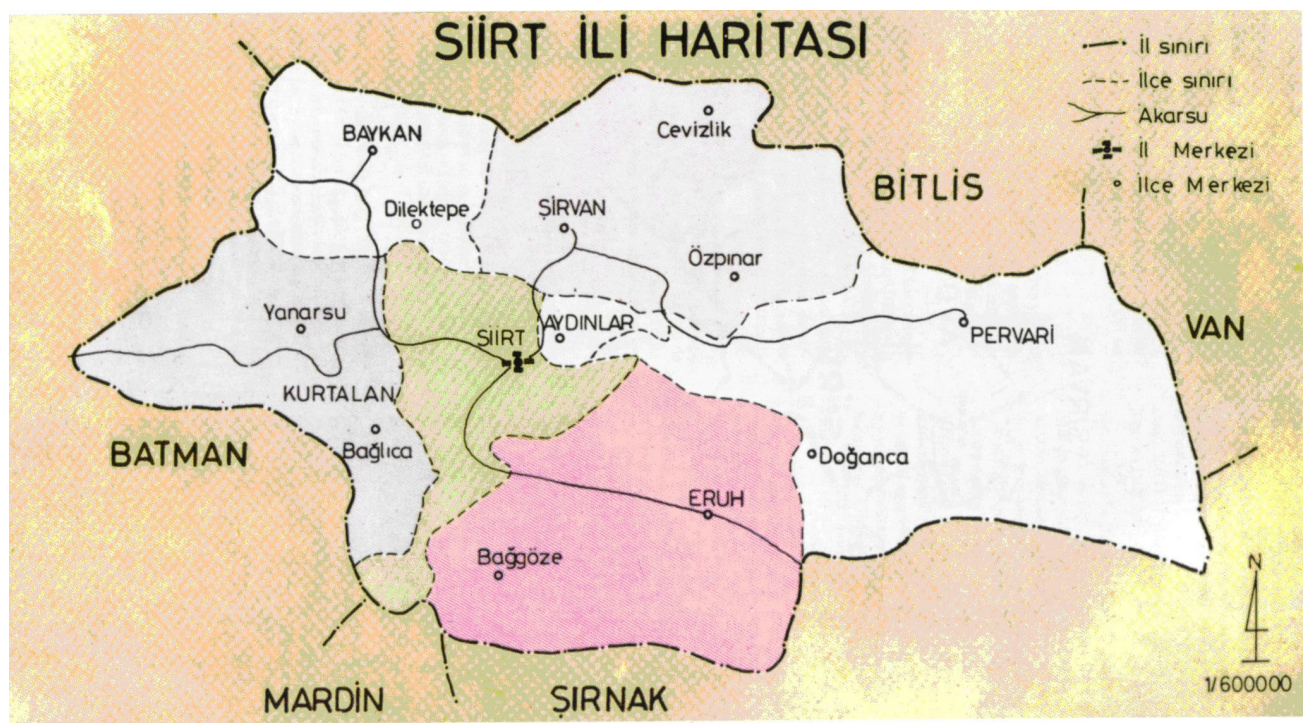

Figure 4. 9 City map for Siirt

Terrestrial climate conditions prevail for the city. Severe winter conditions with snow and arid summer conditions are observed. High evaporation occurs during 
summer periods. Climatic data of the city are simulated using Visual HELP 2.2.03 and average precipitation data for 20 years are obtained as $395 \mathrm{~mm} / \mathrm{y}$.

Investigated site is located in the $1^{\text {st }}$ degree seismic zone, and the average seismic coefficient is given as 0.4 . Elevation of Siirt at the city center is $930 \mathrm{~m}$, and it is surrounded by high mountains. Hydrogeologic data are collected using bore holes drilled by the State Hydraulic Works (DSI). According to the bore logs, the investigation site is composed of impermeable chalk-limestones, having a few fractures. The groundwater table is located far below the ground surface. Information obtained from the bore hole logs are presented in Table 4.19. Location of the bore holes are shown by red circles in topographic map of the site presented in Figure 4.10.

Table 4. 19 Bore hole data for the investigation site

\begin{tabular}{ccc}
\hline WELL NO. & $\begin{array}{c}\text { Thickness of Formation } \\
(\mathbf{m})\end{array}$ & Type of Formation \\
\hline $\mathbf{1}$ & 0.5 & Vegetative soil \\
& 11.0 & Gravel-silty clay \\
$\mathbf{2}$ & 8.5 & Clayey limestone \\
& 0.5 & Vegetative soil \\
& 11.3 & Gravel-silty clay \\
$\mathbf{3}$ & 8.2 & Clayey limestone \\
& 0.5 & Vegetative soil \\
& 11.7 & Gravel-silty clay \\
$\mathbf{4}$ & 7.8 & Clayey limestone \\
& 0.5 & Vegetative soil \\
& 5.5 & Gravel-silty clay \\
$\mathbf{5}$ & 14.0 & Clayey limestone \\
& 0.5 & Vegetative soil \\
& 6.0 & Gravel-silty clay \\
& 13.5 & Clayey limestone \\
\hline
\end{tabular}




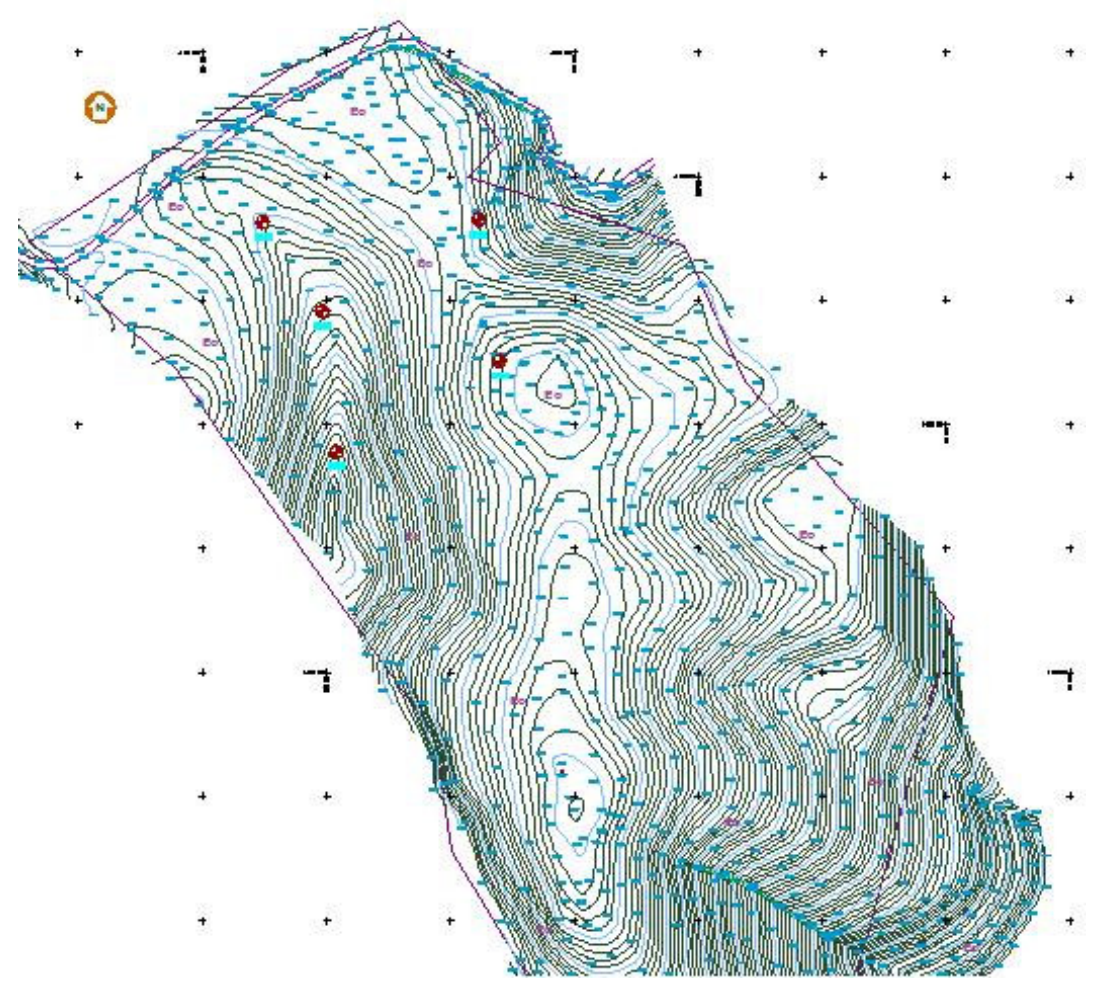

Figure 4. 10 Topographic map of Siirt landfill site and location of the bore wells in the investigation area

The city produces $86720 \mathrm{~kg} /$ day of waste, corresponding to a waste production rate of $0.77 \mathrm{~kg} / \mathrm{cap} / \mathrm{day}$ (according to the projected year 2005 population of 113403). The location of the proposed solid waste disposal facility is given in Figure 4.11. The proposed site is located at the east of the city, $4 \mathrm{~km}$ away from the city centre. The nearest residential area is $1.5 \mathrm{~km}$ away from the site. 


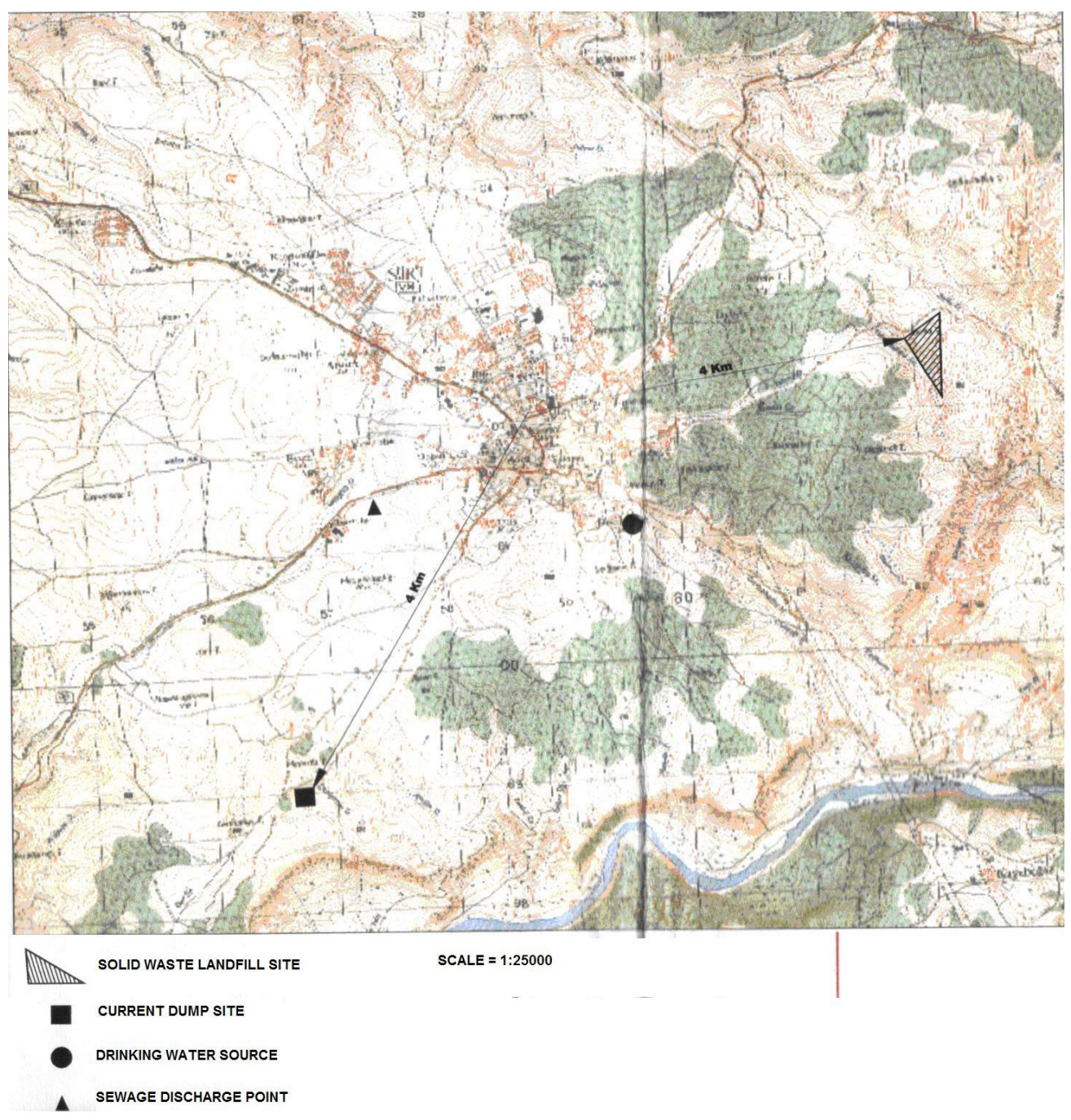

Figure 4. 11 Infrastructure Plan for City of Siirt

The proposed municipal solid waste landfill is planned to be constructed in two stages. The first stage is planned to serve between 2009 and 2020, and the second stage between 2021 and 2035. The waste production rates for first and second stages are projected to be $0.83 \mathrm{~kg} / \mathrm{cap} /$ day and $0.95 \mathrm{~kg} / \mathrm{cap} / \mathrm{day}$, respectively. The projected population for years 2009, 2020, and 2035 are 127372, 175311, and 271015 , respectively. The volumes of the first and second stage landfills are given as $685014 \mathrm{~m}^{3}$, and $1453735 \mathrm{~m}^{3}$, respectively (accepting a density of well compacted waste at landfill); leading to a total landfill volume of $2138749 \mathrm{~m}^{3}$. 
According to the solid waste composition analysis $23 \%$ of the waste is recyclable, $58.5 \%$ is organic, and $19 \%$ is other type of wastes.

For the case presented here, the first stage involving years 2009-2020 was modeled using LFDSS.

\subsubsection{Volume Calculations in LFDSS}

The volume calculation module (VCM) in LFDSS can be a useful tool for the situations where waste amount and volume data are not available to the user by the feasibility reports. For the case studied here, the waste production and landfill volume calculations were available; however, the module was still used in order to check the accuracy of the results. The input data used for the VCM are given in Table 4.20. The module calculated a waste volume of $661500 \mathrm{~m}^{3}$, which is in $10 \%$ range of the volume $\left(685014 \mathrm{~m}^{3}\right)$ given in the feasibility report.

Table 4. 20 Input parameters for volume calculation module

\begin{tabular}{lc}
\hline Design population & $127372(2009)$ \\
Operational lifetime of landfill (y) & $12(2009-2020)$ \\
Waste production rate $(\mathrm{kg} / \mathrm{cap} /$ day $)$ & 0.83 \\
Waste density $\left(\mathrm{kg} / \mathrm{m}^{3}\right)$ & $700^{\mathrm{a}}$ \\
\hline${ }^{\mathrm{a}}$ Accepted for the waste well compacted in the landfill.
\end{tabular}




\subsubsection{Base Grade Design of the Landfill at the Proposed Site}

Base grade design of the landfill at the selected site is a complex process involving the consideration of many factors such as site topography, available in situ clay thickness, groundwater flow direction and depth to water table, etc. Using the site specific hydrogeologic and geotechnical data as input, Virtual Landfill Model (VLF) embedded in LFDSS is capable of demonstrating the distribution of the available in situ clay layers and their thicknesses, groundwater depth and flow direction, and topographic features of site. VLF is capable of calculating base and surface area of landfill, excavation and fill volumes, surface volume after the final cover is placed, and available clay volume beneath the landfill after excavation, by superimposing the original and desired final topographic surfaces. Therefore, VLF was used in this case study to effectively locate and accomplish the base grade design of the first stage of Siirt Municipal Solid Waste Landfill.

VLF requires base, clay and groundwater DEMs (digital elevation model) to perform calculations. Therefore, first, elevation data of the site, obtained from the digital maps presented in the feasibility reports were converted to ASCII DEM files to obtain Base-DEM. As the digital maps were drawn using AutoCAD software, they were re-evaluated using ArcGIS software, and elevation data were created accepting a grid size of $5.3 \mathrm{~m}$. As a second step, in situ clay thicknesses obtained from bore holes of geotechnical investigation were examined to create in situ Clay layer-DEM. As no groundwater was reported, Groundwater-DEM was not created. DEM files are presented in Appendix-F.

Once the Base-DEM and Clay-DEM were imported to the VLF model, the topographic features of the site and clay layers were visible (Figure 4.12). The distribution of in situ clay layers was indicated with pink color, where darker pink shades indicate clay layer thickness around $10 \mathrm{~m}$, and lighter shades indicate clay 
layer thickness around $5 \mathrm{~m}$. Observing the clayey zones, the most suitable location to design the landfill base grade was decided to be approximately within the area shown by the yellow circle in Figure 4.12.

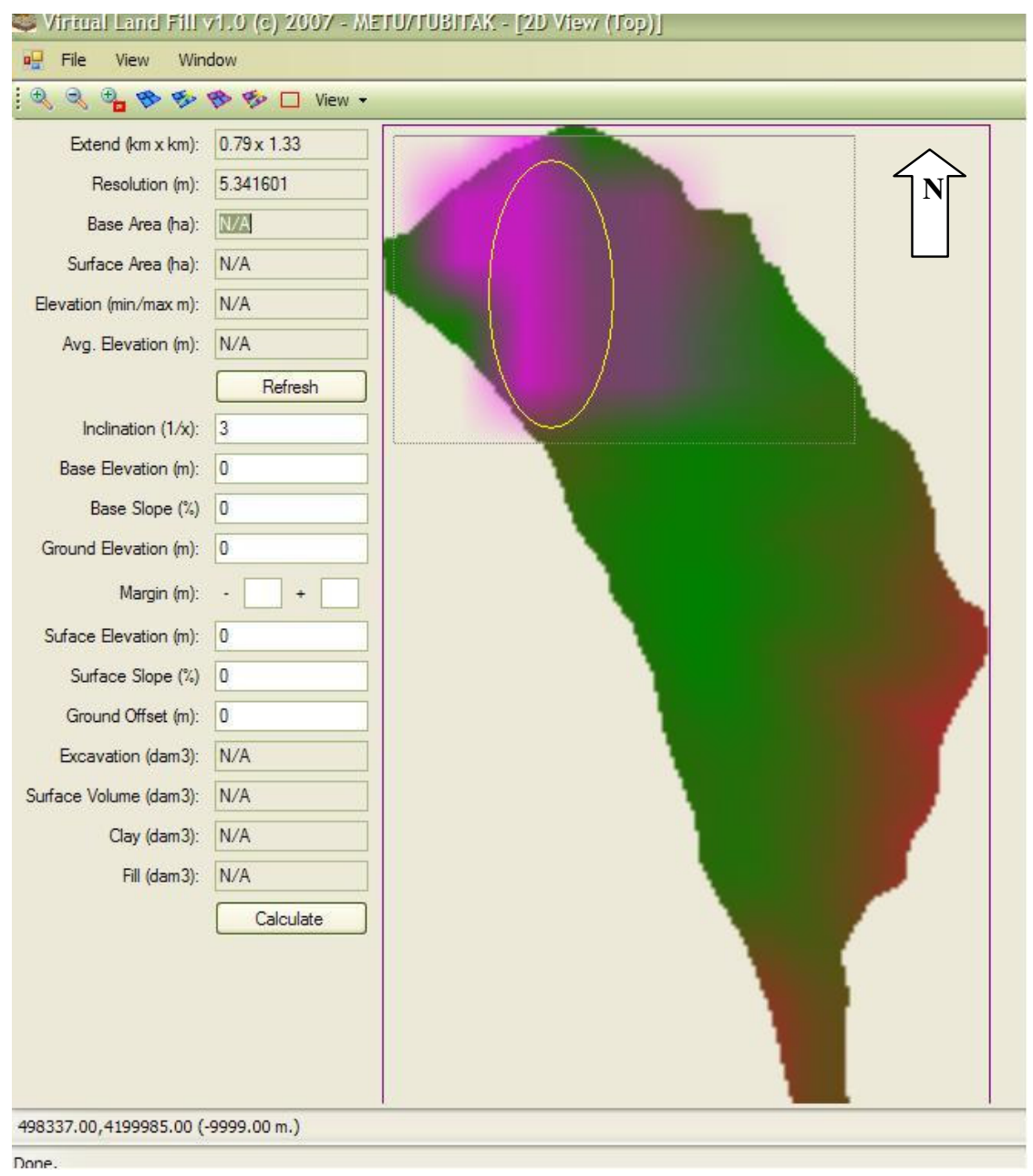

Figure 4. 12 Presentation of topography and clay layers for Siirt landfill in VLF.

Before drawing the landfill base on the natural topography, performing some simple hand calculations were required. For the case examined here, an average waste thickness of $20 \mathrm{~m}$ was accepted for the landfill volume of $685014 \mathrm{~m}^{3}$. Therefore, the base area of the landfill was calculated as: 


$$
A=\frac{V}{t_{w}} \frac{685014 m^{3}}{20 m}=34250.7 m^{2} \cong 3.4 h a
$$

The base length and width of the landfill was selected as $340 \mathrm{~m}$, and $100 \mathrm{~m}$, respectively. The length of the landfill was located from north to south for the best use of the available in situ clay layer thickness. The landfill was drawn on the existing natural topography, and original ground elevations of the corners of landfill were obtained from VLF. Once the base length was determined, the excavation depth, side slopes, and ground elevation could be calculated based on the longer side of the landfill. To preserve some of the clay available on site for the base of the landfill, excavation depth was limited to $5 \mathrm{~m}$. Taking $1 \mathrm{v}: 3 \mathrm{~h}$ side slopes, and $1 \%$ base slope, the base elevation was calculated as $954.4 \mathrm{~m}$, and ground elevation was calculated as $960 \mathrm{~m}$. An above-ground waste thickness of 15 $\mathrm{m}$ was considered to reach a total waste thickness of $20 \mathrm{~m}$. Therefore the surface elevation was calculated as $975 \mathrm{~m}$. The maximum slope of the final cover was selected as 5\%. The base slope and cover slope directions were indicated with red and yellow arrows, respectively (Figure 4.13). Entering the calculated inclination, base slope, base and ground elevation, surface elevation, surface slope, and ground offset value (i.e. an approximate thickness of final cover), the VLF model calculated the excavation $\left(408860 \mathrm{~m}^{3}\right)$, fill $\left(7570 \mathrm{~m}^{3}\right)$, and surface volumes $\left(255510 \mathrm{~m}^{3}\right)$, as well as the available clay volume $\left(115610 \mathrm{~m}^{3}\right)$ beneath the landfill area (Figure 4.13). The total volume of landfill can then be calculated as $656800 \mathrm{~m}^{3}$, which is acceptable as it lies within the $10 \%$ range of the volume calculated $\left(685014 \mathrm{~m}^{3}\right)$ in the feasibility report (Eq. 4.2):

$$
\begin{aligned}
& V_{\text {total }}=V_{\text {excavation }}-V_{\text {fill }}+V_{\text {surface }}=408.86 \mathrm{dam}^{3}-7.57 \mathrm{dam}^{3}+255.51 \mathrm{dam}^{3} \\
& V_{\text {total }}=656.80 \mathrm{dam}^{3}=656800 \mathrm{~m}^{3}
\end{aligned}
$$

After the excavation, VLF calculated that $115.61 \mathrm{dam}^{3}\left(115610 \mathrm{~m}^{3}\right)$ clay was still available at the base of the landfill. 


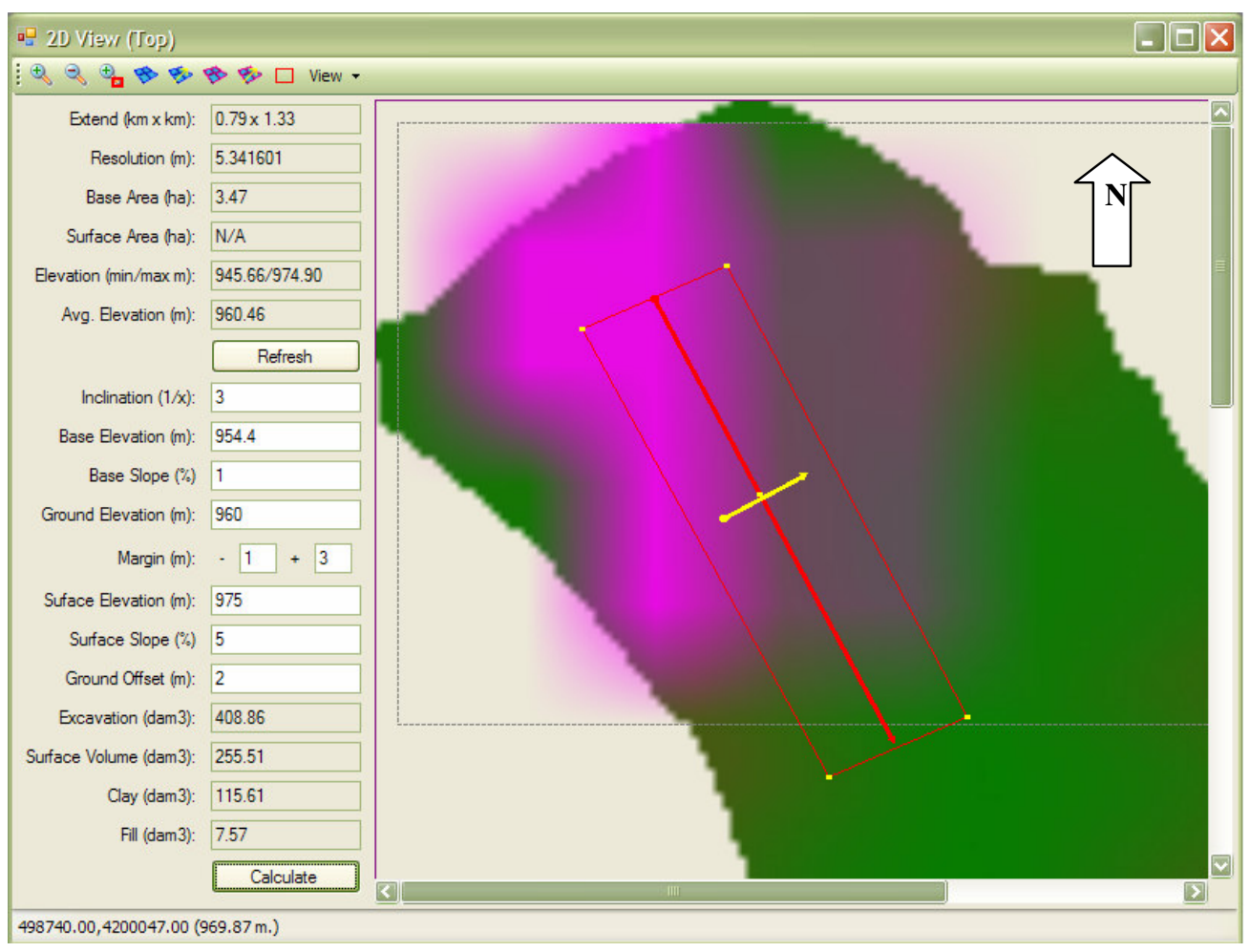

Figure 4. 13 Input data for VLF model and volume calculations

Once the "calculate" button was hit, VLF demonstrated the excavated and filled areas (Figure 4.14), the surface cover (Figure 4.15), and the available clay layers (Figure 4.16) in the 2D window. The landfill with or without final cover was presented by 3D window (Figure 4.17). As can be seen from Figure 4.17, the base grade design of the landfill is also visually found suitable considering the original site topography. 


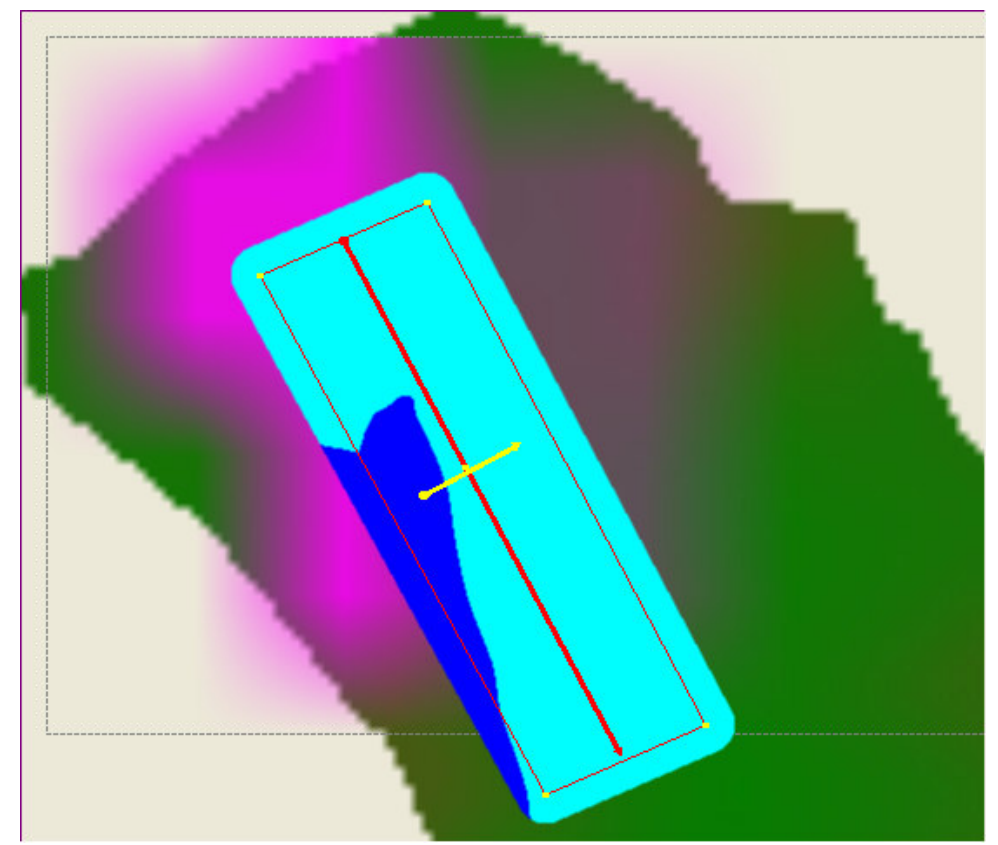

Figure 4. 14 Landfill excavation and fill areas by VLF -excavation areas are shown with light blue, and fill areas are shown with dark blue.

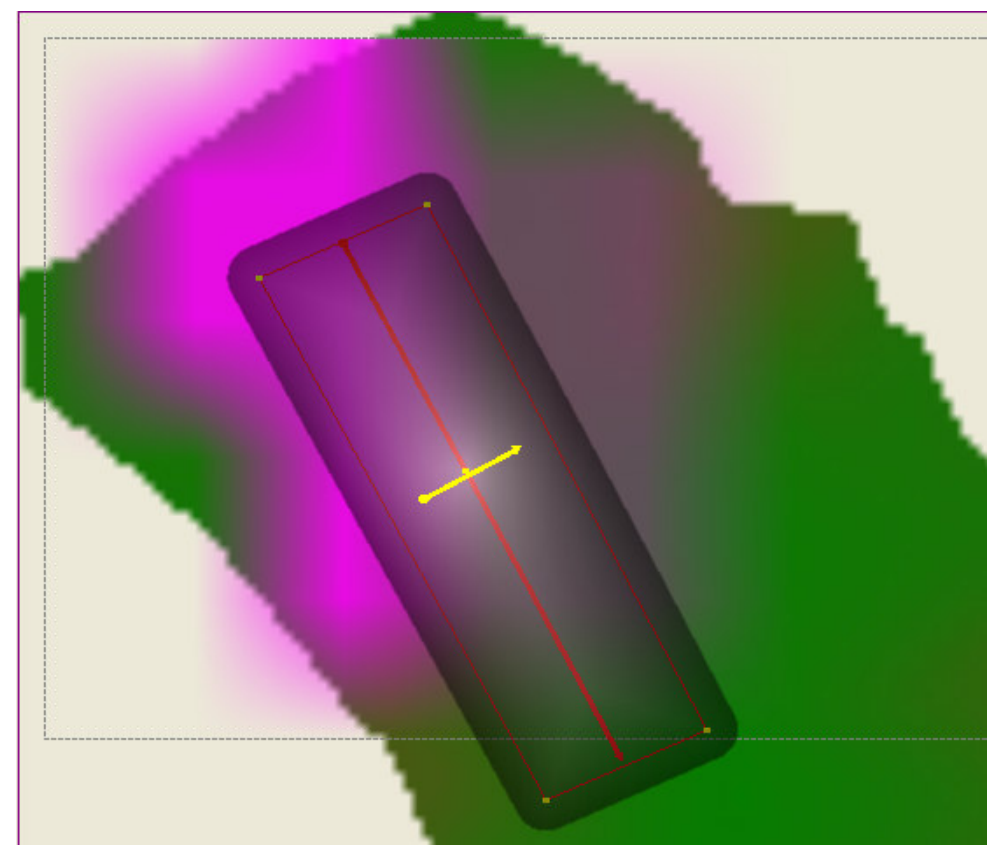

Figure 4. 15 Surface fill by VLF -lighter shades indicate higher elevations on the final cover. 


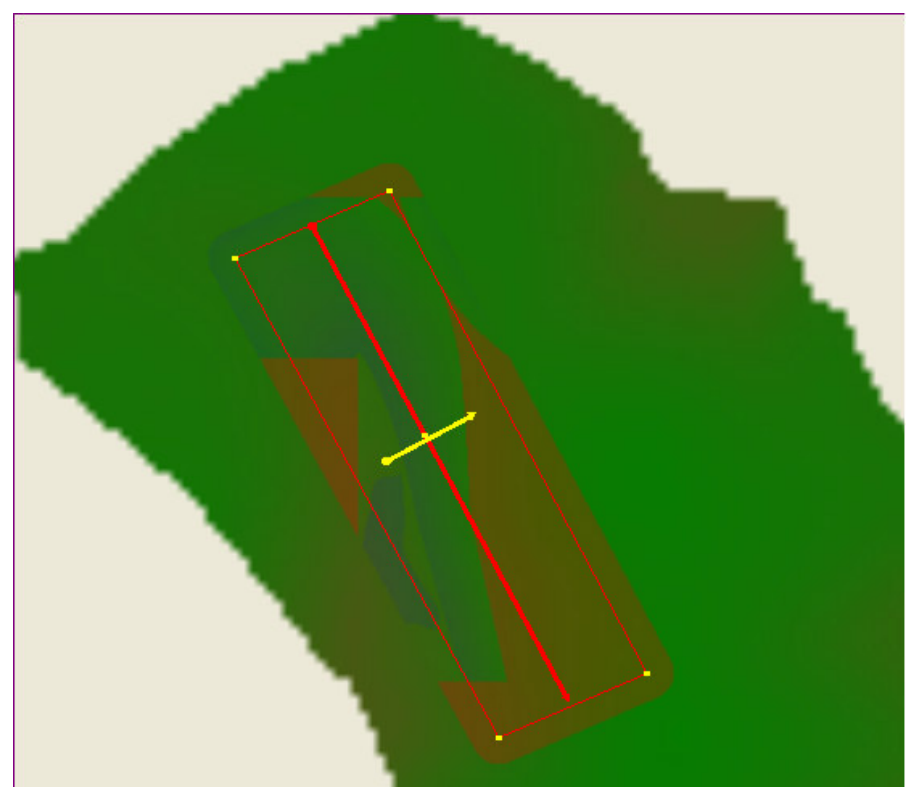

Figure 4. 16 Demonstration of availability of clay layers at the base of the landfill by VLF -green color (within the landfill borders) indicates the presence of the clay layer, whereas red color indicates the absence of clay layer after excavation.

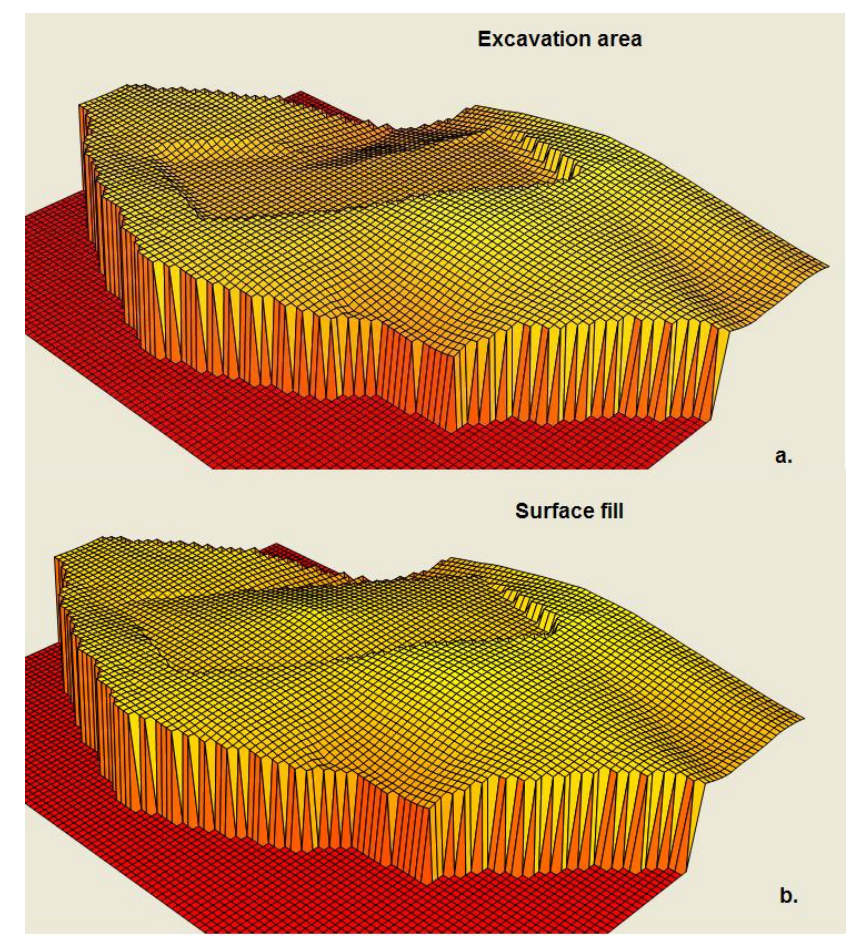

Figure 4. 17 3D demonstration of landfill (a) without and (b) with final cover by VLF 


\subsubsection{Preliminary Design}

After the landfill base contour design was accomplished in the natural topography and volume calculations were performed by VLF, preliminary design phase in LFDSS can be implemented. The aim of the preliminary design phase is to propose alternatives for landfill design components and their design details considering general design variables (i.e. climate -total annual precipitation amount, waste load -landfill area, waste thickness, and site hydrogeology groundwater seepage velocity, hydraulic conductivity, porosity and thickness of vadose zone). The waste thickness was taken as $20 \mathrm{~m}$, size (the base area of the landfill) was calculated as 3.4 ha, and annual precipitation was given by Visual HELP 2.2.0.3 weather simulator for Siirt as $395 \mathrm{~mm} / \mathrm{y}$. As the site hydrogeology reveals the absence of significant groundwater resources, there would not be any groundwater contamination concern at the site. As the site lies in the arid climate range, has a small landfill base area, and groundwater contamination is of no concern, the flexibility and choices of the landfill design increases. This fact was also reflected in the results of the preliminary design module. Entering the design parameters, the preliminary design module proposed that all 18 landfill design alternatives (i.e. C1L1, C1L2, C1L3, C1L4, C1L5, C1L6, C2L1, C2L2, C2L3, C2L4, C2L5, C2L6, C3L1, C3L2, C3L4, C3L5, and C3L6) are appropriate for the given conditions; however, also states that most of these can lead to over designs for arid climates. As the results in Section 4.3.3 and Section 4.3.4.1 demonstrate, leachate collection systems in the bottom liners are not effective under arid climates. Therefore, LFDSS proposes that final cover designs with some level of intensive engineering coupled with simple bottom liner designs (i.e. C1L1, C1L6, C2L1, C2L6, C3L1, C3L6) is satisfactory under given site conditions. The components of the final covers and bottom liners of design alternatives are listed in Table 4.21. 
Table 4. 21 Components of final covers and bottom liners of design alternatives proposed by preliminary design module in LFDSS

\begin{tabular}{cc}
\hline Final Cover & Design Components \\
\hline C1 & Natural soil \\
C2 & Natural soil $+\mathrm{CDS}^{\mathrm{a}}+$ geomembrane + clay liner \\
C3 & Natural soil + CDS + clay liner \\
\hline Bottom Liner & Design Components \\
\hline L1 & Only aquitard below waste \\
L6 & CCL $^{\mathrm{b}}+$ aquitard/unsaturated zone \\
\hline${ }^{\mathrm{a}}$ cover drainage system & ${ }^{\mathrm{b}}$ compacted clay liner
\end{tabular}

As there is no groundwater, the contamination performance criterion for the designs is not applicable. Therefore, compliance of the proposed alternatives with the stability performance criterion (i.e. the leachate head over bottom liner should be less than $1 \mathrm{~m}$, and factor of safety values) should be taken into account in the site specific final design phase.

\subsubsection{Infiltration Rate Calculations and Final Cover Performance Evaluation}

To calculate the infiltration rate that the waste in landfill receives, HELP model in LFDSS was used. All of the proposed final covers (evapotranspiration final cover $-\mathrm{C} 1$, extensive engineering final cover $-\mathrm{C} 2$, and intermediate design final cover C3) were simulated using HELP model. Before the simulation, HELP requires site specific weather data to be loaded. Therefore, files for evapotranspiration, precipitation, temperature, and solar radiation were obtained from the weather simulator of Visual HELP 2.2.0.3 in the format of ASC files, and imported to the HELP model in LFDSS. After the weather conditions were specified, soil and design data for $\mathrm{C} 1, \mathrm{C} 2$ and $\mathrm{C} 3$ were entered in the Soil\&Design tab under the HELP model in LFDSS. Evapotranspiration final cover - $\mathrm{C} 1$ is composed of only natural topsoil above waste. Extensive engineering final cover $-\mathrm{C} 2$ is composed 
of topsoil, cover drainage system, geomembrane, and clay liner. Intermediate design final cover $-\mathrm{C} 3$ is composed of topsoil, cover drainage system, clay liner. The design specifications of the layers were listed in Table 4.22.

Table 4. 22 Layer specifications used in cover designs in HELP model (soil values are obtained from HELP database)

\begin{tabular}{|c|c|c|c|c|}
\hline $\begin{array}{c}\text { Design } \\
\text { Parameters }\end{array}$ & Topsoil & $\mathrm{CDS}^{\mathrm{a}}$ & Clay Liner & Geomembrane \\
\hline Thickness (m) & 0.6 & 0.3 & 0.6 & 0.001 \\
\hline Soil texture & $\begin{array}{c}\text { Fine sandy } \\
\text { loam }\end{array}$ & Coarse sand & Silty clay & $\mathrm{LDPE}^{\mathrm{b}}$ \\
\hline Total porosity & 0.473 & 0.417 & 0.479 & - \\
\hline Field capacity & 0.222 & 0.045 & 0.371 & - \\
\hline Wilting point & 0.104 & 0.018 & 0.251 & - \\
\hline $\mathrm{K}_{\mathrm{sat}}^{\mathrm{c}}(\mathrm{cm} / \mathrm{s})$ & 0.00052 & 0.01 & 0.00001 & $4 \times 10^{-13}$ \\
\hline $\begin{array}{l}\text { Drainage } \\
\text { length (m) }\end{array}$ & - & 30 & - & - \\
\hline Drain slope (\%) & - & 2 & - & - \\
\hline $\begin{array}{l}\mathrm{GM}^{\mathrm{b}} \text { pinhole } \\
\text { density (\#/ha) }\end{array}$ & - & - & - & 2 \\
\hline $\begin{array}{l}\text { GM } \\
\text { installation } \\
\text { defects (\#/ha) }\end{array}$ & - & - & - & 4 \\
\hline $\begin{array}{l}\text { GM placement } \\
\text { quality }\end{array}$ & - & - & - & Poor \\
\hline
\end{tabular}

The module was run from the Run tab under HELP model in LFDSS for 12 years (operational lifetime of first stage for years 2009 - 2020) for each of the cover design options. The infiltration rates were calculated by HELP model as 0.1580 $\mathrm{m} / \mathrm{y}$ for evapotranspiration cover $(\mathrm{C} 1), 0.0105 \mathrm{~m} / \mathrm{y}$ for extensive engineering final 
cover (C2), and as $0.1510 \mathrm{~m} / \mathrm{y}$ for intermediate design final cover -C3. Lower infiltration rate from extensive engineering final cover (C2) option occurred due to the presence of geomembrane (LDPE -low density polyethylene). The infiltration rates were automatically transferred to POLLUTE model by LFDSS, and the simulations were continued with stability performance criterion calculations.

\subsubsection{Landfill Stability Evaluation and Soil Contaminant Concentrations}

As there is no groundwater beneath the landfill, POLLUTE model was run to calculate leachate head over landfill bottom liner in order to evaluate whether the proposed design alternative complies with the stability criterion (i.e. leachate head over bottom liner should be less than $1 \mathrm{~m}$ ) for site specific conditions. Simulations were performed for the proposed design alternatives (i.e. C1L1, C1L6, C2L1, C2L6, C3L1, and C3L6). The design specifications of the designs are given in Table 4.23. Therefore, the necessity of including a leachate collection system in the bottom liner under the given site conditions would be investigated. 
Table 4. 23 Final cover and bottom liner specifications of the investigated design alternatives

\begin{tabular}{|c|c|c|}
\hline $\begin{array}{c}\text { Design } \\
\text { Alternative }\end{array}$ & Final Cover & Bottom Liner \\
\hline C1L1 & $0.6 \mathrm{~m}$ of natural topsoil & Natural aquitard below waste \\
\hline C1L6 & $0.6 \mathrm{~m}$ of natural topsoil & $0.6 \mathrm{~m} \mathrm{CCL}+$ natural aquitard \\
\hline C2L1 & $\begin{array}{l}0.6 \mathrm{~m} \text { of natural topsoil }+0.3 \\
\mathrm{~m} \mathrm{CDS}^{\mathrm{a}}+\text { geomembrane }+ \\
0.6 \mathrm{~m} \mathrm{CCL}^{\mathrm{b}}\end{array}$ & Natural aquitard below waste \\
\hline C2L6 & $\begin{array}{l}0.6 \mathrm{~m} \text { of natural topsoil }+0.3 \\
\mathrm{~m} \mathrm{CDS}+\text { geomembrane }+ \\
0.6 \mathrm{~m} \mathrm{CCL}^{\mathrm{b}}\end{array}$ & $0.6 \mathrm{~m} \mathrm{CCL}+$ natural aquitard \\
\hline C3L1 & $\begin{array}{l}0.6 \mathrm{~m} \text { of natural topsoil }+0.3 \\
\mathrm{~m} \mathrm{CDS}{ }^{\mathrm{a}}+0.6 \mathrm{~m} \mathrm{CCL}^{\mathrm{b}}\end{array}$ & Natural aquitard below waste \\
\hline C3L6 & $\begin{array}{l}0.6 \mathrm{~m} \text { of natural topsoil }+0.3 \\
\mathrm{~m} \mathrm{CDS}{ }^{\mathrm{a}}+0.6 \mathrm{~m} \mathrm{CCL}^{\mathrm{b}}\end{array}$ & $0.6 \mathrm{~m} \mathrm{CCL}+$ natural aquitard \\
\hline
\end{tabular}

The site is composed of low permeability clayey-silty formations; therefore, a hydraulic conductivity value of $1 \times 10^{-8} \mathrm{~m} / \mathrm{s}$ with a porosity of 0.38 was accepted as vadose zone (aquitard) parameters. The input parameters used for POLLUTE simulations are summarized in Table 4.24. 
Table 4. 24 Input parameters used for POLLUTE simulations

\begin{tabular}{lcc}
\hline \multicolumn{1}{c}{ Section } & Parameter & Value \\
\hline Source & Infiltration $(\mathrm{m} / \mathrm{y})^{\mathrm{a}}$ & 0.1580 for C1 final cover \\
& 0.0105 for C2 final cover \\
& 0.1510 for C3 final cover \\
Lutflow & Thickness (m) & 0.6 \\
Clay Liner & Hydraulic conductivity (m/s) & $1 \times 10^{-9}$ \\
& Porosity & 0.40 \\
Thickness (m) & 10 \\
Vadose & Hydraulic conductivity (m/s) & $1 \times 10^{-8} \mathrm{~m} / \mathrm{s}$ \\
Zone/Aquitard & Porosity & 0.38 \\
\hline $\begin{array}{l}\text { a } \text { automatically calculated and transferred as a result of HELP runs } \\
{ }^{\mathrm{b}} \text { calculated by POLLUTE model, and reported at the end of the simulation to check whether the } \\
\text { design satisfies stability criterion (i.e. leachate head should be below 1 m.) }\end{array}$
\end{tabular}

All of the simulations demonstrated that leachate head did not develop over bottom liner -or within waste. As the leachate is not removed, most of the contaminant mass $(86-95 \%)$ passed to the ground below the landfill.

\subsubsection{Structural Stability Calculations}

Although most of the geotechnical parameters were not given in the feasibility report by DOLSAR Engineering Company, illustrative stability analyses were performed using literature values (Sharma and Lewis, 1994) for the types of the soils, final cover, and bottom liner systems examined in the above sections. The stability analyses were performed using the stability module in LFDSS. It should be noted that, excavation slope and refuse fill stability analyses were carried out for a single trial failure surface. Analyses of a representative number of failure surfaces should be performed in order to decide on the stability of the excavation and the refuse. Types of analyses carried out for each of the simulated design 
alternatives are given in Table 4.25. Parameters used in the structural stability analyses are presented in Table 2.26.

Table 4. 25 Stability analyses for the investigated design alternatives

\begin{tabular}{|c|c|c|}
\hline $\begin{array}{c}\text { Design } \\
\text { Alternative }\end{array}$ & Final Cover & Bottom Liner \\
\hline C1L1 & $\begin{array}{l}\text { Cover system stability for } \\
\text { cohesionless soils with seepage }\end{array}$ & $\begin{array}{l}\text { Excavation slope stability } \\
\text {-circular slip surface } \\
\text { Refuse-fill stability - } \\
\text { circular slip surface }\end{array}$ \\
\hline C1L6 & $\begin{array}{l}\text { Cover system stability for } \\
\text { cohesionless soils with seepage }\end{array}$ & $\begin{array}{l}\text { Excavation slope stability } \\
\text {-circular slip surface } \\
\text { Refuse-fill stability - } \\
\text { circular slip surface }\end{array}$ \\
\hline $\mathrm{C} 2 \mathrm{~L} 1$ & $\begin{array}{l}\text { Cover system stability - with } \\
\text { geomembrane } \\
\text { Stability under seismic forces }\end{array}$ & $\begin{array}{l}\text { Excavation slope stability } \\
\text {-circular slip surface } \\
\text { Refuse-fill stability - } \\
\text { circular slip surface }\end{array}$ \\
\hline C2L6 & $\begin{array}{l}\text { Cover system stability -with } \\
\text { geomembrane } \\
\text { Stability under seismic forces }\end{array}$ & $\begin{array}{l}\text { Excavation slope stability } \\
\text {-circular slip surface } \\
\text { Refuse-fill stability - } \\
\text { circular slip surface }\end{array}$ \\
\hline C3L1 & $\begin{array}{l}\text { Cover system stability for } \\
\text { cohesive soils }\end{array}$ & $\begin{array}{l}\text { Excavation slope stability } \\
\text {-circular slip surface } \\
\text { Refuse-fill stability - } \\
\text { circular slip surface }\end{array}$ \\
\hline C3L6 & $\begin{array}{l}\text { Cover system stability for } \\
\text { cohesive soils }\end{array}$ & $\begin{array}{l}\text { Excavation slope stability } \\
\text {-circular slip surface } \\
\text { Refuse-fill stability - } \\
\text { circular slip surface }\end{array}$ \\
\hline
\end{tabular}


Table 4. 26 Parameters used in stability module for factor of safety calculations

\begin{tabular}{|c|c|c|c|c|c|c|}
\hline \multirow[b]{2}{*}{ Parameter } & \multicolumn{4}{|c|}{ Final Cover } & \multicolumn{2}{|c|}{ Bottom Liner } \\
\hline & Cohesionless & Cohesive & $\begin{array}{l}\text { With } \\
G M^{b}\end{array}$ & $\begin{array}{l}\text { Seismic } \\
\text { forces }\end{array}$ & $\begin{array}{c}\text { Excavation } \\
\text { slope }^{g}\end{array}$ & $\begin{array}{c}\text { Refuse } \\
\text { fill }^{g}\end{array}$ \\
\hline $\begin{array}{l}\text { Cohesion } \\
\left(\mathrm{kN} / \mathrm{m}^{2}\right)\end{array}$ & - & - & 0 & 0 & $61^{\mathrm{e}}$ & 19 \\
\hline Friction angle $\left(^{\circ}\right)$ & - & - & 30 & 30 & $5.5^{\mathrm{e}}$ & 20 \\
\hline $\begin{array}{l}\text { Effective friction } \\
\text { angle }\left(^{\circ}\right)\end{array}$ & 30 & 15 & - & - & - & - \\
\hline Slope angle $\left(^{\circ}\right)$ & $2.87(5 \%)^{\mathrm{f}}$ & $2.87^{\mathrm{f}}$ & - & - & - & - \\
\hline $\begin{array}{l}\gamma_{\text {bouyant-soil }}^{\mathrm{a}} \\
\left(\mathrm{kN} / \mathrm{m}^{3}\right)\end{array}$ & 9.1 & 9.1 & - & - & - & - \\
\hline$\gamma_{\text {total-soil }}\left(\mathrm{kN} / \mathrm{m}^{3}\right)$ & 18.9 & 18.9 & - & - & - & - \\
\hline$\gamma_{\text {cover-soil }}\left(\mathrm{kN} / \mathrm{m}^{3}\right)$ & - & - & 18.5 & 18.5 & - & - \\
\hline $\begin{array}{l}\text { Thickness of } \\
\text { cover soil (m) }\end{array}$ & - & - & $1.5^{\mathrm{f}}$ & $1.5^{\mathrm{f}}$ & - & - \\
\hline $\begin{array}{l}\text { Slope length } \\
\text { along GM (m) }\end{array}$ & - & - & $202^{\mathrm{f}}$ & $202^{\mathrm{f}}$ & - & - \\
\hline $\begin{array}{l}\text { Slope angle } \\
\text { beneath GM }\left(^{\circ}\right)\end{array}$ & - & - & $2.87^{\mathrm{f}}$ & $2.87^{\mathrm{f}}$ & - & - \\
\hline$\varphi_{\text {cover soil-GM }}^{\mathrm{c}}\left({ }^{\circ}\right)$ & - & - & 22 & 22 & - & - \\
\hline $\begin{array}{l}\text { Average seismic } \\
\text { coefficient }\end{array}$ & - & - & - & $0.40^{\mathrm{e}}$ & - & - \\
\hline $\begin{array}{l}\text { Effective } \\
\text { cohesion } \\
\left(\mathrm{kN} / \mathrm{m}^{2}\right)\end{array}$ & - & 4.8 & - & - & - & - \\
\hline $\mathrm{H}^{\mathrm{d}}(\mathrm{m})$ & - & $15^{\mathrm{f}}$ & - & - & - & - \\
\hline $\begin{array}{l}\text { Clay liner } \\
\text { thickness (m) }\end{array}$ & - & $0.6^{\mathrm{f}}$ & - & - & - & - \\
\hline$\gamma_{\text {water }}\left(\mathrm{kN} / \mathrm{m}^{3}\right)$ & 9.8 & 9.8 & - & - & - & - \\
\hline
\end{tabular}


Stability analyses for the designs without geomembrane liners in the final cover (C1L1, C1L6, C3L1, and C3L6) produced stable factor of safety values, which were greater than 1.5 (Sharma and Lewis, 1994; Koerner and Daniel, 1997). Although the designs having geomembrane liners in the final cover $(\mathrm{C} 2 \mathrm{~L} 1$, and C2L6) produced a stable factor of safety value with respect to cover stability concerns involving geomembranes, factor of safety value for seismic analysis (FS $=0.94$ ) was less than the acceptable value of 1.00 (Koerner and Daniel, 1997). Therefore, further analysis (e.g. permanent deformation analysis, Koerner and Daniel, 1997) is required for these design alternatives. Designs having clay liners in the final cover ( $\mathrm{C} 3 \mathrm{~L} 1$, and $\mathrm{C} 3 \mathrm{~L} 6)$ happened to be more stable than the other final cover designs due to high factor of safety values (Table 4.27).

Table 4. 27 Factor of safety values calculated by the stability module in LFDSS

\begin{tabular}{cccc}
\hline Design & \multicolumn{3}{c}{ Factor of Safety Values } \\
\cline { 2 - 4 } Alternative & Cover system & Excavation slope $^{b}$ & Refuse fill $^{b}$ \\
\hline C1L1 & 5.54 & 1.94 & 3.49 \\
C1L6 & 5.54 & 1.94 & 3.49 \\
C2L1 & 9.17 (with GM ${ }^{\mathrm{a}}$ ) & 1.94 & 3.49 \\
& 0.94 (seismic forces) & & \\
C2L6 & 9.17 (with GM) & 1.94 & 3.49 \\
& 0.94 (seismic forces) & & 3.49 \\
C3L1 & 66.87 & 1.94 & 3.49 \\
C3L6 & 66.87 & 1.94 & \\
\hline${ }^{a}$ geomembrane & ${ }^{b}$ single trial surface &
\end{tabular}

\subsubsection{Cost Calculations of Major Design Components}

Major landfill components include native soil, topsoil, clay liners, drainage system components, and geosynthetics (i.e. geomembranes). Additional components taken into consideration for Siirt Municipal Solid Waste Landfill 
were geotextile filters. Major, additional, and total costs of design alternatives were calculated using cost estimation module in LFDSS. Majority of the costs is related with soil excavation, which is independent of the design alternative. VLF model of LFDSS calculated the excavation and fill volumes as $408860 \mathrm{~m}^{3}$ and $7570 \mathrm{~m}^{3}$, respectively for the landfill examined in this case. For intermediate soil covers, one to four soil-to-waste ratio is commonly used. Considering $1 \mathrm{v}: 3 \mathrm{~h}$ slopes at the sides of the landfill, the length of the landfill approximately extends to $375 \mathrm{~m}$, and the width of the landfill approximately extends to $130 \mathrm{~m}$ at the surface (Figure 4.18).

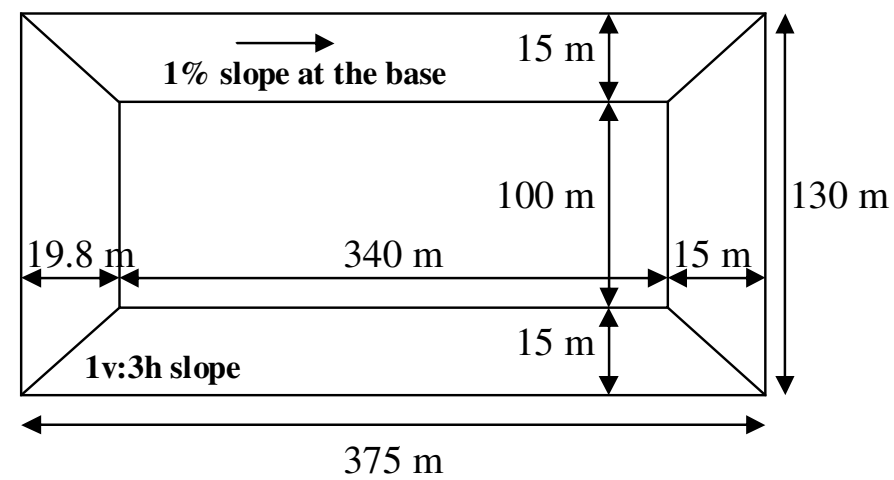

Figure 4. 18 Schematic view of the surface area of the landfill

$0.6 \mathrm{~m}$ thick native topsoil was applied in the final cover that covers an area of approximately 5 ha $(375 \mathrm{~m} \mathrm{x} 130 \mathrm{~m})$. Considering the total landfill volume of $685100 \mathrm{~m}^{3}$, soil requirement for intermediate and final covers were calculated as:

Daily and intermediate covers $\quad V_{\text {int }}=\frac{685100 \mathrm{~m}^{3}}{4}=171275 \mathrm{~m}^{3}$

Final cover $\quad V_{\text {final }}=0.6 m \times 50000 \mathrm{~m}^{2}=30000 \mathrm{~m}^{3}$

Virtual Landfill (VLF) model demonstrated that almost half of the landfill base stayed on top of clayey zones (Figure 4.16). 0.6-m-thick clay layers would be 
used for bottom liners and final covers. Amounts of clay required for bottom liner and final cover were approximately calculated as:

Bottom clay; $V_{\text {clay }}=0.6 m \times 34000 m^{2}=20400 m^{2}$

Final cover clay; $V_{\text {clay }}=0.6 m \times 50000 m^{2}=30000 m^{3}$

As almost half of the clay was visible at the base of the landfill, available clay volume at the base of the landfill was estimated to be $9000 \mathrm{~m}^{3}$. Therefore, the required excavation amount of clay was $11400 \mathrm{~m}^{3}\left(20400 \mathrm{~m}^{3}-9000 \mathrm{~m}^{3}\right)$ for bottom liners, and $30000 \mathrm{~m}^{3}$ for final covers; corresponding to a total of $41400 \mathrm{~m}^{3}$ $\left(11400 \mathrm{~m}^{3}+30000 \mathrm{~m}^{3}\right)$.

Volumes of soil to be used during landfill construction, and excess amount of soil that is needed to be disposed of are given in Table 4.29.

Table 4. 28 Volumes of soil used in landfill construction

\begin{tabular}{|c|c|c|c|c|c|c|}
\hline $\begin{array}{l}\text { Area } \\
\text { (ha) }\end{array}$ & $\begin{array}{c}\text { Excavation } \\
\left(\mathbf{m}^{3}\right)\end{array}$ & $\begin{array}{l}\text { Fill } \\
\left(\mathbf{m}^{3}\right)\end{array}$ & $\begin{array}{c}\text { D\&I } I^{\mathrm{a}} \\
\text { Covers } \\
\left(\mathbf{m}^{3}\right)\end{array}$ & $\begin{array}{c}\text { Final } \\
\text { Cover } \\
\left(\mathrm{m}^{3}\right)\end{array}$ & $\begin{array}{c}\text { Total }^{\mathrm{b}} \\
\left(\mathrm{m}^{3}\right)\end{array}$ & $\begin{array}{c}\text { Excessive } \\
\text { Soil } \\
\text { Volume } \\
\left(\mathbf{m}^{3}\right)\end{array}$ \\
\hline Base Cover & & & & & & \\
\hline $\begin{array}{ll}3.4 & 5.0\end{array}$ & 408860 & 7570 & 171275 & 30000 & 208845 & 200015 \\
\hline
\end{tabular}

Cost analyses that were considered for design alternatives are presented in Table 4.29. Geotextiles for reinforcement were also considered as an additional cost for the designs including geomembranes. 
Table 4. 29 Landfill components of the design alternatives considered for cost analyses

\begin{tabular}{cl}
\hline Design Alternative & \multicolumn{1}{c}{ Cost Analyses } \\
\hline C1L1 & Native soil, topsoil \\
C1L6 & Native soil, topsoil, clay \\
C2L1 & Native soil, topsoil, clay, drainage, geomembrane, \\
& geotextile \\
C2L6 & Native soil, topsoil, clay, drainage, geomembrane, \\
& geotextile \\
C3L1 & Native soil, topsoil, clay, drainage \\
C3L6 & Native soil, topsoil, clay, drainage \\
\hline
\end{tabular}

Soil amounts that were supposed to be used for the construction of various design alternatives are given in Table 4.30, and Table 4.31. Besides the aforementioned design alternatives (C1L1, C1L6, C2L1, C2L6, C3L1, and C3L6), design alternative having evapotranspiration final cover - natural topsoil over waste, with intermediate design bottom liner -leachate collection system coupled with compacted clay liner (C1L5), intermediate design final cover -natural topsoil, cover drainage system, and clay liner, with intermediate design bottom liner (C3L5), and intermediate design final cover with extensive engineering bottom liner -leachate collection system, geomembrane, and compacted clay liner (C3L2) were also included in the cost analyses in order to allow for a comparison. 
Table 4. 30 Amounts of soil to be used in landfill construction

\begin{tabular}{|c|c|c|c|c|c|c|}
\hline Soil Components & C1L1 & C1L6 & C2L1 & C2L6 & C3L1 & C3L6 \\
\hline \multicolumn{7}{|l|}{ Native soil } \\
\hline Excavation $\left(m^{3}\right)$ & 408860 & 408860 & 408860 & 408860 & 408860 & 408860 \\
\hline Loading (add 15\%) $\left(\mathrm{m}^{3}\right)$ & 230017 & 230017 & 230017 & 230017 & 230017 & 230017 \\
\hline Spread native soil $\left(m^{3}\right)$ & $178845^{\mathrm{a}}$ & $178845^{\mathrm{a}}$ & $178845^{\mathrm{a}}$ & $178845^{\mathrm{a}}$ & $178845^{\mathrm{a}}$ & $178845^{\mathrm{a}}$ \\
\hline \multicolumn{7}{|l|}{ Topsoil } \\
\hline Spread topsoil $\left(m^{3}\right)$ & $30000^{\mathrm{b}}$ & $30000^{\mathrm{b}}$ & $30000^{\mathrm{b}}$ & $30000^{\mathrm{b}}$ & $30000^{\mathrm{b}}$ & $30000^{\mathrm{b}}$ \\
\hline Compact topsoil $\left(m^{3}\right)$ & 30000 & 30000 & 30000 & 30000 & 30000 & 30000 \\
\hline \multicolumn{7}{|l|}{ Drainage } \\
\hline Stone $\left(m^{3}\right)$ & & & $15000^{\mathrm{d}}$ & $15000^{\mathrm{d}}$ & $15000^{\mathrm{d}}$ & $15000^{\mathrm{d}}$ \\
\hline Spread stone $\left(m^{3}\right)$ & & & 15000 & 15000 & 15000 & 15000 \\
\hline \multicolumn{7}{|l|}{ Clay (Onsite/Offsite) } \\
\hline Clay excavation $\left(m^{3}\right)$ & & 11400 & 30000 & 41400 & 30000 & 41400 \\
\hline Spread clay $\left(m^{3}\right)$ & & 11400 & $30000^{\mathrm{e}}$ & $50400^{\mathrm{g}}$ & $30000^{\mathrm{e}}$ & $50400^{g}$ \\
\hline Compact clay $\left(m^{3}\right)$ & & $20400^{c}$ & & 20400 & & 20400 \\
\hline \multicolumn{7}{|l|}{ Drainage tile } \\
\hline \multicolumn{7}{|l|}{ Pipe (m) } \\
\hline \multicolumn{7}{|l|}{ Synthetic membrane } \\
\hline \multicolumn{7}{|l|}{60 mil HDPE $\left(m^{2}\right)$} \\
\hline 40 mil PVC $\left(m^{2}\right)$ & & & $50000^{\mathrm{f}}$ & $50000^{\mathrm{f}}$ & & \\
\hline Installation $\left(m^{2}\right)$ & & & 50000 & 50000 & & \\
\hline \multicolumn{7}{|l|}{ Geotextile filter } \\
\hline 10 oz geotextile $\left(\mathrm{m}^{2}\right)$ & & & $50000^{\mathrm{f}}$ & $50000^{\mathrm{f}}$ & & \\
\hline Installation $\left(m^{2}\right)$ & & & 50000 & 50000 & & \\
\hline \multicolumn{7}{|c|}{${ }^{\mathrm{a}}$ total of daily and intermediate covers and fill $\left(171275 \mathrm{~m}^{3}+7570 \mathrm{~m}^{3}\right)$} \\
\hline \multicolumn{7}{|c|}{${ }^{\mathrm{b}}$ soil thickness $\mathrm{x}$ surface area $\left(0.6 \mathrm{~m} \times 50000 \mathrm{~m}^{2}\right)$} \\
\hline \multicolumn{7}{|c|}{${ }^{\mathrm{c}}$ clay thickness $\mathrm{x}$ base area $\left(0.6 \mathrm{~m} \times 34000 \mathrm{~m}^{2}\right)$} \\
\hline \multicolumn{7}{|c|}{ d stone layer thickness x surface area $\left(0.3 \mathrm{~m}\right.$ x $\left.50000 \mathrm{~m}^{2}\right) \backslash$} \\
\hline \multicolumn{7}{|c|}{ e clay thickness x surface area $\left(0.6 \mathrm{~m} \times 50000 \mathrm{~m}^{2}\right)$} \\
\hline f surface area & & & & & & \\
\hline total of surface clay and & om line & y $(2040$ & +30 & & & \\
\hline
\end{tabular}


Table 4. 31 Amounts of soil to be used in landfill construction for additional designs

\begin{tabular}{|c|c|c|c|}
\hline Soil Components & C1L5 & C3L5 & C3L2 \\
\hline \multicolumn{4}{|l|}{ Native soil } \\
\hline Excavation $\left(\mathrm{m}^{3}\right)$ & 408860 & 408860 & 408860 \\
\hline Loading $($ add $15 \%)\left(\mathrm{m}^{3}\right)$ & 230017 & 230017 & 230017 \\
\hline Spread native soil $\left(\mathrm{m}^{3}\right)$ & $178845^{\mathrm{a}}$ & $178845^{\mathrm{a}}$ & $178845^{\mathrm{a}}$ \\
\hline \multicolumn{4}{|l|}{ Topsoil } \\
\hline Spread topsoil $\left(\mathrm{m}^{3}\right)$ & $30000^{\mathrm{b}}$ & $30000^{\mathrm{b}}$ & $30000^{b}$ \\
\hline Compact topsoil $\left(\mathrm{m}^{3}\right)$ & 30000 & 30000 & 30000 \\
\hline \multicolumn{4}{|l|}{ Drainage } \\
\hline Stone $\left(m^{3}\right)$ & $10200^{c}$ & $25200^{f}$ & $25200^{f}$ \\
\hline Spread stone $\left(\mathrm{m}^{3}\right)$ & 10200 & 25200 & 25200 \\
\hline \multicolumn{4}{|l|}{ Clay (Onsite/Offsite) } \\
\hline Clay excavation $\left(\mathrm{m}^{3}\right)$ & 11400 & 41400 & 41400 \\
\hline Spread clay $\left(m^{3}\right)$ & 11400 & $50400^{\mathrm{g}}$ & $50400^{\mathrm{g}}$ \\
\hline Compact clay $\left(m^{3}\right)$ & $20400^{\mathrm{d}}$ & 20400 & 20400 \\
\hline \multicolumn{4}{|l|}{ Drainage tile } \\
\hline Pipe (m) & $600^{\mathrm{e}}$ & $600^{\mathrm{e}}$ & $600^{\mathrm{e}}$ \\
\hline \multicolumn{4}{|l|}{ Synthetic membrane } \\
\hline 60 mil HDPE $\left(m^{2}\right)$ & & & $34000^{\mathrm{h}}$ \\
\hline \multicolumn{4}{|l|}{40 mil PVC $\left(m^{2}\right)$} \\
\hline Installation $\left(\mathrm{m}^{2}\right)$ & & & 34000 \\
\hline \multicolumn{4}{|l|}{ Geotextile filter } \\
\hline 10 oz geotextile $\left(\mathrm{m}^{2}\right)$ & & & $34000^{\mathrm{h}}$ \\
\hline Installation $\left(\mathrm{m}^{2}\right)$ & & & 34000 \\
\hline \multicolumn{4}{|c|}{ a total of daily and intermediate covers and fill $\left(171275 \mathrm{~m}^{3}+7570 \mathrm{~m}^{3}\right)$} \\
\hline \multicolumn{4}{|c|}{ b soil thickness x surface area $\left(0.6 \mathrm{~m} \times 50000 \mathrm{~m}^{2}\right)$} \\
\hline \multicolumn{4}{|c|}{${ }^{c}$ stone layer thickness $x$ base area $\left(0.3 \mathrm{~m} \times 34000 \mathrm{~m}^{2}\right)$} \\
\hline \multicolumn{4}{|c|}{ d clay thickness $x$ base area $\left(0.6 \mathrm{~m} \times 34000 \mathrm{~m}^{2}\right)$} \\
\hline \multicolumn{4}{|c|}{ e pipe installation interval is $50 \mathrm{~m}$; therefore, 6 pipes $(340 \mathrm{~m} / 50 \mathrm{~m})$ of $100-\mathrm{m}-\mathrm{long}$. } \\
\hline \multicolumn{4}{|c|}{${ }^{\mathrm{f}}$ surface drainage + leachate collection system $\left(15000 \mathrm{~m}^{3}+10200 \mathrm{~m}^{3}\right)$} \\
\hline total of surface clay and bot & clay $(2040$ & $\left.0 \mathrm{~m}^{3}\right)$ & \\
\hline
\end{tabular}


For Siirt, the unit costs of the major landfill components were not included in the feasibility report of DOLSAR; therefore, units costs presented in the cost estimation module were taken into consideration. The design alternatives including evapotranspiration final covers $(\mathrm{C} 1)$ resulted in the least cost (less than 1.65 million USD), and the costs of the designs increased as the final cover specifications increased. The highest cost corresponded to the design alternative having cover drainage system, geomembrane liner, and clay liner in the final cover, and compacted clay liner in the bottom liner (C2L6). The cost of this alternative reached almost 2.2 million USD (Table 4.32).

When the additional designs (C1L5, C3L5, and C3L2) were investigated, the most compatible design with respect to financial aspects was determined to be the design with evapotranspiration final cover, and having leachate collection system and compacted clay liner in the bottom liner (C1L5). The cost of this design was around 1.6 million USD. The costs of other more sophisticated designs, having cover drainage, clay liners, leachate collection system, compacted clay liner (C3L5), and geomembrane (for C3L2), reached almost 2.3 million USD (Table 4.32). As there is no groundwater and no contamination concern beneath the landfill, increasing the specifications of the landfill design would not be necessary. Therefore, design alternatives having evapotranspiration covers (C1L1, C1L6, and C1L5) are feasible for the site under investigation. However, the results of stability calculations should be consulted for the final decision. 
Table 4. 32 Major, additional and total costs of design alternatives

\begin{tabular}{cccc}
\hline $\begin{array}{c}\text { Design } \\
\text { Alternative }\end{array}$ & $\begin{array}{c}\text { Major Costs } \\
\text { (USD) }\end{array}$ & $\begin{array}{c}\text { Additional } \\
\text { Costs }^{\mathbf{a}} \\
\text { (USD) }\end{array}$ & $\begin{array}{c}\text { Total Cost } \\
\text { (USD) }\end{array}$ \\
\hline C1L1 & 1365913 & - & 1365913 \\
C1L6 & 1513969 & - & 1513969 \\
C2L1 & 1942563 & 43500 & 1986063 \\
C2L6 & 2106819 & 43500 & 2150319 \\
C3L1 & 1802563 & - & 1802563 \\
C3L6 & 1966819 & - & 1966819 \\
\hline C1L5 & 1639681 & - & 1639681 \\
C3L5 & 2092531 & - & 2092531 \\
C3L2 & 2235331 & 29580 & 2264911 \\
\hline
\end{tabular}

a includes cost of geotextiles

\subsubsection{Presentation of the Assessments and Decision Making}

After all the modules in LFDSS were run for each of the design alternative under investigation (C1L1, C1L6, C2L1, C2L6, C3L1, and C3L6), the results produced by each model and module (i.e. Preliminary design module, POLLUTE model, stability module, and cost estimation module) were saved by the LFDSS in the performance report (Appendix-G). The saved file was imported to MS Excel results template provided with the software to compare the performances of the simulated design alternatives and ease the decision making process. The overall results of the simulations are presented in Table 4.33. Leachate head values were not included in results table (Table 4.33), as simulations are not performed for the designs that do not comply with the stability criterion (i.e. leachate head should be less than $1 \mathrm{~m})$. 
Table 4. 33 Overall results of the landfill design simulations by LFDSS

\begin{tabular}{|c|c|c|c|c|c|c|c|}
\hline \multirow{2}{*}{ Design } & \multicolumn{2}{|c|}{ Performance } & \multicolumn{2}{|l|}{ Stability } & \multicolumn{3}{|c|}{ Cost (USD) } \\
\hline & $\begin{array}{l}\mathrm{Cl}_{\text {max }}{ }^{a} \\
(\mathrm{mg} / \mathrm{L})\end{array}$ & $\begin{array}{c}T_{\max }^{b} \\
(y r)\end{array}$ & FS values & & $\begin{array}{c}\text { Main } \\
\text { Cost }\end{array}$ & $\begin{array}{c}\text { Additional } \\
\text { Cost }\end{array}$ & $\begin{array}{l}\text { Total } \\
\text { Cost }\end{array}$ \\
\hline \multirow[t]{5}{*}{ C1L1 } & 478.5 & 31 & Excavation slope & 1.94 & 1365913 & - & 1365913 \\
\hline & & & Refuse-fill & 3.49 & & & \\
\hline & & & Cover system & 5.54 & & & \\
\hline & & & Geomembrane & - & & & \\
\hline & & & Seismic & - & & & \\
\hline \multirow[t]{5}{*}{ C1L6 } & 477.8 & 32 & Excavation slope & 1.94 & 1513969 & - & 1513969 \\
\hline & & & Refuse-fill & 3.49 & & & \\
\hline & & & Cover system & 5.54 & & & \\
\hline & & & Geomembrane & - & & & \\
\hline & & & Seismic & - & & & \\
\hline \multirow[t]{5}{*}{ C2L1 } & 430.1 & 594 & Excavation slope & 1.94 & 1942563 & 43500 & 1986063 \\
\hline & & & Refuse-fill & 3.49 & & & \\
\hline & & & Cover system & 9.17 & & & \\
\hline & & & Geomembrane & - & & & \\
\hline & & & Seismic & 0.93 & & & \\
\hline \multirow[t]{5}{*}{ C2L6 } & 428.9 & 642 & Excavation slope & 1.94 & 2106819 & 43500 & 2150319 \\
\hline & & & Refuse-fill & 3.49 & & & \\
\hline & & & Cover system & 9.17 & & & \\
\hline & & & Geomembrane & - & & & \\
\hline & & & Seismic & 0.93 & & & \\
\hline \multirow[t]{5}{*}{ C3L1 } & 473.1 & 32 & Excavation slope & 1.94 & 1802563 & - & 1802563 \\
\hline & & & Refuse-fill & 3.49 & & & \\
\hline & & & Cover system & 66.87 & & & \\
\hline & & & Geomembrane & - & & & \\
\hline & & & Seismic & - & & & \\
\hline \multirow[t]{5}{*}{ C3L6 } & 472.1 & 34 & Excavation slope & 1.94 & 1966819 & - & 1966819 \\
\hline & & & Refuse-fill & 3.49 & & & \\
\hline & & & Cover system & 66.87 & & & \\
\hline & & & Geomembrane & - & & & \\
\hline & & & Seismic & - & & & \\
\hline
\end{tabular}

${ }^{\mathrm{a}}$ maximum soil chloride concentration

${ }^{\mathrm{b}}$ time that maximum concentration was observed 
Absence of groundwater eliminated the necessity to evaluate contamination performance of the design alternatives. Stability analyses demonstrated that all of the investigated design alternatives produced stable factor of safety values with respect to slope stability. However, designs having geomembranes in the final cover (C2L1, and C2L6) failed to satisfy the safe factor of safety value (i.e. 1.00) for seismic stability. Moreover, the costs of the designs including geomembranes are much higher than the other investigated designs, and there was no contamination concern for the site. Therefore, design alternatives having geomembranes (C2L1, and C2L6) were excluded from the list of design alternatives.

Considering the flexibility of site requirements, design alternatives having evapotranspiration covers and either a natural aquitard or compacted clay liner below waste (C1L1, or C1L6) would be adequate for Siirt case. Design alternatives having intermediate design final covers composed of natural topsoil, cover drainage system, and clay liner -C3 (i.e. C3L1, and C3L6) may also be considered if higher stability for the cover is required. The decision of alternatives with evapotranspiration final cover $-\mathrm{C} 1$ (C1L1, C1L5, and C1L6) and intermediate design final cover $-\mathrm{C} 3(\mathrm{C} 3 \mathrm{~L} 1$, and $\mathrm{C} 3 \mathrm{~L} 6)$ was also found appropriate due to their low cost requirements.

4.5.2. Designing a Municipal Solid Waste Landfill for a Hypothetical Site

A hypothetical municipal solid waste landfill was designed in order to demonstrate the possible design applications that may be achieved using LFDSS. Maps belonging to the previous case study (Section 4.5.1) were used, as topographic and bore hole data were available. A hypothetical groundwater layer was created in order to demonstrate design situations involving groundwater. Site information of Siirt on geography and demography were used, as these data were 
already available. A humid climate was selected for the hypothetical case from HELP database. All other relevant design data were arranged hypothetically. The site was referred to as $\mathrm{X}$-city.

\subsubsection{General Site Information}

$\mathrm{X}$-city resides at a northern latitude of $36^{\circ} 12^{\prime}$, and eastern longitude of $40^{\circ} 55$. The highest point above sea level is $1000 \mathrm{~m}$, and the lowest point stays at $800 \mathrm{~m}$. Xcity has a humid subtropical climate, where the summers are hot and humid, and winters are chilly. Average annual precipitation reaches $1222 \mathrm{~mm}$, winter and spring being the wettest seasons. According to 2000 census, the population of the city is 98281 .

The city produces $170105 \mathrm{~kg} / \mathrm{d}$ of waste, corresponding to a waste production rate of $1.04 \mathrm{~kg} / \mathrm{cap} / \mathrm{d}$ (according to the year 2005 projected population of 113403). 28$30 \%$ of the waste is recycled in the city.

Hydrogeologic data were adapted using bore hole data of Siirt Municipal Solid Waste Landfill. According to the adapted bore logs, the investigation site is composed of permeable chalk-limestones, demonstrating aquifer properties. The site under investigation is far from the fault lines; therefore, it is considered to be safe with respect to seismicity. The aquifer is located between $6-12 \mathrm{~m}$ below ground, and the potentiometric surface is $1 \mathrm{~m}$ above the top of the aquifer. The groundwater flows from south-east to north-west. Groundwater flow velocity is estimated to be in the range of $0.1-0.8 \mathrm{~m} / \mathrm{d}$. Information obtained from the bore holes are presented in Table 4.34. Location of the bore wells are shown by red circles in Figure 4.19. 
Table 4. 34 Bore well data for the investigation site

\begin{tabular}{ccc}
\hline WELL NO. & $\begin{array}{c}\text { Thickness of Formation } \\
(\mathbf{m})\end{array}$ & Type of Formation \\
\hline $\mathbf{1}$ & 0.5 & Vegetative soil \\
& 11.0 & Gravel-silty clay \\
$\mathbf{2}$ & 8.5 & Chalk-limestone \\
& 0.5 & Vegetative soil \\
& 11.3 & Gravel-silty clay \\
$\mathbf{3}$ & 8.2 & Chalk-limestone \\
& 0.5 & Vegetative soil \\
& 11.7 & Gravel-silty clay \\
$\mathbf{4}$ & 7.8 & Chalk-limestone \\
& 0.5 & Vegetative soil \\
& 5.5 & Gravel-silty clay \\
$\mathbf{5}$ & 14.0 & Chalk-limestone \\
& 0.5 & Vegetative soil \\
& 6.0 & Gravel-silty clay \\
& 13.5 & Chalk-limestone \\
\hline
\end{tabular}

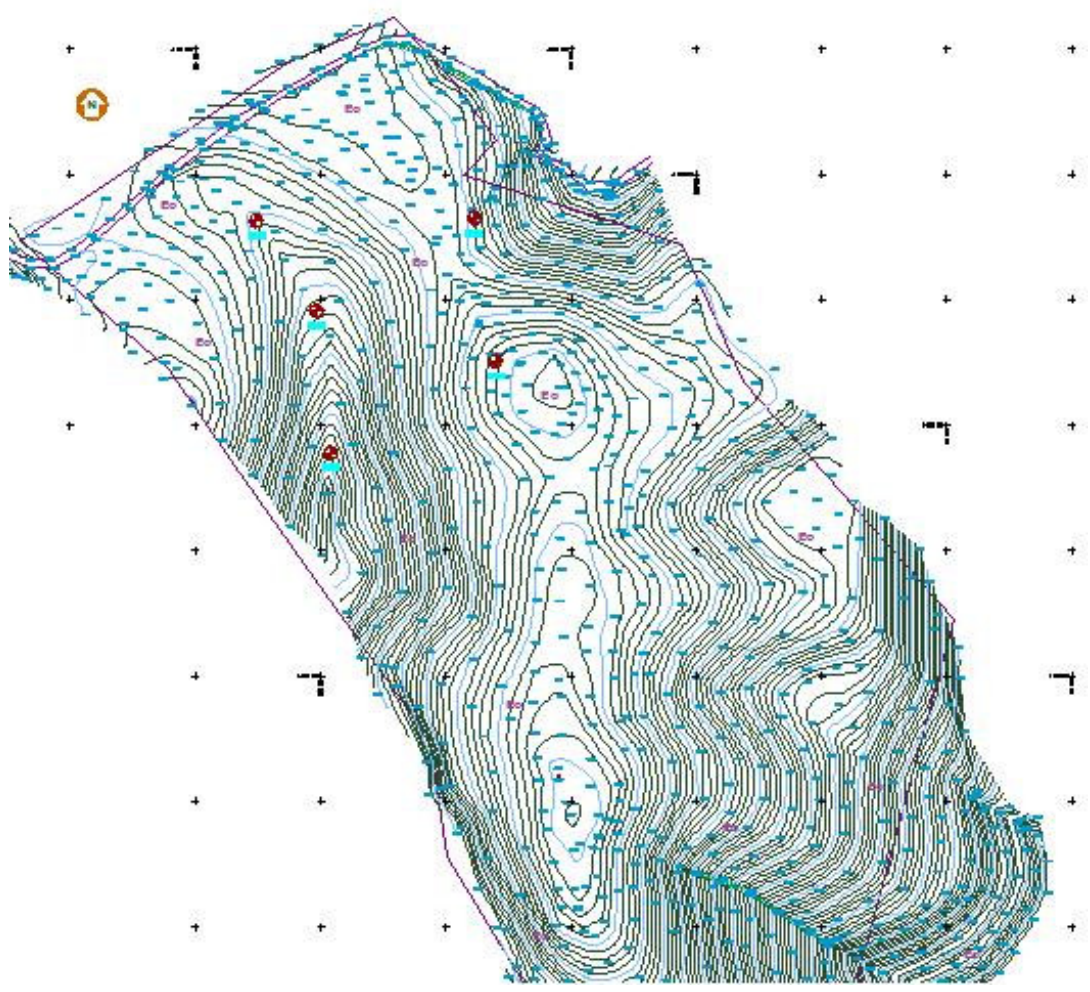

Figure 4. 19 Location of the bore wells in the investigation area 
A municipal solid waste landfill to meet the solid waste disposal requirements of the city for 20 years is planned to be constructed in two stages in the investigated area. First stage will operate during 2010 - 2019, and the second stage during 2020 - 2029. Estimated waste production rate for both stages is $1.04 \mathrm{~kg} / \mathrm{cap} / \mathrm{day}$. The projected populations for years 2010, 2020, and 2025 are 127371, 175311, and 271015, respectively. In this case study, the first stage of the landfill (2010 2019) was modeled and designed.

\subsubsection{Volume Calculations in LFDSS}

To calculate the volume requirement for the first stage of the X-city landfill, design population was accepted as the population for year 2010 (127371). Operational lifetime of landfill for the first stage was 10 years $(2010-2019)$. The density of waste was taken as $600 \mathrm{~kg} / \mathrm{m}^{3}$, which stands in the range accepted for waste well compacted in landfill (İller Bankası, 2000). The input data used for volume calculations are presented in Table 4.35.

Table 4. 35 Input parameters for volume calculation module

\begin{tabular}{lc}
\hline Design population & $127371(2010)$ \\
Operational lifetime of landfill $(\mathrm{y})$ & $10(2010-2029)$ \\
Waste production rate $(\mathrm{kg} / \mathrm{cap} /$ day $)$ & 1.04 \\
Waste density $\left(\mathrm{kg} / \mathrm{m}^{3}\right)$ & $600^{\mathrm{a}}$ \\
\hline
\end{tabular}

${ }^{a}$ Accepted for the waste well compacted in the landfill.

The module calculated a waste volume of $805834 \mathrm{~m}^{3}$. As $28-30 \%$ of the wastes in the city are recycled, the required landfill volume reduced to $564084 \mathrm{~m}^{3}$ (Eq. 4.7).

$$
V_{L F}=805834-805834 \times 0.3=564083.8 m^{3}
$$


Including the daily and intermediate covers, which covers one-fourth of the overall landfill volume, the total landfill volume requirement was calculated as $705105 \mathrm{~m}^{3}$ (Eq. 4.8).

$$
V_{\text {TOTAL }}=564083.8+\frac{564083.8}{4}=705104.8 \mathrm{~m}^{3}
$$

\subsubsection{Base Grade Design of the Landfill at the Proposed Site}

To locate the landfill fulfilling the volume requirements to the given site, topographic conditions, available clay layer thickness, groundwater flow direction, and depth to groundwater were taken into consideration. Virtual Landfill Model was run from the LFDSS to locate the landfill and to perform volume calculations. Base-DEM (digital elevation model), Clay-DEM, and Groundwater-DEM were created and imported to VLF model, as described in Section 4.5.1.3. There are two Groundwater-DEM files, one is used for assigning groundwater direction, and the other is used for assigning depth of potentiometric surface. DEM files are presented in Appendix-F.

Once all the DEM files were imported to VLF model, the topographic features of the site, clay layer, and groundwater flow direction and depth were visible (Figure 4.20). Clay layers were indicated with orange color, and darker zones indicated a clay layer thickness around $11 \mathrm{~m}$, whereas lighter zones indicated clay layer thickness around $5 \mathrm{~m}$. Purple arrows indicated groundwater direction. Darker purple color indicated a groundwater depth of maximum $12 \mathrm{~m}$, whereas lighter purple colors indicated a groundwater depth of minimum $3 \mathrm{~m}$. Observing the clayey zones and zones with deeper aquifer, the most suitable location for landfill was found to be the one shown with yellow circle (Figure 4.20). 
Considering an average waste thickness of $20 \mathrm{~m}$, the landfill base area was calculated as 3.5 ha (Eq. 4.9).

$$
A=\frac{V}{t_{w}}=\frac{705105 m^{3}}{20 m}=35255.2 m^{2} \cong 3.5 h a
$$

The base length and width of the landfill was selected as $350 \mathrm{~m}$, and $100 \mathrm{~m}$, respectively. Two orientations were considered to demonstrate the best available use of in situ clay layer, and importance of presence of groundwater. In the first orientation, the longer side of the landfill was placed in the direction of groundwater flow (Figure 4.21.a), and in the second orientation, the longer side of the landfill was placed perpendicular to the groundwater flow direction (Figure 4.21.b).

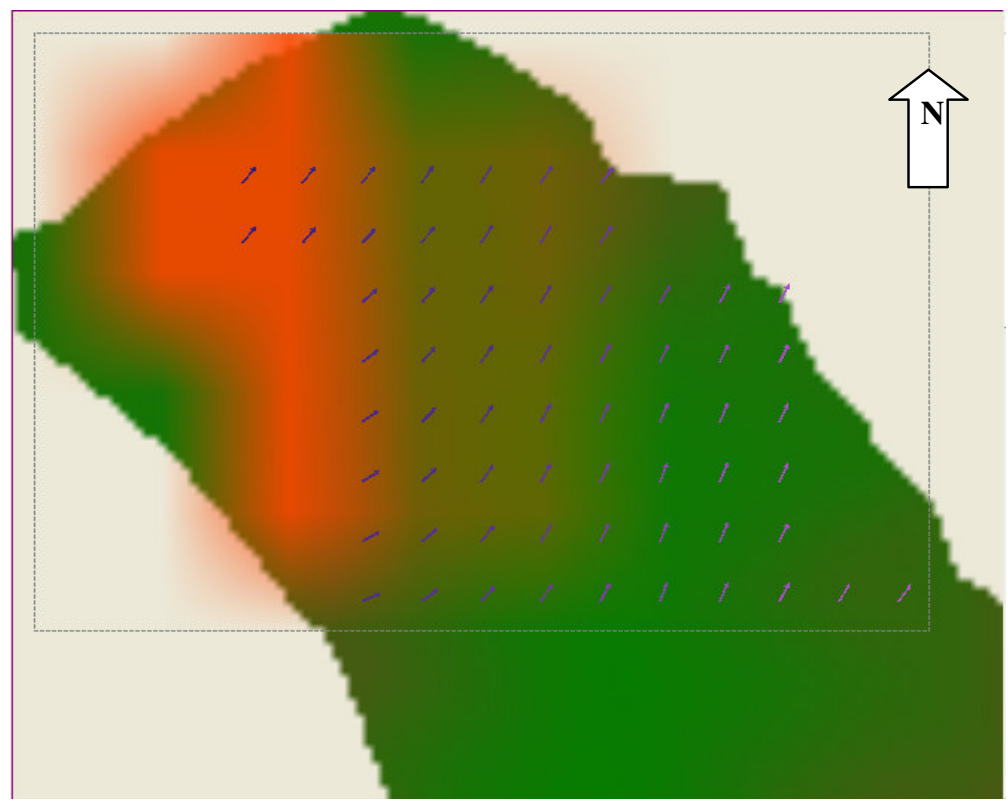

Figure 4. 20 Presentation of topography, clay layers, and groundwater depth and flow direction in VLF. Clay layers, indicated with orange color (such that darker zones indicated a clay layer thickness around $11 \mathrm{~m}$, and lighter zones indicated clay layer thickness around $5 \mathrm{~m}$ ). Purple arrows indicated groundwater direction and depth (such that, darker purple color indicated a groundwater depth of maximum $12 \mathrm{~m}$, and lighter purple colors indicated a groundwater depth of minimum 3 $\mathrm{m})$. 


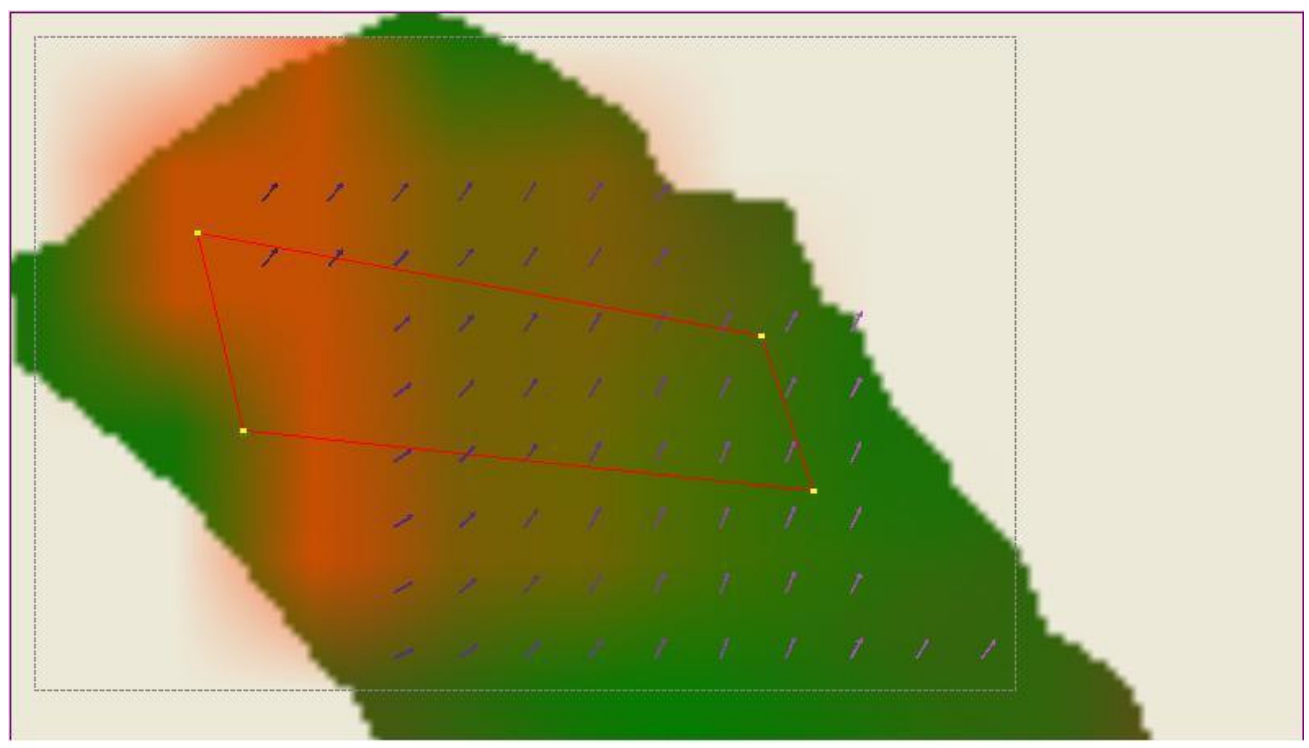

a.

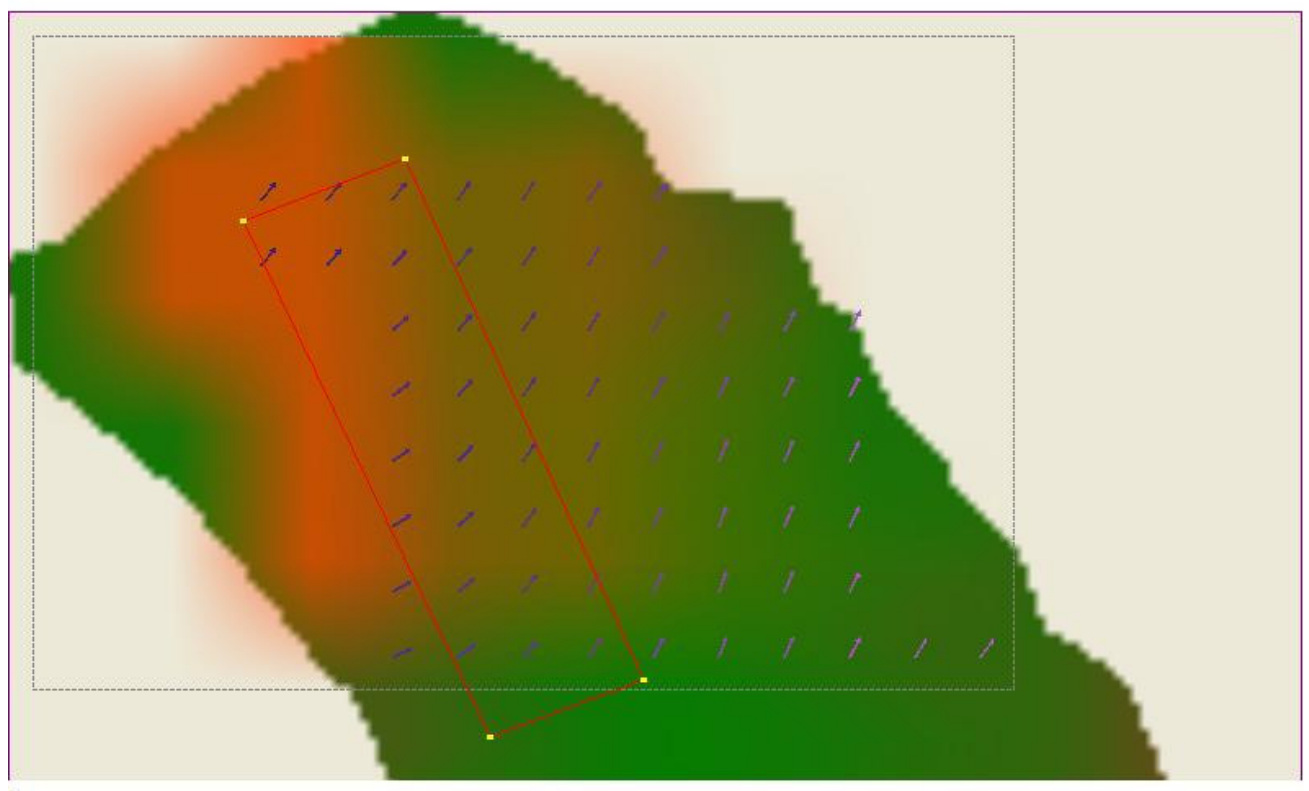

b.

Figure 4. 21 Orientation of the landfill to the given site (a) longer side in the direction of groundwater flow (b) longer side perpendicular to the groundwater flow 


\subsection{Longer Side of the Landfill Perpendicular to}

\section{Groundwater Flow Direction}

Longer side of the landfill was located perpendicular to groundwater direction in VLF. The excavation depth was taken as $5 \mathrm{~m}$, in order to preserve some of the clay layer available on site, and also to prevent reaching the groundwater which is 6 to $10 \mathrm{~m}$ below the ground surface within the borders of the selected landfill site. Side slopes were taken as $1 \mathrm{v}: 3 \mathrm{~h}$, and base slope as $1 \%$. The base elevation was then calculated as $952.5 \mathrm{~m}$, and ground elevation as $957.5 \mathrm{~m}$. An above-ground waste thickness of $15 \mathrm{~m}$ and a below-ground waste thickness of $5 \mathrm{~m}$ were considered to reach a total waste thickness of $20 \mathrm{~m}$. Therefore the surface elevation was calculated as $972.5 \mathrm{~m}$. The final cover was assigned a slope of $8 \%$, and a small surface area of 0.01 ha was formed at the top of the landfill. The base slope direction was indicated with a red arrow. Entering the calculated inclination, base slope, base and ground elevation, surface elevation, surface slope, and ground offset value (i.e. an approximate thickness of final cover), the VLF model calculated the excavation $\left(520950 \mathrm{~m}^{3}\right)$, fill $\left(4470 \mathrm{~m}^{3}\right)$, and surface volumes $\left(247120 \mathrm{~m}^{3}\right)$, as well as the available clay volume $\left(81820 \mathrm{~m}^{3}\right)$ beneath the landfill area (Figure 4.22). The total volume of landfill can then be calculated as 763600 $\mathrm{m}^{3}$, which is acceptable as it lies within the $10 \%$ range of the volume calculated $\left(705105 \mathrm{~m}^{3}\right)$ by the volume calculation module (Eq. 4.10):

$$
\begin{aligned}
& V_{\text {total }}=V_{\text {excavation }}-V_{\text {fill }}+V_{\text {surface }}=520.95 \mathrm{dam}^{3}-4.47 \mathrm{dam}^{3}+247.12 \mathrm{dam}^{3} \\
& V_{\text {total }}=763.6 \mathrm{dam}^{3}=763600 \mathrm{~m}^{3}
\end{aligned}
$$

After the excavation, VLF calculated that $81.82 \mathrm{dam}^{3}\left(81820 \mathrm{~m}^{3}\right)$ clay was still available at the base of the landfill. 


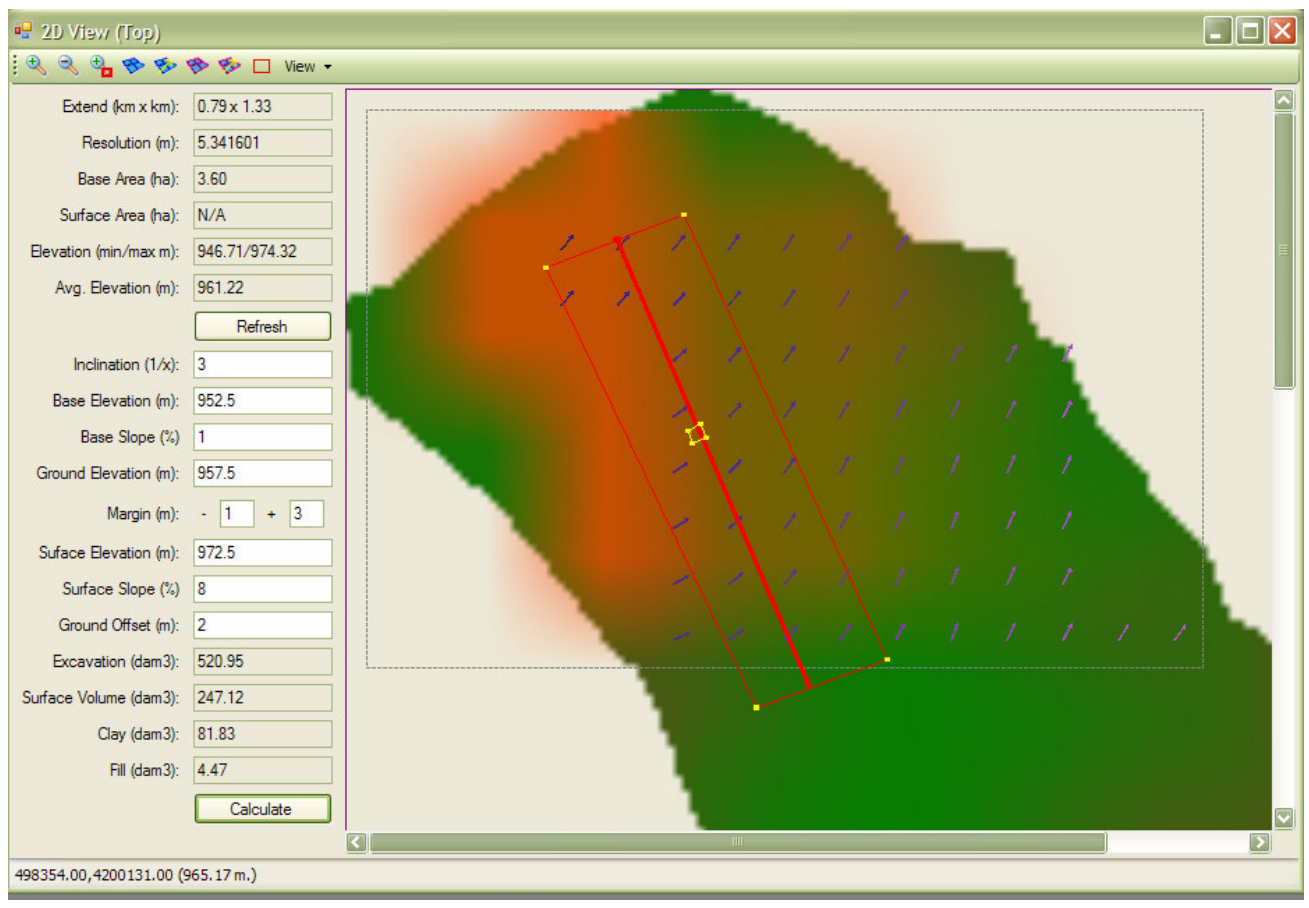

Figure 4. 22 Input data for VLF model and volume calculations for the case in which the landfill length is perpendicular to groundwater flow

Figure 4.22 demonstrates that depth to groundwater below the landfill varies between 6 to $10 \mathrm{~m}$. Therefore, an excavation depth of $5 \mathrm{~m}$ represents a safe design with respect to the stability of the landfill.

Once the "calculate" button was hit, VLF demonstrated the excavated and filled areas (Figure 4.23), the surface fill (Figure 4.24), and the available clay layers (Figure 4.25) in the 2D window. A 3D visualization of the landfill with or without final cover was presented by 3D window (Figure 4.26). As can be seen from Figure 4.26, the orientation of the landfill was also found suitable considering the site topography. 


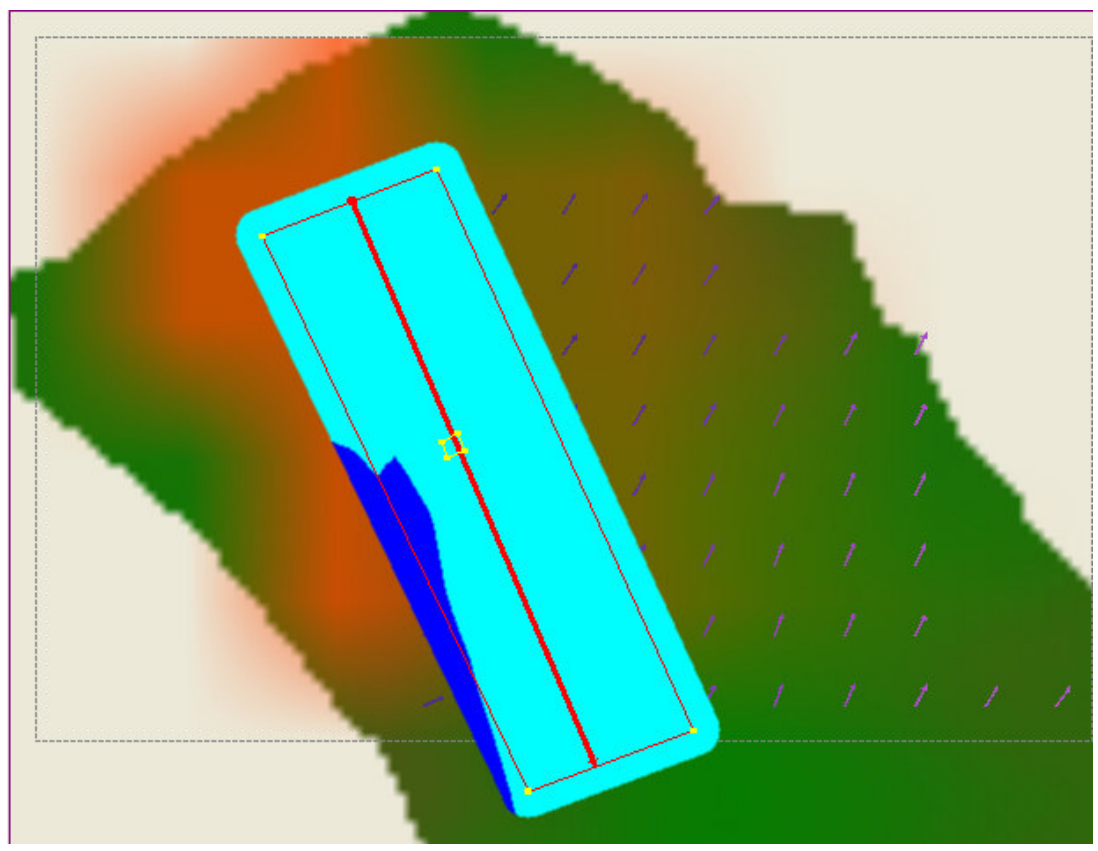

Figure 4. 23 Landfill excavation (light blue) and fill (dark blue) areas by VLF -landfill length perpendicular to groundwater

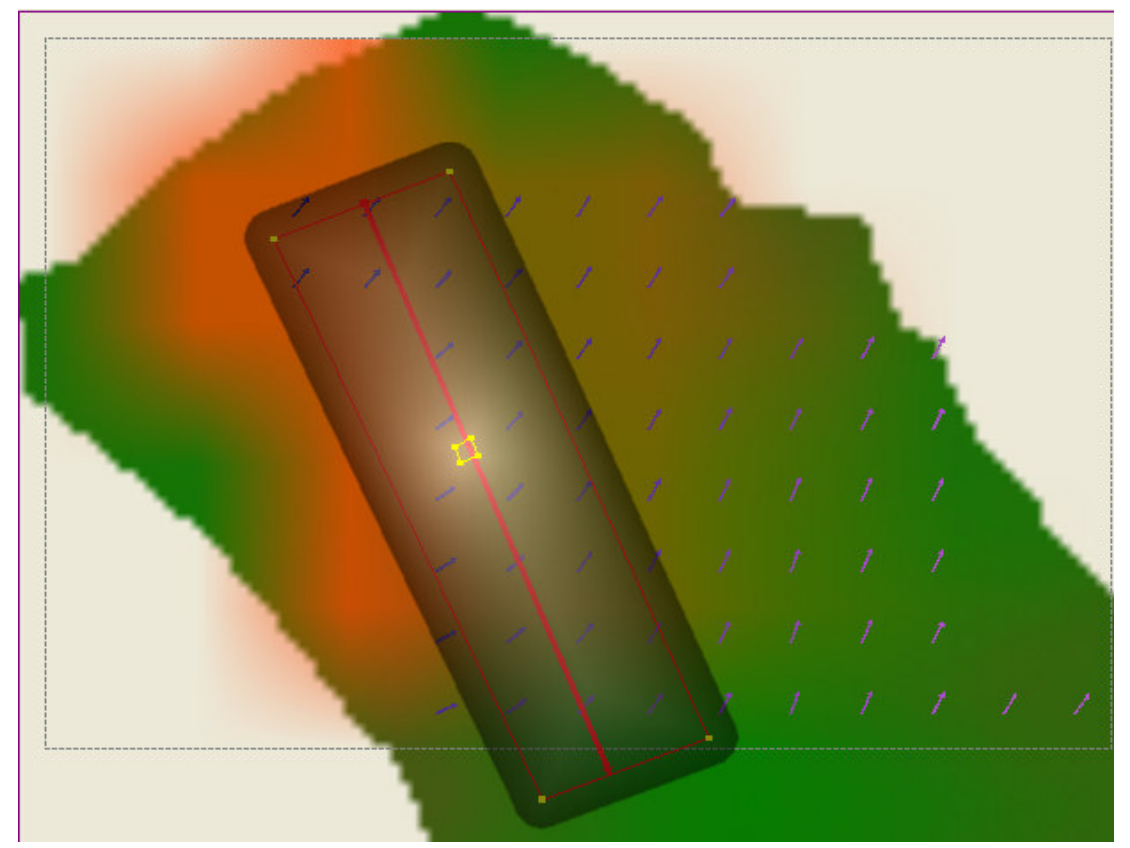

Figure 4. 24 Surface fill by VLF (lighter shades indicate higher elevations on the final cover) landfill length perpendicular to groundwater 


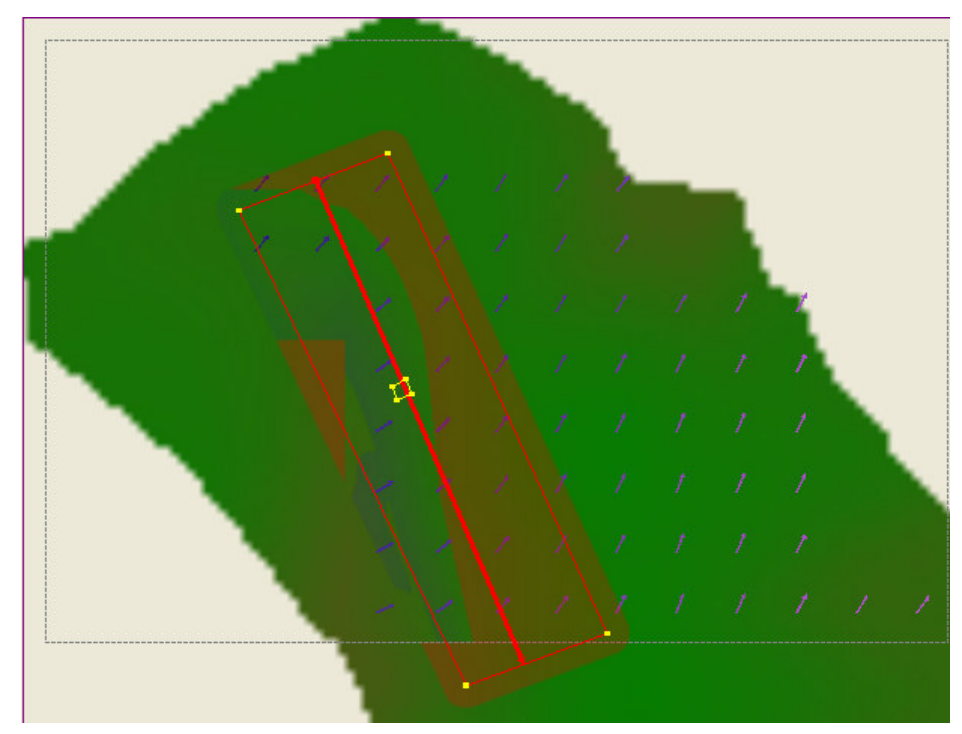

Figure 4. 25 Demonstration of availability of clay layers at the base of the landfill by VLF -green color (within the landfill borders) indicates the presence of the clay layer, whereas red color indicates the absence of clay layer after excavation -landfill length perpendicular to groundwater

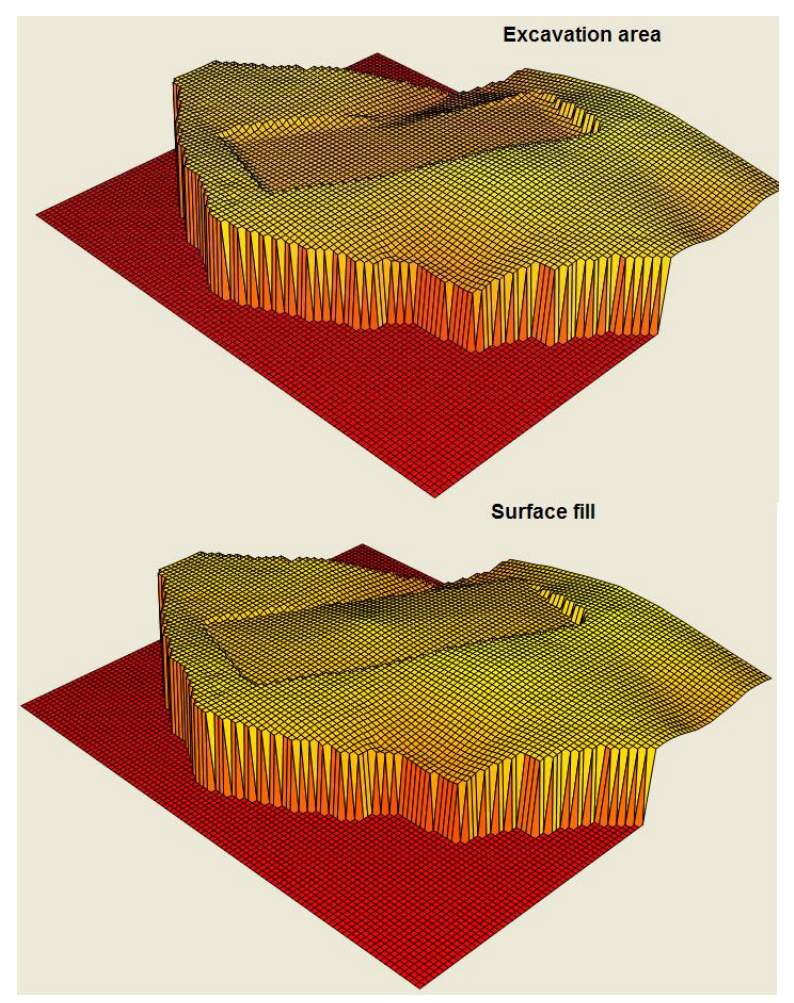

Figure 4. 26 3D demonstration of landfill with and without final cover by VLF -landfill length perpendicular to groundwater 


\subsection{Longer Side of the Landfill in the Direction of}

\section{Groundwater Flow}

Longer side of the landfill was located in the direction of groundwater flow in VLF. As can be seen from Figure 4.27, depth to groundwater at the eastern side of the landfill is around $4 \mathrm{~m}$. Therefore, the excavation depth at the eastern side was limited to $3 \mathrm{~m}$. Base slope direction was given to east to west side of the landfill; therefore, the excavation depth at the western side was $11.5 \mathrm{~m}$. The original elevation was $969 \mathrm{~m}$ at that point, and with $1 \%$ slope along $350 \mathrm{~m}$ starting from an elevation of $961 \mathrm{~m}$ (the original elevation of the eastern end minus excavation depth; $964 m-3 m=961 m$ ) results in a base elevation of $957.5 \mathrm{~m}$, which was still above the piezometric surface present at an elevation of $957 \mathrm{~m}$.

Considering an average excavation depth of $5 \mathrm{~m}$, the ground elevation was calculated as $964 \mathrm{~m}$. Side slopes were considered to be 1v:3h. 15-m-above-ground waste thickness was considered to reach a total waste thickness of $20 \mathrm{~m}$. Therefore the surface elevation was calculated as $979 \mathrm{~m}$. The final cover was assigned a slope of $3 \%$. The base slope direction was indicated with a red arrow. Entering the calculated inclination, base slope, base and ground elevation, surface elevation, surface slope, and ground offset value (i.e. an approximate thickness of final cover), the VLF model calculated the excavation $\left(408380 \mathrm{~m}^{3}\right)$, fill $\left(6560 \mathrm{~m}^{3}\right)$, and surface volumes $\left(277320 \mathrm{~m}^{3}\right)$, as well as the available clay volume (94810 $\mathrm{m}^{3}$ ) beneath the landfill area (Figure 4.27). The total volume of landfill can then be calculated as $679140 \mathrm{~m}^{3}$, which is acceptable as it lies within the $10 \%$ range of the volume calculated $\left(705105 \mathrm{~m}^{3}\right)$ by the volume calculation module (Eq. 4.11):

$$
\begin{aligned}
& V_{\text {total }}=V_{\text {excavation }}-V_{\text {fill }}+V_{\text {surface }}=408.38 \mathrm{dam}^{3}-6.56 \mathrm{dam}^{3}+277.32 \mathrm{dam}^{3} \\
& V_{\text {total }}=697.14 \mathrm{dam}^{3}=679140 \mathrm{~m}^{3}
\end{aligned}
$$


After the excavation, VLF calculated that $94.18 \mathrm{dam}^{3}\left(94180 \mathrm{~m}^{3}\right)$ clay was still available at the base of the landfill.

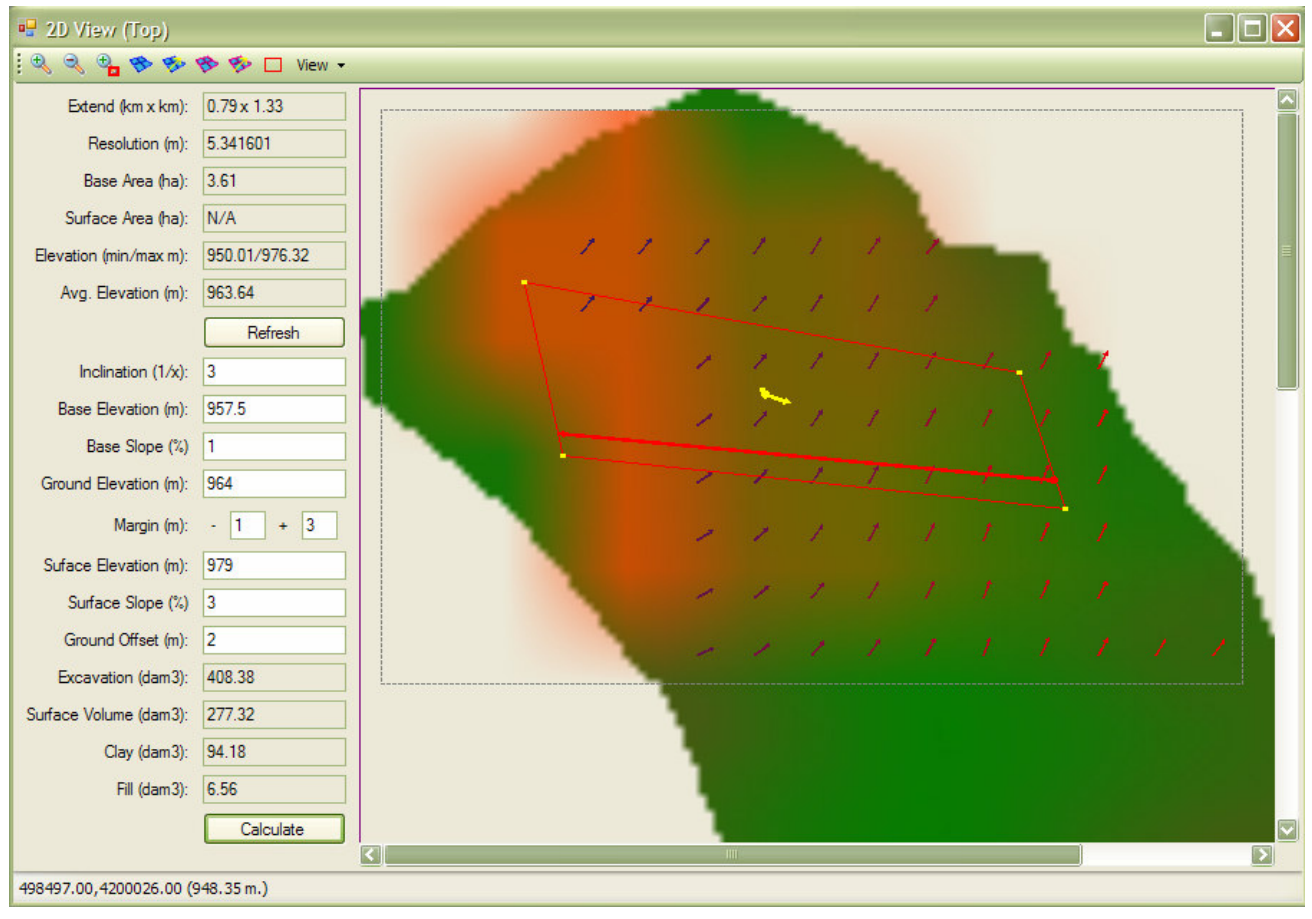

Figure 4. 27 Input data for VLF model and volume calculations for the case in which the landfill length is in the direction of groundwater flow

Once the "calculate" button was hit, VLF demonstrated the excavated and filled areas (Figure 4.28), the surface fill (Figure 4.29), and the available clay layers (Figure 4.30) in the 2D window. 3D visualization of the landfill with or without final cover was presented by 3D window (Figure 4.31). As can be seen from Figure 4.31, the orientation of the landfill was also found suitable considering the site topography. 


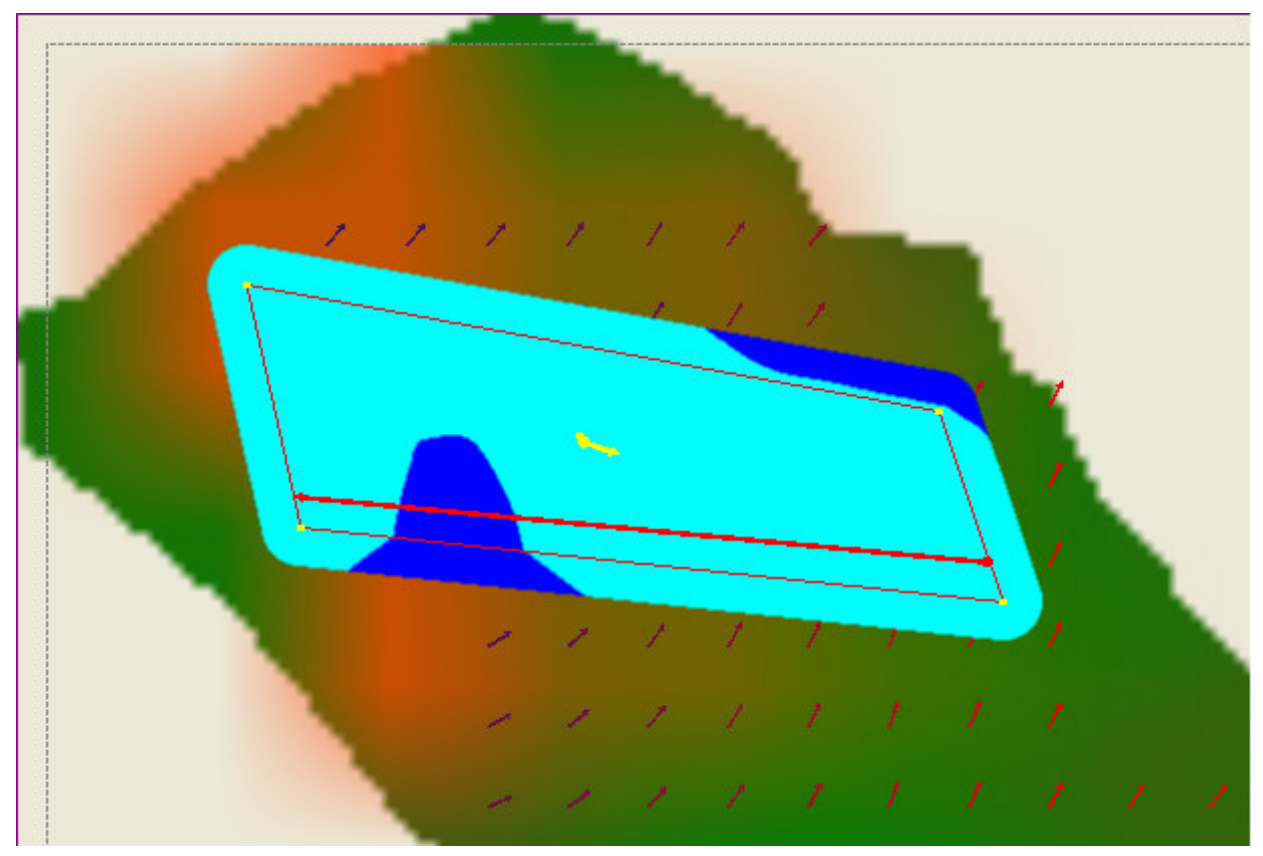

Figure 4. 28 Landfill excavation (light blue) and fill (dark blue) areas by VLF -landfill length in the direction of groundwater flow

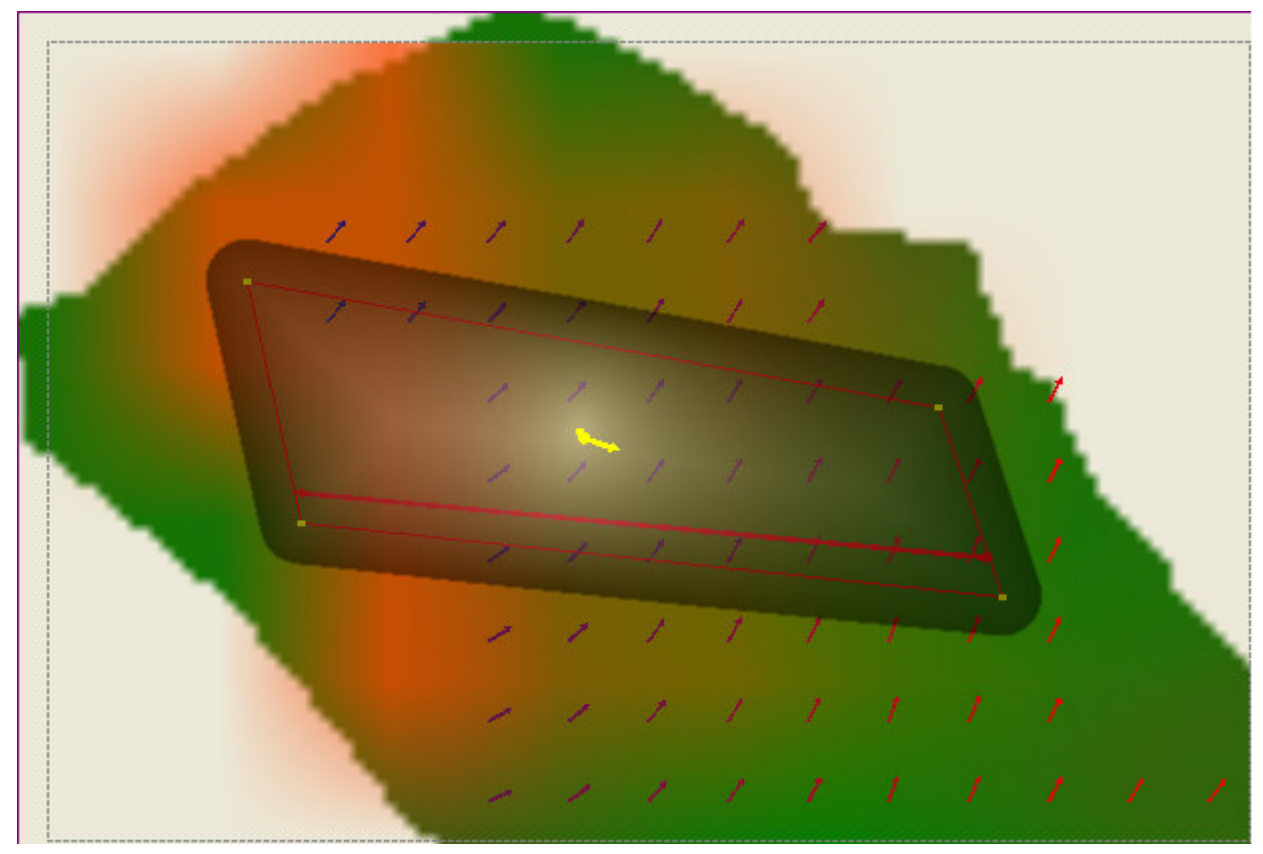

Figure 4. 29 Surface fill by VLF (lighter shades indicate higher elevations on the final cover) landfill length in the direction of groundwater flow 


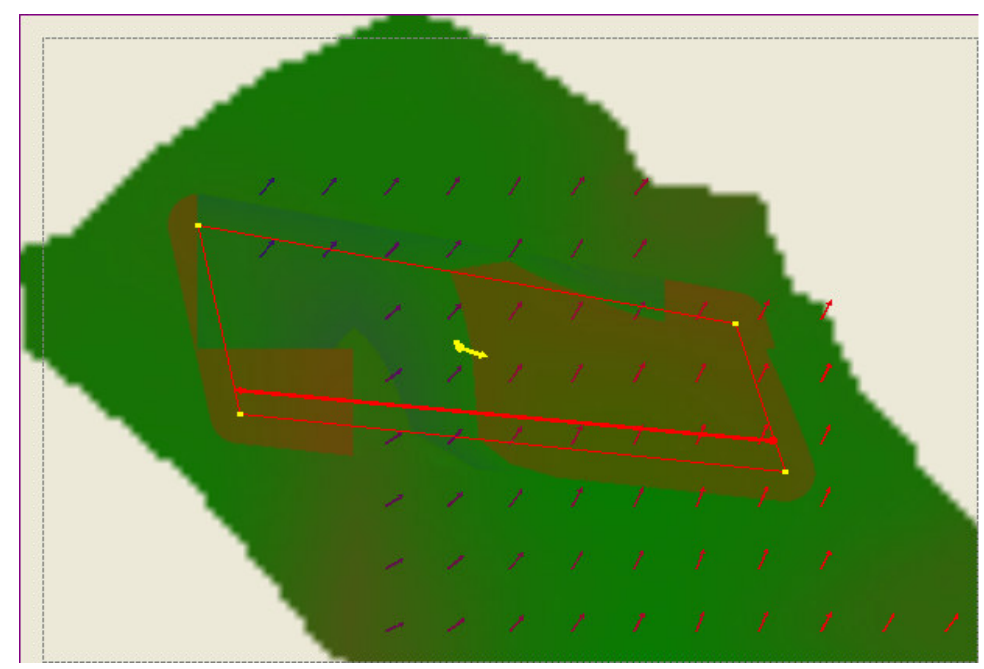

Figure 4. 30 Demonstration of availability of clay layers at the base of the landfill by VLF -green color (within the landfill borders) indicates the presence of the clay layer, whereas red color indicates the absence of clay layer after excavation -landfill length in the direction of groundwater flow

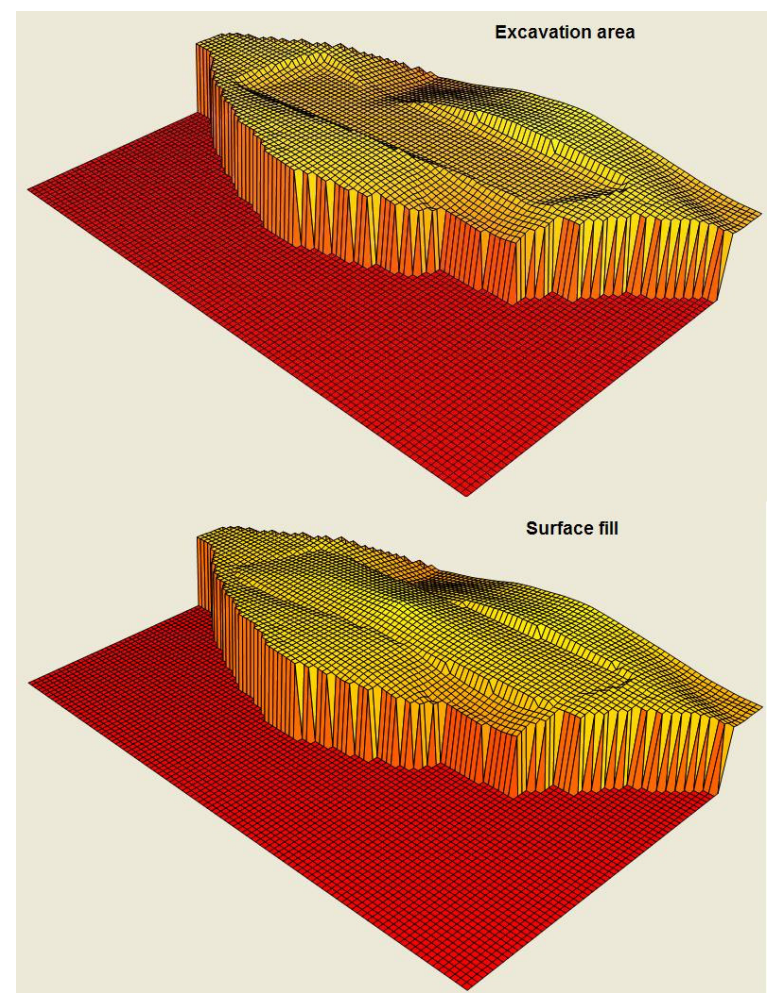

Figure 4. 31 3D demonstration of landfill with and without final cover by VLF -landfill length in the direction of groundwater flow 
Both of the base grade designs were applicable for the design of the landfill for Xcity. However, the second case might cause instabilities where piezometric surface rises above $1 \mathrm{~m}$ in wet seasons. Moreover, orienting the longer side of the landfill in the direction of groundwater flow potentially increases the mass load to the aquifer. The longer side of the landfill is $350 \mathrm{~m}$, whereas the shorter side is $100 \mathrm{~m}$. The peak concentrations calculated for each of the configurations demonstrated that orienting the longer side of the landfill parallel to the groundwater flow direction resulted in almost 3.5 folds increase in peak concentrations (e.g. the simulated peak chloride concentration for design with extensive engineering final cover coupled with a natural attenuation bottom linerC2L1 - increased from $27.3 \mathrm{mg} / \mathrm{L}$ to $94.7 \mathrm{mg} / \mathrm{L}$ ). The excavation volume in the latter case (i.e. longer side parallel to groundwater flow direction, $408380 \mathrm{~m}^{3}$ ) is calculated to be smaller than the first orientation (i.e. longer side perpendicular to groundwater flow direction, $520950 \mathrm{~m}^{3}$ ) due to limited excavation depth. However, to satisfy the required landfill volume, the fill volume requirement increases from $4470 \mathrm{~m}^{3}$ to $6560 \mathrm{~m}^{3}$ and surface volume requirement increases from $247120 \mathrm{~m}^{3}$ to $277320 \mathrm{~m}^{3}$ when the longer side of the landfill is oriented parallel to groundwater flow direction. Therefore, the orientation considering the length of the landfill in the direction of groundwater flow would not be considered as a design option.

\subsubsection{Preliminary Design}

Once the landfill was located on the given area and the dimensions were obtained using VLF, preliminary design alternatives were proposed by the Preliminary Design module in LFDSS, considering general site parameters. The thickness and area of the landfill were known from the VLF model, and annual precipitation was given as $1222 \mathrm{~mm}$. It was reported that the groundwater velocity was in the range of $0.1-0.8 \mathrm{~m} / \mathrm{d}$. To observe the effect of the velocity range, lower end $(0.1 \mathrm{~m} / \mathrm{d})$ and upper end $(0.8 \mathrm{~m} / \mathrm{d})$ velocities were used for evaluation. The preliminary 
design module proposed design alternatives $\mathrm{C} 1 \mathrm{~L} 2, \mathrm{C} 1 \mathrm{~L} 4^{\mathrm{L}}, \mathrm{C} 3 \mathrm{~L} 2$, and $\mathrm{C} 3 \mathrm{~L} 4^{\mathrm{L}}$ for the cases where groundwater flow velocity was around $0.1 \mathrm{~m} / \mathrm{d}$. Superscript L indicates that the design alternative performs well only when placed above lowpermeability aquitards. Increasing the flow velocity increased the number of design alternatives, and C2LX (i.e. C2L1, C2L2, C2L3, C2L4, C2L5, and C2L6) were also added to the proposed designs where groundwater flow velocity was around $0.8 \mathrm{~m} / \mathrm{d}$. Specifications of the design alternatives were given in Table 4.37.

Table 4. 36 Components of final covers and bottom liners of design alternatives proposed by preliminary design module in LFDSS for X-city

\begin{tabular}{|c|c|c|}
\hline Design & Final Cover & Bottom Liner \\
\hline C1L2 & Natural topsoil & $\begin{array}{l}\mathrm{LCS}^{\mathrm{b}}+\text { geomembrane }+\mathrm{CCL}^{\mathrm{c}}+ \\
\text { aquitard/vadose zone }\end{array}$ \\
\hline $\mathrm{C} 1 \mathrm{~L} 4^{\mathrm{L}}$ & Natural topsoil & $\mathrm{LCS}^{\mathrm{b}}+$ geomembrane + aquitard \\
\hline $\mathrm{C} 3 \mathrm{~L} 2$ & Natural topsoil $+\mathrm{CDS}^{\mathrm{a}}+$ Clay liner & $\begin{array}{l}\mathrm{LCS}^{\mathrm{b}}+\text { geomembrane }+\mathrm{CCL}^{\mathrm{c}}+ \\
\text { aquitard/vadose zone }\end{array}$ \\
\hline $\mathrm{C} 3 \mathrm{~L} 4^{\mathrm{L}}$ & Natural topsoil $+\mathrm{CDS}^{\mathrm{a}}+$ Clay liner & $\mathrm{LCS}^{\mathrm{b}}+$ geomembrane + aquitard \\
\hline $\mathrm{C} 2 \mathrm{~L} 1$ & $\begin{array}{l}\text { Natural topsoil }+\mathrm{CDS}^{\mathrm{a}}+ \\
\text { geomembrane + Clay liner }\end{array}$ & Natural aquitard below waste \\
\hline $\mathrm{C} 2 \mathrm{~L} 2$ & $\begin{array}{l}\text { Natural topsoil }+\mathrm{CDS}^{\mathrm{a}}+ \\
\text { geomembrane + Clay liner }\end{array}$ & $\begin{array}{l}\mathrm{LCS}^{\mathrm{b}}+\text { geomembrane }+\mathrm{CCL}^{\mathrm{c}}+ \\
\text { aquitard/vadose zone }\end{array}$ \\
\hline $\mathrm{C} 2 \mathrm{~L} 3$ & $\begin{array}{l}\text { Natural topsoil }+\mathrm{CDS}^{\mathrm{a}}+ \\
\text { geomembrane + Clay liner }\end{array}$ & $\mathrm{LCS}^{\mathrm{b}}+$ aquitard \\
\hline $\mathrm{C} 2 \mathrm{~L} 4$ & $\begin{array}{l}\text { Natural topsoil + } \mathrm{CDS}^{\mathrm{a}}+ \\
\text { geomembrane + Clay liner }\end{array}$ & $\begin{array}{l}\text { LCS }^{\mathrm{b}}+\text { geomembrane + } \\
\text { aquitard/vadose zone }\end{array}$ \\
\hline C2L5 & $\begin{array}{l}\text { Natural topsoil }+\mathrm{CDS}^{\mathrm{a}}+ \\
\text { geomembrane + Clay liner }\end{array}$ & $\begin{array}{l}\mathrm{LCS}^{\mathrm{b}}+\mathrm{CCL}^{\mathrm{c}}+\text { aquitard} / \text { vadose } \\
\text { zone }\end{array}$ \\
\hline C2L6 & $\begin{array}{l}\text { Natural topsoil }+\mathrm{CDS}^{\mathrm{a}}+ \\
\text { geomembrane + Clay liner }\end{array}$ & $\mathrm{CCL}^{\mathrm{c}}+$ aquitard/vadose zone \\
\hline
\end{tabular}


Unlike Siirt Municipal Solid Waste Landfill case study, the groundwater was susceptible to pollution due to leakage from the landfill. Therefore, each of 10 proposed design alternatives were simulated using HELP and POLLUTE models in LFDSS.

\subsubsection{Infiltration Rate Calculations and Final Cover Performance Evaluation}

HELP model in LFDSS was used to calculate infiltration rate passing through the final cover and reaching the waste in landfill. All of the proposed final covers (evapotranspiration final cover $-\mathrm{C} 1$, extensive engineering final cover $-\mathrm{C} 2$, and intermediate design final cover -C3) were simulated using HELP model. Site specific weather data were imported to HELP model tabs for evapotranspiration, precipitation, temperature, and solar radiation. Soil and design data for each of the final cover designs were identified in the Soil\&Design tab. As described in Section 4.5.1.5, evapotranspiration final cover $-\mathrm{C} 1$ is composed of only natural topsoil above waste. Extensive engineering final cover $-\mathrm{C} 2$ is composed of topsoil, cover drainage system, geomembrane, and clay liner. Intermediate design final cover $-\mathrm{C} 3$ is composed of topsoil, cover drainage system, clay liner. The design specifications of the layers are the same as listed in Table 4.22 of Section 4.5.1.5.

The model was run from the Run tab for 10 years (operational lifetime of first stage for years 2010 - 2019) for all of the final cover design options. The infiltration rates were calculated as $0.519 \mathrm{~m} / \mathrm{y}$ for evapotranspiration cover $(\mathrm{C} 1)$, $0.034 \mathrm{~m} / \mathrm{y}$ for extensive engineering final cover (C2), and as $0.495 \mathrm{~m} / \mathrm{y}$ for intermediate design final cover $-\mathrm{C} 3$. Lower infiltration rate from extensive engineering final cover $(\mathrm{C} 2)$ option occurred due to the presence of geomembrane layer (LDPE -low density polyethylene). The infiltration rates were automatically 
transferred to POLLUTE model by LFDSS, and the simulations were continued with groundwater contamination calculations.

\subsubsection{Groundwater Contamination and Landfill Design Performance Evaluation}

POLLUTE model was run in order to calculate leachate head over landfill bottom liner for the designs without leachate collection systems, and to calculate groundwater contaminant concentrations at the top of the aquifer. Each of 10 design alternatives $\left(\mathrm{C} 1 \mathrm{~L} 2, \mathrm{C} 1 \mathrm{~L} 44^{\mathrm{L}}, \mathrm{C} 3 \mathrm{~L} 2, \mathrm{C} 3 \mathrm{~L} 4{ }^{\mathrm{L}}, \mathrm{C} 2 \mathrm{~L} 1, \mathrm{C} 2 \mathrm{~L} 2, \mathrm{C} 2 \mathrm{~L} 3, \mathrm{C} 2 \mathrm{~L} 4\right.$, C2L5, and C2L6) were simulated using POLLUTE model. The design specifications of the landfill alternatives were given in Table 4.37. 
Table 4. 37 Final cover and bottom liner specifications of the investigated design alternatives for X-City

\begin{tabular}{|c|c|c|}
\hline $\begin{array}{c}\text { Design } \\
\text { Alternative }\end{array}$ & Final Cover & Bottom Liner \\
\hline C1L2 & $0.6 \mathrm{~m}$ of natural topsoil & $\begin{array}{l}0.3 \mathrm{~m} \mathrm{LCS}{ }^{\mathrm{b}}+2 \mathrm{~mm} \\
\text { geomembrane }+0.6 \mathrm{~m} \mathrm{CCL}^{\mathrm{c}}+ \\
\text { vadose zone/aquitard }\end{array}$ \\
\hline $\mathrm{C} 1 \mathrm{~L} 4^{\mathrm{L}}$ & $0.6 \mathrm{~m}$ of natural topsoil & $\begin{array}{l}0.3 \mathrm{~m} \mathrm{LCS}+2 \mathrm{~mm} \\
\text { geomembrane }+ \text { aquitard }\end{array}$ \\
\hline C3L2 & $\begin{array}{l}0.6 \mathrm{~m} \text { of natural topsoil }+0.3 \mathrm{~m} \\
\mathrm{CDS}^{\mathrm{a}}+0.6 \mathrm{~m} \text { clay liner }\end{array}$ & $\begin{array}{l}0.3 \mathrm{~m} \mathrm{LCS}+2 \mathrm{~mm} \\
\text { geomembrane + } 0.6 \mathrm{~m} \mathrm{CCL}+ \\
\text { vadose zone/aquitard }\end{array}$ \\
\hline $\mathrm{C} 3 \mathrm{~L} 4^{\mathrm{L}}$ & $\begin{array}{l}0.6 \mathrm{~m} \text { of natural topsoil }+0.3 \mathrm{~m} \\
\mathrm{CDS}^{\mathrm{a}}+0.6 \mathrm{~m} \text { clay liner }\end{array}$ & $\begin{array}{l}0.3 \mathrm{~m} \mathrm{LCS}+2 \mathrm{~mm} \\
\text { geomembrane + aquitard }\end{array}$ \\
\hline C2L1 & $\begin{array}{l}0.6 \mathrm{~m} \text { of natural topsoil }+0.3 \mathrm{~m} \\
\mathrm{CDS}^{\mathrm{a}}+1 \mathrm{~mm} \text { geomembrane }+ \\
0.6 \mathrm{~m} \text { clay liner }\end{array}$ & Natural aquitard below waste \\
\hline C2L2 & $\begin{array}{l}0.6 \mathrm{~m} \text { of natural topsoil }+0.3 \mathrm{~m} \\
\mathrm{CDS}^{\mathrm{a}}+1 \mathrm{~mm} \text { geomembrane }+ \\
0.6 \mathrm{~m} \text { clay liner }\end{array}$ & $\begin{array}{l}0.3 \mathrm{~m} \mathrm{LCS}+2 \mathrm{~mm} \\
\text { geomembrane }+0.6 \mathrm{~m} \mathrm{CCL}+ \\
\text { vadose zone/aquitard }\end{array}$ \\
\hline C2L3 & $\begin{array}{l}0.6 \mathrm{~m} \text { of natural topsoil }+0.3 \mathrm{~m} \\
\mathrm{CDS}^{\mathrm{a}}+1 \mathrm{~mm} \text { geomembrane }+ \\
0.6 \mathrm{~m} \text { clay liner }\end{array}$ & $0.3 \mathrm{~m} \mathrm{LCS}+$ aquitard \\
\hline C2L4 & $\begin{array}{l}0.6 \mathrm{~m} \text { of natural topsoil }+0.3 \mathrm{~m} \\
\mathrm{CDS}^{\mathrm{a}}+1 \mathrm{~mm} \text { geomembrane }+ \\
0.6 \mathrm{~m} \text { clay liner }\end{array}$ & $\begin{array}{l}0.3 \mathrm{~m} \mathrm{LCS}+2 \mathrm{~mm} \\
\text { geomembrane + vadose } \\
\text { zone/aquitard }\end{array}$ \\
\hline C2L5 & $\begin{array}{l}0.6 \mathrm{~m} \text { of natural topsoil }+0.3 \mathrm{~m} \\
\mathrm{CDS}^{\mathrm{a}}+1 \mathrm{~mm} \text { geomembrane }+ \\
0.6 \mathrm{~m} \text { clay liner }\end{array}$ & $\begin{array}{l}0.3 \mathrm{~m} \mathrm{LCS}+2 \mathrm{~mm}+0.6 \mathrm{~m} \mathrm{CCL} \\
+ \text { vadose zone/aquitard }\end{array}$ \\
\hline C2L6 & $\begin{array}{l}0.6 \mathrm{~m} \text { of natural topsoil }+0.3 \mathrm{~m} \\
\mathrm{CDS}^{\mathrm{a}}+1 \mathrm{~mm} \text { geomembrane }+ \\
0.6 \mathrm{~m} \text { clay liner }\end{array}$ & $\begin{array}{l}0.6 \mathrm{~m} \mathrm{CCL}+\text { vadose } \\
\text { zone/aquitard }\end{array}$ \\
\hline
\end{tabular}


For the simulations, initial peak contaminant (chloride) concentration in the leachate was accepted as $1000 \mathrm{mg} / \mathrm{L}$, which is typical for municipal solid waste leachate (İller Bankas1, 2000). Waste density was accepted as $600 \mathrm{~kg} / \mathrm{m}^{3}$, as previously reported. Effective mixing thickness in the aquifer was accepted as 3 $\mathrm{m}$. As the potentiometric surface is $1 \mathrm{~m}$ above the aquifer top, groundwater level relative to the top of the aquifer was taken as $1 \mathrm{~m}$. Lower $(0.1 \mathrm{~m} / \mathrm{d})$ and upper $(0.8$ $\mathrm{m} / \mathrm{d}$ ) end groundwater velocity values were used for outflow velocity. As longer side of the landfill was placed perpendicular to the groundwater flow, the waste length was accepted as $100 \mathrm{~m}$, which was the length of the landfill base in the direction of groundwater flow. Aquitard thickness -remaining after excavationwas $5 \mathrm{~m}$. The aquitard was composed of low-permeability silty clay. The hydraulic conductivity of the drainage material used for leachate collection system was taken as $0.001 \mathrm{~m} / \mathrm{s}$. The input parameters used in POLLUTE simulations are given in Table 4.39. 
Table 4. 38 Input parameters used for POLLUTE simulations

\begin{tabular}{|c|c|c|}
\hline Section & Parameter & Value \\
\hline \multirow[t]{7}{*}{ Source } & Concentration (mg/L) & 1000 \\
\hline & Waste length (m) & 100 \\
\hline & Waste thickness (m) & 20 \\
\hline & Infiltration $(\mathrm{m} / \mathrm{y})^{\mathrm{a}}$ & 0.519 for $\mathrm{C} 1$ final cover \\
\hline & & 0.034 for $\mathrm{C} 2$ final cover \\
\hline & & 0.495 for C3 final cover \\
\hline & Waste density $\left(\mathrm{kg} / \mathrm{m}^{3}\right)$ & 600 \\
\hline Hydraulic & Groundwater level relative to top & 1 \\
\hline Heads & of aquifer (m) & \\
\hline Leakage & LCS $^{\mathrm{b}}$ Conductivity $(\mathrm{m} / \mathrm{s})$ & 0.001 \\
\hline \multirow[t]{3}{*}{ Outflow } & Outflow velocity (m/y) & $36.5 \mathrm{~m} / \mathrm{y}(0.1 \mathrm{~m} / \mathrm{d})$ \\
\hline & & 292 m/y $(0.8$ m/d) \\
\hline & Leachate head $(\mathrm{m})^{\mathrm{c}}$ & \\
\hline \multirow[t]{3}{*}{ Clay Liner } & Thickness (m) & 0.6 \\
\hline & Hydraulic conductivity $(\mathrm{m} / \mathrm{s})$ & $1 \times 10^{-9}$ \\
\hline & Porosity & 0.40 \\
\hline Vadose & Thickness (m) & 5 \\
\hline \multirow[t]{2}{*}{ Zone/Aquitard } & Hydraulic conductivity $(\mathrm{m} / \mathrm{s})$ & $1 \times 10^{-8} \mathrm{~m} / \mathrm{s}$ \\
\hline & Porosity & 0.38 \\
\hline \multirow[t]{2}{*}{ Aquifer } & Thickness (m) & 3 \\
\hline & Porosity & 0.30 \\
\hline
\end{tabular}

$\bar{a}$ automatically calculated and transferred as a result of HELP runs

${ }^{\mathrm{b}}$ leachate collection system

${ }^{c}$ calculated by POLLUTE model for the designs without leachate collection systems, and reported at the end of the simulation to check whether the design satisfies stability criterion (i.e. leachate head should be below $1 \mathrm{~m}$.)

The design alternatives without leachate collection systems (C2L1, and C2L6) satisfied the stability criterion. Both of the designs resulted in zero hydraulic head 
over bottom liner. Therefore, stability with respect to leachate head criterion was satisfied for each of the design alternatives.

Although the design component selection matrix was constructed conservatively allowing for a maximum of $25 \mathrm{mg} / \mathrm{L}$ chloride concentration at the groundwater (TSE, 1997), the maximum allowable concentration reported for chloride in groundwater is $250 \mathrm{mg} / \mathrm{L}$ (TSE, 2005). Therefore, it is reasonable to evaluate the performance of the design alternatives with respect to $250-\mathrm{mg} / \mathrm{L}$ standard. Each of 10 design alternatives satisfied less than $250 \mathrm{mg} / \mathrm{L}$ chloride concentration at the groundwater table, for both of the groundwater velocity values. With respect to 25 $\mathrm{mg} / \mathrm{L}$ standard, design alternatives lacking geomembranes in the bottom liner failed to satisfy the contamination criterion for lower end velocity value of 0.1 $\mathrm{m} / \mathrm{d}$. The results are presented in Table 4.39.

Table 4. 39 POLLUTE simulation results for leachate head and soil contamination

\begin{tabular}{ccccc}
\hline \multirow{2}{*}{$\begin{array}{c}\text { Design } \\
\text { Alternative }\end{array}$} & \multicolumn{4}{c}{ Groundwater Contamination } \\
\cline { 2 - 5 } & $C_{\max }{ }^{a}(\mathrm{mg} / \mathrm{L})$ & \multicolumn{2}{c}{$T_{\max }{ }^{b}(y)$} \\
\hline & $0.1 \mathrm{~m} / \mathrm{d}$ & $v_{s}=0.8 \mathrm{~m} / \mathrm{d}$ & $v_{s}=0.1 \mathrm{~m} / \mathrm{d}$ & $v_{s}=0.8 \mathrm{~m} / \mathrm{d}$ \\
\hline C1L2 & 1.17 & 0.05 & 177 & 177 \\
C1L4 & 0.15 & 130 & 130 \\
C3L2 & 0.43 & 0.05 & 177 & 177 \\
C3L4 & 1.21 & 0.15 & 130 & 130 \\
C2L1 & 27.30 & 3.41 & 85 & 85 \\
C2L2 & 2.35 & 0.29 & 340 & 312 \\
C2L3 & 27.32 & 3.42 & 85 & 85 \\
C2L4 & 5.23 & 0.65 & 235 & 235 \\
C2L5 & 27.11 & 3.39 & 92 & 92 \\
C2L6 & 27.11 & 3.39 & 92 & 92 \\
\hline
\end{tabular}

${ }^{a}$ maximum groundwater concentration of chloride

${ }^{\mathrm{b}}$ time that the maximum concentration is observed 
Although all of the simulations satisfied the contamination criterion, the design alternatives having geomembrane liners both in the cover and in the liner (i.e. C2L2, and C2L4) would not be investigated further, due to possible high cost. Also, designs with extensive engineering final cover (C2) having only leachate collection system or compacted clay liner above aquitard in the bottom liner (i.e. C2L3, and C2L6) was not taken into consideration as they produced almost the same contaminant concentrations with natural attenuation bottom liner (C2L1) and intermediate design bottom liner (C2L5) (Table 4.39). These design alternatives might be considered if the compatible designs did not produce stable factor of safety values. Therefore, the number of design alternatives to be investigated reduced to six (C1L2, C1L4 $4^{\mathrm{L}}, \mathrm{C} 3 \mathrm{~L} 2, \mathrm{C} 3 \mathrm{~L} 4^{\mathrm{L}}, \mathrm{C} 2 \mathrm{~L} 1$, and $\left.\mathrm{C} 2 \mathrm{~L} 5\right)$.

As the designs satisfied the contamination criterion for both of the groundwater velocity values, contaminant concentrations produced as a result of lower end velocity value $(0.1 \mathrm{~m} / \mathrm{d})$ was accepted for conservative results.

\subsubsection{Structural Stability Calculations}

Illustrative stability analyses were performed using literature values for the types of the soils, final cover, and bottom liner systems examined in the above sections. The stability analyses were performed using the stability module in LFDSS. Types of analyses carried out for each of the simulated design alternatives are given in Table 4.40. It should be noted that, excavation slope and refuse fill stability analyses were carried out for a single trial failure surface. Analyses of a representative number of failure surfaces should be performed in order to decide on the stability of the excavation and the refuse. Seismic analysis was not carried out as the area was not reported to be in the earthquake zone. Parameters used in stability analyses are presented in Table 4.41 . 
Table 4. 40 Stability analyses for the investigated design alternatives for X-City

\begin{tabular}{|c|c|c|}
\hline $\begin{array}{c}\text { Design } \\
\text { Alternative }\end{array}$ & Final Cover & Bottom Liner \\
\hline C1L2 & $\begin{array}{l}\text { Cover system stability for } \\
\text { cohesionless soils with seepage }\end{array}$ & $\begin{array}{l}\text { Excavation slope stability - } \\
\text { circular slip surface } \\
\text { Refuse-fill stability -circular } \\
\text { slip surface } \\
\text { Geomembrane stability }\end{array}$ \\
\hline $\mathrm{C} 1 \mathrm{~L} 4^{\mathrm{L}}$ & $\begin{array}{l}\text { Cover system stability for } \\
\text { cohesionless soils with seepage }\end{array}$ & $\begin{array}{l}\text { Excavation slope stability - } \\
\text { circular slip surface } \\
\text { Refuse-fill stability -circular } \\
\text { slip surface } \\
\text { Geomembrane stability }\end{array}$ \\
\hline C3L2 & $\begin{array}{l}\text { Cover system stability for cohesive } \\
\text { soils }\end{array}$ & $\begin{array}{l}\text { Excavation slope stability - } \\
\text { circular slip surface } \\
\text { Refuse-fill stability -circular } \\
\text { slip surface } \\
\text { Geomembrane stability }\end{array}$ \\
\hline $\mathrm{C} 3 \mathrm{~L} 4^{\mathrm{L}}$ & $\begin{array}{l}\text { Cover system stability for cohesive } \\
\text { soils }\end{array}$ & $\begin{array}{l}\text { Excavation slope stability - } \\
\text { circular slip surface } \\
\text { Refuse-fill stability -circular } \\
\text { slip surface } \\
\text { Geomembrane stability }\end{array}$ \\
\hline $\mathrm{C} 2 \mathrm{~L} 1$ & $\begin{array}{l}\text { Cover system stability -with } \\
\text { geomembrane }\end{array}$ & $\begin{array}{l}\text { Excavation slope stability - } \\
\text { circular slip surface } \\
\text { Refuse-fill stability -circular } \\
\text { slip surface }\end{array}$ \\
\hline C2L5 & $\begin{array}{l}\text { Cover system stability -with } \\
\text { geomembrane }\end{array}$ & $\begin{array}{l}\text { Excavation slope stability - } \\
\text { circular slip surface } \\
\text { Refuse-fill stability -circular } \\
\text { slip surface }\end{array}$ \\
\hline
\end{tabular}


Table 4. 41 Parameters used in stability module for factor of safety calculations for X-City ${ }^{\mathrm{f}}$

\begin{tabular}{|c|c|c|c|c|c|c|}
\hline \multirow[b]{2}{*}{ Parameter } & \multicolumn{3}{|c|}{ Final Cover } & \multicolumn{3}{|c|}{ Bottom Liner } \\
\hline & Cohesionless & $\begin{array}{c}\text { Cohesiv } \\
e\end{array}$ & $\begin{array}{l}\text { With } \\
G M^{b}\end{array}$ & $\begin{array}{c}\text { Excavation } \\
\text { slope }^{g}\end{array}$ & $\begin{array}{c}\text { Refuse } \\
\text { fill }^{g}\end{array}$ & $\begin{array}{c}\text { GM } \\
\text { stability }\end{array}$ \\
\hline $\begin{array}{l}\text { Cohesion } \\
\left(\mathrm{kN} / \mathrm{m}^{2}\right)\end{array}$ & - & - & 0 & 15 & 19 & - \\
\hline Friction angle $\left(^{\circ}\right)$ & - & - & 30 & 1.3 & 20 & 15 \\
\hline $\begin{array}{l}\text { Effective friction } \\
\text { angle }\left(^{\circ}\right)\end{array}$ & 30 & 15 & - & - & - & - \\
\hline Slope angle $\left(^{\circ}\right)$ & $4.57(8 \%)^{\mathrm{e}}$ & $4.57^{\mathrm{e}}$ & - & - & - & - \\
\hline$\gamma_{\text {total-soil }}\left(\mathrm{kN} / \mathrm{m}^{3}\right)$ & 18.9 & 18.9 & - & - & - & - \\
\hline$\gamma_{\text {cover-soil }}\left(\mathrm{kN} / \mathrm{m}^{3}\right)$ & - & - & 18.5 & - & - & 18.7 \\
\hline $\begin{array}{l}\text { Thickness of } \\
\text { cover soil (m) }\end{array}$ & - & - & $1.5^{\mathrm{e}}$ & - & - & - \\
\hline $\begin{array}{l}\text { Slope length along } \\
\text { GM (m) }\end{array}$ & - & - & $194^{\mathrm{e}}$ & - & - & - \\
\hline $\begin{array}{l}\text { Slope angle } \\
\text { beneath GM }\left(^{\circ}\right)\end{array}$ & - & - & $24.57^{\mathrm{e}}$ & - & - & - \\
\hline$\varphi_{\text {cover soil-GM }}^{\mathrm{c}}\left({ }^{\circ}\right)$ & - & - & 22 & - & - & - \\
\hline $\begin{array}{l}\text { Effective cohesion } \\
\left(\mathrm{kN} / \mathrm{m}^{2}\right)\end{array}$ & - & 4.8 & - & - & - & - \\
\hline $\mathrm{H}^{\mathrm{d}}(\mathrm{m})$ & - & $15^{\mathrm{e}}$ & - & - & - & $5,7.5$ \\
\hline $\begin{array}{l}\text { Clay liner } \\
\text { thickness (m) }\end{array}$ & - & $0.6^{\mathrm{e}}$ & - & - & - & - \\
\hline$\gamma_{\text {water }}\left(\mathrm{kN} / \mathrm{m}^{3}\right)$ & 9.8 & 9.8 & - & - & - & - \\
\hline Height of LCS (m) & - & - & - & - & - & 0.3 \\
\hline$\gamma_{\text {granular }}\left(\mathrm{kN} / \mathrm{m}^{3}\right)$ & - & - & - & - & - & 14.2 \\
\hline Slope angle $\left(^{\circ}\right)$ & - & - & - & - & - & $\begin{array}{c}18.4 \\
(1 \mathrm{v}: 3 \mathrm{~h})^{\mathrm{e}}\end{array}$ \\
\hline$\varphi_{\text {geotextile-GM }}^{\mathrm{c}}\left({ }^{\circ}\right)$ & - & - & - & - & - & 20 \\
\hline Anchor height (m) & - & - & - & - & - & $1,1.5$ \\
\hline
\end{tabular}


Stability analyses for all six design alternatives produced stable factor of safety values which were calculated to be greater than 1.5 (Sharma and Lewis, 1994; Koerner and Daniel, 1997). Especially, cover systems with compacted clay liners (cohesive soils) resulted in high stability (Table 4.42). The bottom liners having geomembranes were found stable when the anchor height was greater than or equal to $1 \mathrm{~m}$. Therefore, each of six design alternatives may be considered safe for construction.

Table 4. 42 Factor of safety values calculated by the stability module in LFDSS for X-city designs

\begin{tabular}{|c|c|c|c|c|c|c|}
\hline \multirow{3}{*}{ Design } & \multicolumn{6}{|c|}{ Factor of Safety Values (FS) } \\
\hline & \multirow[b]{2}{*}{ Cover system } & \multirow{2}{*}{$\begin{array}{c}\text { Excavation } \\
\text { slope }^{a}\end{array}$} & \multirow[b]{2}{*}{ Refuse fill ${ }^{a}$} & \multicolumn{3}{|c|}{ Geomembrane stability } \\
\hline & & & & $\begin{array}{c}\text { Slope } \\
\text { height }(m)\end{array}$ & $\begin{array}{c}\text { Anchor } \\
\text { height (m) }\end{array}$ & $F S$ \\
\hline \multirow[t]{4}{*}{ C1L2 } & 3.48 & 3.20 & 3.49 & 5 & 1 & 2.42 \\
\hline & & & & 7.5 & 1 & 1.61 \\
\hline & & & & 5 & 1.5 & 5.44 \\
\hline & & & & 7.5 & 1.5 & 3.63 \\
\hline \multirow[t]{4}{*}{$\mathrm{C} 1 \mathrm{~L} 4^{\mathrm{L}}$} & 3.48 & 3.20 & 3.49 & 5 & 1 & 2.42 \\
\hline & & & & 7.5 & 1 & 1.61 \\
\hline & & & & 5 & 1.5 & 5.44 \\
\hline & & & & 7.5 & 1.5 & 3.63 \\
\hline \multirow[t]{4}{*}{ C3L2 } & 44.69 & 3.20 & 3.49 & 5 & 1 & 2.42 \\
\hline & & & & 7.5 & 1 & 1.61 \\
\hline & & & & 5 & 1.5 & 5.44 \\
\hline & & & & 7.5 & 1.5 & 3.63 \\
\hline \multirow[t]{4}{*}{$\mathrm{C} 3 \mathrm{~L} 4^{\mathrm{L}}$} & 44.69 & 3.20 & 3.49 & 5 & 1 & 2.42 \\
\hline & & & & 7.5 & 1 & 1.61 \\
\hline & & & & 5 & 1.5 & 5.44 \\
\hline & & & & 7.5 & 1.5 & 3.63 \\
\hline $\mathrm{C} 2 \mathrm{~L} 1$ & 9.17 & 3.20 & 3.49 & - & - & - \\
\hline C2L5 & 9.17 & 3.20 & 3.49 & - & - & - \\
\hline
\end{tabular}

a single trial surface 


\subsubsection{Cost Calculations of Major Design Components}

Major landfill components include native soil, topsoil, clay liners, drainage system components, and geosynthetics (i.e. geomembranes). Additional component taken into consideration here was geotextile filters. Major, additional, and total costs of design alternatives were calculated using cost estimation module in LFDSS. Majority of the costs was related with soil excavation, which was independent of the design alternative. VLF model of LFDSS calculated the excavation and fill volumes as $520950 \mathrm{~m}^{3}$ and $4470 \mathrm{~m}^{3}$ respectively for the landfill examined for X-City. For intermediate soil covers one to four soil to waste ratio is commonly accepted. Considering $1 \mathrm{v}: 3 \mathrm{~h}$ slopes at the sides of the landfill, the length of the landfill approximately extends to $388 \mathrm{~m}$, and the width of the landfill approximately extends to $130 \mathrm{~m}$ at the surface (Figure 4.32).

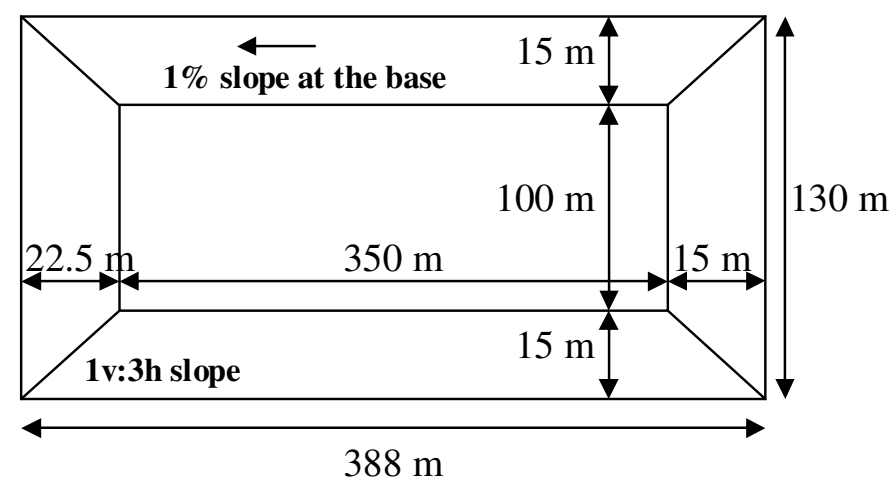

Figure 4. 32 Schematic view of the surface area of the landfill for X-City

A native topsoil of $0.6 \mathrm{~m}$ thick was applied in the final cover, which covers an area of approximately $5 \mathrm{ha}(388 \mathrm{~m} \times 130 \mathrm{~m})$. Considering the total landfill volume of $705105 \mathrm{~m}^{3}$, soil requirement for intermediate and final covers were calculated as: 
Daily and intermediate covers $\quad V_{\text {int }}=\frac{705105 \mathrm{~m}^{3}}{4}=176276 \mathrm{~m}^{3}$

Final cover

$$
V_{\text {final }}=0.6 m \times 50000 m^{2}=30000 m^{3}
$$

Volumes of soil to be used during landfill construction, and excess amount of soil that is needed to be disposed are given in Table 4.43 .

Table 4. 43 Volumes of soil used in landfill construction for X-City landfill

\begin{tabular}{|c|c|c|c|c|c|c|}
\hline $\begin{array}{l}\text { Area } \\
\text { (ha) }\end{array}$ & $\begin{array}{c}\text { Excavation } \\
\left(\mathbf{m}^{3}\right)\end{array}$ & $\begin{array}{l}\text { Fill } \\
\left(\mathbf{m}^{3}\right)\end{array}$ & $\begin{array}{c}D \& I^{a} \\
\text { Covers } \\
\left(\mathbf{m}^{3}\right)\end{array}$ & $\begin{array}{c}\text { Final } \\
\text { Cover } \\
\left(\mathbf{m}^{3}\right)\end{array}$ & $\begin{array}{c}\text { Total }^{\mathrm{b}} \\
\left(\mathbf{m}^{3}\right)\end{array}$ & $\begin{array}{c}\text { Excessive } \\
\text { Soil } \\
\text { Volume } \\
\left(\mathbf{m}^{3}\right)\end{array}$ \\
\hline Base Cover & & & & & & \\
\hline $\begin{array}{ll}3.5 & 5.0\end{array}$ & 520950 & 4470 & 176276 & 30000 & 210746 & 310204 \\
\hline
\end{tabular}

Analyses that were considered for design alternatives are presented in Table 4.44. Geotextiles for reinforcement were also considered as an additional cost for the designs including geomembranes. 
Table 4. 44 Landfill components of the design alternatives considered for cost analyses

\begin{tabular}{|c|c|}
\hline Design Alternative & Cost Analyses \\
\hline C1L2 & $\begin{array}{l}\text { Native soil, topsoil, drainage, drainage tile, clay, } \\
\text { geomembrane, geotextile }\end{array}$ \\
\hline $\mathrm{C} 1 \mathrm{~L} 4^{\mathrm{L}}$ & $\begin{array}{l}\text { Native soil, topsoil, drainage, drainage tile, } \\
\text { geomembrane, geotextile }\end{array}$ \\
\hline C3L2 & $\begin{array}{l}\text { Native soil, topsoil, drainage, drainage tile, clay, } \\
\text { geomembrane, geotextile }\end{array}$ \\
\hline $\mathrm{C} 3 \mathrm{~L} 4^{\mathrm{L}}$ & $\begin{array}{l}\text { Native soil, topsoil, drainage, drainage tile, } \\
\text { geomembrane, geotextile }\end{array}$ \\
\hline C2L1 & $\begin{array}{l}\text { Native soil, topsoil, drainage, clay, geomembrane, } \\
\text { geotextile }\end{array}$ \\
\hline C2L5 & $\begin{array}{l}\text { Native soil, topsoil, drainage, clay, geomembrane, } \\
\text { geotextile }\end{array}$ \\
\hline
\end{tabular}

Virtual Landfill (VLF) model demonstrated that almost half of the landfill base stayed on top of clayey zones. A 0.6-m-thick clay layer would be used for bottom liners and final covers. Amounts of clay required for bottom liner and final cover were approximately calculated as:

$$
\begin{aligned}
& \text { Bottom clay; } V_{\text {clay }}=0.6 \mathrm{~m} \times 35000 \mathrm{~m}^{2}=21000 \mathrm{~m}^{2} \\
& \text { Final cover clay; } 0.6 \mathrm{~m} \times 50000 \mathrm{~m}^{2}=30000 \mathrm{~m}^{3}
\end{aligned}
$$

As almost half of the clay was visible at the base of the landfill, available clay volume was estimated to be $10000 \mathrm{~m}^{3}$. Therefore, the required excavation amount of clay was $11000 \mathrm{~m}^{3}\left(21000 \mathrm{~m}^{3}-10000 \mathrm{~m}^{3}\right)$ for bottom liners, and $30000 \mathrm{~m}^{3}$ for final covers; corresponding to a total of $41000 \mathrm{~m}^{3}\left(11000 \mathrm{~m}^{3}+30000 \mathrm{~m}^{3}\right)$.

Soil amounts that were supposed to be used for the construction of various design alternatives are given in Table 4.45. 
Table 4. 45 Amounts of soil to be used in landfill construction for X-City landfill

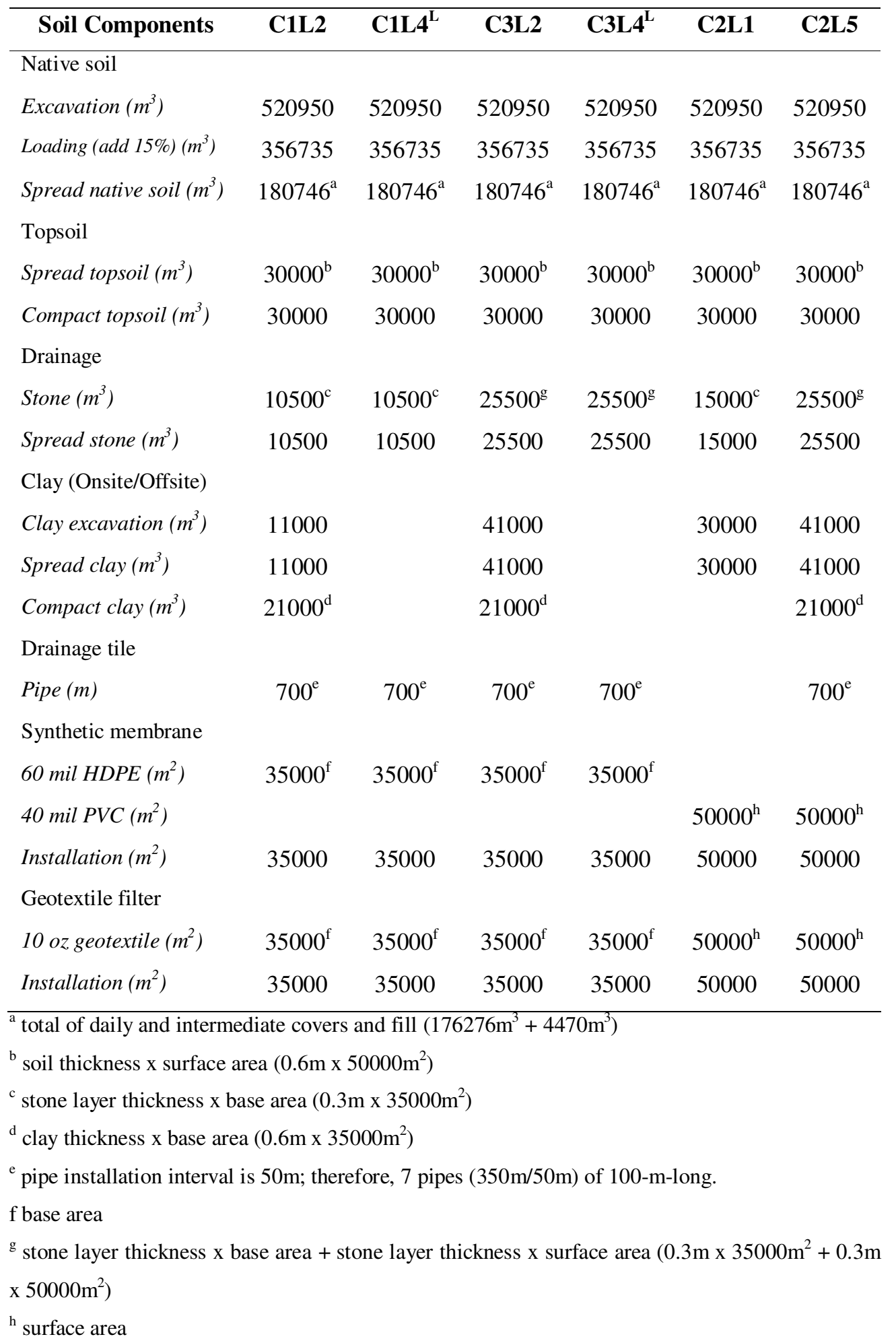


The design alternatives resulted in costs around $2.0-2.5$ million USD (Table 4.46). The design alternatives including evapotranspiration final covers (C1) resulted in the least cost $(1.9-2.1$ million USD), and the costs of the designs increased as the final cover specifications increased. This occurred due to larger surface area of the final cover and higher requirement of the surface materials (geomembranes, clay liners, etc.) associated with larger surface area. The highest cost corresponded to the design alternative with extensive engineering final cover having cover drainage system, geomembrane, and clay liner, and intermediate design bottom liner having leachate collection system and compacted clay liner (C2L5). Cost of this alternative exceeded 2.5 million USD. As groundwater in the area is susceptible to contamination, and the site receives considerable amount of precipitation, sophisticated bottom liners having geomembranes should be considered, instead of more sophisticated final covers. This kind of decision will not only increase the performance of the design, but also reduce the costs associated with construction.

Table 4. 46 Major, additional and total costs of design alternatives for X-City

\begin{tabular}{cccc}
\hline $\begin{array}{c}\text { Design } \\
\text { Alternative }\end{array}$ & $\begin{array}{c}\text { Major Costs } \\
\text { (USD) }\end{array}$ & $\begin{array}{c}\text { Additional } \\
\text { Costs }^{\mathbf{a}}\end{array}$ & $\begin{array}{c}\text { Total Cost } \\
\text { (USD) }\end{array}$ \\
\hline C1L2 & 2071164 & 30450 & 2101614 \\
C1L4 ${ }^{\mathrm{L}}$ & 1925224 & 30450 & 1955674 \\
C3L2 & 2507814 & 30450 & 2538264 \\
C3L4 & 2097874 & 30450 & 2128324 \\
C2L1 & 2224324 & 43500 & 2267824 \\
C2L5 & 2501694 & 43500 & 2545194 \\
\hline${ }^{\text {includes cost of geotextiles }}$ & & &
\end{tabular}




\subsubsection{Presentation of the Assessments and Decision Making}

After all the modules in LFDSS were run for each of the design alternative under investigation $\left(\mathrm{C} 1 \mathrm{~L} 2, \mathrm{C} 1 \mathrm{~L} 4^{\mathrm{L}}, \mathrm{C} 3 \mathrm{~L} 2, \mathrm{C} 3 \mathrm{~L} 4^{\mathrm{L}}, \mathrm{C} 2 \mathrm{~L} 1\right.$, and $\left.\mathrm{C} 2 \mathrm{~L} 5\right)$, the results produced by each model and module (i.e. Preliminary design module, POLLUTE model, stability module, and cost estimation module) were saved by the LFDSS in the performance report (Appendix-G). The saved file was imported to MS Excel results template provided with the software to compare the performances of the simulated design alternatives and ease the decision making process. The overall results of the simulations of design alternatives are presented in Table 4.47. Leachate head values were not included in results table (Table 4.47), as simulations are not performed for the designs that do not comply with the stability criterion (i.e. leachate head should be less than $1 \mathrm{~m}$ ). 
Table 4. 47 Overall results of the landfill design simulations by LFDSS for X-City

\begin{tabular}{|c|c|c|c|c|c|c|c|}
\hline \multirow{3}{*}{$\begin{array}{l}\text { Design } \\
\text { C1L2 }\end{array}$} & \multicolumn{2}{|c|}{ Performance } & \multicolumn{2}{|c|}{ Stability } & \multicolumn{3}{|c|}{ Cost (USD) } \\
\hline & \multirow{2}{*}{$\begin{array}{c}\mathrm{Cl}_{\text {max }}{ }^{a} \\
(\mathrm{mg} / \mathrm{L})\end{array}$} & \multirow{2}{*}{$\begin{array}{c}T_{\max }^{b} \\
(y r) \\
177\end{array}$} & \multicolumn{2}{|c|}{ FS values } & \multirow{2}{*}{$\begin{array}{c}\begin{array}{c}\text { Main } \\
\text { Cost }\end{array} \\
2071164\end{array}$} & \multirow{2}{*}{$\begin{array}{c}\begin{array}{c}\text { Additional } \\
\text { Cost }\end{array} \\
30450\end{array}$} & \multirow{2}{*}{$\begin{array}{c}\begin{array}{c}\text { Total } \\
\text { Cost }\end{array} \\
2101614\end{array}$} \\
\hline & & & $\begin{array}{l}\text { Excavation } \\
\text { slope }\end{array}$ & 3.20 & & & \\
\hline & & & Refuse-fill & 3.49 & & & \\
\hline & & & Cover system & 3.48 & & & \\
\hline & & & Geomembrane & $5 / 1 / 2.42^{\mathrm{c}}$ & & & \\
\hline & & & & $7.5 / 1 / 1.61$ & & & \\
\hline & & & & $5 / 1.5 / 5.44$ & & & \\
\hline & & & & $7.5 / 1.5 / 3.63$ & & & \\
\hline & & & Seismic & - & & & \\
\hline \multirow[t]{8}{*}{$\mathrm{C} 1 \mathrm{~L} 4^{\mathrm{L}}$} & 1.17 & 130 & $\begin{array}{l}\text { Excavation } \\
\text { slope }\end{array}$ & 3.20 & 1925224 & 30450 & 1955674 \\
\hline & & & Refuse-fill & 3.49 & & & \\
\hline & & & Cover system & 3.48 & & & \\
\hline & & & Geomembrane & $5 / 1 / 2.42^{\mathrm{c}}$ & & & \\
\hline & & & & 7.5/1/1.61 & & & \\
\hline & & & & $5 / 1.5 / 5.44$ & & & \\
\hline & & & & $7.5 / 1.5 / 3.63$ & & & \\
\hline & & & Seismic & - & & & \\
\hline \multirow[t]{8}{*}{ C3L2 } & 0.43 & 177 & $\begin{array}{l}\text { Excavation } \\
\text { slope }\end{array}$ & 3.20 & 2507814 & 30450 & 2538264 \\
\hline & & & Refuse-fill & 3.49 & & & \\
\hline & & & Cover system & 45.68 & & & \\
\hline & & & Geomembrane & $5 / 1 / 2.42^{c}$ & & & \\
\hline & & & & 7.5/1/1.61 & & & \\
\hline & & & & $5 / 1.5 / 5.44$ & & & \\
\hline & & & & $7.5 / 1.5 / 3.63$ & & & \\
\hline & & & Seismic & - & & & \\
\hline
\end{tabular}


Table 4. 47 Overall results of the landfill design simulations by LFDSS for X-City (cont'd)

\begin{tabular}{|c|c|c|c|c|c|c|c|}
\hline \multirow[b]{2}{*}{ Design } & \multicolumn{2}{|c|}{ Performance } & \multicolumn{2}{|c|}{ Stability } & \multicolumn{3}{|c|}{ Cost (USD) } \\
\hline & $\begin{array}{l}\mathrm{Cl}_{\max }{ }^{a} \\
(\mathrm{mg} / \mathrm{L})\end{array}$ & $\begin{array}{l}T_{\max }{ }^{b} \\
(y r)\end{array}$ & \multicolumn{2}{|c|}{ FS values } & $\begin{array}{l}\text { Main } \\
\text { Cost }\end{array}$ & $\begin{array}{l}\text { Additional } \\
\text { Cost }\end{array}$ & $\begin{array}{l}\text { Total } \\
\text { Cost }\end{array}$ \\
\hline \multirow[t]{8}{*}{$\mathrm{C} 3 \mathrm{~L}^{\mathrm{L}}$} & 1.21 & 130 & $\begin{array}{l}\text { Excavation } \\
\text { slope }\end{array}$ & 3.20 & 2097874 & 30450 & 2128324 \\
\hline & & & Refuse-fill & 3.49 & & & \\
\hline & & & Cover system & 45.68 & & & \\
\hline & & & Geomembrane & $5 / 1 / 2.42^{c}$ & & & \\
\hline & & & & 7.5/1/1.61 & & & \\
\hline & & & & $5 / 1.5 / 5.44$ & & & \\
\hline & & & & $7.5 / 1.5 / 3.63$ & & & \\
\hline & & & Seismic & - & & & \\
\hline \multirow[t]{5}{*}{ C2L1 } & 27.30 & 85 & $\begin{array}{l}\text { Excavation } \\
\text { slope }\end{array}$ & 3.20 & 2224324 & 43500 & 2267824 \\
\hline & & & Refuse-fill & 3.49 & & & \\
\hline & & & Cover system & 9.17 & & & \\
\hline & & & Geomembrane & - & & & \\
\hline & & & Seismic & - & & & \\
\hline \multirow[t]{5}{*}{ C2L5 } & 27.11 & 92 & $\begin{array}{l}\text { Excavation } \\
\text { slope }\end{array}$ & 3.20 & 2501694 & 43500 & 2545194 \\
\hline & & & Refuse-fill & 3.49 & & & \\
\hline & & & Cover system & 9.17 & & & \\
\hline & & & Geomembrane & - & & & \\
\hline & & & Seismic & - & & & \\
\hline
\end{tabular}

${ }^{\mathrm{a}}$ maximum soil chloride concentration ${ }^{\mathrm{b}}$ time that maximum concentration was observed

${ }^{\mathrm{c}}$ slope height $(\mathrm{m}) /$ anchor height $(\mathrm{m}) /$ factor of safety

Although each of 6 design alternatives resulted in groundwater chloride concentrations less than $250 \mathrm{mg} / \mathrm{L}$, the design alternatives having extensive engineering final covers (C2) and either natural attenuation bottom liners (L1) or intermediate design bottom liners having leachate collection systems and compacted clay liners (L5) produced higher chloride concentrations $(27.30 \mathrm{mg} / \mathrm{L}$ and $27.11 \mathrm{mg} / \mathrm{L}$, respectively) at the groundwater table. Considering the high costs associated with the aforementioned designs, these design alternatives (C2L1, and C2L5) would not be selected for X-City. 
Remaining four design alternatives $\left(\mathrm{C} 1 \mathrm{~L} 2, \mathrm{C} 1 \mathrm{~L} 44^{\mathrm{L}}, \mathrm{C} 3 \mathrm{~L} 2\right.$, and $\left.\mathrm{C} 3 \mathrm{~L} 4^{\mathrm{L}}\right)$ produced negligible amounts of chloride concentration at the groundwater table $(0.41 \mathrm{mg} / \mathrm{L}$, $1.17 \mathrm{mg} / \mathrm{L}, 0.43 \mathrm{mg} / \mathrm{L}$, and $1.21 \mathrm{mg} / \mathrm{L}$, respectively for C1L2, C1L4 ${ }^{\mathrm{L}}, \mathrm{C} 3 \mathrm{~L} 2$, and $\mathrm{C} 3 \mathrm{~L} 4^{\mathrm{L}}$ ). The result was mainly associated with geomembrane liners installed in the bottom liner. Extensive engineering bottom liners (L2) include leachate collection systems, geomembrane liners, and compacted clay liners; whereas, C4 bottom liners include leachate collection systems and geomembrane liners placed over low-permeability aquitards. The designs also produced stable factor of safety values. However, design alternatives having final covers composed of cohesive soils (i.e. covers including clay liners; such as C3) were found to be more stable with respect to factor of safety values. If the final cover stability is guaranteed for design alternatives having evapotranspiration final covers (C1), these design alternatives $\left(\mathrm{C} 1 \mathrm{~L} 2\right.$, and $\left.\mathrm{C} 1 \mathrm{~L} 4^{\mathrm{L}}\right)$ may be preferred due to relatively low construction costs $(1.95-2.10$ million USD). Otherwise, alternatives with intermediate design final covers having cover drainage system and clay liners (C3) should be considered, although the costs of these design alternatives (C3L2, and $\left.\mathrm{C} 3 \mathrm{~L} 4{ }^{\mathrm{L}}\right)$ are higher $(2.13-2.54$ million USD). 


\section{CHAPTER 5}

\section{CONCLUSIONS}

Conclusions of the study are presented under three main headings: evaluation of the effects of design variables on the performance of landfill designs, evaluation of the results of the performance-based landfill design simulation, and evaluation of the strengths and weaknesses of the developed DSS (LFDSS) based on case study results.

\subsection{Effects of Design Variables on the Performance of Landfills}

The contaminant concentrations in the aquifer decreased as the seepage velocity increased, due to dilution. The effect of dilution is stronger for lower contaminant concentrations; therefore, the decrease is observed to be predominant for extensive engineering designs (C2L2) and a weaker dilution effect was observed for designs with less-engineered components (C1L1, and C3L5). The effect of waste thickness is not as evident as seepage velocity. The contaminant concentrations increased with increasing waste thickness, reaching an asymptotic threshold depth of $(30 \mathrm{~m})$. This phenomenon is related to faster waste stabilization as the older waste at the bottom treats the leachate of fresh waste at the top due to increased biological activity in the older waste. The sensitivity analyses for the combined effect of seepage velocity and waste thickness demonstrated that the 
effects of both parameters are additive, which was expected as these variables are independent of each other.

Hydraulic properties of the vadose zone appeared to have a much more complex effect on the performance of the landfill. Failure to consider the presence of an unsaturated zone beneath a CCL and the assumption of zero suction at the base of the CCL can result in substantial underestimation of the leakage through the clay liner. This consideration should be given to the effect of the vadose zone on the leakage through the CCL.

Unsaturated soil hydraulic conductivity is a function of water content and, hence, it increases with increasing water content towards the water table. Because the thickness of soil with low moisture content, and hence low hydraulic conductivity, increases with increasing vadose zone thickness, the harmonic mean hydraulic conductivity values of the vadose zone decrease with increasing thickness of the vadose zone. When the barrier system is simulated using unsaturated soil hydraulic conductivity functions, the resulting harmonic mean hydraulic conductivity values of the coarse textured vadose zones are $3-4$ orders of magnitude less than the uniform saturated hydraulic conductivity values. For fine textured vadose zones, however, the difference is only one order of magnitude. Therefore, the representative values to be used in the design of landfills were selected as $10^{-7} \mathrm{~m} / \mathrm{s}$ for sandy vadose zones and $10^{-7}-10^{-8} \mathrm{~m} / \mathrm{s}$ for silty aquitards.

For both coarse and fine textured vadose zones, the effective hydraulic conductivity of the overall barrier system increases with increasing thickness of the vadose zone. The increased effective hydraulic conductivity values result in a gradual increase in the steady state leakage rates into the aquifer. Steady-state leakage rates in the fine and coarse textured vadose zones reach an asymptotic value at about $5 \mathrm{~m}$ and $10 \mathrm{~m}$ thickness, respectively, for the cases examined herein. The coarse textured vadose zones thicker than $10 \mathrm{~m}$ and fine textured 
vadose zones thicker than $5 \mathrm{~m}$ start to act as a part of the barrier system. A 5 to 10-m-thick vadose zone can be not only an effective advective barrier, but also be an effective diffusive barrier. For inorganic contaminants, as the thicknesses of CCL and vadose increase, the diffusive mass flux and thus concentrations of contaminants diffusing through the barrier tend to decrease due to the decrease in concentration gradients.

Modeling the barrier systems using uniform saturated hydraulic conductivity values resulted in 2.0 - 3.5 times greater steady-state leakage rates than using unsaturated hydraulic conductivity functions, for coarse textured vadose zones. For fine textured vadose zones, the same steady-state leakage rates were obtained by modeling both with uniform saturated hydraulic conductivities and unsaturated hydraulic conductivity functions for vadose zones, shallower than $5 \mathrm{~m}$. When the vadose zone thickness was increased beyond $5 \mathrm{~m}$, nearly 1.5 to 2.5 times greater steady-state leakage rates were produced by using uniform saturated hydraulic conductivity values. Therefore, it was concluded that, realistic modeling of the barrier systems composed of coarse textured vadose zones requires the consideration of the unsaturated soil hydraulic conductivities. On the other hand, uniform saturated hydraulic conductivity values can still be used for modeling the barrier systems composed of fine textured vadose zones to achieve conservative results.

One order of magnitude decrease in the hydraulic conductivity of the CCL resulted in the same order of magnitude decrease in the steady-state leakage rate; whereas, the same order of magnitude increase in the vadose zone thickness only resulted in half order of magnitude increase in the steady-state leakage rate. While the vadose zone thickness affects the effective hydraulic conductivity of the overall barrier system, and in turn the steady-state leakage rates, the CCL hydraulic conductivity was the primary factor controlling the steady-state leakage rates through the barrier system. 
As the climate gets wetter, the specifications of the landfill design should be more stringent. As the waste thickness and landfill size (base length in the direction of groundwater flow) increased, contaminant concentration reaching the aquifer increased. However, as landfill size and precipitation increased, the effect of waste thickness on contaminant concentrations diminished. Seepage velocity dilutes the contaminants in the leachate; therefore, lower contaminant concentrations were observed at the receptor when the seepage velocity was higher. The hydraulic properties of the vadose zone (i.e. hydraulic conductivity, porosity, and vadose zone thickness) affected the effective hydraulic conductivity of the bottom liner; and therefore, the rate of leakage into the aquifer. The leakage rate decreased with decreasing vadose zone hydraulic conductivity.

Therefore, climate, landfill area, waste thickness, seepage velocity, and site hydrogeology were selected to be considered as design variables that would be used for the design component selection matrix. The design component selection matrix accommodates the results of 1300 simulations performed considering the aforementioned design variables. It is used as a knowledge-base in the preliminary phase of the landfill decision support system. The design component selection matrix offers guidance in design selection and is beneficial in selecting preliminary landfill design alternatives when general site parameters are known.

\subsection{Evaluation of Performance-based Landfill Design Simulations}

Evapotranspiration final covers composed of only natural topsoil over waste $(\mathrm{C} 1)$ produced the highest infiltration rate; whereas, extensive engineering final covers including natural topsoil, drainage layer, geomembrane, and clay liner (C2) restricted the infiltration rate to a great extent. Clay liners without geomembranes were not sufficient in limiting the infiltration to the waste. If the leakage below landfill is controlled by final cover design, then geomembranes in final covers or capillary barrier final covers should be considered. 
Hydraulic head developed on top of landfill barrier for the designs lacking leachate collection systems (L1, L6). For arid climates, as the infiltration rate was lower than the hydraulic conductivity of the compacted clay liner in the aforementioned designs, hydraulic head development above the liner was not observed. Under moderate climates, significant hydraulic head (> $1 \mathrm{~m}$ ) was developed when the vadose zone hydraulic conductivity was less than $10^{-7} \mathrm{~m} / \mathrm{s}$. Under humid climates, both natural attenuation bottom liner composed only of aquitard below waste (L1) and bottom liner composed of compacted clay liner without leachate collection system (L6) resulted in a hydraulic head greater than 1 m. Therefore, it is concluded that leachate collection systems are required for designs under moderate and humid climates regardless of the type of final cover design, in order to satisfy the stability of the landfill design (i.e. less than 1-mleachate head over bottom liner).

Under arid climates, as the infiltration rate was much lower than any of the bottom liner hydraulic conductivities composed of natural material (L1, L3, L5, and L6); leachate collection system was not functional. In this case, leakage rate is controlled by the final cover. Under moderate climates, the leachate collection systems were effective only when coupled with a compacted clay liner. Under humid climates, the infiltration rate was higher than any of the bottom liner design hydraulic conductivities. Efficiency of leachate collection systems coupled with compacted clay liners was not sufficient, and inclusion of geomembranes were required.

Under arid climates, when groundwater seepage velocities were in the range of medium to fast $(0.5-1 \mathrm{~m} / \mathrm{d})$, all the design alternatives complied with the performance criterion for communal to small sized landfills (A $<15$ ha). For medium sized landfills having shallow waste thickness $(5 \mathrm{~m})$, all design alternatives implemented on low conductivity vadose zones complied with performance criterion. Except for very slow seepage velocities $(0.05 \mathrm{~m} / \mathrm{d})$ which 
required geomembrane inclusion in the bottom liner, design alternatives composed of extensive engineering final cover (C2) performed satisfactorily. For large landfills ( $>50 \mathrm{ha}$ ) having a waste thickness of $20 \mathrm{~m}$, the seepage velocity was insufficient in diluting the contaminant load in the aquifer; and, inclusion of geomembranes in the bottom liner designs became necessary. For shallower waste thicknesses $(5 \mathrm{~m})$, geomembranes were optional for performance.

Under moderate climates, as the efficiency of leachate collection system coupled with compacted clay liner (L5) was not sufficient, this design alternative did not comply with the performance criterion. Similar to the results under arid climates, except for very slow seepage velocities $(0.05 \mathrm{~m} / \mathrm{d})$ which required geomembrane inclusion in the bottom liner, design alternatives composed of extensive engineering final cover $(\mathrm{C} 2)$ performed satisfactorily. For faster velocities $(v>0.1$ $\mathrm{m} / \mathrm{d}$ ), designs having compacted clay liners in their bottom liners complied with the performance criterion. For large landfills (A > 50 ha), the seepage velocity was insufficient in diluting the contaminant load in the aquifer; and, inclusion of geomembranes in the bottom liner designs became obligatory.

Under humid climates, as the infiltration rate was higher than the effective hydraulic conductivity of natural attenuation bottom liners composed of only aquitard below waste (L1) and of bottom liners composed of leachate collection systems placed on low conductivity aquitards (L3), the hydraulic properties of these designs were insufficient to comply with the performance criterion. Moreover, designs having leachate collection systems coupled with compacted clay liners did not satisfy the contaminant concentration requirement at the receptor, either. Only for communal size landfills ( $\mathrm{A}<2$ ha) placed on low conductivity vadose zones, bottom liner designs composed of leachate collection systems coupled with compacted clay liners performed satisfactorily. For small size landfills ( 2 - 15 ha) having extensive engineering covers (C2), and for medium size landfills (15 - 50 ha) under medium to fast seepage velocities ( $v>$ 
$0.5 \mathrm{~m} / \mathrm{d}$ ), geomembranes could be excluded from the bottom liner. For larger landfills, geomembranes were required in the bottom liners. Bottom liner designs having geomembranes complied with the performance criterion for all circumstances. The waste thickness was not effective in controlling the contaminant concentrations under humid climates.

Operational concerns like leachate circulation and design of cells in the landfill may change design performance; therefore, under such circumstances, the designer should change default design conditions. For example, a site under arid climatic conditions may be simulated considering moderate or humid climate effect if leachate recirculation is applied.

\subsection{Evaluation of the Developed DSS (LFDSS)}

Volume Calculation Module (VCM) provides a good estimate of required landfill volume, when detailed data on waste production and amounts are not available to the user. Landfill design model (Virtual Landfill -VLF) is a unique model developed specifically for LFDSS. The user is guided on the best available area to locate the landfill with respect to groundwater and clay layer thickness concerns. As many configurations as required can be drawn on the given map, and different orientations of the landfill may be examined. The drawbacks of VLF include the requirement of map digitalization and interpretation of topographic, clay layer, and groundwater layer data into ASCII files to create digital elevation models, and the requirement of a priori hand-calculated base and ground elevations based on side and base slopes, and original ground elevations. Preliminary design module offers a rule-based expert system composed of the results of 1300 landfill design simulations. The module achieves preliminary evaluation of required design specifications based on general site data; in other words, proposes preliminary design alternatives appropriate for the given site conditions. Coupled with landfill bottom liner design and subsurface transport model (POLLUTE), landfill cover 
design model (HELP) becomes a part of a complete landfill design and subsurface transport model running under LFDSS. Although the model requires extensive amount of climatic data (i.e. evapotranspiration, daily precipitation, daily temperature, and daily solar radiation), it is yet the best available hydrologic model. Stability and major cost estimation modules offer fast preliminary stability analyses and total landfill construction cost, respectively; although, collecting geotechnical data and calculating soil and material amounts may be a tedious work.

Besides the model- and module-specific benefits, LFDSS has some major strengths. LFDSS provides a systematic and practical approach to determine the best performing landfill design(s), which pose acceptable environmental risks and low investment costs, for given site and waste conditions. The developed DSS allows for a complete landfill design, which starts from landfill volume calculation, and proceeds with landfill base contour design, final cover and bottom liner design, and subsurface transport modeling. A similar complete landfill design model has not been reported in the literature. It offers fast preliminary design and guidance on the selection of preliminary design alternatives (i.e. design components and their design details). LFDSS provides evaluations of landfill design alternatives allowing for comparison between each simulated landfill design alternative, and helps in making decisions based on performance, stability and cost analyses.

Among all the advantages that the LFDSS proposes, being a prototype decision support system, LFDSS has some drawbacks. LFDSS is designed for Windows operating system, and the operation under Macintosh operation system is not tested. The system requires some hand calculations to be performed for some of the modules (i.e. VLF, and cost estimation module), and extensive amount of data for HELP, and stability module. As POLLUTE model does not provide opencodes, LFDSS requires POLLUTE model to be a registered software in the 
computer under which LFDSS runs. Possible improvements on the listed drawbacks are proposed in the Recommendations for Future Studies (Chapter 6). 


\section{CHAPTER 6}

\section{RECOMMENDATIONS FOR FUTURE STUDIES}

The developed decision support system serves as a prototype DSS for an integral landfill design, starting from waste and landfill volume calculations, and proceeding with landfill base contour design, final cover design, bottom liner design, and subsurface transport modeling. This prototype system is open to development and future research.

HELP and POLLUTE software integrated under LFDSS may be replaced with a complete landfill design and simulation model, performing the processes of both models. A hydrologic model, which is to include a database under which Turkish climatic data are stored, can be developed instead of HELP. A weather simulator can be added to the new model in order to simulate the climatic data for given number of years. Therefore, extensive amount of climatic data requirement may be eliminated. Also, capillary barrier modeling for final cover systems can be achieved if unsaturated modeling components are also added to the hydrologic model. A bottom liner design and subsurface transport model can also be developed and integrated to the hydrologic model. Therefore, a complete landfill design model may be developed and used instead of HELP-POLLUTE integration. This integral model can not only serve as new landfill design software, but also can eliminate the need of a licensed POLLUTE software in the computer under which the DSS runs. 
The landfill design model (Virtual Landfill -VLF) can be improved to be more user friendly by minimizing hand calculations, and to present the cross-sectional profiles of the landfill, and clay and groundwater layers beneath the landfill to the user. Stability module can also be improved if it is given the capability of drawing slip surface vs. factor of safety graphs and presenting the graphical solution to the user. Hydrogeologic, cost, and geotechnical parameter databases can be added to the DSS to be used when the user needs to use literature values in case of unavailability of site-specific data. A complete new module on hydraulic calculations for the design of leachate collection and surface drainage systems can be developed and integrated to the system, in order to optimize leachate collection and surface drainage efficiency.

Besides the improvements in models and modules, the prototype DSS can be improved by adding decision modules on waste management and pre-landfilling strategies, and site selection process. The user can be guided to decide on best waste management applications with respect to waste minimization strategies like reuse, and recycling, and evaluations on disposal alternatives such as combustion, composting, etc. Site selection processes can be guided by multiple-criteria decision analysis.

It can be concluded that, this thesis study not only proposed a new approach on landfill design and modeling, but also has given rise to future research and development on an integral solid waste management and landfill design. Each of the possible studies summarized in the above paragraphs can a subject of new research projects and thesis studies. 


\section{REFERENCES}

Adenso-Diaz B., Tuya J., and Goitia M., (2005). EDSS for the evaluation of alternatives in waste water collecting systems design. Environmental Modelling and Software, Volume 20, Issue 5, 639-649.

Ascough II J. C., Lane L. J., and Hakonson T.E., (1994). Intelligent design and remediation of shallow landfill burial systems. ASCE. New York, NY, USA, No. $1,257-264$.

Barlishen K. D., and Baetz B. W., (1994). Development of a decision support system for municipal solid waste management systems planning. Waste Management and Research 14, 71-86.

Bivand R., and Lucas A., (2000). Integrating models and Geographical Information Systems. In: Openshaw, S.; Abrahart, R. J. ed. Geocomputation. London: Taylor \& Francis, Cap. 14, p. 331-364.

Blodgett C. F., Egbert S. L., Sun H., and Bian L., (1995). Developing graphical links between ARC/Info, Visual Basic, and SWAT. In: GIS/LIS '95 Annual Conference and Exposition Proceedings, Vol 1, ASPRS, 62-69.

Booty W. G., Lam D. C. L., Wong I. W. S., and Siconolfi P., (2001). Design and implementation of an environmental decision support system. Environmental Modelling and Software 16, 453-458.

Brandmeyer J. E., and Karimi H. A., (2000). Coupling methodologies for environmental models. Environmental Modelling and Software 15, 479-488. 
Chou H., and Ding Y., (1992). Methodology of integrating spatial analysis/modeling and GIS. In: Proceedings of the $5^{\text {th }}$ International Symposium on Spatial Data Handling University of South Carolina, 514-523.

Daniel E. (1995). Geotechnical Practice for Waste Disposal. Chapman and Hall, London, pp: 244-268.

Djokic D., (1996). Toward a general decision support system using existing technologies. In: Goodchild M. F., Steyaert L.T., Parks B. O., Johnston C., Maidment D., Crane M., Glendenning S., GIS and Environmental Modeling: Progress and Research Issues. USA. GIS World Inc.

Domenico PA, Schwartz FW (1990) Physical and Chemical Hydrogeology, John Wiley and Sons Inc., pg: 65.

Dörhöfer G, Siebert H (1998) The search for landfill sites -requirements and implementation in Lower Saxony, Germany. Environmental Geology 35 (1): 55 65

El-Fadel, M. and Khoury, R. (2000). Modeling Settlement in MSW Landfills: a Critical Review. Critical Reviews in Environmental Science and Technology, 30 (3): $327-361$.

Environment Canada (2003), Specialized Computer Software, www.nwri.ca/software-e.html.

Freudlund, D.G., Raharjdo, H., (1993). Soil Mechanics for Unsaturated Soils. John Wiley and Sons Inc., USA, p. 136-140.

Green, R.E. and Corey, J.C., (1971). Calculation of hydraulic conductivity: A further evaluation of some predictive methods. Soil Science Society of America Proceedings, Vol 35, pp. $3-8$.

Hauser V. L., Weand B. L., and Gill M. D., (2001). Natural covers for landfills and burried waste. Journal of Environmental Engineering, Vol. 127, No. 9, 768775 . 
Hazardous Substance Research Centre (2002), Sediment Management in the Anacostia and Grasse River, http://www.hsrc-ssw.org/lowry03.pdf.

Ho C. K., Arnold B. W., John R. C., Taira R. Y., and Pelton M. A., (2004). A probabilistic model and software tool for evaluating long-term performance of landfill covers. Environmental Modelling and Software 19, 63-88.

Hudak P F, (2005). Sensitivity of groundwater monitoring networks to contaminant source width for various seepage velocities. Water Resources Research, Vol. 41, W0851, doi:10.1029/2005WR003968.

Kampf, SK, Salazar M, Tyler SW, (2002). Primary investigations of effluent drainage from mining heap leach facilities. Vadose Zone Journal 1: 186-196

Karimi H. A., and Houston B. H., (1996). Evaluating strategies for integrating environmental models with GIS: curent trends and future needs. Environment and Urban Systems 20 (6), 413-425.

Kim K., Kim J., Choi J., Sung M., (1995). Application of GIS to water quality management. In: GIS/LIS '95 Annual Conference and Exposition Proceedings, Vol 1, ASPRS, 554-562.

Koerner, R. M., Daniel, E. D. (1997). Final Covers for Solid Waste Landfills and Abandoned Dumps. Thomas Telford, United Kingdom.

Koerner RM, Soong TY, (2000). Leachate in landfills: the stability issues. Geotextiles and Geomembranes 18: 193-309.

Koerner RM, Soong TY, (2005). Analysis and design of veneer cover soils. Geosynthetics International, Special Issue on Giroud Lectures, 12, No. 1, 28-49.

Kramer, S. L. (1996). Geotechnical Earthquake Engineering. Prentice Hall, Section 10.6. 
Lam D., Leon L., Hamilton S., Crookshank N., Bonin D., and Swayne D., (2004). Multi-model integration in a decision support system: a technical user interface approach for watershed and lake management scenarios. Environmental Modelling and Software 19, 317-324.

Lilbourne L., (1996). The integration challenge. In: Proceedings of the Spatial Information Research Centre's $8^{\text {th }}$ Colloqium University of Otago, New Zealand, 85-94.

Lim L. L., Hughes S., and Hellawell E. E., (2004). Integrated decision support system for urban air quality assessment. Environmental modeling and Software, In press, corrected proof.

Lukasheh A. F., Droste R. L., and Warith M. A., (2001). Review of Expert System (ES), Geographic Information System (GIS), Decision Support System (DSS) andtheir applications on landfill design and management. Waste Management and Research 19, 177-185.

Maekawa T, Wu X F, Masuhara N, (2002). Study on real seepage velocity. In: Proceedings of Spring Symposium, Japanese Association of Groundwater and Hydrology, $62-65$.

MIMKO (2006). Katı Atık Ana Planı Nihai Rapor Cilt I. T.C. Çevre ve Orman Bakanlığı Çevre Yönetimi Genel Müdürlüğü Atık Yönetimi Daire Başkanlığı. İstanbul.

Mohammed N, and Allayla R I, (2000). Effect of seepage velocity on pilot scale bioremediation of gasoline contaminated sandy aquifers. Water, Air, and Soil Pollution, 120: 315 - 329 .

Mono (2007), Main Page Mono, http://www.mono-project.com.

Newell CJ, Hopkins LP, Bedient PB, (1990). A hydrogeologic database for ground-water modeling. Ground Water, v. 28, no. 5: 703-714 
Nyerges T. L., (1992). Coupling GIS and spatial analytic models. In: Proceedings of the $5^{\text {th }}$ International Symposium on Spatial Data Handling University of South Carolina, 534-543.

O'Geen AT, McDaniel PA, Boll J, (2002). Chloride distribution as indicators of vadose zone stratigraphy in palouse loess deposits. Vadose Zone Journal, 1:150157

Oxley T., McIntosh B. S., Winder N., Mulligan M, and Engelen G., (2004). Integrated modelling and decision-support tools: a Mediterranean example. Environmental modeling and Software, Volume 19, Issue 11, 999-1010.

Pacific Northwest National Laboratory (2007). EARTH: Environmental Assessment and Risk Tools Homepage, http://mepas.pnl.gov/FRAMESV1/index.html.

Poch M., Comas J., Rodriguez-Roda I., Sanchez-Marre M., and Cortes U., (2003). Designing and building real environmental decision support systems. Environmental Modelling and Software, Volume 19, Issue 9, 857-873.

R.S.A Department of Water Affairs and Forestry, (1998). Minimum Requirements for Waste Disposal by Landfill, $2^{\text {nd }}$ Edition, CTP Book Printers, Cape

Rowe, R.K., (1990). Background Documentation for Programmes POLLUTE and MIGRATE. Geotechnical Research Centre, The University of Western Ontario, Faculty of Engineering and Science, Report Number: GEOP 90-2, London, Ontario, Canada.

Rowe, R. K., (2005). Long-term performance of contaminant barrier systems. Geotechnique, 55, No. 9, $631-678$.

Rizzoli A. E., and Young W.J., (1997). Delivering environmental decision support systems: software tools and techniques. Environmental Modelling and Software, Volume 12, Nos 2-3, 237-249. 
Scientific Software Group, (1998). POLLUTE -finite-layer contaminant migration model -landfill design-, http://www.scisoftware.com/products/pollute_overview/pollute_overview.html.

Sharma D. H. and Lewis S. P., 1994. Waste Containment Systems, Waste Stabilization, and Landfills. John Wiley and Sons, New York, pp: 514-567.

SEEP/W, (2002). GEO-SLOPE International Ltd., Calgary, Alberta, Canada.

Soncini-Sessa R., Nardini A., Gandolfi C., and Kraszewski A., (1990). Computer aided water reservoir management: a prototype two-level DSS. Invited paper: NATO ARW on Computer Aided Support Systems in Water Resources Research and Management, Ericeirca, Portugal.

T.C. Başbakanlık Devlet İstatistik Enstitüsü, (2000). Çevre İstatistikleri Hanehalkı Katı Atık Kompozisyonu Araştırması ve Eğilim Anketi Sonuçları (1998), Ankara, 2001.

T.C. İller Bankası, (2000). Katı Atık Tesisi Projesi Proje Yapımı İşine Ait Genel Teknik Şartnamesi, Ankara

T.C. Türk Standardları Enstitüsü, (1997). TS 266 Türk Standardı: Sular -İçme ve Kullanma Suları, 1. Baskı, Ankara.

T.C. Türk Standardları Enstitüsü, (2005). TS 266 Türk Standardı: Sular -İçme ve Kullanma Suları, Nisan 2005, Ankara.

Tarhan B., (2003). Sanitary Landfill Design Evaluation using Geographic Information Systems (GIS) Interfaced with Sstem Simulation Models (SSM). The Graduate School of Natural and Applied Sciences Middle East Technical University, M.Sc. Thesis, Ankara.

U.S. E.P.A., (1994). The Hydrogeologic Evaluation of Landfill Performance (HELP) Model User's Guide for Version 3, EPA/600/R-94/168a, Washington D.C. 
University of Waterloo, Delft Hydraulics, and United Nations University, (2000). Preparation of Preliminary Physical Processes and Water Quality Model for Lake Malawi/Nyasa. Final Report, Lilongwe, Malawi.

Visudmedanukul P, Kamon M, and Katsumi T, (2007). Chloride transport through cement-bentonite barriers. Journal of Geotechnical and Geoenvironmental Engineering, Vol. 133, No. 2, pp175-185.

Waterloo Hydrogeologic, (2002). Visual HELP User's Manual -Predicting Landfill Hydrology and Optimizing Landfill Designs, Canada.

$\mathrm{Wu} \mathrm{X}$, and Tang J, (2004). Selection of dispersivity in groundwater risk assessment. Tsinghua Science and Technology, Vol. 9, No. 6, pp704-709.

Yen, B. C. and Scanlan, B., (1975). Sanitary Landfill Settlement Rates. Journal of the Geotechnical Engineering Division, Vol. 101, No. 5, pp. 475-487 


\section{APPENDIX-A}

\section{SCHEMATIC DRAWINGS OF LANDFILL DESIGN ALTERNATIVES}

\begin{tabular}{|c|} 
C1L1 \\
\hline Natural topsoil \\
\hline WASTE \\
\hline Aquitard \\
\hline
\end{tabular}

C1L2

\begin{tabular}{|c|}
\hline Natural topsoil \\
\hline WASTE \\
\hline Leachate collection system \\
\hline \hline Geomembrane \\
\hline Compacted clay liner \\
\hline Vadose zone/aquitard \\
\hline
\end{tabular}

C1L4

\begin{tabular}{|c|}
\hline Natural topsoil \\
\hline WASTE \\
\hline Leachate collection system \\
\hline Geomembrane \\
\hline Vadose Zone/Aquitard \\
\hline
\end{tabular}

C1L5

\begin{tabular}{|c|}
\hline Natural topsoil \\
\hline WASTE \\
\hline Leachate collection system \\
\hline Compacted clay liner \\
\hline Vadose zone/aquitard \\
\hline
\end{tabular}

C1L3

\begin{tabular}{|c|}
\hline Natural topsoil \\
\hline WASTE \\
\hline Leachate collection system \\
\hline Aquitard \\
\hline
\end{tabular}

C1L6

\begin{tabular}{|c|}
\hline Natural topsoil \\
\hline WASTE \\
\hline Compacted clay iner \\
\hline Aquitard \\
\hline
\end{tabular}

Figure A. 1 Design alternatives having evapotranspiration final cover $-\mathrm{C} 1$ 
C2L1

\begin{tabular}{|c|}
\hline Natural topsoil \\
\hline Cover drainage system \\
\hline \hline Geomembrane \\
\hline Clay layer \\
\hline WASTE \\
\hline Aquitard \\
\hline
\end{tabular}

C2L4

\begin{tabular}{|c|}
\hline Natural topsoil \\
\hline WASTE \\
\hline Cover drainage system \\
\hline Geomembrane \\
\hline Clay layer \\
\hline Leachate collection system \\
\hline Geomembrane \\
\hline
\end{tabular}

C2L2

\begin{tabular}{|c|}
\hline Natural topsoil \\
\hline Cover drainage system \\
\hline Geomembrane \\
\hline Clay layer \\
\hline WASTE \\
\hline Leachate collection system \\
\hline Geomembrane \\
\hline Compacted clay liner \\
\hline Vadose zone/aquitard \\
\hline
\end{tabular}

C2L5

\begin{tabular}{|c|}
\hline Natural topsoil \\
\hline WASTE \\
\hline Cover drainage system \\
\hline Geomembrane \\
\hline \hline Clay layer \\
\hline Leachate collection system \\
\hline Compacted clay liner \\
\hline Vadose zone/aquitard \\
\hline
\end{tabular}

C2L3

\begin{tabular}{|c|}
\hline Natural topsoil \\
\hline Cover drainage system \\
\hline \hline Geomembrane \\
\hline Clay layer \\
\hline WASTE \\
\hline Leachate collection system \\
\hline Aquitard \\
\hline
\end{tabular}

\section{C2L6}

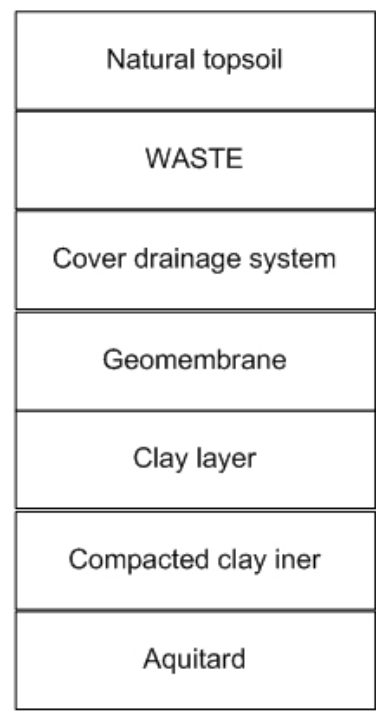

Figure A. 2 Design alternatives having extensive engineering design final cover $-\mathrm{C} 2$ 
C3L1

\begin{tabular}{|c|}
\hline Natural topsoil \\
\hline Cover drainage system \\
\hline Clay layer \\
\hline WASTE \\
\hline Aquitard \\
\hline
\end{tabular}

C3L4

\begin{tabular}{|c|}
\hline Natural topsoil \\
\hline WASTE \\
\hline Cover drainage system \\
\hline Clay layer \\
\hline Leachate collection system \\
\hline Geomembrane \\
\hline Vadose Zone/Aquitard \\
\hline
\end{tabular}

C3L2

\begin{tabular}{|c|}
\hline Natural topsoil \\
\hline Cover drainage system \\
\hline Clay layer \\
\hline WASTE \\
\hline Leachate collection system \\
\hline Geomembrane \\
\hline Compacted clay liner \\
\hline
\end{tabular}

\section{C3L5}

\begin{tabular}{|c|}
\hline Natural topsoil \\
\hline WASTE \\
\hline Cover drainage system \\
\hline Clay layer \\
\hline \hline Leachate collection system \\
\hline Compacted clay liner \\
\hline Vadose zone/aquitard \\
\hline
\end{tabular}

C3L3

\begin{tabular}{|c|}
\hline Natural topsoil \\
\hline Cover drainage system \\
\hline Clay layer \\
\hline WASTE \\
\hline Leachate collection system \\
\hline Aquitard
\end{tabular}

\section{C3L6}

\begin{tabular}{|c|}
\hline Natural topsoil \\
\hline WASTE \\
\hline Cover drainage system \\
\hline Clay layer \\
\hline \hline Compacted clay iner \\
\hline Aquitard \\
\hline
\end{tabular}

Figure A. 3 Design alternatives having intermediate design final cover $-\mathrm{C} 3$ 
APPENDIX-B

\section{TECHNICAL DOCUMENTATION FOR LANDFILL DECISION SUPPORT SYSTEM (LFDSS)}

Landfill Decision Support System (LFDSS) is a decision support system application developed in order to aid the user in solid waste landfill design. LFDSS was developed in C\# programming language based on "Windows Forms" visual user interface library. The programme operates on Windows 2000 or higher; however, it is anticipated that the programme may perform under different operating environment (such as Linux, MacOS, etc.) with small changes, except for HELP and POLLUTE. LFDSS accommodates six modules: Preliminary Design, HELP, POLLUTE, Stability, Cost, and Volume Calculation. This section presents technical and design data of each module.

\section{B.1. Preliminary Design}

"Preliminary Design" is a tool that proposes how the layers in a particular landfill design should be, based on user defined parameter values for design variables (i.e. thickness, velocity, size, and climate) (Figure B.1). The proposed landfill designs are selected from the previously identified design alternatives. 


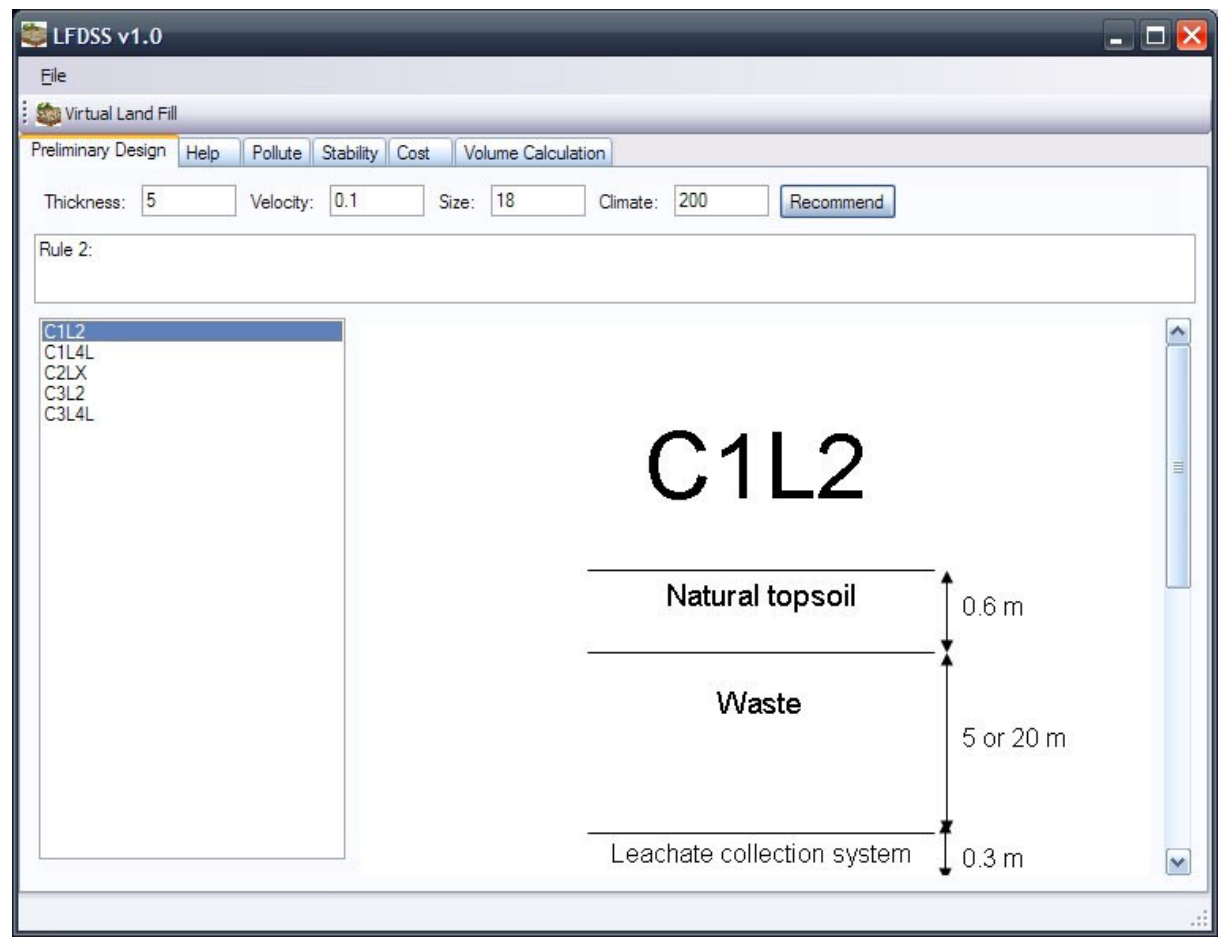

Figure B. 1 Preliminary Design module in LFDSS

Preliminary Design tool is composed of a backend that defines the design alternatives proposed under particular conditions, and a frontend that presents the design alternatives visually to the user. Backend is basically a rule-interpreter. Each rule is a mathematical expression which identifies the restrictions on parameter values (i.e. being smaller than/smaller than or equal to/greater than/greater or equal to/equal to a certain value). More than one restriction can be defined for the any parameter. These rules, restrictions for different parameters, are defined to be separated by commas (,) (e.g. climate $=500$, thickness $=5$, velocit $=0.1$, size $>2$, size $<15$ ), and read from a file called "rules.txt" to allow for easy upgrade. Backend loads the rules contained by the file in the given order, forms the respective mathematical expression, and checks whether the consistency of the user defined parameters with the rule for each rule. Any consistent rule is performed by frontend. There are two actions defined: displaying a message or displaying a landfill design alternative. Actions are 
defined as separated by semicolons (;) at the end of the rule statement. If a message is to be displayed, the definition is in the shape of a message text contained within double quotation marks (“") (e.g. "USE DOUBLE LINER SYSTEMS"). If a landfill design alternative is to be displayed, the definition is made by stating the corresponding cells in a comma separated value (CSV) spreadsheet file. For example, a definition in the form of mod.csv:A2-A5 states that the corresponding cells are formed by the values contained between $2^{\text {nd }}$ and $5^{\text {th }}$ rows of column A of file mod.csv. This definition format allows easier rule landfill design matching, especially when there are more than one rule for a special group of cells. Spreadsheet files in CSV format can easily be created and arranged using spreadsheet software (e.g. MS Excel or Openoffice) or a text editor. An example for a rule file is give in Figure B.2.

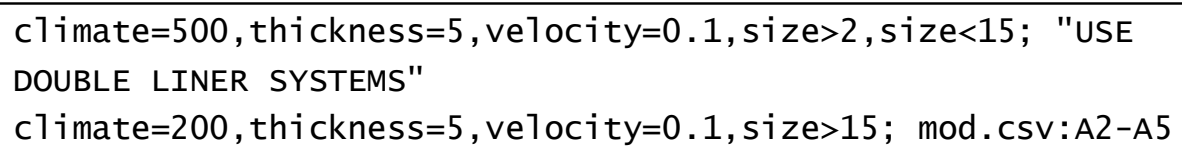

Figure B. 2 A rule file defined in preliminary design module in LFDSS

Frontend performs the action and displays it to the user when a matching rule is found. If the action is displaying a message, this message is displayed at the top of the Preliminary Design page together with the rule number. If the action is displaying a schematic view of the landfill design, the list of design alternatives is displayed on the left hand-side of the page. When any of the listed designs is selected by the user, a schematic view belonging to that particular design is displayed on the page. These schemes are loaded from image files contained in images folder under LFDSS operating folder (Figure B.1). Image files should be in PNG format and have the same name as the design alternative. Instead of embedding the images into the software, they are read from a folder specified by the user; therefore, addition of new designs is allowed when new landfill design 
alternatives are defined. Image files in PNG format can easily be created and arranged using imaging software (e.g. Paint).

\section{B.2. HELP}

Hydrologic Evaluation of Landfill Performance (HELP) is a software developed for hydrologic evaluation of landfill performance. HELP operates under MSDOS operating system; therefore, fast and easy definition of input data is not possible under up-to-date operating systems. HELP software under LFDSS compensates this drawback and automatically calculates the infiltration rate input data required for landfill design calculations. HELP is composed of six sub-modules: "Soil\&Design", "Evapotranspiration”, "Precipitation”, “Temperature”, and "Solar Radiation". Each module is defined as separate pages under a tab view, and allows entering required input or uploading HELP input files (Figure B.3).

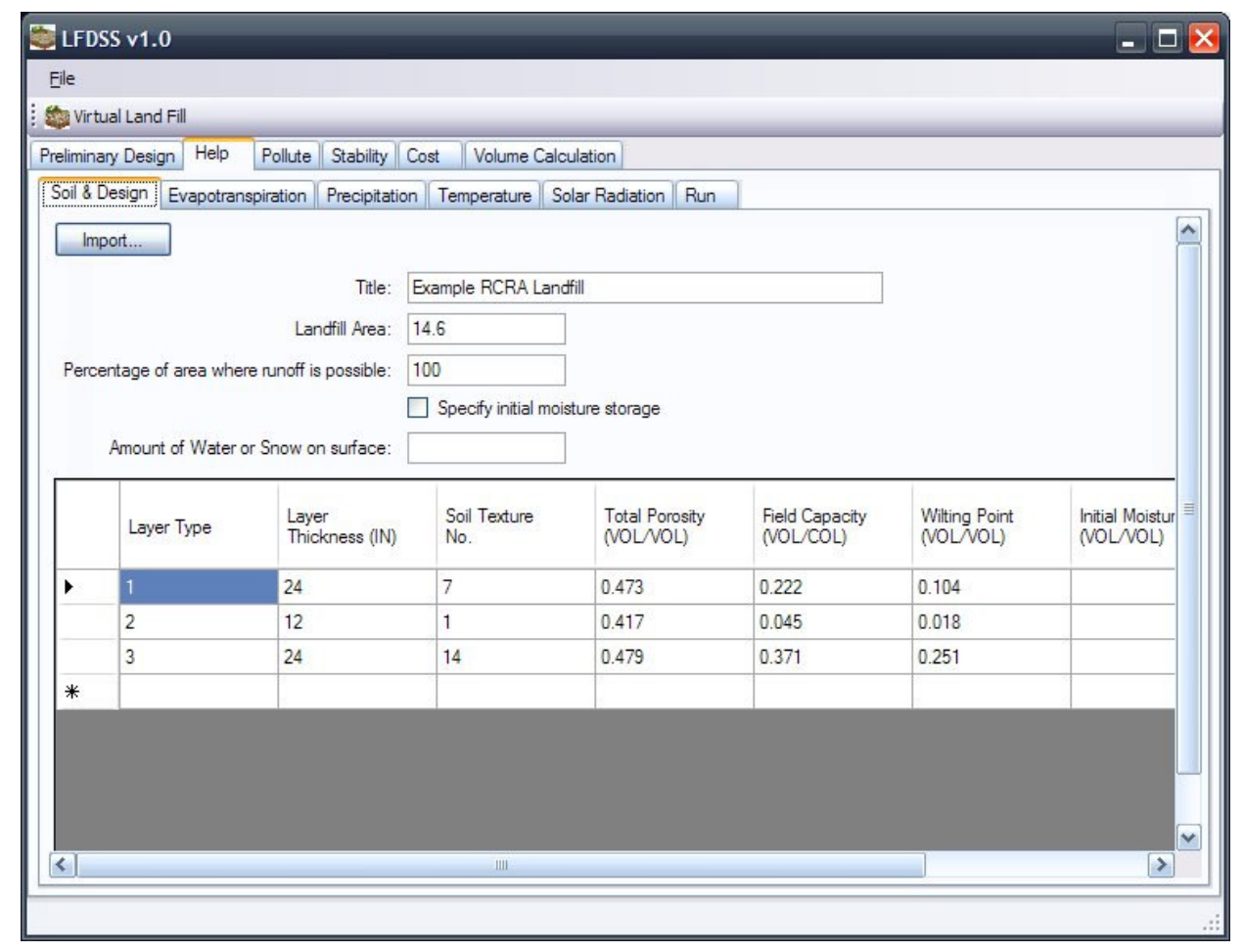

Figure B. 3 HELP module under LFDSS 
HELP input data are stored under text files with different formats. To upload these data and to create similar files before running the model, the file formats were examined, the way that HELP stores the data within each file format was determined, and parsers to read those data and savers to record the data were developed. LFDSS stores user-defined or uploaded data in a single file in XML format. This allows processing of data by other software, and easy transfer of data. Data can be saved on the current file via "Save" option, or on another file via "Save as" option, under File menu. Data stored in a particular file can be reloaded using "Load" option. Once the input data are entered, and the user selects "Run" option under Run sub-module, the data are transferred to the format that can be processed by HELP, and then, depending on the user-defined parameters (e.g. number of years to simulate), HELP is run as a separate process and "infiltration rate" data is separated from the processed output. The value of "infiltration rate" is displayed to the user in the related box (Figure B.4). Moreover, it is transferred to POLLUTE module.

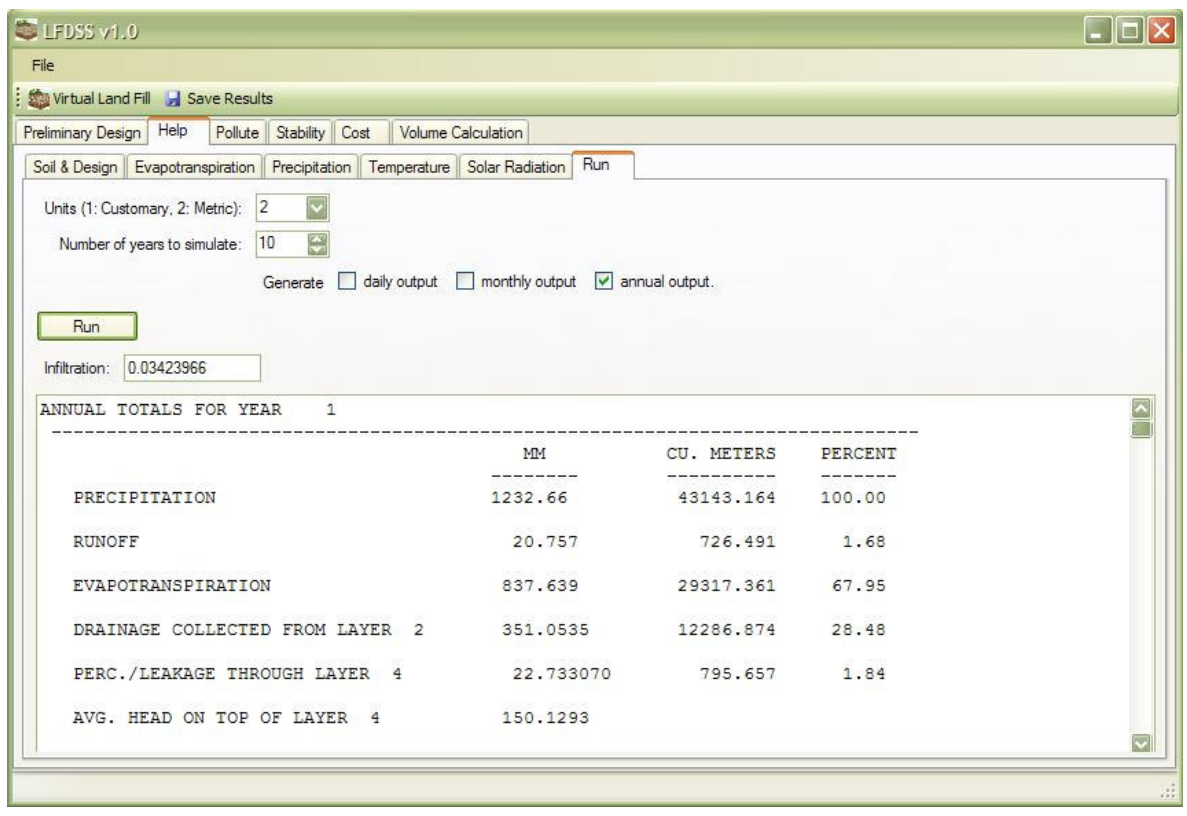

Figure B. 4 Run sub-module under HELP in LFDSS 


\section{B.3.POLLUTE}

POLLUTE is a software developed for contaminant migration analyses and the code operates under Microsoft Windows operating system. To perform analyses using this software, first a model is required to be set and input data related to that model are required to be entered in multiple dialog boxes. This is a time consuming process for the user. POLLUTE module under LFDSS is capable of running POLLUTE software automatically based on infiltration rate data obtained from HELP model and other user-defined input, calculating maximum contaminant concentration at the groundwater table and saving the result to a text file, and displaying the POLLUTE result report of contaminant concentrations at specified times. In maximum concentrations analysis, the text file that is created as a result of the analysis is displayed to the user automatically. POLLUTE module consists of three sub-modules. The first sub-module (parameters) allows the user to select landfill bottom liner components and to enter input parameters belonging to the selected components (Figure B.5). Infiltration rate data, which is one of the parameters, is obtained via HELP module using HELP software, and transferred to POLLUTE automatically.

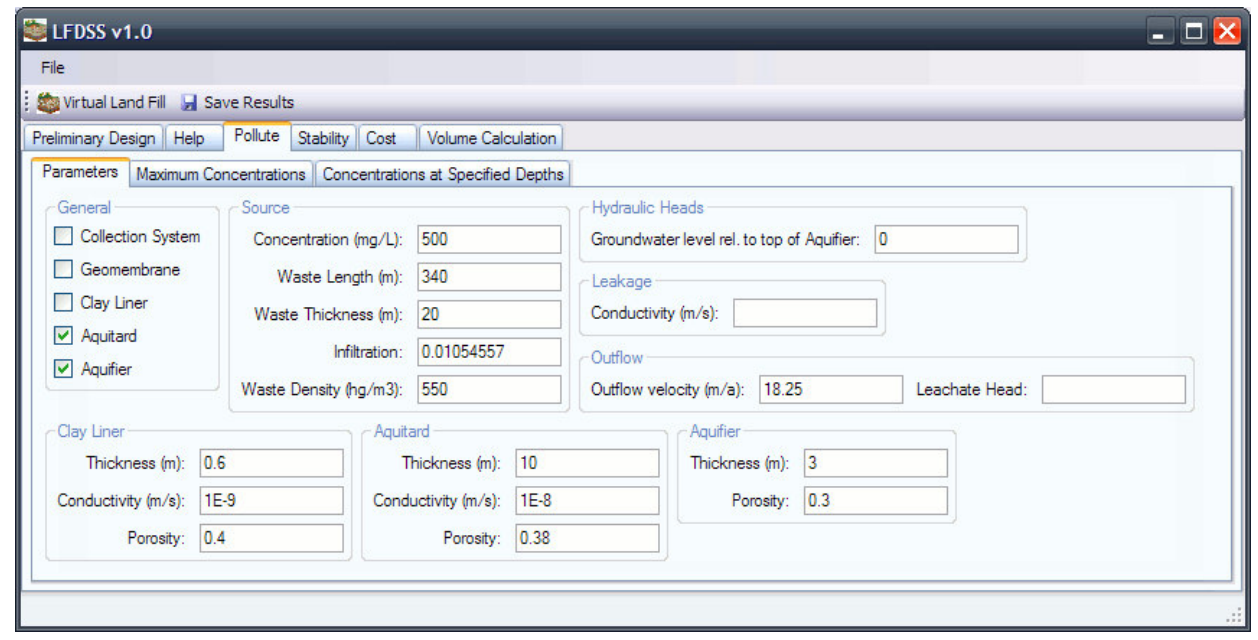

Figure B. 5 POLLUTE module in LFDSS -Parameters sub-module 
Using the second sub-module (maximum concentrations), parameters belonging to maximum concentration analyses is entered and the maximum concentrations file is obtained (Figure B.6.a). The third sub-module (concentration at specified times) allows the user to enter input parameters to obtain concentrations at specified times. (Figure B.6.b)

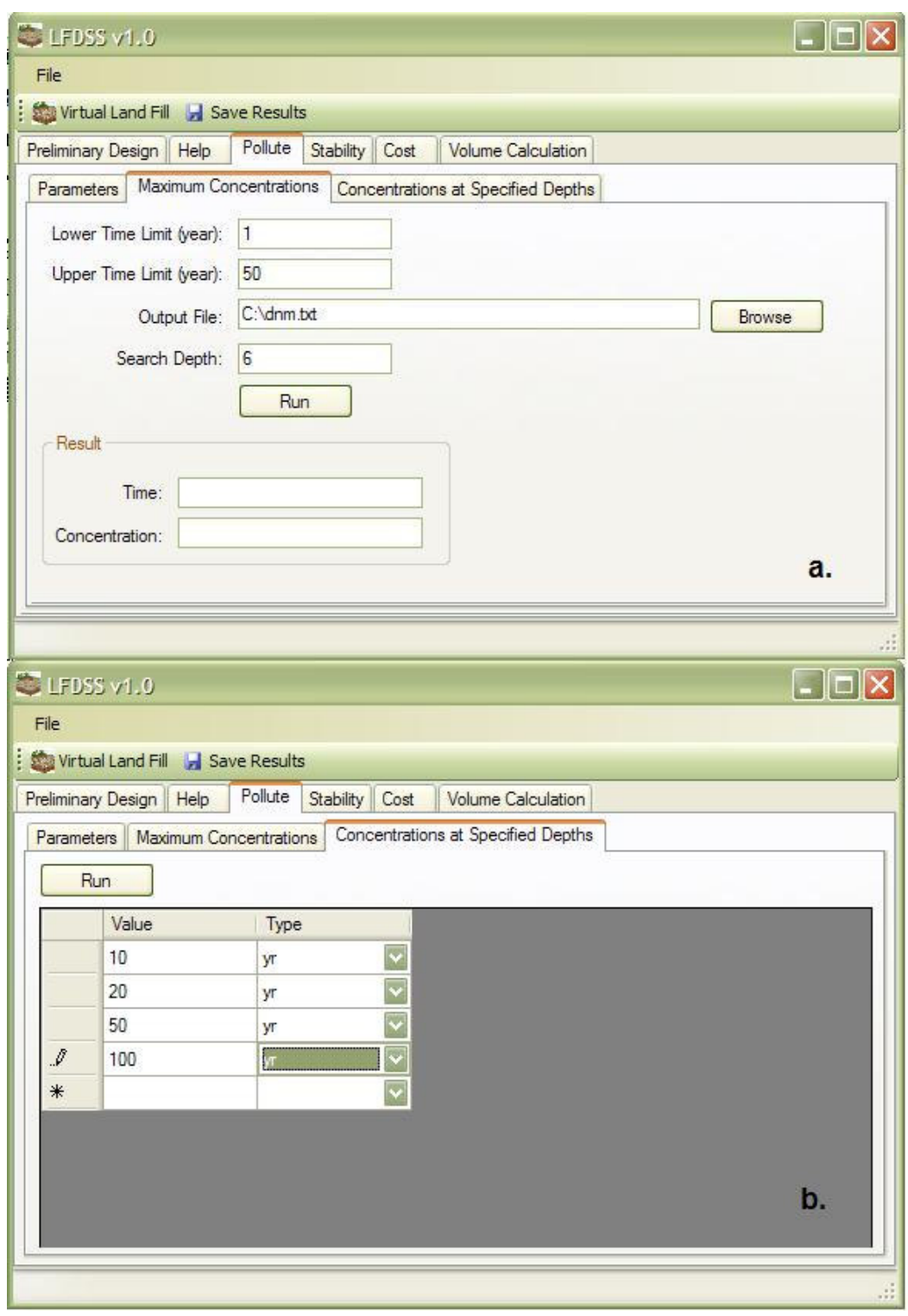

Figure B. 6 POLLUTE module in LFDSS. a. Maximum concentrations sub-module. b. concentrations at specified times sub-module 
Normally, POLLUTE programme does not allow commands outside the programme, and it does not have external support for parameter entry. To establish interaction between LFDSS and POLLUTE, a free software called AutoIt was used. This programme defines macros to any programme running under Microsoft Windows operating system, and allows sending external windows messages, and keyboard or mouse commands, as if it is being used by a real user. In other words, it allows automation. AutoIt has a script language similar to BASIC language, developed for this purpose. First, steps to be followed while creating models and entering input parameters were identified in POLLUTE programme, then windows elements required to receive commands were determined, and scripts that enter input parameters to the related window elements based on the type of analysis in the identified order were developed. These scripts are given in the Annex. AutoIt can create an EXE file that runs independently from a defined script file. When the user selects "Run" under any of the analysis sub-modules (i.e. maximum concentrations, or concentrations at specified times), LFDSS stores the related parameters in a text file, having a format that can be read by the script file, and as a separate process, first runs POLLUTE programme and then runs the EXE file of the related type of analysis created by AutoIt. When POLLUTE is closed by completing the analysis process, if the maximum analysis sub-module is selected, LFDSS displays the output file to the user as a text file. The basic advantage of using AutoIt programme to establish interaction between LFDSS and POLLUTE is the ability of supporting the new versions of POLLUTE by updating the script file only without requiring any changes in LFDSS programme. 


\section{B.3.1. Annex -Scripts for POLLUTE}

\section{B.3.1.1. Maximum Concentrations Sub-Module}

; Wait for activation

Dim \$params

Dim \$iniFile = "LFSim_Pollute.ini"

Dim \$title

Func GetParam(\$name)

$\operatorname{Dim} \$ \mathrm{n}=\$$ params $[0][0]$

$\operatorname{Dim} \$ \mathrm{i}$

For $\$ \mathrm{i}=1$ to $\$ \mathrm{n}$

If $\$$ params $[\$ i][0]==\$$ name Then

EndIf

Return \$params[\$i][1]

Next

Return ""

EndFunc

Func CheckBox (\$name)

ControlCommand(\$title, "", \$name, "Check")

EndFunc

Func TextBox (\$name, \$val)

ControlSetText(\$title, "", \$name, GetParam(\$val))

EndFunc

\$params = IniReadSection(\$iniFile, "Parameters")

if @ error ==1 Then

$\operatorname{MsgBox}(0$, "Error", "Unable to open " \& \$iniFile \& ". Please check your installation.")

Exit

EndIf

FileDelete("leachate_head.txt")

WinWaitActive("POLLUTE")

Send(" $\{$ Enter $\} ")$

Sleep(200);

; Open project

Send("!f");

Send("p");

Send("o");

WinWaitActive("Open Project");

Send("\{Enter $\} ") ;$

; Open model 


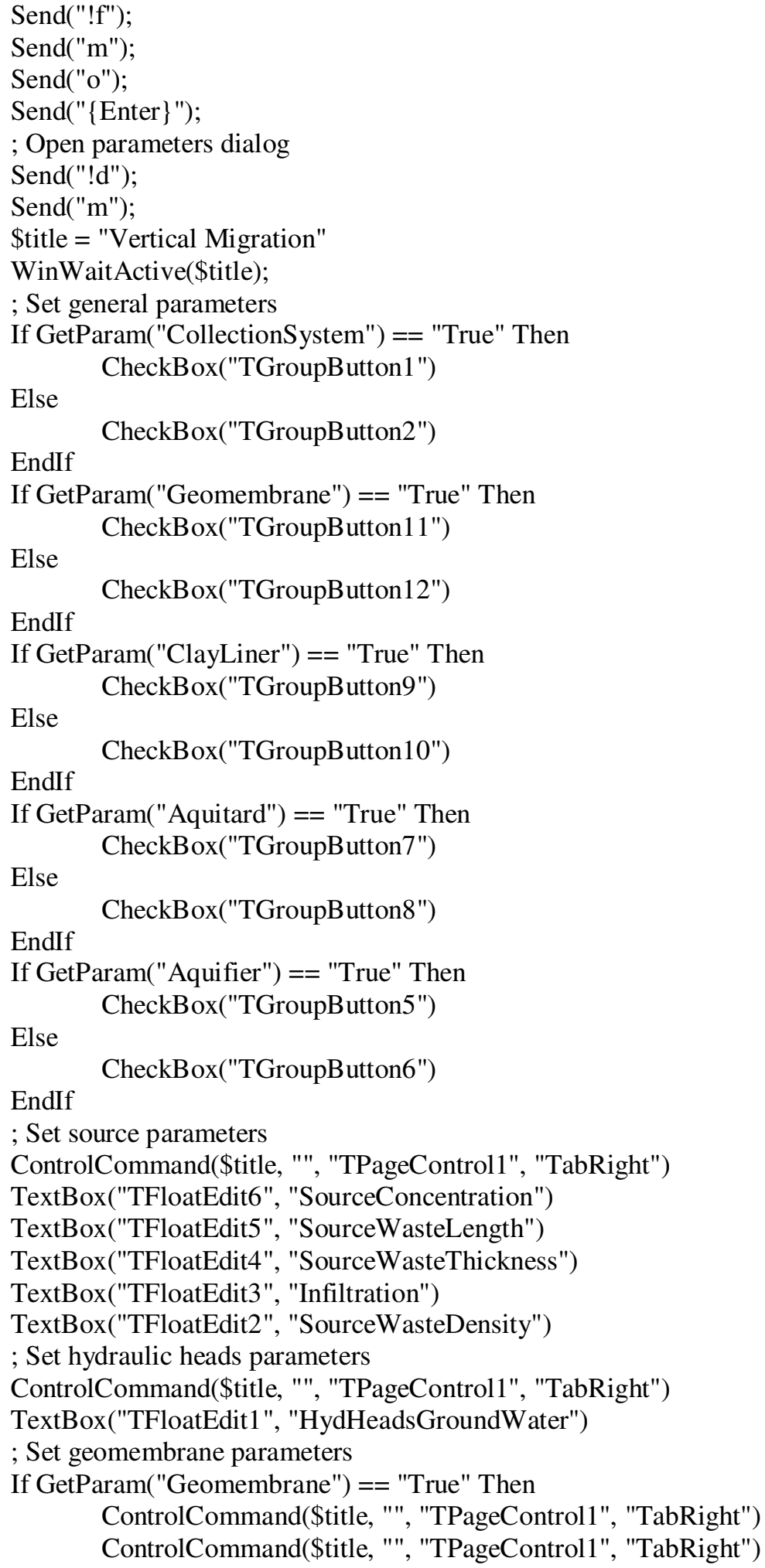




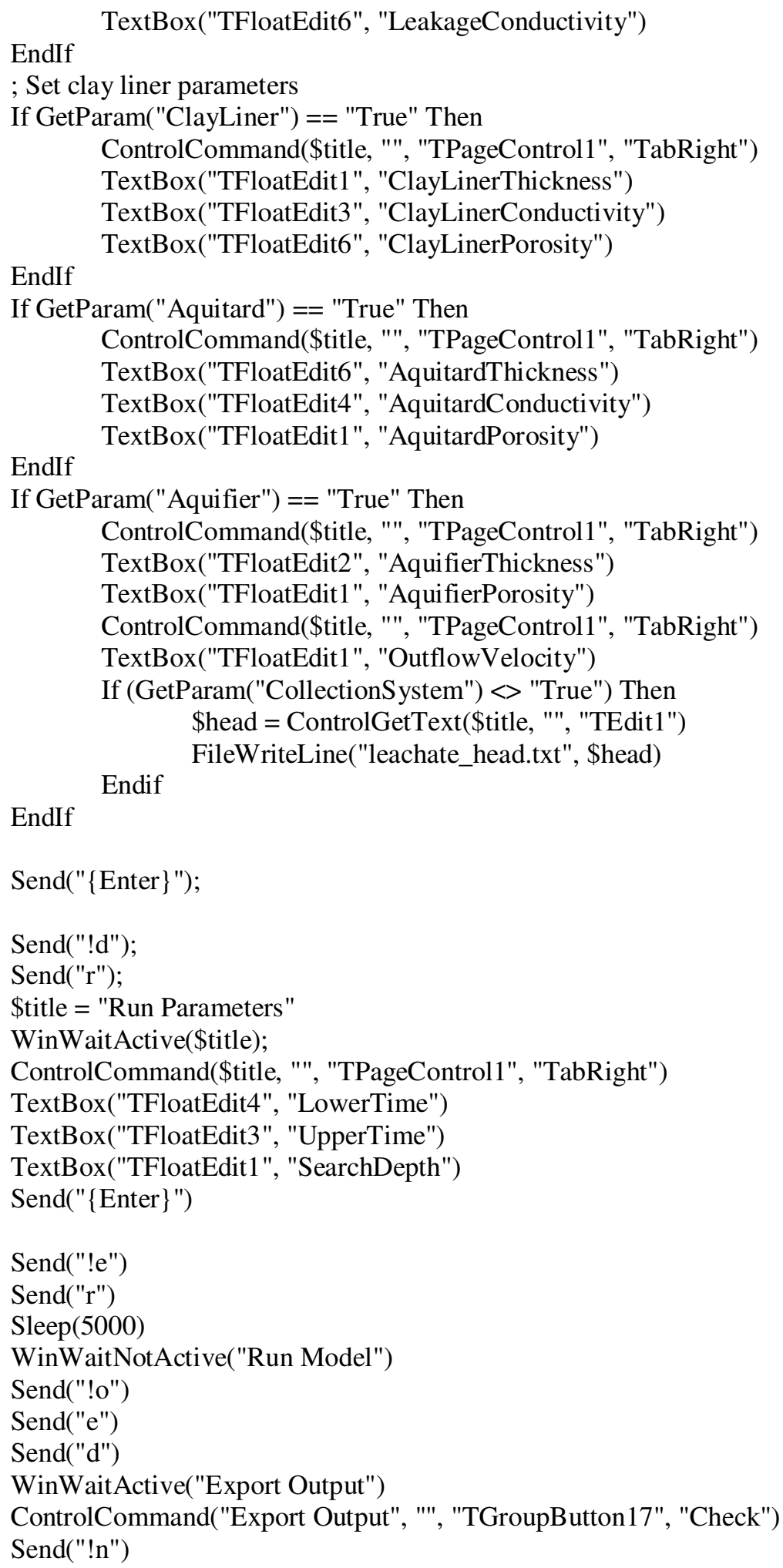




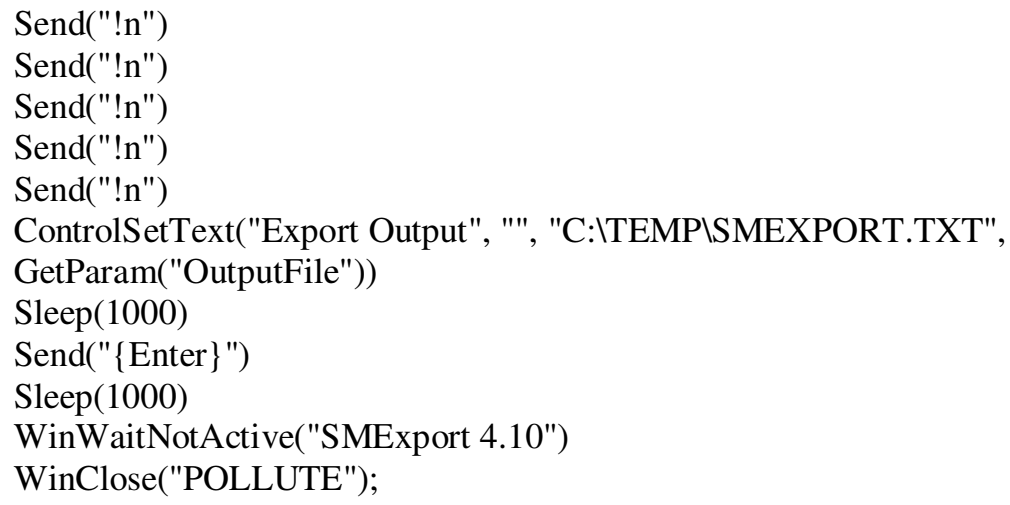

\section{B.3.1.2. Concentrations at Specified Times Sub-Module}

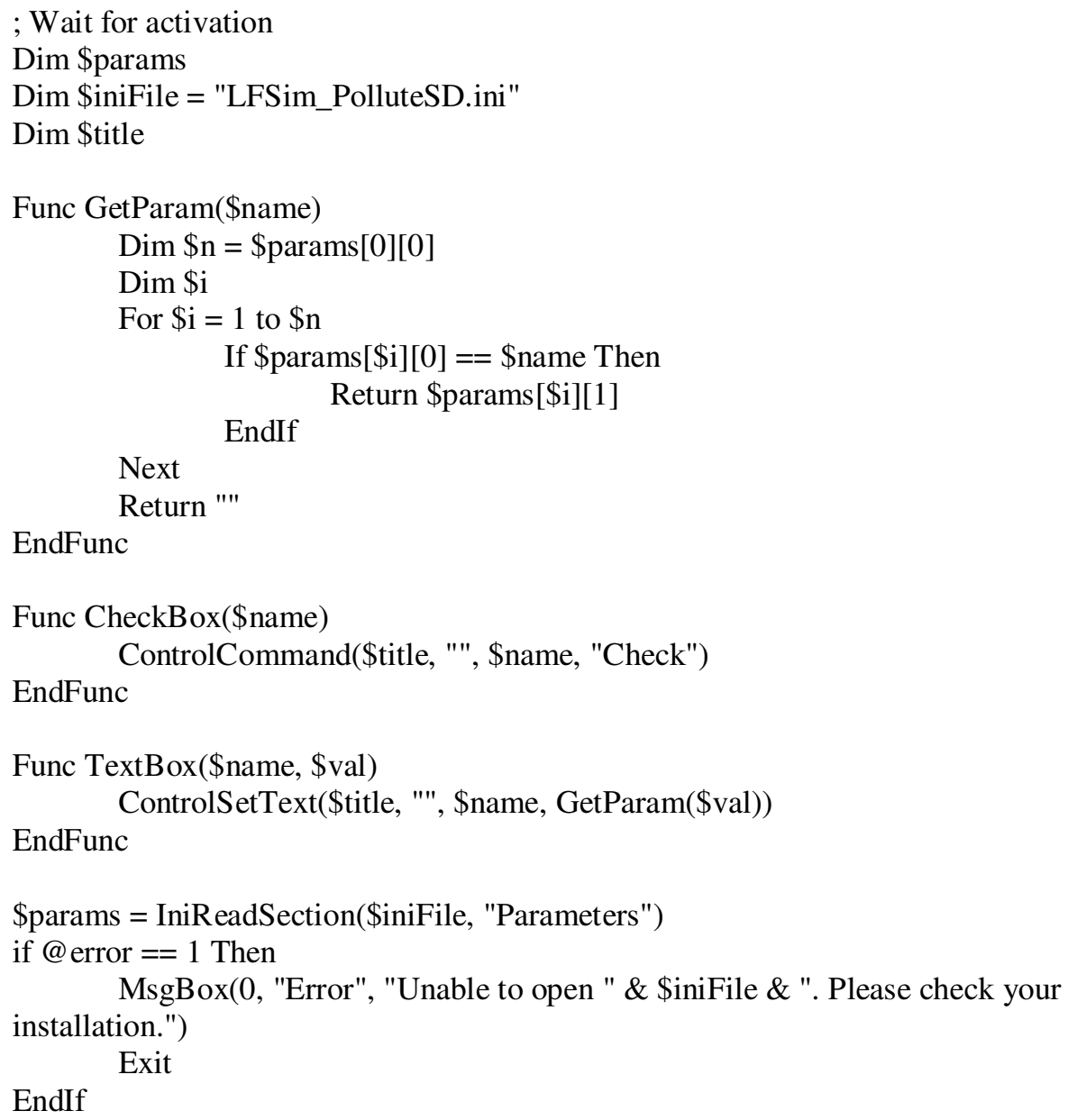

FileDelete("leachate_head.txt") 


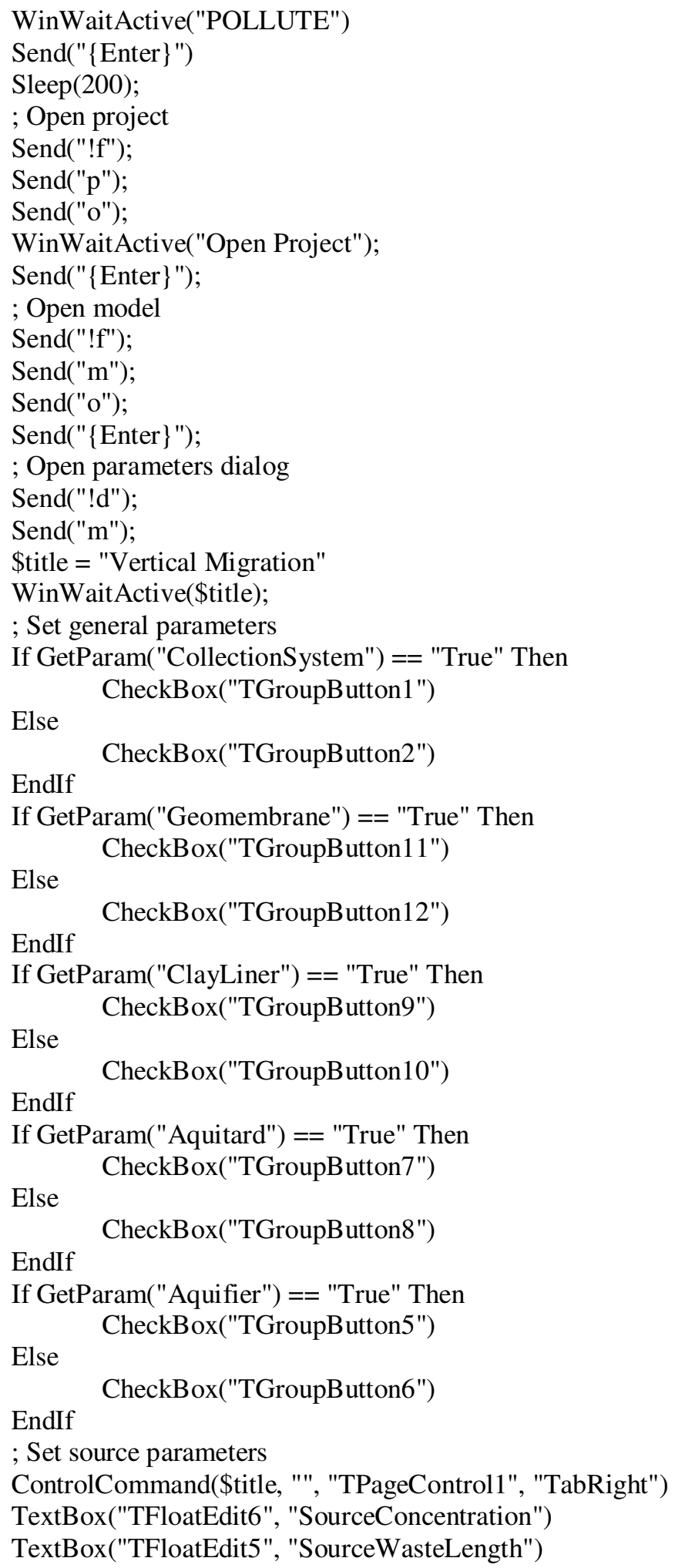




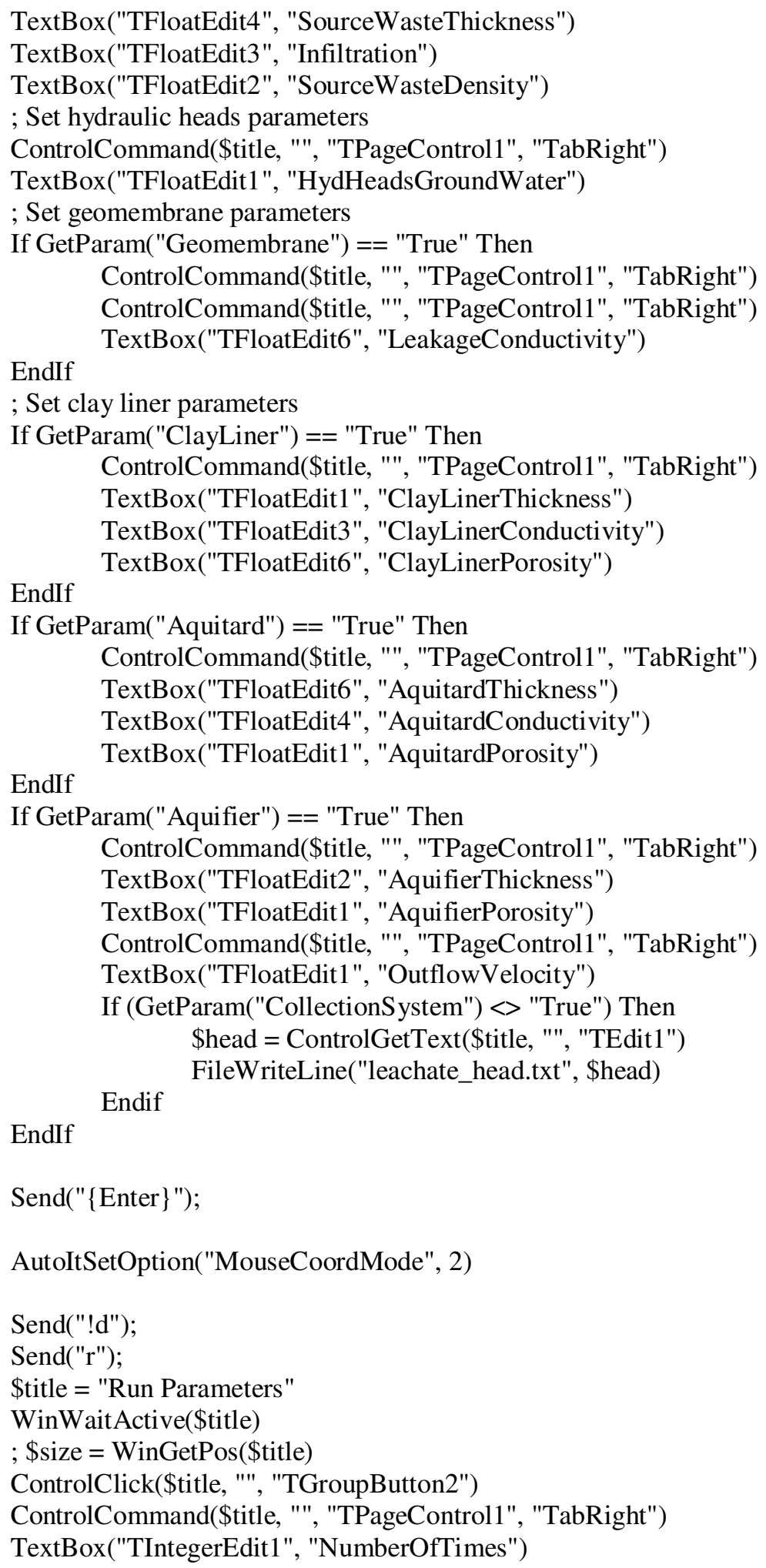




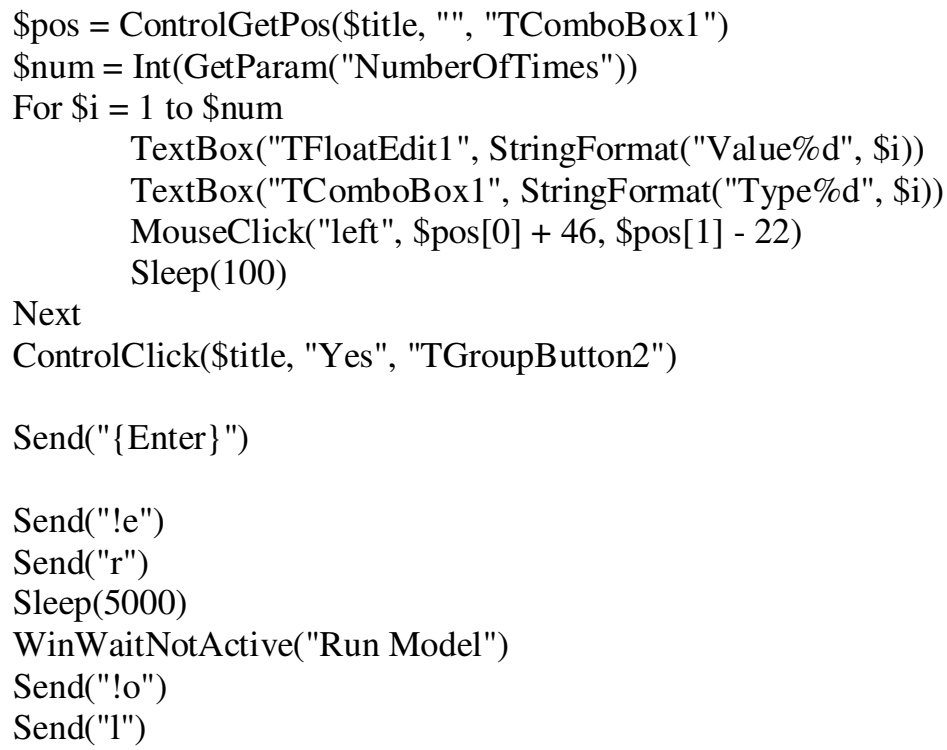

\section{B.4. Stability}

Stability module is a tool developed to perform stability analyses of landfills. It is composed of five sub-modules: "Excavation-slope", "Refuse-fill", "Cover System", "Geomembrane Stability", and "Seismic Forces". These sub-modules are developed as separate pages in a tab-view. Each sub-module contains a tabular data entry area based on the pre-defined formulae (Figure B.7). Data input via copy-paste from external sources (e.g. MS Excel) is allowed, and a system was developed to separate pasted data into parts and entering the separated data into related boxes. After data input, the user selects the "Calculate" option to easily calculate two factor of safety values for "Excavation-slope" and "Refuse-fill", four FS values for "Cover System", and one FS value for "Geomembrane Stability", and "Seismic Forces". 


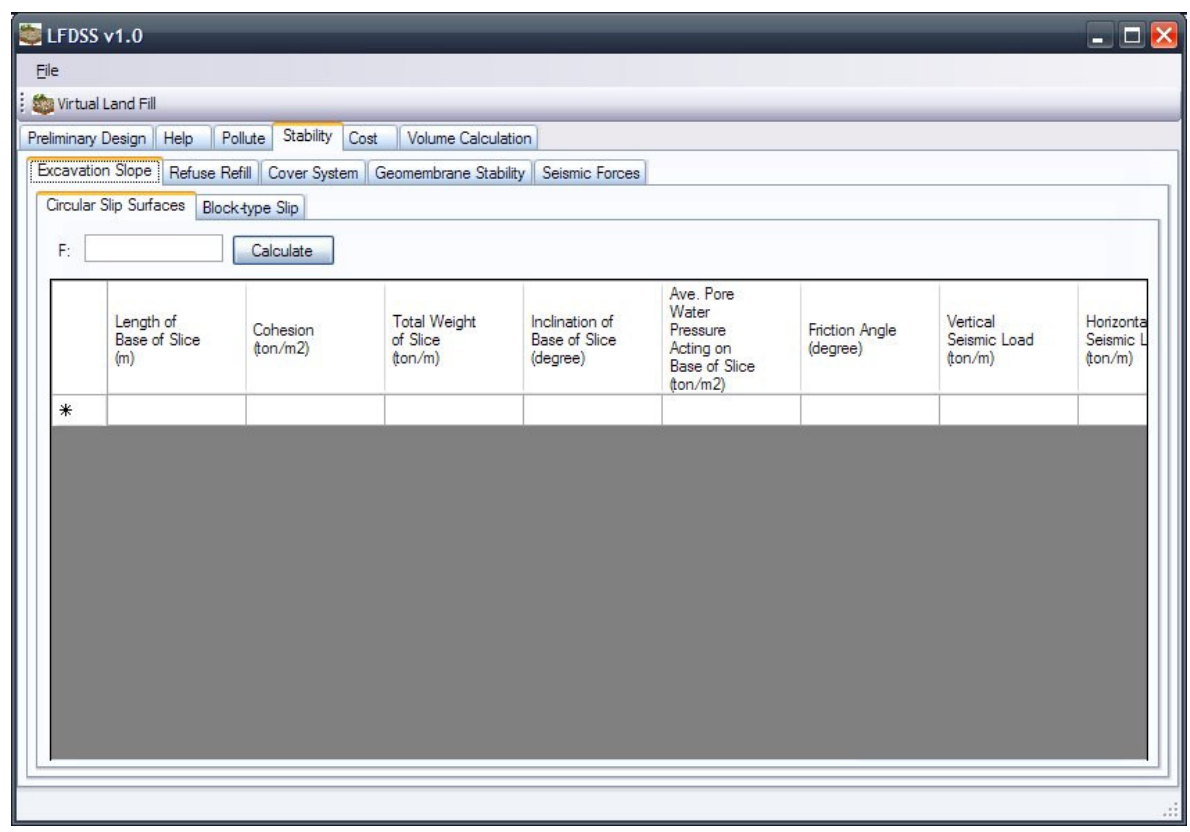

Figure B. 7 Stability module in LFDSS

\section{B.5. Cost}

Cost module is a tool for performing major, additional, and total financial landfill analyses for different landfill design components, collected under main headings of "Native Soil”, “Top Soil", "Drainage”, Clay -Onsite and Offsite”, "Drainage Tile", "Synthetic Membrane", "Geotextiles", and "Vegetative Soil". A tabular data entry area was defined for each heading/component. These tables display the name of the component, brief description of the processes related to the component, units, and it is possible to enter unit costs and amounts of materials used (Figure B.8). Each table is displayed on the same page to allow the user view the general condition. When the user selects "Calculate", each component in the tables are scanned and total for components are calculated. Based on the calculated cost, the total cost is summed and displayed in the "Total Main Component Cost" box. The procedure is repeated for additional components as well, and the total cost is written in "Total Additional Component Cost" box. Total landfill construction cost is the sum of main and additional component 
costs. The input data can be transferred to other programmes using copy-paste feature.

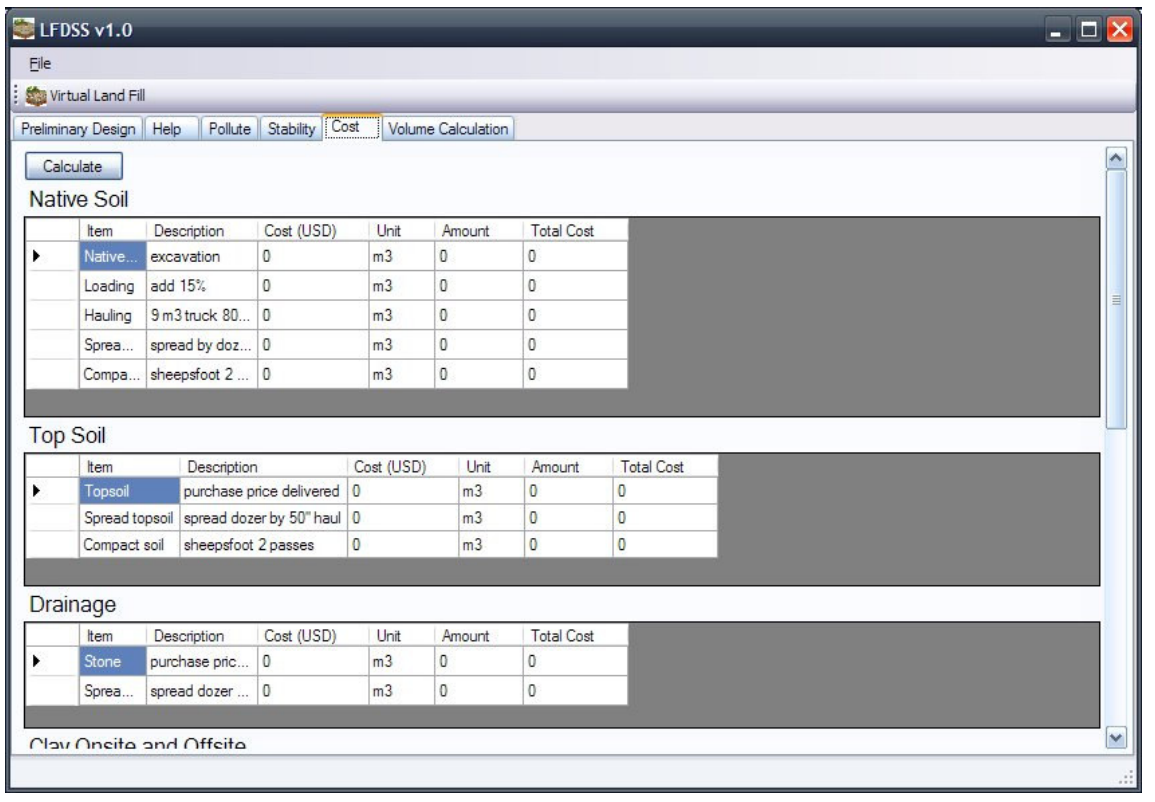

Figure B. 8 Cost calculation module in LFDSS

\section{B.6. Volume Calculation}

Volume module is a tool that calculates the required landfill volume based on design parameters such as population, operational lifetime of landfill, waste production rate, waste density, recycling ratio, and daily and intermediate cover ratio. The module contains the related boxes for parameter entry (Figure B.9). When the "Calculate" option is selected, the landfill volume is calculated based on the formulae defined in MS Excel, and the result is displayed to the user. For a reference of waste density, reference waste density values given by the Bank of States (İler Bankas1) are presented to the user as guidance at the bottom of the page. 


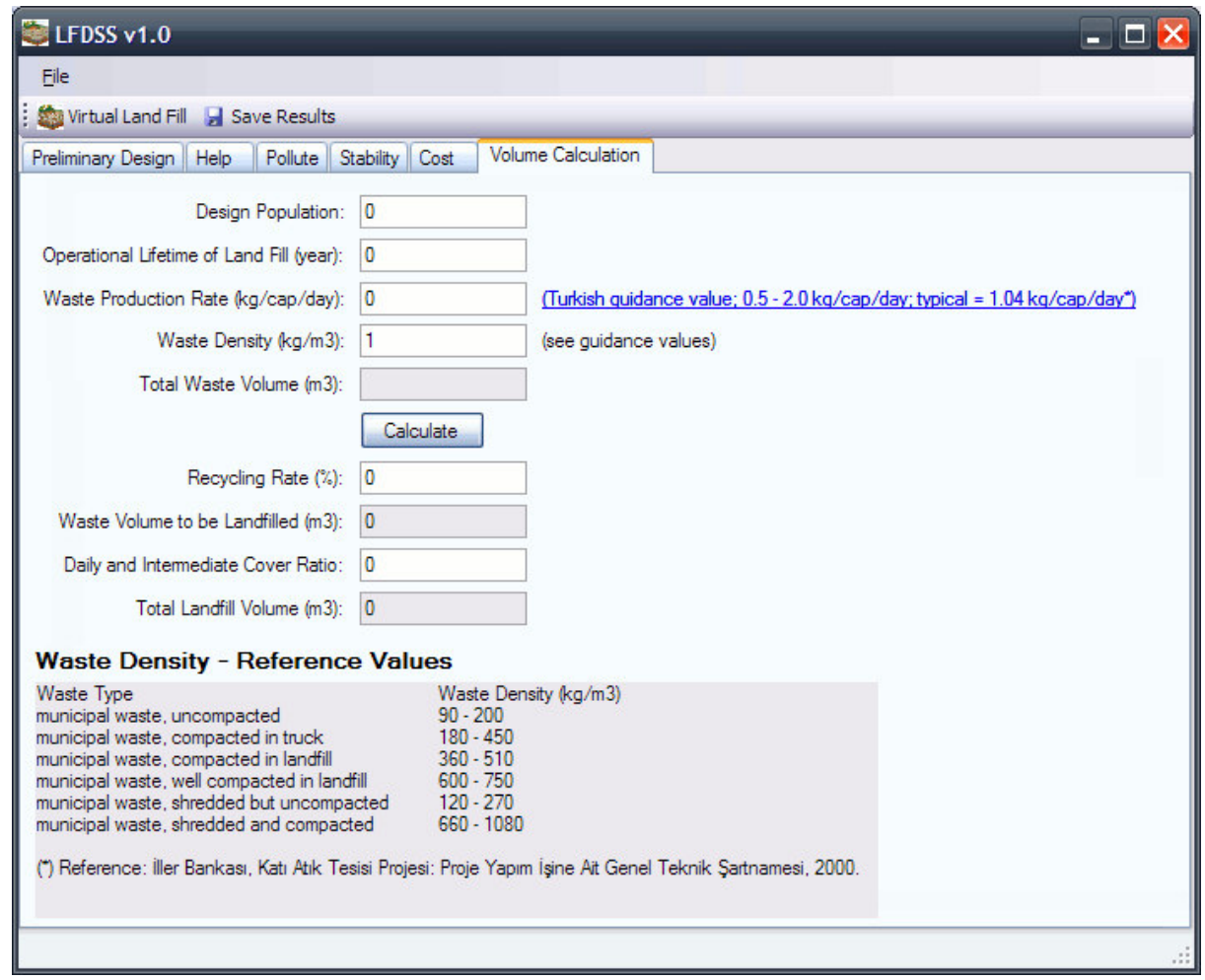

Figure B. 9 Cost module in LFDSS 


\section{APPENDIX-C}

\section{DESIGN COMPONENT SELECTION MATRIX RULES}

1. climate $<=500$, thickness $=5$, velocity $>0$, velocity $<=0.05$, size $<=2$; sample.csv:S1-S5

2. climate $<=500$, thickness $=5$, velocity $>0.05$, velocity $<=0.1$, size $<=2$; sample.csv:T1-T5

3. climate $<=500$, thickness $=5$, velocity $>0.1$, velocity $<=0.5$, size $<=2$; $\quad$ "ALL DESIGN ALTERNATIVES ARE APPROPRIATE FOR THE SITE CONDITIONS; BUT, SOME OF THEM CAN BE OVERDESIGNS! FOR ARID CLIMATES, ONLY COVER WITH SOME LEVEL OF INTENSIVE ENGINEERING (C1L1, C1L6, C2L1, C2L6, C3L1, C3L6) IS SATISFACTORY!"

4. climate $<=500$, thickness $=5$, velocity $>0.5$, velocity $<=1.0$, size $<=2$; $\quad$ "ALL DESIGN ALTERNATIVES ARE APPROPRIATE FOR THE SITE CONDITIONS; BUT, SOME OF THEM CAN BE OVERDESIGNS! FOR ARID CLIMATES, ONLY COVER WITH SOME LEVEL OF INTENSIVE ENGINEERING (C1L1, C1L6, C2L1, C2L6, C3L1, C3L6) IS SATISFACTORY!"

5. climate $<=500$, thickness $=20$, velocity $>0$, velocity $<=0.05$, size $<=2$; sample.csv:W1-W4

6. climate $<=500$, thickness $=20$, velocity $>0.05$, velocity $<=0.1$, size $<=2$; sample.csv:X1-X5 
7. climate $<=500$, thickness $=20$, velocity $>0.1$, velocity $<=0.5$, size $<=2$; $\quad$ "ALL DESIGN ALTERNATIVES ARE APPROPRIATE FOR THE SITE CONDITIONS; BUT, SOME OF THEM CAN BE OVERDESIGNS! FOR ARID CLIMATES, ONLY COVER WITH SOME LEVEL OF INTENSIVE ENGINEERING (C1L1, C1L6, C2L1, C2L6, C3L1, C3L6) IS SATISFACTORY!"

8. climate $<=500$, thickness $=20$, velocity $>0.5$, velocity $<=1.0$, size $<=2$; $\quad$ ALL DESIGN ALTERNATIVES ARE APPROPRIATE FOR THE SITE CONDITIONS; BUT, SOME OF THEM CAN BE OVERDESIGNS! FOR ARID CLIMATES, ONLY COVER WITH SOME LEVEL OF INTENSIVE ENGINEERING (C1L1, C1L6, C2L1, C2L6, C3L1, C3L6) IS SATISFACTORY!"

9. climate $<=500$, thickness $=5$, velocity $>0$, velocity $<=0.05$, size $>2$, size $<=15$; sample.csv:S14-S17

10. climate $<=500$, thickness $=5$, velocity $>0.05$, velocity $<=0.1$, size $>2$, size $<=15$; sample.csv:T14-T18

11. climate $<=500$, thickness $=5$, velocity $>0.1$, velocity $<=0.5$, size $>2$, size $<=15$;

"ALL DESIGN ALTERNATIVES ARE APPROPRIATE FOR THE SITE CONDITIONS; BUT, SOME OF THEM CAN BE OVERDESIGNS! FOR ARID CLIMATES, ONLY COVER WITH SOME LEVEL OF INTENSIVE ENGINEERING (C1L1, C1L6, C2L1, C2L6, C3L1, C3L6) IS SATISFACTORY!"

12. climate $<=500$, thickness $=5$, velocity $>0.5$, velocity $<=1.0$, size $>2$, size $<=15$;

"ALL DESIGN ALTERNATIVES ARE APPROPRIATE FOR THE SITE CONDITIONS; BUT, SOME OF THEM CAN BE OVERDESIGNS! FOR ARID CLIMATES, ONLY COVER WITH SOME LEVEL OF INTENSIVE ENGINEERING (C1L1, C1L6, C2L1, C2L6, C3L1, C3L6) IS SATISFACTORY!"

13. climate $<=500$, thickness $=20$, velocity $>0$, velocity $<=0.05$, size $>2$, size $<=15$; sample.csv:W14-W15 
14. climate $<=500$, thickness $=20$, velocity $>0.05$, velocity $<=0.1$, size $>2$, size $<=15$; sample.csv:X14-X17

15. climate $<=500$, thickness $=20$, velocity $>0.1$, velocit $y<=0.5$, size $>2$, size $<=15$; sample.csv:Y14-Y18

16. climate $<=500$, thickness $=20$, velocity $>0.5$, velocit $<<=1.0$, size $>2$, size $<=15$;

"ALL DESIGN ALTERNATIVES ARE APPROPRIATE FOR THE SITE CONDITIONS; BUT, SOME OF THEM CAN BE OVERDESIGNS! FOR ARID CLIMATES, ONLY COVER WITH SOME LEVEL OF INTENSIVE ENGINEERING (C1L1, C1L6, C2L1, C2L6, C3L1, C3L6) IS SATISFACTORY!"

17. climate $<=500$, thickness $=5$, velocity $>0$, velocity $<=0.05$, size $>15$, size $<=50$; sample.csv:S27-S28

18. climate $<=500$, thickness $=5$, velocity $>0.05$, velocit $y<=0.1$, size $>15$, size $<=50$; sample.csv:T27-T30

19. climate $<=500$, thickness $=5$, velocity $>0.1$, velocity $<=0.5$, size $>15$, size $<=50$; sample.csv:U27-U31

20. climate $<=500$, thickness $=5$, velocity $>0.5$, velocity $<=1.0$, size $>15$, size $<=50$;

"ALL DESIGN ALTERNATIVES ARE APPROPRIATE FOR THE SITE CONDITIONS; BUT, SOME OF THEM CAN BE OVERDESIGNS! FOR ARID CLIMATES, ONLY COVER WITH SOME LEVEL OF INTENSIVE ENGINEERING (C1L1, C1L6, C2L1, C2L6, C3L1, C3L6) IS SATISFACTORY!"

21. climate $<=500$, thickness $=20$, velocity $>0$, velocity $<=0.05$, size $>15$, size $<=50$; sample.csv:W27-W28

22. climate $<=500$, thickness $=20$, velocity $>0.05$, velocity $<=0.1$, size $>15$, size $<=50$ ; sample.csv:X27-X28

23. climate $<=500$, thickness $=20$, velocity $>0.1$, velocity $<=0.5$, size $>15$, size $<=50$; sample.csv:Y27-Y31

24. climate $<=500$, thickness $=20$, velocity $>0.5$, velocity $<=1.0$, size $>15$, size $<=50$; sample.csv:Z27-Z31 
25. climate $<=500$, thickness $=5$, velocity $>0$, velocity $<=0.05$, size $>50$; sample.csv:S40-S41

26. climate $<=500$, thickness $=5$, velocity $>0.05$, velocity $<=0.1$, size $>50$; sample.csv:T40-T41

27. climate $<=500$, thickness $=5$, velocity $>0.1$, velocity $<=0.5$, size $>50$; sample.csv:U40-U43

28. climate $<=500$, thickness $=5$, velocity $>0.5$, velocity $<=1.0$, size $>50$; sample.csv:V40-V44

29. climate $<=500$, thickness $=20$, velocity $>0$, velocity $<=0.05$, size $>50 ; \quad$ "USE DOUBLE LINER SYSTEMS; OR EXTENSIVE ENGINEERING LANDFILL DESIGN ON CLAYEY SOILS"

30. climate $<=500$, thickness $=20$, velocity $>0.05$, velocity $<=0.1$, size $>50$; sample.csv:X40-X41

31. climate $<=500$, thickness $=20$, velocity $>0.1$, velocity $<=0.5$, size $>50$; sample.csv:Y40-Y43

32. climate $<=500$, thickness $=20$, velocity $>0.5$, velocity $<=1.0$, size $>50$; sample.csv:Z40-Z44

33. climate $>500$, climate $<=1000$, thickness $=5$, velocity $>0$, velocit $y<=0.05$, size $<$ $=2$; sample.csv:A1-A5

34. climate $>500$, climate $<=1000$, thickness $=5$, velocity $>0.05$, velocit $y<=0.1$, size $<=2$; sample.csv:B1-B5

35. climate $>500$, climate $<=1000$, thickness $=5$, velocit $y>0.1$, velocit $\mathrm{x}<=0.5$, size $<$ $=2$; sample.csv:C1-C7

36. climate $>500$, climate $<=1000$, thickness $=5$, velocit $y>0.5$, velocit $y<=1.0$, size $<$ =2; sample.csv:D1-D7

37. climate $>500$, climate $<=1000$, thickness $=20$, velocit $y>0$, velocit $y<=0.05$, size $<=2$; sample.csv:E1-E5

38. climate $>500$, climate $<=1000$, thickness $=20$, velocity $>0.05$, velocit $y<=0.1$,siz $\mathrm{e}<=2$; sample.csv:F1-F5 
39. climate $>500$, climate $<=1000$, thickness $=20$, velocity $>0.1$, velocit $y<=0.5$, size $<=2$; sample.csv:G1-G7

40. climate $>500$, climate $<=1000$, thickness $=20$, velocity $>0.5$, velocit $<<=1.0$, size $<=2$; sample.csv:H1-H7

41. climate $>500$, climate $<=1000$, thickness $=5$, velocit $y>0$, velocit $y<=0.05$, size $>$ 2 ,size $<=15$; sample.csv:A8-A12

42. climate $>500$, climate $<=1000$, thickness $=5$, velocit $y>0.05$, velocity $<=0.1$, size $>2$, size $<=15$; sample.csv:B8-B12

43. climate $>500$, climate $<=1000$, thickness $=5$, velocity $>0.1$, velocity $<=0.5$, size $>$ 2 ,size $<=15$; sample.csv:C8-C14

44. climate $>500$, climate $<=1000$, thickness $=5$, velocit $y>0.5$, velocit $y<=1.0$, size $>$ 2 ,size $<=15$; sample.csv:D8-D14

45. climate $>500$, climate $<=1000$, thickness $=20$, velocity $>0$, velocit $y<=0.05$, size $>2$, size $<=15$; sample.csv:E8-E9

46. climate $>500$, climate $<=1000$, thickness $=20$, velocity $>0.05$, velocit $y<=0.1$,siz e $>2$,size $<=15$; sample.csv:F8-F12

47. climate $>500$, climate $<=1000$, thickness $=20$, velocity $>0.1$, velocit $y<=0.5$, size $>2$, size $<=15$; sample.csv:G8-G12

48. climate $>500$, climate $<=1000$, thickness $=20$, velocity $>0.5$, velocit $y<=1.0$, size $>2$, size $<=15$; sample.csv:H8-H14

49. climate $>500$, climate $<=1000$, thickness $=5$, velocit $y>0$, velocit $y<=0.05$, size $>$ 15, size<=50; sample.csv:A15-A18

50. climate $>500$, climate $<=1000$, thickness $=5$, velocit $y>0.05$, velocit $y<=0.1$, size $>15$,size<=50; sample.csv:B15-B19

51. climate $>500$, climate $<=1000$, thickness $=5$, velocity $>0.1$, velocity $<=0.5$, size $>$ 15,size<=50; sample.csv:C15-C19

52. climate $>500$, climate $<=1000$, thickness $=5$, velocity $>0.5$, velocity $<=1.0$, size $>$ 15,size<=50; sample.csv:D15-D21

53. climate $>500$, climate $<=1000$, thickness $=20$, velocity $>0$, velocit $y<=0.05$, size $>15$,size<=50; sample.csv:E15-E16 
54. climate $>500$, climate $<=1000$, thickness $=20$, velocity $>0.05$, velocit $y<=0.1$, siz e $>15$,size $<=50$; sample.csv:F15-F16

55. climate $>500$, climate $<=1000$, thickness $=20$, velocity $>0.1$, velocit $<<=0.5$, size $>15$, size $<=50$; sample.csv:G15-G19

56. climate $>500$, climate $<=1000$, thickness $=20$, velocity $>0.5$, velocit $y<=1.0$, size $>15$,size<=50; sample.csv:H15-H19

57. climate $>500$, climate $<=1000$, thickness $=5$, velocity $>0$, velocit $y<=0.05$, size $>$ 50; sample.csv:A22-A23

58. climate $>500$, climate $<=1000$, thickness $=5$, velocity $>0.05$, velocity $<=0.1$, size $>50$; sample.csv:B22-B25

59. climate $>500$, climate $<=1000$, thickness $=5$, velocity $>0.1$, velocit $y<=0.5$, size $>$ 50; sample.csv:C22-C26

60. climate $>500$, climate $<=1000$, thickness $=5$, velocit $y>0.5$, velocit $y<=1.0$, size $>$ 50; sample.csv:D22-D26

61. climate $>500$, climate $<=1000$, thickness $=20$, velocity $>0$, velocit $y<=0.05$, size >50; "USE DOUBLE LINER SYSTEMS; OR EXTENSIVE ENGINEERING LANDFILL DESIGN ON CLAYEY SOILS"

62. climate $>500$, climate $<=1000$, thickness $=20$, velocity $>0.05$, velocity $<=0.1$, siz e $>50$; sample.csv:F22-F23

63. climate $>500$, climate $<=1000$, thickness $=20$, velocity $>0.1$, velocit $y<=0.5$, size >50; sample.csv:G22-G26

64. climate $>500$, climate $<=1000$, thickness $=20$, velocity $>0.5$, velocit $y<=1.0$, size $>50$; sample.csv:H22-H26

65 . climate $>1000$, thickness $=5$, velocity $>0$, velocit $y<=0.05$, size $<=2$; sample.csv:J1-J5

66. climate $>1000$, thickness $=5$, velocity $>0.05$, velocity $<=0.1$, size $<=2$; sample.csv:K1-K5

67. climate $>1000$, thickness $=5$, velocity $>0.1$, velocity $<=0.5$, size $<=2$; sample.csv:L1-L5 
68. climate $>1000$, thickness $=5$, velocity $>0.5$, velocity $<=1.0$, size $<=2$; sample.csv:M1-M7

69. climate $>1000$, thickness $=20$, velocity $>0$, velocity $<=0.05$, size $<=2$; sample.csv:N1-N5

70. climate $>1000$, thickness $=20$, velocity $>0.05$, velocity $<=0.1$, size $<=2$; sample.csv:01-05

71. climate $>1000$, thickness $=20$, velocity $>0.1$, velocity $<=0.5$, size $<=2$; sample.csv:P1-P5

72. climate $>1000$, thickness $=20$, velocity $>0.5$, velocity $<=1.0$, size $<=2$; sample.csv:Q1-Q5

73. climate $>1000$, thickness $=5$, velocity $>0$, velocit $y<=0.05$, size $>2$, size $<=15$; sample.csv:J8-J11

74. climate $>1000$, thickness $=5$, velocity $>0.05$, velocit $<<=0.1$, size $>2$, size $<=15$; sample.csv:K8-K12

75. climate $>1000$, thickness $=5$, velocity $>0.1$, velocity $<=0.5$, size $>2$, size $<=15$; sample.csv:L8-L12

76. climate $>1000$, thickness $=5$, velocity $>0.5$, velocity $<=1.0$, size $>2$, size $<=15$; sample.csv:M8-M12

77. climate $>1000$, thickness $=20$, velocity $>0$, velocity $<=0.05$, size $>2$, size $<=15$; sample.csv:N8-N11

78. climate $>1000$, thickness $=20$, velocity $>0.05$, velocit $y<=0.1$, size $>2$, size $<=15$; sample.csv:O8-O11

79. climate $>1000$, thickness $=20$, velocit $y>0.1$, velocit $<<=0.5$, size $>2$, size $<=15$; sample.csv:P8-P12

80. climate $>1000$, thickness $=20$, velocity $>0.5$, velocity $<=1.0$, size $>2$, size $<=15$; sample.csv:Q8-Q12

81. climate $>1000$, thickness $=5$, velocity $>0$, velocit $y<=0.05$, size $>15$, size $<=50$; sample.csv:J13-J16

82. climate $>1000$, thickness $=5$, velocity $>0.05$, velocit $<<=0.1$, size $>15$, size $<=50$; sample.csv:K13-K16 
83. climate $>1000$, thickness $=5$, velocity $>0.1$, velocit $<<=0.5$, size $>15$, size $<=50$; sample.csv:L13-L17

84. climate $>1000$, thickness $=5$, velocit $y>0.5$, velocity $<=1.0$, size $>15$, size $<=50$; sample.csv:M13-M17

85. climate $>1000$, thickness $=20$, velocit $y>0$, velocit $y<=0.05$, size $>15$, size $<=50$; sample.csv:N13-N14

86. climate $>1000$, thickness $=20$, velocity $>0.05$, velocity $<=0.1$, size $>15$, size $<=50$ ; sample.csv:O13-O16

87. climate $>1000$, thickness $=20$, velocity $>0.1$, velocit $y<=0.5$, size $>15$, size $<=50$; sample.csv:P13-P17

88. climate $>1000$, thickness $=20$, velocity $>0.5$, velocit $<<=1.0$, size $>15$, size $<=50$; sample.csv:Q13-Q17

89. climate $>1000$, thickness $=5$, velocity $>0$, velocit $y<=0.05$, size $>50$; sample.csv:J18-J20

90. climate $>1000$, thickness $=5$, velocity $>0.05$, velocity $<=0.1$, size $>50$; sample.csv:K18-K20

91. climate $>1000$, thickness $=5$, velocity $>0.1$, velocity $<=0.5$, size $>50$; sample.csv:L18-L22

92. climate $>1000$, thickness $=5$, velocity $>0.5$, velocity $<=1.0$, size $>50$; sample.csv:M18-M22

93. climate $>1000$, thickness $=20$, velocity $>0$, velocity $<=0.05$, size $>50$; sample.csv:N18-N19

94. climate $>1000$, thickness $=20$, velocity $>0.05$, velocity $<=0.1$, size $>50$; sample.csv:018-O19

95. climate $>1000$, thickness $=20$, velocity $>0.1$, velocity $<=0.5$, size $>50$; sample.csv:P18-P22

96. climate $>1000$, thickness $=20$, velocity $>0.5$, velocity $<=1.0$, size $>50$; sample.csv:Q18-Q22 
APPENDIX-D

TECHNICAL DOCUMENTATION FOR VIRTUAL LANDFILL (VLF)

VLF is developed for the purpose of virtual landfill base contour design on digital maps. It is written on .NET Framework using C\#, based on "Windows Forms" visual user interface library. The programme operates on Windows 2000 or higher and developed using Microsoft Visual 2005. It is anticipated that the programme may perform under different operating environment (such as Linux, MacOS, etc.) via Mono project (Mono, 2007). The general view of the programme is given in Figure D.1.

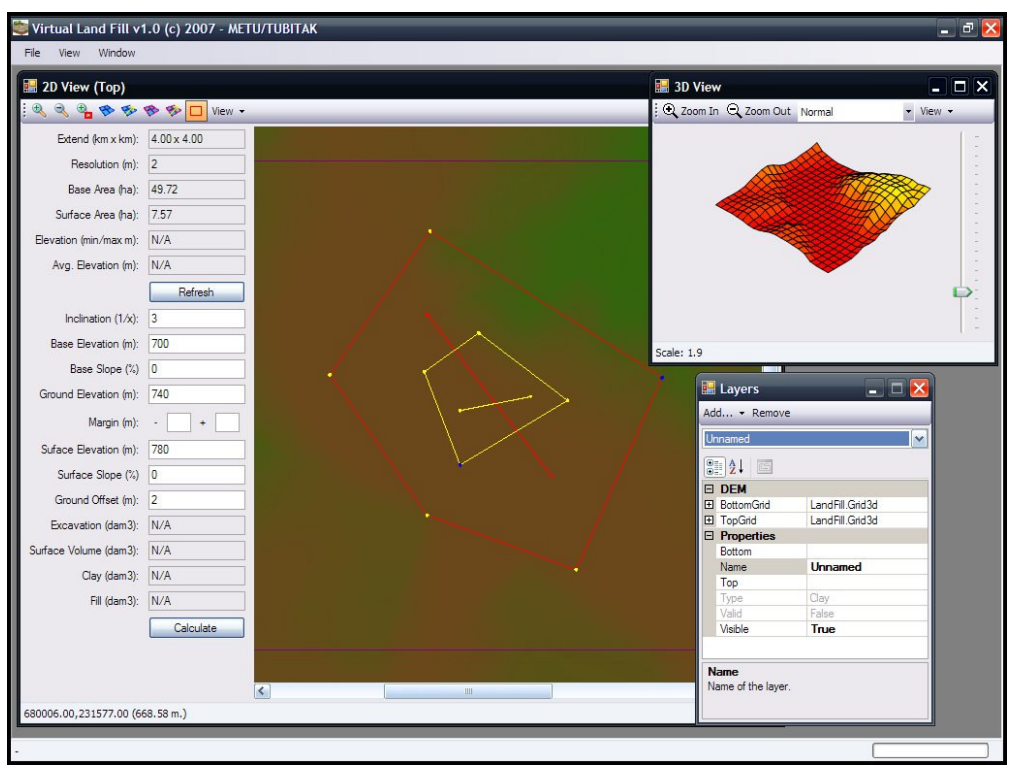

Figure D. 1 General view of VLF 
VLF can perform the operations listed below:

i. Unlimited number of 3 dimensional topographic, clay layer, and groundwater layer maps of the site for landfill construction can be uploaded to the model (the number of maps are actually limited by the capacity of the computer).

ii. Topographic map and landfill can be viewed both in 2 and 3 dimensions; whereas, other layers (i.e. clay and groundwater) can be viewed in 2 dimensions.

iii. On the 2 dimensional topographic map, landfill base and final cover can be drawn in any kind of geometric shape. Also, the slope directions of both landfill base and final cover can be identified.

iv. Based on the shape, dimensions, and slopes of the landfill, excavation and fill processes on the site and the final view of the site after the landfill is placed can be viewed both in $2 \mathrm{D}$ and $3 \mathrm{D}$.

\section{D.1. VLF Technical Details}

VLF is based on Single document interface (SDI)/Multiple view approach. This approach allows the user to view the working area in different shapes and properties while working on a single landfill. For this purpose, 2 and 3D views are included in the software.

Primarily, topographic information of the site is required to place the landfill on the site and to perform volume calculations. Site elevation information can be uploaded to VLF in USGS Digital Elevation Model format. For this purpose, a parser was written to process text-based ASCII DEM files. DEM files to be uploaded must be converted to metric projection to be used in the calculations. There are no limitations for resolution or size of the DEM data. Elevation data of particular points only on a regular grid of the site are present in DEM files. In grid 
class, there are functions that calculate the elevation of any point in the site using elevation data of points nearby the point of interest, by interpolation. By this way, the resolution of the topographic data and calculations are independent of each other. Elevation data can be uploaded to the programme using "File/Import Base DEM" menu. The working area is shown in $2 \mathrm{D}$ and $3 \mathrm{D}$ after the upload process is completed.

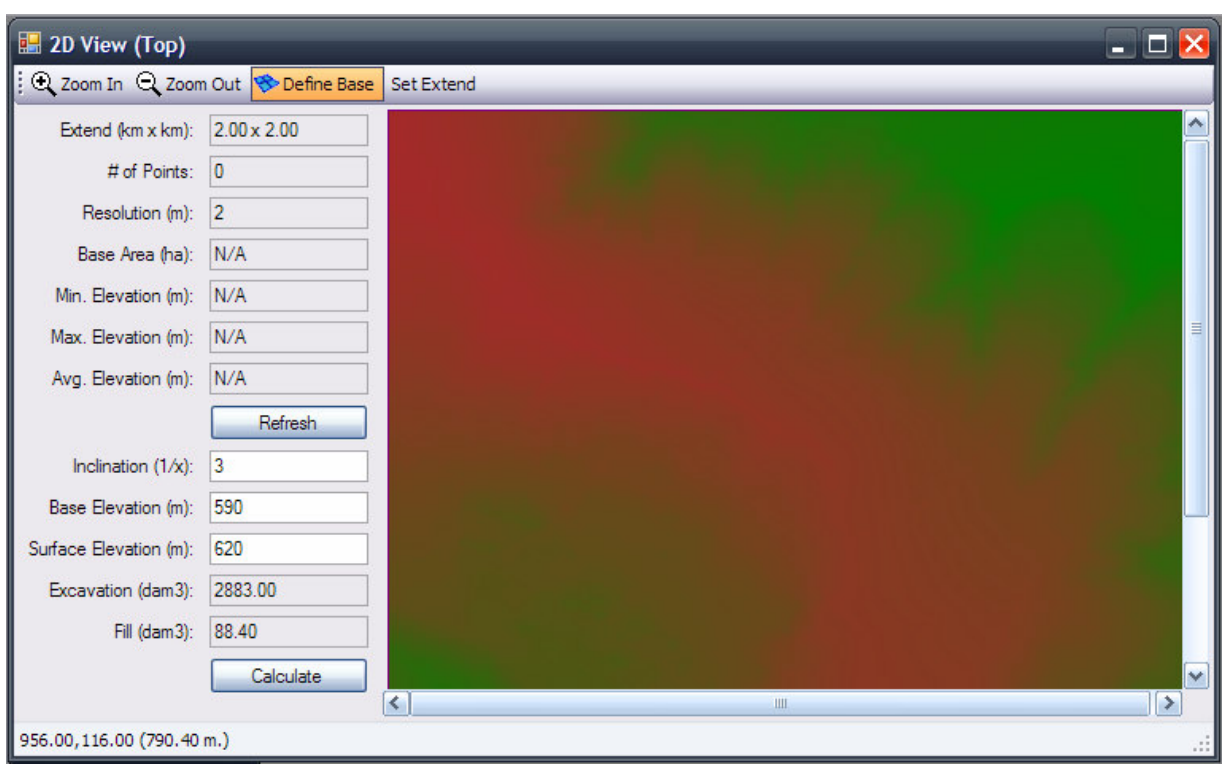

Figure D. 2 Displaying the elevation (topographic map) in VLF

To display the elevation map, instead of point-by-point drawing using DEM data each time, a bitmap view is formed by processing DEM data only once. The size of the bitmap is the same as DEM data, higher elevations are colored in green whereas lower elevations are colored in brown. This bitmap is printed on the screen to display the elevation map. This enables faster display. Site map can be zoomed in or zoomed out using "zoom in" and "zoom out" buttons in the toolbar (Figure D.3). Zoom in and zoom out functions are performed using "scale transform" function of "Graphics" class in .NET Framework. 


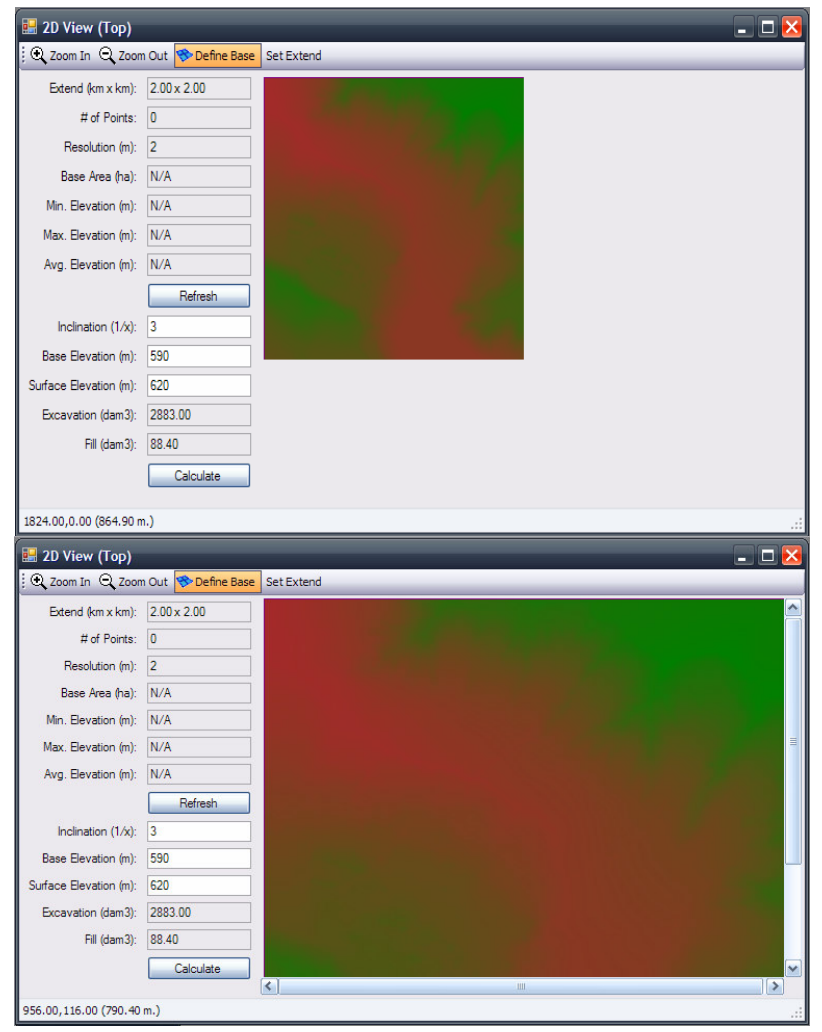

Figure D. 3 Zoom in and Zoom out functions

Landfill base area can be defined on the site using "Define Base" button. Base area can be defined as a polygon, which can either be concave or convex. While the "define base" button is clicked, the edges of the polygon are defined using left-button of the mouse on the desired points around the site. Right-click of the mouse takes the last selected point back (Figure D.4). To ease the point selection process, coordinates and elevation of the point that the cursor is on is shown instantaneously on the status bar. 


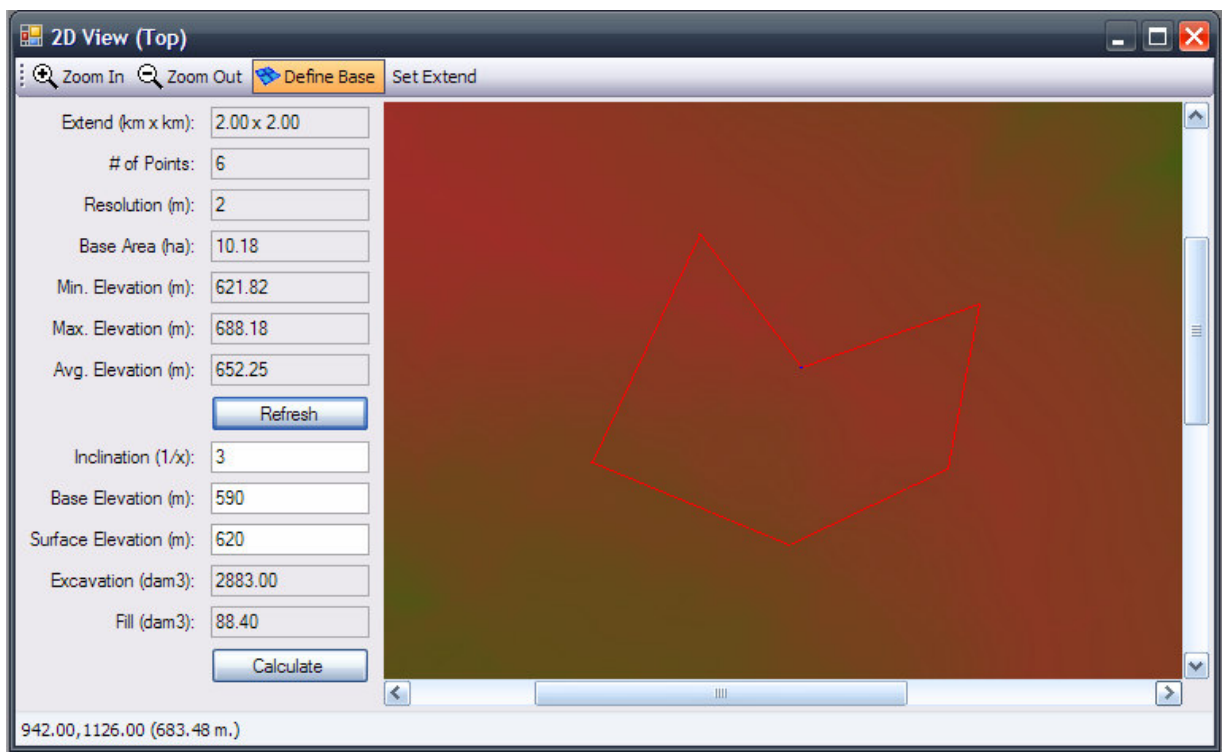

Figure D. 4 Defining landfill base area

Using "Refresh" button in the knowledge sheet, minimum, maximum, and average elevation of the base can be calculated. A class called "Polygon" was written to process polygonal data. Points forming the polygon are stored as float data type. VLF can perform various calculations on the inner area of the polygon; such as finding the minimum elevation of the base, calculating cut and fill volumes, etc. To perform these calculations, the points included by the polygon need to be determined. The simplest way to achieve this is to check whether or not a particular point is inside the polygon. However, this is an inefficient and timeconsuming way. Instead, scanline conversion method is used. The polygon is scanned from top to bottom, the points intersecting a horizontal line are determined and the lines between these points are processed (Figure D.5). Therefore, unnecessary points are not processed. For this purpose, a generic scanline conversion algorithm that supports active edge list based convex polygons was written in Polygon class. This algorithm is used to calculate minimum, maximum, and average elevations of the base. 


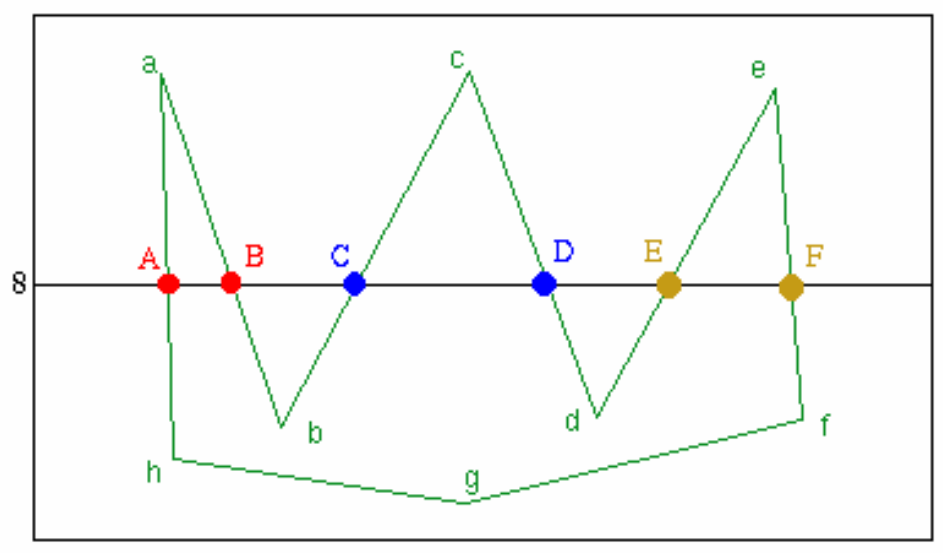

Figure D. 5 Scanline conversion method

Once the landfill base is defined, it is possible to perform volume calculations by entering the values into the bottom part of the knowledge sheet. These parameters are base elevation, surface elevation and inclination/slope. Slope is defined as the ratio of depth to length (Figure D.6).

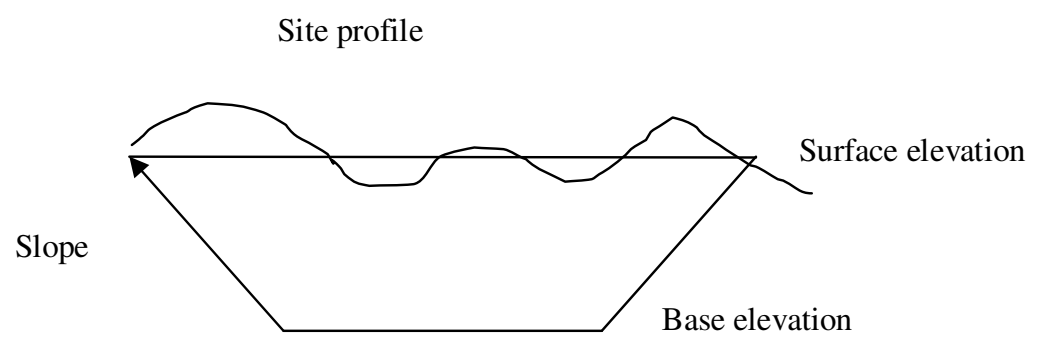

Figure D. 6 Site parameters

Minimum, maximum and average elevations can be used while determining the site parameters. After the values of the site parameters are entered, cut and fill volumes are calculated pressing "Calculate" button. Cut volume is displayed in the "excavation" part and fill volume is displayed in the "fill" part of the knowledge sheet in cubic decameters. Areas to be excavated are shown in light blue, whereas, areas to be filled are shown in dark blue. Calculations are 
performed with $1 \mathrm{~m}$ sensitivity. These areas are determined using scanline conversion method by calculating the elevation difference between surface elevation and base elevation. Then, for all the sides of the base area, outward horizontal projection is taken and calculations are performed for these areas. For the edges, angular scanning is used to determine the intermediate points and the areas staying between the projections of the adjacent sides are calculated inside the polygons formed by these points (Figure D.7).

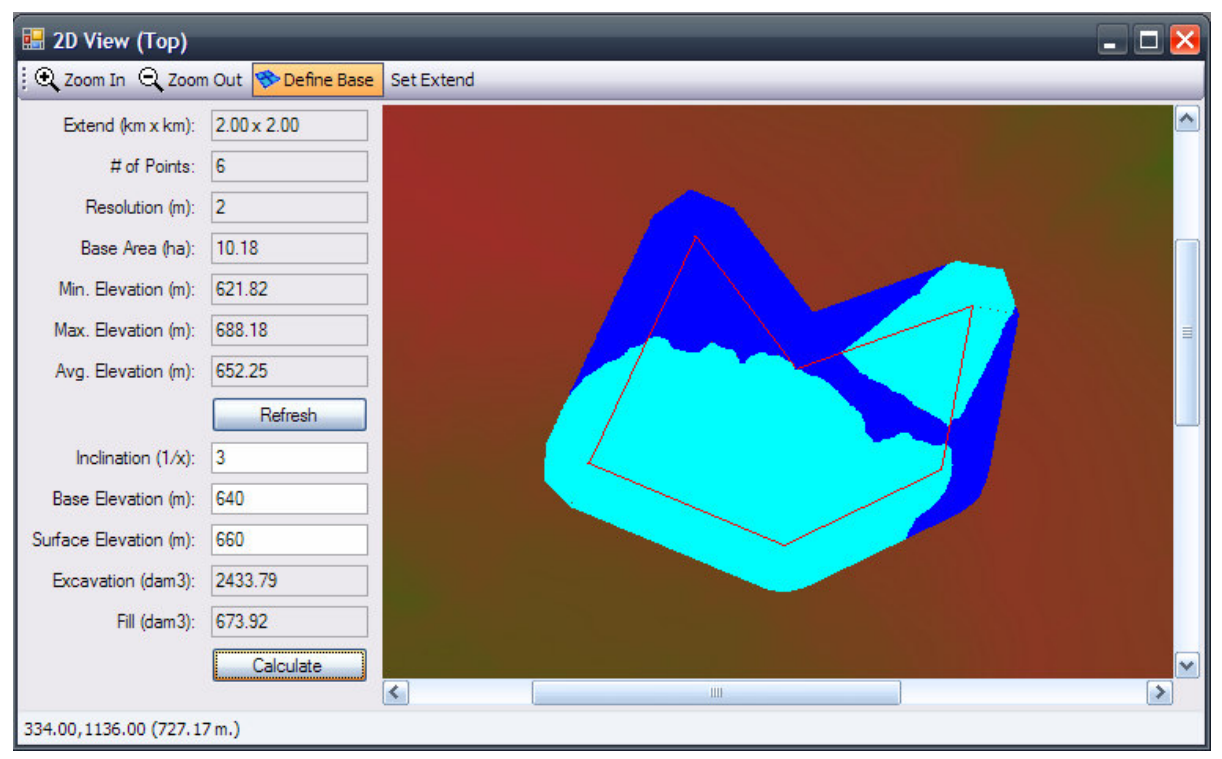

Figure D. 7 Cut and fill calculation results

As the polygon can be convex or concave, it is possible that the horizontal projections of different sides can coincide with each other and inner area of the polygon (Figure D.8). To eliminate miscalculations due to this phenomenon (multiple calculations of a single point), a matrix with $1 \mathrm{~m}$ sensitivity around the landfill site is created and calculation results are recorded in this matrix. Calculations are not repeated for the previously recorded elements. To accelerate the display on elevation map, a bitmap is created from the matrix and used in printing on the screen. 


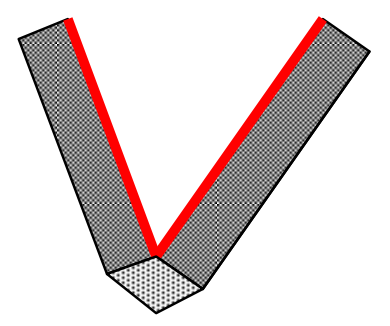

a

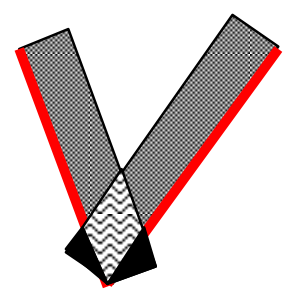

b

Figure D. 8 (a) Empty edges as a result of horizontal projection (lighter shades) (b) Areas that coincide (waving shades) and rest in the polygon (black shades) as a result of horizontal projection

3D view of any working area can be obtained in VLF. For this purpose, a class that supports surface-based display (Surface3Drenderer) is used. 3D display calculations are performed without using any 3D drawing library (i.e. OpenGL or Direct3D); therefore, the system is able to operate under any platform and with low requirements. For 3D display, particular points are sampled from a regular grid area and adjacent points are linked to each other by a plane. 2 dimensional projections are taken using virtual aspect and direction of the user while drawing the planes. Higher quality views can be obtained by changing the sampling intervals (Figure D.9).

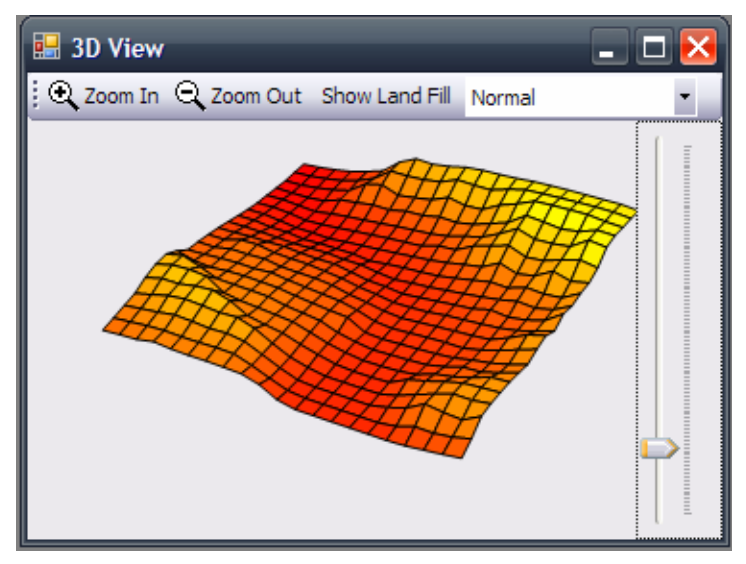

Figure D. 9 3D view 
Using "zoom in" and "zoom out" buttons on the tool bar at the top of the 3D view window, it is possible to approach to the site. It is possible to rotate and view the site from different aspects by moving the mouse while the left button is clicked. Using the pull down menu on the right hand side of the toolbar, sampling and display quality (low to high) can be selected. The cursor on the right hand side of the window can be slid to exaggerate elevation differences up to 10 times (Figure D.10).

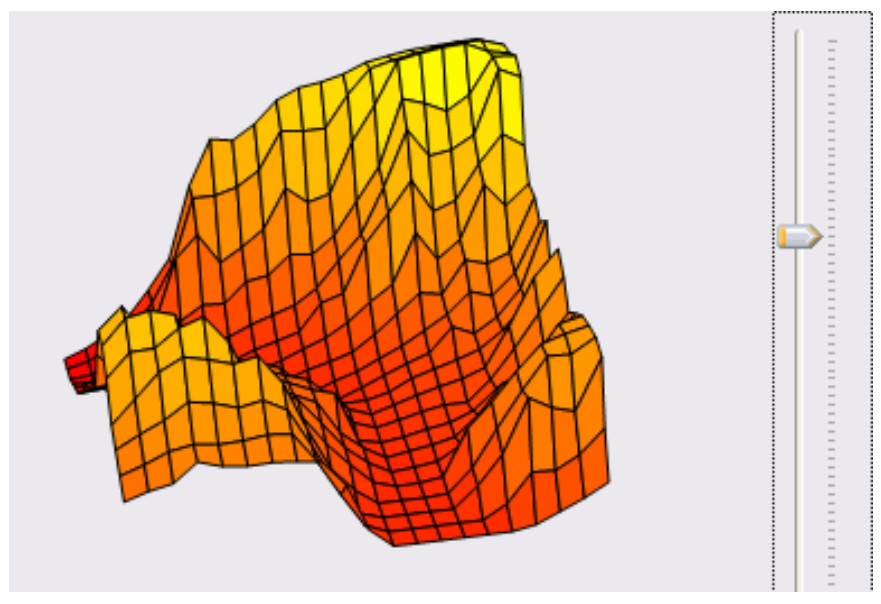

Figure D. 10 Exaggerated elevation difference

The calculated landfill is displayed in 3D on the site when "Show Landfill" button on the toolbar is clicked (Figure D.11). It is also possible to view only a part of the site (e.g. landfill) in 3D. The desired rectangular area is selected using "Set extend" button in the toolbar of 2D display window. While the button is selected, upper left and lower right corners of the rectangle are defined by left clicking the mouse. Right clicking the mouse selects the entire area. 


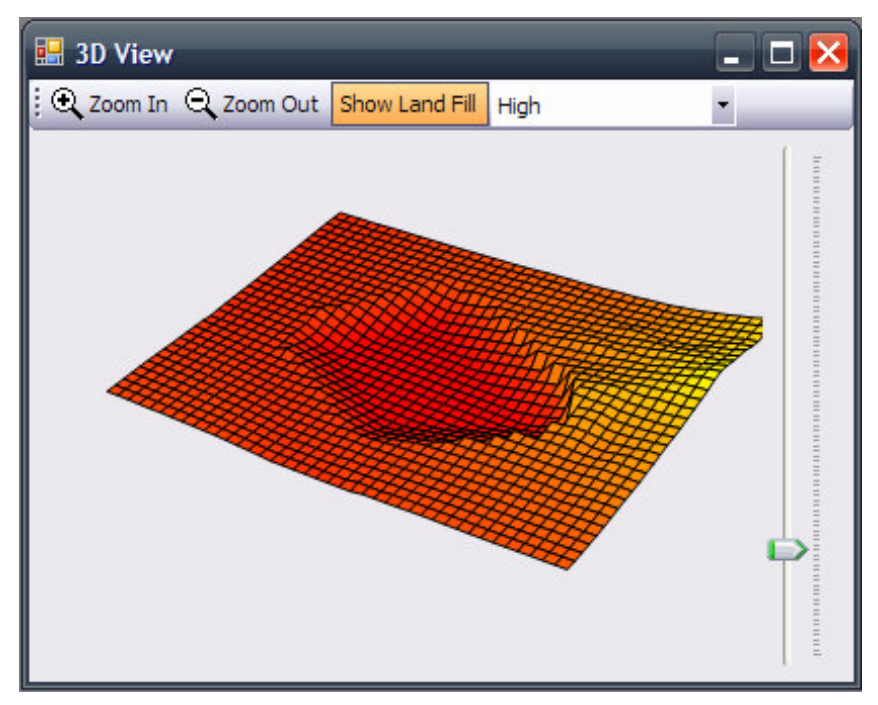

Figure D. 11 3D View of the landfill

\section{D.2.VLF Sub-modules}

VLF is basically composed of six interrelated sub-modules, called "Regional Data Map", "Layers", "Polygon”, "Landfill”, “2-Dimensional (2D) View”, and "3Dimensional (3D) View". Technical and design details of VLF application based on these sub-modules are presented in the following sections.

\section{D.2.1. Regional Data Map (RDM)}

Regional data map (RDM) was developed to upload any numeric data belonging to the site (e.g. elevation of the site) and to calculate the value of any point within the given area. RDM module allows the data to be uploaded in ASCII DEM (digital elevation model) file format. In this file format, an area having rectangular borders can be divided into regular grids at a specified interval (e.g. $4 \mathrm{~m}$ ), and data of each point on the grid are stored in a matrix composed of values corresponding to each point. Information on the area and the matrix are stored as a text file. The first six rows of the matrix belong to number of columns (NCLOS), number of rows (NROWS), coordinate of the upper left corner of the area (XLLCORNER), 
coordinate of the lower right corner of the area (YLLCORNER), resolution (CELLSIZE), and no data value to define points that do not have any data (NODATA_VALUE). Following the first six rows, there are NROWS-number of rows containing NOLCS-number of numbers showing the values of points at that row. An example ASCII DEM file part is given below:

NCOLS 2001

NROWS 2001

XLLCORNER 678999.000

YLLCORNER 233999.000

CELLSIZE 2.000

NODATA_VALUE -9999.000

$597.96597 .97598 .03598 .14598 .18 \ldots$

$598.03598 .03598 .08598 .16598 .25 \ldots$

$598.13598 .18598 .21598 .26598 .31 \ldots$

RDM module contains a parser to upload ASCII DEM files. The parser reads the information in text file, and converts the information to a data structure that can be processed and defined as an independent class. If the borders of the area are large and the resolution is high, size of ASCII DEM file can be big, and the upload process can take longer time. The upload progress is presented to the user via a progress bar, using event-base interaction features of $\mathrm{C \#}$ language. Another important feature of RDM module is that the module can bilinearly interpolate the value of any point on the map from the data on the grid. In bilinear interpolation, the value of the point is calculated using the data of nearest four points. By this way, if required, higher resolution processes can be performed without being restricted to the resolution of the map. RDM module is used to upload elevation map and data that belongs to layers (Section D.2.2) and to access these data in VLF. 


\section{D.2.2. Layers}

In landfill design, the distribution and thickness of the clay layers, and the groundwater level and flow direction directly affect the design. VLF model allows the user to define as many numbers of layers as he/she requires. These layers are managed by "Layers" module. A major class was defined in order to collect all layers under the same structure, and to perform the functions and to manage the information common to all layers (e.g. layer coordinates, type, name, visibility, etc.). All layers are derived from this major class. Each class contains one or more RDM. For example, clay layers consist of two RDMs that define top and bottom of clay layers. RDMs of clay layers can differ from the site elevation map in resolution and dimensions. Layers module uploads and accesses these data using RDM module.

In VLF software, the user interaction with layers is achieved by Layers window (Figure D.12). This window allows the user to add new layers, change layer properties, or delete existing layers. Layers window is composed of three sections: process buttons on top, layers list below the buttons, and property grid that demonstrates the layer properties at the bottom. Every process selected by the user is forwarded to Layers module and performed by the module. Layer classes were defined to include "category" and "description" characteristics of C\# language; therefore, the connection between layers, and property grid and processes defined in property grid was easily established. 


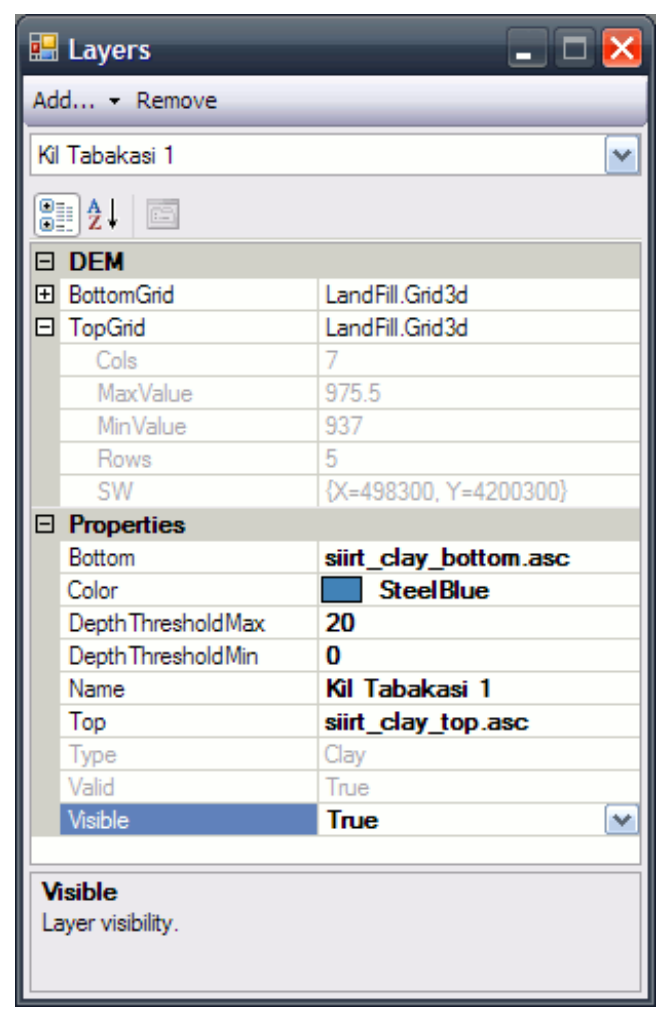

Figure D. 12 Layers window in VLF

Clay layer is defined by RDMs defining top and bottom borders of the layer (i.e. "TopGrid" and "BottomGrid"), layer color (i.e. "Color"), and lower and upper color threshold values (i.e. "DepthTresholdMin" and "DepthTresholdMax". The values of the parameters can be defined visually by the user. Moreover, detailed information on RDMs of the layer are presented in the Layers window. Color threshold values define the visualization of the clay layer in 2D view. Deeper clay thickness is shown by darker shades; whereas, thinner layers are shown by lighter shades (Figure D.13). Threshold values allow increasing the accent on the layer to make it more visible on the topographic (elevation) map. 


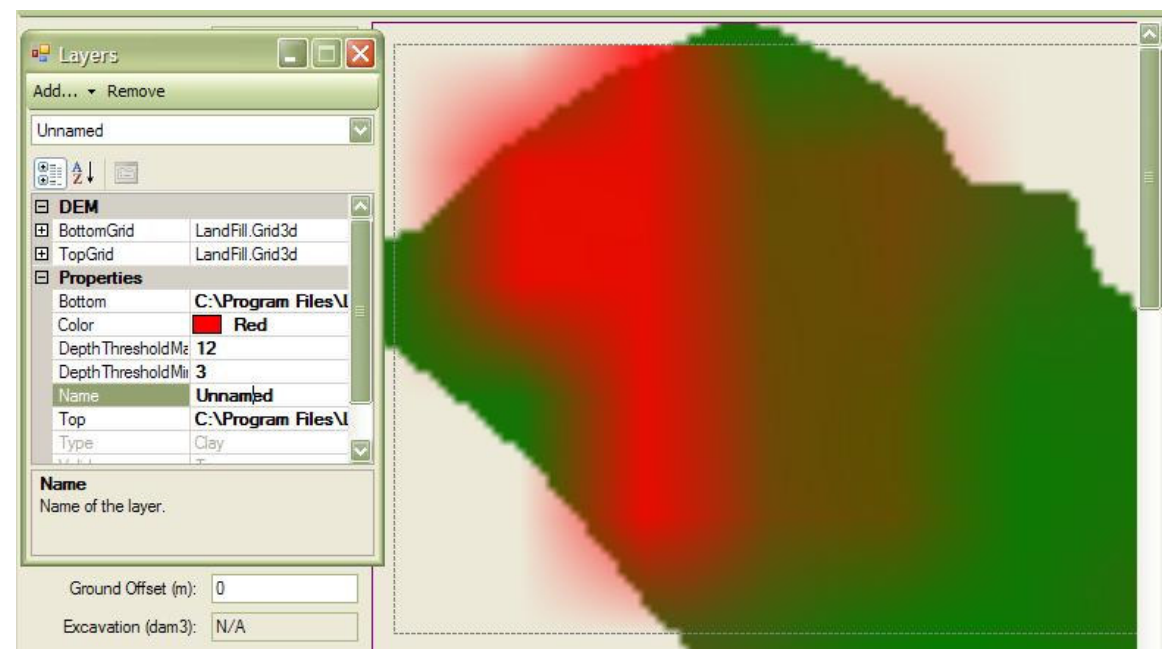

Figure D. 13 Demonstrating clay layers; darker red shade indicates clay layer thickness around 12 $\mathrm{m}$, and lighter red indicates clay layer thickness around $3 \mathrm{~m}$.

Groundwater layer is defined by RDMs defining depth and flow direction of the layer (i.e. "Depth" and "Direction"), layer colors (i.e. "ColorMin" and "ColorMax"), and lower and upper color threshold values (i.e. "DepthTresholdMin" and "DepthTresholdMax". Similar to the clay layers, the values of the parameters can be defined visually by the user. The values should be in degrees in the direction-RDM, which defines the flow direction of groundwater. Groundwater layers are demonstrated by arrows showing the direction of flow in 2D view. Regarding the ground elevation, layers deeper than the upper threshold value are shown by arrows in "ColorMax" color, and layers above the lower threshold value are shown by arrows in "ColorMin" color. Layers between the upper and lower threshold values are colored linearly between these two colors (Figure D.14). For the sake of visibility of the arrows, they are drawn in equal intervals depending on the degree of the zoom. 


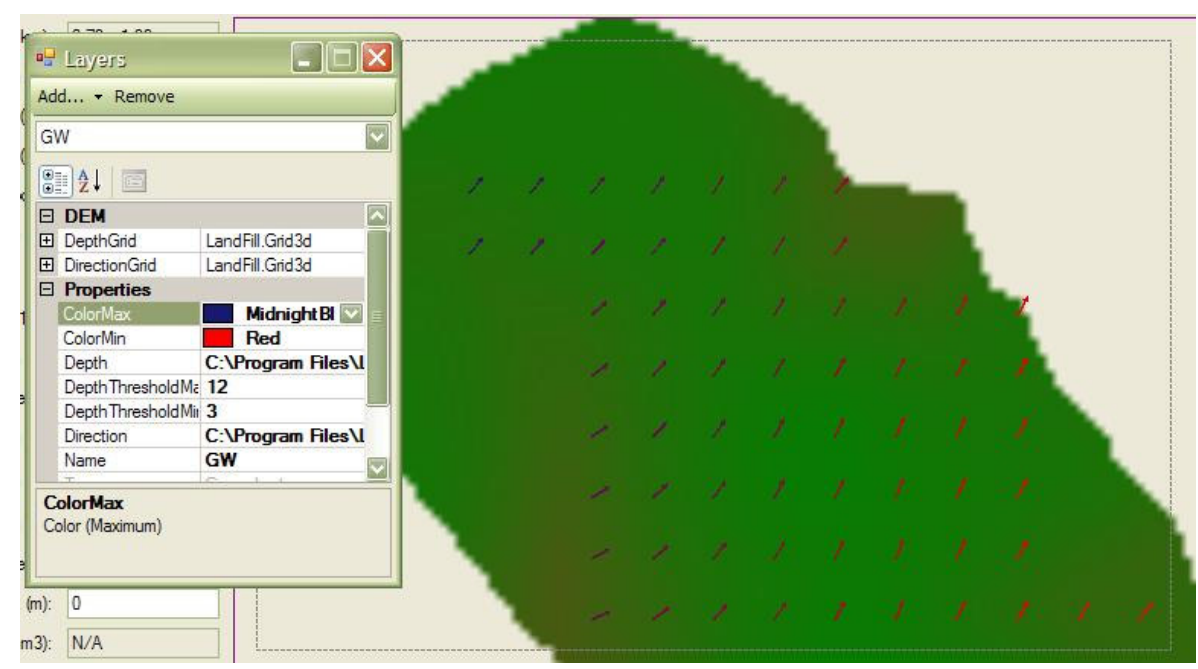

Figure D. 14 Demonstration of groundwater layers in VLF

\section{D.2.3. Polygon}

The landfill is designed by defining the base area, final cover limits, and design parameters (e.g. side slopes, base elevation, etc.) in VLF. Base and surface area are defined as polygons. "Polygon" module was developed to create polygons and to perform the following processes on the polygons:

i. Adding points (corners) to polygon, changing the coordinates of an existing point, or deleting the point from polygon.

ii. Holding any point on the polygon as selected (active).

iii. Calculating the area and the center of the polygon.

iv. Calculating the distance of a point to the polygon.

v. Determining the polygon edge closest to a particular point.

vi. Identifying whether a particular point is enclosed by the polygon.

Besides the above-listed functions, the "Polygon" module includes the additional functions that determine whether or not two lines intersect, find the intersection 
point of two lines, and calculate the distance of a particular point to a line. All the calculations are based on related geometry formulae.

\section{D.2.4. Landfill}

"Landfill" module was developed to form a realistic model of landfill on the given site based on the site elevation map and other layers, defined landfill base and ground elevations, and other defined parameters. Landfill module both performs volume calculations and determines the way that the other layers are affected by the calculations. This module uses RDM module for elevation map, Layers module for layer information, and Polygon module to obtain landfill borders. All calculations are performed 1-m resolution. A landfill is composed of two main components; landfill base and landfill final cover. Besides the landfill base and final cover, the landfill is defined by the parameters listed below:

i. Base elevation: base reference elevation of landfill

ii. Base slope: landfill base slope and direction

iii. Ground elevation: landfill ground/excavation elevation

iv. Inclination: value of side slopes

v. Margin: defines how high the ground elevation from the original topographic elevation can be

vi. Surface elevation: reference elevation of the final cover

vii. Surface slope: slope and slope direction of final cover

viii. Ground offset: approximate thickness of final cover

Landfill module can create base and/or final cover models. As the shape of the final cover depends on the base of the landfill and limits of the excavation, it cannot be calculated independently. To create the landfill model, the largest possible ground borders are defined using base borders, and "Base elevation", "Ground elevation" and "Inclination" parameters. The technical details of drawing 
the landfill base were previously described in Section D.1. Base profile is calculated by considering the base slope and direction for the points inside the polygon, and inclination and distance to base polygon for the points outside the polygon. After base elevation for each point is calculated, layers are analyzed and the relation of the base with these layers (e.g. whether or not the base resides within the top and bottom layers of the clay) are determined. The statistics are updated based on these relations. When the final cover is designed, ground limits are created using ground offset parameter, and the final cover profile is created similar to the base profile. Interaction with layers is not required during final cover design.

As a result of calculations, changes that the landfill excavation and final cover create on the original topography are stored as separate RDMs. These RDMs are reflected to the user by $2 \mathrm{D}$ and 3D View modules (Sections D.2.5, and D.2.6).

\section{D.2.5. Two-Dimensional (2D) View}

"2D" module is a tool that allows the user to visually interact with the topographic map, design the landfill, and view the results of the design. 2D window in VLF is managed by this module. This window is composed of four parts: toolbar at the top, knowledge sheet on the left, bird's-eye view demonstration on the right, and status bar at the bottom (Figure D.15). Bird's-eye view demonstration is the main area that the model visually presents the user topographic map and layers, and the user can define base, reference points, and slopes of the landfill, and view the results of the design. For this area, a special class derived from UserControl of "Windows Forms" library. The features and capabilities (e.g. fast display, zoom in and out) of this class are described in Section D.1. 


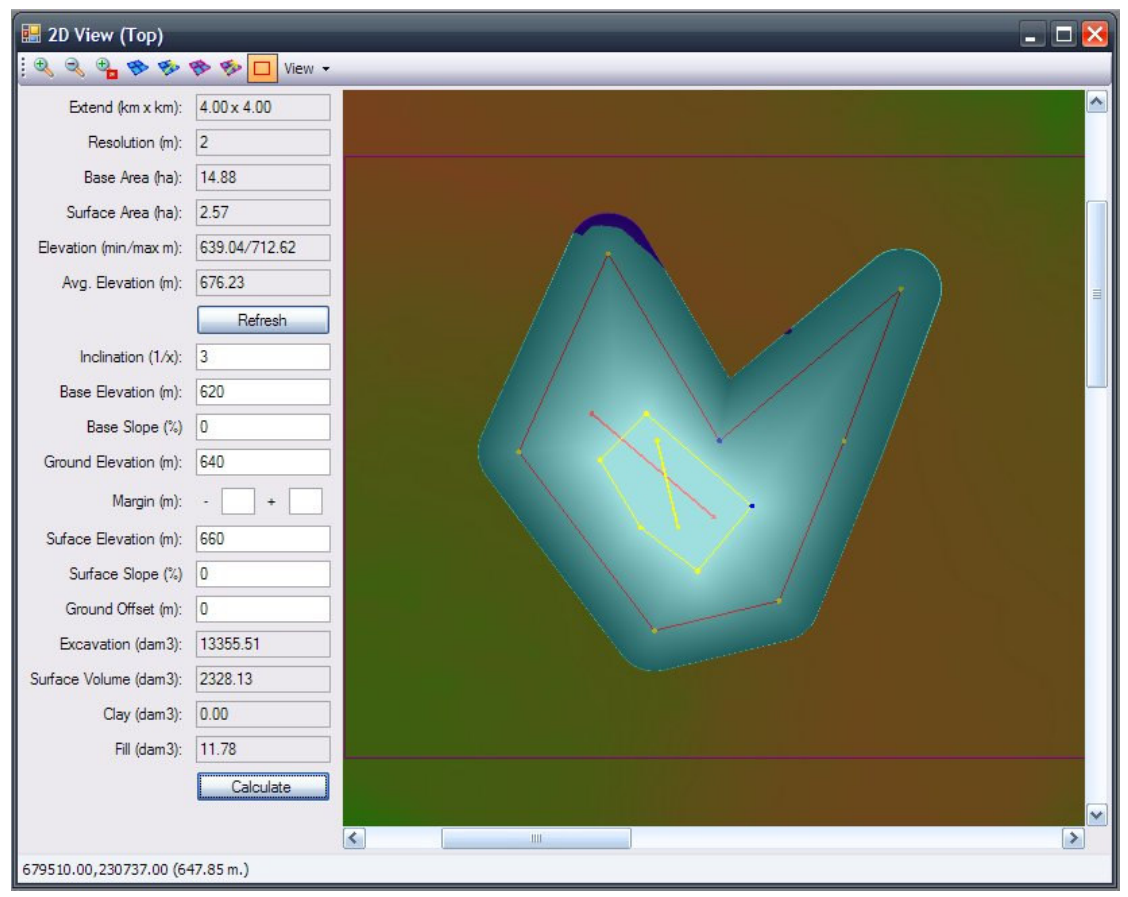

Figure D. 15 2D View window in VLF

Four buttons on the tool bar following "zoom in", "zoom out", "zoom special" buttons are used to define base and final cover of the landfill. These are "define base", "define base slope", "define surface", and "define surface slope" buttons. "Define base" and "define surface" buttons allow the user to draw the polygon of landfill base or final cover using the mouse. When any of these buttons is selected, a second toolbar appears below the main toolbar (Figure D.16). This new toolbar includes point selection, point addition, and point deletion buttons. Point selection button allows activating any point of the polygon, and dragging the point to the desired location. Point addition button allows the addition of a new point, following the currently active point. Point deletion button deletes the selected corner of the polygon. These tools allow easy definition and alteration of the base and final cover polygons. 


\section{$+x$}

Figure D. 16 Second toolbar in VLF

When the "define base slope" and "Define surface slope" buttons are selected, the user can define the direction of the slope with an arrow. Beginning-point of the arrow is also considered as the reference point. The coordinates and elevation of the particular point is displayed in the status bar when the mouse is browsed on topographic map. This allows sensitive placement of landfill corners, if necessary.

The knowledge sheet on the left-hand side has two main functions. "Refresh" button allows the user to observe the area of the base and surface of the landfill in hectares (ha), and also access the statistics of the site (e.g. minimum, maximum, and average elevation of the area including the landfill base). These statistics are calculated by RDM and Polygon modules. The boxes below Refresh button are reserved for landfill design parameters. Once the "Calculate" button is hit, the input data are forwarded to the Landfill module and design calculations are performed. Model results are visually presented to the user in the bird's-eye view area. Also, the excavation, fill and available clay layer volumes are presented to the user in cubic decameters. The user can select which features of the design (i.e. base area, surface area, landfill, surface fill (final cover), clay layer, groundwater layer) to view using the "View" button in toolbar.

\section{D.2.6. Three-Dimensional (3D) View}

"3D View" module is a tool to demonstrate the original topography and the landfill in three dimensions. All or a part of the site, and landfill with or without final cover can be viewed. 3D view window is managed by this module. This window consists of toolbar at the top, zooming level on the right, 3D view in the middle, and status bar at the bottom (Figure D.17). Creation of 3D image is described in Section D.1. The 3D image can be viewed from different angles by 
holding the cursor on the image and moving the cursor to the left and right. The 3D View module accesses the related information for demonstration using RDM and Landfill modules.

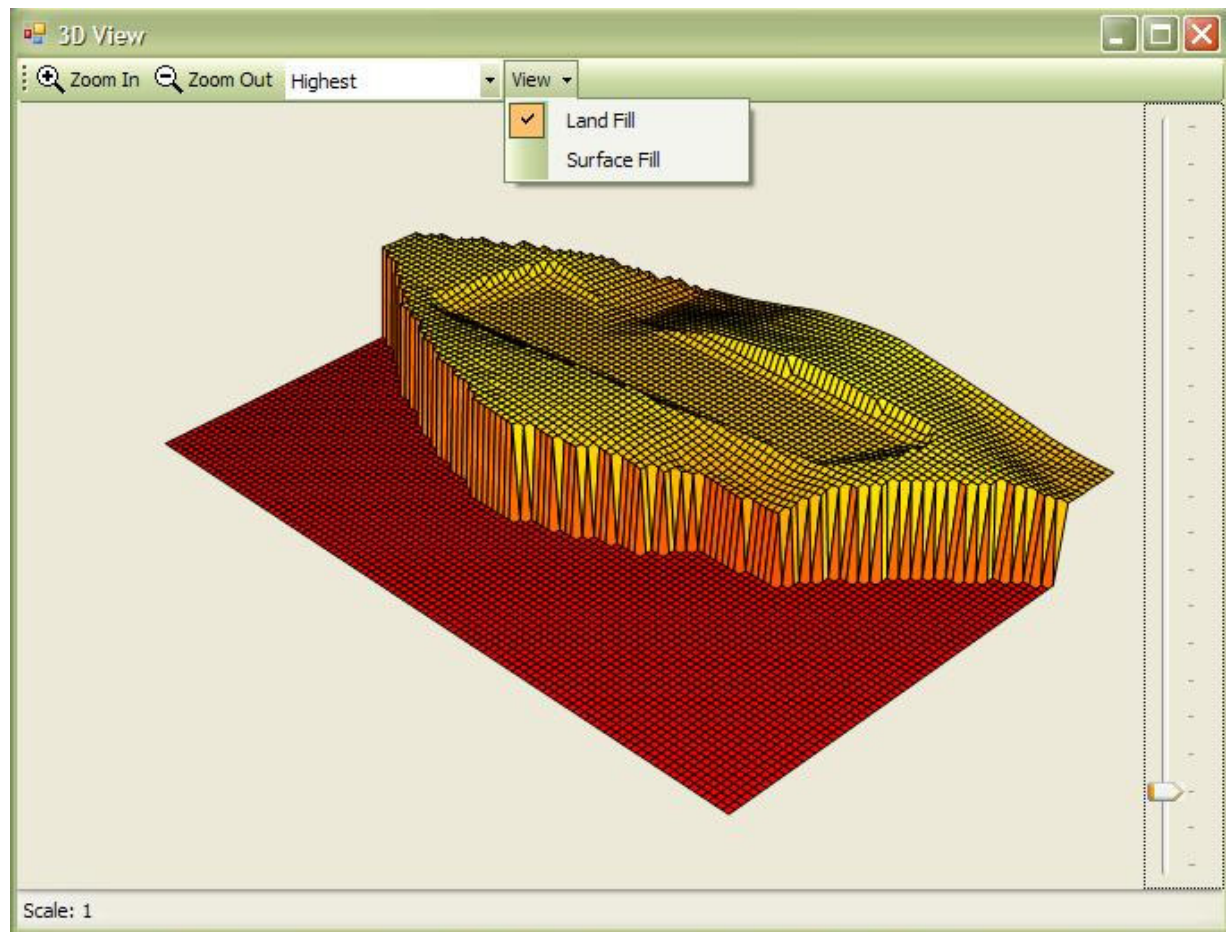

Figure D. 17 3D View window in VLF 
APPENDIX-E

\section{SIMULATION RESULTS OF LANDFILL DESIGN ALTERNATIVES}

The encoding of the simulations is as follows:

Table E. 1Coding of the simulations

\begin{tabular}{cllllc}
\hline $\begin{array}{c}\text { Cover } \\
\text { Design }\end{array}$ & $\begin{array}{c}\text { Liner } \\
\text { Design }\end{array}$ & Climate & $\begin{array}{c}\text { Area } \\
\text { (ha) }\end{array}$ & $\begin{array}{c}\text { Waste } \\
\text { Thickness }\end{array}$ & $\begin{array}{c}\text { Seepage } \\
\text { Velocity } \\
\text { (m/d) }\end{array}$ \\
\hline 1: C1 & 1: L1 & 1: Arid & $02: 2$ & 05: 5-m thick & V1: 0.05 \\
2: C2 & 2: L2 & 2: Moderate & 15: 15 & waste & V2: 0.1 \\
3: C3 & 3:L3 & 3: Humid & 50:50 & 20: 20-m thick & V3: 0.5 \\
& 4: L4 & & waste & V4: 1 \\
& 5: L5 & & & \\
& 6: L6 & & & & \\
\hline
\end{tabular}

For example, the design code 1121505V2 means C1L1 (11) landfill design, under moderate climate (2), having an area of 15 ha (15), with a waste thickness of $5 \mathrm{~m}$ (05), and the groundwater seepage velocity is $0.1 \mathrm{~m} / \mathrm{d}(\mathrm{V} 2)$. 
Table E. 2 Simulation results for C1L1 design alternative

\begin{tabular}{|c|c|c|c|c|c|c|c|c|}
\hline \multicolumn{3}{|c|}{ Arid } & \multicolumn{3}{|c|}{ Moderate } & \multicolumn{3}{|c|}{ Humid } \\
\hline Design $^{a}$ & $\begin{array}{l}\mathbf{T}^{\mathbf{b}} \\
(\mathbf{y})\end{array}$ & $\begin{array}{c}\mathrm{C}^{\mathrm{c}} \\
(\mathrm{mg} / \mathrm{L})\end{array}$ & Design & $\begin{array}{c}\mathbf{T} \\
(\mathbf{y})\end{array}$ & $\begin{array}{c}\mathrm{C} \\
(\mathrm{mg} / \mathrm{L})\end{array}$ & Design & $\begin{array}{l}\mathbf{T} \\
(\mathbf{y})\end{array}$ & $\begin{array}{c}\mathrm{C} \\
(\mathrm{mg} / \mathrm{L})\end{array}$ \\
\hline $1110205 \mathrm{~V} 1$ & 119 & 94.5 & $1120205 \mathrm{~V} 1$ & 24 & 521.1 & $1130205 \mathrm{~V} 1$ & 10 & 571.1 \\
\hline $1110205 \mathrm{~V} 2$ & 119 & 47.4 & $1120205 \mathrm{~V} 2$ & 23 & 302.3 & $1130205 \mathrm{~V} 2$ & 10 & 571.1 \\
\hline $1110205 \mathrm{~V} 3$ & 114.5 & 9.5 & $1120205 \mathrm{~V} 3$ & 21 & 66.7 & $1130205 \mathrm{~V} 3$ & 9 & 164.3 \\
\hline $1110205 \mathrm{~V} 4$ & 114.5 & 4.8 & $1120205 \mathrm{~V} 4$ & 21 & 33.6 & $1130205 \mathrm{~V} 4$ & 9 & 85.4 \\
\hline $1110220 \mathrm{~V} 1$ & 134 & 136.7 & $1120220 \mathrm{~V} 1$ & 28 & 728.8 & $1130220 \mathrm{~V} 1$ & 12 & 796.2 \\
\hline $1110220 \mathrm{~V} 2$ & 134 & 68.4 & $1120220 \mathrm{~V} 2$ & 24 & 392.5 & $1130220 \mathrm{~V} 2$ & 12 & 796.2 \\
\hline $1110220 \mathrm{~V} 3$ & 127 & 13.7 & $1120220 \mathrm{~V} 3$ & 22 & 82.3 & $1130220 \mathrm{~V} 3$ & 9 & 195.6 \\
\hline $1110220 \mathrm{~V} 4$ & 127 & 6.8 & $1120220 \mathrm{~V} 4$ & 22 & 41.2 & $1130220 \mathrm{~V} 4$ & 9 & 99.4 \\
\hline $1111505 \mathrm{~V} 1$ & 123 & 227.7 & $1121505 \mathrm{~V} 1$ & 24 & 558.1 & $1131505 \mathrm{~V} 1$ & 10 & 571.1 \\
\hline $1111505 \mathrm{~V} 2$ & 119 & 117.6 & $1121505 \mathrm{~V} 2$ & 24 & 558.1 & $1131505 \mathrm{~V} 2$ & 10 & 571.1 \\
\hline $1111505 \mathrm{~V} 3$ & 114.5 & 23.8 & $1121505 \mathrm{~V} 3$ & 21 & 162.5 & $1131505 \mathrm{~V} 3$ & 10 & 359.0 \\
\hline $1111505 \mathrm{~V} 4$ & 114.5 & 11.9 & $1121505 \mathrm{~V} 4$ & 21 & 83.5 & $1131505 \mathrm{~V} 4$ & 9 & 200.8 \\
\hline $1111520 \mathrm{~V} 1$ & 142 & 336.6 & $1121520 \mathrm{~V} 1$ & 29 & 790.5 & $1131520 \mathrm{~V} 1$ & 12 & 796.2 \\
\hline $1111520 \mathrm{~V} 2$ & 134 & 170.5 & $1121520 \mathrm{~V} 2$ & 29 & 790.5 & $1131520 \mathrm{~V} 2$ & 12 & 796.2 \\
\hline $1111520 \mathrm{~V} 3$ & 131 & 34.3 & $1121520 \mathrm{~V} 3$ & 22 & 203.8 & $1131520 \mathrm{~V} 3$ & 10.5 & 460.0 \\
\hline $1111520 \mathrm{~V} 4$ & 127 & 17.1 & $1121520 \mathrm{~V} 4$ & 22 & 102.8 & $1131520 \mathrm{~V} 4$ & 10 & 241.9 \\
\hline $1115005 \mathrm{~V} 1$ & 134 & 418.6 & $1125005 \mathrm{~V} 1$ & 25 & 557.9 & $1135005 \mathrm{~V} 1$ & 10 & 571.1 \\
\hline $1115005 \mathrm{~V} 2$ & 123 & 227.8 & $1125005 \mathrm{~V} 2$ & 25 & 557.9 & $1135005 \mathrm{~V} 2$ & 10 & 571.1 \\
\hline $1115005 \mathrm{~V} 3$ & 119 & 47.4 & $1125005 \mathrm{~V} 3$ & 22 & 302.3 & $1135005 \mathrm{~V} 3$ & 10 & 571.1 \\
\hline $1115005 \mathrm{~V} 4$ & 117.5 & 23.8 & $1125005 \mathrm{~V} 4$ & 21 & 162.5 & $1135005 \mathrm{~V} 4$ & 10 & 359.0 \\
\hline $1115020 \mathrm{~V} 1$ & 156 & 644.1 & $1125020 \mathrm{~V} 1$ & 29 & 790.5 & $1135020 \mathrm{~V} 1$ & 12 & 795.4 \\
\hline $1115020 \mathrm{~V} 2$ & 142 & 336.6 & $1125020 \mathrm{~V} 2$ & 29 & 790.5 & $1135020 \mathrm{~V} 2$ & 12 & 795.4 \\
\hline $1115020 \mathrm{~V} 3$ & 134 & 68.4 & $1125020 \mathrm{~V} 3$ & 24 & 392.5 & $1135020 \mathrm{~V} 3$ & 12 & 795.4 \\
\hline $1115020 \mathrm{~V} 4$ & 131 & 34.3 & $1125020 \mathrm{~V} 4$ & 23 & 203.2 & $1135020 \mathrm{~V} 4$ & 10.5 & 459.6 \\
\hline
\end{tabular}


Table E. 3 Simulation results for C1L2 design alternative

\begin{tabular}{|c|c|c|c|c|c|c|c|c|}
\hline \multicolumn{3}{|c|}{ Arid } & \multicolumn{3}{|c|}{ Moderate } & \multicolumn{3}{|c|}{ Humid } \\
\hline Design $^{a}$ & $\begin{array}{l}\mathbf{T}^{\mathbf{b}} \\
(\mathbf{y})\end{array}$ & $\begin{array}{c}\mathbf{C}^{\mathrm{c}} \\
(\mathrm{mg} / \mathrm{L})\end{array}$ & Design & $\begin{array}{l}\mathbf{T} \\
(\mathbf{y})\end{array}$ & $\begin{array}{c}\mathrm{C} \\
(\mathrm{mg} / \mathrm{L})\end{array}$ & Design & $\begin{array}{l}\mathbf{T} \\
(\mathbf{y})\end{array}$ & $\begin{array}{c}\mathrm{C} \\
(\mathrm{mg} / \mathrm{L})\end{array}$ \\
\hline $1210205 \mathrm{~V} 1$ & 259 & 16.8 & $1220205 \mathrm{~V} 1$ & 218 & 4.1 & $1230205 \mathrm{~V} 1$ & 210 & 1.75 \\
\hline $1210205 \mathrm{~V} 2$ & 250 & 8.5 & $1220205 \mathrm{~V} 2$ & 218 & 2.0 & $1230205 \mathrm{~V} 2$ & 205 & 0.88 \\
\hline $1210205 \mathrm{~V} 3$ & 250 & 1.7 & $1220205 \mathrm{~V} 3$ & 211 & 0.4 & $1230205 \mathrm{~V} 3$ & 205 & 0.18 \\
\hline $1210205 \mathrm{~V} 4$ & 250 & 0.9 & $1220205 \mathrm{~V} 4$ & 211 & 0.2 & $1230205 \mathrm{~V} 4$ & 205 & 0.09 \\
\hline $1210220 \mathrm{~V} 1$ & 309 & 34.0 & $1220220 \mathrm{~V} 1$ & 248 & 13.7 & $1230220 \mathrm{~V} 1$ & 225.5 & 6.72 \\
\hline $1210220 \mathrm{~V} 2$ & 297 & 17.0 & $1220220 \mathrm{~V} 2$ & 242 & 6.9 & $1230220 \mathrm{~V} 2$ & 225.5 & 3.36 \\
\hline $1210220 \mathrm{~V} 3$ & 297 & 3.4 & $1220220 \mathrm{~V} 3$ & 243 & 1.4 & $1230220 \mathrm{~V} 3$ & 220 & 0.67 \\
\hline $1210220 \mathrm{~V} 4$ & 297 & 1.7 & $1220220 \mathrm{~V} 4$ & 243 & 0.7 & $1230220 \mathrm{~V} 4$ & 220 & 0.34 \\
\hline $1211505 \mathrm{~V} 1$ & 258 & 41.7 & $1221505 \mathrm{~V} 1$ & 226 & 10.0 & $1231505 \mathrm{~V} 1$ & 215 & 4.35 \\
\hline $1211505 \mathrm{~V} 2$ & 250 & 21.2 & $1221505 \mathrm{~V} 2$ & 215 & 5.1 & $1231505 \mathrm{~V} 2$ & 211 & 2.21 \\
\hline $1211505 \mathrm{~V} 3$ & 250 & 4.3 & $1221505 \mathrm{~V} 3$ & 215 & 1.0 & $1231505 \mathrm{~V} 3$ & 205 & 0.44 \\
\hline $1211505 \mathrm{~V} 4$ & 250 & 2.1 & $1221505 \mathrm{~V} 4$ & 215 & 0.5 & $1231505 \mathrm{~V} 4$ & 205 & 0.22 \\
\hline $1211520 \mathrm{~V} 1$ & 314 & 84.4 & $1221520 \mathrm{~V} 1$ & 248 & 34.0 & $1231520 \mathrm{~V} 1$ & 231 & 16.59 \\
\hline $1211520 \mathrm{~V} 2$ & 304.5 & 42.1 & $1221520 \mathrm{~V} 2$ & 248 & 17.1 & $1231520 \mathrm{~V} 2$ & 225.5 & 8.39 \\
\hline $1211520 \mathrm{~V} 3$ & 297 & 8.5 & $1221520 \mathrm{~V} 3$ & 242 & 3.4 & $1231520 \mathrm{~V} 3$ & 220 & 1.69 \\
\hline $1211520 \mathrm{~V} 4$ & 297 & 4.3 & $1221520 \mathrm{~V} 4$ & 242 & 1.7 & $1231520 \mathrm{~V} 4$ & 220 & 0.84 \\
\hline $1215005 \mathrm{~V} 1$ & 275.5 & 81.1 & $1225005 \mathrm{~V} 1$ & 232 & 19.3 & $1235005 \mathrm{~V} 1$ & 225.5 & 8.35 \\
\hline $1215005 \mathrm{~V} 2$ & 259 & 41.7 & $1225005 \mathrm{~V} 2$ & 226 & 10.0 & $1235005 \mathrm{~V} 2$ & 215 & 4.35 \\
\hline $1215005 \mathrm{~V} 3$ & 248 & 8.4 & $1225005 \mathrm{~V} 3$ & 215 & 2.0 & $1235005 \mathrm{~V} 3$ & 205 & 0.88 \\
\hline $1215005 \mathrm{~V} 4$ & 248 & 4.2 & $1225005 \mathrm{~V} 4$ & 215 & 1.0 & $1235005 \mathrm{~V} 4$ & 205 & 0.44 \\
\hline $1215020 \mathrm{~V} 1$ & 316 & 166.7 & $1225020 \mathrm{~V} 1$ & 260.5 & 65.8 & $1235020 \mathrm{~V} 1$ & 242 & 32.0 \\
\hline $1215020 \mathrm{~V} 2$ & 316 & 84.3 & $1225020 \mathrm{~V} 2$ & 248 & 34.0 & $1235020 \mathrm{~V} 2$ & 231 & 16.59 \\
\hline $1215020 \mathrm{~V} 3$ & 301 & 17.0 & $1225020 \mathrm{~V} 3$ & 242 & 6.9 & $1235020 \mathrm{~V} 3$ & 225.5 & 3.36 \\
\hline $1215020 \mathrm{~V} 4$ & 301 & 8.4 & $1225020 \mathrm{~V} 4$ & 242 & 3.4 & $1235020 \mathrm{~V} 4$ & 220 & 1.69 \\
\hline
\end{tabular}


Table E. 4 Simulation results for C1L3 design alternative

\begin{tabular}{|c|c|c|c|c|c|c|c|c|}
\hline \multicolumn{3}{|c|}{ Arid } & \multicolumn{3}{|c|}{ Moderate } & \multicolumn{3}{|c|}{ Humid } \\
\hline Design $^{a}$ & $\begin{array}{l}\mathbf{T}^{\mathbf{b}} \\
(\mathbf{y})\end{array}$ & $\begin{array}{c}\mathrm{C}^{\mathrm{c}} \\
(\mathrm{mg} / \mathrm{L})\end{array}$ & Design & $\begin{array}{l}\mathbf{T} \\
(\mathbf{y})\end{array}$ & $\begin{array}{c}C \\
(\mathrm{mg} / \mathrm{L})\end{array}$ & Design & $\begin{array}{l}\mathbf{T} \\
(\mathbf{y})\end{array}$ & $\begin{array}{c}\mathrm{C} \\
(\mathrm{mg} / \mathrm{L})\end{array}$ \\
\hline $1310205 \mathrm{~V} 1$ & 119 & 94.5 & $1320205 \mathrm{~V} 1$ & 24 & 521.1 & $1330205 \mathrm{~V} 1$ & 18 & 445.5 \\
\hline $1310205 \mathrm{~V} 2$ & 119 & 47.4 & $1320205 \mathrm{~V} 2$ & 23 & 302.3 & $1330205 \mathrm{~V} 2$ & 17 & 311.7 \\
\hline $1310205 \mathrm{~V} 3$ & 114.5 & 9.5 & $1320205 \mathrm{~V} 3$ & 21 & 66.7 & $1330205 \mathrm{~V} 3$ & 15.5 & 76.7 \\
\hline $1310205 \mathrm{~V} 4$ & 114.5 & 4.8 & $1320205 \mathrm{~V} 4$ & 21 & 33.6 & $1330205 \mathrm{~V} 4$ & 15 & 38.9 \\
\hline $1310220 \mathrm{~V} 1$ & 134 & 136.7 & $1320220 \mathrm{~V} 1$ & 28 & 728.8 & $1330220 \mathrm{~V} 1$ & 20 & 708.1 \\
\hline $1310220 \mathrm{~V} 2$ & 134 & 68.4 & $1320220 \mathrm{~V} 2$ & 24 & 392.5 & $1330220 \mathrm{~V} 2$ & 19 & 460.2 \\
\hline $1310220 \mathrm{~V} 3$ & 127 & 13.7 & $1320220 \mathrm{~V} 3$ & 22 & 82.3 & $1330220 \mathrm{~V} 3$ & 16 & 102.4 \\
\hline $1310220 \mathrm{~V} 4$ & 127 & 6.8 & $1320220 \mathrm{~V} 4$ & 22 & 41.2 & $1330220 \mathrm{~V} 4$ & 16 & 51.4 \\
\hline $1311505 \mathrm{~V} 1$ & 123 & 227.7 & $1321505 \mathrm{~V} 1$ & 24 & 558.1 & $1331505 \mathrm{~V} 1$ & 18 & 445.5 \\
\hline $1311505 \mathrm{~V} 2$ & 119 & 117.6 & $1321505 \mathrm{~V} 2$ & 24 & 558.1 & $1331505 \mathrm{~V} 2$ & 18 & 445.5 \\
\hline $1311505 \mathrm{~V} 3$ & 114.5 & 23.8 & $1321505 \mathrm{~V} 3$ & 21 & 162.5 & $1331505 \mathrm{~V} 3$ & 16 & 178.9 \\
\hline $1311505 \mathrm{~V} 4$ & 114.5 & 11.9 & $1321505 \mathrm{~V} 4$ & 21 & 83.5 & $1331505 \mathrm{~V} 4$ & 16 & 95.0 \\
\hline $1311520 \mathrm{~V} 1$ & 142 & 336.6 & $1321520 \mathrm{~V} 1$ & 29 & 790.5 & $1331520 \mathrm{~V} 1$ & 20 & 708.0 \\
\hline 1311520V2 & 134 & 170.5 & $1321520 \mathrm{~V} 2$ & 29 & 790.5 & $1331520 \mathrm{~V} 2$ & 20 & 708.0 \\
\hline $1311520 \mathrm{~V} 3$ & 131 & 34.3 & $1321520 \mathrm{~V} 3$ & 22 & 203.8 & $1331520 \mathrm{~V} 3$ & 17 & 247.4 \\
\hline 1311520V4 & 127 & 17.1 & $1321520 \mathrm{~V} 4$ & 22 & 102.8 & $1331520 \mathrm{~V} 4$ & 16.5 & 127.4 \\
\hline $1315005 \mathrm{~V} 1$ & 134 & 418.6 & $1325005 \mathrm{~V} 1$ & 25 & 557.9 & $1335005 \mathrm{~V} 1$ & 18 & 445.5 \\
\hline $1315005 \mathrm{~V} 2$ & 123 & 227.8 & $1325005 \mathrm{~V} 2$ & 25 & 557.9 & $1335005 \mathrm{~V} 2$ & 18 & 445.5 \\
\hline $1315005 \mathrm{~V} 3$ & 119 & 47.4 & $1325005 \mathrm{~V} 3$ & 22 & 302.3 & $1335005 \mathrm{~V} 3$ & 17 & 311.7 \\
\hline $1315005 \mathrm{~V} 4$ & 117.5 & 23.8 & $1325005 \mathrm{~V} 4$ & 21 & 162.5 & $1335005 \mathrm{~V} 4$ & 16 & 178.9 \\
\hline $1315020 \mathrm{~V} 1$ & 156 & 644.1 & $1325020 \mathrm{~V} 1$ & 29 & 790.5 & $1335020 \mathrm{~V} 1$ & 20 & 708.1 \\
\hline $1315020 \mathrm{~V} 2$ & 142 & 336.6 & $1325020 \mathrm{~V} 2$ & 29 & 790.5 & $1335020 \mathrm{~V} 2$ & 20 & 708.1 \\
\hline $1315020 \mathrm{~V} 3$ & 134 & 68.4 & $1325020 \mathrm{~V} 3$ & 24 & 392.5 & $1335020 \mathrm{~V} 3$ & 19 & 460.2 \\
\hline $1315020 \mathrm{~V} 4$ & 131 & 34.3 & $1325020 \mathrm{~V} 4$ & 23 & 203.2 & $1335020 \mathrm{~V} 4$ & 17 & 247.4 \\
\hline
\end{tabular}


Table E. 5 Simulation results for C1L4 design alternative over low hydraulic conductivity aquitards $\left(\mathrm{k}=1 \times 10^{-8} \mathrm{~m} / \mathrm{s}\right)$

\begin{tabular}{|c|c|c|c|c|c|c|c|c|}
\hline \multicolumn{3}{|c|}{ Arid } & \multicolumn{3}{|c|}{ Moderate } & \multicolumn{3}{|c|}{ Humid } \\
\hline Design $^{a}$ & $\begin{array}{l}\mathbf{T}^{\mathbf{b}} \\
(\mathbf{y})\end{array}$ & $\begin{array}{c}\mathrm{C}^{\mathrm{c}} \\
(\mathrm{mg} / \mathrm{L})\end{array}$ & Design & $\begin{array}{l}\mathbf{T} \\
(\mathbf{y})\end{array}$ & $\begin{array}{c}\mathrm{C} \\
(\mathrm{mg} / \mathrm{L})\end{array}$ & Design & $\begin{array}{c}\mathbf{T} \\
(\mathbf{y})\end{array}$ & $\begin{array}{c}C \\
(\mathrm{mg} / \mathrm{L})\end{array}$ \\
\hline $1410205 \mathrm{~V} 1$ & 371 & 6.3 & $1420205 \mathrm{~V} 1$ & 312.5 & 1.3 & $1430205 \mathrm{~V} 1$ & 306 & 0.56 \\
\hline $1410205 \mathrm{~V} 2$ & 363 & 3.1 & $1420205 \mathrm{~V} 2$ & 312.5 & 0.75 & $1430205 \mathrm{~V} 2$ & 306 & 0.28 \\
\hline $1410205 \mathrm{~V} 3$ & 354 & 0.6 & $1420205 \mathrm{~V} 3$ & 312.5 & 0.13 & $1430205 \mathrm{~V} 3$ & 301 & 0.056 \\
\hline $1410205 \mathrm{~V} 4$ & 354 & 0.3 & $1420205 \mathrm{~V} 4$ & 312.5 & 0.066 & $1430205 \mathrm{~V} 4$ & 301 & 0.028 \\
\hline $1410220 \mathrm{~V} 1$ & 458.5 & 16.0 & $1420220 \mathrm{~V} 1$ & 352 & 4.91 & $1430220 \mathrm{~V} 1$ & 316 & 2.21 \\
\hline $1410220 \mathrm{~V} 2$ & 458.5 & 8.0 & $1420220 \mathrm{~V} 2$ & 352 & 2.46 & $1430220 \mathrm{~V} 2$ & 316 & 1.11 \\
\hline $1410220 \mathrm{~V} 3$ & 458.5 & 1.6 & $1420220 \mathrm{~V} 3$ & 352 & 0.49 & $1430220 \mathrm{~V} 3$ & 316 & 0.22 \\
\hline $1410220 \mathrm{~V} 4$ & 458.5 & 0.8 & $1420220 \mathrm{~V} 4$ & 352 & 0.25 & $1430220 \mathrm{~V} 4$ & 316 & 0.11 \\
\hline $1411505 \mathrm{~V} 1$ & 372 & 15.6 & $1421505 \mathrm{~V} 1$ & 327 & 3.25 & $1431505 \mathrm{~V} 1$ & 316 & 1.39 \\
\hline $1411505 \mathrm{~V} 2$ & 372 & 7.8 & $05 \mathrm{~V} 2$ & 312.5 & 1.64 & $431505 \mathrm{~V} 2$ & 306 & 0.70 \\
\hline $1411505 \mathrm{~V} 3$ & 363 & 1.6 & $1421505 \mathrm{~V} 3$ & 312.5 & 0.33 & $1431505 \mathrm{~V} 3$ & 301 & 0.14 \\
\hline $1411505 \mathrm{~V} 4$ & 354 & 0.8 & $05 \mathrm{~V} 4$ & 312.5 & 0.16 & 1431 & 301 & 0.07 \\
\hline $1411520 \mathrm{~V} 1$ & 458.5 & 39.8 & $1421520 \mathrm{~V} 1$ & 352 & 12.19 & $1431520 \mathrm{~V} 1$ & 327 & 5.49 \\
\hline $1411520 \mathrm{~V} 2$ & 458.5 & 20.0 & $1421520 \mathrm{~V} 2$ & 352 & 6.13 & $1431520 \mathrm{~V} 2$ & 316 & 2.76 \\
\hline $1411520 \mathrm{~V} 3$ & 458.5 & 4.0 & $1421520 \mathrm{~V} 3$ & 352 & 1.23 & $1431520 \mathrm{~V} 3$ & 316 & 0.56 \\
\hline $1411520 \mathrm{~V} 4$ & 458.5 & 2.0 & $1421520 \mathrm{~V} 4$ & 352 & 0.61 & $1431520 \mathrm{~V} 4$ & 316 & 0.28 \\
\hline $1415005 \mathrm{~V} 1$ & 382 & 30.7 & $1425005 \mathrm{~V} 1$ & 327 & 6.36 & $1435005 \mathrm{~V} 1$ & 327 & 2.73 \\
\hline $1415005 \mathrm{~V} 2$ & 372 & 15.6 & $1425005 \mathrm{~V} 2$ & 327 & 3.25 & $1435005 \mathrm{~V} 2$ & 316 & 1.39 \\
\hline $1415005 \mathrm{~V} 3$ & 363 & 3.1 & $1425005 \mathrm{~V} 3$ & 312.5 & 0.66 & $1435005 \mathrm{~V} 3$ & 306 & 0.28 \\
\hline $1415005 \mathrm{~V} 4$ & 363 & 1.6 & $1425005 \mathrm{~V} 4$ & 312.5 & 0.33 & $1435005 \mathrm{~V} 4$ & 301 & 0.14 \\
\hline $1415020 \mathrm{~V} 1$ & 477 & 79.0 & $1425020 \mathrm{~V} 1$ & 367 & 23.95 & $1435020 \mathrm{~V} 1$ & 343 & 10.80 \\
\hline $1415020 \mathrm{~V} 2$ & 458.5 & 39.8 & $1425020 \mathrm{~V} 2$ & 352 & 12.19 & $1435020 \mathrm{~V} 2$ & 327 & 5.49 \\
\hline $1415020 \mathrm{~V} 3$ & 458.5 & 8.0 & $1425020 \mathrm{~V} 3$ & 352 & 2.46 & $1435020 \mathrm{~V} 3$ & 316 & 1.11 \\
\hline $1415020 \mathrm{~V} 4$ & 458.5 & 4.0 & $1425020 \mathrm{~V} 4$ & 352 & 1.23 & $1435020 \mathrm{~V} 4$ & 316 & 0.56 \\
\hline
\end{tabular}

${ }^{\mathrm{a}}$ simulation code

${ }^{\mathrm{b}}$ time that maximum concentration occurs

${ }^{c}$ maximum concentration at the groundwater table 
Table E. 6 Simulation results for C1L4 design alternative over high hydraulic conductivity aquitards $\left(\mathrm{k}=1 \times 10^{-7} \mathrm{~m} / \mathrm{s}\right)$

\begin{tabular}{|c|c|c|c|c|c|c|c|c|}
\hline \multicolumn{3}{|c|}{ Arid } & \multicolumn{3}{|c|}{ Moderate } & \multicolumn{3}{|c|}{ Humid } \\
\hline Design $^{a}$ & $\begin{array}{l}\mathbf{T}^{\mathbf{b}} \\
(\mathbf{y})\end{array}$ & $\begin{array}{c}\mathrm{C}^{\mathrm{c}} \\
(\mathrm{mg} / \mathrm{L})\end{array}$ & Design & $\begin{array}{c}\mathbf{T} \\
(\mathbf{y})\end{array}$ & $\begin{array}{c}C \\
(\mathrm{mg} / \mathrm{L})\end{array}$ & Design & $\begin{array}{l}\mathbf{T} \\
(\mathbf{y})\end{array}$ & $\begin{array}{c}\mathrm{C} \\
(\mathrm{mg} / \mathrm{L})\end{array}$ \\
\hline $1410205 \mathrm{~V} 1$ & 97 & 105.6 & $1420205 \mathrm{~V} 1$ & 43 & 312.5 & $1430205 \mathrm{~V} 1$ & 41 & 106.1 \\
\hline $1410205 \mathrm{~V} 2$ & 94 & 54.7 & $1420205 \mathrm{~V} 2$ & 41 & 312.5 & $1430205 \mathrm{~V} 2$ & 40 & 58.5 \\
\hline $1410205 \mathrm{~V} 3$ & 93 & 11.0 & $1420205 \mathrm{~V} 3$ & 40 & 312.5 & $1430205 \mathrm{~V} 3$ & 38 & 12.3 \\
\hline $1410205 \mathrm{~V} 4$ & 93 & 5.5 & $1420205 \mathrm{~V} 4$ & 40 & 312.5 & $1430205 \mathrm{~V} 4$ & 38 & 6.2 \\
\hline $1410220 \mathrm{~V} 1$ & 107 & 144.4 & $1420220 \mathrm{~V} 1$ & 47 & 352 & $1430220 \mathrm{~V} 1$ & 45 & 217.7 \\
\hline $1410220 \mathrm{~V} 2$ & 104 & 72.4 & $1420220 \mathrm{~V} 2$ & 44.5 & 352 & $1430220 \mathrm{~V} 2$ & 42 & 115.6 \\
\hline $1410220 \mathrm{~V} 3$ & 104 & 14.5 & $1420220 \mathrm{~V} 3$ & 43.5 & 352 & $1430220 \mathrm{~V} 3$ & 41 & 23.7 \\
\hline $1410220 \mathrm{~V} 4$ & 104 & 7.2 & $1420220 \mathrm{~V} 4$ & 42 & 352 & $1430220 \mathrm{~V} 4$ & 41 & 11.9 \\
\hline $1411505 \mathrm{~V} 1$ & 104 & 257.9 & $1421505 \mathrm{~V} 1$ & 47 & 327 & $1431505 \mathrm{~V} 1$ & 43 & 198.0 \\
\hline $1411505 \mathrm{~V} 2$ & 97 & 134.9 & $1421505 \mathrm{~V} 2$ & 43.5 & 312.5 & 1431505V2 & 41 & 126.0 \\
\hline $1411505 \mathrm{~V} 3$ & 93 & 27.4 & $1421505 \mathrm{~V} 3$ & 40 & 312.5 & $1431505 \mathrm{~V} 3$ & 38.5 & 30.4 \\
\hline $1411505 \mathrm{~V} 4$ & 93 & 13.7 & $1421505 \mathrm{~V} 4$ & 40 & 312.5 & $1431505 \mathrm{~V} 4$ & 38 & 15.3 \\
\hline $1411520 \mathrm{~V} 1$ & 115 & 353.1 & $1421520 \mathrm{~V} 1$ & 54 & 352 & 1431520V1 & 49 & 445.6 \\
\hline 1411520V2 & 107 & 180.1 & $1421520 \mathrm{~V} 2$ & 48 & 352 & 1431520V2 & 44.5 & 262.5 \\
\hline $1411520 \mathrm{~V} 3$ & 107 & 36.2 & $1421520 \mathrm{~V} 3$ & 43.5 & 352 & $1431520 \mathrm{~V} 3$ & 42 & 58.9 \\
\hline $1411520 \mathrm{~V} 4$ & 104 & 18.1 & $1421520 \mathrm{~V} 4$ & 43.5 & 352 & $1431520 \mathrm{~V} 4$ & 41 & 29.6 \\
\hline $1415005 \mathrm{~V} 1$ & 110 & 462.5 & $1425005 \mathrm{~V} 1$ & 47 & 327 & $1435005 \mathrm{~V} 1$ & 43.5 & 208.9 \\
\hline $1415005 \mathrm{~V} 2$ & 104 & 257.9 & $1425005 \mathrm{~V} 2$ & 47 & 327 & $1435005 \mathrm{~V} 2$ & 43.5 & 198.0 \\
\hline $1415005 \mathrm{~V} 3$ & 94 & 54.7 & $1425005 \mathrm{~V} 3$ & 41 & 312.5 & $1435005 \mathrm{~V} 3$ & 40 & 58.5 \\
\hline $1415005 \mathrm{~V} 4$ & 93 & 27.4 & $1425005 \mathrm{~V} 4$ & 40 & 312.5 & $1435005 \mathrm{~V} 4$ & 39 & 30.4 \\
\hline $1415020 \mathrm{~V} 1$ & 127 & 666.8 & $1425020 \mathrm{~V} 1$ & 54 & 367 & 1435020V1 & 49 & 475.9 \\
\hline $1415020 \mathrm{~V} 2$ & 115 & 353.1 & $1425020 \mathrm{~V} 2$ & 54 & 352 & $1435020 \mathrm{~V} 2$ & 49 & 445.6 \\
\hline $1415020 \mathrm{~V} 3$ & 104 & 72.4 & $1425020 \mathrm{~V} 3$ & 44.5 & 352 & $1435020 \mathrm{~V} 3$ & 42 & 115.6 \\
\hline $1415020 \mathrm{~V} 4$ & 104 & 36.2 & $1425020 \mathrm{~V} 4$ & 43.5 & 352 & $1435020 \mathrm{~V} 4$ & 42 & 58.9 \\
\hline
\end{tabular}


Table E. 7 Simulation results for C1L5 design alternative over low hydraulic conductivity aquitards $\left(\mathrm{k}=1 \times 10^{-8} \mathrm{~m} / \mathrm{s}\right)$

\begin{tabular}{|c|c|c|c|c|c|c|c|c|}
\hline \multicolumn{3}{|c|}{ Arid } & \multicolumn{3}{|c|}{ Moderate } & \multicolumn{3}{|c|}{ Humid } \\
\hline Design $^{a}$ & $\begin{array}{l}\mathbf{T}^{\mathbf{b}} \\
(\mathbf{y})\end{array}$ & $\begin{array}{c}\mathrm{C}^{\mathrm{c}} \\
(\mathrm{mg} / \mathrm{L})\end{array}$ & Design & $\begin{array}{c}\mathbf{T} \\
(\mathbf{y})\end{array}$ & $\begin{array}{c}C \\
(\mathrm{mg} / \mathrm{L})\end{array}$ & Design & $\begin{array}{c}\mathbf{T} \\
(\mathbf{y})\end{array}$ & $\begin{array}{c}\mathrm{C} \\
(\mathrm{mg} / \mathrm{L})\end{array}$ \\
\hline $1510205 \mathrm{~V} 1$ & 123 & 93.7 & $1520205 \mathrm{~V} 1$ & 29 & 440.0 & $1530205 \mathrm{~V} 1$ & 27 & 299.2 \\
\hline $1510205 \mathrm{~V} 2$ & 123 & 47.2 & $1520205 \mathrm{~V} 2$ & 27 & 251.6 & $1530205 \mathrm{~V} 2$ & 26 & 178.6 \\
\hline $1510205 \mathrm{~V} 3$ & 123 & 9.4 & $1520205 \mathrm{~V} 3$ & 25 & 54.5 & $1530205 \mathrm{~V} 3$ & 24 & 40.1 \\
\hline $1510205 \mathrm{~V} 4$ & 121 & 4.7 & $1520205 \mathrm{~V} 4$ & 25 & 27.3 & $1530205 \mathrm{~V} 4$ & 24 & 20.2 \\
\hline $1510220 \mathrm{~V} 1$ & 142 & 136.3 & $1520220 \mathrm{~V} 1$ & 32 & 625.8 & $1530220 \mathrm{~V} 1$ & 30 & 521.9 \\
\hline $1510220 \mathrm{~V} 2$ & 142 & 68.2 & $1520220 \mathrm{~V} 2$ & 29 & 335.0 & $1530220 \mathrm{~V} 2$ & 28 & 290.2 \\
\hline $1510220 \mathrm{~V} 3$ & 142 & 13.6 & $1520220 \mathrm{~V} 3$ & 26 & 69.5 & $1530220 \mathrm{~V} 3$ & 26 & 61.7 \\
\hline $1510220 \mathrm{~V} 4$ & 134 & 6.8 & $1520220 \mathrm{~V} 4$ & 26 & 348 & $1530220 \mathrm{~V} 4$ & 26 & 31.0 \\
\hline $1511505 \mathrm{~V} 1$ & 131 & 227 & $1521505 \mathrm{~V} 1$ & 29 & 524.2 & $1531505 \mathrm{~V} 1$ & 27 & 348.9 \\
\hline $1511505 \mathrm{~V} 2$ & 127 & 116.8 & $1521505 \mathrm{~V} 2$ & 29 & 524.2 & $1531505 \mathrm{~V} 2$ & 27 & 348.0 \\
\hline $1511505 \mathrm{~V} 3$ & 123 & 23.6 & $1521505 \mathrm{~V} 3$ & 26 & 133.3 & $1531505 \mathrm{~V} 3$ & 25 & 97.1 \\
\hline $1511505 \mathrm{~V} 4$ & 123 & 11.8 & $1521505 \mathrm{~V} 4$ & 25 & 67.9 & $1531505 \mathrm{~V} 4$ & 24 & 50.0 \\
\hline $1511520 \mathrm{~V} 1$ & 149 & 335.9 & $1521520 \mathrm{~V} 1$ & 33 & 757.5 & $1531520 \mathrm{~V} 1$ & 31 & 630.1 \\
\hline $1511520 \mathrm{~V} 2$ & 142 & 170.1 & $1521520 \mathrm{~V} 2$ & 33 & 757.5 & $1531520 \mathrm{~V} 2$ & 31 & 630.1 \\
\hline $1511520 \mathrm{~V} 3$ & 142 & 34.1 & $1521520 \mathrm{~V} 3$ & 27 & 172.3 & $1531520 \mathrm{~V} 3$ & 26 & 152.0 \\
\hline $1511520 \mathrm{~V} 4$ & 142 & 17 & $1521520 \mathrm{~V} 4$ & 26 & 86.7 & $1531520 \mathrm{~V} 4$ & 26 & 77.0 \\
\hline $1515005 \mathrm{~V} 1$ & 142 & 416.7 & $1525005 \mathrm{~V} 1$ & 29 & 524.2 & $1535005 \mathrm{~V} 1$ & 27 & 348.9 \\
\hline $1515005 \mathrm{~V} 2$ & 131 & 227 & $1525005 \mathrm{~V} 2$ & 29 & 524.2 & $1535005 \mathrm{~V} 2$ & 27 & 348.9 \\
\hline $1515005 \mathrm{~V} 3$ & 123 & 47.2 & $1525005 \mathrm{~V} 3$ & 27 & 251.6 & $1535005 \mathrm{~V} 3$ & 26 & 178.6 \\
\hline $1515005 \mathrm{~V} 4$ & 123 & 23.6 & $1525005 \mathrm{~V} 4$ & 26 & 133.3 & $1535005 \mathrm{~V} 4$ & 25 & 97.1 \\
\hline $1515020 \mathrm{~V} 1$ & 164 & 643.1 & $1525020 \mathrm{~V} 1$ & 33 & 770.0 & $1535020 \mathrm{~V} 1$ & 31 & 630.1 \\
\hline $1515020 \mathrm{~V} 2$ & 149 & 335.9 & $1525020 \mathrm{~V} 2$ & 33 & 770.0 & $1535020 \mathrm{~V} 2$ & 31 & 630.1 \\
\hline $1515020 \mathrm{~V} 3$ & 142 & 68.2 & $1525020 \mathrm{~V} 3$ & 29 & 335.0 & $1535020 \mathrm{~V} 3$ & 28 & 290.2 \\
\hline $1515020 \mathrm{~V} 4$ & 142 & 34.1 & $1525020 \mathrm{~V} 4$ & 27 & 172.3 & $1535020 \mathrm{~V} 4$ & 26 & 152.0 \\
\hline
\end{tabular}


Table E. 8 Simulation results for C1L5 design alternative over high hydraulic conductivity aquitards $\left(\mathrm{k}=1 \times 10^{-7} \mathrm{~m} / \mathrm{s}\right)$

\begin{tabular}{|c|c|c|c|c|c|c|c|c|}
\hline \multicolumn{3}{|c|}{ Arid } & \multicolumn{3}{|c|}{ Moderate } & \multicolumn{3}{|c|}{ Humid } \\
\hline Design $^{a}$ & $\begin{array}{l}\mathbf{T}^{\mathbf{b}} \\
(\mathbf{y})\end{array}$ & $\begin{array}{c}\mathrm{C}^{\mathrm{c}} \\
(\mathrm{mg} / \mathrm{L})\end{array}$ & Design & $\begin{array}{c}\mathbf{T} \\
(\mathbf{y})\end{array}$ & $\begin{array}{c}C \\
(\mathrm{mg} / \mathrm{L})\end{array}$ & Design & $\begin{array}{c}\mathbf{T} \\
(\mathbf{y})\end{array}$ & $\begin{array}{c}\mathrm{C} \\
(\mathrm{mg} / \mathrm{L})\end{array}$ \\
\hline $1510205 \mathrm{~V} 1$ & 100 & 106.0 & $1520205 \mathrm{~V} 1$ & 21 & 531.7 & $1530205 \mathrm{~V} 1$ & 10 & 540.6 \\
\hline $1510205 \mathrm{~V} 2$ & 97 & 53.4 & $1520205 \mathrm{~V} 2$ & 19 & 312.7 & $1530205 \mathrm{~V} 2$ & 10 & 502.7 \\
\hline $1510205 \mathrm{~V} 3$ & 97 & 10.7 & $1520205 \mathrm{~V} 3$ & 17 & 71.5 & $1530205 \mathrm{~V} 3$ & 9 & 140.0 \\
\hline $1510205 \mathrm{~V} 4$ & 97 & 5.4 & $1520205 \mathrm{~V} 4$ & 17 & 36.0 & $1530205 \mathrm{~V} 4$ & 8.5 & 72.4 \\
\hline $1510220 \mathrm{~V} 1$ & 115 & 143.0 & $1520220 \mathrm{~V} 1$ & 25 & 731.6 & $1530220 \mathrm{~V} 1$ & 12 & 774.8 \\
\hline $1510220 \mathrm{~V} 2$ & 110.5 & 71.8 & $1520220 \mathrm{~V} 2$ & 20.5 & 395.5 & $1530220 \mathrm{~V} 2$ & 12 & 707.4 \\
\hline $1510220 \mathrm{~V} 3$ & 107 & 14.4 & $1520220 \mathrm{~V} 3$ & 18 & 84.3 & $1530220 \mathrm{~V} 3$ & 9 & 164.5 \\
\hline $1510220 \mathrm{~V} 4$ & 107 & 7.2 & $1520220 \mathrm{~V} 4$ & 18 & 42.2 & $1530220 \mathrm{~V} 4$ & 9 & 83.7 \\
\hline $1511505 \mathrm{~V} 1$ & 106 & 252.7 & $1521505 \mathrm{~V} 1$ & 21 & 568.1 & $1531505 \mathrm{~V} 1$ & 10.5 & 540.6 \\
\hline $1511505 \mathrm{~V} 2$ & 101.5 & 131.8 & $1521505 \mathrm{~V} 2$ & 21 & 568.1 & $505 \mathrm{~V} 2$ & 10.5 & 540.6 \\
\hline $1511505 \mathrm{~V} 3$ & 97 & 26.8 & $1521505 \mathrm{~V} 3$ & 18 & 171.6 & $1531505 \mathrm{~V} 3$ & 9 & 302.6 \\
\hline $1511505 \mathrm{~V} 4$ & 97 & 13.4 & $1521505 \mathrm{~V} 4$ & 17 & 89.0 & $1531505 \mathrm{~V} 4$ & 9 & 169.8 \\
\hline $1511520 \mathrm{~V} 1$ & 121 & 350.6 & $1521520 \mathrm{~V} 1$ & 25 & 794.8 & $1531520 \mathrm{~V} 1$ & 12 & 774.7 \\
\hline $1511520 \mathrm{~V} 2$ & 115 & 178.6 & $1521520 \mathrm{~V} 2$ & 25 & 794.8 & 1531520V2 & 12 & 774.7 \\
\hline $1511520 \mathrm{~V} 3$ & 107 & 36.0 & $1521520 \mathrm{~V} 3$ & 19.5 & 206.4 & $1531520 \mathrm{~V} 3$ & 11 & 385.8 \\
\hline $1511520 \mathrm{~V} 4$ & 107 & 18.0 & $1521520 \mathrm{~V} 4$ & 18 & 105.0 & $1531520 \mathrm{~V} 4$ & 9 & 203.1 \\
\hline $1515005 \mathrm{~V} 1$ & 115 & 454.0 & $1525005 \mathrm{~V} 1$ & 21 & 568.1 & $1535005 \mathrm{~V} 1$ & 10.5 & 540.6 \\
\hline $1515005 \mathrm{~V} 2$ & 106 & 252.7 & $1525005 \mathrm{~V} 2$ & 21 & 568.1 & $1535005 \mathrm{~V} 2$ & 10.5 & 540.6 \\
\hline $1515005 \mathrm{~V} 3$ & 97 & 53.4 & $1525005 \mathrm{~V} 3$ & 19 & 312.9 & $1535005 \mathrm{~V} 3$ & 10 & 502.7 \\
\hline $1515005 \mathrm{~V} 4$ & 97 & 26.8 & $1525005 \mathrm{~V} 4$ & 18 & 171.6 & $1535005 \mathrm{~V} 4$ & 9 & 302.6 \\
\hline $1515020 \mathrm{~V} 1$ & 134 & 663.6 & $1525020 \mathrm{~V} 1$ & 25 & 794.8 & $1535020 \mathrm{~V} 1$ & 12 & 774.8 \\
\hline $1515020 \mathrm{~V} 2$ & 121 & 350.6 & $1525020 \mathrm{~V} 2$ & 25 & 794.8 & $1535020 \mathrm{~V} 2$ & 12 & 774.8 \\
\hline $1515020 \mathrm{~V} 3$ & 110.5 & 71.8 & $1525020 \mathrm{~V} 3$ & 20.5 & 395.5 & $1535020 \mathrm{~V} 3$ & 12 & 707.4 \\
\hline $1515020 \mathrm{~V} 4$ & 107 & 36.0 & $1525020 \mathrm{~V} 4$ & 19.5 & 206.4 & $1535020 \mathrm{~V} 4$ & 10.5 & 385.8 \\
\hline
\end{tabular}


Table E. 9 Simulation results for C1L6 design alternative over low hydraulic conductivity aquitards $\left(\mathrm{k}=1 \times 10^{-8} \mathrm{~m} / \mathrm{s}\right)$

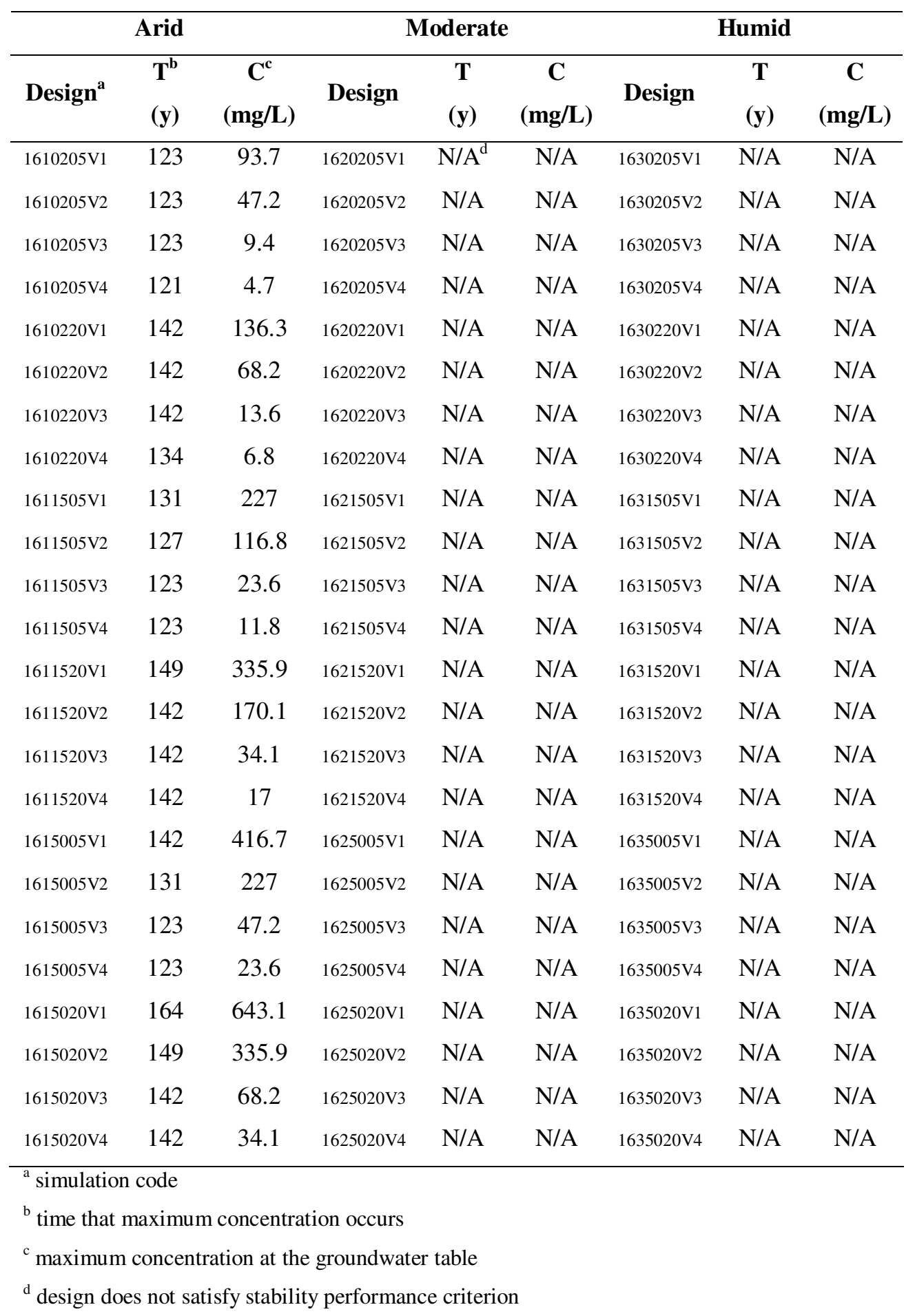


Table E. 10 Simulation results for C1L6 design alternative over high hydraulic conductivity aquitards $\left(\mathrm{k}=1 \times 10^{-7} \mathrm{~m} / \mathrm{s}\right)$

\begin{tabular}{|c|c|c|c|c|c|c|c|c|}
\hline \multicolumn{3}{|c|}{ Arid } & \multicolumn{3}{|c|}{ Moderate } & \multicolumn{3}{|c|}{ Humid } \\
\hline Design $^{a}$ & $\begin{array}{l}\mathbf{T}^{\mathbf{b}} \\
(\mathbf{y})\end{array}$ & $\begin{array}{c}\mathrm{C}^{\mathrm{c}} \\
(\mathrm{mg} / \mathrm{L})\end{array}$ & Design & $\begin{array}{c}\mathbf{T} \\
(\mathbf{y})\end{array}$ & $\begin{array}{c}\mathrm{C} \\
(\mathrm{mg} / \mathrm{L})\end{array}$ & Design & $\begin{array}{l}\mathbf{T} \\
(\mathbf{y})\end{array}$ & $\begin{array}{c}\mathrm{C} \\
(\mathrm{mg} / \mathrm{L})\end{array}$ \\
\hline $1610205 \mathrm{~V} 1$ & 100 & 106.0 & $1620205 \mathrm{~V} 1$ & 21 & 531.7 & $1630205 \mathrm{~V} 1$ & $\mathrm{~N} / \mathrm{A}^{\mathrm{d}}$ & N/A \\
\hline $1610205 \mathrm{~V} 2$ & 97 & 53.4 & $1620205 \mathrm{~V} 2$ & 19 & 312.7 & $1630205 \mathrm{~V} 2$ & N/A & N/A \\
\hline $1610205 \mathrm{~V} 3$ & 97 & 10.7 & $1620205 \mathrm{~V} 3$ & 17 & 71.5 & $1630205 \mathrm{~V} 3$ & N/A & N/A \\
\hline $1610205 \mathrm{~V} 4$ & 97 & 5.4 & $1620205 \mathrm{~V} 4$ & 17 & 36.0 & $1630205 \mathrm{~V} 4$ & N/A & N/A \\
\hline $1610220 \mathrm{~V} 1$ & 115 & 143.0 & $1620220 \mathrm{~V} 1$ & 25 & 731.6 & 1630220V1 & N/A & N/A \\
\hline $1610220 \mathrm{~V} 2$ & 110.5 & 71.8 & $1620220 \mathrm{~V} 2$ & 20.5 & 395.5 & $1630220 \mathrm{~V} 2$ & N/A & N/A \\
\hline $1610220 \mathrm{~V} 3$ & 107 & 14.4 & $1620220 \mathrm{~V} 3$ & 18 & 84.3 & $1630220 \mathrm{~V} 3$ & N/A & N/A \\
\hline $1610220 \mathrm{~V} 4$ & 107 & 7.2 & $1620220 \mathrm{~V} 4$ & 18 & 42.2 & $1630220 \mathrm{~V} 4$ & N/A & N/A \\
\hline $1611505 \mathrm{~V} 1$ & 106 & 252.7 & $1621505 \mathrm{~V} 1$ & 21 & 568.1 & $1631505 \mathrm{~V} 1$ & N/A & N/A \\
\hline $1611505 \mathrm{~V} 2$ & 101.5 & 131.8 & $1621505 \mathrm{~V} 2$ & 21 & 568.1 & $1631505 \mathrm{~V} 2$ & N/A & N/A \\
\hline $1611505 \mathrm{~V} 3$ & 97 & 26.8 & $1621505 \mathrm{~V} 3$ & 18 & 171.6 & $1631505 \mathrm{~V} 3$ & N/A & N/A \\
\hline $1611505 \mathrm{~V} 4$ & 97 & 13.4 & $1621505 \mathrm{~V} 4$ & 17 & 89.0 & $1631505 \mathrm{~V} 4$ & N/A & N/A \\
\hline $1611520 \mathrm{~V} 1$ & 121 & 350.6 & $1621520 \mathrm{~V} 1$ & 25 & 794.8 & 1631520V1 & N/A & N/A \\
\hline $1611520 \mathrm{~V} 2$ & 115 & 178.6 & $1621520 \mathrm{~V} 2$ & 25 & 794.8 & $1631520 \mathrm{~V} 2$ & N/A & N/A \\
\hline $1611520 \mathrm{~V} 3$ & 107 & 36.0 & $1621520 \mathrm{~V} 3$ & 19.5 & 206.4 & $1631520 \mathrm{~V} 3$ & N/A & N/A \\
\hline $1611520 \mathrm{~V} 4$ & 107 & 18.0 & $1621520 \mathrm{~V} 4$ & 18 & 105.0 & $1631520 \mathrm{~V} 4$ & N/A & N/A \\
\hline $1615005 \mathrm{~V} 1$ & 115 & 454.0 & $1625005 \mathrm{~V} 1$ & 21 & 568.1 & $1635005 \mathrm{~V} 1$ & N/A & N/A \\
\hline $1615005 \mathrm{~V} 2$ & 106 & 252.7 & $1625005 \mathrm{~V} 2$ & 21 & 568.1 & $1635005 \mathrm{~V} 2$ & N/A & N/A \\
\hline $1615005 \mathrm{~V} 3$ & 97 & 53.4 & $1625005 \mathrm{~V} 3$ & 19 & 312.9 & $1635005 \mathrm{~V} 3$ & N/A & N/A \\
\hline $1615005 \mathrm{~V} 4$ & 97 & 26.8 & $1625005 \mathrm{~V} 4$ & 18 & 171.6 & $1635005 \mathrm{~V} 4$ & N/A & N/A \\
\hline $1615020 \mathrm{~V} 1$ & 134 & 663.6 & $1625020 \mathrm{~V} 1$ & 25 & 794.8 & $1635020 \mathrm{~V} 1$ & N/A & N/A \\
\hline $1615020 \mathrm{~V} 2$ & 121 & 350.6 & $1625020 \mathrm{~V} 2$ & 25 & 794.8 & $1635020 \mathrm{~V} 2$ & N/A & N/A \\
\hline $1615020 \mathrm{~V} 3$ & 110.5 & 71.8 & $1625020 \mathrm{~V} 3$ & 20.5 & 395.5 & $1635020 \mathrm{~V} 3$ & N/A & N/A \\
\hline $1615020 \mathrm{~V} 4$ & 107 & 36.0 & $1625020 \mathrm{~V} 4$ & 19.5 & 206.4 & $1635020 \mathrm{~V} 4$ & N/A & N/A \\
\hline
\end{tabular}


Table E. 11 Simulation results for C2L1 design alternative

\begin{tabular}{|c|c|c|c|c|c|c|c|c|}
\hline \multicolumn{3}{|c|}{ Arid } & \multicolumn{3}{|c|}{ Moderate } & \multicolumn{3}{|c|}{ Humid } \\
\hline Design $^{a}$ & $\begin{array}{l}\mathbf{T}^{\mathbf{b}} \\
(\mathbf{y})\end{array}$ & $\begin{array}{c}C^{c} \\
(m g / L)\end{array}$ & Design & $\begin{array}{c}\mathbf{T} \\
(\mathbf{y})\end{array}$ & $\begin{array}{c}\mathrm{C} \\
(\mathrm{mg} / \mathrm{L})\end{array}$ & Design & $\begin{array}{c}\mathbf{T} \\
(\mathbf{y})\end{array}$ & $\begin{array}{c}\mathrm{C} \\
(\mathrm{mg} / \mathrm{L})\end{array}$ \\
\hline $2110205 \mathrm{~V} 1$ & 1171 & 2.89 & $2120205 \mathrm{~V} 1$ & 800 & 6.30 & $2130205 \mathrm{~V} 1$ & 522 & 13.60 \\
\hline $2110205 \mathrm{~V} 2$ & 1171 & 1.45 & $2120205 \mathrm{~V} 2$ & 800 & 3.15 & $2130205 \mathrm{~V} 2$ & 522 & 6.80 \\
\hline $2110205 \mathrm{~V} 3$ & 1171 & 0.29 & $2120205 \mathrm{~V} 3$ & 800 & 0.63 & $2130205 \mathrm{~V} 3$ & 522 & 1.36 \\
\hline $2110205 \mathrm{~V} 4$ & 1171 & 0.15 & $2120205 \mathrm{~V} 4$ & 800 & 0.32 & $2130205 \mathrm{~V} 4$ & 522 & 0.68 \\
\hline $2110220 \mathrm{~V} 1$ & 1727 & 4.74 & $2120220 \mathrm{~V} 1$ & 1171 & 10.74 & $2130220 \mathrm{~V} 1$ & 645 & 22.81 \\
\hline $2110220 \mathrm{~V} 2$ & 1727 & 2.37 & $2120220 \mathrm{~V} 2$ & 1171 & 5.37 & $2130220 \mathrm{~V} 2$ & 645 & 11.41 \\
\hline $2110220 \mathrm{~V} 3$ & 1727 & 0.47 & $2120220 \mathrm{~V} 3$ & 1088 & 1.08 & $2130220 \mathrm{~V} 3$ & 645 & 2.28 \\
\hline $2110220 \mathrm{~V} 4$ & 1727 & 0.24 & $2120220 \mathrm{~V} 4$ & 1088 & 0.54 & $2130220 \mathrm{~V} 4$ & 645 & 1.14 \\
\hline $2111505 \mathrm{~V} 1$ & 1171 & 7.19 & $2121505 \mathrm{~V} 1$ & 800 & 15.68 & $2131505 \mathrm{~V} 1$ & 522 & 33.81 \\
\hline $2111505 \mathrm{~V} 2$ & 1171 & 3.61 & $2121505 \mathrm{~V} 2$ & 800 & 7.87 & $2131505 \mathrm{~V} 2$ & 522 & 16.94 \\
\hline $2111505 \mathrm{~V} 3$ & 1171 & 0.75 & $2121505 \mathrm{~V} 3$ & 800 & 1.58 & $2131505 \mathrm{~V} 3$ & 522 & 3.39 \\
\hline $2111505 \mathrm{~V} 4$ & 1171 & 0.36 & $2121505 \mathrm{~V} 4$ & 800 & 0.79 & $2131505 \mathrm{~V} 4$ & 522 & 1.69 \\
\hline $2111520 \mathrm{~V} 1$ & 1727 & 11.81 & $2121520 \mathrm{~V} 1$ & 1171 & 26.81 & $2131520 \mathrm{~V} 1$ & 645 & 56.91 \\
\hline $2111520 \mathrm{~V} 2$ & 1727 & 5.92 & $2121520 \mathrm{~V} 2$ & 1171 & 13.42 & $2131520 \mathrm{~V} 2$ & 645 & 28.51 \\
\hline $2111520 \mathrm{~V} 3$ & 1727 & 1.19 & $2121520 \mathrm{~V} 3$ & 1171 & 2.69 & $2131520 \mathrm{~V} 3$ & 645 & 5.71 \\
\hline $2111520 \mathrm{~V} 4$ & 1727 & 0.59 & $2121520 \mathrm{~V} 4$ & 1088 & 1.34 & $2131520 \mathrm{~V} 4$ & 645 & 2.85 \\
\hline $2115005 \mathrm{~V} 1$ & 1171 & 14.27 & $2125005 \mathrm{~V} 1$ & 856 & 31.18 & $2135005 \mathrm{~V} 1$ & 522 & 67.11 \\
\hline $2115005 \mathrm{~V} 2$ & 1171 & 7.19 & $2125005 \mathrm{~V} 2$ & 800 & 15.68 & $2135005 \mathrm{~V} 2$ & 522 & 33.81 \\
\hline $2115005 \mathrm{~V} 3$ & 1171 & 1.45 & $2125005 \mathrm{~V} 3$ & 800 & 3.15 & $2135005 \mathrm{~V} 3$ & 522 & 6.78 \\
\hline $2115005 \mathrm{~V} 4$ & 1171 & 0.72 & $2125005 \mathrm{~V} 4$ & 800 & 1.58 & $2135005 \mathrm{~V} 4$ & 522 & 3.39 \\
\hline $2115020 \mathrm{~V} 1$ & 1727 & 23.5 & $2125020 \mathrm{~V} 1$ & 1171 & 53.48 & $2135020 \mathrm{~V} 1$ & 701 & 113.56 \\
\hline $2115020 \mathrm{~V} 2$ & 1727 & 11.81 & $2125020 \mathrm{~V} 2$ & 1171 & 26.81 & $2135020 \mathrm{~V} 2$ & 645 & 56.91 \\
\hline $2115020 \mathrm{~V} 3$ & 1727 & 2.37 & $2125020 \mathrm{~V} 3$ & 1171 & 5.37 & $2135020 \mathrm{~V} 3$ & 645 & 11.41 \\
\hline $2115020 \mathrm{~V} 4$ & 1727 & 1.19 & $2125020 \mathrm{~V} 4$ & 1171 & 2.69 & $2135020 \mathrm{~V} 4$ & 645 & 5.71 \\
\hline
\end{tabular}


Table E. 12 Simulation results for C2L2 design alternative

\begin{tabular}{|c|c|c|c|c|c|c|c|c|}
\hline \multicolumn{3}{|c|}{ Arid } & \multicolumn{3}{|c|}{ Moderate } & \multicolumn{3}{|c|}{ Humid } \\
\hline Design $^{a}$ & $\begin{array}{l}\mathbf{T}^{\mathbf{b}} \\
(\mathbf{y})\end{array}$ & $\begin{array}{c}\mathrm{C}^{\mathrm{c}} \\
(\mathrm{mg} / \mathrm{L})\end{array}$ & Design & $\begin{array}{l}T \\
(\mathbf{y})\end{array}$ & $\begin{array}{c}\mathrm{C} \\
(\mathrm{mg} / \mathrm{L})\end{array}$ & Design & $\begin{array}{c}\mathbf{T} \\
(\mathbf{y})\end{array}$ & $\begin{array}{c}\mathrm{C} \\
(\mathrm{mg} / \mathrm{L})\end{array}$ \\
\hline $2210205 \mathrm{~V} 1$ & 1375 & 2.8 & $2220205 \mathrm{~V} 1$ & 778 & 7.5 & $2230205 \mathrm{~V} 1$ & 473 & 15.8 \\
\hline $2210205 \mathrm{~V} 2$ & 1375 & 1.4 & $2220205 \mathrm{~V} 2$ & 737 & 3.7 & $2230205 \mathrm{~V} 2$ & 473 & 7.9 \\
\hline $2210205 \mathrm{~V} 3$ & 1375 & 0.28 & $2220205 \mathrm{~V} 3$ & 737 & 0.75 & $2230205 \mathrm{~V} 3$ & 473 & 1.6 \\
\hline $2210205 \mathrm{~V} 4$ & 1375 & 0.14 & $2220205 \mathrm{~V} 4$ & 737 & 0.37 & $2230205 \mathrm{~V} 4$ & 473 & 0.8 \\
\hline $2210220 \mathrm{~V} 1$ & 1952 & 4.32 & $2220220 \mathrm{~V} 1$ & 1067 & 11.6 & $2230220 \mathrm{~V} 1$ & 587 & 24.5 \\
\hline $2210220 \mathrm{~V} 2$ & 1952 & 2.16 & $2220220 \mathrm{~V} 2$ & 1067 & 5.8 & $2230220 \mathrm{~V} 2$ & 587 & 12.3 \\
\hline $2210220 \mathrm{~V} 3$ & 1952 & 0.43 & $2220220 \mathrm{~V} 3$ & 1067 & 1.2 & $2230220 \mathrm{~V} 3$ & 587 & 2.5 \\
\hline $2210220 \mathrm{~V} 4$ & 1952 & 0.22 & $2220220 \mathrm{~V} 4$ & 1067 & 0.6 & $2230220 \mathrm{~V} 4$ & 587 & 1.2 \\
\hline $2211505 \mathrm{~V} 1$ & 1333 & 6.9 & $2221505 \mathrm{~V} 1$ & 859 & 17.4 & $2231505 \mathrm{~V} 1$ & 473 & 39.4 \\
\hline $2211505 \mathrm{~V} 2$ & 1333 & 3.5 & $2221505 \mathrm{~V} 2$ & 818 & 8.7 & $2231505 \mathrm{~V} 2$ & 473 & 19.8 \\
\hline $2211505 \mathrm{~V} 3$ & 1333 & 0.69 & $2221505 \mathrm{~V} 3$ & 818 & 1.7 & $2231505 \mathrm{~V} 3$ & 473 & 4.0 \\
\hline $2211505 \mathrm{~V} 4$ & 1333 & 0.35 & $2221505 \mathrm{~V} 4$ & 818 & 0.9 & $2231505 \mathrm{~V} 4$ & 473 & 2.0 \\
\hline $2211520 \mathrm{~V} 1$ & 1952 & 10.8 & $2221520 \mathrm{~V} 1$ & 1142 & 28 & $2231520 \mathrm{~V} 1$ & 587 & 61.2 \\
\hline $2211520 \mathrm{~V} 2$ & 1952 & 5.4 & $2221520 \mathrm{~V} 2$ & 1067 & 14 & $2231520 \mathrm{~V} 2$ & 587 & 30.7 \\
\hline $2211520 \mathrm{~V} 3$ & 1952 & 1.1 & $20 \mathrm{~V} 3$ & 1067 & 2.8 & $2231520 \mathrm{~V} 3$ & 587 & 6.1 \\
\hline $2211520 \mathrm{~V} 4$ & 1952 & 0.54 & $2221520 \mathrm{~V} 4$ & 1067 & 1.4 & $2231520 \mathrm{~V} 4$ & 587 & 3.1 \\
\hline $2215005 \mathrm{~V} 1$ & 1333 & 13.7 & $2225005 \mathrm{~V} 1$ & 859 & 34.6 & $2235005 \mathrm{~V} 1$ & 496 & 78.4 \\
\hline $2215005 \mathrm{~V} 2$ & 1333 & 6.9 & $2225005 \mathrm{~V} 2$ & 859 & 17.4 & $2235005 \mathrm{~V} 2$ & 473 & 39.4 \\
\hline $2215005 \mathrm{~V} 3$ & 1333 & 1.4 & $2225005 \mathrm{~V} 3$ & 818 & 3.5 & $2235005 \mathrm{~V} 3$ & 473 & 7.9 \\
\hline $2215005 \mathrm{~V} 4$ & 1333 & 0.69 & $2225005 \mathrm{~V} 4$ & 818 & 1.7 & $2235005 \mathrm{~V} 4$ & 473 & 4.0 \\
\hline $2215020 \mathrm{~V} 1$ & 1952 & 21.5 & $2225020 \mathrm{~V} 1$ & 1142 & 55.9 & $2235020 \mathrm{~V} 1$ & 628 & 122.2 \\
\hline $2215020 \mathrm{~V} 2$ & 1952 & 10.8 & $2225020 \mathrm{~V} 2$ & 1142 & 28 & $2235020 \mathrm{~V} 2$ & 587 & 61.2 \\
\hline $2215020 \mathrm{~V} 3$ & 1952 & 2.16 & $2225020 \mathrm{~V} 3$ & 1067 & 5.6 & $2235020 \mathrm{~V} 3$ & 587 & 12.3 \\
\hline $2215020 \mathrm{~V} 4$ & 1952 & 1.08 & $2225020 \mathrm{~V} 4$ & 1067 & 2.8 & $2235020 \mathrm{~V} 4$ & 587 & 6.1 \\
\hline
\end{tabular}

${ }^{\text {a }}$ simulation code

${ }^{\mathrm{b}}$ time that maximum concentration occurs

${ }^{c}$ maximum concentration at the groundwater table 
Table E. 13 Simulation results for C2L3 design alternative

\begin{tabular}{|c|c|c|c|c|c|c|c|c|}
\hline \multicolumn{3}{|c|}{ Arid } & \multicolumn{3}{|c|}{ Moderate } & \multicolumn{3}{|c|}{ Humid } \\
\hline Design $^{a}$ & $\begin{array}{l}\mathbf{T}^{\mathbf{b}} \\
(\mathbf{y})\end{array}$ & $\begin{array}{c}C^{c} \\
(m g / L)\end{array}$ & Design & $\begin{array}{c}\mathbf{T} \\
(\mathbf{y})\end{array}$ & $\begin{array}{c}C \\
(\mathrm{mg} / \mathrm{L})\end{array}$ & Design & $\begin{array}{c}\mathbf{T} \\
(\mathbf{y})\end{array}$ & $\begin{array}{c}\mathrm{C} \\
(\mathrm{mg} / \mathrm{L})\end{array}$ \\
\hline $2310205 \mathrm{~V} 1$ & 1171 & 2.89 & $2320205 \mathrm{~V} 1$ & 800 & 6.30 & $2330205 \mathrm{~V} 1$ & 522 & 13.60 \\
\hline $2310205 \mathrm{~V} 2$ & 1171 & 1.45 & $2320205 \mathrm{~V} 2$ & 800 & 3.15 & $2330205 \mathrm{~V} 2$ & 522 & 6.80 \\
\hline $2310205 \mathrm{~V} 3$ & 1171 & 0.29 & $2320205 \mathrm{~V} 3$ & 800 & 0.63 & $2330205 \mathrm{~V} 3$ & 522 & 1.36 \\
\hline $2310205 \mathrm{~V} 4$ & 1171 & 0.15 & $2320205 \mathrm{~V} 4$ & 800 & 0.32 & $2330205 \mathrm{~V} 4$ & 522 & 0.68 \\
\hline $2310220 \mathrm{~V} 1$ & 1727 & 4.74 & $2320220 \mathrm{~V} 1$ & 1171 & 10.74 & $2330220 \mathrm{~V} 1$ & 645 & 22.81 \\
\hline $2310220 \mathrm{~V} 2$ & 1727 & 2.37 & $2320220 \mathrm{~V} 2$ & 1171 & 5.37 & $2330220 \mathrm{~V} 2$ & 645 & 11.41 \\
\hline $2310220 \mathrm{~V} 3$ & 1727 & 0.47 & $2320220 \mathrm{~V} 3$ & 1088 & 1.08 & $2330220 \mathrm{~V} 3$ & 645 & 2.28 \\
\hline $2310220 \mathrm{~V} 4$ & 1727 & 0.24 & $2320220 \mathrm{~V} 4$ & 1088 & 0.54 & $2330220 \mathrm{~V} 4$ & 645 & 1.14 \\
\hline $2311505 \mathrm{~V} 1$ & 1171 & 7.19 & $2321505 \mathrm{~V} 1$ & 800 & 15.68 & $2331505 \mathrm{~V} 1$ & 522 & 33.81 \\
\hline $2311505 \mathrm{~V} 2$ & 1171 & 3.61 & $2321505 \mathrm{~V} 2$ & 800 & 7.87 & $2331505 \mathrm{~V} 2$ & 522 & 16.94 \\
\hline $2311505 \mathrm{~V} 3$ & 1171 & 0.75 & $2321505 \mathrm{~V} 3$ & 800 & 1.58 & $2331505 \mathrm{~V} 3$ & 522 & 3.39 \\
\hline $2311505 \mathrm{~V} 4$ & 1171 & 0.36 & $2321505 \mathrm{~V} 4$ & 800 & 0.79 & $2331505 \mathrm{~V} 4$ & 522 & 1.69 \\
\hline $2311520 \mathrm{~V} 1$ & 1727 & 11.81 & $2321520 \mathrm{~V} 1$ & 1171 & 26.81 & $2331520 \mathrm{~V} 1$ & 645 & 56.91 \\
\hline $2311520 \mathrm{~V} 2$ & 1727 & 5.92 & $2321520 \mathrm{~V} 2$ & 1171 & 13.42 & $2331520 \mathrm{~V} 2$ & 645 & 28.51 \\
\hline $2311520 \mathrm{~V} 3$ & 1727 & 1.19 & $2321520 \mathrm{~V} 3$ & 1171 & 2.69 & $2331520 \mathrm{~V} 3$ & 645 & 5.71 \\
\hline $2311520 \mathrm{~V} 4$ & 1727 & 0.59 & $2321520 \mathrm{~V} 4$ & 1088 & 1.34 & $2331520 \mathrm{~V} 4$ & 645 & 2.85 \\
\hline $2315005 \mathrm{~V} 1$ & 1171 & 14.27 & $2325005 \mathrm{~V} 1$ & 856 & 31.18 & $2335005 \mathrm{~V} 1$ & 522 & 67.11 \\
\hline $2315005 \mathrm{~V} 2$ & 1171 & 7.19 & $2325005 \mathrm{~V} 2$ & 800 & 15.68 & $2335005 \mathrm{~V} 2$ & 522 & 33.81 \\
\hline $2315005 \mathrm{~V} 3$ & 1171 & 1.45 & $2325005 \mathrm{~V} 3$ & 800 & 3.15 & $2335005 \mathrm{~V} 3$ & 522 & 6.78 \\
\hline $2315005 \mathrm{~V} 4$ & 1171 & 0.72 & $2325005 \mathrm{~V} 4$ & 800 & 1.58 & $2335005 \mathrm{~V} 4$ & 522 & 3.39 \\
\hline $2315020 \mathrm{~V} 1$ & 1727 & 23.5 & $2325020 \mathrm{~V} 1$ & 1171 & 53.48 & $2335020 \mathrm{~V} 1$ & 701 & 113.56 \\
\hline $2315020 \mathrm{~V} 2$ & 1727 & 11.81 & $2325020 \mathrm{~V} 2$ & 1171 & 26.81 & $2335020 \mathrm{~V} 2$ & 645 & 56.91 \\
\hline $2315020 \mathrm{~V} 3$ & 1727 & 2.37 & $2325020 \mathrm{~V} 3$ & 1171 & 5.37 & $2335020 \mathrm{~V} 3$ & 645 & 11.41 \\
\hline $2315020 \mathrm{~V} 4$ & 1727 & 1.19 & $2325020 \mathrm{~V} 4$ & 1171 & 2.69 & $2335020 \mathrm{~V} 4$ & 645 & 5.71 \\
\hline
\end{tabular}


Table E. 14 Simulation results for C2L4 design alternative over low hydraulic conductivity aquitards $\left(\mathrm{k}=1 \times 10^{-8} \mathrm{~m} / \mathrm{s}\right)$

\begin{tabular}{|c|c|c|c|c|c|c|c|c|}
\hline \multicolumn{3}{|c|}{ Arid } & \multicolumn{3}{|c|}{ Moderate } & \multicolumn{3}{|c|}{ Humid } \\
\hline Design $^{a}$ & $\begin{array}{l}\mathbf{T}^{\mathbf{b}} \\
(\mathbf{y})\end{array}$ & $\begin{array}{c}C^{c} \\
(m g / L)\end{array}$ & Design & $\begin{array}{c}\mathbf{T} \\
(\mathbf{y})\end{array}$ & $\begin{array}{c}\mathrm{C} \\
(\mathrm{mg} / \mathrm{L})\end{array}$ & Design & $\begin{array}{c}\mathbf{T} \\
(\mathbf{y})\end{array}$ & $\begin{array}{c}\mathrm{C} \\
(\mathrm{mg} / \mathrm{L})\end{array}$ \\
\hline $2410205 \mathrm{~V} 1$ & 1339 & 2.85 & $2420205 \mathrm{~V} 1$ & 859 & 6.34 & $2430205 \mathrm{~V} 1$ & 536 & 13.76 \\
\hline $2410205 \mathrm{~V} 2$ & 1264 & 1.43 & $2420205 \mathrm{~V} 2$ & 859 & 3.17 & $2430205 \mathrm{~V} 2$ & 536 & 6.89 \\
\hline $2410205 \mathrm{~V} 3$ & 1264 & 0.29 & $2420205 \mathrm{~V} 3$ & 859 & 0.63 & $2430205 \mathrm{~V} 3$ & 536 & 1.38 \\
\hline $2410205 \mathrm{~V} 4$ & 1264 & 0.14 & $2420205 \mathrm{~V} 4$ & 859 & 0.32 & $2430205 \mathrm{~V} 4$ & 536 & 0.69 \\
\hline $2410220 \mathrm{~V} 1$ & 1698 & 4.63 & $2420220 \mathrm{~V} 1$ & 1203 & 10.72 & $2430220 \mathrm{~V} 1$ & 679 & 22.91 \\
\hline $2410220 \mathrm{~V} 2$ & 1698 & 2.32 & $2420220 \mathrm{~V} 2$ & 1203 & 5.36 & $2430220 \mathrm{~V} 2$ & 679 & 11.46 \\
\hline $2410220 \mathrm{~V} 3$ & 1698 & 0.46 & $2420220 \mathrm{~V} 3$ & 1203 & 1.07 & $2430220 \mathrm{~V} 3$ & 679 & 2.29 \\
\hline $2410220 \mathrm{~V} 4$ & 1698 & 0.23 & $2420220 \mathrm{~V} 4$ & 1203 & 0.54 & $2430220 \mathrm{~V} 4$ & 679 & 1.15 \\
\hline $2411505 \mathrm{~V} 1$ & 1339 & 7.09 & $2421505 \mathrm{~V} 1$ & 859 & 15.79 & $2431505 \mathrm{~V} 1$ & 536 & 34.32 \\
\hline $2411505 \mathrm{~V} 2$ & 1339 & 3.56 & $2421505 \mathrm{~V} 2$ & 859 & 7.92 & $2431505 \mathrm{~V} 2$ & 536 & 17.20 \\
\hline $2411505 \mathrm{~V} 3$ & 1264 & 0.72 & $2421505 \mathrm{~V} 3$ & 859 & 1.59 & $2431505 \mathrm{~V} 3$ & 536 & 3.44 \\
\hline $2411505 \mathrm{~V} 4$ & 1264 & 0.36 & $2421505 \mathrm{~V} 4$ & 859 & 0.79 & $2431505 \mathrm{~V} 4$ & 536 & 1.72 \\
\hline $2411520 \mathrm{~V} 1$ & 1833 & 11.55 & $2421520 \mathrm{~V} 1$ & 1203 & 26.76 & $2431520 \mathrm{~V} 1$ & 679 & 57.19 \\
\hline $2411520 \mathrm{~V} 2$ & 1698 & 5.78 & $2421520 \mathrm{~V} 2$ & 1203 & 13.40 & $2431520 \mathrm{~V} 2$ & 679 & 28.64 \\
\hline $2411520 \mathrm{~V} 3$ & 1698 & 1.16 & $2421520 \mathrm{~V} 3$ & 1203 & 2.68 & $2431520 \mathrm{~V} 3$ & 679 & 5.73 \\
\hline $2411520 \mathrm{~V} 4$ & 1698 & 0.58 & $2421520 \mathrm{~V} 4$ & 1203 & 1.34 & $2431520 \mathrm{~V} 4$ & 679 & 2.87 \\
\hline $2415005 \mathrm{~V} 1$ & 1339 & 14.08 & $2425005 \mathrm{~V} 1$ & 859 & 31.37 & $2435005 \mathrm{~V} 1$ & 566 & 68.05 \\
\hline $2415005 \mathrm{~V} 2$ & 1339 & 7.09 & $2425005 \mathrm{~V} 2$ & 859 & 15.79 & $2435005 \mathrm{~V} 2$ & 536 & 34.32 \\
\hline $2415005 \mathrm{~V} 3$ & 1264 & 1.43 & $2425005 \mathrm{~V} 3$ & 859 & 3.18 & $2435005 \mathrm{~V} 3$ & 536 & 6.89 \\
\hline $2415005 \mathrm{~V} 4$ & 1264 & 0.72 & $2425005 \mathrm{~V} 4$ & 859 & 1.59 & $2435005 \mathrm{~V} 4$ & 536 & 3.44 \\
\hline $2415020 \mathrm{~V} 1$ & 1834 & 22.96 & $2425020 \mathrm{~V} 1$ & 1203 & 53.36 & $2435020 \mathrm{~V} 1$ & 734 & 114.00 \\
\hline $2415020 \mathrm{~V} 2$ & 1834 & 11.55 & $2425020 \mathrm{~V} 2$ & 1203 & 26.76 & $2435020 \mathrm{~V} 2$ & 679 & 57.19 \\
\hline $2415020 \mathrm{~V} 3$ & 1698 & 2.32 & $2425020 \mathrm{~V} 3$ & 1203 & 5.36 & $2435020 \mathrm{~V} 3$ & 679 & 11.46 \\
\hline $2415020 \mathrm{~V} 4$ & 1698 & 1.16 & $2425020 \mathrm{~V} 4$ & 1203 & 2.68 & $2435020 \mathrm{~V} 4$ & 679 & 5.73 \\
\hline
\end{tabular}


Table E. 15 Simulation results for C2L4 design alternative over high hydraulic conductivity aquitards $\left(\mathrm{k}=1 \times 10^{-7} \mathrm{~m} / \mathrm{s}\right)$

\begin{tabular}{|c|c|c|c|c|c|c|c|c|}
\hline \multicolumn{3}{|c|}{ Arid } & \multicolumn{3}{|c|}{ Moderate } & \multicolumn{3}{|c|}{ Humid } \\
\hline Design $^{a}$ & $\begin{array}{l}\mathbf{T}^{\mathbf{b}} \\
(\mathbf{y})\end{array}$ & $\begin{array}{c}\mathrm{C}^{\mathrm{c}} \\
(\mathrm{mg} / \mathrm{L})\end{array}$ & Design & $\begin{array}{c}\mathbf{T} \\
(\mathbf{y})\end{array}$ & $\begin{array}{c}\mathrm{C} \\
(\mathrm{mg} / \mathrm{L})\end{array}$ & Design & $\begin{array}{c}\mathbf{T} \\
(\mathbf{y})\end{array}$ & $\mathrm{C}(\mathrm{mg} / \mathrm{L})$ \\
\hline $2410205 \mathrm{~V} 1$ & 1264 & 2.88 & $2420205 \mathrm{~V} 1$ & 778 & 7.13 & $2430205 \mathrm{~V} 1$ & 457 & 16.04 \\
\hline $2410205 \mathrm{~V} 2$ & 1273 & 1.44 & $2420205 \mathrm{~V} 2$ & 778 & 3.57 & $2430205 \mathrm{~V} 2$ & 457 & 8.02 \\
\hline $2410205 \mathrm{~V} 3$ & 1273 & 0.29 & $2420205 \mathrm{~V} 3$ & 778 & 0.71 & $2430205 \mathrm{~V} 3$ & 457 & 1.6 \\
\hline $2410205 \mathrm{~V} 4$ & 1273 & 0.14 & $2420205 \mathrm{~V} 4$ & 778 & 0.36 & $2430205 \mathrm{~V} 4$ & 457 & 0.80 \\
\hline $2410220 \mathrm{~V} 1$ & 1727 & 4.45 & $2420220 \mathrm{~V} 1$ & 1067 & 11.33 & $2430220 \mathrm{~V} 1$ & 567 & 24.68 \\
\hline $2410220 \mathrm{~V} 2$ & 1727 & 2.23 & $2420220 \mathrm{~V} 2$ & 1067 & 5.66 & $2430220 \mathrm{~V} 2$ & 567 & 12.35 \\
\hline $2410220 \mathrm{~V} 3$ & 1727 & 0.45 & $2420220 \mathrm{~V} 3$ & 1067 & 1.13 & 2430220V3 & 567 & 2.47 \\
\hline $2410220 \mathrm{~V} 4$ & 1727 & 0.22 & $2420220 \mathrm{~V} 4$ & 1067 & 0.57 & $2430220 \mathrm{~V} 4$ & 567 & 1.23 \\
\hline $2411505 \mathrm{~V} 1$ & 1339 & 7.16 & $2421505 \mathrm{~V} 1$ & 778 & 17.79 & $2431505 \mathrm{~V} 1$ & 457 & 40.03 \\
\hline $2411505 \mathrm{~V} 2$ & 1264 & 3.60 & $2421505 \mathrm{~V} 2$ & 778 & 8.91 & $2431505 \mathrm{~V} 2$ & 457 & 20.05 \\
\hline $2411505 \mathrm{~V} 3$ & 1264 & 0.72 & $2421505 \mathrm{~V} 3$ & 778 & 1.78 & $2431505 \mathrm{~V} 3$ & 457 & 4.01 \\
\hline $2411505 \mathrm{~V} 4$ & 1203 & 0.36 & $2421505 \mathrm{~V} 4$ & 778 & 0.89 & $2431505 \mathrm{~V} 4$ & 457 & 2.01 \\
\hline $2411520 \mathrm{~V} 1$ & 1698 & 11.09 & $2421520 \mathrm{~V} 1$ & 1067 & 28.29 & 2431520V1 & 580 & 61.65 \\
\hline $2411520 \mathrm{~V} 2$ & 1698 & 5.55 & 24 & 1067 & 14.16 & 243154 & 567 & 30.85 \\
\hline $2411520 \mathrm{~V} 3$ & 1698 & 1.11 & $2421520 \mathrm{~V} 3$ & 1067 & 2.83 & $2431520 \mathrm{~V} 3$ & 567 & 6.17 \\
\hline $2411520 \mathrm{~V} 4$ & 1698 & 0.56 & $2421520 \mathrm{~V} 4$ & 1067 & 1.42 & 2431520V4 & 567 & 3.09 \\
\hline $2415005 \mathrm{~V} 1$ & 1339 & 14.26 & $2425005 \mathrm{~V} 1$ & 798 & 35.44 & $2435005 \mathrm{~V} 1$ & 457 & 79.43 \\
\hline $2415005 \mathrm{~V} 2$ & 1339 & 7.16 & $2425005 \mathrm{~V} 2$ & 778 & 17.79 & $2435005 \mathrm{~V} 2$ & 457 & 40.03 \\
\hline $2415005 \mathrm{~V} 3$ & 1264 & 1.44 & $2425005 \mathrm{~V} 3$ & 778 & 3.57 & $2435005 \mathrm{~V} 3$ & 457 & 8.02 \\
\hline $2415005 \mathrm{~V} 4$ & 1264 & 0.72 & $2425005 \mathrm{~V} 4$ & 778 & 1.78 & $2435005 \mathrm{~V} 4$ & 457 & 4.01 \\
\hline $2415020 \mathrm{~V} 1$ & 1698 & 22.08 & $2425020 \mathrm{~V} 1$ & 1067 & 56.48 & $2435020 \mathrm{~V} 1$ & 595 & 123.00 \\
\hline $2415020 \mathrm{~V} 2$ & 1698 & 11.09 & $2425020 \mathrm{~V} 2$ & 1067 & 28.29 & $2435020 \mathrm{~V} 2$ & 580 & 61.65 \\
\hline $2415020 \mathrm{~V} 3$ & 1698 & 2.22 & $2425020 \mathrm{~V} 3$ & 1067 & 5.66 & $2435020 \mathrm{~V} 3$ & 566 & 12.34 \\
\hline $2415020 \mathrm{~V} 4$ & 1698 & 1.11 & $2425020 \mathrm{~V} 4$ & 1067 & 2.83 & $2435020 \mathrm{~V} 4$ & 566 & 6.17 \\
\hline
\end{tabular}

${ }^{\mathrm{a}}$ simulation code

${ }^{\mathrm{b}}$ time that maximum concentration occurs

${ }^{c}$ maximum concentration at the groundwater table 
Table E. 16 Simulation results for C2L5 design alternative over low hydraulic conductivity aquitards $\left(\mathrm{k}=1 \times 10^{-8} \mathrm{~m} / \mathrm{s}\right)$

\begin{tabular}{|c|c|c|c|c|c|c|c|c|}
\hline \multicolumn{3}{|c|}{ Arid } & \multicolumn{3}{|c|}{ Moderate } & \multicolumn{3}{|c|}{ Humid } \\
\hline Design $^{a}$ & $\begin{array}{l}\mathbf{T}^{\mathbf{b}} \\
(\mathbf{y})\end{array}$ & $\begin{array}{c}\mathrm{C}^{\mathrm{c}} \\
(\mathrm{mg} / \mathrm{L})\end{array}$ & Design & $\begin{array}{l}\mathbf{T} \\
(\mathbf{y})\end{array}$ & $\begin{array}{c}\mathrm{C} \\
(\mathrm{mg} / \mathrm{L})\end{array}$ & Design & $\begin{array}{c}\mathbf{T} \\
(\mathbf{y})\end{array}$ & $\begin{array}{c}\mathrm{C} \\
(\mathrm{mg} / \mathrm{L})\end{array}$ \\
\hline $2510205 \mathrm{~V} 1$ & 1339 & 2.74 & $2520205 \mathrm{~V} 1$ & 856 & 6.11 & $2530205 \mathrm{~V} 1$ & 536 & 13.33 \\
\hline $2510205 \mathrm{~V} 2$ & 1273 & 1.37 & $2520205 \mathrm{~V} 2$ & 917 & 3.05 & $2530205 \mathrm{~V} 2$ & 536 & 6.67 \\
\hline $2510205 \mathrm{~V} 3$ & 1273 & 0.27 & $2520205 \mathrm{~V} 3$ & 917 & 0.61 & $2530205 \mathrm{~V} 3$ & 536 & 1.34 \\
\hline $2510205 \mathrm{~V} 4$ & 1273 & 0.14 & $2520205 \mathrm{~V} 4$ & 849 & 0.31 & $2530205 \mathrm{~V} 4$ & 536 & 0.67 \\
\hline $2510220 \mathrm{~V} 1$ & 1834 & 4.55 & $2520220 \mathrm{~V} 1$ & 1151 & 10.60 & $2530220 \mathrm{~V} 1$ & 734 & 22.58 \\
\hline $2510220 \mathrm{~V} 2$ & 1834 & 2.28 & $2520220 \mathrm{~V} 2$ & 1151 & 5.28 & $2530220 \mathrm{~V} 2$ & 679 & 11.31 \\
\hline $2510220 \mathrm{~V} 3$ & 1834 & 0.46 & $2520220 \mathrm{~V} 3$ & 1151 & 1.06 & $2530220 \mathrm{~V} 3$ & 679 & 2.26 \\
\hline $2510220 \mathrm{~V} 4$ & 1834 & 0.23 & $2520220 \mathrm{~V} 4$ & 1151 & 0.53 & $2530220 \mathrm{~V} 4$ & 679 & 1.13 \\
\hline $2511505 \mathrm{~V} 1$ & 1273 & 6.81 & $2521505 \mathrm{~V} 1$ & 917 & 15.20 & $2531505 \mathrm{~V} 1$ & 566 & 33.19 \\
\hline $2511505 \mathrm{~V} 2$ & 1273 & 3.42 & $2521505 \mathrm{~V} 2$ & 917 & 7.62 & $2531505 \mathrm{~V} 2$ & 536 & 16.65 \\
\hline $2511505 \mathrm{~V} 3$ & 1273 & 0.69 & $2521505 \mathrm{~V} 3$ & 917 & 1.53 & $2531505 \mathrm{~V} 3$ & 536 & 3.34 \\
\hline $2511505 \mathrm{~V} 4$ & 1273 & 0.34 & $2521505 \mathrm{~V} 4$ & 917 & 0.76 & $2531505 \mathrm{~V} 4$ & 536 & 1.67 \\
\hline $2511520 \mathrm{~V} 1$ & 1834 & 11.34 & $2521520 \mathrm{~V} 1$ & 1273 & 26.34 & $2531520 \mathrm{~V} 1$ & 734 & 56.44 \\
\hline $2511520 \mathrm{~V} 2$ & 1834 & 5.68 & $2521520 \mathrm{~V} 2$ & 1151 & 13.20 & $2531520 \mathrm{~V} 2$ & 734 & 28.22 \\
\hline $2511520 \mathrm{~V} 3$ & 1834 & 1.14 & $2521520 \mathrm{~V} 3$ & 1151 & 2.64 & $2531520 \mathrm{~V} 3$ & 679 & 5.66 \\
\hline $2511520 \mathrm{~V} 4$ & 1834 & 0.57 & $2521520 \mathrm{~V} 4$ & 1151 & 1.32 & $2531520 \mathrm{~V} 4$ & 679 & 2.83 \\
\hline $2515005 \mathrm{~V} 1$ & 1375 & 13.50 & $2525005 \mathrm{~V} 1$ & 902 & 30.30 & $2535005 \mathrm{~V} 1$ & 566 & 66.05 \\
\hline $2515005 \mathrm{~V} 2$ & 1273 & 6.81 & $2525005 \mathrm{~V} 2$ & 917 & 15.22 & $2535005 \mathrm{~V} 2$ & 566 & 33.09 \\
\hline $2515005 \mathrm{~V} 3$ & 1273 & 1.37 & $2525005 \mathrm{~V} 3$ & 917 & 3.05 & $2535005 \mathrm{~V} 3$ & 536 & 6.67 \\
\hline $2515005 \mathrm{~V} 4$ & 1273 & 0.69 & $2525005 \mathrm{~V} 4$ & 917 & 1.53 & $2535005 \mathrm{~V} 4$ & 536 & 3.34 \\
\hline $2515020 \mathrm{~V} 1$ & 1834 & 22.54 & $2525020 \mathrm{~V} 1$ & 1273 & 52.57 & $2535020 \mathrm{~V} 1$ & 734 & 112.70 \\
\hline $2515020 \mathrm{~V} 2$ & 1834 & 11.34 & $2525020 \mathrm{~V} 2$ & 1273 & 26.34 & $2535020 \mathrm{~V} 2$ & 734 & 56.44 \\
\hline $2515020 \mathrm{~V} 3$ & 1834 & 2.28 & $2525020 \mathrm{~V} 3$ & 1151 & 52.28 & $2535020 \mathrm{~V} 3$ & 679 & 11.31 \\
\hline $2515020 \mathrm{~V} 4$ & 1834 & 1.14 & $2525020 \mathrm{~V} 4$ & 1151 & 2.64 & $2535020 \mathrm{~V} 4$ & 679 & 5.66 \\
\hline
\end{tabular}


Table E. 17 Simulation results for C2L5 design alternative over high hydraulic conductivity aquitards $\left(\mathrm{k}=1 \times 10^{-7} \mathrm{~m} / \mathrm{s}\right)$

\begin{tabular}{|c|c|c|c|c|c|c|c|c|}
\hline \multicolumn{3}{|c|}{ Arid } & \multicolumn{3}{|c|}{ Moderate } & \multicolumn{3}{|c|}{ Humid } \\
\hline Design $^{a}$ & $\begin{array}{l}\mathbf{T}^{\mathbf{b}} \\
(\mathbf{y})\end{array}$ & $\begin{array}{c}\mathrm{C}^{\mathrm{c}} \\
(\mathrm{mg} / \mathrm{L})\end{array}$ & Design & $\begin{array}{c}\mathbf{T} \\
(\mathbf{y})\end{array}$ & $\begin{array}{c}\mathrm{C} \\
(\mathrm{mg} / \mathrm{L})\end{array}$ & Design & $\begin{array}{c}\mathbf{T} \\
(\mathbf{y})\end{array}$ & $\begin{array}{c}C \\
(\mathrm{mg} / \mathrm{L})\end{array}$ \\
\hline $2510205 \mathrm{~V} 1$ & 1339 & 2.75 & $2520205 \mathrm{~V} 1$ & 800 & 6.86 & $2530205 \mathrm{~V} 1$ & 457 & 15.47 \\
\hline $2510205 \mathrm{~V} 2$ & 1339 & 1.38 & $2520205 \mathrm{~V} 2$ & 781 & 3.42 & $2530205 \mathrm{~V} 2$ & 457 & 7.74 \\
\hline $2510205 \mathrm{~V} 3$ & 1339 & 0.28 & $2520205 \mathrm{~V} 3$ & 781 & 0.69 & $2530205 \mathrm{~V} 3$ & 457 & 1.55 \\
\hline $2510205 \mathrm{~V} 4$ & 1339 & 0.14 & $2520205 \mathrm{~V} 4$ & 781 & 0.34 & $2530205 \mathrm{~V} 4$ & 457 & 0.77 \\
\hline $2510220 \mathrm{~V} 1$ & 1698 & 4.36 & $2520220 \mathrm{~V} 1$ & 1009 & 11.13 & $2530220 \mathrm{~V} 1$ & 580 & 24.36 \\
\hline $2510220 \mathrm{~V} 2$ & 1698 & 2.18 & $2520220 \mathrm{~V} 2$ & 1009 & 5.57 & $2530220 \mathrm{~V} 2$ & 580 & 12.81 \\
\hline $2510220 \mathrm{~V} 3$ & 1698 & 0.44 & $2520220 \mathrm{~V} 3$ & 1009 & 1.11 & $2530220 \mathrm{~V} 3$ & 580 & 2.44 \\
\hline $2510220 \mathrm{~V} 4$ & 1698 & 0.22 & $2520220 \mathrm{~V} 4$ & 1083 & 0.56 & $2530220 \mathrm{~V} 4$ & 580 & 1.22 \\
\hline $2511505 \mathrm{~V} 1$ & 1339 & 6.86 & $2521505 \mathrm{~V} 1$ & 798 & 17.10 & $2531505 \mathrm{~V} 1$ & 457 & 38.54 \\
\hline $2511505 \mathrm{~V} 2$ & 1339 & 3.44 & $2521505 \mathrm{~V} 2$ & 798 & 8.57 & $2531505 \mathrm{~V} 2$ & 457 & 19.33 \\
\hline $2511505 \mathrm{~V} 3$ & 1339 & 0.69 & $2521505 \mathrm{~V} 3$ & 798 & 1.72 & $2531505 \mathrm{~V} 3$ & 457 & 3.87 \\
\hline $2511505 \mathrm{~V} 4$ & 1339 & 0.34 & 2521 & 798 & 0.86 & $\mathrm{v} 4$ & 457 & 1.94 \\
\hline $2511520 \mathrm{~V} 1$ & 1698 & 10.88 & $2521520 \mathrm{~V} 1$ & 1009 & 27.78 & $2531520 \mathrm{~V} 1$ & 580 & 6.83 \\
\hline $2511520 \mathrm{~V} 2$ & 1698 & 5.45 & $2521520 \mathrm{~V} 2$ & 1009 & 13.91 & $2531520 \mathrm{~V} 2$ & 580 & 30.45 \\
\hline $2511520 \mathrm{~V} 3$ & 1698 & 1.09 & $2521520 \mathrm{~V} 3$ & 1009 & 2.79 & $2531520 \mathrm{~V} 3$ & 580 & 6.09 \\
\hline $2511520 \mathrm{~V} 4$ & 1698 & 0.55 & $2521520 \mathrm{~V} 4$ & 1009 & 1.39 & $2531520 \mathrm{~V} 4$ & 580 & 3.05 \\
\hline $2515005 \mathrm{~V} 1$ & 1339 & 13.65 & $2525005 \mathrm{~V} 1$ & 818 & 34.07 & $2535005 \mathrm{~V} 1$ & 481 & 76.75 \\
\hline $2515005 \mathrm{~V} 2$ & 1339 & 6.86 & $2525005 \mathrm{~V} 2$ & 798 & 17.10 & $2535005 \mathrm{~V} 2$ & 457 & 38.54 \\
\hline $2515005 \mathrm{~V} 3$ & 1339 & 1.38 & $2525005 \mathrm{~V} 3$ & 798 & 8.43 & $2535005 \mathrm{~V} 3$ & 457 & 7.74 \\
\hline $2515005 \mathrm{~V} 4$ & 1339 & 0.69 & $2525005 \mathrm{~V} 4$ & 798 & 1.72 & $2535005 \mathrm{~V} 4$ & 457 & 3.87 \\
\hline $2515020 \mathrm{~V} 1$ & 1834 & 21.73 & $2525020 \mathrm{~V} 1$ & 1009 & 55.35 & $2535020 \mathrm{~V} 1$ & 625 & 121.19 \\
\hline $2515020 \mathrm{~V} 2$ & 1698 & 10.88 & $2525020 \mathrm{~V} 2$ & 1009 & 27.78 & $2535020 \mathrm{~V} 2$ & 580 & 6.83 \\
\hline $2515020 \mathrm{~V} 3$ & 1698 & 2.18 & $2525020 \mathrm{~V} 3$ & 1009 & 5.57 & $2535020 \mathrm{~V} 3$ & 580 & 12.18 \\
\hline $2515020 \mathrm{~V} 4$ & 1698 & 1.09 & $2525020 \mathrm{~V} 4$ & 1009 & 2.79 & $2535020 \mathrm{~V} 4$ & 580 & 6.09 \\
\hline
\end{tabular}


Table E. 18 Simulation results for C2L6 design alternative over low hydraulic conductivity aquitards $\left(\mathrm{k}=1 \times 10^{-8} \mathrm{~m} / \mathrm{s}\right)$

\begin{tabular}{|c|c|c|c|c|c|c|c|c|}
\hline \multicolumn{3}{|c|}{ Arid } & \multicolumn{3}{|c|}{ Moderate } & \multicolumn{3}{|c|}{ Humid } \\
\hline Design $^{a}$ & $\begin{array}{l}\mathbf{T}^{\mathbf{b}} \\
(\mathbf{y})\end{array}$ & $\begin{array}{c}\mathrm{C}^{\mathrm{c}} \\
(\mathrm{mg} / \mathrm{L})\end{array}$ & Design & $\begin{array}{l}\mathbf{T} \\
(\mathbf{y})\end{array}$ & $\begin{array}{c}\mathrm{C} \\
(\mathrm{mg} / \mathrm{L})\end{array}$ & Design & $\begin{array}{c}\mathbf{T} \\
(\mathbf{y})\end{array}$ & $\begin{array}{c}\mathrm{C} \\
(\mathrm{mg} / \mathrm{L})\end{array}$ \\
\hline $2610205 \mathrm{~V} 1$ & 1339 & 2.74 & $2620205 \mathrm{~V} 1$ & 856 & 6.11 & $2630205 \mathrm{~V} 1$ & 536 & 13.33 \\
\hline $2610205 \mathrm{~V} 2$ & 1273 & 1.37 & $2620205 \mathrm{~V} 2$ & 917 & 3.05 & $2630205 \mathrm{~V} 2$ & 536 & 6.67 \\
\hline $2610205 \mathrm{~V} 3$ & 1273 & 0.27 & $2620205 \mathrm{~V} 3$ & 917 & 0.61 & $2630205 \mathrm{~V} 3$ & 536 & 1.34 \\
\hline $2610205 \mathrm{~V} 4$ & 1273 & 0.14 & $2620205 \mathrm{~V} 4$ & 849 & 0.31 & $2630205 \mathrm{~V} 4$ & 536 & 0.67 \\
\hline $2610220 \mathrm{~V} 1$ & 1834 & 4.55 & $2620220 \mathrm{~V} 1$ & 1151 & 10.60 & $2630220 \mathrm{~V} 1$ & 734 & 22.58 \\
\hline $2610220 \mathrm{~V} 2$ & 1834 & 2.28 & $2620220 \mathrm{~V} 2$ & 1151 & 5.28 & $2630220 \mathrm{~V} 2$ & 679 & 11.31 \\
\hline $2610220 \mathrm{~V} 3$ & 1834 & 0.46 & $2620220 \mathrm{~V} 3$ & 1151 & 1.06 & $2630220 \mathrm{~V} 3$ & 679 & 2.26 \\
\hline $2610220 \mathrm{~V} 4$ & 1834 & 0.23 & $2620220 \mathrm{~V} 4$ & 1151 & 0.53 & $2630220 \mathrm{~V} 4$ & 679 & 1.13 \\
\hline $2611505 \mathrm{~V} 1$ & 1273 & 6.81 & $2621505 \mathrm{~V} 1$ & 917 & 15.20 & $2631505 \mathrm{~V} 1$ & 566 & 33.19 \\
\hline $2611505 \mathrm{~V} 2$ & 1273 & 3.42 & $2621505 \mathrm{~V} 2$ & 917 & 7.62 & $2631505 \mathrm{~V} 2$ & 536 & 16.65 \\
\hline $2611505 \mathrm{~V} 3$ & 1273 & 0.69 & $2621505 \mathrm{~V} 3$ & 917 & 1.53 & $2631505 \mathrm{~V} 3$ & 536 & 3.34 \\
\hline $2611505 \mathrm{~V} 4$ & 1273 & 0.34 & $2621505 \mathrm{~V} 4$ & 917 & 0.76 & $2631505 \mathrm{~V} 4$ & 536 & 1.67 \\
\hline $2611520 \mathrm{~V} 1$ & 1834 & 11.34 & $2621520 \mathrm{~V} 1$ & 1273 & 26.34 & $2631520 \mathrm{~V} 1$ & 734 & 56.44 \\
\hline $2611520 \mathrm{~V} 2$ & 1834 & 5.68 & $2621520 \mathrm{~V} 2$ & 1151 & 13.20 & $2631520 \mathrm{~V} 2$ & 734 & 28.22 \\
\hline $2611520 \mathrm{~V} 3$ & 1834 & 1.14 & $2621520 \mathrm{~V} 3$ & 1151 & 2.64 & $2631520 \mathrm{~V} 3$ & 679 & 5.66 \\
\hline $2611520 \mathrm{~V} 4$ & 1834 & 0.57 & $2621520 \mathrm{~V} 4$ & 1151 & 1.32 & $2631520 \mathrm{~V} 4$ & 679 & 2.83 \\
\hline $2615005 \mathrm{~V} 1$ & 1375 & 13.50 & $2625005 \mathrm{~V} 1$ & 902 & 30.30 & $2635005 \mathrm{~V} 1$ & 566 & 66.05 \\
\hline $2615005 \mathrm{~V} 2$ & 1273 & 6.81 & $2625005 \mathrm{~V} 2$ & 917 & 15.22 & $2635005 \mathrm{~V} 2$ & 566 & 33.09 \\
\hline $2615005 \mathrm{~V} 3$ & 1273 & 1.37 & $2625005 \mathrm{~V} 3$ & 917 & 3.05 & $2635005 \mathrm{~V} 3$ & 536 & 6.67 \\
\hline $2615005 \mathrm{~V} 4$ & 1273 & 0.69 & $2625005 \mathrm{~V} 4$ & 917 & 1.53 & $2635005 \mathrm{~V} 4$ & 536 & 3.34 \\
\hline $2615020 \mathrm{~V} 1$ & 1834 & 22.54 & $2625020 \mathrm{~V} 1$ & 1273 & 52.57 & $2635020 \mathrm{~V} 1$ & 734 & 112.70 \\
\hline $2615020 \mathrm{~V} 2$ & 1834 & 11.34 & $2625020 \mathrm{~V} 2$ & 1273 & 26.34 & $2635020 \mathrm{~V} 2$ & 734 & 56.44 \\
\hline $2615020 \mathrm{~V} 3$ & 1834 & 2.28 & $2625020 \mathrm{~V} 3$ & 1151 & 52.28 & $2635020 \mathrm{~V} 3$ & 679 & 11.31 \\
\hline $2615020 \mathrm{~V} 4$ & 1834 & 1.14 & $2625020 \mathrm{~V} 4$ & 1151 & 2.64 & $2635020 \mathrm{~V} 4$ & 679 & 5.66 \\
\hline
\end{tabular}


Table E. 19 Simulation results for C2L6 design alternative over high hydraulic conductivity aquitards $\left(\mathrm{k}=1 \times 10^{-7} \mathrm{~m} / \mathrm{s}\right)$

\begin{tabular}{|c|c|c|c|c|c|c|c|c|}
\hline \multicolumn{3}{|c|}{ Arid } & \multicolumn{3}{|c|}{ Moderate } & \multicolumn{3}{|c|}{ Humid } \\
\hline Design $^{a}$ & $\begin{array}{l}\mathbf{T}^{\mathbf{b}} \\
(\mathbf{y})\end{array}$ & $\begin{array}{c}\mathrm{C}^{\mathrm{c}} \\
(\mathrm{mg} / \mathrm{L})\end{array}$ & Design & $\begin{array}{l}\text { T } \\
(\mathbf{y})\end{array}$ & $\begin{array}{c}C \\
(\mathrm{mg} / \mathrm{L})\end{array}$ & Design & $\begin{array}{c}\mathbf{T} \\
(\mathbf{y})\end{array}$ & $\begin{array}{c}\mathrm{C} \\
(\mathrm{mg} / \mathrm{L})\end{array}$ \\
\hline $2610205 \mathrm{~V} 1$ & 1339 & 2.75 & $2620205 \mathrm{~V} 1$ & 800 & 6.86 & $2630205 \mathrm{~V} 1$ & 457 & 15.47 \\
\hline $2610205 \mathrm{~V} 2$ & 1339 & 1.38 & $2620205 \mathrm{~V} 2$ & 781 & 3.42 & $2630205 \mathrm{~V} 2$ & 457 & 7.74 \\
\hline $2610205 \mathrm{~V} 3$ & 1339 & 0.28 & $2620205 \mathrm{~V} 3$ & 781 & 0.69 & $2630205 \mathrm{~V} 3$ & 457 & 1.55 \\
\hline $2610205 \mathrm{~V} 4$ & 1339 & 0.14 & $2620205 \mathrm{~V} 4$ & 781 & 0.34 & $2630205 \mathrm{~V} 4$ & 457 & 0.77 \\
\hline $2610220 \mathrm{~V} 1$ & 1698 & 4.36 & $2620220 \mathrm{~V} 1$ & 1009 & 11.13 & $2630220 \mathrm{~V} 1$ & 580 & 24.36 \\
\hline 2610220V2 & 1698 & 2.18 & 2620220V2 & 1009 & 5.57 & 2630220V2 & 580 & 12.81 \\
\hline $2610220 \mathrm{~V} 3$ & 1698 & 0.44 & $2620220 \mathrm{~V} 3$ & 1009 & 1.11 & $2630220 \mathrm{~V} 3$ & 580 & 2.44 \\
\hline $2610220 \mathrm{~V} 4$ & 1698 & 0.22 & $2620220 \mathrm{~V} 4$ & 1083 & 0.56 & $2630220 \mathrm{~V} 4$ & 580 & 1.22 \\
\hline $2611505 \mathrm{~V} 1$ & 1339 & 6.86 & $2621505 \mathrm{~V} 1$ & 798 & 17.10 & $2631505 \mathrm{~V} 1$ & 457 & 38.54 \\
\hline $2611505 \mathrm{~V} 2$ & 1339 & 3.44 & $05 \mathrm{~V} 2$ & 798 & 8.57 & $2631505 \mathrm{~V} 2$ & 457 & 19.33 \\
\hline $2611505 \mathrm{~V} 3$ & 1339 & 0.69 & $2621505 \mathrm{~V} 3$ & 798 & 1.72 & $2631505 \mathrm{~V} 3$ & 457 & 3.87 \\
\hline $2611505 \mathrm{~V} 4$ & 1339 & 0.34 & $2621505 \mathrm{~V} 4$ & 798 & 0.86 & $2631505 \mathrm{~V} 4$ & 457 & 1.94 \\
\hline $2611520 \mathrm{~V} 1$ & 1698 & 10.88 & $2621520 \mathrm{~V} 1$ & 1009 & 27.78 & $2631520 \mathrm{~V} 1$ & 580 & 6.83 \\
\hline 2611520V2 & 1698 & 5.45 & $2621520 \mathrm{~V} 2$ & 1009 & 13.91 & $2631520 \mathrm{~V} 2$ & 580 & 30.45 \\
\hline $2611520 \mathrm{~V} 3$ & 1698 & 1.09 & $2621520 \mathrm{~V} 3$ & 1009 & 2.79 & $2631520 \mathrm{~V} 3$ & 580 & 6.09 \\
\hline $2611520 \mathrm{~V} 4$ & 1698 & 0.55 & $2621520 \mathrm{~V} 4$ & 1009 & 1.39 & $2631520 \mathrm{~V} 4$ & 580 & 3.05 \\
\hline $2615005 \mathrm{~V} 1$ & 1339 & 13.65 & $2625005 \mathrm{~V} 1$ & 818 & 34.07 & $2635005 \mathrm{~V} 1$ & 481 & 76.75 \\
\hline $2615005 \mathrm{~V} 2$ & 1339 & 6.86 & $2625005 \mathrm{~V} 2$ & 798 & 17.10 & $2635005 \mathrm{~V} 2$ & 457 & 38.54 \\
\hline $2615005 \mathrm{~V} 3$ & 1339 & 1.38 & $2625005 \mathrm{~V} 3$ & 798 & 8.43 & $2635005 \mathrm{~V} 3$ & 457 & 7.74 \\
\hline $2615005 \mathrm{~V} 4$ & 1339 & 0.69 & $2625005 \mathrm{~V} 4$ & 798 & 1.72 & $2635005 \mathrm{~V} 4$ & 457 & 3.87 \\
\hline $2615020 \mathrm{~V} 1$ & 1834 & 21.73 & $2625020 \mathrm{~V} 1$ & 1009 & 55.35 & $2635020 \mathrm{~V} 1$ & 625 & 121.19 \\
\hline $2615020 \mathrm{~V} 2$ & 1698 & 10.88 & 2625020V2 & 1009 & 27.78 & 2635020V2 & 580 & 6.83 \\
\hline $2615020 \mathrm{~V} 3$ & 1698 & 2.18 & $2625020 \mathrm{~V} 3$ & 1009 & 5.57 & $2635020 \mathrm{~V} 3$ & 580 & 12.18 \\
\hline $2615020 \mathrm{~V} 4$ & 1698 & 1.09 & $2625020 \mathrm{~V} 4$ & 1009 & 2.79 & $2635020 \mathrm{~V} 4$ & 580 & 6.09 \\
\hline
\end{tabular}


Table E. 20 Simulation results for C3L1 design alternative

\begin{tabular}{|c|c|c|c|c|c|c|c|c|}
\hline \multicolumn{3}{|c|}{ Arid } & \multicolumn{3}{|c|}{ Moderate } & \multicolumn{3}{|c|}{ Humid } \\
\hline Design $^{a}$ & $\begin{array}{l}\mathbf{T}^{\mathbf{b}} \\
(\mathbf{y})\end{array}$ & $\begin{array}{c}\mathrm{C}^{\mathrm{c}} \\
(\mathrm{mg} / \mathrm{L})\end{array}$ & Design & $\begin{array}{l}\mathbf{T} \\
(\mathbf{y})\end{array}$ & $\begin{array}{c}\mathrm{C} \\
(\mathrm{mg} / \mathrm{L})\end{array}$ & Design & $\begin{array}{l}\mathbf{T} \\
(\mathbf{y})\end{array}$ & $\begin{array}{c}\mathrm{C} \\
(\mathrm{mg} / \mathrm{L})\end{array}$ \\
\hline $3110205 \mathrm{~V} 1$ & 123 & 92.00 & $3120205 \mathrm{~V} 1$ & 24.5 & 515.10 & $3130205 \mathrm{~V} 1$ & 10 & 570.60 \\
\hline $3110205 \mathrm{~V} 2$ & 119 & 46.30 & $3120205 \mathrm{~V} 2$ & 23 & 298.00 & $3130205 \mathrm{~V} 2$ & 10 & 570.60 \\
\hline $3110205 \mathrm{~V} 3$ & 119 & 9.30 & $3120205 \mathrm{~V} 3$ & 21 & 65.80 & $3130205 \mathrm{~V} 3$ & 9 & 162.10 \\
\hline $3110205 \mathrm{~V} 4$ & 119 & 4.60 & $3120205 \mathrm{~V} 4$ & 21 & 32.94 & $3130205 \mathrm{~V} 4$ & 9 & 84.20 \\
\hline $3110220 \mathrm{~V} 1$ & 142 & 133.10 & $3120220 \mathrm{~V} 1$ & 29 & 717.10 & $3130220 \mathrm{~V} 1$ & 12 & 795.80 \\
\hline $3110220 \mathrm{~V} 2$ & 134 & 66.90 & $3120220 \mathrm{~V} 2$ & 25 & 386.00 & $3130220 \mathrm{~V} 2$ & 12 & 795.80 \\
\hline $3110220 \mathrm{~V} 3$ & 134 & 13.40 & $3120220 \mathrm{~V} 3$ & 22 & 80.90 & $3130220 \mathrm{~V} 3$ & 9.5 & 192.90 \\
\hline $3110220 \mathrm{~V} 4$ & 134 & 6.70 & $3120220 \mathrm{~V} 4$ & 22 & 40.50 & $3130220 \mathrm{~V} 4$ & 9 & 97.90 \\
\hline $3111505 \mathrm{~V} 1$ & 127 & 222.70 & $3121505 \mathrm{~V} 1$ & 25 & 556.70 & $3131505 \mathrm{~V} 1$ & 10 & 570.90 \\
\hline $3111505 \mathrm{~V} 2$ & 123 & 114.60 & $3121505 \mathrm{~V} 2$ & 25 & 556.70 & $3131505 \mathrm{~V} 2$ & 10 & 570.90 \\
\hline $3111505 \mathrm{~V} 3$ & 119 & 23.20 & $3121505 \mathrm{~V} 3$ & 22 & 160.00 & $3131505 \mathrm{~V} 3$ & 10 & 354.60 \\
\hline $3111505 \mathrm{~V} 4$ & 119 & 11.60 & $3121505 \mathrm{~V} 4$ & 21 & 82.00 & $3131505 \mathrm{~V} 4$ & 9 & 198.00 \\
\hline $3111520 \mathrm{~V} 1$ & 145 & 329.00 & 31 & 29 & 790.60 & $\mathrm{~V} 1$ & 12 & 795.80 \\
\hline $3111520 \mathrm{~V} 2$ & 141 & 166.30 & $3121520 \mathrm{~V} 2$ & 29 & 790.60 & $3131520 \mathrm{~V} 2$ & 12 & 795.80 \\
\hline $3111520 \mathrm{~V} 3$ & 134 & 33.40 & $3121520 \mathrm{~V} 3$ & 24 & 199.30 & $3131520 \mathrm{~V} 3$ & 11 & 753.49 \\
\hline $3111520 \mathrm{~V} 4$ & 134 & 16.70 & $3121520 \mathrm{~V} 4$ & 22 & 101.10 & $3131520 \mathrm{~V} 4$ & 10 & 238.60 \\
\hline $3115005 \mathrm{~V} 1$ & 138 & 409.60 & $3125005 \mathrm{~V} 1$ & 25 & 556.80 & $3135005 \mathrm{~V} 1$ & 10 & 570.80 \\
\hline $3115005 \mathrm{~V} 2$ & 127 & 222.70 & $3125005 \mathrm{~V} 2$ & 25 & 556.80 & $3135005 \mathrm{~V} 2$ & 10 & 570.80 \\
\hline $3115005 \mathrm{~V} 3$ & 119 & 46.30 & 312 & 23 & 298.00 & $3135005 \mathrm{~V} 3$ & 10 & 570.80 \\
\hline $3115005 \mathrm{~V} 4$ & 119 & 23.20 & $3125005 \mathrm{~V} 4$ & 22 & 160.00 & $3135005 \mathrm{~V} 4$ & 10 & 354.60 \\
\hline $3115020 \mathrm{~V} 1$ & 156 & 630.40 & $3125020 \mathrm{~V} 1$ & 29 & 790.60 & $3135020 \mathrm{~V} 1$ & 12 & 795.60 \\
\hline $3115020 \mathrm{~V} 2$ & 145 & 330.00 & $3125020 \mathrm{~V} 2$ & 29 & 790.60 & $3135020 \mathrm{~V} 2$ & 12 & 795.60 \\
\hline $3115020 \mathrm{~V} 3$ & 134 & 66.90 & $3125020 \mathrm{~V} 3$ & 25 & 386.00 & $3135020 \mathrm{~V} 3$ & 12 & 795.60 \\
\hline $3115020 \mathrm{~V} 4$ & 134 & 33.40 & $3125020 \mathrm{~V} 4$ & 24 & 199.30 & $3135020 \mathrm{~V} 4$ & 11 & 453.90 \\
\hline
\end{tabular}


Table E. 21 Simulation results for C3L2 design alternative

\begin{tabular}{|c|c|c|c|c|c|c|c|c|}
\hline \multicolumn{3}{|c|}{ Arid } & \multicolumn{3}{|c|}{ Moderate } & \multicolumn{3}{|c|}{ Humid } \\
\hline Design $^{a}$ & $\begin{array}{l}\mathbf{T}^{\mathbf{b}} \\
(\mathbf{y})\end{array}$ & $\begin{array}{c}\mathrm{C}^{\mathrm{c}} \\
(\mathrm{mg} / \mathrm{L})\end{array}$ & Design & $\begin{array}{l}\mathbf{T} \\
(\mathbf{y})\end{array}$ & $\begin{array}{c}C \\
(\mathrm{mg} / \mathrm{L})\end{array}$ & Design & $\begin{array}{l}\mathbf{T} \\
(\mathbf{y})\end{array}$ & $\begin{array}{c}\mathrm{C} \\
(\mathrm{mg} / \mathrm{L})\end{array}$ \\
\hline $3210205 \mathrm{~V} 1$ & 207 & 1.79 & $3220205 \mathrm{~V} 1$ & 218 & 4.14 & $3230205 \mathrm{~V} 1$ & 212 & 1.79 \\
\hline $3210205 \mathrm{~V} 2$ & 207 & 0.90 & $3220205 \mathrm{~V} 2$ & 312 & 2.07 & $3230205 \mathrm{~V} 2$ & 206 & 0.90 \\
\hline $3210205 \mathrm{~V} 3$ & 207 & 0.18 & $3220205 \mathrm{~V} 3$ & 312 & 0.42 & $3230205 \mathrm{~V} 3$ & 206 & 0.18 \\
\hline $3210205 \mathrm{~V} 4$ & 207 & 0.09 & $3220205 \mathrm{~V} 4$ & 312 & 0.21 & $3230205 \mathrm{~V} 4$ & 206 & 0.09 \\
\hline $3210220 \mathrm{~V} 1$ & 222 & 6.80 & $3220220 \mathrm{~V} 1$ & 246 & 13.86 & $3230220 \mathrm{~V} 1$ & 223 & 6.81 \\
\hline $3210220 \mathrm{~V} 2$ & 222 & 3.41 & $3220220 \mathrm{~V} 2$ & 246 & 6.94 & $3230220 \mathrm{~V} 2$ & 223 & 3.41 \\
\hline $3210220 \mathrm{~V} 3$ & 222 & 0.68 & $3220220 \mathrm{~V} 3$ & 239.5 & 1.39 & $3230220 \mathrm{~V} 3$ & 223 & 0.68 \\
\hline $3210220 \mathrm{~V} 4$ & 221 & 0.34 & $3220220 \mathrm{~V} 4$ & 239.5 & 0.69 & $3230220 \mathrm{~V} 4$ & 223 & 0.34 \\
\hline $3211505 \mathrm{~V} 1$ & 214 & 4.41 & $3221505 \mathrm{~V} 1$ & 232 & 10.21 & $3231505 \mathrm{~V} 1$ & 218.5 & 4.40 \\
\hline $3211505 \mathrm{~V} 2$ & 211 & 2.23 & $3221505 \mathrm{~V} 2$ & 218 & 5.16 & $3231505 \mathrm{~V} 2$ & 212 & 2.23 \\
\hline $3211505 \mathrm{~V} 3$ & 207 & 0.45 & $3221505 \mathrm{~V} 3$ & 212 & 1.04 & $3231505 \mathrm{~V} 3$ & 206 & 0.45 \\
\hline $3211505 \mathrm{~V} 4$ & 207 & 0.22 & $3221505 \mathrm{~V} 4$ & 212 & 0.52 & $3231505 \mathrm{~V} 4$ & 206 & 0.22 \\
\hline $3211520 \mathrm{~V} 1$ & 229 & 16.80 & $3221520 \mathrm{~V} 1$ & 252 & 34.31 & $3231520 \mathrm{~V} 1$ & 229 & 16.81 \\
\hline $3211520 \mathrm{~V} 2$ & 229 & 8.48 & $3221520 \mathrm{~V} 2$ & 246 & 17.31 & $3231520 \mathrm{~V} 2$ & 223 & 8.49 \\
\hline $3211520 \mathrm{~V} 3$ & 222 & 1.71 & $3221520 \mathrm{~V} 3$ & 246 & 3.47 & $3231520 \mathrm{~V} 3$ & 223 & 1.71 \\
\hline $3211520 \mathrm{~V} 4$ & 222 & 0.85 & $3221520 \mathrm{~V} 4$ & 239.5 & 0.17 & $3231520 \mathrm{~V} 4$ & 223 & 0.85 \\
\hline $3215005 \mathrm{~V} 1$ & 229 & 8.45 & $3225005 \mathrm{~V} 1$ & 229 & 19.61 & $3235005 \mathrm{~V} 1$ & 223 & 0.46 \\
\hline $3215005 \mathrm{~V} 2$ & 214 & 4.41 & $3225005 \mathrm{~V} 2$ & 223 & 10.21 & $3235005 \mathrm{~V} 2$ & 218.5 & 4.40 \\
\hline $3215005 \mathrm{~V} 3$ & 207 & 0.90 & $3225005 \mathrm{~V} 3$ & 212 & 2.07 & $3235005 \mathrm{~V} 3$ & 206 & 0.90 \\
\hline $3215005 \mathrm{~V} 4$ & 207 & 0.45 & $3225005 \mathrm{~V} 4$ & 212 & 1.04 & $3235005 \mathrm{~V} 4$ & 206 & 0.45 \\
\hline $3215020 \mathrm{~V} 1$ & 240.5 & 32.40 & $3225020 \mathrm{~V} 1$ & 264 & 66.57 & $3235020 \mathrm{~V} 1$ & 239.5 & 32.39 \\
\hline $3215020 \mathrm{~V} 2$ & 229 & 16.80 & $3225020 \mathrm{~V} 2$ & 252 & 34.31 & $3235020 \mathrm{~V} 2$ & 229 & 16.81 \\
\hline $3215020 \mathrm{~V} 3$ & 222 & 3.41 & $3225020 \mathrm{~V} 3$ & 246 & 6.94 & $3235020 \mathrm{~V} 3$ & 223 & 3.41 \\
\hline $3215020 \mathrm{~V} 4$ & 222 & 1.71 & $3225020 \mathrm{~V} 4$ & 246 & 3.47 & $3235020 \mathrm{~V} 4$ & 223 & 1.71 \\
\hline
\end{tabular}


Table E. 22 Simulation results for C3L3 design alternative

\begin{tabular}{|c|c|c|c|c|c|c|c|c|}
\hline \multicolumn{3}{|c|}{ Arid } & \multicolumn{3}{|c|}{ Moderate } & \multicolumn{3}{|c|}{ Humid } \\
\hline Design $^{a}$ & $\begin{array}{l}\mathbf{T}^{\mathbf{b}} \\
(\mathbf{y})\end{array}$ & $\begin{array}{c}\mathrm{C}^{\mathrm{c}} \\
(\mathrm{mg} / \mathrm{L})\end{array}$ & Design & $\begin{array}{l}\mathbf{T} \\
(\mathbf{y})\end{array}$ & $\begin{array}{c}\mathrm{C} \\
(\mathrm{mg} / \mathrm{L})\end{array}$ & Design & $\begin{array}{l}\mathbf{T} \\
(\mathbf{y})\end{array}$ & $\begin{array}{c}\mathrm{C} \\
(\mathrm{mg} / \mathrm{L})\end{array}$ \\
\hline $3310205 \mathrm{~V} 1$ & 123 & 92.00 & $3320205 \mathrm{~V} 1$ & 24.5 & 515.10 & $3330205 \mathrm{~V} 1$ & 18 & 447.40 \\
\hline $3310205 \mathrm{~V} 2$ & 119 & 46.30 & $3320205 \mathrm{~V} 2$ & 23 & 298.00 & $3330205 \mathrm{~V} 2$ & 17 & 313.40 \\
\hline $3310205 \mathrm{~V} 3$ & 119 & 9.30 & $3320205 \mathrm{~V} 3$ & 21 & 65.80 & $3330205 \mathrm{~V} 3$ & 16 & 77.00 \\
\hline $3310205 \mathrm{~V} 4$ & 119 & 4.60 & $3320205 \mathrm{~V} 4$ & 21 & 32.94 & $3330205 \mathrm{~V} 4$ & 15 & 39.00 \\
\hline $3310220 \mathrm{~V} 1$ & 142 & 133.10 & $3320220 \mathrm{~V} 1$ & 29 & 717.10 & $3330220 \mathrm{~V} 1$ & 20 & 710.30 \\
\hline $3310220 \mathrm{~V} 2$ & 134 & 66.90 & $3320220 \mathrm{~V} 2$ & 25 & 386.00 & $3330220 \mathrm{~V} 2$ & 19 & 461.00 \\
\hline $3310220 \mathrm{~V} 3$ & 134 & 13.40 & $3320220 \mathrm{~V} 3$ & 22 & 80.90 & $3330220 \mathrm{~V} 3$ & 16 & 102.50 \\
\hline $3310220 \mathrm{~V} 4$ & 134 & 6.70 & $3320220 \mathrm{~V} 4$ & 22 & 40.50 & $3330220 \mathrm{~V} 4$ & 16 & 51.50 \\
\hline $3311505 \mathrm{~V} 1$ & 127 & 222.70 & $3321505 \mathrm{~V} 1$ & 25 & 556.70 & $3331505 \mathrm{~V} 1$ & 18 & 448.00 \\
\hline $3311505 \mathrm{~V} 2$ & 123 & 114.60 & $3321505 \mathrm{~V} 2$ & 25 & 556.70 & $3331505 \mathrm{~V} 2$ & 18 & 448.00 \\
\hline $3311505 \mathrm{~V} 3$ & 119 & 23.20 & $3321505 \mathrm{~V} 3$ & 22 & 160.00 & $3331505 \mathrm{~V} 3$ & 16 & 180.00 \\
\hline $3311505 \mathrm{~V} 4$ & 119 & 11.60 & $3321505 \mathrm{~V} 4$ & 21 & 82.00 & $3331505 \mathrm{~V} 4$ & 15.5 & 95.20 \\
\hline $3311520 \mathrm{~V} 1$ & 145 & 329.00 & $3321520 \mathrm{~V} 1$ & 29 & 790.60 & $3331520 \mathrm{~V} 1$ & 20 & 710.20 \\
\hline $3311520 \mathrm{~V} 2$ & 141 & 166.30 & $3321520 \mathrm{~V} 2$ & 29 & 790.60 & $3331520 \mathrm{~V} 2$ & 20 & 710.20 \\
\hline $3311520 \mathrm{~V} 3$ & 134 & 33.40 & $3321520 \mathrm{~V} 3$ & 24 & 199.30 & $3331520 \mathrm{~V} 3$ & 17 & 247.90 \\
\hline $3311520 \mathrm{~V} 4$ & 134 & 16.70 & $3321520 \mathrm{~V} 4$ & 22 & 101.10 & $3331520 \mathrm{~V} 4$ & 17 & 127.40 \\
\hline $3315005 \mathrm{~V} 1$ & 138 & 409.60 & $3325005 \mathrm{~V} 1$ & 25 & 556.80 & $3335005 \mathrm{~V} 1$ & 18 & 448.00 \\
\hline $3315005 \mathrm{~V} 2$ & 127 & 222.70 & $3325005 \mathrm{~V} 2$ & 25 & 556.80 & $3335005 \mathrm{~V} 2$ & 18 & 448.00 \\
\hline $3315005 \mathrm{~V} 3$ & 119 & 46.30 & $3325005 \mathrm{~V} 3$ & 23 & 298.00 & $3335005 \mathrm{~V} 3$ & 17 & 313.90 \\
\hline $3315005 \mathrm{~V} 4$ & 119 & 23.20 & $3325005 \mathrm{~V} 4$ & 22 & 160.00 & $3335005 \mathrm{~V} 4$ & 16 & 180.00 \\
\hline $3315020 \mathrm{~V} 1$ & 156 & 630.40 & $3325020 \mathrm{~V} 1$ & 29 & 790.60 & $3335020 \mathrm{~V} 1$ & 20 & 710.30 \\
\hline $3315020 \mathrm{~V} 2$ & 145 & 330.00 & $3325020 \mathrm{~V} 2$ & 29 & 790.60 & $3335020 \mathrm{~V} 2$ & 20 & 710.30 \\
\hline $3315020 \mathrm{~V} 3$ & 134 & 66.90 & $3325020 \mathrm{~V} 3$ & 25 & 386.00 & $3335020 \mathrm{~V} 3$ & 19 & 461.00 \\
\hline $3315020 \mathrm{~V} 4$ & 134 & 33.40 & $3325020 \mathrm{~V} 4$ & 24 & 199.30 & $3335020 \mathrm{~V} 4$ & 17 & 247.90 \\
\hline
\end{tabular}


Table E. 23 Simulation results for C3L4 design alternative over low hydraulic conductivity aquitards $\left(\mathrm{k}=1 \times 10^{-8} \mathrm{~m} / \mathrm{s}\right)$

\begin{tabular}{|c|c|c|c|c|c|c|c|c|}
\hline \multicolumn{3}{|c|}{ Arid } & \multicolumn{3}{|c|}{ Moderate } & \multicolumn{3}{|c|}{ Humid } \\
\hline Design $^{a}$ & $\begin{array}{l}\mathbf{T}^{\mathbf{b}} \\
(\mathbf{y})\end{array}$ & $\begin{array}{c}\mathrm{C}^{\mathrm{c}} \\
(\mathrm{mg} / \mathrm{L})\end{array}$ & Design & $\begin{array}{c}\mathbf{T} \\
(\mathbf{y})\end{array}$ & $\begin{array}{c}C \\
(\mathrm{mg} / \mathrm{L})\end{array}$ & Design & $\begin{array}{l}\mathbf{T} \\
(\mathbf{y})\end{array}$ & $\begin{array}{c}\mathrm{C} \\
(\mathrm{mg} / \mathrm{L})\end{array}$ \\
\hline $3410205 \mathrm{~V} 1$ & 372 & 6.38 & $3420205 \mathrm{~V} 1$ & 316 & 1.33 & $3430205 \mathrm{~V} 1$ & 306 & 0.57 \\
\hline $3410205 \mathrm{~V} 2$ & 363 & 3.20 & $3420205 \mathrm{~V} 2$ & 316 & 0.67 & $3430205 \mathrm{~V} 2$ & 306 & 0.29 \\
\hline $3410205 \mathrm{~V} 3$ & 363 & 0.64 & $3420205 \mathrm{~V} 3$ & 316 & 0.13 & $3430205 \mathrm{~V} 3$ & 301 & 0.06 \\
\hline $3410205 \mathrm{~V} 4$ & 363 & 0.32 & $3420205 \mathrm{~V} 4$ & 316 & 0.07 & $3430205 \mathrm{~V} 4$ & 301 & 0.03 \\
\hline $3410220 \mathrm{~V} 1$ & 458.5 & 16.17 & $3420220 \mathrm{~V} 1$ & 354 & 4.98 & $3430220 \mathrm{~V} 1$ & 316 & 2.24 \\
\hline $3410220 \mathrm{~V} 2$ & 458.5 & 8.09 & $3420220 \mathrm{~V} 2$ & 354 & 2.49 & $3430220 \mathrm{~V} 2$ & 316 & 1.12 \\
\hline $3410220 \mathrm{~V} 3$ & 458.5 & 1.62 & $3420220 \mathrm{~V} 3$ & 354 & 0.50 & $3430220 \mathrm{~V} 3$ & 316 & 0.23 \\
\hline $3410220 \mathrm{~V} 4$ & 458.5 & 0.81 & $3420220 \mathrm{~V} 4$ & 354 & 0.24 & $3430220 \mathrm{~V} 4$ & 316 & 0.11 \\
\hline $3411505 \mathrm{~V} 1$ & 372 & 15.87 & $3421505 \mathrm{~V} 1$ & 316 & 3.30 & $3431505 \mathrm{~V} 1$ & 316 & 1.41 \\
\hline $3411505 \mathrm{~V} 2$ & 372 & 7.98 & 2 & 316 & 1.66 & $3431505 \mathrm{~V} 2$ & 306 & 0.71 \\
\hline $3411505 \mathrm{~V} 3$ & 363 & 1.60 & $3421505 \mathrm{~V} 3$ & 316 & 0.33 & $3431505 \mathrm{~V} 3$ & 301 & 0.14 \\
\hline $3411505 \mathrm{~V} 4$ & 363 & 0.80 & $3421505 \mathrm{~V} 4$ & 316 & 0.17 & $3431505 \mathrm{~V} 4$ & 301 & 0.07 \\
\hline $3411520 \mathrm{~V} 1$ & 458.5 & 40.23 & $3421520 \mathrm{~V} 1$ & 354 & 12.36 & $3431520 \mathrm{~V} 1$ & 327 & 5.57 \\
\hline $3411520 \mathrm{~V} 2$ & 458.5 & 20.20 & $3421520 \mathrm{~V} 2$ & 354 & 6.22 & 3431 & 316 & 2.80 \\
\hline $3411520 \mathrm{~V} 3$ & 458.5 & 4.05 & $3421520 \mathrm{~V} 3$ & 354 & 1.25 & $3431520 \mathrm{~V} 3$ & 316 & 0.56 \\
\hline $3411520 \mathrm{~V} 4$ & 458.5 & 2.02 & $3421520 \mathrm{~V} 4$ & 354 & 0.62 & $3431520 \mathrm{~V} 4$ & 316 & 0.28 \\
\hline $3415005 \mathrm{~V} 1$ & 391 & 31.22 & $3425005 \mathrm{~V} 1$ & 335 & 6.47 & $3435005 \mathrm{~V} 1$ & 327 & 2.76 \\
\hline $3415005 \mathrm{~V} 2$ & 372 & 15.87 & $3425005 \mathrm{~V} 2$ & 316 & 3.30 & $3435005 \mathrm{~V} 2$ & 316 & 1.41 \\
\hline $3415005 \mathrm{~V} 3$ & 363 & 3.20 & $3425005 \mathrm{~V} 3$ & 316 & 0.67 & $3435005 \mathrm{~V} 3$ & 306 & 0.29 \\
\hline $3415005 \mathrm{~V} 4$ & 363 & 1.60 & $3425005 \mathrm{~V} 4$ & 316 & 0.33 & $3435005 \mathrm{~V} 4$ & 301 & 0.14 \\
\hline $3415020 \mathrm{~V} 1$ & 477 & 79.88 & $3425020 \mathrm{~V} 1$ & 372 & 24.29 & $3435020 \mathrm{~V} 1$ & 343 & 10.90 \\
\hline $3415020 \mathrm{~V} 2$ & 458.5 & 40.23 & $3425020 \mathrm{~V} 2$ & 354 & 12.36 & $3435020 \mathrm{~V} 2$ & 327 & 5.57 \\
\hline $3415020 \mathrm{~V} 3$ & 458.5 & 8.09 & $3425020 \mathrm{~V} 3$ & 354 & 2.49 & $3435020 \mathrm{~V} 3$ & 316 & 1.12 \\
\hline $3415020 \mathrm{~V} 4$ & 458.5 & 4.05 & $3425020 \mathrm{~V} 4$ & 354 & 1.25 & $3435020 \mathrm{~V} 4$ & 316 & 0.56 \\
\hline
\end{tabular}

\footnotetext{
${ }^{\mathrm{a}}$ simulation code

${ }^{\mathrm{b}}$ time that maximum concentration occurs

${ }^{c}$ maximum concentration at the groundwater table
} 
Table E. 24 Simulation results for C3L4 design alternative over high hydraulic conductivity aquitards $\left(\mathrm{k}=1 \times 10^{-7} \mathrm{~m} / \mathrm{s}\right)$

\begin{tabular}{|c|c|c|c|c|c|c|c|c|}
\hline \multicolumn{3}{|c|}{ Arid } & \multicolumn{3}{|c|}{ Moderate } & \multicolumn{3}{|c|}{ Humid } \\
\hline Design $^{a}$ & $\begin{array}{l}\mathbf{T}^{\mathbf{b}} \\
(\mathbf{y})\end{array}$ & $\begin{array}{c}\mathrm{C}^{\mathrm{c}} \\
(\mathrm{mg} / \mathrm{L})\end{array}$ & Design & $\begin{array}{c}\mathbf{T} \\
(\mathbf{y})\end{array}$ & $\begin{array}{c}C \\
(\mathrm{mg} / \mathrm{L})\end{array}$ & Design & $\begin{array}{l}\mathbf{T} \\
(\mathbf{y})\end{array}$ & $\begin{array}{c}\mathrm{C} \\
(\mathrm{mg} / \mathrm{L})\end{array}$ \\
\hline $3410205 \mathrm{~V} 1$ & 98 & 106.00 & $3420205 \mathrm{~V} 1$ & 43 & 176.20 & $3430205 \mathrm{~V} 1$ & 41 & 107.10 \\
\hline $3410205 \mathrm{~V} 2$ & 95 & 53.30 & $3420205 \mathrm{~V} 2$ & 41 & 94.90 & $3430205 \mathrm{~V} 2$ & 39 & 59.20 \\
\hline $3410205 \mathrm{~V} 3$ & 95 & 10.70 & $3420205 \mathrm{~V} 3$ & 40 & 19.60 & $3430205 \mathrm{~V} 3$ & 38 & 12.40 \\
\hline $3410205 \mathrm{~V} 4$ & 95 & 5.30 & $3420205 \mathrm{~V} 4$ & 40 & 9.80 & $3430205 \mathrm{~V} 4$ & 38 & 6.20 \\
\hline $3410220 \mathrm{~V} 1$ & 109 & 141.10 & $3420220 \mathrm{~V} 1$ & 47 & 276.40 & $3430220 \mathrm{~V} 1$ & 45 & 219.00 \\
\hline $3410220 \mathrm{~V} 2$ & 106 & 70.80 & $3420220 \mathrm{~V} 2$ & 45 & 143.70 & $3430220 \mathrm{~V} 2$ & 42 & 116.20 \\
\hline $3410220 \mathrm{~V} 3$ & 106 & 14.20 & $3420220 \mathrm{~V} 3$ & 43 & 29.10 & $3430220 \mathrm{~V} 3$ & 41 & 23.80 \\
\hline $3410220 \mathrm{~V} 4$ & 106 & 7.10 & $220 \mathrm{~V} 4$ & 43 & 14.60 & $3430220 \mathrm{~V} 4$ & 41 & 11.90 \\
\hline $3411505 \mathrm{~V} 1$ & 103 & 252.30 & $3421505 \mathrm{~V} 1$ & 46 & 347.30 & $3431505 \mathrm{~V} 1$ & 43 & 200.10 \\
\hline $3411505 \mathrm{~V} 2$ & 98 & 131.50 & $3421505 \mathrm{~V} 2$ & 43 & 211.30 & $3431505 \mathrm{~V} 2$ & 41 & 127.30 \\
\hline $3411505 \mathrm{~V} 3$ & 95 & 26.70 & $3421505 \mathrm{~V} 3$ & 40 & 48.70 & $3431505 \mathrm{~V} 3$ & 38 & 30.60 \\
\hline $3411505 \mathrm{~V} 4$ & 95 & 13.40 & $3421505 \mathrm{~V} 4$ & 40 & 24.50 & $3431505 \mathrm{~V} 4$ & 38 & 15.50 \\
\hline $3411520 \mathrm{~V} 1$ & 117 & 345.50 & $3421520 \mathrm{~V} 1$ & 54 & 601.10 & $3431520 \mathrm{~V} 1$ & 48 & 448.00 \\
\hline $3411520 \mathrm{~V} 2$ & 112 & 176.00 & $3421520 \mathrm{~V} 2$ & 48 & 337.60 & $3431520 \mathrm{~V} 2$ & 46 & 263.90 \\
\hline $3411520 \mathrm{~V} 3$ & 106 & 305.40 & $3421520 \mathrm{~V} 3$ & 43 & 72.60 & $3431520 \mathrm{~V} 3$ & 42 & 59.20 \\
\hline $3411520 \mathrm{~V} 4$ & 106 & 17.70 & $3421520 \mathrm{~V} 4$ & 43 & 36.40 & $3431520 \mathrm{~V} 4$ & 41 & 29.70 \\
\hline $3415005 \mathrm{~V} 1$ & 112 & 453.40 & $3425005 \mathrm{~V} 1$ & 46 & 368.20 & $3435005 \mathrm{~V} 1$ & 43 & 211.00 \\
\hline $3415005 \mathrm{~V} 2$ & 103 & 252.30 & $3425005 \mathrm{~V} 2$ & 46 & 347.30 & $3435005 \mathrm{~V} 2$ & 43 & 200.10 \\
\hline $3415005 \mathrm{~V} 3$ & 95 & 53.30 & $3425005 \mathrm{~V} 3$ & 41 & 94.90 & $3435005 \mathrm{~V} 3$ & 39 & 59.20 \\
\hline $3415005 \mathrm{~V} 4$ & 95 & 26.70 & $3425005 \mathrm{~V} 4$ & 40 & 48.70 & $3435005 \mathrm{~V} 4$ & 39 & 30.60 \\
\hline $3415020 \mathrm{~V} 1$ & 132 & 654.30 & $3425020 \mathrm{~V} 1$ & 55 & 648.00 & $3435020 \mathrm{~V} 1$ & 50 & 478.80 \\
\hline $3415020 \mathrm{~V} 2$ & 117 & 345.50 & $3425020 \mathrm{~V} 2$ & 54 & 601.10 & $3435020 \mathrm{~V} 2$ & 48 & 448.00 \\
\hline $3415020 \mathrm{~V} 3$ & 106 & 70.80 & $3425020 \mathrm{~V} 3$ & 45 & 143.70 & $3435020 \mathrm{~V} 3$ & 42 & 116.20 \\
\hline $3415020 \mathrm{~V} 4$ & 106 & 35.40 & $3425020 \mathrm{~V} 4$ & 43 & 72.60 & $3435020 \mathrm{~V} 4$ & 42 & 59.20 \\
\hline
\end{tabular}


Table E. 25 Simulation results for C3L5 design alternative over low hydraulic conductivity aquitards $\left(\mathrm{k}=1 \times 10^{-8} \mathrm{~m} / \mathrm{s}\right)$

\begin{tabular}{|c|c|c|c|c|c|c|c|c|}
\hline \multicolumn{3}{|c|}{ Arid } & \multicolumn{3}{|c|}{ Moderate } & \multicolumn{3}{|c|}{ Humid } \\
\hline Design $^{a}$ & $\begin{array}{l}\mathbf{T}^{\mathbf{b}} \\
(\mathbf{y})\end{array}$ & $\begin{array}{c}\mathrm{C}^{\mathrm{c}} \\
(\mathrm{mg} / \mathrm{L})\end{array}$ & Design & $\begin{array}{c}\mathbf{T} \\
(\mathbf{y})\end{array}$ & $\begin{array}{c}C \\
(\mathrm{mg} / \mathrm{L})\end{array}$ & Design & $\begin{array}{c}\mathbf{T} \\
(\mathbf{y})\end{array}$ & $\begin{array}{c}\mathrm{C} \\
(\mathrm{mg} / \mathrm{L})\end{array}$ \\
\hline $3510205 \mathrm{~V} 1$ & 127 & 91.5 & $3520205 \mathrm{~V} 1$ & 28.5 & 444 & $3530205 \mathrm{~V} 1$ & 27 & 301.2 \\
\hline $3510205 \mathrm{~V} 2$ & 126 & 46.0 & $3520205 \mathrm{~V} 2$ & 26 & 253.5 & $3530205 \mathrm{~V} 2$ & 26 & 179.8 \\
\hline $3510205 \mathrm{~V} 3$ & 123 & 9.2 & $3520205 \mathrm{~V} 3$ & 25 & 55.0 & $3530205 \mathrm{~V} 3$ & 24.5 & 40.3 \\
\hline $3510205 \mathrm{~V} 4$ & 123 & 4.6 & $3520205 \mathrm{~V} 4$ & 25 & 27.6 & $3530205 \mathrm{~V} 4$ & 24 & 20.3 \\
\hline $3510220 \mathrm{~V} 1$ & 143 & 133.1 & $3520220 \mathrm{~V} 1$ & 32 & 627.4 & $3530220 \mathrm{~V} 1$ & 30 & 523.9 \\
\hline $3510220 \mathrm{~V} 2$ & 143 & 66.6 & $3520220 \mathrm{~V} 2$ & 29 & 335.6 & $3530220 \mathrm{~V} 2$ & 28 & 291.1 \\
\hline $3510220 \mathrm{~V} 3$ & 142 & 13.4 & $3520220 \mathrm{~V} 3$ & 26 & 70 & $3530220 \mathrm{~V} 3$ & 26 & 61.9 \\
\hline $3510220 \mathrm{~V} 4$ & 142 & 6.7 & $3520220 \mathrm{~V} 4$ & 26 & 35 & $3530220 \mathrm{~V} 4$ & 26 & 31.0 \\
\hline $3511505 \mathrm{~V} 1$ & 131 & 223.1 & $3521505 \mathrm{~V} 1$ & 29 & 527.9 & $3531505 \mathrm{~V} 1$ & 27 & 351.5 \\
\hline $3511505 \mathrm{~V} 2$ & 127 & 115.0 & $3521505 \mathrm{~V} 2$ & 29 & 527.9 & $3531505 \mathrm{~V} 2$ & 27 & 351.1 \\
\hline $3511505 \mathrm{~V} 3$ & 123 & 23.2 & $3521505 \mathrm{~V} 3$ & 26 & 134.6 & $3531505 \mathrm{~V} 3$ & 25 & 97.7 \\
\hline $3511505 \mathrm{~V} 4$ & 123 & 11.6 & $3521505 \mathrm{~V} 4$ & 25 & 69 & $3531505 \mathrm{~V} 4$ & 24.5 & 50.2 \\
\hline $3511520 \mathrm{~V} 1$ & 149 & 329.2 & $3521520 \mathrm{~V} 1$ & 33 & 759.6 & $3531520 \mathrm{~V} 1$ & 31 & 623.7 \\
\hline $3511520 \mathrm{~V} 2$ & 142 & 166.5 & $3521520 \mathrm{~V} 2$ & 33 & 759.6 & $3531520 \mathrm{~V} 2$ & 31 & 623.7 \\
\hline $3511520 \mathrm{~V} 3$ & 142 & 33.4 & $3521520 \mathrm{~V} 3$ & 28 & 172.5 & $3531520 \mathrm{~V} 3$ & 26 & 152.4 \\
\hline $3511520 \mathrm{~V} 4$ & 142 & 16.7 & $3521520 \mathrm{~V} 4$ & 27 & 87.1 & $3531520 \mathrm{~V} 4$ & 26 & 77.2 \\
\hline $3515005 \mathrm{~V} 1$ & 142 & 411.4 & $3525005 \mathrm{~V} 1$ & 29 & 527.9 & $3535005 \mathrm{~V} 1$ & 27 & 351.5 \\
\hline $3515005 \mathrm{~V} 2$ & 131 & 223.1 & $3525005 \mathrm{~V} 2$ & 29 & 527.9 & $3535005 \mathrm{~V} 2$ & 27 & 351.5 \\
\hline $3515005 \mathrm{~V} 3$ & 23 & 46.3 & $3525005 \mathrm{~V} 3$ & 26 & 253.5 & $3535005 \mathrm{~V} 3$ & 26 & 179.8 \\
\hline $3515005 \mathrm{~V} 4$ & 123 & 23.2 & $3525005 \mathrm{~V} 4$ & 25 & 134.4 & $3535005 \mathrm{~V} 4$ & 25 & 97.7 \\
\hline $3515020 \mathrm{~V} 1$ & 164 & 631.6 & $3525020 \mathrm{~V} 1$ & 33 & 771.6 & $3535020 \mathrm{~V} 1$ & 31 & 632.7 \\
\hline $3515020 \mathrm{~V} 2$ & 149 & 329.2 & $3525020 \mathrm{~V} 2$ & 33 & 771.6 & $3535020 \mathrm{~V} 2$ & 31 & 632.7 \\
\hline $3515020 \mathrm{~V} 3$ & 142 & 66.9 & $3525020 \mathrm{~V} 3$ & 29 & 336 & $3535020 \mathrm{~V} 3$ & 28 & 291.1 \\
\hline $3515020 \mathrm{~V} 4$ & 142 & 33.4 & $3525020 \mathrm{~V} 4$ & 28 & 172.5 & $3535020 \mathrm{~V} 4$ & 26 & 152.4 \\
\hline
\end{tabular}


Table E. 26 Simulation results for C3L5 design alternative over high hydraulic conductivity aquitards $\left(\mathrm{k}=1 \times 10^{-7} \mathrm{~m} / \mathrm{s}\right)$

\begin{tabular}{|c|c|c|c|c|c|c|c|c|}
\hline \multicolumn{3}{|c|}{ Arid } & \multicolumn{3}{|c|}{ Moderate } & \multicolumn{3}{|c|}{ Humid } \\
\hline Design $^{a}$ & $\begin{array}{l}\mathbf{T}^{\mathbf{b}} \\
(\mathbf{y})\end{array}$ & $\begin{array}{c}\mathrm{C}^{\mathrm{c}} \\
(\mathrm{mg} / \mathrm{L})\end{array}$ & Design & $\begin{array}{c}\mathbf{T} \\
(\mathbf{y})\end{array}$ & $\begin{array}{c}\mathrm{C} \\
(\mathrm{mg} / \mathrm{L})\end{array}$ & Design & $\begin{array}{c}\mathbf{T} \\
(\mathbf{y})\end{array}$ & $\begin{array}{c}\mathrm{C} \\
(\mathrm{mg} / \mathrm{L})\end{array}$ \\
\hline $3510205 \mathrm{~V} 1$ & 103 & 104.4 & $3520205 \mathrm{~V} 1$ & 19 & 530 & $3530205 \mathrm{~V} 1$ & 10.5 & 543.5 \\
\hline $3510205 \mathrm{~V} 2$ & 101 & 52.6 & $3520205 \mathrm{~V} 2$ & 17 & 313.5 & $3530205 \mathrm{~V} 2$ & 10 & 505.3 \\
\hline $3510205 \mathrm{~V} 3$ & 98 & 10.6 & $3520205 \mathrm{~V} 3$ & 15 & 73.1 & $3530205 \mathrm{~V} 3$ & 9 & 140 \\
\hline $3510205 \mathrm{~V} 4$ & 98 & 5.3 & $3520205 \mathrm{~V} 4$ & 15 & 36.9 & $3530205 \mathrm{~V} 4$ & 8.5 & 72.7 \\
\hline $3510220 \mathrm{~V} 1$ & 113 & 140.5 & $3520220 \mathrm{~V} 1$ & 23 & 725 & $3530220 \mathrm{~V} 1$ & 12 & 708.5 \\
\hline $3510220 \mathrm{~V} 2$ & 113 & 70.4 & $3520220 \mathrm{~V} 2$ & 20 & 405.8 & $3530220 \mathrm{~V} 2$ & 12 & 708.5 \\
\hline $3510220 \mathrm{~V} 3$ & 108 & 14.1 & $3520220 \mathrm{~V} 3$ & 16 & 85.5 & $3530220 \mathrm{~V} 3$ & 9 & 164.8 \\
\hline $3510220 \mathrm{~V} 4$ & 108 & 7.0 & $3520220 \mathrm{~V} 4$ & 16 & 42.9 & $3530220 \mathrm{~V} 4$ & 9 & 83.9 \\
\hline $3511505 \mathrm{~V} 1$ & 108 & 34.9 & $3521505 \mathrm{~V} 1$ & 21.5 & 567.9 & $3531505 \mathrm{~V} 1$ & 10 & 543.1 \\
\hline $3511505 \mathrm{~V} 2$ & 103 & 129.9 & $3521505 \mathrm{~V} 2$ & 21.5 & 567.9 & $3531505 \mathrm{~V} 2$ & 10 & 543.1 \\
\hline $3511505 \mathrm{~V} 3$ & 98 & 26.4 & $3521505 \mathrm{~V} 3$ & 18 & 169.6 & $3531505 \mathrm{~V} 3$ & 9 & 304.2 \\
\hline $3511505 \mathrm{~V} 4$ & 98 & 13.2 & $3521505 \mathrm{~V} 4$ & 17 & 88 & $3531505 \mathrm{~V} 4$ & 9 & 170.6 \\
\hline $3511520 \mathrm{~V} 1$ & 121 & 344.1 & $3521520 \mathrm{~V} 1$ & 25 & 794.7 & $3531520 \mathrm{~V} 1$ & 12 & 776.4 \\
\hline $3511520 \mathrm{~V} 2$ & 113 & 175.2 & $3521520 \mathrm{~V} 2$ & 25 & 794.7 & $3531520 \mathrm{~V} 2$ & 12 & 776.4 \\
\hline $3511520 \mathrm{~V} 3$ & 108 & 35.2 & $3521520 \mathrm{~V} 3$ & 19 & 203.8 & $3531520 \mathrm{~V} 3$ & 10 & 387 \\
\hline $3511520 \mathrm{~V} 4$ & 108 & 17.6 & $3521520 \mathrm{~V} 4$ & 18 & 103.5 & $3531520 \mathrm{~V} 4$ & 9.5 & 203.6 \\
\hline $3515005 \mathrm{~V} 1$ & 117 & 448.8 & $3525005 \mathrm{~V} 1$ & 21.5 & 567.9 & $3535005 \mathrm{~V} 1$ & 10 & 543.1 \\
\hline $3515005 \mathrm{~V} 2$ & 108 & 349.4 & $3525005 \mathrm{~V} 2$ & 21.5 & 567.9 & $3535005 \mathrm{~V} 2$ & 10 & 543.1 \\
\hline $3515005 \mathrm{~V} 3$ & 101 & 52.6 & $3525005 \mathrm{~V} 3$ & 19 & 309.6 & $3535005 \mathrm{~V} 3$ & 10 & 505.2 \\
\hline $3515005 \mathrm{~V} 4$ & 98 & 26.4 & $3525005 \mathrm{~V} 4$ & 18 & 169.6 & $3535005 \mathrm{~V} 4$ & 9 & 304.2 \\
\hline $3515020 \mathrm{~V} 1$ & 134 & 651.7 & $3525020 \mathrm{~V} 1$ & 25 & 794.7 & $3535020 \mathrm{~V} 1$ & 12 & 776.5 \\
\hline $3515020 \mathrm{~V} 2$ & 121 & 344.1 & $3525020 \mathrm{~V} 2$ & 25 & 794.7 & $3535020 \mathrm{~V} 2$ & 12 & 776.5 \\
\hline $3515020 \mathrm{~V} 3$ & 113 & 70.4 & $3525020 \mathrm{~V} 3$ & 21 & 390.6 & $3535020 \mathrm{~V} 3$ & 12 & 709.2 \\
\hline $3515020 \mathrm{~V} 4$ & 108 & 35.2 & $3525020 \mathrm{~V} 4$ & 19 & 203.8 & $3535020 \mathrm{~V} 4$ & 10 & 387 \\
\hline
\end{tabular}


Table E. 27 Simulation results for C3L6 design alternative over low hydraulic conductivity aquitards $\left(\mathrm{k}=1 \times 10^{-8} \mathrm{~m} / \mathrm{s}\right)$

\begin{tabular}{|c|c|c|c|c|c|c|c|c|}
\hline \multicolumn{3}{|c|}{ Arid } & \multicolumn{3}{|c|}{ Moderate } & \multicolumn{3}{|c|}{ Humid } \\
\hline Design $^{a}$ & $\begin{array}{c}\mathbf{T}^{\mathbf{b}} \\
(\mathbf{y})\end{array}$ & $\begin{array}{c}\mathrm{C}^{\mathrm{c}} \\
(\mathrm{mg} / \mathrm{L})\end{array}$ & Design & $\begin{array}{c}\mathbf{T} \\
(\mathbf{y})\end{array}$ & $\begin{array}{c}C \\
(\mathrm{mg} / \mathrm{L})\end{array}$ & Design & $\begin{array}{l}\mathbf{T} \\
(\mathbf{y})\end{array}$ & $\begin{array}{c}C \\
(\mathrm{mg} / \mathrm{L})\end{array}$ \\
\hline $3610205 \mathrm{~V} 1$ & 127 & 91.5 & $3620205 \mathrm{~V} 1$ & N/A ${ }^{\mathrm{d}}$ & N/A & $3630205 \mathrm{~V} 1$ & $\mathrm{~N} / \mathrm{A}^{\mathrm{d}}$ & N/A \\
\hline $3610205 \mathrm{~V} 2$ & 126 & 46.0 & $3620205 \mathrm{~V} 2$ & N/A & N/A & $3630205 \mathrm{~V} 2$ & N/A & N/A \\
\hline $3610205 \mathrm{~V} 3$ & 123 & 9.2 & $3620205 \mathrm{~V} 3$ & N/A & N/A & $3630205 \mathrm{~V} 3$ & N/A & N/A \\
\hline $3610205 \mathrm{~V} 4$ & 123 & 4.6 & $3620205 \mathrm{~V} 4$ & N/A & N/A & $3630205 \mathrm{~V} 4$ & N/A & N/A \\
\hline $3610220 \mathrm{~V} 1$ & 143 & 133.1 & $3620220 \mathrm{~V} 1$ & N/A & N/A & $3630220 \mathrm{~V} 1$ & N/A & N/A \\
\hline $3610220 \mathrm{~V} 2$ & 143 & 66.6 & $3620220 \mathrm{~V} 2$ & N/A & N/A & $3630220 \mathrm{~V} 2$ & N/A & N/A \\
\hline $3610220 \mathrm{~V} 3$ & 142 & 13.4 & $3620220 \mathrm{~V} 3$ & N/A & N/A & $3630220 \mathrm{~V} 3$ & N/A & N/A \\
\hline $3610220 \mathrm{~V} 4$ & 142 & 6.7 & $3620220 \mathrm{~V} 4$ & N/A & N/A & $3630220 \mathrm{~V} 4$ & N/A & N/A \\
\hline $3611505 \mathrm{~V} 1$ & 131 & 223.1 & $3621505 \mathrm{~V} 1$ & N/A & N/A & $3631505 \mathrm{~V} 1$ & N/A & N/A \\
\hline $3611505 \mathrm{~V} 2$ & 127 & 115.0 & $3621505 \mathrm{~V} 2$ & N/A & N/A & $3631505 \mathrm{~V} 2$ & N/A & N/A \\
\hline $3611505 \mathrm{~V} 3$ & 123 & 23.2 & $3621505 \mathrm{~V} 3$ & N/A & N/A & $3631505 \mathrm{~V} 3$ & N/A & N/A \\
\hline $3611505 \mathrm{~V} 4$ & 123 & 11.6 & $3621505 \mathrm{~V} 4$ & N/A & N/A & $3631505 \mathrm{~V} 4$ & N/A & N/A \\
\hline $3611520 \mathrm{~V} 1$ & 149 & 329.2 & $3621520 \mathrm{~V} 1$ & N/A & N/A & $3631520 \mathrm{~V} 1$ & N/A & N/A \\
\hline $3611520 \mathrm{~V} 2$ & 142 & 166.5 & $3621520 \mathrm{~V} 2$ & N/A & N/A & $3631520 \mathrm{~V} 2$ & N/A & N/A \\
\hline $3611520 \mathrm{~V} 3$ & 142 & 33.4 & $3621520 \mathrm{~V} 3$ & N/A & N/A & $3631520 \mathrm{~V} 3$ & N/A & N/A \\
\hline $3611520 \mathrm{~V} 4$ & 142 & 16.7 & $3621520 \mathrm{~V} 4$ & N/A & N/A & $3631520 \mathrm{~V} 4$ & N/A & N/A \\
\hline $3615005 \mathrm{~V} 1$ & 142 & 411.4 & $3625005 \mathrm{~V} 1$ & N/A & N/A & $3635005 \mathrm{~V} 1$ & N/A & N/A \\
\hline $3615005 \mathrm{~V} 2$ & 131 & 223.1 & $3625005 \mathrm{~V} 2$ & N/A & N/A & $3635005 \mathrm{~V} 2$ & N/A & N/A \\
\hline $3615005 \mathrm{~V} 3$ & 23 & 46.3 & $3625005 \mathrm{~V} 3$ & N/A & N/A & $3635005 \mathrm{~V} 3$ & N/A & N/A \\
\hline $3615005 \mathrm{~V} 4$ & 123 & 23.2 & $3625005 \mathrm{~V} 4$ & N/A & N/A & $3635005 \mathrm{~V} 4$ & N/A & N/A \\
\hline $3615020 \mathrm{~V} 1$ & 164 & 631.6 & $3625020 \mathrm{~V} 1$ & N/A & N/A & $3635020 \mathrm{~V} 1$ & N/A & N/A \\
\hline $3615020 \mathrm{~V} 2$ & 149 & 329.2 & $3625020 \mathrm{~V} 2$ & N/A & N/A & $3635020 \mathrm{~V} 2$ & N/A & N/A \\
\hline $3615020 \mathrm{~V} 3$ & 142 & 66.9 & $3625020 \mathrm{~V} 3$ & N/A & N/A & $3635020 \mathrm{~V} 3$ & N/A & N/A \\
\hline $3615020 \mathrm{~V} 4$ & 142 & 33.4 & $3625020 \mathrm{~V} 4$ & N/A & N/A & $3635020 \mathrm{~V} 4$ & N/A & N/A \\
\hline
\end{tabular}


Table E. 28 Simulation results for C3L6 design alternative over high hydraulic conductivity aquitards $\left(\mathrm{k}=1 \times 10^{-7} \mathrm{~m} / \mathrm{s}\right)$

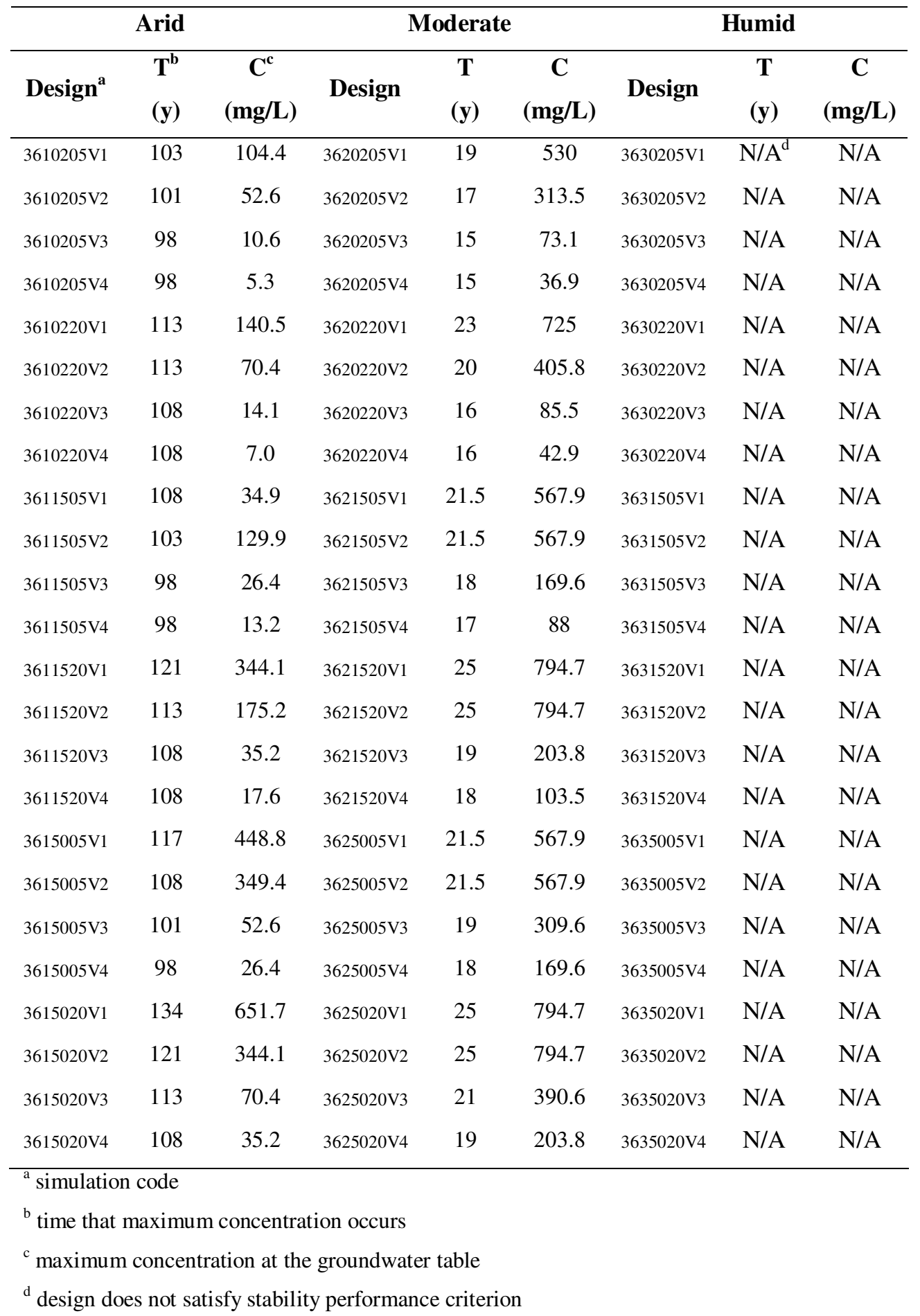




\section{APPENDIX-F}

\section{DIGITAL ELEVATION MODELS (DEM) FOR VIRTUAL LANDFILL MODEL}

\section{F.1. Base-DEM}

$\begin{array}{ll}\text { ncols } & 149 \\ \text { nrows } & 250 \\ \text { xllcorner } & 498285.4254264 \\ \text { yllcorner } & 4198984.8884888 \\ \text { cellsize } & 5.3416012000043\end{array}$

NODATA_value -9999

-

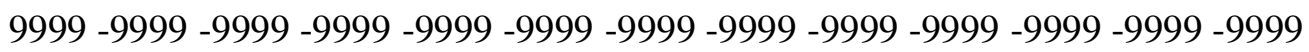
-9999 9999 -9999 -9999 -9999 -9999 -9999 -9999 -9999 969.0527 968.5507 967.9955 -

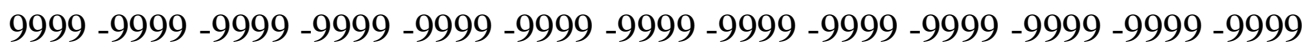
9999969.2311968 .9075968 .5374968 .1226967 .692967 .2805966 .874966 .4358 965.8516965 .2787 -9999 -9999 -9999-9999 -9999 9999 -9999 -9999-9999-9999-9999 -9999 -9999-9999 -9999-9999 -9999 
-9999 -9999 -9999-9999-9999 -9999-9999-9999 969.3267969 .129968 .8751 968.4844968 .1465967 .8778967 .528967 .1334966 .7068966 .1889965 .6017 9999 -9999 -9999-9999 -9999-9999-9999-9999-9999-9999 -9999-9999 -9999-9999-9999-9999-

(similar set of data for 225 rows)

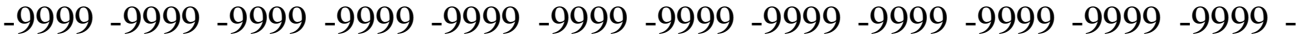
9999 -9999 -9999-9999-9999-9999 -9999 -9999-9999-9999-9999-9999 -9999 9999 -9999-9999-9999-9999-9999-9999-9999-9999-9999 -9999-9999 -9999999 -9999 -9999-9999 -9999-9999-9999 -9999 -9999-9999 -9999-9999 9999-9999-9999-9999-9999-9999-9999-9999-9999-9999-9999-999 -

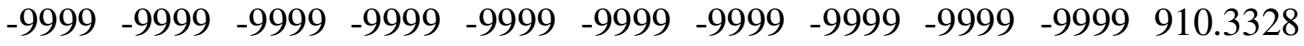
911.4579912 .0288911 .9052911 .2775909 .8486908 .3707 -9999 -9999 -9999 9999 -9999 -9999-9999-9999-9999-9999 -9999 -9999-9999-9999 -9999 9999 -9999 -9999-9999 -9999-9999 -9999 -9999 -9999-9999 -9999-9999 9999 -9999 -9999-9999-9999-9999 -9999 -9999-9999 -9999-9999 -9999 9999 -9999 -9999-9999-9999 -9999-9999 -9999 -9999 -9999-9999 -9999 9999 -9999-9999-9999-9999-9999-9999-9999-9999-9999 -9999-99999999 -9999-9999-9999-9999-9999-9999-9999-9999-9999-9999-9999- 
9999 -9999 -9999-9999-9999 -9999 -9999 -9999 -9999 -9999 -9999 -9999

$9999-9999-9999-9999$

\section{F.2. Clay-DEM: Top}

\section{NCOLS 7}

NROWS 5

XLLCORNER 498300

YLLCORNER 4199900

CELLSIZE 100.00

NODATA_VALUE -9999.000

-9999.000-9999.000 968.794-9999.000-9999.000 -9999.000-9999.000

-9999.000960.584964.660966.200944.000 -9999.000 -9999.000

-9999.000965.100953.064965.900966.800 965.300 -9999.000

-9999.000 -9999.000 944.459966.650 975.200967.500-9999.000

-9999.000-9999.000937.000959.500975.500963.600951.000

\section{F.3. Clay-DEM: Bottom}

NCOLS 7

NROWS 5

XLLCORNER 498300

YLLCORNER 4199900

CELLSIZE 100.00

NODATA_VALUE -9999.000

-9999.000-9999.000 957.794-9999.000-9999.000-9999.000-9999.000

-9999.000949.584953.660 960.200938.000 -9999.000 -9999.000

-9999.000 954.100942.064959.900960.800962.300-9999.000

-9999.000-9999.000933.459960.650 969.200 964.500 -9999.000 
-9999.000 -9999.000926.000953.500969.500960.600950.000

\section{F.4. Groundwater-DEM: Depth}

NCOLS 7

NROWS 5

XLLCORNER 498300

YLLCORNER 4199900

CELLSIZE 100.00

NODATA_VALUE -9999.000

-9999.000-9999.000 10.794-9999.000-9999.000 -9999.000-9999.000

-9999.000 11.5849.660 8.200 6.000-9999.000 -9999.000

-9999.000 11.100 9.064 8.9006.800 3.300 -9999.000

-9999.000 -9999.000 9.459 8.650 5.200 3.500 -9999.000

-9999.000-9999.000 9.000 7.500 5.500 3.600 3.000

\section{F.5. Groundwater-DEM: Direction}

\section{NCOLS 7}

NROWS 5

XLLCORNER 498300

YLLCORNER 4199900

CELLSIZE 100.00

NODATA_VALUE -9999.000

-9999.000 -9999.000 57.794-9999.000-9999.000 -9999.000-9999.000

-9999.000 $49.58453 .66060 .20038 .000-9999.000-9999.000$

-9999.000 54.100 42.06459.90060.800 62.300 -9999.000

-9999.000-9999.000 33.45960.650 69.200 64.500 -9999.000

-9999.000-9999.000 26.000 53.500 69.50060.600 50.000 


\section{APPENDIX-G}

\section{PERFORMANCE REPORTS PRESENTED BY LFDSS}

\section{G.1. Siirt Municipal Solid Waste Landfill Case Study}

C1L2,0.412059310093705,177.77202359375,3.19753280971486,,3.48939250033 $159,,, 3.47976810827197,, 2.41804742076412: 1.61203161384274: 5.44060669671$ 926:3.62707113114617,,1914468.51,30450,1944918.51

C1L4L,1.17249841380301,135.54014234375,3.19753280971486,,3.4893925003 $3159,, 3.47976810827197,, 2.41804742076412: 1.61203161384274: 5.4406066967$ 1926:3.62707113114617,,1768528.51,30450,1798978.51

C3L2,0.43108218233377,180.77375,3.19753280971486,,3.48939250033159,,,,45 6805678449124,,2.41804742076412:1.61203161384274:5.44060669671926:3.6 $2707113114617,, 2507813.51,30450,2538263.51$

C3L4L,1.21587401637304,135.54014234375,3.19753280971486,,3.4893925003 $3159,,, 45.6805678449124,, 2.41804742076412: 1.61203161384274: 5.4406066967$ 1926:3.62707113114617,2097873.51,30450,2128323.51

C2L1,27.300851078987,91.7644375,3.19753280971486,,3.48939250033159,„,,,9. $16546829404725,, 2224323.51,43500,2267823.51$ 
C2L5,27.1129931286085,95.470440625,3.19753280971486,,3.48939250033159, ,,9.16546829404725,,,2501693.51,43500,2545193.51

\section{G.2. X-City Municipal Solid Waste Landfill Case Study}

C1L1,478.543042393043,30.627090625,1.93698511401535,,4.92608534100826,, ,5.52787104235528,,,,,1365913.27,0,1365913.27

C1L6,477.801922884831,32.04772515625,1.93698511401535,,4.9260853410082 $6,,, 5.52787104235528,,,,, 1513969.27,0,1513969.27$

C2L1,430.051536018161,594.27625,1.93698511401535,,4.92608534100826,„,,,1 $6.6330993279735,1.70555641358764,1942563.27,43500,1986063.27$

C2L6,428.853358456206,641.8519375,1.93698511401535,,4.92608534100826,,,, ,16.6330993279735,,1.70555641358764,2106819.27,43500,2150319.27

C3L1,473.111119403799,32.04772515625,1.93698511401535,„4.9260853410082 $6,,, 135.337487570689,,,, 1802563.27,0,1802563.27$

C3L6,472.180902137091,34.2481130714453,1.93698511401535,,4.92608534100 $826,,, 135.337487570689,,, 1966819.27,0,1966819.27$ 


\section{CURRICULUM VITAE}

\section{PERSONAL INFORMATION}

Surname, Name: ÇELIK, Başak

Nationality: Turkish (TC)

Date and Place of Birth: 16 February 1979, İstanbul

Marital Status: Married

Phone: +90 3122105865

Fax: +90 3122102646

email: btarhan@metu.edu.tr

\section{EDUCATION}

$\begin{array}{lll}\text { Degree } & \text { Institution } & \text { Year of Graduation } \\ \text { MS } & \text { METU Environmental Engineering } & 2003 \\ \text { BS } & \text { METU Environmental Engineering } & 2001 \\ \text { High School } & \text { Atatürk Anatolian High School, } & 1997 \\ & \text { Ankara } & \end{array}$




\section{WORK EXPERIENCE}

$\begin{array}{lll}\text { Year } & \text { Place } & \text { Enrollment } \\ \text { 2003- Present } & \text { METU Department of } & \text { Research Assistant } \\ & \text { Environmental Engineering } & \\ \text { 2002 March - } & \text { Foundation for Environmental } & \text { National Coordinator } \\ \text { 2003 January } & \text { Education -Turkey } & \\ \text { 2000 June - } & \text { Turkish Petroleum Refineries Inc. } & \text { Intern Engineering } \\ \text { 2000 August } & & \text { Student } \\ \text { 1999 June - } & \text { Ankara Metropolitan Municipality } & \text { Intern Engineering } \\ \text { 1999 August } & & \text { Student }\end{array}$

FOREIGN LANGUAGES

Advanced English, Intermediate French, Beginning German

SELECTED PUBLICATIONS

Papers Published in International Peer-Reviewed Journals (Science Citation Index)

1. Çelik, B., Girgin, S., Yazıcı, A., and Ünlü, K., A Decision Support System for Assessing Landfill Performance -in preparation.

2. Çelik, B., Rowe, R. K., and Ünlü, K., Effect of Vadose Zone on Steady State Leakage Rates from Landfill Barrier Systems. Waste Management -in print.

3. Tarhan, B., and Ünlü, K., (2005). Performance-based landfill design: Development of a design selection matrix using GIS and system simulation models (SSM), Environmental Geology, Vol.49, No.1, 133-147. 


\section{Papers Published in National Peer-Reviewed Journals}

1. Tarhan, B., ve Ünlü, K., (2004). Performans (Başarım) Bazlı Katı Atık Deponi Sahası Tasarımı: ABD, AB, Güney Afrika ile Türkiye Uygulamalarının Karşılaştırılması, Çevre, Bilim ve Teknoloji Teknik Dergi, Sayı: 2, Cilt: 2, ISSN: 1302-5627.

\section{National and International Conference Proceeding Publications}

1. Çelik, B., Rowe, R. K., and Ünlü, K., (2007). Effect of Sandy Vadose Zone on the Performance of Landfill Barrier Systems. CD-ROM: SARDINIA 2007 11th Waste Management and Landfill Symposium, 1-5 Ekim 2007, S. Margherita di Pula-Cagliari, Sardinia, ITALY.

2. Çelik, B., Poçan, S., Yazıcı, A., and Ünlü, K., (2007). Coupling GIS and System Simulation Models under a Decision Support System for Assessing Sanitary Landfill Performance. CD-ROM: SARDINIA 2007 11th Waste Management and Landfill Symposium, 1-5 Ekim 2007, S. Margherita di Pula -Cagliari, Sardinia, ITALY.

3. Çelik, B., ve Ünlü, K., (2007). Performans Bazlı Katı Atık Depolama Sahası Tasarımı için Karar Destek Sistemi Geliştirilmesi. CD-ROM: TÜRKAY 2007 AB Sürecinde Türkiye'de Katı Atık Yönetimi ve Çevre Sorunları Sempozyumu, 28-31 May 2007, İstanbul, TURKEY.

4. Çelik, B., and Ünlü, K., (2006). Development of a decision support system for a performance-based landfill design: coupling GIS and system simulation models. CD-ROM: ISWA Annual Congress 2006 "Waste Site Stories", 1-5 October 2006, Copenhagen, Denmark.

5. Ateş, N., Tarhan, B., Ünlü, K., and Yetiş, Ü. (2006). Wastewater Management Plan for Gelibolu (Gallipoli) Peninsula National Historical Park, Turkey. CDROM: MEDA WATER International Conference on Sustainable Water Management Rational Water Use, Wastewater and Reuse RUWTR 2006, 8-10 June 2006, Marrakesh, Morocco. 
6. Yetiş, Ü., Ateş, N., Tarhan, B., and Ünlü, K. (2006). Water and wastewater management plans for Gelibolu (Gallipoli) Peninsula National Historical Park, Turkey. CD-ROM: $7^{\text {th }}$ Specialised Conference on Small Water and Wastewater Systems, 7-10 March 2006, Mexico City, Mexico.

7. Tarhan, B., ve Ünlü, K., (2004). Performance Based Sanitary Landfill Design: Geographic Information Systems Interfaced with System Simulation Models. CD-ROM: ISWA 2004 World Environment Congress and Exhibition, 17-21 October 2004, Rome, Italy.

8. Tarhan B., Ünlü K., Türker M., Tortamış O. (2003). Coğrafi Bilgi Sistemleri (CBS) ve Sistem Simülasyon Modelleri (SSM) Kullanarak Katı Atık Deponi Sahası Tasarımlarının Değerlendirilmesi, 2. Ulusal Çevre Kirliliği Kontrolü Sempozyumu, Bildiriler, ODTÜ, Ankara, ISBN: 975-429-211-6, pp: 212.

9. Tarhan B., Ünlü K., Türker M., Tortamış O. (2003). Performance Based Sanitary Landfill Design: A Methodology Interfacing Geographic Information Systems (GIS) with System Simulation Models (SSM) and A Hydrogeologic Database, $12^{\text {th }}$ International Symposium on Environmental Pollution and Its Impact on Life in the Mediterranean Region, Abstract Book, MESAEP\&SECOTOX, Antalya, TURKEY, ISBN: 975-288-621-3, pp: B-85.

\section{Other Publications}

1. Başak Çelik, Toprak öcünü almadan dersimizi çalışmaya başlamalıyız. Radikal Gazetesi, 20.10.2006.

2. Tarhan B. (2003). Sanitary Landfill Design Evaluation using Geographic Information Systems (GIS) Interfaced with System Simulation Models (SSM), M.Sc. Thesis, Orta Doğu Teknik Üniversitesi, Ankara. 